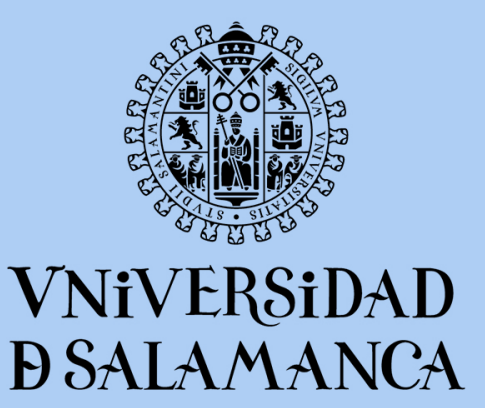

TESIS DOCTORAL

\title{
ENTORNOS DE VISIÓN ANATOMO-RADIOLÓGICA EN 3D para EL ESTUDIO DE ESTRUCTURAS PÉLVICAS
}

LOURDES ASENSIO ROMERO

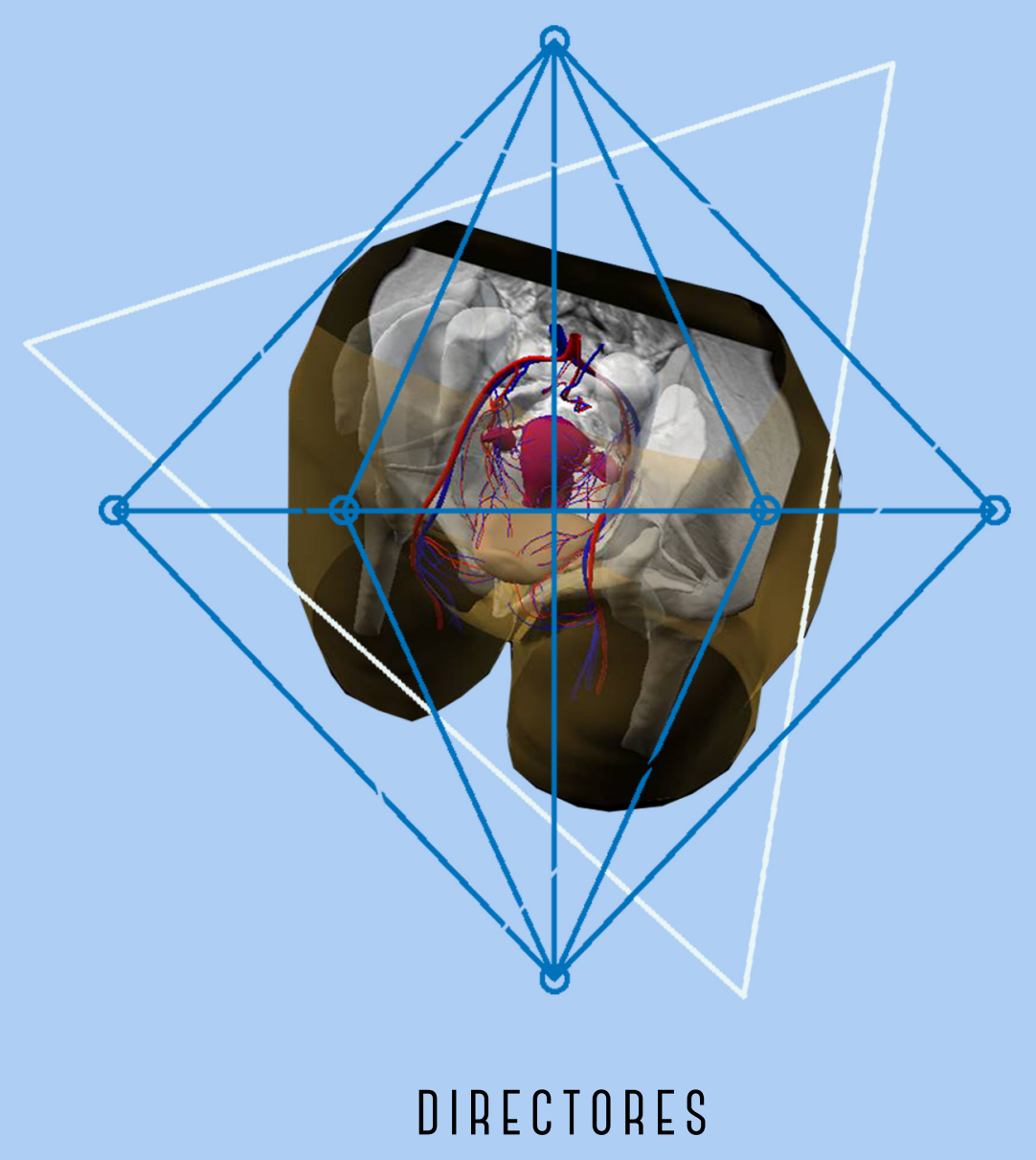

Juan A. Juanes Méndez y Manuel Asensio Gómez Salamanca, 2020 

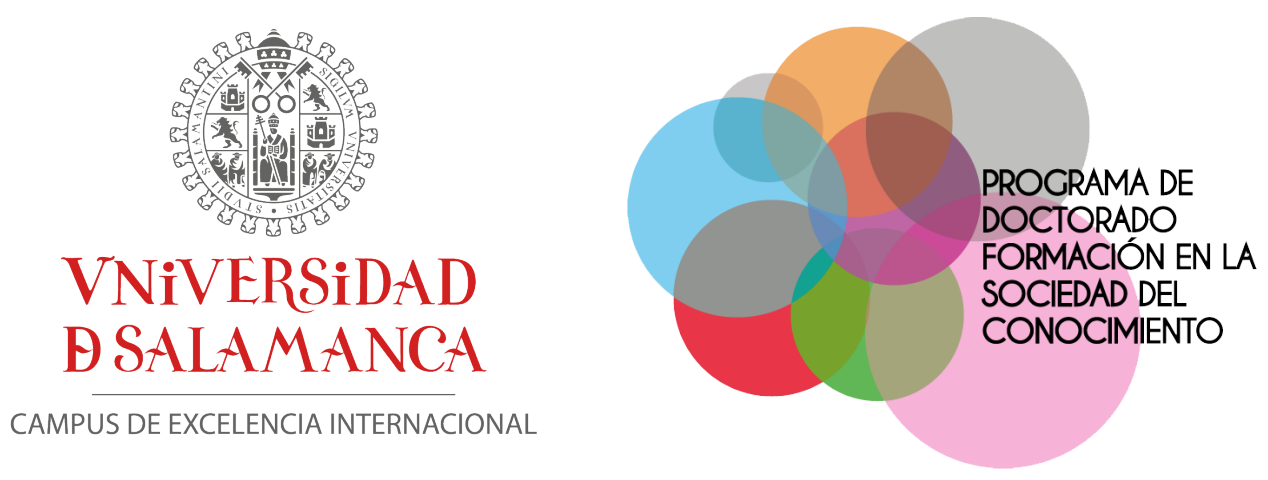

Entornos tecnológicos de visión

anatomo-radiológica en 3D para el estudio de estructuras pélvicas.

\author{
Lourdes Asensio Romero
}

Tesis Doctoral

Salamanca - 2020 


\section{JUAN ANTONIO JUANES MÉNDEZ Y D. MANUEL ASENSIO} GÓMEZ, DOCTORES EN MEDICINA Y CIRUGÍA, PROFESORES DEL DEPARTAMENTO DE ANATOMÍA E hISTOLOGÍA HUMANAS DE LA UNIVERSIDAD DE SALAMANCA

\section{CERTIFICAMOS:}

Que el trabajo titulado "ENTORNOS TECNOLÓGICOS DE VISIÓN ANATOMORADIOLÓGICA EN 3D PARA EL ESTUDIO DE ESTRUCTURAS PÉLVICAS", ha sido realizado por Dña. Lourdes Asensio Romero, bajo nuestra dirección; reuniendo, a nuestro juicio, los requisitos y méritos suficientes para que la autora del mismo pueda optar al Grado de Doctor por la Universidad de Salamanca.

Y para que así conste, firmamos la presente certificación en Salamanca a uno de junio de 2020.

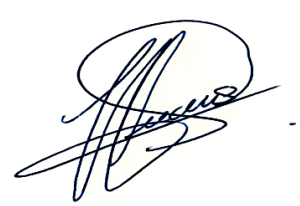

$F^{\text {do }}$ : Juan Antonio Juanes Méndez

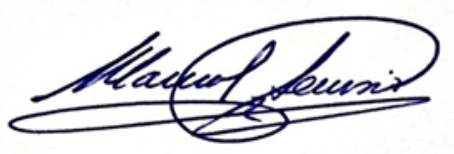

F ${ }^{\text {do }}$ : Manuel Asensio Gómez 
A Víctor

$Y$ a mi familia 


\section{ÍNDICE}

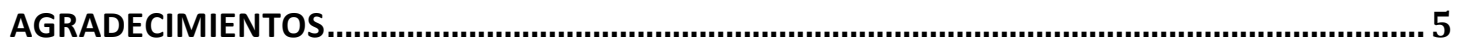

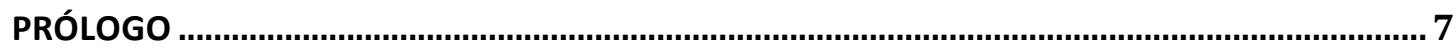

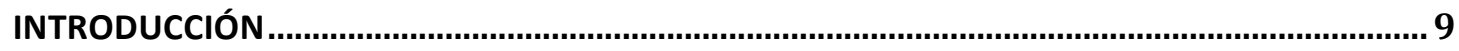

PLANTEAMIENTO DEL TRABAJO

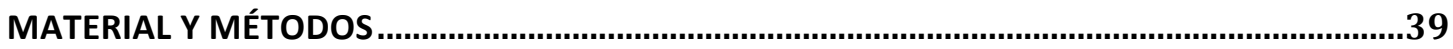

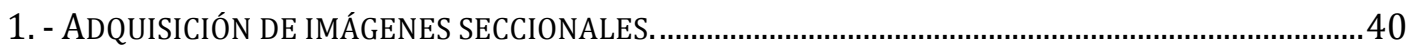

1.a.- Imágenes de resonancia magnética ………..................................................................40

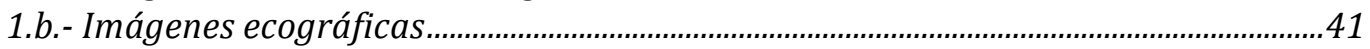

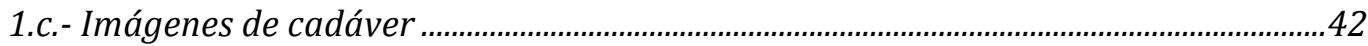

2. - SEGMENTACIÓN DE ESTRUCTURAS ANATÓMICAS, DELIMITACIÓN DE REGIONES DE INTERÉS

(ROIS) Y RECONSTRUCCIÓN DE MODELOS TRIDIMENSIONALES........................................................4

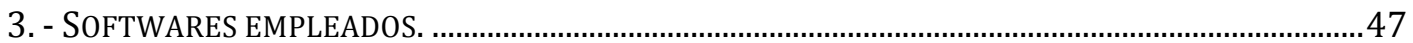

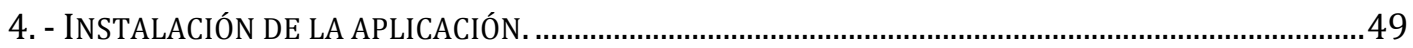

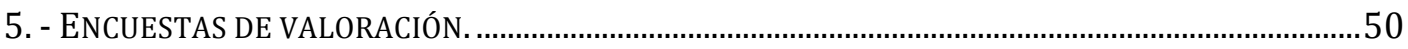

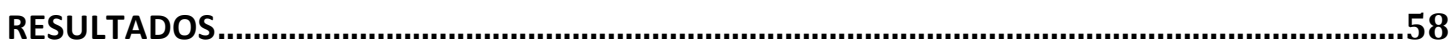

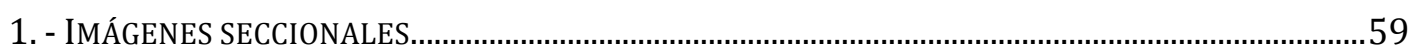

1.a.- Imágenes seccionales de cadáver..................................................................................59

1.b.- Imágenes seccionales de resonancia magnética .........................................................66

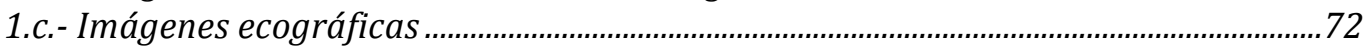

2. - MODELOS ANATÓMICOS TRIDIMENSIONALES...........................................................................76

2.a.- Modelos óseos de la pelvis femenina …………………................................................76

2.b. - Modelos musculares 3D de la pelvis femenina ...........................................................79

2.c. - Reconstrucciones en $3 D$ de estructuras nerviosas de la pelvis femenina.................81

2.d. - Modelos 3D de la vascularización (arterias y venas)...................................................86

2.e. - Modelos tridimensionales de las vísceras .......................................................................92

3. - FUNCIONALIDAD DE LA APLICACIÓN INFORMÁTICA: INTERFAZ DE USUARIO...............................102

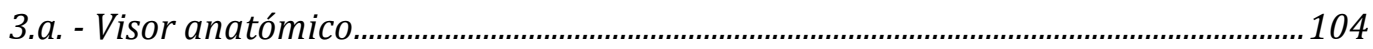

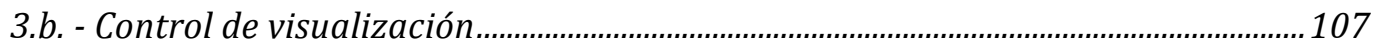

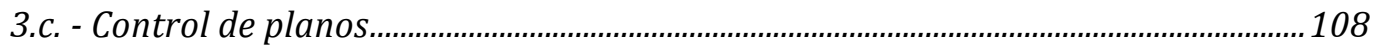

3.d. - Control de los modelos 3D de las estructuras anatómicas de la pelvis .................110

3.e. - Correlación entre imágenes de resonancia magnética e imágenes ecográficas

4. - ENCUESTA DE VALORACIÓN DE LOS USUARIOS.......................................................................117

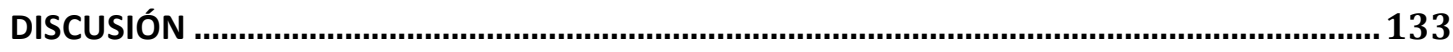

CONCLUSIONES

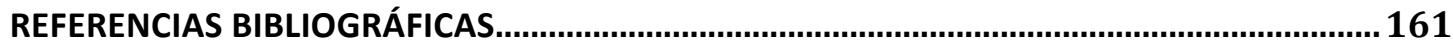

ANEXOS 


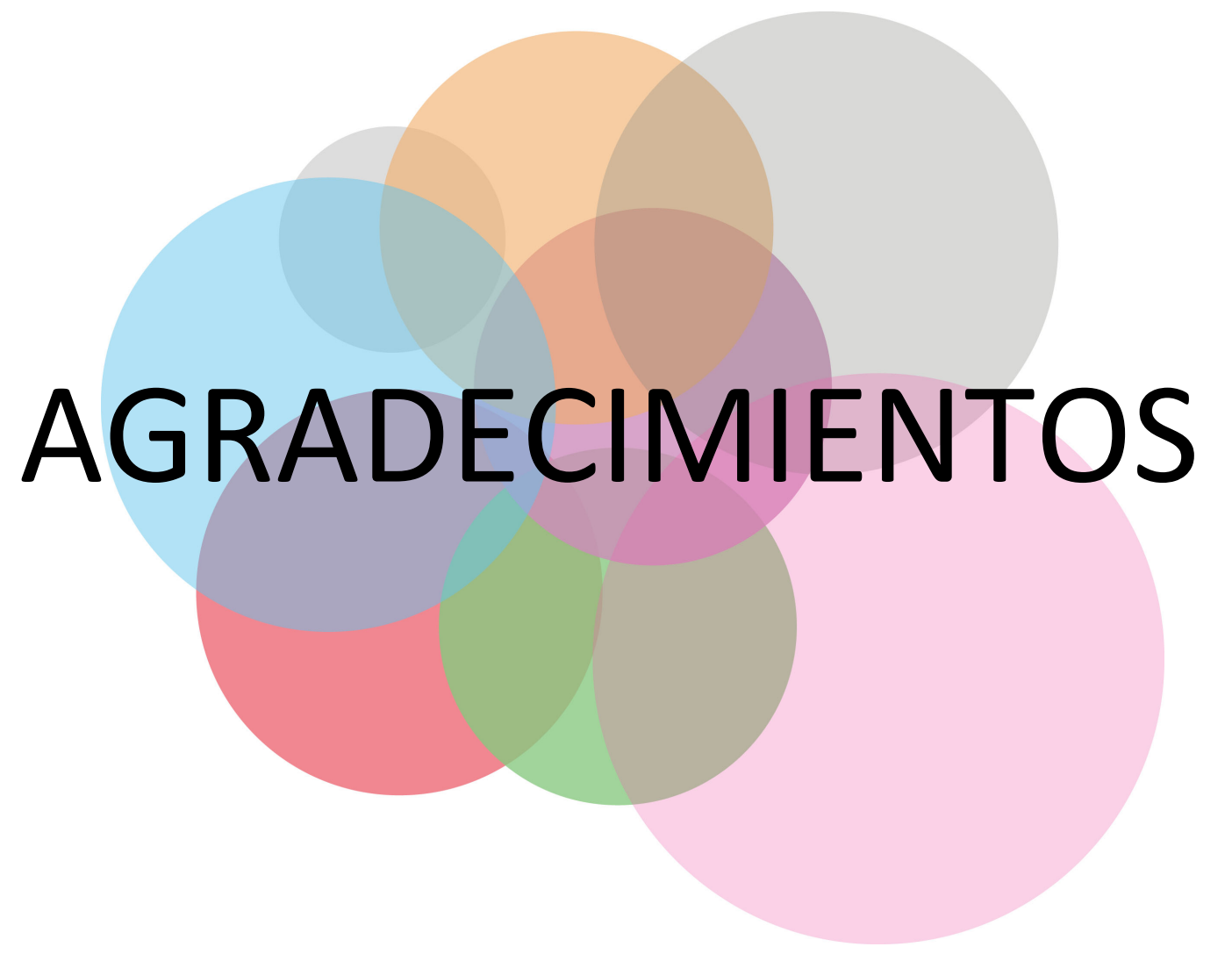


Quiero expresar mi más sincero agradecimiento a los Profesores Doctores D. Juan Antonio Juanes Méndez y D. Manuel Asensio Gómez, de la Universidad de Salamanca, por el gran esfuerzo y tiempo dedicado a la dirección y desarrollo de este trabajo de Tesis Doctoral, sin cuya guía y dedicación no hubiera sido posible realizarlo.

Deseo extender también mi agradecimiento al Profesor Doctor D. Alberto Prats Galino, de la Universidad de Barcelona, por su aportación a este proyecto, así como a todos aquellos que, con su colaboración, han contribuido al desarrollo de este trabajo.

Mi agradecimiento más especial a mi marido y mi familia, por su apoyo incondicional y por su comprensión, porque el tiempo que he dedicado a esta Tesis Doctoral, se ha traducido en momentos que no he podido compartir con ellos.

También agradezco a mis amigas que siempre hayan estado ahí, animándome a conseguir finalizar este proyecto.

A todos, muchas gracias. 


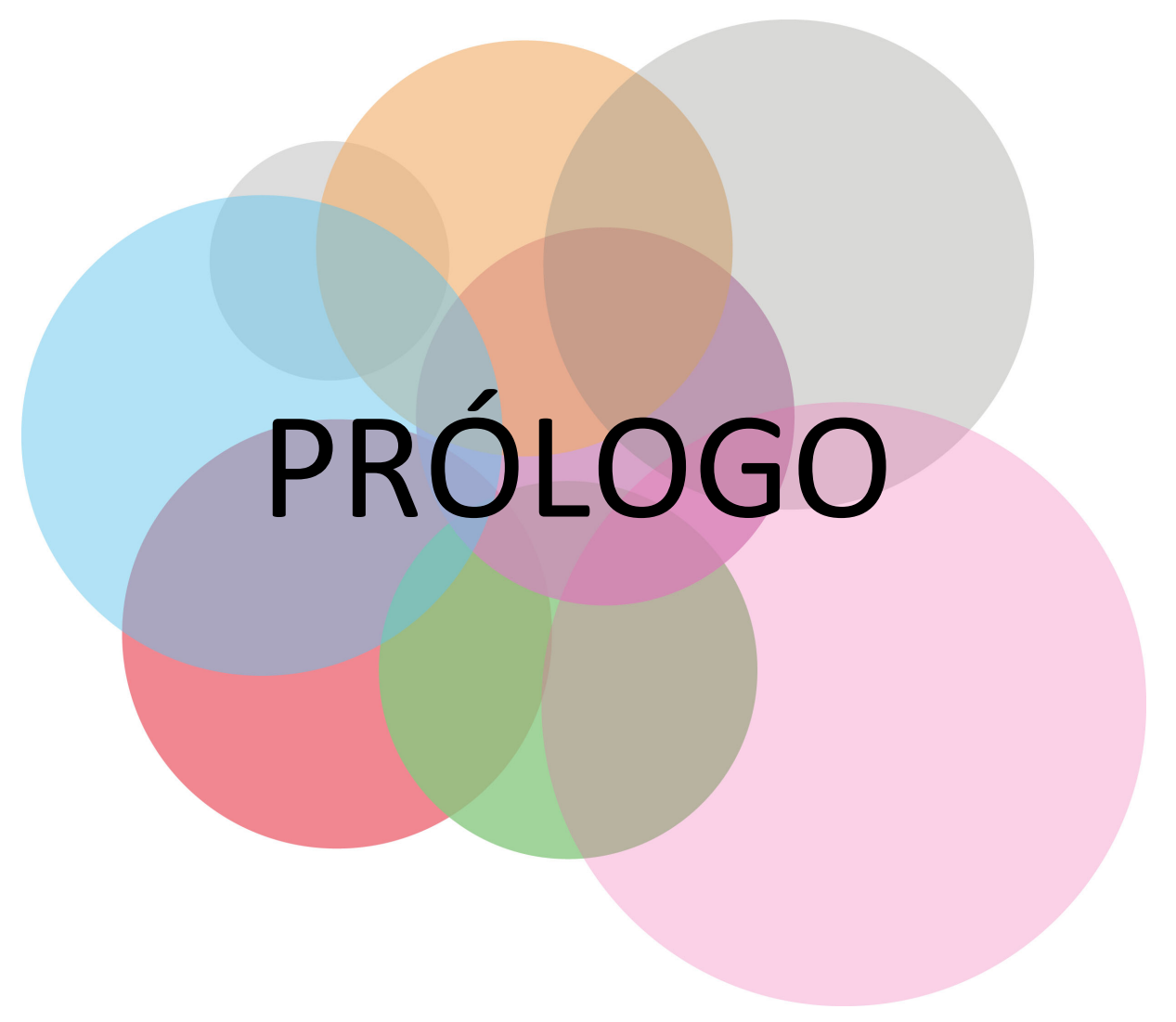


Tras finalizar mis estudios de Medicina se me planteó, como supongo que les ocurre a todos los compañeros, elegir la especialidad a la que desearía dedicar mi actividad asistencial.

Elegí Obstetricia y Ginecología, a la que actualmente me dedico, porque me atraía principalmente poder dar atención a los problemas y patologías que sufren muchas mujeres. Una de las facetas de mi trabajo es dar formación a los residentes de esta especialidad, y ahí es cuando surgió mi interés por la docencia, aunque también debo señalar la influencia que ha tenido en mi trayectoria profesional observar la dedicación y satisfacción con que mi padre se ha involucrado a lo largo de varios años en la docencia de Anatomía y que ha compaginado siempre con su actividad asistencial.

Mi especialidad incluye una región muy compleja, con numerosas estructuras anatómicas y con variadas y frecuentes patologías, que requiere un conocimiento anatómico bastante exhaustivo de la zona pélvica. Creo que llegar a cualquier especialidad médica con unos buenos conocimientos de anatomía es básico y contar con metodologías didácticas que faciliten esta tarea, primordial. Por eso cuando surgió la posibilidad de realizar esta Tesis Doctoral me sentí muy atraída por el proyecto, porque me pareció una herramienta didáctica muy ilustrativa, que podía aportar numerosas ventajas sobre la docencia que tradicionalmente hemos recibido, y aplicable a variados campos médicos.

He dedicado muchas horas y esfuerzo a este proyecto porque creo en su potencialidad didáctica, de hecho, yo también he aprendido con él, y porque me planteo seriamente la posibilidad de dedicar parte de mi actividad profesional a intentar transmitir a otros los conocimientos que vaya adquiriendo a lo largo de mi vida laboral. 


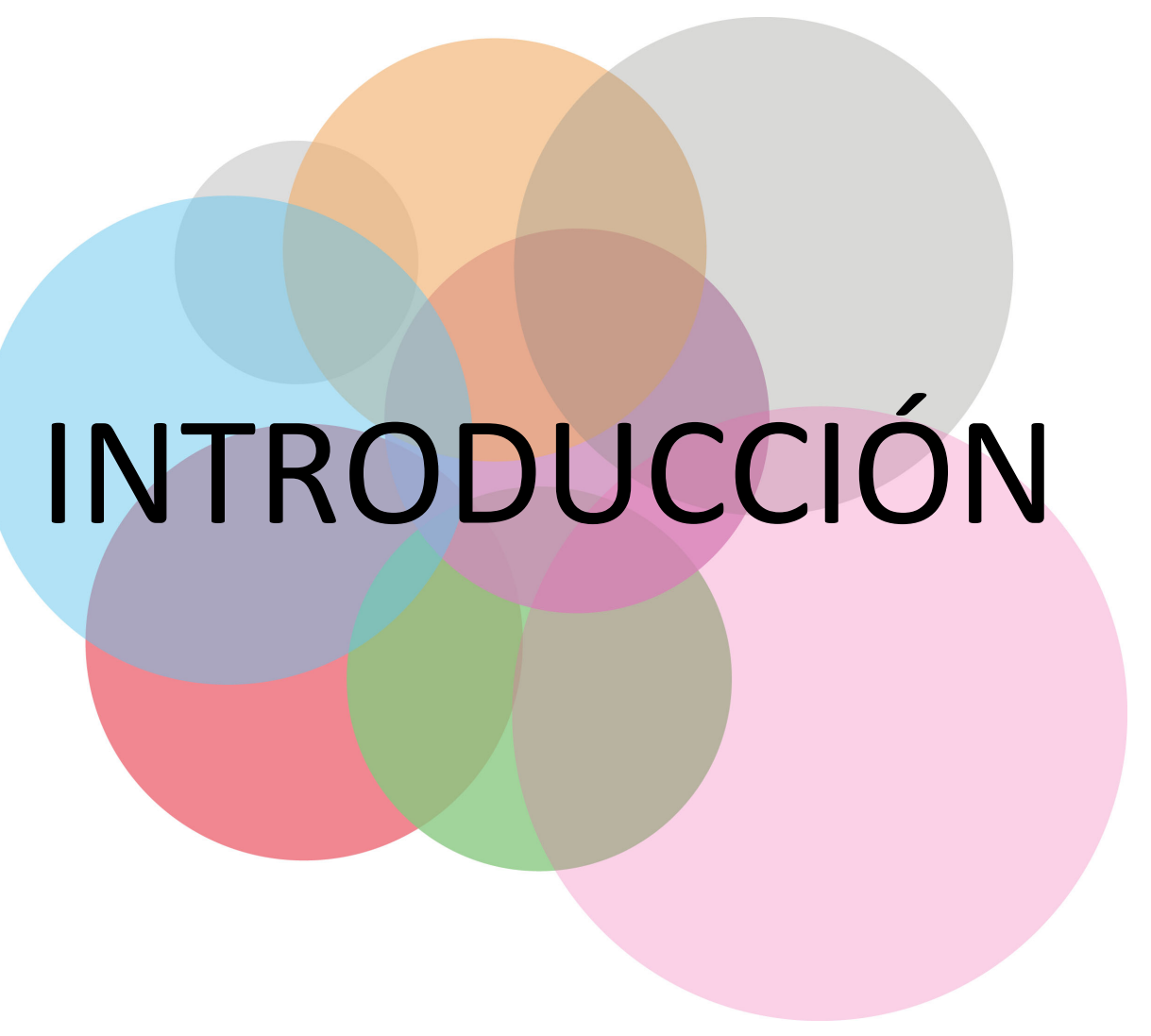


La "anatomía", definida como ciencia que estudia la estructura del organismo humano, es una disciplina fundamental en la formación sanitaria, que no solo proporciona conocimientos sobre la estructura del cuerpo humano (forma, colocación, disposición de los distintos órganos y estructuras y las relaciones existentes entre ellos) como señala su definición, sino que también ayuda a potenciar el desarrollo de habilidades y actitudes esenciales para el ejercicio de las profesiones dedicadas al cuidado de la salud. En medicina es un pilar esencial, ya que otras ciencias como la fisiología, la patología, la semiología clínica e incluso la terapéutica requieren de su conocimiento.

No disponer de conocimientos anatómicos dificulta enormemente el ejercicio médico, ya que realizar una adecuada exploración clínica del paciente, una apropiada interpretación de los signos y síntomas de los diversos cuadros clínicos, una acertada descripción de los hallazgos patológicos o un abordaje correcto, tanto con fines diagnósticos como terapéuticos, de las distintas regiones del cuerpo, exige tener suficiente dominio sobre la anatomía humana. (Rodríguez-Herrera et al., 2019).

La enseñanza de anatomía es básica en todas las ciencias de la salud. En medicina, al tratarse de una profesión en constante evolución, requiere del estudio continuado a lo largo de toda la vida profesional y no solo en las primeras fases de formación. La finalidad principal de esta asignatura en la universidad es conseguir que el estudiante de la disciplina conozca y se familiarice con los órganos y estructuras que constituyen el cuerpo humano y pueda reconocer las relaciones existentes entre ellos, de manera que pueda aplicar esta información en su futuro desempeño profesional. (MompeóCorredera, 2014; Torres Merchán, 2013; Guiraldes et al., 2001).

Etimológicamente la palabra "anatomía" deriva del griego, y significa volver a cortar ("ana", volver y "tomos", cortar), lo que ya nos indica que la metodología preferida para el aprendizaje de anatomía desde la antigüedad ha sido la disección de cadáveres. 
A través de esta práctica, Herófilo de Calcedonia (335 a.C.- 280 a.C.), considerado el primer anatomista de la historia, junto con Erasístrato de Ceos, realizó numerosas aportaciones a la anatomía humana, entre ellas, diferenciar las venas de las arterias, establecer la sincronía entre el pulso y los latidos cardiacos, identificar la disposición del confluyente venoso de la parte posterior del cerebro (prensa de Herófilo), diferenciar el cerebro del cerebelo, describir las distintas capas oculares o estudiar en profundidad el sistema reproductor femenino. (Araujo Cuauro, 2018).

Sin embargo, fue Galeno de Pérgamo (129 - 216) el primero en comenzar a realizar informes anatómicos con descripciones detalladas de diversos órganos y sistemas basándose en disecciones principalmente de animales, pues las disecciones humanas estaban prohibidas por la ley en aquella época en Roma, aunque si recibió lecciones anatómicas en el "Museum" de Alejandría basadas en disecciones de cadáveres humanos. (Campohermoso Rodríguez et al., 2016).

Sus informes fueron durante siglos la base de la medicina, hasta que en 1543 se publicó "De humani corporis fabrica", con más de 200 ilustraciones, obra de Andreas Vesalius (1514-1564) (Fig. 1), quien ha sido considerado como el precursor de la anatomía moderna. (Romero Reveron, 2007). 


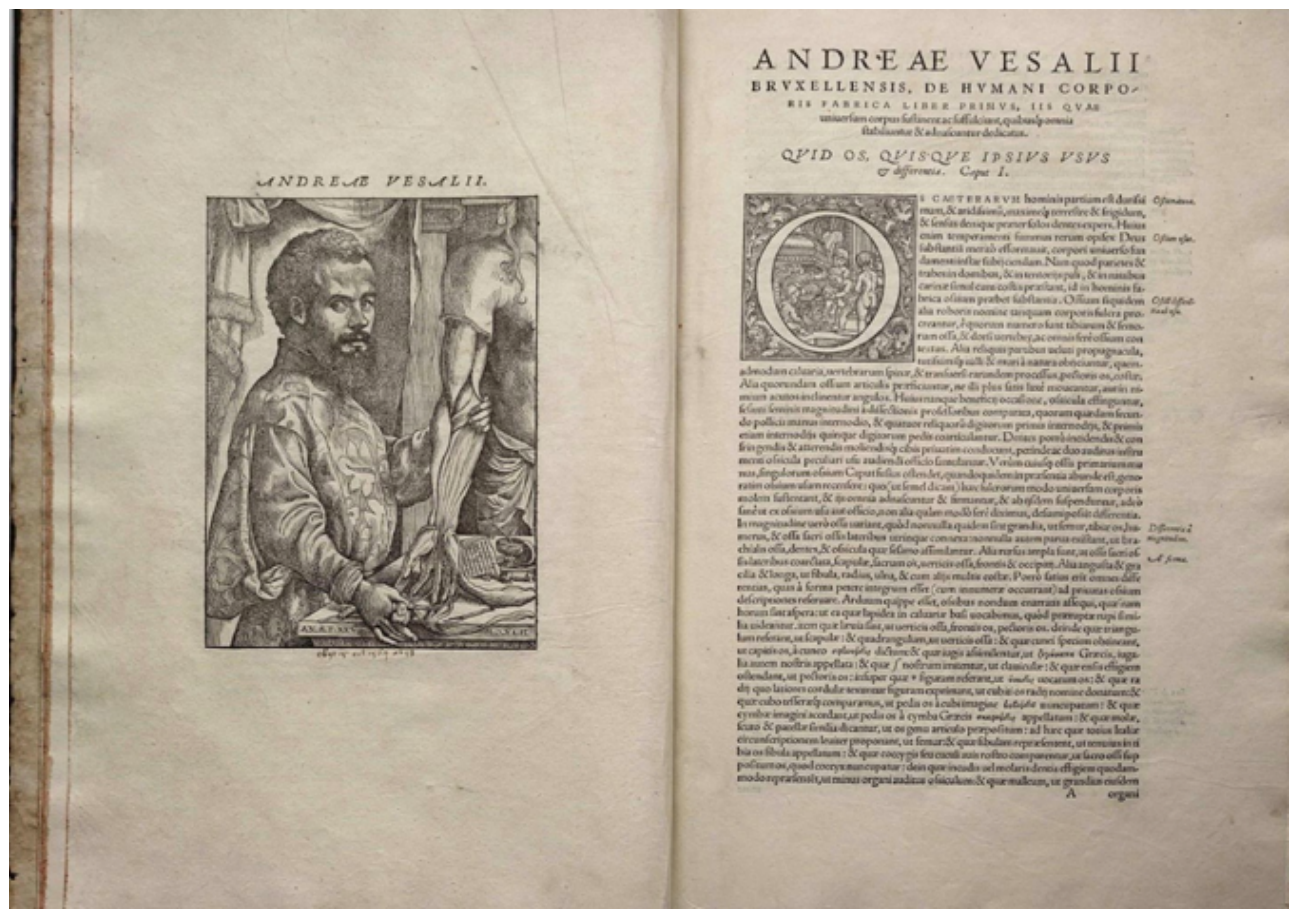

Figura 1. Ilustración perteneciente a "De humani corporis fabrica".

Consta de siete libros, el primero dedicado a los huesos y a los cartílagos, el segundo a los músculos y a los ligamentos (Figs. 2 y 3).

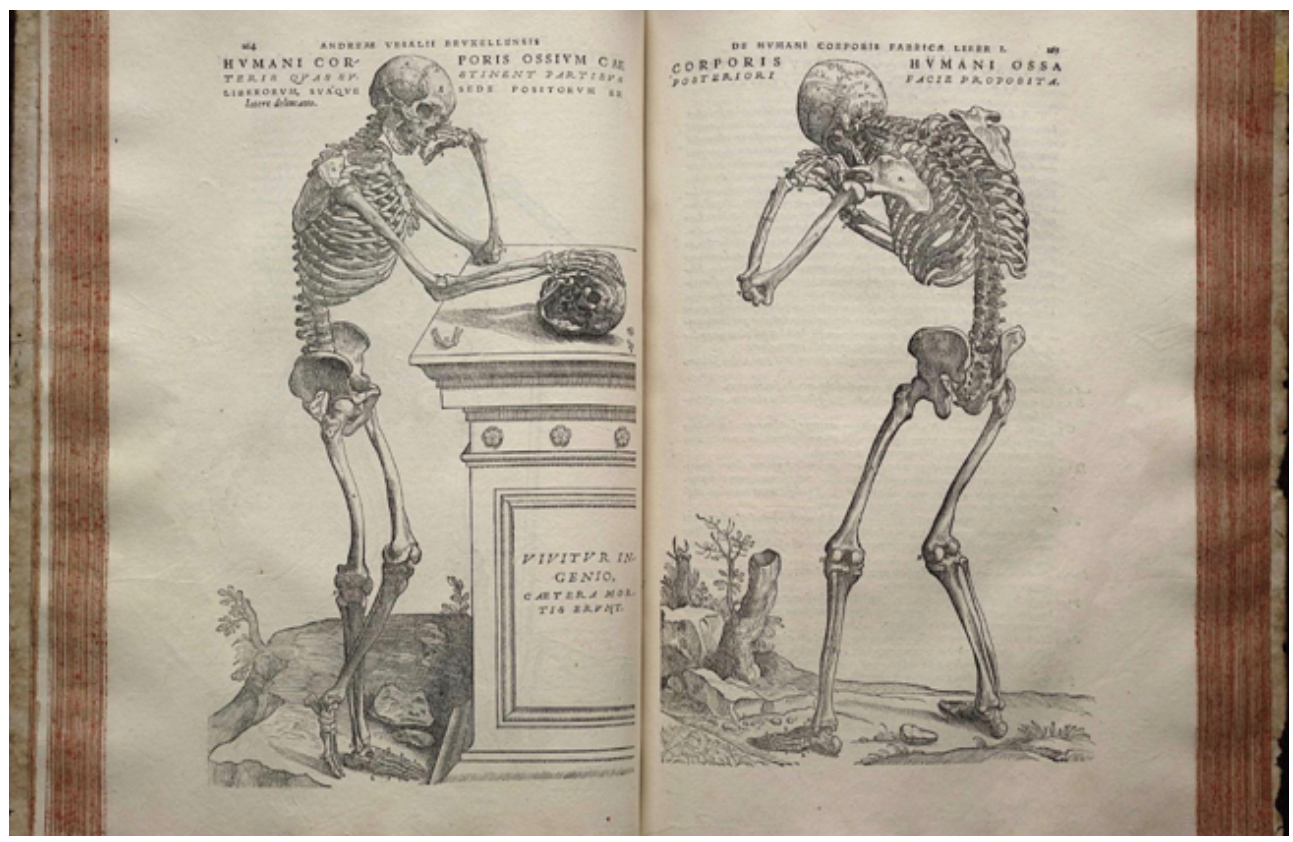

Figura 2. Ilustración perteneciente a "De humani corporis fabrica". 


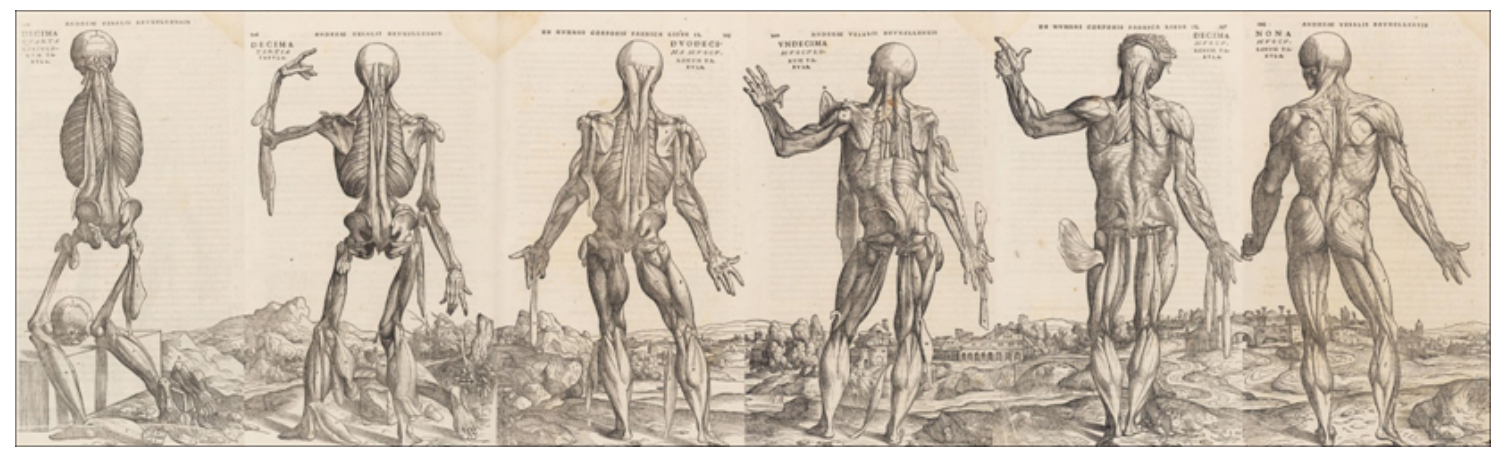

Figura 3. Ilustración perteneciente a "De humani corporis fabrica".

El tercero a las venas y a las arterias (Fig. 4), el cuarto a los nervios (Fig. 5), el quinto a los aparatos digestivo y reproductor, el sexto al corazón y otros órganos del tórax y el séptimo al sistema nervioso central y a los órganos de los sentidos (Fig. 6).

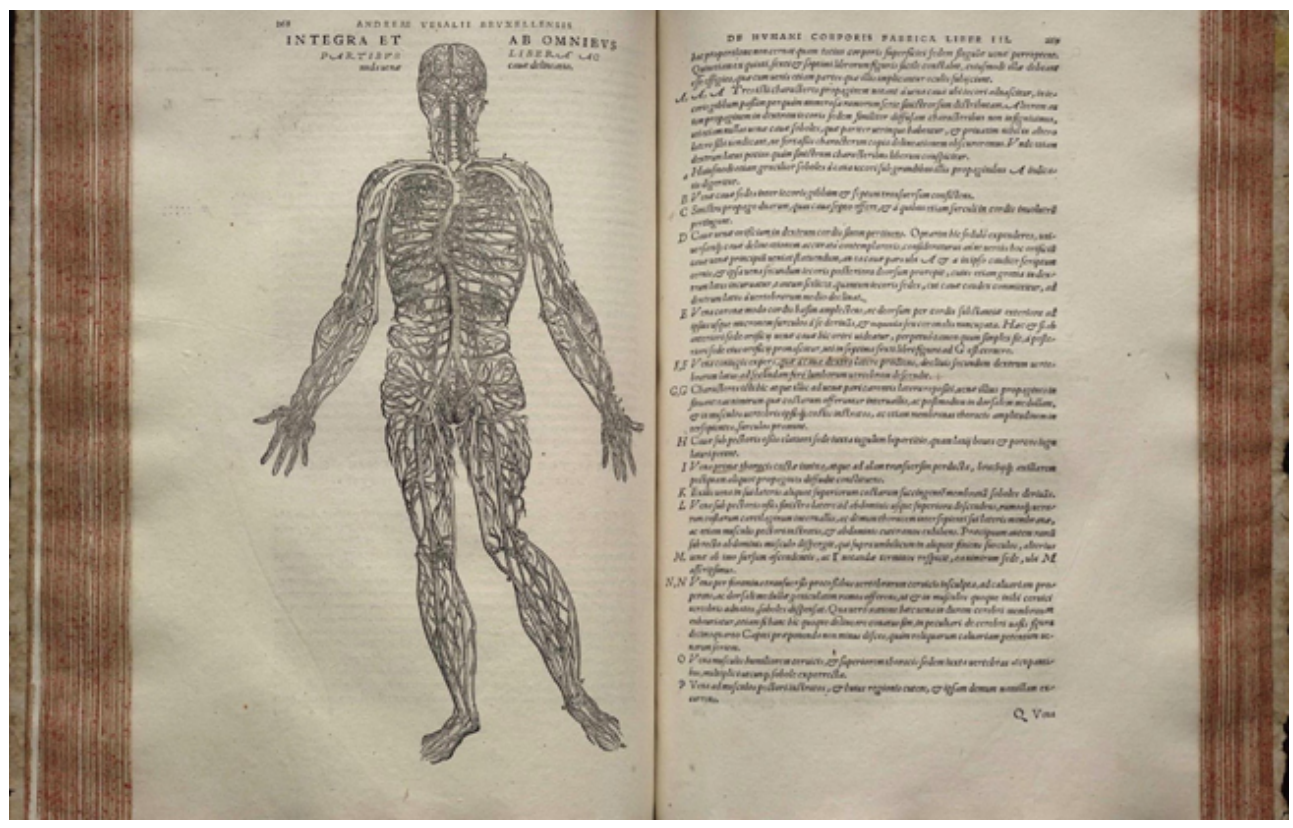

Figura 4. Ilustración perteneciente a "De humani corporis fabrica". 


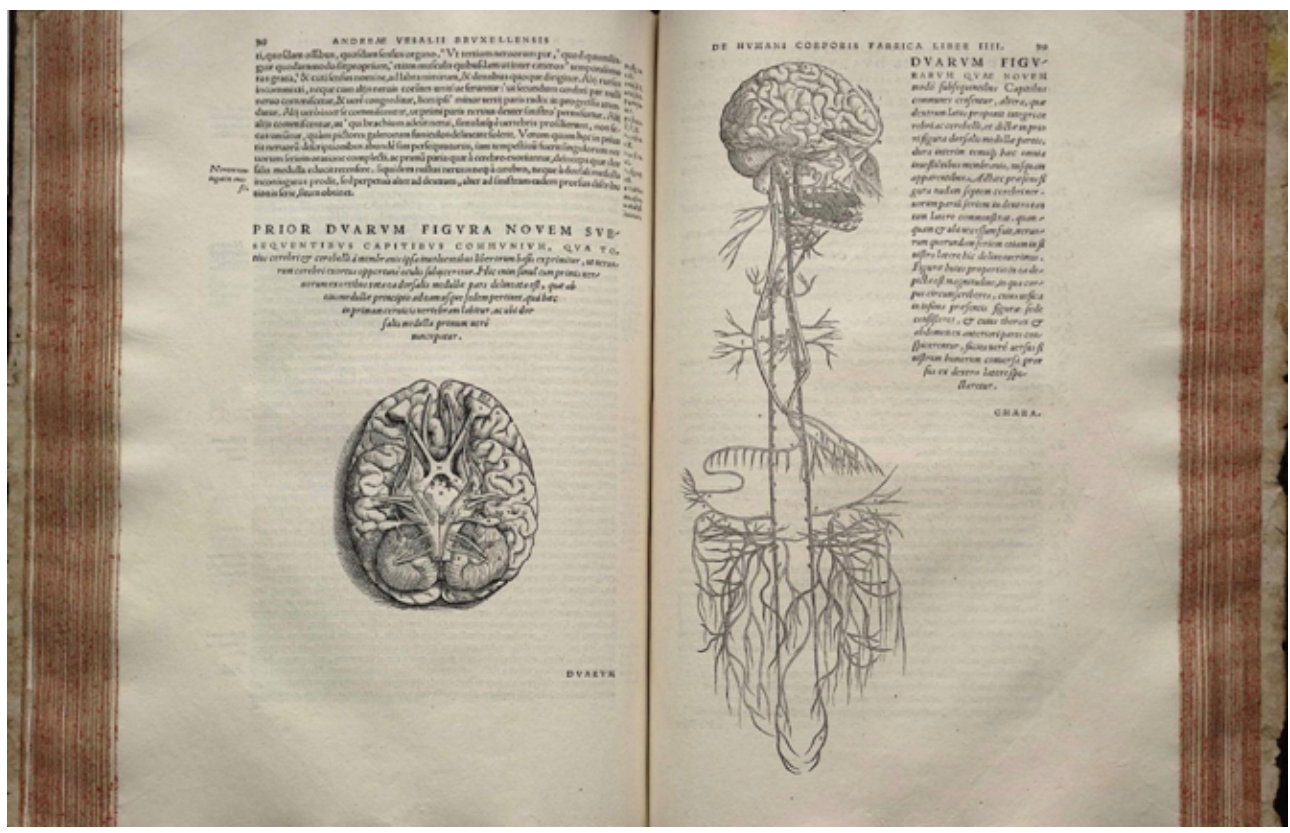

Figura 5. Ilustración perteneciente a "De humani corporis fabrica".

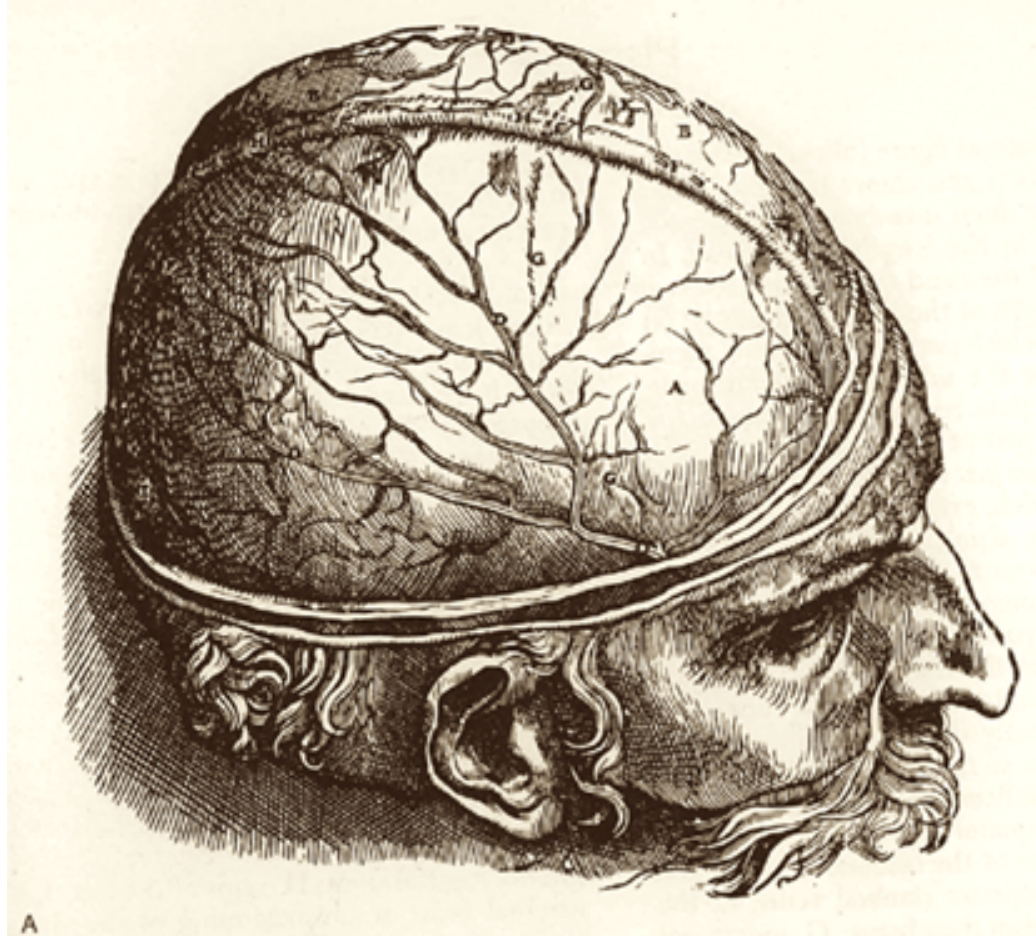

Figura 6. Ilustración perteneciente a "De humani corporis fabrica". 
Es reconocido como el primer tratado moderno de anatomía, tanto por su claridad como por el rigor expositivo de sus contenidos. Vesalius consideraba la disección como la herramienta primordial de enseñanza y la observación directa como la mejor forma de aprendizaje. Aportó innovaciones al sistema de enseñanza al mostrar la anatomía combinando el uso de cadáveres, libros y dibujos con la finalidad de mejorar la comprensión del cuerpo humano. (Ghosh, 2015; Vesalius, 1543).

Desde entonces se han realizado numerosas aportaciones al conocimiento de la anatomía del cuerpo humano, destacando personalidades como William Harvey, Marcello Malpighi, Charles Bell, Luigi Rolando, Jacob Henle, Paul Broca o Jean Leon Testut, entre otros. (Ferrando Castro, 2019).

A partir de mediados del siglo XX, considerado ya éste como el "periodo moderno de la anatomía", y tras haber descubierto y descrito todos los órganos y estructuras anatómicas del cuerpo humano, se inicia una nueva etapa, con la finalidad de facilitar y mejorar la visualización de las estructuras y órganos de los seres humanos de una forma inocua, in vivo. Aunque la enseñanza de la anatomía no sufre grandes variaciones con respecto al siglo anterior, pues las prácticas docentes se siguen basando en la disección del cadáver humano. (Valenzuela Torres et al., 2010).

Aunque la disección de cadáveres permite la visualización directa y la posterior manipulación de las estructuras anatómicas, las imágenes también han sido unas grandes aliadas para la enseñanza de esta disciplina. Sin embargo, establecer la relación espacial entre distintas estructuras anatómicas a partir de la representación bidimensional, plana, en dibujos, ilustraciones o fotografías de modelos físicos tridimensionales o cuerpos reales es difícil y requiere un elevado esfuerzo mental. (Montemayor Flores, 2006; García Barrios et al., 1999). 
El descubrimiento de las técnicas de imagen, principalmente orientadas al diagnóstico, como la Resonancia Magnética (1948), la Ecografía (1950) o la Tomografía Axial Computarizada (1967), así como el perfeccionamiento de las mismas y la consecución posterior de la denominada "Reconstrucción Multiplanar" (1990), ha permitido el estudio tridimensional de estructuras anatómicas en personas vivas. (Canals, 2008).

Estas innovaciones tecnológicas aplicadas a la medicina clínica, junto con el vertiginoso desarrollo de las tecnologías de la información y la comunicación, han propiciado la aparición de una nueva metodología de enseñanza. (Darras et al., 2018; Fang et al., 2017; Govsa et al., 2017; Moore et al., 2017; Smit et al., 2017; Balaya et al., 2016; Gonzalo Domínguez et al., 2016; Drapkin et al., 2015; Mavar-Haramija et al., 2015; Juanes et al., 2014b; De Notaris et al., 2013; Nowinski et al., 2013; Sora et al., 2011; Larson et al., 2010).

Podríamos sintetizar que la enseñanza de anatomía ha pasado por diversas fases a lo largo de la historia, comenzando en las primeras épocas con la simple observación, siguiendo con la disección de cadáveres, y llegando hasta el momento actual, en el que prima la enseñanza asociada a la tecnología. (Keenan y Awadh, 2019; Rodríguez Rubio et al., 2019; Arantes et al., 2018; Hecht y Larrazábal, 2018; Alapati y Jambhekar, 2017; Darras et al., 2017; Ackerman, 2016; Comaniciu et al., 2016; Hackett y Proctor, 2016; Trelease, 2016; Ugidos Lozano et al., 2016; Ghosh, 2015; Legendre et al., 2015; Framiñán et al., 2013; Shin et al., 2013; Dai et al., 2012; Sergovich et al., 2010).

Las Tecnologías de la Información y la Comunicación (TIC), que podríamos definir como aquellas tecnologías relacionadas con el almacenamiento, procesamiento, recuperación y comunicación de la información mediante el uso de dispositivos 
electrónicos e informáticos, han transformado el sistema de enseñanza-aprendizaje, afectando a los papeles que desempeñan tanto el profesor como el estudiante. (Bringman et al., 2020; Moro y Gregory, 2019; Wilson et al., 2019; García y López, 2011; Juanes et al., 2010).

Las nuevas tecnologías favorecen el aprendizaje constructivista y significativo. El alumno construye su saber mediante la unión de los conocimientos previos que ya posee con los nuevos conocimientos que aprende por medio de la indagación y la búsqueda de información.

Las TIC fomentan una actitud activa en el alumno, convirtiendo a éste en protagonista y actor de su propio aprendizaje. Refuerzan la memoria visual, lo que facilita tanto la comprensión de los contenidos como el recuerdo de los mismos. Proporcionan así mismo flexibilidad, versatilidad, interactividad y conectividad al estudiante, de manera que permiten complementar, enriquecer y transformar su educación. (Lai y Bower, 2020; Moro et al., 2020; Astudillo et al., 2018; Clunie et al., 2018; Gutiérrez Tapias, 2018; Pickering y Swinnerton, 2018; Sáez-López, 2018; BrizPonce et al., 2017; Ricardo Barreto y Diazgranados, 2017; Guerrero, 2014; Belloch, 2012; Ruiz et al., 2012; Domínguez Merlano, 2010).

La posibilidad de construir imágenes tridimensionales a partir de las obtenidas con la tecnología actual, y permitir la interacción del usuario con las mismas, ha llevado hacia el aprendizaje de un nuevo tipo de anatomía, una anatomía más dinámica, en la que el estudiante dirige su propia formación y marca su ritmo de aprendizaje. (Darras et al., 2018; Fang et al., 2017; Govsa et al., 2017; Moore et al., 2017; Smit et al., 2017; Balaya et al., 2016; Gonzalo Domínguez et al., 2016; Drapkin et al., 2015; Mavar-Haramija et al., 2015; Juanes et al., 2014d; De Notaris et al., 2013; Nowinski et al., 2013; Sora et al., 2011; Larson et al., 2010). 
La aplicación de entornos 3D para la formación es una nueva fuente de oportunidades para los procesos de enseñanza-aprendizaje. Ofrecen una representación tridimensional de los órganos y estructuras, permitiendo visualizar los mismos desde distintos ángulos y distancias, facilitando la comprensión de conceptos complejos y abstractos. Son intuitivos y resultan atractivos para los estudiantes, lo que proporciona una motivación extra para el aprendizaje. (O'Rourke et al., 2020; Kenway y Bakr, 2019; Triepels et al., 2019; Ugidos Lozano et al., 2019; Barbeito et al., 2017; Peterson y Mlynarczyk, 2016; Sanchís López, 2015; Khot et al., 2013; Preece et al., 2013; Abid et al., 2010; Corton et al., 2006).

En el estudio de anatomía no sólo basta con ver estructuras y órganos, hay que saber identificar, interpretar y situar lo que se ve.

Es evidente que la conformación de los órganos y estructuras anatómicas de la pelvis femenina en los tres planos del espacio es compleja y difícil de representar. Por ello, consideramos que la aplicación de modelos anatómicos digitales tridimensionales interactivos facilita a los usuarios la visualización de los mismos, y especialmente, la percepción de las relaciones espaciales que establecen entre ellos, algo que no todos los estudiantes consiguen con las imágenes en 2D. (Jamil et al., 2019; Guimarães et al., 2018; Karakas et al., 2018; Vernez et al., 2017; Azer y Azer, 2016; Pujol et al., 2016; Allen et al., 2015; Berney et al., 2015; Kurobe et al., 2015; Juanes et al., 2013; De Notaris et al., 2010; Estévez et al., 2010).

Nuestro trabajo pretende ofrecer una metodología 3D interactiva, que resulte atractiva para el aprendizaje de la anatomía pélvica femenina, de manera que sirva para guiar tanto al estudiante de anatomía como al profesional sanitario en su práctica clínica diaria. 
La introducción de estas herramientas didácticas en las aulas enriquece de manera considerable el proceso de enseñanza-aprendizaje. Aprender haciendo, es decir, interactuando con la información, motiva y proporciona la adopción de una actitud activa en los individuos y la realización de un aprendizaje autónomo y significativo, en el que la responsabilidad del mismo ya no recae básicamente en el profesor. El alumno se convierte en responsable directo de su proceso de aprendizaje, aunque sin olvidar que el docente debe asumir también su papel, actuando como guía y dirigente de estos nuevos modelos educativos. (Lai y Bower, 2020; Moro et al., 2020; Astudillo et al., 2018; Clunie et al., 2018; Gutiérrez Tapias, 2018; Pickering y Swinnerton, 2018; Sáez-López, 2018; Briz-Ponce et al., 2017; Ricardo Barreto y Diazgranados, 2017; Guerrero, 2014; Belloch, 2012; Ruiz et al., 2012; Domínguez Merlano, 2010).

La introducción de la enseñanza asociada a la tecnología en las instituciones educativas, y especialmente en las universitarias, es hoy en día obligada, máxime cuando la generación actual de estudiantes está acostumbrada a utilizar dispositivos digitales en su vida cotidiana, lo que les permite acceder a gran cantidad de información, con una facilidad, velocidad y profundidad sin precedentes, en cualquier momento y en cualquier lugar.

Las universidades deben asumir el reto de aportar creatividad y flexibilidad curricular, incluyendo la interactividad, la independencia y la autonomía en las experiencias de aprendizaje, de manera que los estudiantes adquieran competencias para llevar adelante un aprendizaje significativo y autónomo a lo largo de toda su vida, incluida la profesional. (Moro et al., 2019; Papadopoulou et al., 2019; Houser y Kondrashov, 2018; Ward et al., 2018; Rea, 2016; Briz-Ponce et al., 2015; Juanes y Ruisoto, 2015; Briz et al., 2014; Briz Ponce et al., 2014a; Briz Ponce et al., 2014b; Juanes y Ruisoto, 2014; Noguera et al., 2013; Cook et al., 2011; Bustos Sánchez y Coll Salvador, 2010). 
La tecnología se ha convertido en una baza indispensable a la hora de transmitir conocimientos, y por ello, en pleno siglo XXI, se espera una integración de las TIC como cultura institucional en las universidades, que impulse además de una transformación en los modelos pedagógicos, un cambio en los escenarios, de manera que fomente el desarrollo de las potencialidades del alumnado y proporcione un acceso en igualdad de oportunidades para todos los estudiantes.

Las TIC facilitan los contenidos, mediante las experiencias de aprendizaje, propician ambientes de estudio idóneos, desarrollan habilidades y destrezas cognitivas y enriquecen las dinámicas educativas. Aprender por medio de la interacción con las herramientas tecnológicas, favorece la comprensión de los conceptos y posibilita la transformación de la información en conocimiento.

En definitiva, las TIC son parte de los cambios que se están produciendo a todos los niveles de la sociedad actual y las instituciones educativas no pueden mantenerse al margen, puesto que la aplicación de experiencias de aprendizaje, combinando la enseñanza asistida por la tecnología y la instrucción centrada en el profesor, puede ser muy beneficiosa en las aulas.

Para mayor comprensión de las imágenes y modelos que empleamos en nuestra aplicación, se debe poseer un conocimiento anatómico básico, por este motivo, haremos un repaso anatómico de la pelvis y de las estructuras que la componen. Nos centraremos únicamente en la anatomía de la pelvis femenina, objeto de nuestra aplicación informática, dando unas pinceladas simples para centrarnos en la materia que nos ocupa, basándonos en diversos autores. (Wineski, 2019; Rohen et al., 2011; Cael, 2010; Dykes y Watson, 2010; Lippert, 2009; Gilroy et al., 2008; Canby, 2007; Moore y Agur, 2007; Netter, 2007; Tórtora y Derrickson, 2007; García-Porrero y 
Hurlé, 2005; Shünke et al., 2005; Perlemuter, 1999; Feneis y Dauber, 1998; Rouviére y Delmas, 1987).

La pelvis es la región del cuerpo situada por debajo del abdomen, área de transición entre el tronco y los miembros inferiores, cuya cavidad se continúa, formando un ángulo posterior, con la abdominal.

El termino pelvis significa "vasija", aunque en lenguaje común se aplica más específicamente a la cintura pélvica o pelvis ósea, por lo que estaríamos hablando de una estructura ósea con forma de vasija, cuya función principal es transmitir el peso del cuerpo desde la columna vertebral hacia los fémures. Además, sirve como zona de inserción para numerosos músculos del tronco y de los miembros inferiores. En su cavidad contiene las porciones inferiores de las vías urinarias y del tubo digestivo, así como los órganos reproductores e importantes nervios, vasos sanguíneos y linfáticos.

Está formada por cuatro huesos: dos coxales que forman las paredes lateral y anterior; y el sacro y el cóccix, que constituyen la pared posterior.

Los coxales se articulan entre sí en la zona anterior, en la sínfisis del pubis y en la zona posterior, con el sacro a través de las articulaciones sacroilíacas.

El hueso sacro está conformado por la fusión de cinco vértebras en una pieza ósea única, con forma de cuña de concavidad anterior, y atravesada por un conducto (conducto sacro), resultado de la unión de los agujeros o forámenes vertebrales y que contiene las raíces anterior y posterior de los nervios espinales lumbares, sacros y coccígeos, el filum terminal y la sustancia fibroadiposa. Se articula por su borde superior o base con la vértebra L5, por su borde inferior con el cóccix y lateralmente con los huesos ilíacos (parte del hueso coxal), mediante las articulaciones sacroilíacas.

El cóccix es un pequeño hueso triangular formado por cuatro vértebras fusionadas, que se articula en su base con el extremo inferior del sacro. 
El hueso coxal en los niños está formado por el ilion, el isquion y el pubis, se fusionan durante la pubertad dando origen a un único hueso grande e irregular, con una profunda depresión en la cara externa, el acetábulo, que se articula con la cabeza hemisférica del fémur.

Posteriormente a este acetábulo, encontramos una gran muesca, la escotadura ciática mayor (salida desde la pelvis hacia el interior de la región glútea para el nervio ciático, el nervio pudendo y los nervios y vasos glúteos), separada de la escotadura ciática menor (vía de entrada al periné desde la región glútea para el nervio pudendo y los vasos pudendos internos) por la espina ciática.

La pelvis, con forma de cuenco, consta de una pared anterior, una posterior, dos laterales y una inferior o suelo. Las paredes están formadas por huesos y ligamentos parcialmente revestidos por músculos cubiertos por fascia y peritoneo parietal.

La pared anterior está formada por los cuerpos del pubis, las ramas púbicas y la sínfisis del pubis.

La pared posterior la constituyen el sacro y el cóccix, junto con los músculos piriformes y su revestimiento de fascia pélvica parietal.

Ambas paredes laterales están compuestas por parte del hueso coxal, la membrana obturatriz, los ligamentos sacrotuberoso y sacroespinoso, y el músculo obturador interno con su fascia.

El suelo pélvico o periné es la pared inferior de la pelvis, compuesto por el diafragma pélvico y otros músculos. La musculatura que constituye el suelo pélvico está dispuesta en tres planos que diferenciaremos a continuación, al describir los músculos de la pelvis.

El plano profundo (diafragma pélvico) está constituido por los músculos elevador del ano y coccígeo. 
El músculo elevador del ano es una lámina muscular amplia y delgada constituida por 3 fascículos diferenciados, de anterior a posterior, que son el fascículo pubococcígeo (conformado por tres músculos: pubovaginal, puboperineal y puboanal), el fascículo puborrectal y el fascículo iliococcígeo. Este músculo sostiene las vísceras pélvicas en su posición, haciendo que resistan el aumento de presión intrapélvica que se produce durante las contracciones abdominales (por ejemplo, al toser), y muestran una importante acción esfinteriana sobre la unión anorrectal y, en la mujer, también sobre la vagina.

El otro músculo que forma una pequeña parte posterior del diafragma pélvico en este plano más profundo es el coccígeo. Es un músculo de forma triangular, que se origina en la espina ciática y se inserta en el extremo inferior del sacro y en el cóccix.

El plano medio, lo forman la membrana perineal (anteriormente denominada "musculo transverso profundo del periné") y el músculo esfínter de la uretra.

El plano superficial, lo constituyen cinco músculos: el esfínter externo del ano, el transverso superficial del periné, el isquiocavernoso, el bulbocavernoso y el constrictor de la vulva.

Entre la vagina y el ano se encuentra una masa fibromuscular que constituye el cuerpo perineal, punto de inserción de varias fibras musculares y fascias (músculos bulbocavernosos, transversos superficiales, hemivainas de la membrana perineal, esfínter anal externo, fibras puboperineales del fascículo pubococcígeo del músculo elevador del ano).

La inervación de la pelvis y las estructuras que contiene deriva de los plexos lumbar y sacro y de la cadena simpática, formando grandes redes a través de las paredes pélvicas para inervar la pelvis, el periné, el abdomen inferior y los miembros inferiores.

El plexo lumbar se divide en dos ramos fundamentales, el tronco lumbosacro (formado por la unión del ramo anterior del nervio L4 y el ramo anterior del nervio L5) y el nervio obturador (ramo del plexo lumbar L3-L4, emerge del borde medial del 
músculo psoas, cruza la cara anterior de la articulación sacroilíaca y discurre por la pared pélvica lateral entre los vasos ilíacos internos y externos, alcanza el conducto obturador y se divide).

El plexo sacro, ubicado por delante del músculo piriforme, está compuesto por el tronco lumbosacro y el ramo anterior de los nervios S1 a S4. Proporciona ramos para el miembro inferior como son: nervio ciático, nervio glúteo superior e inferior, nervio para el músculo cuadrado femoral (y músculo gemelo inferior), nervio para el músculo obturador interno (también para el músculo gemelo superior), nervio cutáneo femoral posterior. Y ramos para los músculos pélvicos, las vísceras pélvicas y el periné: nervio pudendo, nervio para el músculo piriforme, nervios esplácnicos pélvicos y nervio cutáneo perforante.

Las fibras simpáticas y parasimpáticas se entrelazan, al igual que los previos, para formar plexos (plexo hipogástrico superior e hipogástricos inferiores) que inervan la pelvis, el periné y parte del intestino.

La vascularización de la pelvis es una de las partes anatómicas más difíciles de comprender y representar junto con los nervios. Las arterias que irrigan la pelvis y sus estructuras derivan de la aorta que a nivel de L4 - L5 se divide en las iliacas comunes. Estos vasos se bifurcan en las arterias ilíacas externa e interna. La arteria iliaca externa es la encargada de transportar la sangre oxigenada hacia el miembro inferior. La arteria iliaca interna es la que aporta el suministro sanguíneo a las estructuras pélvicas. Las ramas de la división anterior de la iliaca interna son las siguientes:

- Arteria umbilical: emite la arteria vesical superior, en el adulto solo es permeable su tramo pélvico.

- Arteria obturatriz: irriga los músculos obturadores y la parte alta de los aproximadores. 
- Arteria vesical inferior: es en realidad una arteria genitourinaria, que irriga el fondo y la parte inferior de la vejiga.

- Arteria rectal media: irriga el músculo de la porción inferior del recto y se anastomosa con las rectales superiores e inferiores.

- Arteria pudenda interna: es la arteria principal del periné y de los órganos genitales externos. Da ramas colaterales: rama glútea; arteria rectal inferior; arteria perineal (irriga los músculos isquiocavernosos, bulbocavernosos y perineales transversos). Sus ramas terminales son las arterias labiales posteriores y la arteria del clítoris.

- Arteria glútea inferior: irriga músculos y piel de la región glútea y de la parte posterior del muslo.

- Arteria uterina: desciende siguiendo la pared lateral de la pelvis, penetra en la base del ligamento ancho en dirección al cuello uterino, donde se cruza por delante y por encima del uréter. Finalmente asciende, siguiendo el borde lateral del útero dando una rama tubárica y una rama ovárica que se anastomosan con la arteria ovárica a nivel del mesoovario. Da múltiples ramas para el cuerpo y el cuello uterino y algunas para la cúpula vaginal.

- Arteria vaginal: Irriga la vagina y da ramas vesicales para el fondo y la parte inferior de la vejiga. En la pared de la vagina se anastomosa con la del lado opuesto y con la arteria uterina.

La arteria iliolumbar, la sacra lateral y la glútea superior conforman las ramas de la división posterior.

Por otro lado, la arteria rectal superior es continuación directa de la arteria mesentérica inferior, recibe su nombre cuando cruza la arteria ilíaca común. Irriga la membrana mucosa del recto y la mitad superior del canal anal.

La arteria ovárica, emerge de la porción abdominal de la aorta a nivel de L1, cruza la arteria ilíaca externa en la entrada a la pelvis, penetra en el ligamento suspensorio del ovario, alcanza el ligamento ancho y entra en el ovario por el mesovario. Da 
ramas ováricas, tubáricas y para el ligamento redondo, con el que alcanza la piel de los labios mayores. Se anastomosa con la arteria uterina en el espesor del ligamento ancho.

La arteria sacra media es rama terminal de la aorta, siendo una arteria única, al contrario que la mayoría de las anteriores, que son bilaterales.

Los plexos venosos pélvicos están formados por vasos interconectados que rodean las vísceras de la pelvis. Los diversos plexos (rectal, vesical, uterino y vaginal), se unen y drenan principalmente a las venas ilíacas internas, aunque alguno de ellos drena a través de la vena rectal superior en la vena mesentérica inferior o a través de las venas sacras laterales, en el plexo venoso vertebral interno. Las vías adicionales de drenaje venoso de la pelvis incluyen la vena sacra media parietal, la vena rectal superior y las venas ováricas.

Las venas ilíacas internas se unen con las ilíacas externas, para formar las venas ilíacas comunes, que se fusionan a nivel de la cuarta o quinta vértebra lumbar para constituir la vena cava inferior.

Realizado un pequeño repaso de los huesos, músculos, nervios y vasos que conforman la pelvis, únicamente nos queda por revisar la anatomía de las vísceras que contiene.

Empezaremos por las porciones del aparato digestivo que se encuentran en la pelvis.

El colon sigmoide es un órgano intraperitoneal, que comienza como continuación del colon descendente a nivel del borde interno del psoas izquierdo y termina a la altura del recto. Tiene gran motilidad por disponer de un meso que lo une al peritoneo parietal posterior, el mesocolon sigmoide. 
Se relaciona por delante con la cara posterior del útero y superior de la vagina y por detrás con el recto y el sacro.

La porción terminal del intestino grueso es el recto, comienza como continuación del colon sigmoide a nivel de la tercera vértebra sacra, desciende, dilatándose en la parte inferior para formar la ampolla rectal y finaliza, perforando el diafragma pélvico, en el canal anal.

Se relaciona en la parte posterior con el sacro, el cóccix, los músculos piriforme, coccígeo y elevador del ano, el plexo sacro y los troncos simpáticos; y por delante, los dos tercios superiores con el colon sigmoide, las asas del íleon, que ocupan el fórnix rectouterino, y con el útero, mientras que el tercio inferior se relaciona con la cara posterior de la vagina.

El canal anal con $4 \mathrm{~cm}$ de largo discurre desde la ampolla rectal hasta el ano. Se relaciona en la zona posterior con una masa de tejido fibroso o cuerpo anococcígeo, lateralmente con las fosas isquioanales y en la parte anterior con el cuerpo perineal, el diafragma urogenital y la porción inferior de la vagina. Cuenta con un esfínter interno involuntario y otro externo voluntario.

En la pelvis también se encuentra parte del sistema urinario, como son la vejiga y la uretra.

La vejiga situada a nivel de los huesos púbicos tiene forma de pirámide triangular y consta de un vértice, una base o fondo, un cuello, una cara superior y dos caras ínfero-laterales. Guarda una estrecha relación en su cara superior con el cuerpo del útero, y en la base con la vagina, que la separa del recto.

La uretra femenina es un conducto corto que se extiende desde el cuello de la vejiga hasta la vulva. Desciende por detrás de la sínfisis del pubis y por delante de la vagina, desembocando en la vulva por el orificio uretral externo por detrás del clítoris y por delante del orificio vaginal. 
Puesto que nuestra aplicación informática únicamente contiene imágenes y modelos de la pelvis femenina, el repaso anatómico lo vamos a centrar en esta y explicaremos de forma concisa el aparato reproductor femenino.

Los ovarios, de forma ovoide, situados a los lados de la pelvis, en la fosa ovárica, se encuentran unidos al ligamento ancho por el mesoovario y se mantienen vinculados al útero por el ligamento propio del ovario. Son los órganos responsables de la producción de los óvulos, así como de los estrógenos y la progesterona.

Las trompas de Falopio son estructuras tubulares de aproximadamente $10 \mathrm{~cm}$ de longitud, que conectan la cavidad peritoneal, en la región del ovario, con la cavidad uterina. En las trompas se pueden diferenciar varias porciones, denominadas: infundíbulo, ampolla, istmo y porción uterina. Su función es recibir el óvulo desde el ovario y proporcionar un conducto para que los espermatozoides lleguen a él y se produzca la fecundación, que habitualmente tiene lugar en la parte denominada ampolla. Proporcionan nutrición al óvulo fecundado y lo transportan a la cavidad uterina.

El útero, es un órgano hueco con forma de pera y gruesas paredes musculares de músculo liso (miometrio), en el que distinguimos tres zonas: fondo, cuerpo y cuello o cérvix. El cuerpo uterino está relacionado en la zona anterior con el fórnix uterovesical y la cara superior de la vejiga; en la zona posterior, con el fórnix rectouterino y las asas del íleon o el colon sigmoide; y lateralmente con el ligamento ancho y los vasos uterinos. La porción supravaginal del cuello uterino se relaciona con la cara superior de la vejiga en la parte anterior y con el uréter en la parte lateral; y la porción vaginal del cuello con el fórnix anterior de la vagina en la zona anterior y lateralmente, con el fórnix lateral de la vagina.

El tubo muscular de aproximadamente $8 \mathrm{~cm}$ que va desde el útero hasta la vulva, se denomina vagina, presenta su mitad superior localizada en la cavidad pélvica, y su 
mitad inferior en el periné. Está relacionada anteriormente, en la parte superior con la vejiga, y en la parte inferior con la uretra. En la zona posterior, el tercio superior, con el fórnix rectouterino, el tercio medio con la ampolla del recto, y el tercio inferior con el cuerpo perineal, que lo separa del canal anal. Lateralmente tiene relaciones con el uréter en la zona superior, con las fibras puborrectales del elevador del ano en la zona media, y con el diafragma urogenital (conjunto de músculos del plano medio y superficial del periné) y el bulbo del vestíbulo en la parte inferior.

Dada la gran complejidad anatómica de esta región corporal, como ha quedado descrito anteriormente, nos proponemos, con este trabajo de Tesis Doctoral, llevar a cabo un desarrollo tecnológico que permita un mejor conocimiento morfológico de las estructuras que constituyen la pelvis femenina; todo ello, bajo una visión tridimensional, construidas desde secciones seriadas de cadáver y de resonancia magnética; buscando con este procedimiento un mejor aprovechamiento docente de las posibilidades que nos ofrecen hoy día las tecnologías informáticas. 


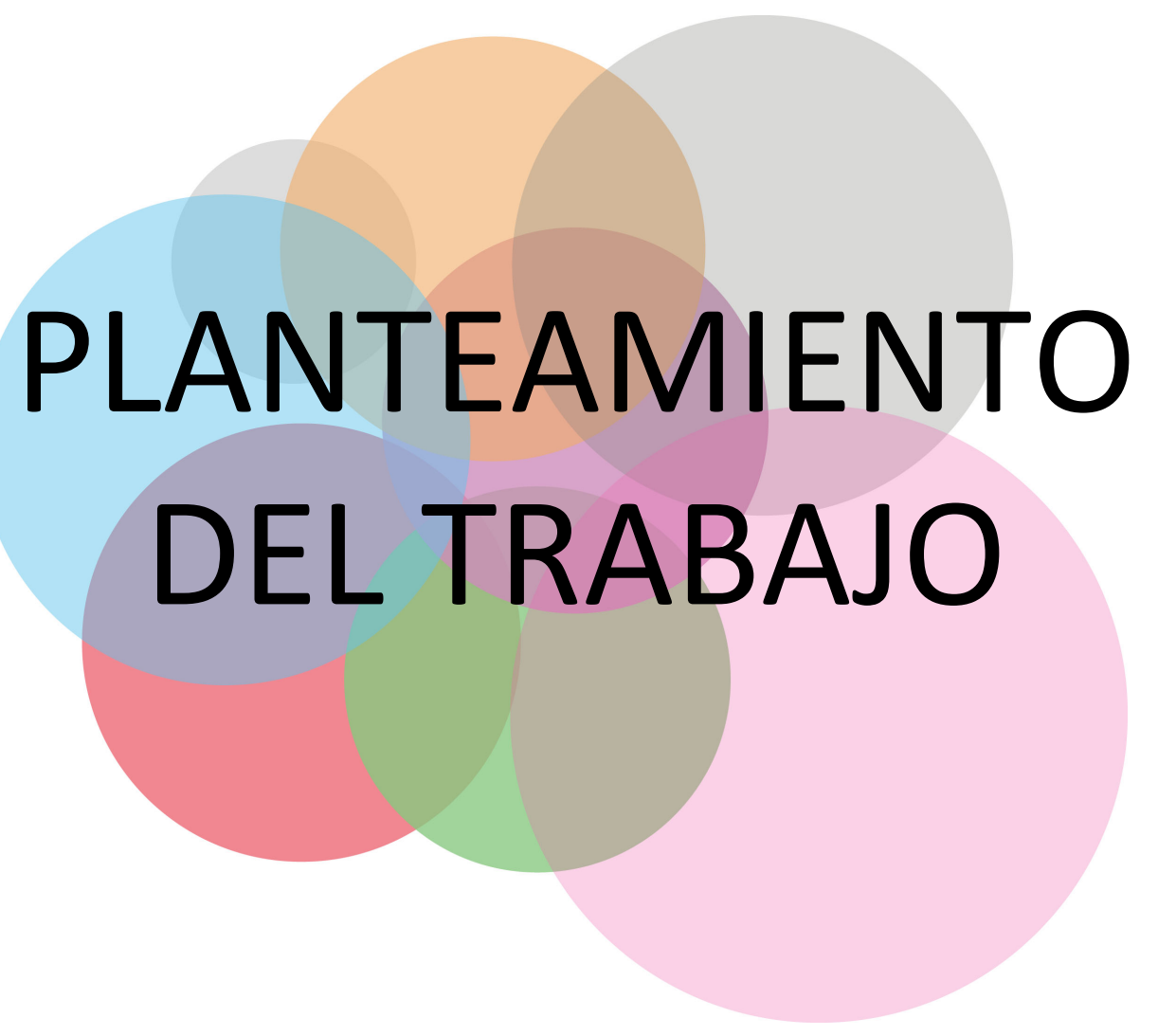


Vivimos en la era de la globalización, en la denominada "sociedad del conocimiento", en la que el vertiginoso desarrollo de las tecnologías de la información y la comunicación (TIC), han promovido cambios en todos los ámbitos de la actividad humana: social, económico, político, cultural, laboral, educativo, etc. (Moreira, 2019; Morrissey, 2010).

En el entorno educativo, la llegada de las TIC y las ventajas que ofrecen en la enseñanza, han hecho que se cuestionen los modelos pedagógicos empleados tradicionalmente y que se plantee la introducción de nuevos métodos didácticos, lo que ha supuesto un reto importante para las instituciones educativas, y especialmente para las universidades, cuya finalidad siempre ha sido dotar a los estudiantes de conocimientos, capacidades y habilidades que les permitan desenvolverse en futuros entornos laborales, potenciar el avance científico, contribuir al desarrollo económico y social y servir de plataforma para la educación a lo largo de toda la vida. (Lai y Bower, 2020; Moro et al., 2020; Astudillo et al., 2018; Clunie et al., 2018; Gutiérrez Tapias, 2018; Pickering y Swinnerton, 2018; Sáez-López, 2018; Briz-Ponce et al., 2017; Ricardo Barreto y Diazgranados, 2017; Guerrero, 2014; Belloch, 2012; Ruiz et al., 2012; Domínguez Merlano, 2010).

El proceso de innovación educativa impulsado por las TIC, en el que las universidades se encuentren inmersas, ha obligado a establecer cambios y reorientaciones en los métodos de enseñanza de sus disciplinas. (Moro et al., 2019; Papadopoulou et al., 2019; Houser y Kondrashov, 2018; Ward et al., 2018; Rea, 2016; Briz-Ponce y García Peñalvo, 2015; Juanes y Ruisoto, 2015; Briz et al., 2014; Briz Ponce et al., 2014a; Briz Ponce et al., 2014b; Juanes y Ruisoto, 2014; Noguera et al., 2013; Cook et al., 2011; Bustos Sánchez, 2010). 
Los objetivos del nuevo modelo educativo residen principalmente en situar a los estudiantes como protagonistas del proceso de enseñanza-aprendizaje e introducir métodos didácticos digitales accesibles para todos, libres de restricciones espaciotemporales, que motiven y promuevan un tipo de aprendizaje autónomo, activo, constructivo, participativo, interactivo, responsable y permanente. (Bringman Rodenbarger y Hortsch, 2020; Moro y Gregory, 2019; Wilson et al., 2019; García y López, 2011; Juanes et al., 2010).

Esta corriente universitaria, decidida a aprovechar las potencialidades de las TIC en la enseñanza, junto con el avance alcanzado por las técnicas de imagen para el diagnóstico y la clínica médica, han impulsado también la necesidad de implementar nuevos métodos didácticos en la disciplina de Anatomía Humana. (Golenhofen et al., 2020; Labovitz y Hubbard, 2020; Barrie et al., 2019; Chakraborty y Cooperstein, 2018; Deng et al., 2018; Izard et al., 2018; Lone et al., 2018; Fenesi et al., 2017; Jiménez López et al., 2017; Moro et al., 2017; Svirko y Mellanby, 2017; Tabernero Rico et al., 2017; Ugidos Lozano et al., 2017; Estai y Bunt, 2016; Morris et al., 2016; Rea, 2016; Yanamadala et al., 2016; Inzunza et al., 2015; Juanes et al., 2014b; Juanes et al., 2014c; Ruisoto Palomera et al., 2014; Ruisoto et al., 2012; Luo et al., 2011; Moszkowicz et al., 2011; Hampton y Sung, 2010; Larson et al., 2010; Seixas-Mikelus et al., 2010).

Enseñar a los alumnos a observar, analizar, interpretar y aprender anatomía, con vistas a la práctica clínica, al diagnóstico y al tratamiento de enfermedades, ha sido una constante a lo largo de la historia. (Hu et al, 2018)

Desde la antigüedad, la evolución médica y social ha conducido el paso de la didáctica de la Anatomía Humana por diversas fases (observación, ilustraciones, disección de cadáveres, etc.) en las que la se ha ido modificando la forma y el modo de ver e interpretar las diferentes estructuras del cuerpo humano. (Keenan y Awadh, 2019; Rodríguez Rubio et al., 2019; Arantes et al., 2018; Hecht y Larrazábal, 2018; 
Alapati y Jambhekar, 2017; Darras et al., 2017; Ackerman, 2016; Comaniciu et al., 2016; Hackett y Proctor, 2016; Trelease, 2016; Ugidos Lozano et al., 2016; Ghosh, 2015; Legendre et al., 2015; Framiñán et al., 2013; Shin et al., 2013; Dai et al., 2012; Sergovich et al., 2010).

Actualmente, los avances tecnológicos ofrecen nuevas posibilidades metodológicas, nuevas formas de estudiar y aprender anatomía. La introducción de modelos digitales que permiten la representación de imágenes anatómicas tridimensionales a partir de las obtenidas de cadáveres o de técnicas diagnósticas como la resonancia magnética, ha supuesto una forma novedosa de entender la anatomía. (Darras et al., 2018; Fang et al., 2017; Govsa et al., 2017; Moore et al., 2017; Smit et al., 2017; Balaya et al., 2016; Gonzalo Domínguez et al., 2016; Drapkin et al., 2015; MavarHaramija et al., 2015; Juanes et al., 2014d; De Notaris et al., 2013; Nowinski et al., 2013; Sora et al., 2011; Larson et al., 2010).

La visión tridimensional supone una herramienta crucial para la comprensión de numerosas estructuras y regiones anatómicas complejas, en especial de las que requieren mayores capacidades de habilidad espacial (Jamil et al., 2019; Guimarães et al., 2018; Vernez et al., 2017; Azer y Azer, 2016; Pujol et al., 2016; Allen et al., 2015; Berney et al., 2015; Kurobe et al., 2015; Juanes et al., 2013; De Notaris et al., 2010; Estévez et al., 2010).

En Medicina, la reconstrucción de estructuras corporales en tres dimensiones permitirá no solo un mejor conocimiento y comprensión de su morfología y de las relaciones espaciales que establecen entre ellas, sino un mayor acercamiento a datos diagnósticos de patologías y su posible tratamiento quirúrgico posterior, disminuyendo o evitando riesgos para los pacientes. (Erolin, 2019; Abdulaziz et al., 2017; Calderwood et al., 2017; Chen et al., 2017; Doumouchtsis et al., 2017; Giannini 
et al., 2017; Kostusiak et al., 2017; Weinstock et al., 2017; Yiasemidou et al., 2017; Alt et al., 2016; Araujo Júnior et al., 2014; Bertrand et al., 2014; Juanes et al., 2014d; Brown et al., 2013; Das y Mitchell, 2013; De Notaris et al., 2011).

La generación de este tipo de recursos digitales, de visión 3D, independiente de plataformas de software o hardware, que permite manipular los modelos anatómicos a voluntad, supera la visualización que se obtiene con los clásicos atlas anatómicos que se emplean en la enseñanza tradicional. (O'Rourke et al., 2020; Kenway y Bakr, 2019; Triepels et al., 2019; Ugidos Lozano et al., 2019; Barbeito et al., 2017; Peterson y Mlynarczyk, 2016; Sanchís López, 2015; Khot et al., 2013; Preece et al., 2013; Abid et al., 2010; Corton et al., 2006).

Diversos estudios han demostrado que estos modelos tridimensionales ofrecen mayor calidad de visualización que los métodos tradicionales, mejoran la comprensión de la anatomía al permitir la visión de los detalles anatómicos de manera "directa", y facilitan el proceso de aprendizaje, optimizando el tiempo dedicado al estudio. (Jamil et al., 2019; Ekstrand et al., 2018; Ellington et al., 2018; Guimarães et al., 2018; Van Nuland y Rogers, 2017; Allen et al., 2016; Pujol et al., 2016; Van Nuland y Rogers, 2016; Yammine y Violato, 2016; Lombardi et al., 2014; Yammine y Violato, 2014).

Teniendo en consideración estas apreciaciones comentadas previamente se plantea desarrollar un trabajo de Tesis Doctoral de características tecnológicas, bajo el título: “Entornos tecnológicos de visión anatomo-radiológica en 3D para el estudio de estructuras pélvicas", con la finalidad de poner al servicio de la formación médica una herramienta que permita la visualización y el análisis 3D de las estructuras anatómicas de la pelvis femenina, con secciones simultáneas de cadáver y de resonancia magnética, en los tres planos del espacio (axial, sagital y coronal), para facilitar el estudio y la comprensión de las estructuras que componen esta región corporal, dotada de gran complejidad anatómica. 
Con la aplicación del procedimiento informático elaborado se pretende que los usuarios (alumnos de ciencias de la salud, médicos residentes en la especialidad de ginecología, e incluso facultativos interesados en una visión 3D de estas estructuras corporales) experimenten con medios que se adapten a la realidad tecnológica actual en las áreas de las ciencias médicas. Creemos que el diseño de procedimientos tecnológicos interactivos para la docencia de la anatomía del organismo humano ayudará a obtener un conocimiento más adecuado de materias complejas que requieren de imágenes tridimensionales para su mejor valoración y análisis.

En este sentido, el desarrollo tecnológico que planteamos en nuestro trabajo de Tesis Doctoral quiere pretender que los usuarios que lo utilicen puedan interactuar con los modelos anatómicos tridimensionales de la pelvis femenina, de forma fácil, rápida y dinámica y ofrecer una visualización en cualquier posición espacial, aplicando movimientos de rotación, traslación, zoom, etc.

Para el desarrollo de esta aplicación utilizaremos estándares del mercado, con la finalidad de que el desarrollo informático se presente en un soporte compatible con la mayoría de los equipos informáticos y con las diferentes versiones del sistema operativo Windows, de los que disponen la mayor parte de los alumnos y de los centros universitarios españoles.

Por tanto, nuestro propósito con este trabajo de Tesis es generar una herramienta informática docente interactiva, para la visualización y el análisis 3D de las estructuras anatómicas de la pelvis femenina, con el fin de servir de ayuda y complemento a la formación anatómica tradicional llevada a cabo habitualmente bajo formatos de imágenes planas estáticas en los diferentes atlas anatómicos clásicos, utilizados en las diferentes carreras de las ciencias de la salud; para de esta forma, intentar lograr, en los usuarios que la manejen (alumnos fundamentalmente), 
un mejor conocimiento y comprensión de la anatomía pélvica, principalmente de la topografía estructural de esta compleja región corporal.

Pretendemos que este recurso didáctico interactivo para la enseñanza de la anatomía pélvica suponga una metodología docente que cumpla y cubra los requerimientos actuales de la docencia universitaria para una mejora significativa de la calidad formativa. Con este trabajo se busca además crear un modelo pedagógico que motive y sitúe al estudiante como responsable y centro de su proceso de enseñanza-aprendizaje, intentando con esta herramienta tecnológica proporcionar interactividad y estímulo en el aprendizaje activo y autónomo de los alumnos, sin limitaciones de tiempo y espacio.

De esta manera, nuestro propósito con este trabajo de Tesis es lograr los siguientes objetivos:

Nuestro objetivo global o general del trabajo es introducir a los alumnos universitarios en la adquisición de capacidades y destrezas a través de la utilización de los sistemas informatizados interactivos de visualización espacial, buscando aumentar la motivación de los estudiantes, e intentando proporcionarles un mejor aprendizaje en el conocimiento de las estructuras que conforman la pelvis femenina. Es además nuestro propósito ampliar la utilización de esta herramienta tecnológica a otros usuarios a los que les puede resultar de utilidad, como es en diversas especialidades médicas o quirúrgicas (anatomistas, radiólogos, ginecólogos, urólogos, anestesistas, etc.) así como en todas aquellas ramas del saber en las que se precise el conocimiento y la comprensión de estas regiones anatómicas complejas. 
Como objetivos más específicos de nuestro desarrollo tecnológico estarían los siguientes:

1‥- Llevar a cabo una generación volumétrica de estructuras anatómicas de la pelvis femenina a partir de imágenes seccionales de cadáver del "Visible Human Project", e imágenes radiológicas de Resonancia Magnética, que ilustren iconográficamente las estructuras en su morfología 3D en diferentes posiciones espaciales y que sirvan de apoyo en los procesos formativos.

2‥- Desarrollar un recurso tecnológico interactivo de visión 3D de estructuras anatómicas de la pelvis femenina, embebidas en las secciones de cadáver y resonancia magnética, que facilite a los usuarios su navegación por el visor anatómico para su visualización en diferentes posiciones espaciales, con el fin de valorar la morfología de la anatomía pélvica femenina y las relaciones espaciales de vecindad que mantienen unas estructuras con otras. Todo ello mediante un procedimiento informático de fácil usabilidad y de navegación muy intuitiva para que cualquier usuario pueda manejar sin dificultad la herramienta docente.

3‥- Proporcionar una colección iconográfica de imágenes seccionales de cadáver, resonancia magnética y ecografía de la pelvis femenina, y su correlación con las estructuras anatómicas que la configuran, en 3D, con el objeto de servir de apoyo a la docencia, intentando mejorar la presentación y visualización frente a los clásicos y tradicionales atlas anatómicos. De esta forma, con este sistema tecnológico se pretende facilitar, mediante las imágenes en 3D, una mejor observación, análisis y comprensión de las complejas estructuras anatómicas pélvicas. 
4ㅇ.- Favorecer la reducción del tiempo de estudio necesario para el aprendizaje de la anatomía de la región pélvica, mediante la utilización de instrumentos interactivos mucho más visuales que los tradicionales. De esta forma, se pretende además aportar a la docencia un método de estudio alternativo, que complemente y refuerce la enseñanza tradicional.

5‥- Valorar el grado de satisfacción de la herramienta tecnológica, mediante un cuestionario, en un grupo de usuarios alumnos, con el fin de obtener una información del grado de utilidad práctica en la docencia de esta región anatómica.

Para la consecución de los objetivos que nos hemos propuesto, procederemos al análisis de las diferentes secciones anatómicas tanto de cadáver como radiológicas, mediante el apoyo de expertos en las disciplinas de anatomía, radiología y ginecología, con el fin de poder identificar con precisión las diferentes estructuras anatómicas, para su segmentación. Además, contaremos también con la ayuda y asesoramiento de expertos informáticos para el desarrollo tecnológico planteado.

En los últimos años se ha investigado fuertemente los sistemas de segmentación automática de estructuras anatómicas desde imágenes seccionales; para el apoyo de las tareas diagnósticas; sin embargo, las aplicaciones totalmente automáticas aún ofrecen algunas deficiencias sobre todo en campos tan complicados como lo es el de la imagen médica 3D y especialmente en áreas tan complejas anatómicamente, como la pelvis femenina. Por este motivo en nuestro procedimiento informático se optó una interacción manual la cual pensamos nos aporta una mayor robustez y fiabilidad en la generación de las imágenes tridimensionales. Para ello se contó con la colaboración de especialistas expertos en imágenes seccionales (anatomistas y radiólogos y ginecólogos). 


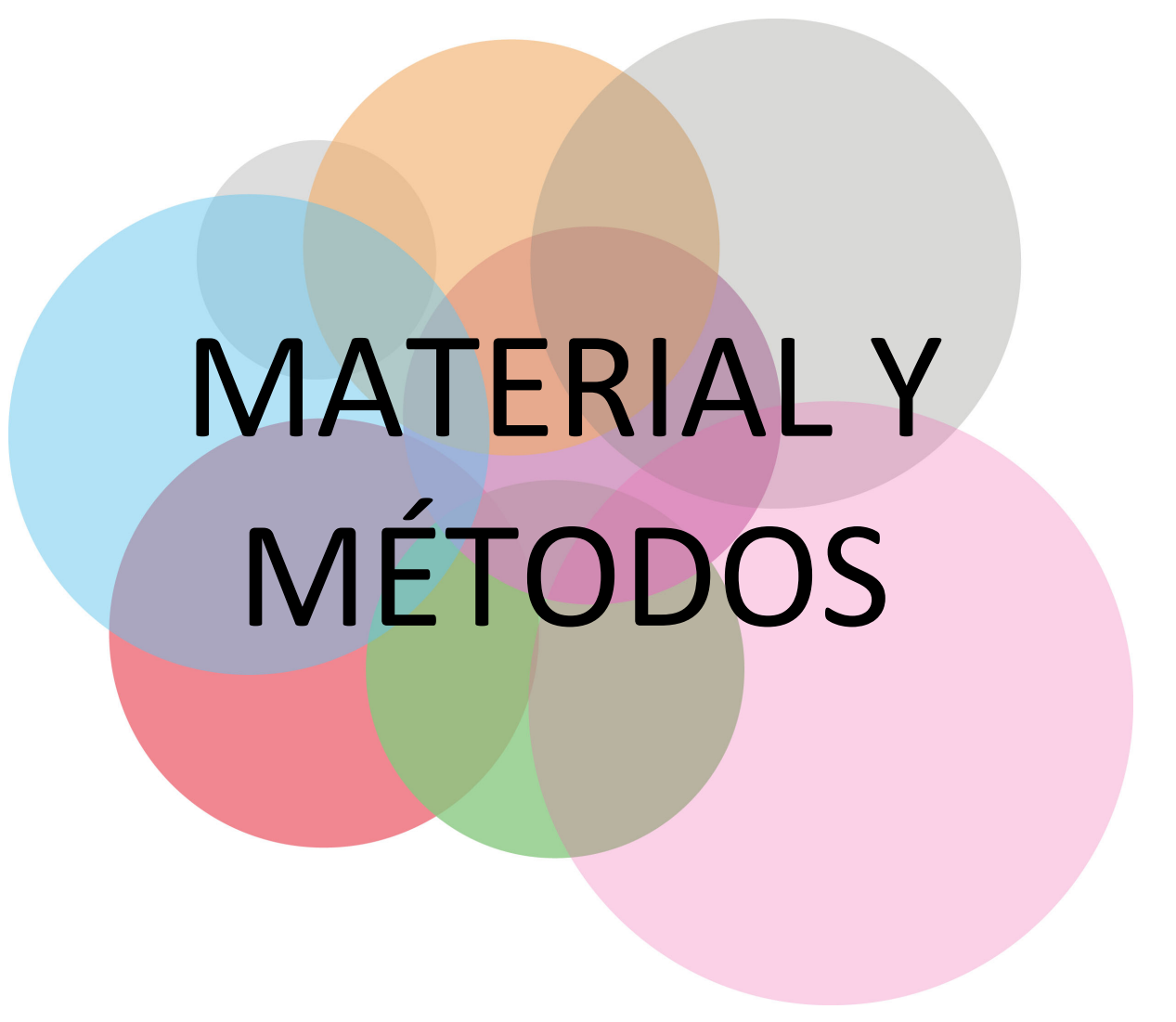




\section{1. - Adquisición de imágenes seccionales.}

Para la adquisición de las imágenes ecográficas y de RM se exploró a una mujer de 59 años, sin patología manifiesta, que sirvió de adiestramiento y reconocimiento para la reconstrucción posterior de las estructuras anatómicas a estudio.

La exploración radiológica se llevó a cabo, previo consentimiento informado y sin remuneración económica por su participación, en los servicios de radiodiagnóstico del Hospital Clínico Universitario de Salamanca.

Además, se emplearon secciones de cadáver, procedentes del Visible Human Project.

1.a.- Imágenes de resonancia magnética: Para las imágenes de resonancia magnética se obtuvieron imágenes de alta resolución potenciadas en diferentes secuencias, T1, T2 y en densidad protónica (DP) en los tres planos ortogonales (axial, coronal y sagital) de la región abdomino-pélvica, para el estudio anatómico global de la pelvis. No obstante, para el procedimiento informático únicamente se adquirieron imágenes de alta resolución, con un espaciado de $0.5 \mathrm{~mm}$, potenciadas en DP (densidad protónica), de la región pélvica. Específicamente se obtuvieron tres RM ortogonales, cada una en un plano espacial diferente, utilizando un scanner de 1.5 Teslas (marca Signa General \& Electric) (Fig. 7) de una mujer voluntaria de 59 años de edad, nulípara y sin antecedentes conocidos de patología ginecológica.

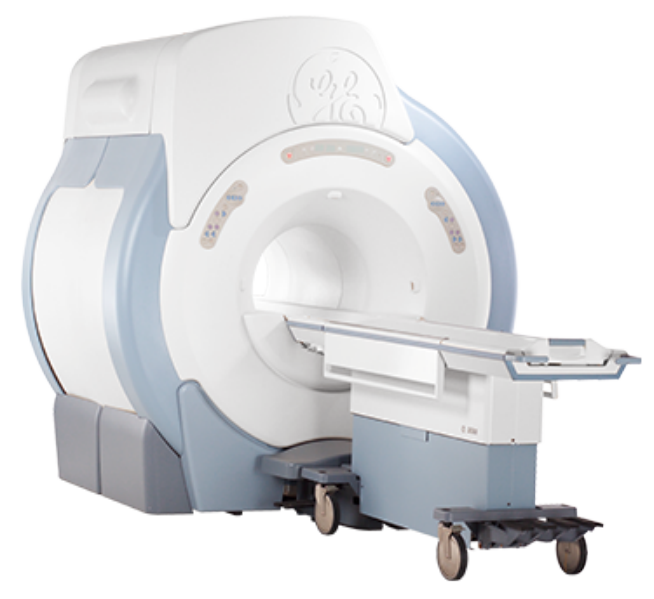

Figura 7. Equipo de Resonancia Magnética, modelo Signa General \& Electric, utilizado en nuestro trabajo. 
El protocolo de adquisición ha consistido en secuencias 2D de la región abdominopélvica con los siguientes parámetros comunes a las tres orientaciones: repetition time $=3220 ;$ echo time $=14 ; 3-\mathrm{mm}$ slice thickness; matrix $=512 \times 512 ;$ flip angle $=$ $150^{\circ}$. Los parámetros de adquisición específicos a cada orientación fueron: planos axial y sagital: slice spacing $=3.6 \mathrm{~mm}$; pixel spacing $=0.547 \mathrm{~mm} \times 0.547 \mathrm{~mm}$; plano coronal: slice spacing $=4.8 \mathrm{~mm}$; pixel spacing $=0.586 \mathrm{~mm} \times 0.586 \mathrm{~mm}$.

A partir de los ficheros raw data DICOM se reconstruyó, para cada orientación, un volumen DP, que fue salvado en formato ANALYZE 7.5 mediante el software de libre distribución MRIcro (Nottingham, UK).

Además, se obtuvo secuencia flash-3D de la misma región (repetition time $=19$; echo time $=3.25 ; 2-\mathrm{mm}$ slice thickness; matrix $=256 \times 256$; flip angle $=90^{\circ} ;$ pixel spacing $=$ $0.156 \mathrm{~mm} \times 0.156 \mathrm{~mm}$, resultando en un volumen de $256 \times 104 \times 256$ slices)

Esta image-volume ha sido exclusivamente utilizada para la verificación de las estructuras identificadas en la DP.

Con la finalidad de homogeneizar al máximo las dimensiones entre los tres volúmenes, éstos fueron alineados, tomando como referencia el adquirido en el plano axial. A continuación, se redimensionaron aplicando un filtro Lanczos, resultando en un volumen axial de $600 \times 560 \times 30$ slices (voxelsize $=0.5 \times 0.5 \times 3.5 \mathrm{~mm}^{3}$ ), un volumen sagital de $30 \times 560 \times 560$ slices (voxelsize $3.5 \times 0.5 \times 0.5 \mathrm{~mm}^{3}$ ) y un volumen coronal de $600 \times 28 \times 560$ slices (voxelsize $0.5 \times 5.0 \times 0.5 \mathrm{~mm}^{3}$ ). De cada uno de estos volúmenes se exportaron imágenes en formato png para su representación en un visor 3D (ver la sección visualización y renderización).

Así mismo, para facilitar la fase de modelización, los 3 volúmenes fueron redimensionados (reslicing), obteniéndose imágenes isotrópicas con vóxeles de 1 $\mathrm{mm}$, es decir, con vóxeles que poseen el mismo tamaño en todas las dimensiones.

1.b.- Imágenes ecográficas: Para la adquisición de las imágenes ultrasonográficas se utilizaron los ecógrafos Siemens Acuson Antares y Voluson E6 (Fig. 8).

Mediante ecografía transperineal/transintroital (TPUS), se emplearon las siguientes sondas: 
- Sonda convexa convencional 2D (transperineal), en los planos sagital medio y coronal.

- Sonda endovaginal convencional 2D en plano sagital medio.

- Sonda multifrecuencia 3D/4D, en plano axial.

Mediante ecografía endovaginal (EVUS), se utilizaron las siguientes sondas:

- Sonda electrónica biplanar 3D, en plano sagital medio ampliado a compartimento anterior y posterior.

- Sonda mecánica rotacional 360 3D en plano axial endovaginal y plano axial endoanal.
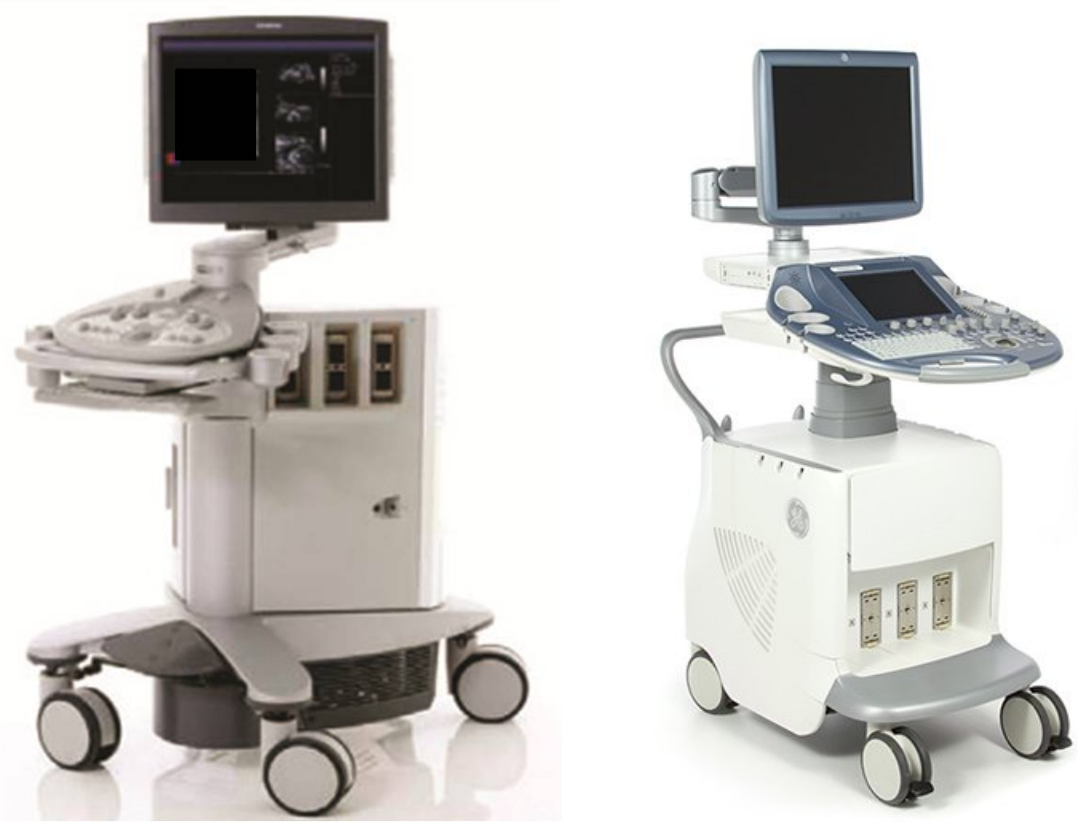

Figura 8. Equipos de ecografía, modelo Siemens Acuson Antares el de la izquierda y modelo Voluson E6 el de la derecha, utilizados en nuestro trabajo.

1.c.- Imágenes de cadáver: Se utilizaron múltiples secciones axiales de 0,33 $\mathrm{mm}$ de espesor, de alta resolución, procedentes del cadáver de una mujer de 59 años, con un tamaño original de 576 x 768 px, obtenidas a partir del Visible Human CD Versión 2.0 de la Nacional Library of Medicine de EEUU, (Fig. 9 y 10) bajo licencia autorizada número HW1-020645 para uso con fines docentes y de investigación. 

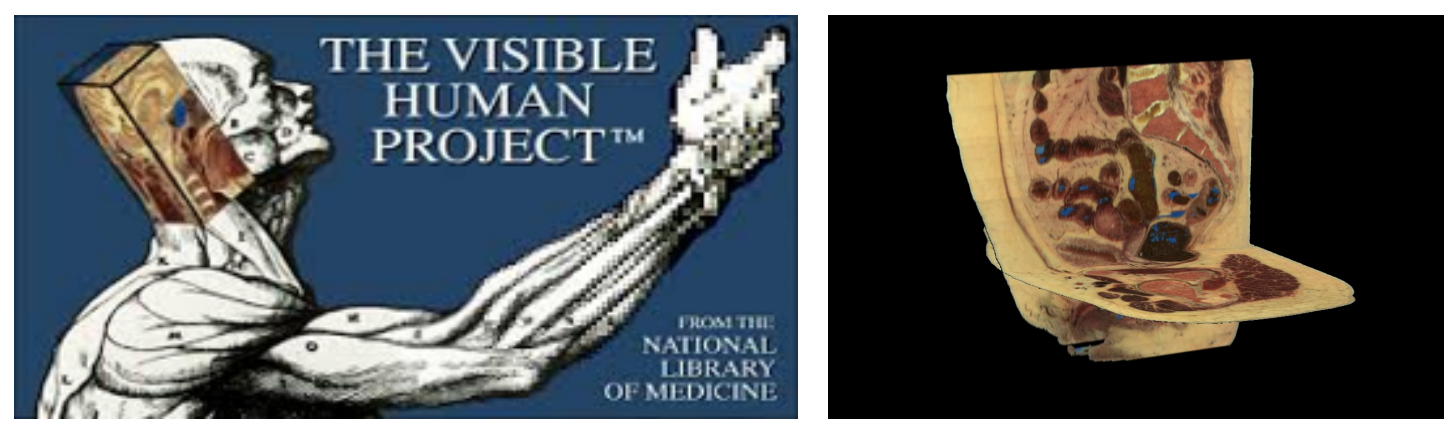

Figuras 9 y 10. Las secciones anatómicas procedieron del Proyecto Human Visible.

2. - Segmentación de estructuras anatómicas, delimitación de regiones de interés (ROIs) y reconstrucción de modelos tridimensionales.

La segmentación y delimitación de las ROls consistió en la subdivisión de cada imagen anatómica adquirida en regiones homogéneas (Fig. 11). En nuestro caso se usó un kit de herramientas de aplicaciones de interacción de imágenes médicas que se desarrolló para ayudar a la manipulación de datos, registro y segmentación.

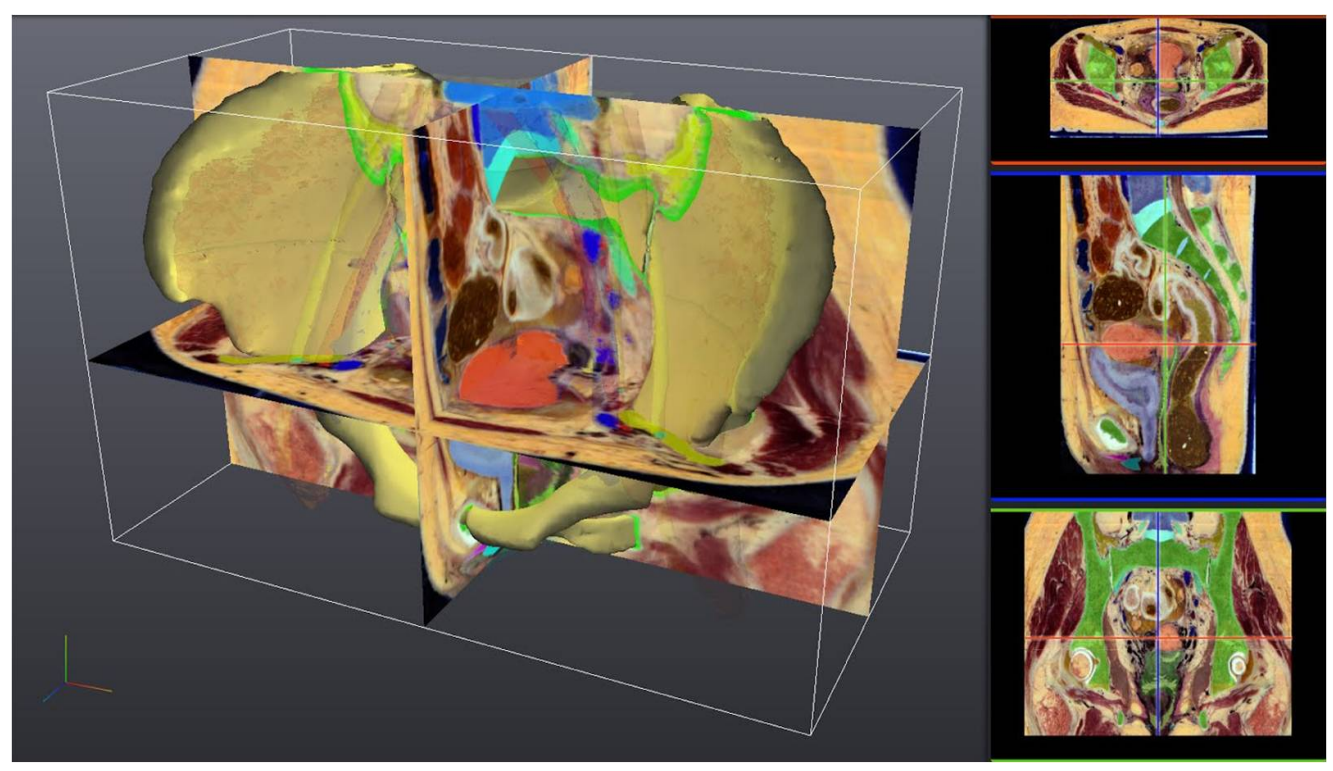

Figura 11. Proceso de segmentación manual de las secciones anatómicas.

La mayor dificultad estuvo en la reconstrucción 3D de los nervios y vasos sanguíneos, dado el calibre tan pequeño que tienen, para ello se creó una herramienta para la simulación de los trayectos nerviosos y vasculares. Cada uno de estos nodos funcionales y curvas representan secciones de estas estructuras definidas por los 
puntos de control, que pueden ser colocados en el mundo virtual utilizando referencias anatómicas.

En la reconstrucción de los trayectos nerviosos y vasculares se obtuvieron polilíneas. Para cada nervio y vaso se colocó una serie de puntos de referencia (landmarks) a lo largo de su trayecto. Los diferentes landmarks se unieron mediante polilíneas que fueron utilizadas como base para generar una secuencia de cilindros de pequeño diámetro representando el trayecto nervioso y vascular.

La segmentación se basó en la delimitación manual empleando Autodesk Maya y la supervisión por parte de observadores expertos (anatomistas, radiólogos y ginecólogos), aportándole más robustez que otros métodos de segmentación automática disponibles a través de algoritmos. Se procedió a la detección de bordes relativos a las diferentes estructuras anatómicas en base a su forma, tamaño y localización (Fig. 12). Un buen proceso de detección de bordes facilita la elaboración de las fronteras de las estructuras 3D a modelar, con lo que el reconocimiento de objetos se facilita. Precisamente, dado que el cambio de intensidad o borde entre muchas de las estructuras que nos ocupan es difícilmente perceptible por la falta de nitidez en sus límites, empleamos estrategias de segmentación manuales, en vez de algoritmos de segmentación automáticos. El suavizado de bordes sí se realizó de forma automática, a través del módulo de Maya correspondiente, basándose en el promediado de los píxeles de una región.

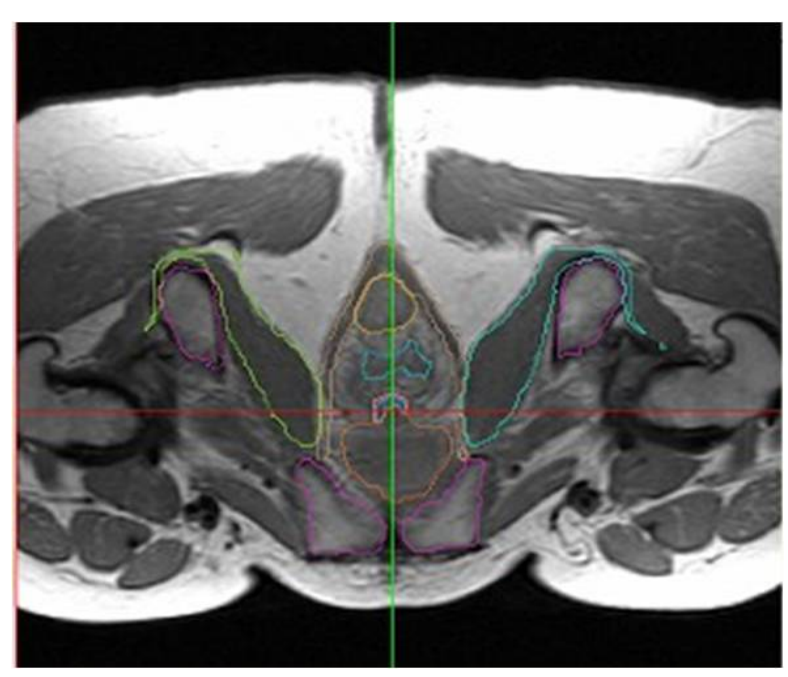

Figura 12. Proceso de segmentación manual de las secciones de resonancia magnética. 
El correcto etiquetado requiere cuidar la forma en la que se hayan escrito los nombres, incluyendo mayúsculas y minúsculas y asegurarse de que se hayan incluido todas ellas. Para ello, se creó un campo de etiquetado (LabelField) para cada uno de los conjuntos de datos con la lista completa de estructuras en orden jerárquico y a los que se les asignó un color diferente. Inicialmente se diferenció entre los diferentes músculos.

Posteriormente, se identificaron las estructuras vasculares, a partir del conocimiento anatómico y organización espacial de las distintas estructuras. Se identificaron para su reconstrucción las siguientes estructuras: huesos, músculos, vasos y nervios.

El proceso de segmentación fue muy laborioso y exigente en cuanto a consumo de tiempo, al realizarse de forma individual para cada conjunto de datos y bajo la supervisión de un anatomista, radiólogo y ginecólogo. Los diferentes componentes se identificaron en las imágenes seriadas del VHP y RM, para su posterior etiquetado manual con diferentes códigos de colores mediante el software Maya.

Para la visualización de volúmenes en ordenadores convencionales se requirió un paso previo que consistió en la extracción de la superficie. Este paso redujo significativamente el peso de los datos y como resultado, también los tiempos de procesamiento requeridos para su visualización. Consistió en crear representaciones intermedias de la superficie en forma de mallas poligonales, asociadas a las estructuras anatómicas seleccionadas, que contenían la información a partir de la cual se renderizaron las imágenes. En nuestro caso los elementos empleados para la composición de la superficie fueron estructuras poligonales.

Por otra parte, se realinearon las regiones de interés (ROIs) en los tres planos de referencia. La alineación supuso la incorporación de los diferentes conjuntos de datos originales, adquiridos desde diferentes orientaciones, a un sistema de coordenadas común. El registro consistió en la comparación y ajuste de la posición y orientación de los conjuntos de datos correspondientes a las imágenes, hasta que la información mutua de los conjuntos de datos se maximiza. 
A partir de cada una de las regiones de interés resultantes se obtuvo un modelo de superficie compuesto por una malla mediante el procedimiento de marching cubes. A los modelos se aplicaron algoritmos de decimación para simplificarlos y suavizarlos. Finalmente se exportaron a formato DirectX.

Las Imágenes seccionales procedentes del VHP seleccionadas, así como los cortes de RM y todos los modelos 3D de superficie obtenidos en la fase anterior, fueron visualizados en un visor específicamente desarrollado para esta aplicación informática, programado en Visual $\mathrm{C}++$ y que incluye controles directX para la renderización de imágenes y modelos de malla poligonal.

El renderizado del volumen, consistió en la visualización de datos volumétricos a partir de imágenes correspondientes a las diferentes estructuras anatómicas, mediante la aplicación de color y textura.

El renderizado directo del volumen consistió en la visualización directa de la superficie de una estructura anatómica a partir de los datos del volumen. En este caso, la visualización resultó de la aplicación de un sofisticado algoritmo denominado Proyección de Máxima Intensidad, según el cual, se asignan parámetros de emisión y absorción de luz a cada punto del volumen. Esta simulación del paso de luz a través del volumen hace posible mostrar los datos desde cualquier dirección sin construir modelos poligonales intermedios. El algoritmo utilizado fue Marching Cubes que permitió la extracción de mallas poligonales de una isosuperficie a partir de vóxeles. Requiere dividir el espacio en vóxeles formados por los valores de intensidad de los 8 vértices del vóxel, correspondientes a los datos volumétricos originales. El procedimiento de elaboración de modelos en malla a partir del algoritmo Marching Cubes fue seguido de la aplicación de determinados algoritmos con la intención de simplificarlos y suavizarlos.

El guiado visual acompañó todo el proceso, lo que requirió de la visualización simultánea del modelo de superficie y de los planos de la imagen de referencia. Finalmente, se obtuvo un fichero en formato DirectX del modelo de superficie definitivo de las estructuras anatómicas a reconstruir. 
La herramienta empleada durante el proceso de segmentación, edición de superficies, suavizado libre de intersecciones, registro, creación de modelos poligonales y mallas volumétricas necesarias para la simulación avanzada de los volúmenes reconstruidos y el renderizado final, fue Autodesk Maya (Fig. 13).

\section{3. - Softwares empleados.}

Para la generación volumétrica no probabilística de estructuras anatómicas se utilizó Autodesk ${ }^{\circledR}$ Maya $^{\circledR}$ (Fig. 13). Es un software de animación en 3D que proporciona un conjunto completo de funciones creativas con herramientas para realizar animación, modelado, simulación, renderización, rastreo de movimiento y composición dentro de una plataforma de producción sumamente ampliable. Maya ${ }^{\circledR}$ ayuda a cumplir los exigentes requisitos de producción con herramientas específicas para creación de efectos visuales, desarrollo de juegos, postproducción y otros proyectos de animación en 3D.

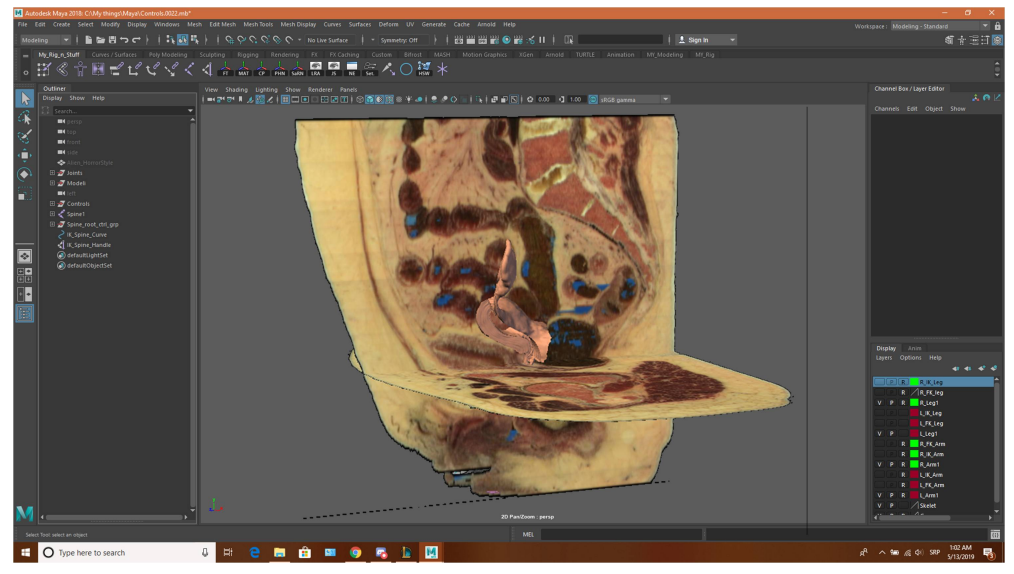

Figura 13. Proceso de tratamiento y manipulación de las secciones anatómicas con el software Autodesk $^{\circledR}$ Maya $^{\circledR}$.

La adaptación de tamaño y formato de las imágenes se realizó mediante Pixresizer Software versión 2.0.4 ${ }^{\circledR}$. El formato final fue jpg de 380 píxeles de ancho, optimizadas para la presentación en resoluciones de pantalla 800 × 600 píxel.

La delimitación del área de respuesta para la localización de las estructuras anatómicas de cada parte se realizó con Image Mapper versión $1.0^{\circledR}$. Dicha área se 
definió a partir de las coordenadas $(x-y)$ establecidas para cada una de las imágenes empleadas, que oscilaron de 50 a 500 coordenadas según la estructura.

La aplicación informática está desarrollada para plataformas Windows y programada en Visual $\mathrm{C}++$, el cual, como entorno integrado de desarrollo, nos permitió realizar una programación orientada a objetos (POO) bajo los lenguajes de programación $\mathrm{C}$, $\mathrm{C}++$ y $\mathrm{C}++/ \mathrm{CLI}$, conjuntamente con el sistema de desarrollo SDK (también denominado API, Application Programming Interface) de Windows.

Visual C++ nos permitió el desarrollo y la depuración de código escrito para las API's de Microsoft Windows, DirectX y tecnología Microsoft .NET Framework.

Por otra parte, al tratarse de un entorno integrado, Visual C++ utiliza otras herramientas complementarias de desarrollo:

- Editor orientado a la codificación C/C++.

- Compilador/Enlazador incremental, que aceleró el proceso de construcción de nuestro desarrollo informático.

- Depurador visual, que modifica el contenido de variables y áreas de memoria.

- Visor de datos (browser) que permitió fácilmente controlar dependencias y referencias a funciones, datos, etc. Además, se visualiza la jerarquía de las clases utilizadas en el programa.

- Herramientas adicionales como un analizador de ventanas (Spy ++) o un trazador de funciones MFC (Microsoft Foundation Classes), el cual es una implementación que utiliza el API (Application Programming Interface) encapsulando todas las estructuras y llamadas a funciones en objetos fáciles de utilizar. En este sentido y, basándose en la potencia de la MFC, Visual C++ se convierte así en un generador de programas $\mathrm{C}++$ para Windows.

Visual C++ incluye además la librería de clases MFC que nos permitió crear y gestionar de manera intuitiva componentes típicos de Windows.

De esta manera, el lenguaje de programación que hemos utilizado para esta aplicación informática es compatible en la mayor parte de su código con este lenguaje, a la vez que su sintaxis es exactamente igual. 
Para crear cualquier programa con Visual C++ comenzamos creando un proyecto para él, codificando y añadiendo los módulos necesarios a dicho proyecto, y definiendo los recursos asociados.

En Visual $\mathrm{C}++$, la construcción de nuestro procedimiento informático se inscribe dentro del concepto de proyecto (workspace). Un proyecto define los pasos a seguir para alcanzar la construcción de un objetivo (un programa, una DLL, etc.), en realidad es un concepto análogo a lo que se conoce como "makefile" en otros entornos típicos de desarrollo en C. En realidad, Visual C++ genera para cada proyecto dos ficheros que lo definen, el fichero de workspace (con extensión wsp) y un makefile (con extensión mak) estándar que permitiría la utilización del mismo proyecto en otro entorno distinto.

Desde el punto de vista funcional, el proyecto contiene referencias a cada uno de los ficheros fuentes $(\mathrm{C} / \mathrm{C}++$, con extensiones $c$ y $c p p$ respectivamente), objetos, librerías o ficheros de recursos (extensión $r c$ ) que se deben utilizar para construir el objetivo final del proyecto.

Nuestro desarrollo informático, tiene además estas características:

- No utiliza navegador.

- Emplea estándares de manera que la información puede ser visualizada y tratada en las mismas condiciones, con las mismas funciones y con el mismo aspecto en cualquier ordenador.

- El acceso no será restringido ni selectivo.

- Incluye como elemento básico una interfaz gráfica común, con un único punto de acceso, de manera que en ella se integran los diferentes elementos multimedia que constituyen el procedimiento tecnológico: textos, imágenes, animaciones, etc.

- Realiza la presentación de la información en formato hipermedia.

\section{4. - Instalación de la aplicación.}

El procedimiento tecnológico de visualización anatómica y ecográfica para la formación médica en el campo de la obstetricia y la ginecología, se ha diseñado para su instalación en ordenadores con los siguientes requisitos del sistema: 
Hardware (mínimo)

- Pantalla de 1280 x 800 con tarjeta de vídeo a 512 MB o superior.

- Procesador de $1 \mathrm{GHz}$ o superior.

- 1 GB de memoria RAM.

- 1 GB de espacio libre en el disco duro.

- Unidad de DVD-ROM o CD-ROM.

Hardware (Recomendado)

- Pantalla de 1280 × 800 con tarjeta de video a 1 GB o superior.

- Procesador de $1.2 \mathrm{GHz}$ o superior.

- 2 GB de memoria RAM.

- 2 GB de espacio libre en disco duro.

- Unidad de DVD-ROM o CD-ROM.

Software

- Sistema operativo Windows XP, Vista o Windows 7, 32 y 64 bits.

- Software de Direct 9.0 o superior.

- Microsoft. NET Framework 3.0 o superior.

- Adobe Acrobat Reader 5.0 o superior.

- Adobe Flash Player 10.0 o superior.

\section{5. - Encuestas de valoración.}

Se practicaron encuestas de satisfacción a alumnos de ciencias de la salud $(n=35)$, con el fin de valorar y conocer el grado de utilidad docente de esta herramienta informática (Fig. 14). La limitación del número de usuarios vino dada por la disponibilidad de equipos tecnológicos para validar el desarrollo informático, considerando un número suficientemente representativo para obtener una muestra que nos oriente sobre la satisfacción de los estudiantes ante el desarrollo tecnológico presentado. Todos los alumnos tenían conocimientos previos de la materia, y todos ellos habían superado la asignatura de anatomía humana sobre esplacnología, antes de efectuar la encuesta de satisfacción. 
Previamente a la realización de la encuesta de satisfacción de nuestro procedimiento tecnológico, se llevó a cabo otra encuesta para conocer el grado de usabilidad de dispositivos portables que tenían estos mismos alumnos a los que se les practicó la prueba de valoración del software generado (Fig. 15). Esta encuesta buscaba conocer los tipos de dispositivos portables que utilizan de forma habitual y el grado de manejo de los mismos.

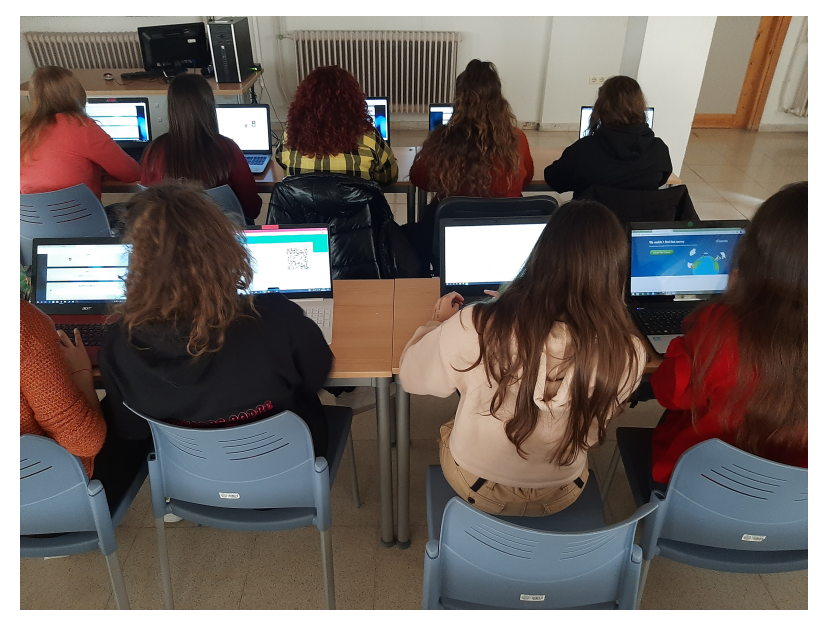

Figura 14. Grupo de alumnos validando la aplicación informática y efectuando la encuesta de satisfacción.

Las preguntas formuladas en la "encuesta sobre usabilidad de dispositivos tecnológicos portables" fueron las siguientes (Fig. 15):
A. Edad:
B. Sexo: $F-M$
C. Indique el sistema operativo de su móvil:

1.No dispongo. 2. iOS. 3. Android. 4. Windows.

D. Indique si dispone de algún modelo de Tablet:

1.No dispongo. 2. Ipad. 3. Android. 4. Windows.

E. ¿Qué marca de teléfono móvil tiene?:

1. Apple (IPhone). 2. Samsung. 3. Huawei 4. Xiaomi. 5. Otro. 
F. ¿Su smartphone tiene tecnología 4G?:

1. Si. 2. No.

G. ¿Su dispositivo es Touch?:

1. Si. 2. No.

H. El uso que hace de su smartphone es principalmente:

1. Llamadas de voz. 2. Redes sociales, WhatsApp, 3. Actividades docentes (campus virtual).

I. El tiempo que utiliza al día su dispositivo portátil es:

1. Menos de una hora al día. 2. Una o dos horas día. 3. Tres o cuatro horas día. 4. Mas de cinco horas día.

J. ¿Qué tipo de aplicaciones utiliza de forma más frecuente con su smartphone en su actividad diaria?:

1. Manejo de información. 2. Lectura de noticias. 3. Entretenimiento. 4. Otro.

K. La destreza que tiene con su smartphone para la instalación/desinstalación de Apps es:

1.Mala. 2. Regular. 3. Buena. 4. Muy buena.

L. El uso de su smartphone le ayuda a mejorar el aprendizaje y su rendimiento docente en la formación médica:

1. Nada. 2. Un poco en algunas cosas. 3. Mucho si se utiliza adecuadamente.

4. En el futuro serán herramientas indispensables.

M. ¿Utiliza con frecuencia alguna aplicación (App) como apoyo complementario a su formación médica?

1. Nunca. 2. Casi nunca. 3. A veces. 4. Frecuentemente. 5. Muy a menudo. 
N. En el supuesto de utilizar aplicaciones en su smartphone como soporte para mejorar su formación médica, las aplicaciones, además de aportar información en formato texto, ¿implementan su conocimiento con formatos multimedia del tipo imágenes y vídeos?:

1. Sí. 2. No. 3. No uso aplicaciones sobre medicina.

O. ¿Ha experimentado alguna vez un simulador de Realidad Virtual?:

1.Sí. 2. No. 3. No sé qué es.

P. ¿Dispone de alguna gafa de Realidad Virtual?:

\section{Sí. 2. No.}

Q. ¿Cree que la Realidad Virtual puede ser un espacio de formación universitaria complementaria?:

1. No lo veo posible. 2. Sí, pienso que puede ser aplicable. 3. Parcialmente, porque influyen muchos factores. 4. No, influyen muchos factores. 5. Desconozco el tema.

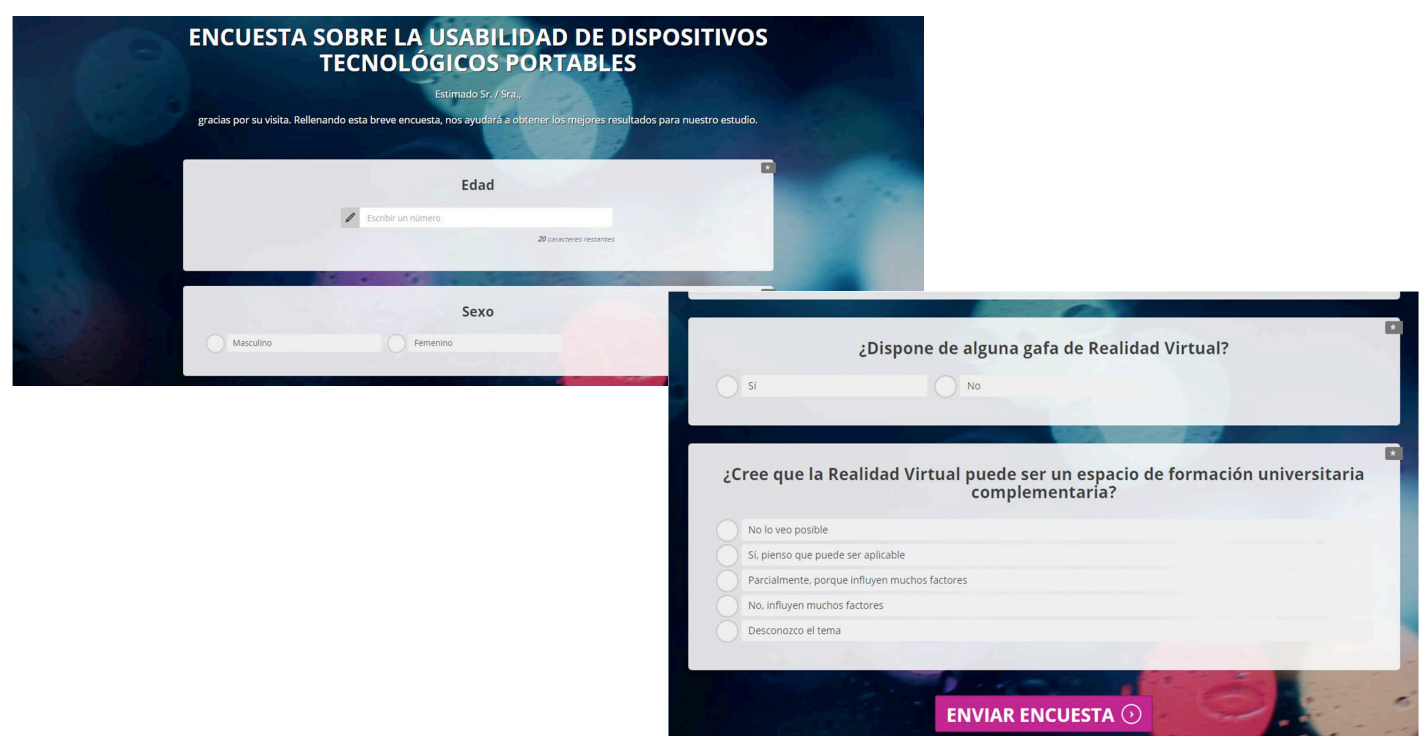

Figura 15. Visualización de algunos de los ítems formulados en la encuesta sobre usabilidad de dispositivos tecnológicos. 
La segunda encuesta elaborada, se centró exclusivamente en el propio desarrollo informático (Fig. 17), intentando valorar la eficacia y satisfacción de los usuarios que manejaron el programa docente sobre la anatomía radiológica de la pelvis femenina con visiones tridimensionales de las estructuras óseas, musculares, viscerales, vasculares y nerviosas, embebidas en las secciones de resonancia magnética y secciones de cadáver.

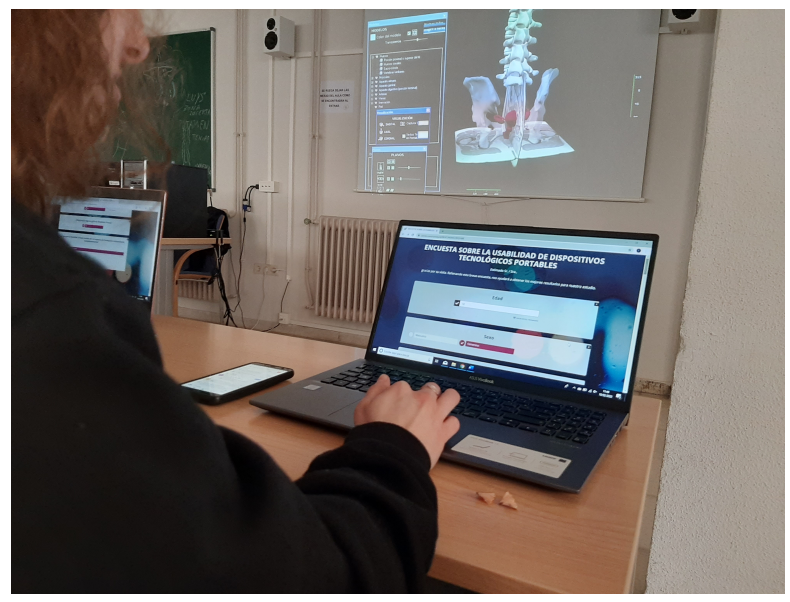

Figura 16. Alumna desarrollando la encuesta sobre la aplicación tecnológica.

Las preguntas a considerar en la "encuesta sobre el software de la anatomía del suelo pélvico y de la pelvis femenina" fueron las siguientes (Fig. 17):

A. La instalación del software fue:

1. Complicada. 2. Más bien difícil. 3. De dificultad media. 4. Más bien fácil. 5 muy sencilla.

B. ¿Con qué frecuencia se bloquea el software?:

1. Muy a menudo. 2. Frecuentemente. 3. A veces. 4. Casi nunca. 5. Nunca.

C. ¿Qué grado de satisfacción tiene con el software empleado?:

1. Muy insatisfecho. 2. Insatisfecho. 3. Normal. 4. Satisfecho. 5. Muy satisfecho.

D. La ayuda para complementar el estudio que aporta el software es:

1. Totalmente inútil. 2. Más bien inútil. 3. Normal. 4. Más bien útil. 5. Muy útil. 
E. La visión tridimensional de las estructuras viscerales de la pelvis le facilita una mejor comprensión y análisis de cada una de ellas:

(1-5 estrellas): 1 Baja. 5 Altísima.

F. Considera este procedimiento tecnológico mejor que muchos atlas anatómicos para el estudio morfológico de la anatomía de la pelvis femenina y del suelo pélvico:

(1-5 estrellas): 1 Baja. 5 Altísima.

G. El contenido incorporado en el programa informático es suficiente para su formación académica, siendo bastante completo e ilustrativo:

(1-5 estrellas): 1 Baja. 5 Altísima.

H. Mediante la tecnología de visión tridimensional utilizada ha empleado menos tiempo para el aprendizaje de la anatomía de la pelvis femenina, respecto a otros métodos tradicionales (uso de libros ilustrados, clases teóricas, prácticas, videos, etc.):

(1-5 estrellas): 1 Baja. 5 Altísima.

I. Considera esta tecnología de visión 3D interactiva un buen recurso docente complementario para el proceso de enseñanza y aprendizaje:

(1-5 estrellas): 1 Baja. 5 Altísima.

J. Desde el punto de vista de presentación visual, ¿cómo evaluaría los contenidos visualizados?:

(1-5 estrellas): 1 Baja. 5 Altísima.

K. La navegación por el programa es muy intuitiva y presenta un desarrollo metodológico que motiva su aprendizaje de forma ágil y sencilla:

(1-5 estrellas): 1 Baja. 5 Altísima.

L. Los comentarios explicativos breves y concisos que aparecen en la pantalla le ayudan a comprender mejor la anatomía de la pelvis femenina, así como a afianzar su conocimiento:

(1-5 estrellas): 1 Baja. 5 Altísima.

M. La interfaz del programa es intuitiva y de fácil manejo:

(1-5 estrellas): 1 Baja. 5 Altísima.

N. Cómo considera la aportación de este material docente complementario a la formación médica para el estudio de la pelvis femenina: 
(1-5 estrellas): 1 Baja. 5 Altísima.

O. Recomendaría a otros compañeros estos desarrollos informáticos para el aprendizaje y estudio de la Anatomía y Radiología de la pelvis femenina, del suelo pélvico y su contenido:

(1-5 estrellas): 1 Baja. 5 Altísima.
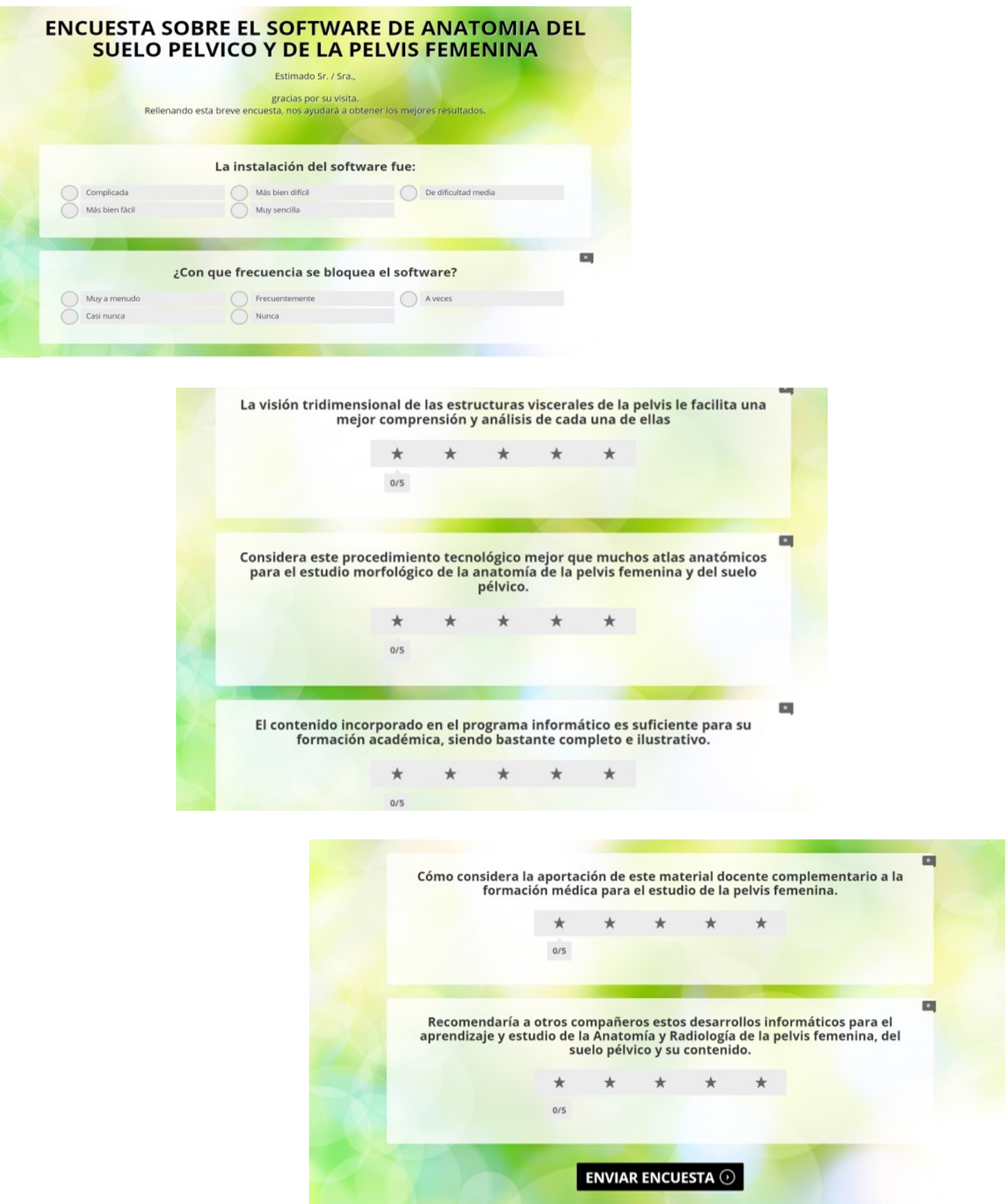

Figura 17. Visualización de algunos de los ítems formulados en la encuesta sobre el software desarrollado del suelo pélvico femenino. 
Los datos fueron tratados con el software Excel (Figura 18), hoja de cálculo de Microsoft, que nos permitió analizar y procesar todos los datos de las encuestas y presentar las diferentes gráficas.

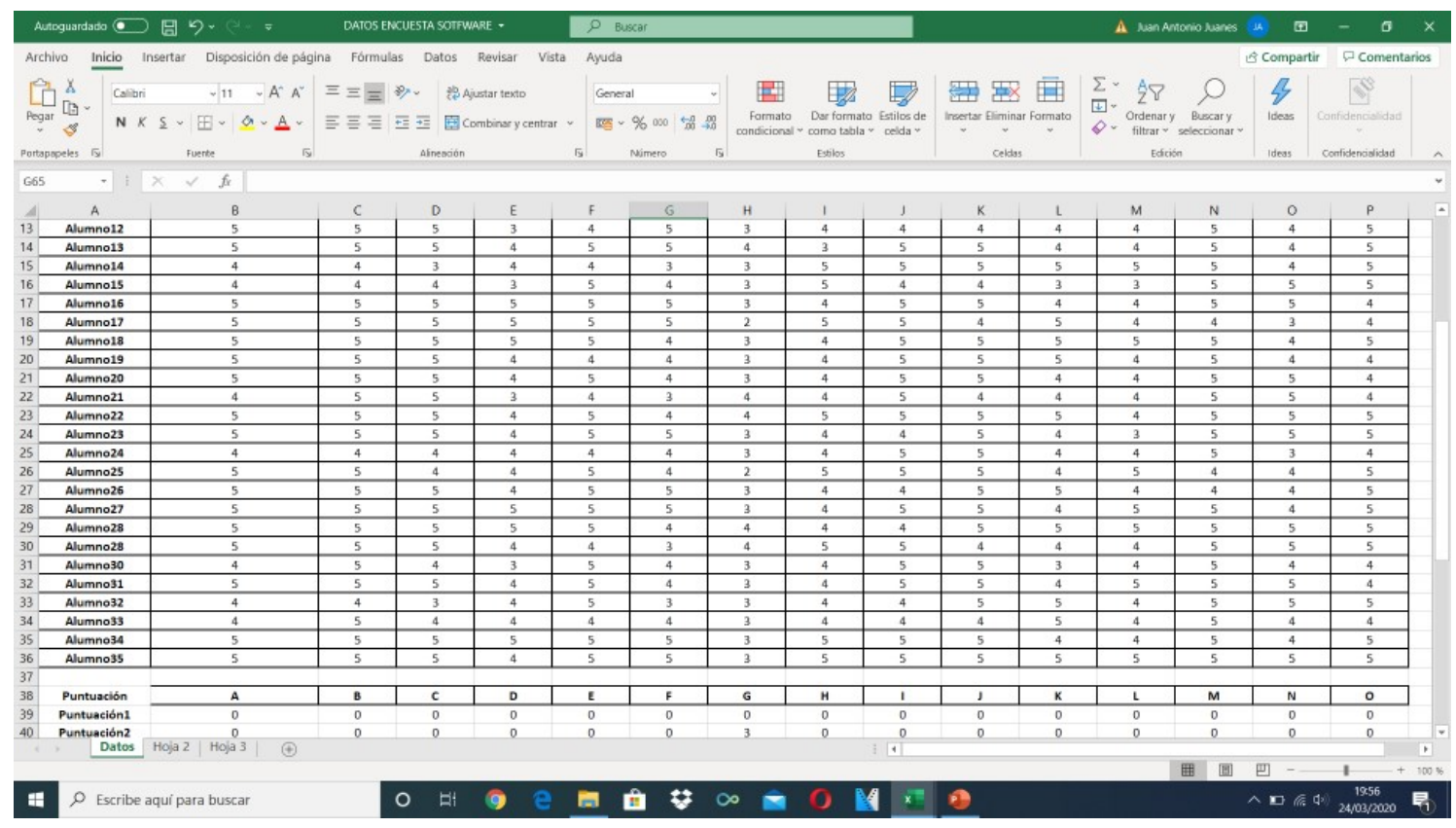

Figura 18. Datos en Excel. 


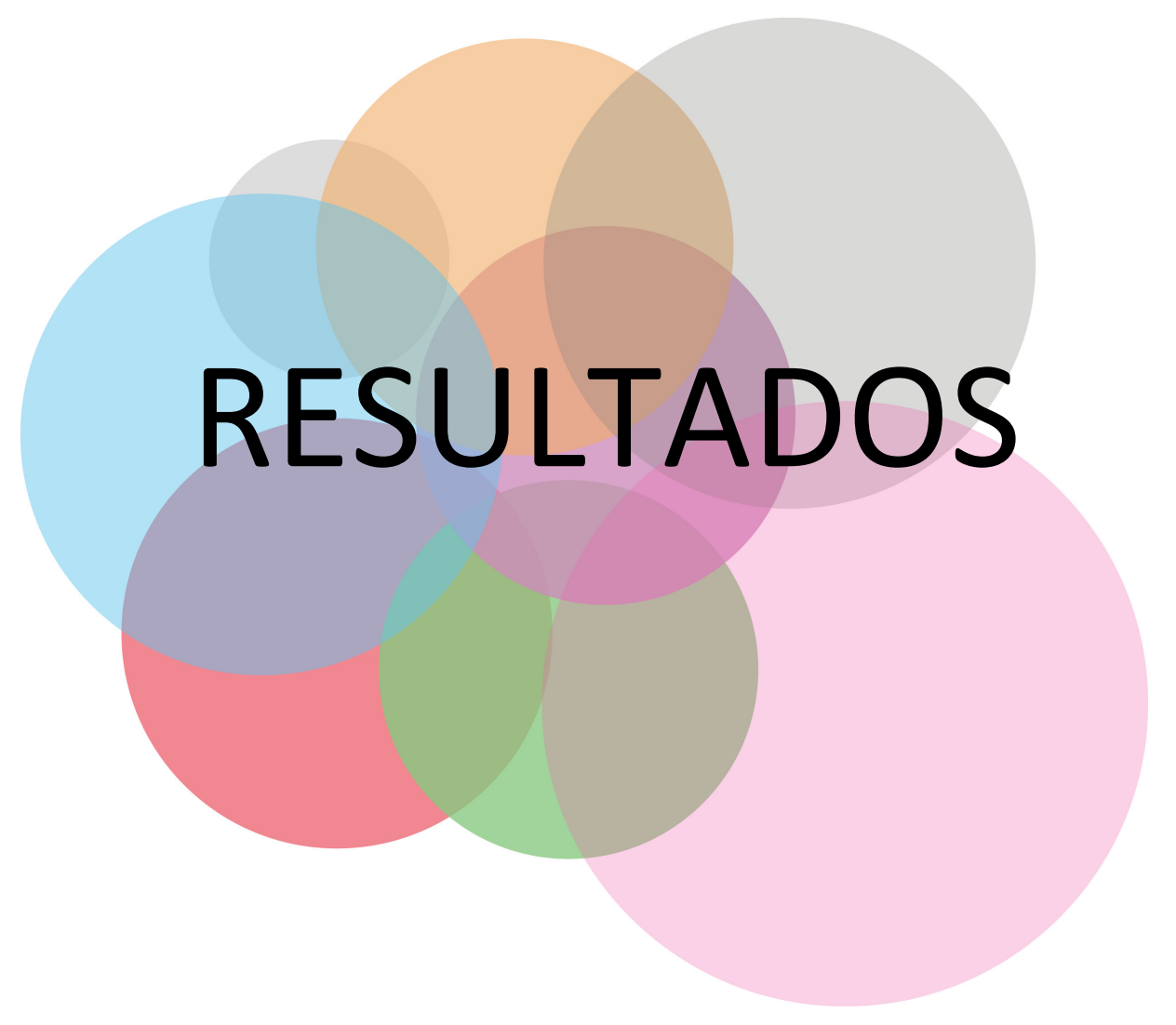




\section{1. - Imágenes seccionales.}

Nuestro desarrollo informático consta de una colección de imágenes seccionales procedentes de cadáver (Figs. 19 - 49), de RM (Figs. 50 - 75) y de ecografía (Figs. 76 y 77), como referencia para realizar una amplia valoración tridimensional de la anatomía ósea, muscular y visceral, así como de las arterias, venas y nervios que integran la pelvis femenina.

1.a.- Imágenes seccionales de cadáver: En las siguientes figuras presentamos imágenes seccionales de cadáver en los tres planos del espacio: axiales (Figs. 19, 22 29), sagitales (Figs. 20, 30 - 37) y coronales (Figs. 21, 38 - 45).

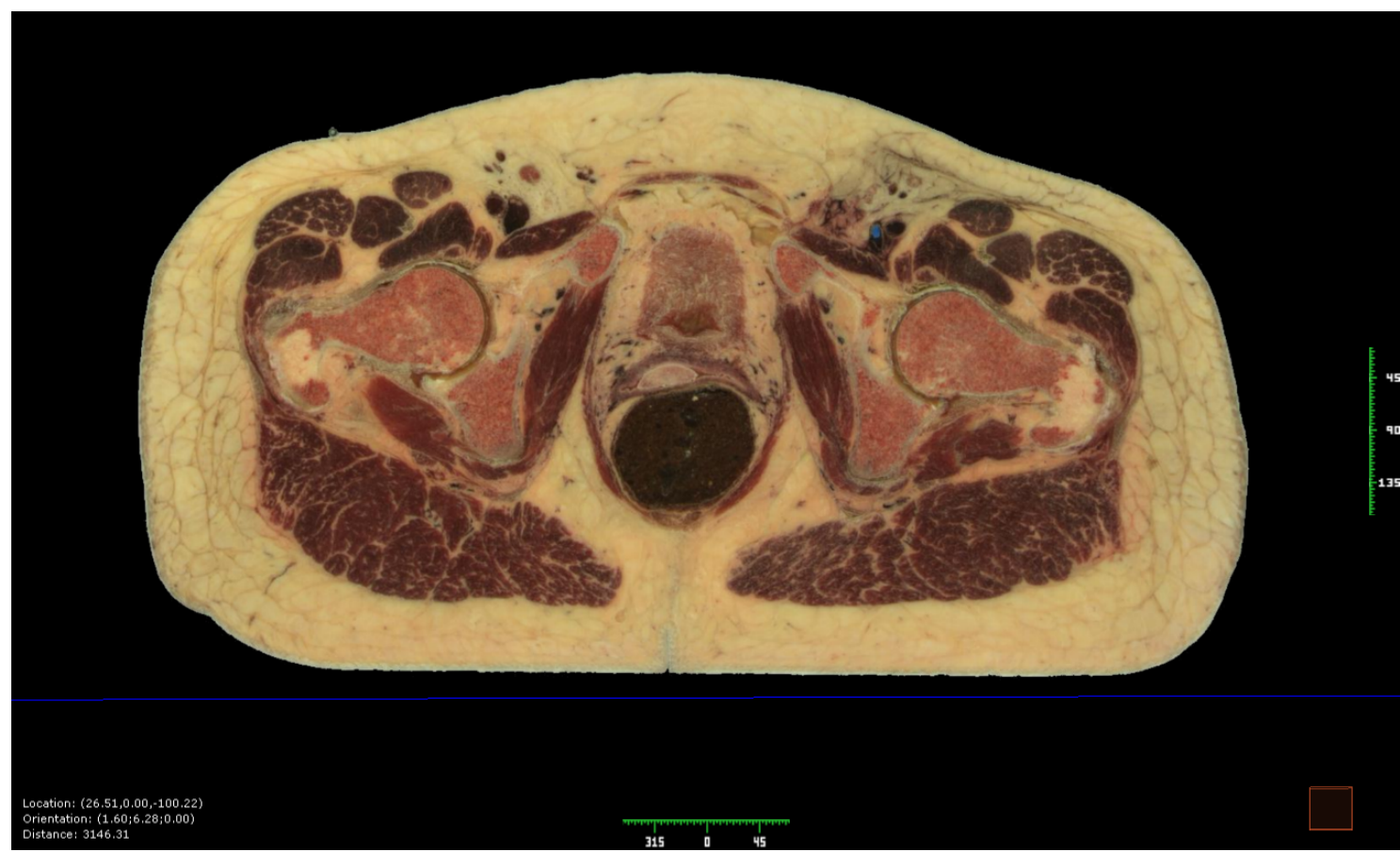

Figura 19. Corte axial de la pelvis femenina del proyecto "Visible Human". 


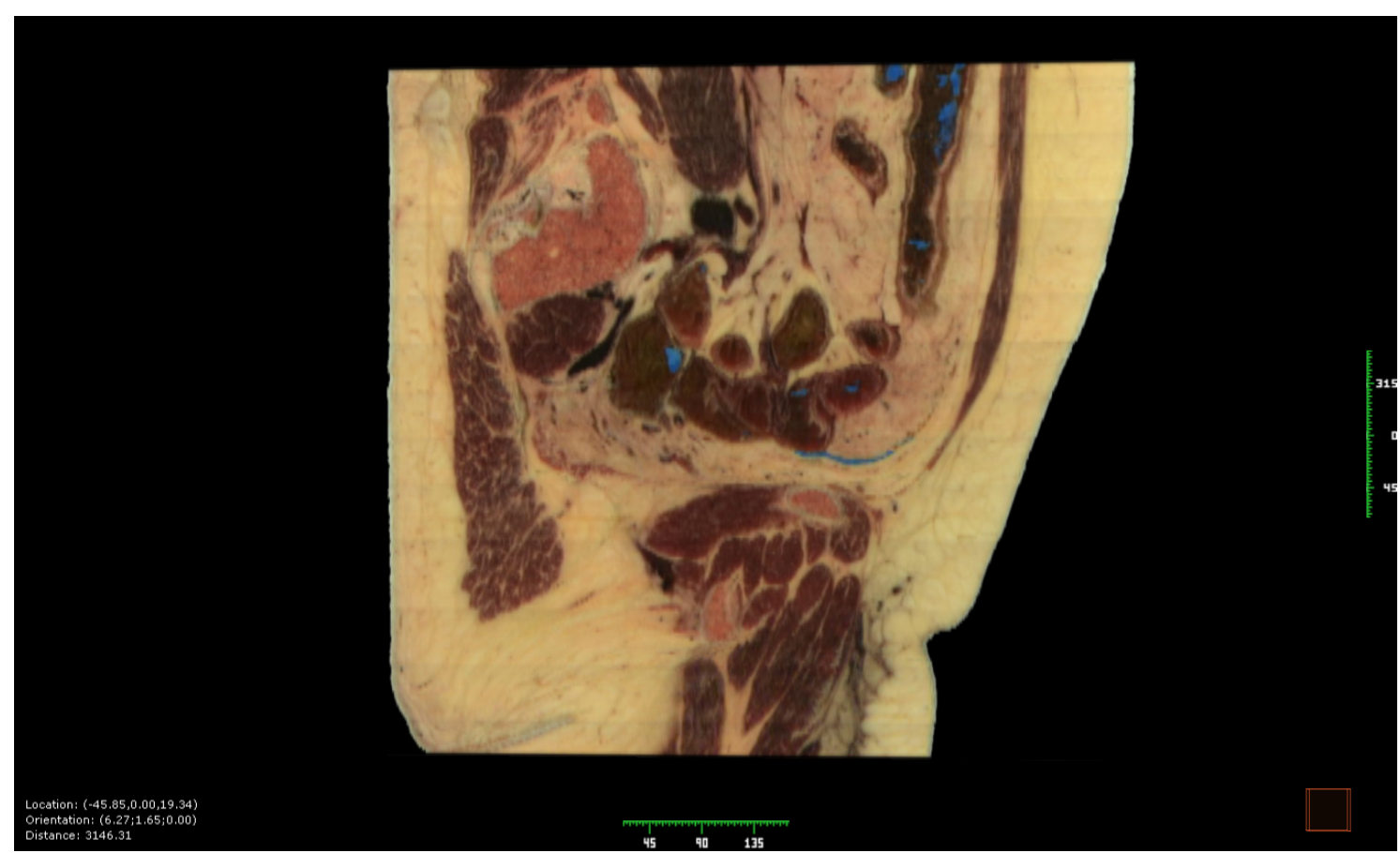

Figura 20. Corte sagital de la pelvis femenina del proyecto "Visible Human".

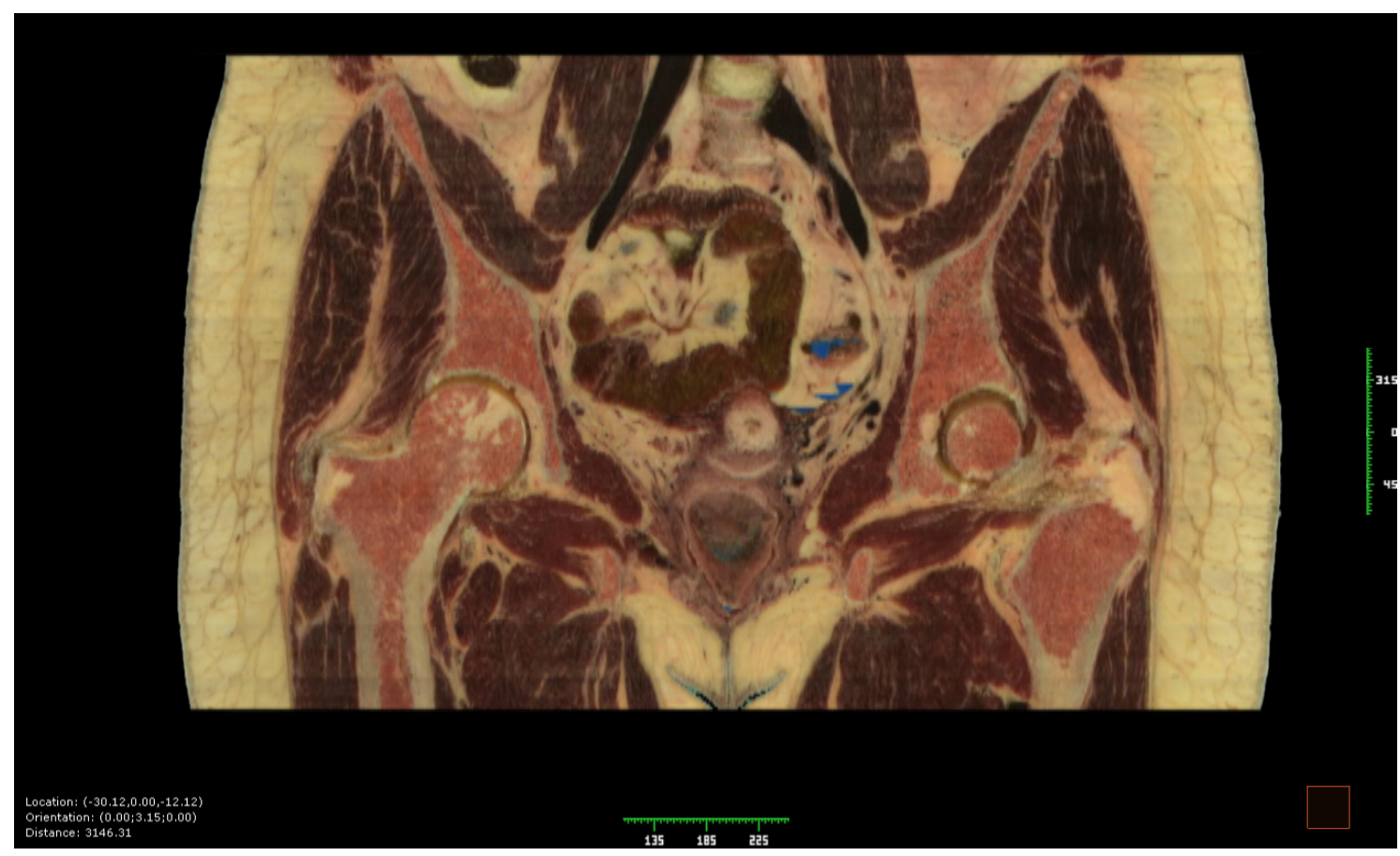

Figura 21. Corte coronal de la pelvis femenina del proyecto "Visible Human". 


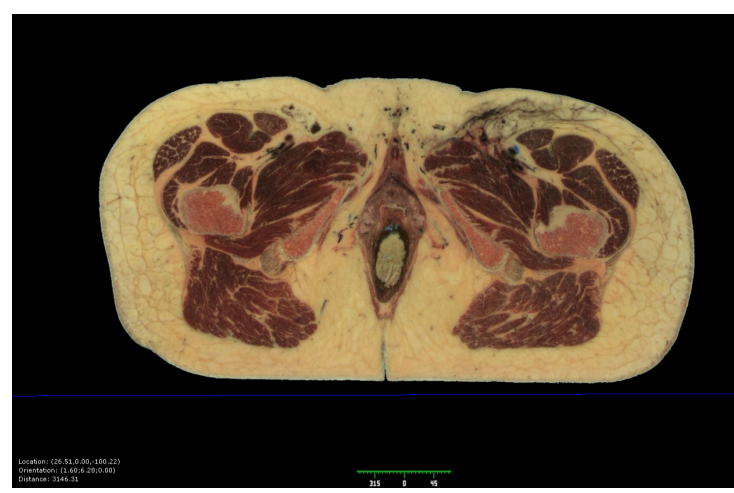

Figura 22

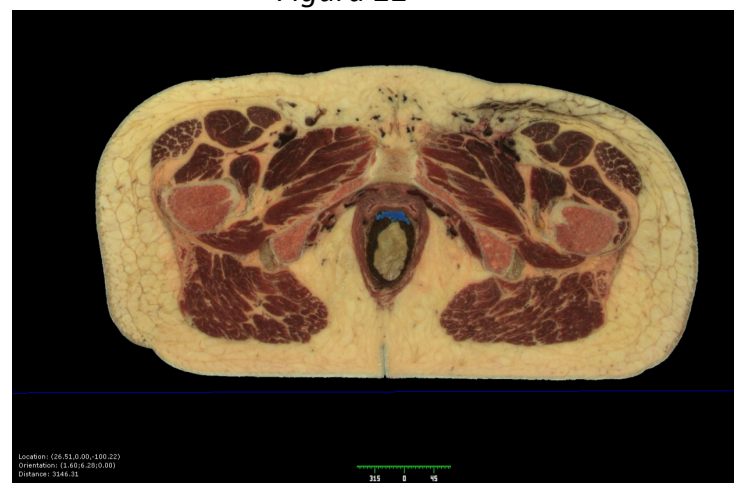

Figura 23

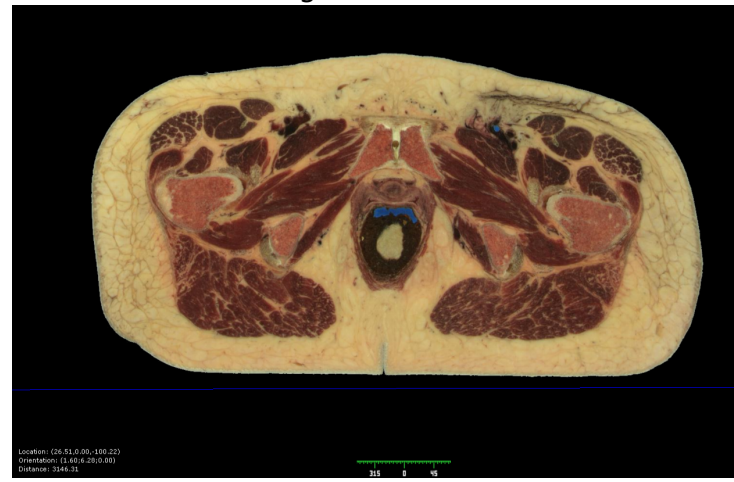

Figura 24

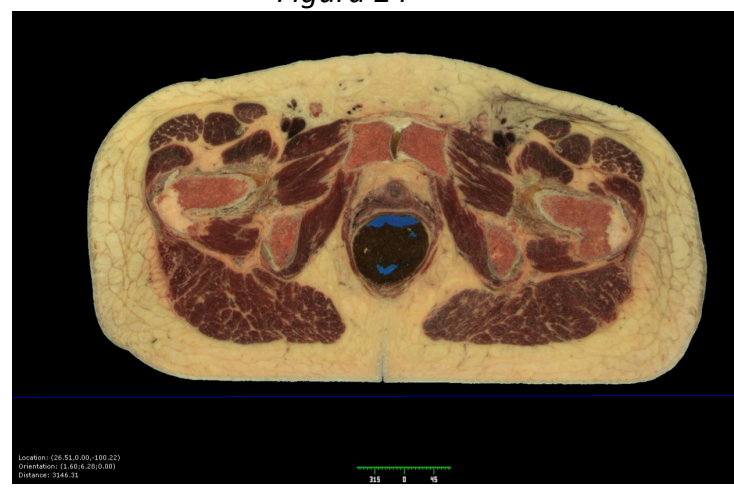

Figura 25

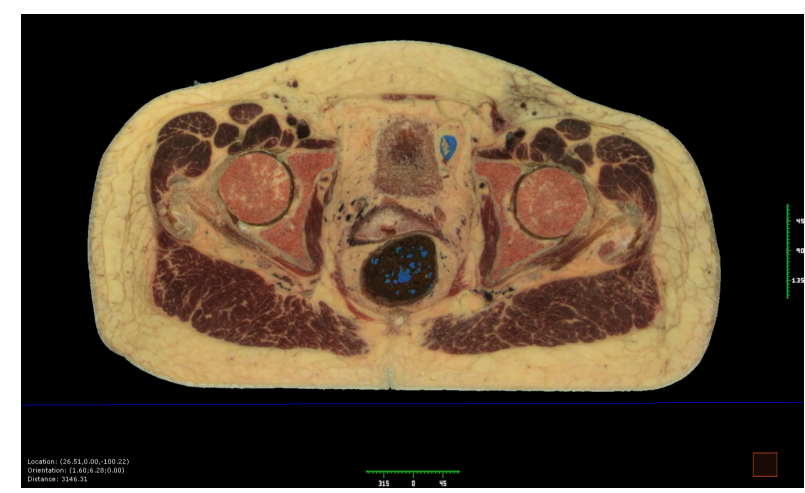

Figura 26

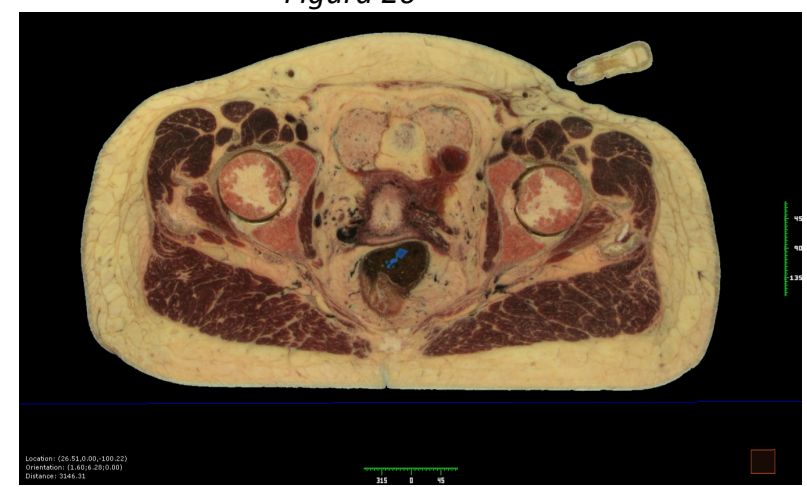

Figura 27

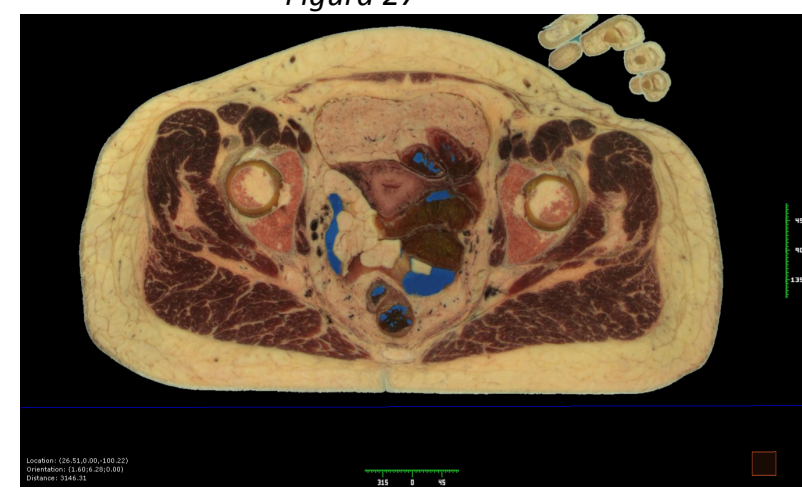

Figura 28

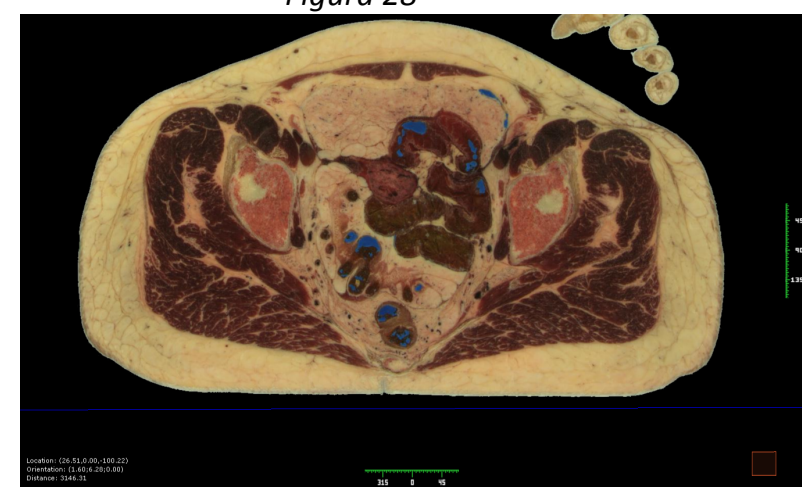

Figura 29

Figs. 22-29. Cortes axiales seriados del Visible Human Project. 


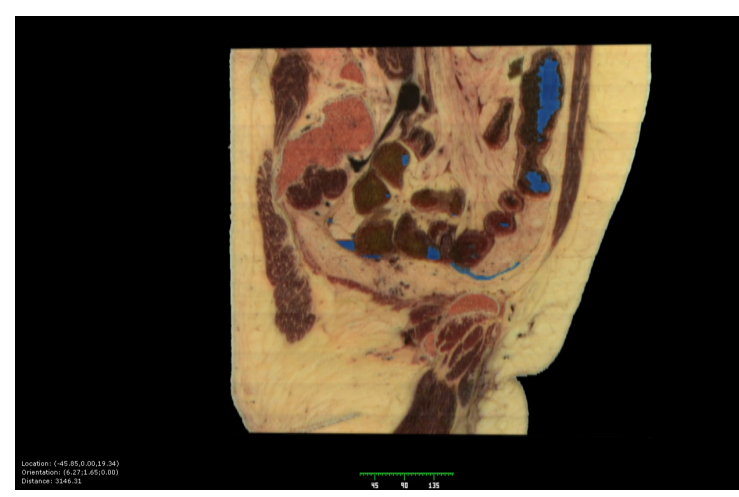

Figura 30

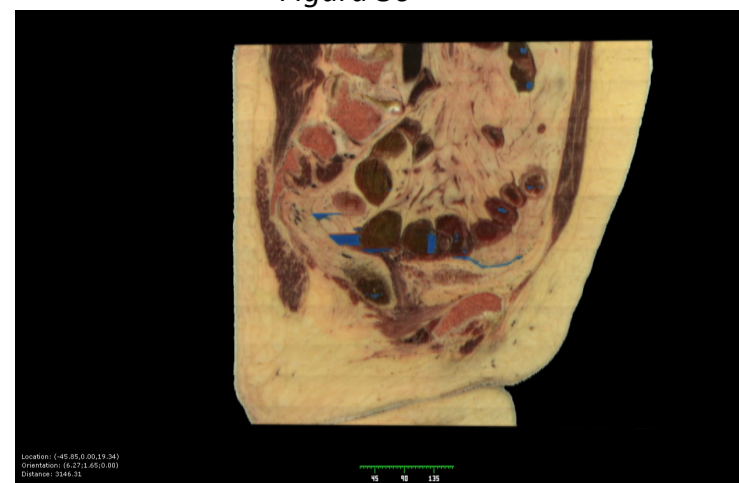

Figura 31

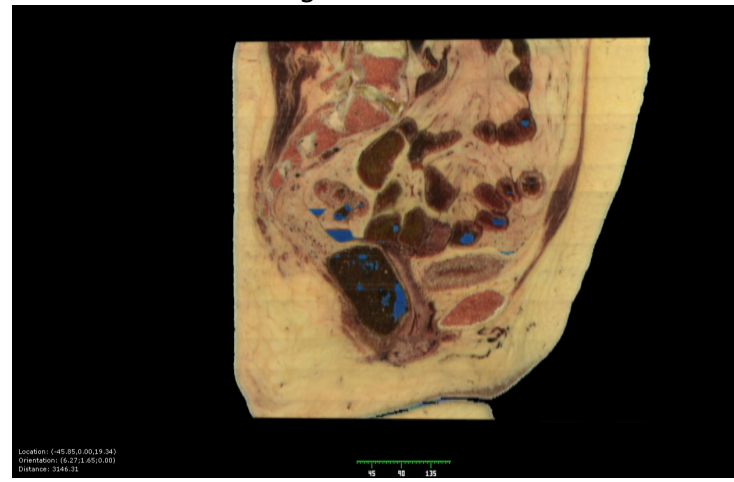

Figura 32

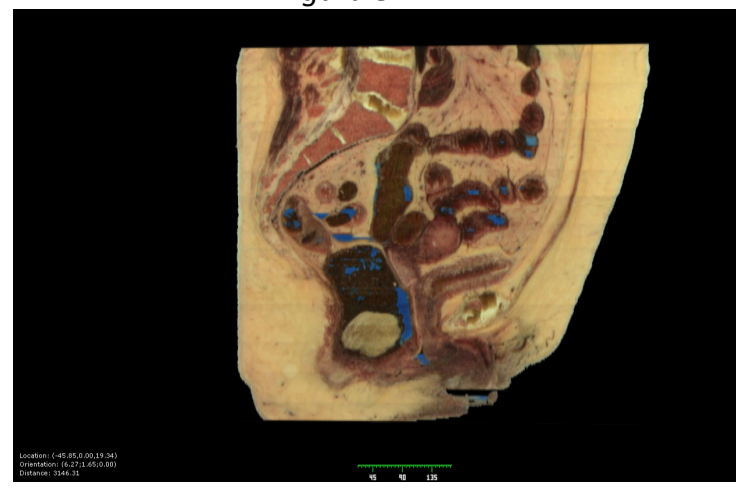

Figura 33

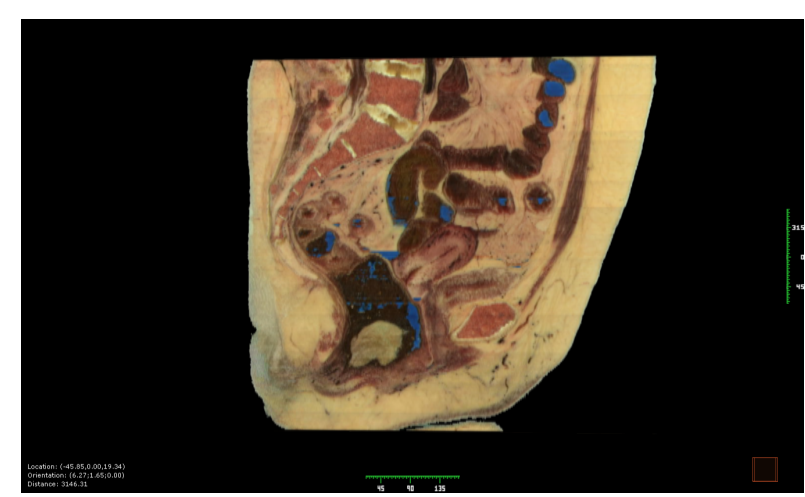

Figura 34

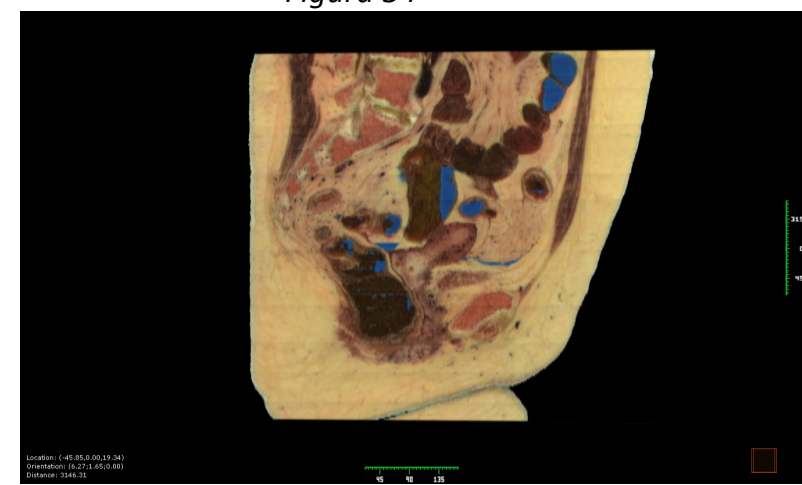

Figura 35

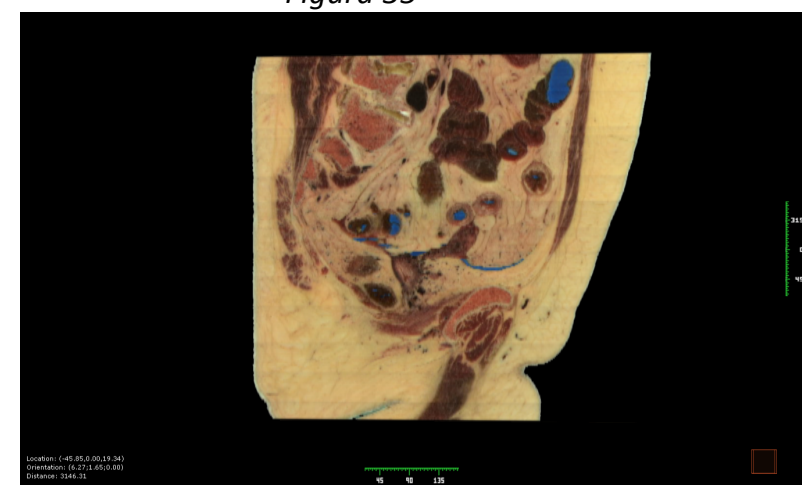

Figura 36

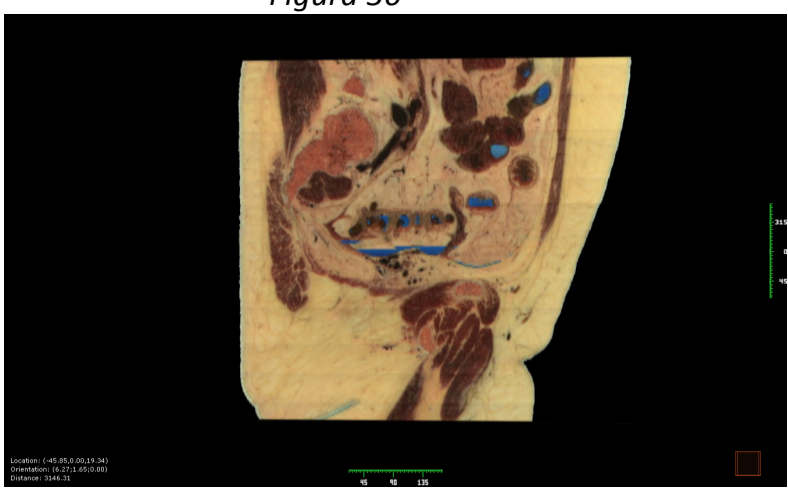

Figura 37

Figs. 30 - 37. Cortes sagitales seriados de la pelvis femenina, reconstrucciones realizadas por ordenador a partir de los cortes axiales. 


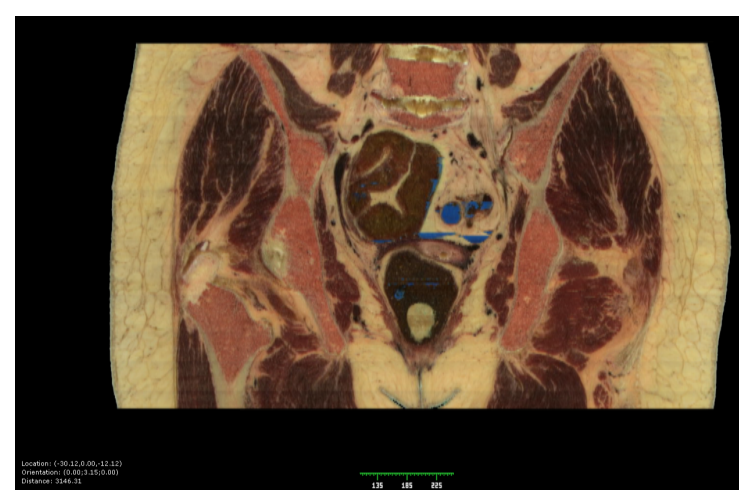

Figura 38

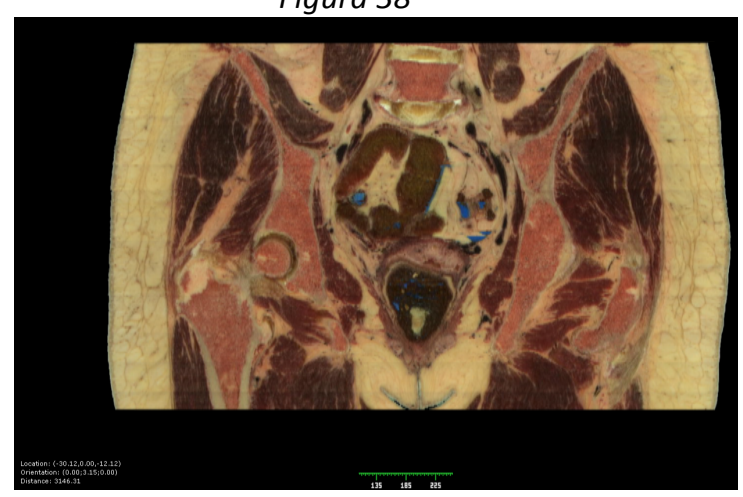

Figura 39

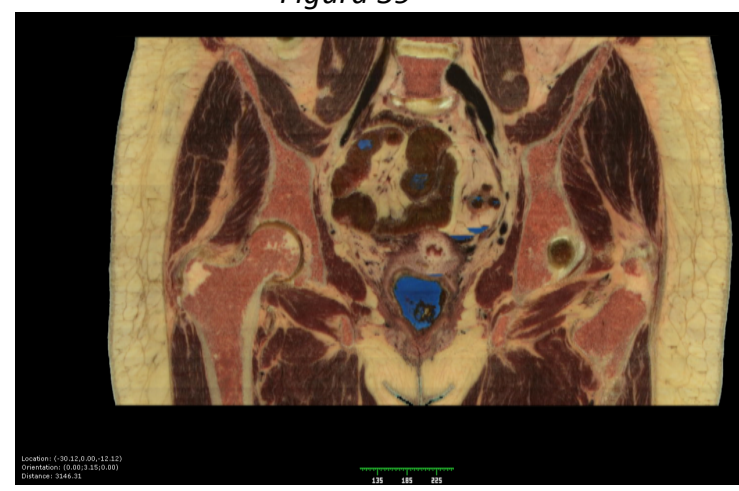

Figura 40

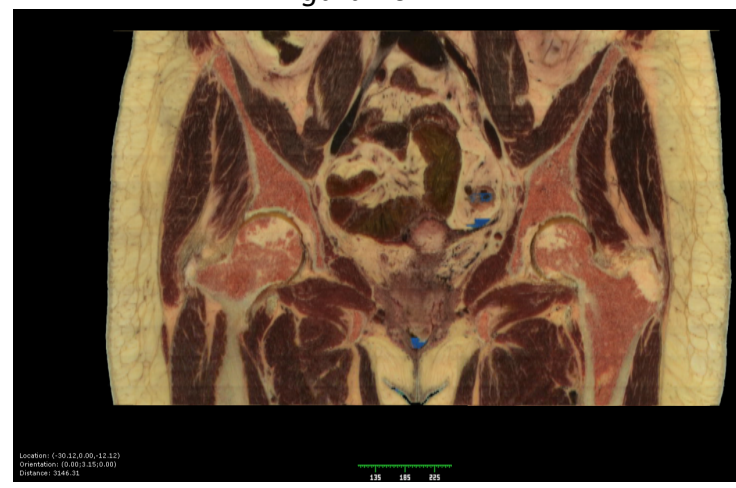

Figura 41

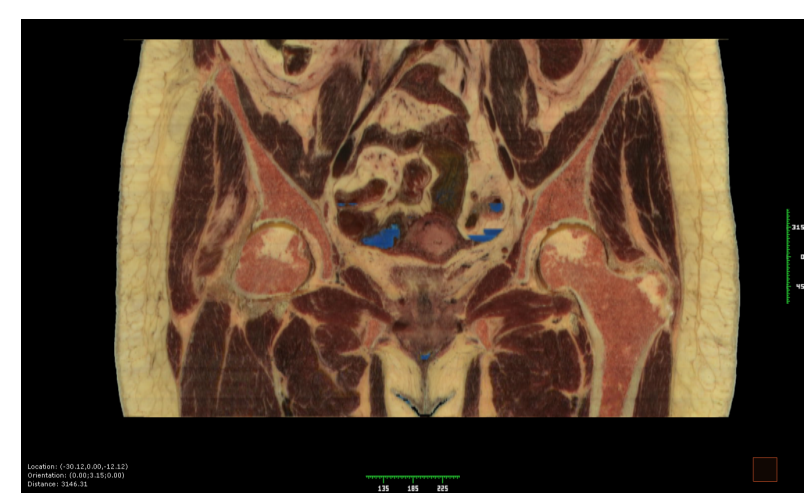

Figura 42

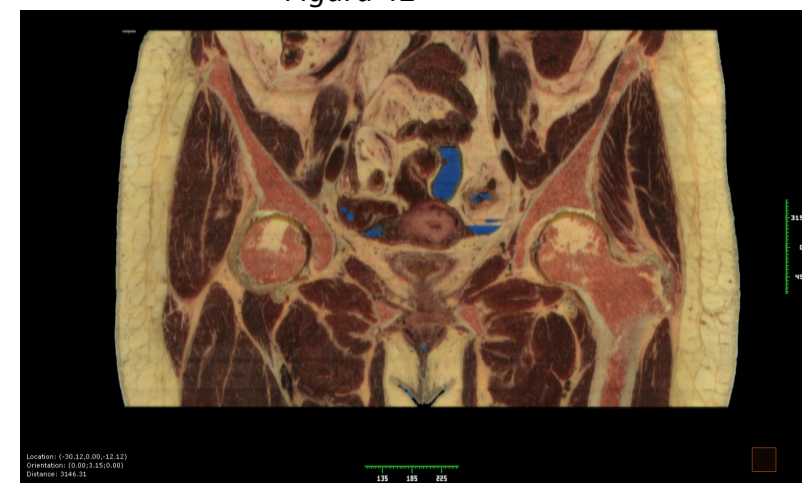

Figura 43

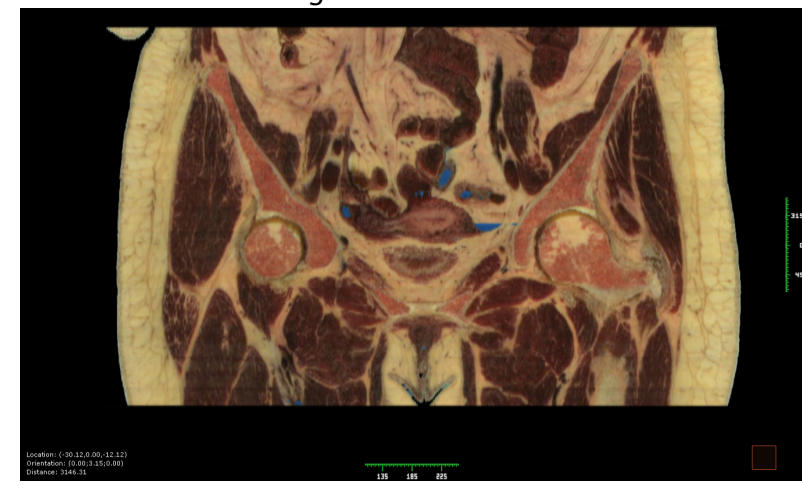

Figura 44

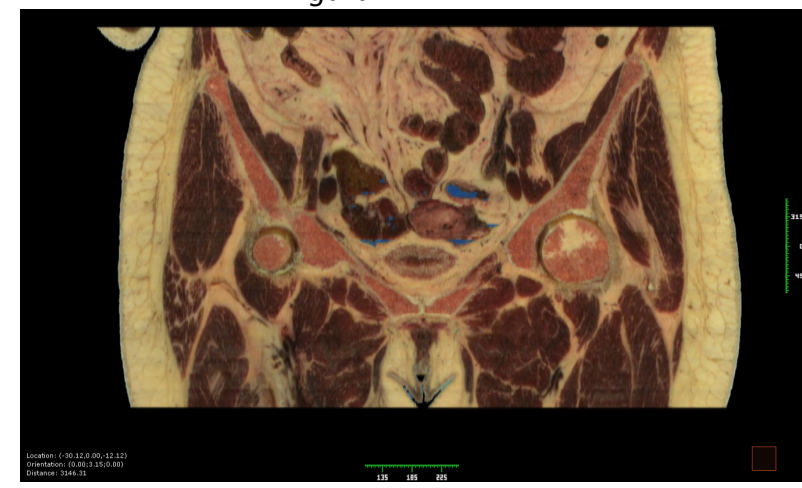

Figura 45

Figs. 38 - 45. Cortes coronales de cadáver seriados, reconstruidos de los axiales. 
Además, estas secciones de cadáver pueden visualizarse conjuntamente (axial, sagital y coronal) y en cualquier posición espacial (Figs. 46-49).

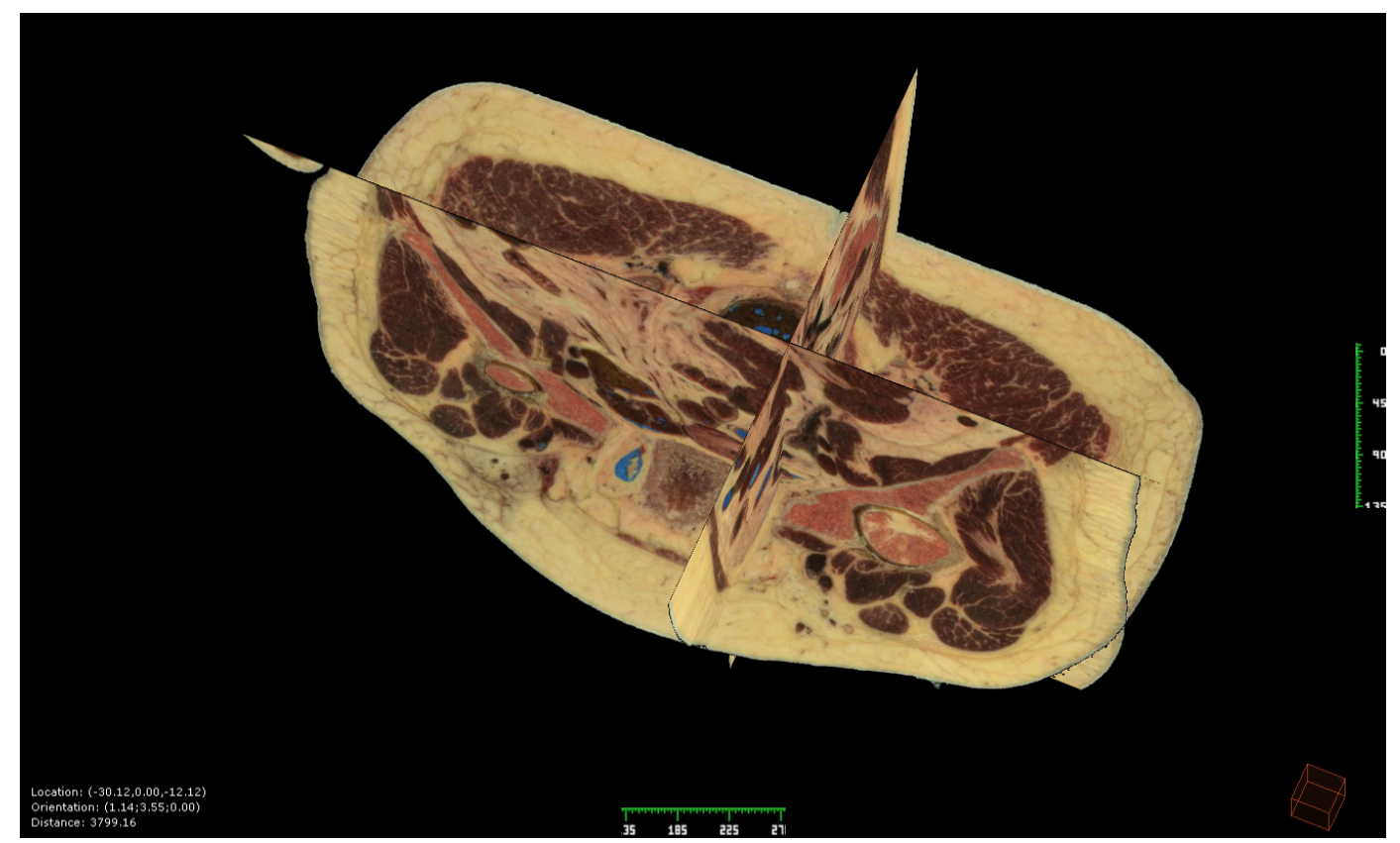

Figura 46

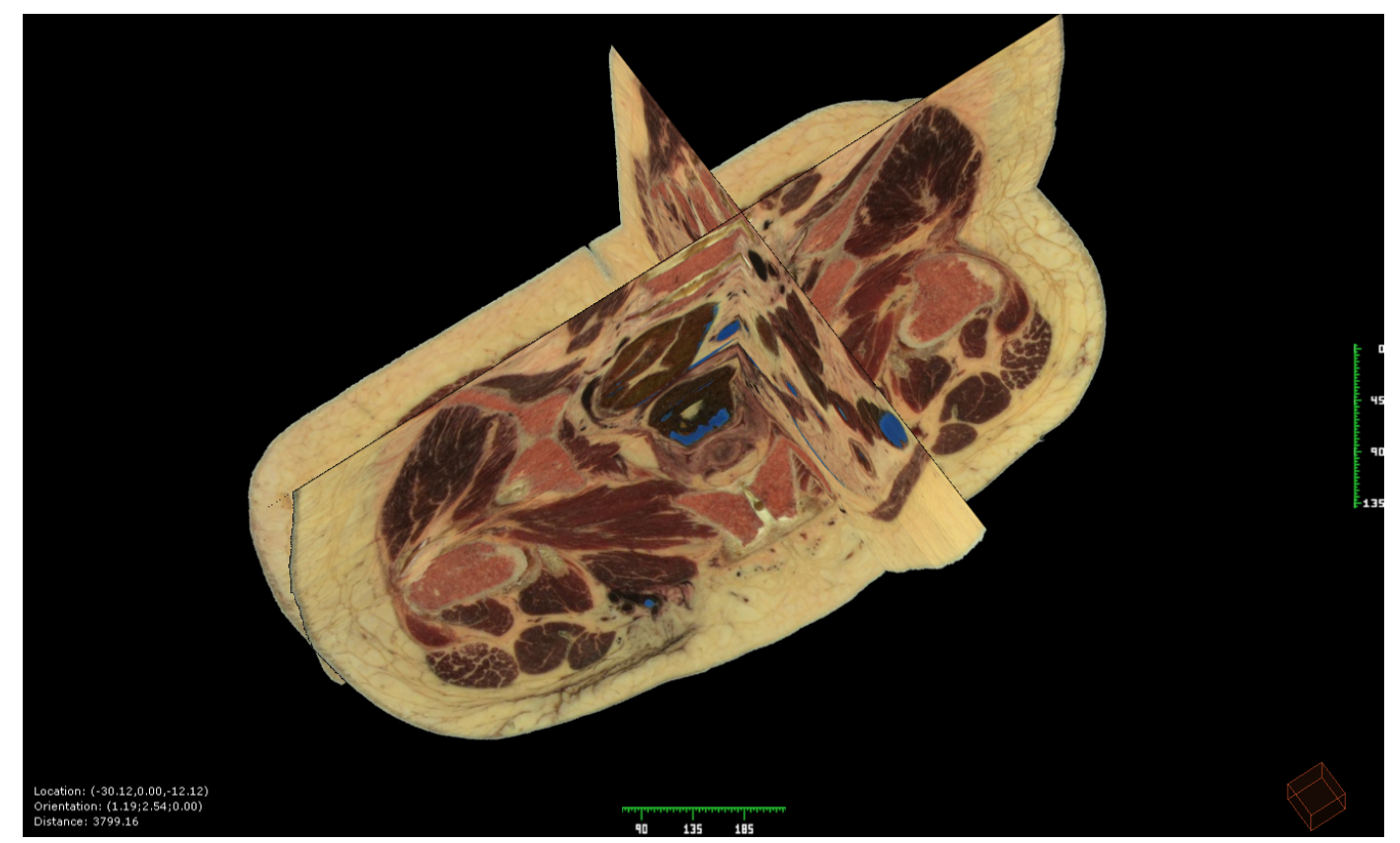

Figura 47 


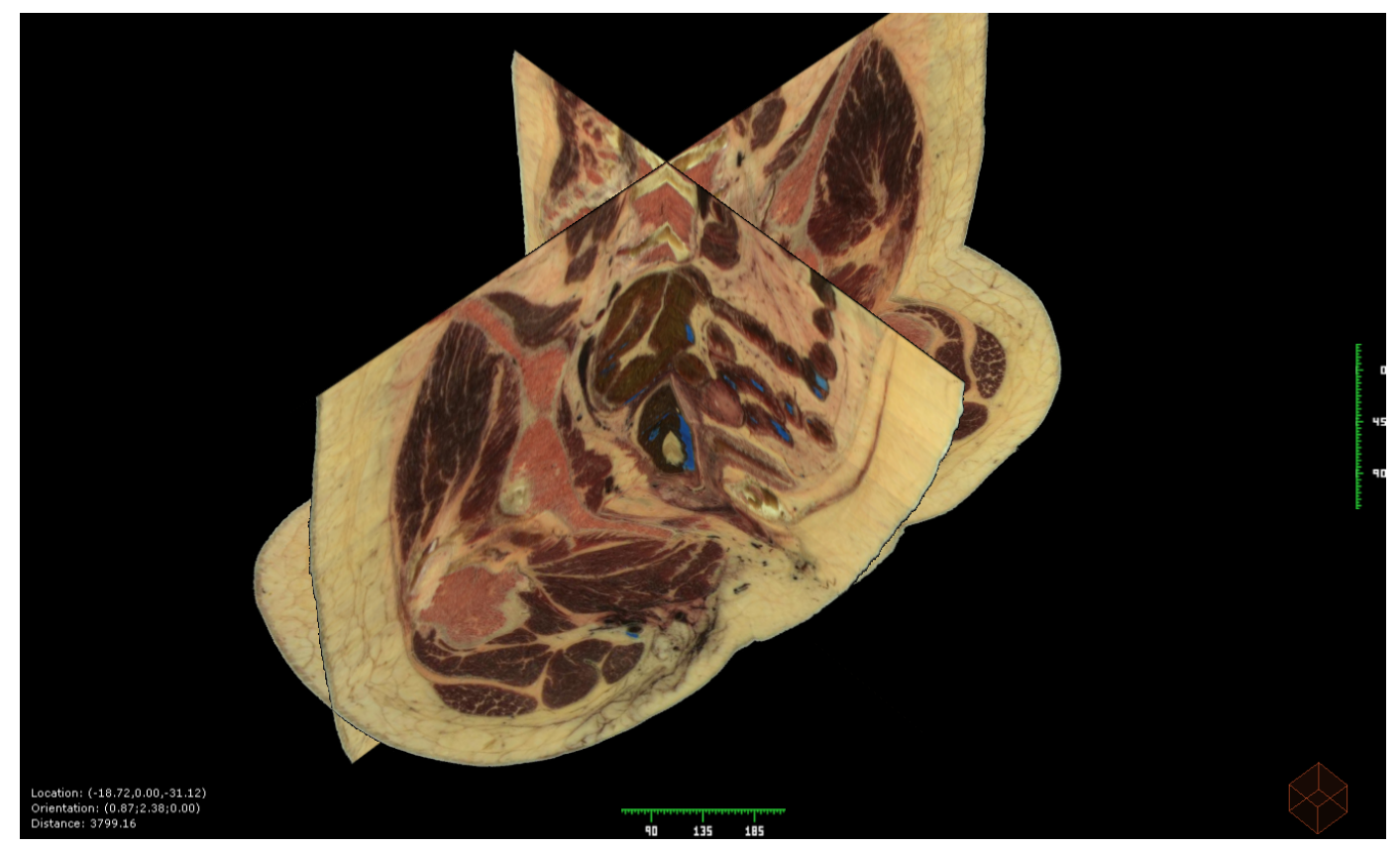

Figura 48

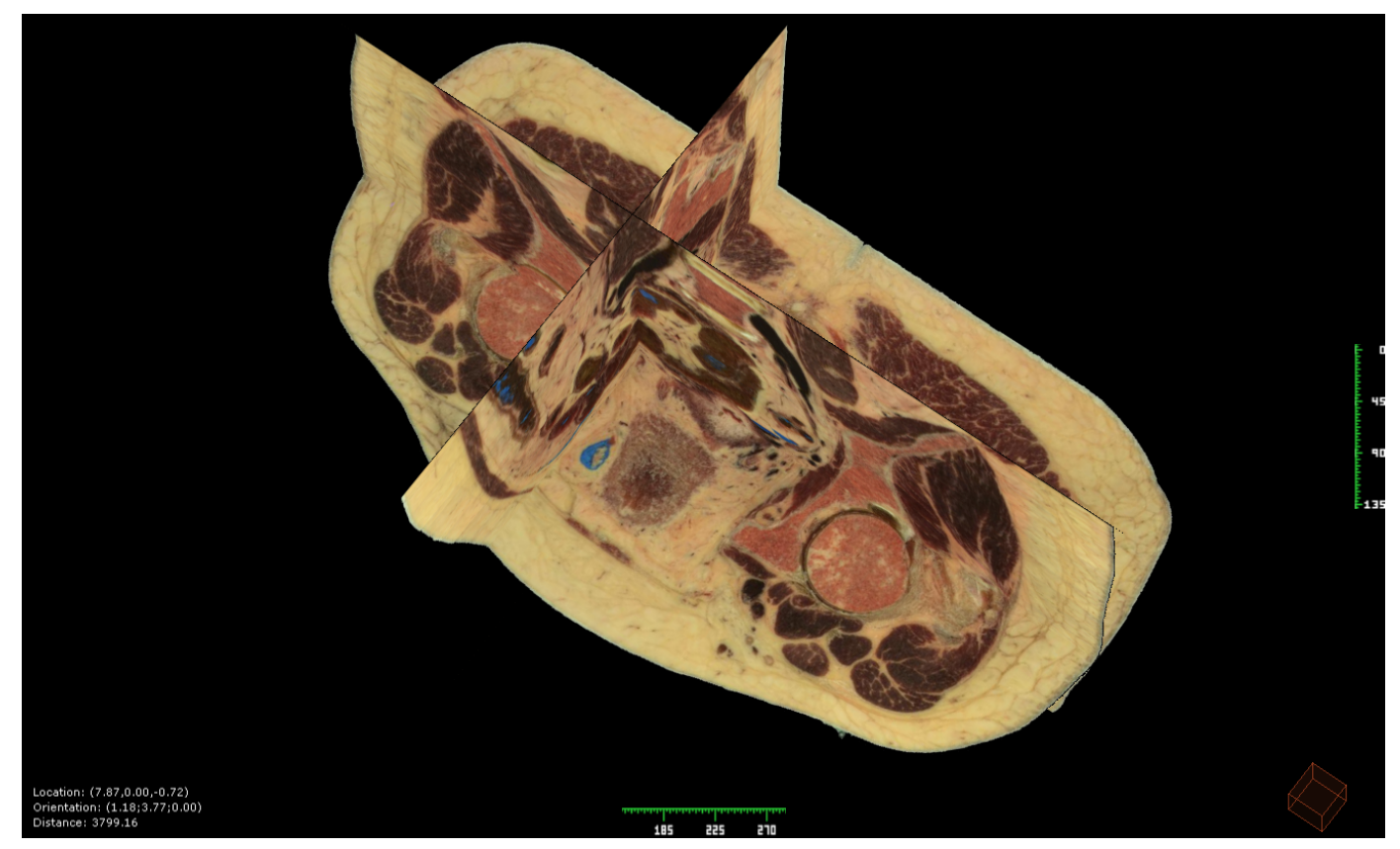

Figura 49 
1.b.- Imágenes seccionales de resonancia magnética: De la misma manera, nuestro desarrollo tecnológico presenta un conjunto de secciones de RM, en los tres ejes ortogonales del espacio (Figs. 50 - 75).

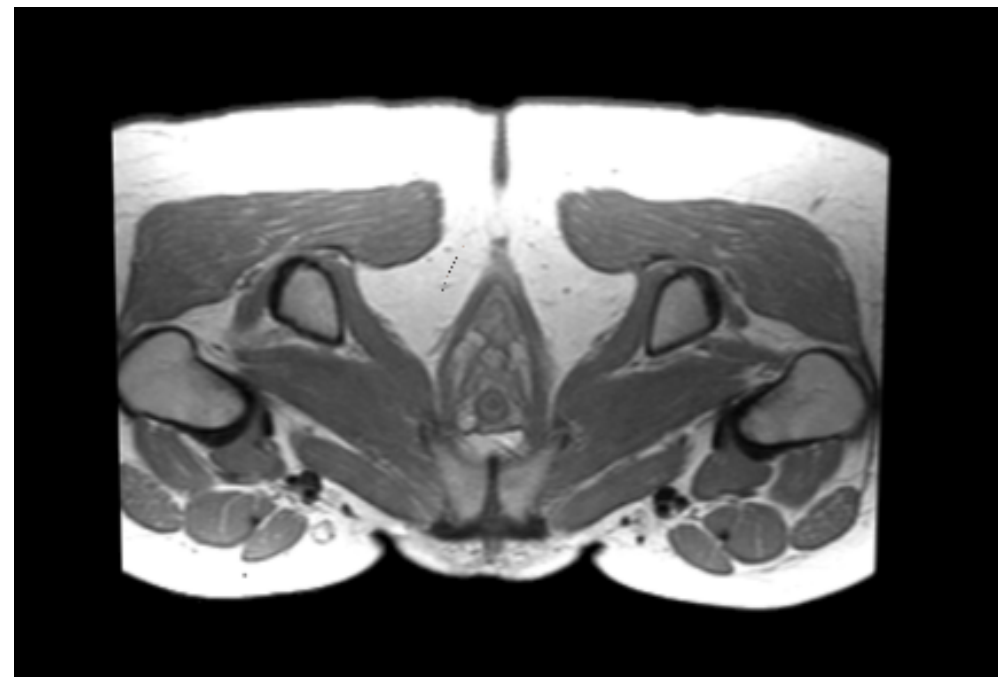

Figura 50. Imagen de un corte axial de RM de la pelvis.

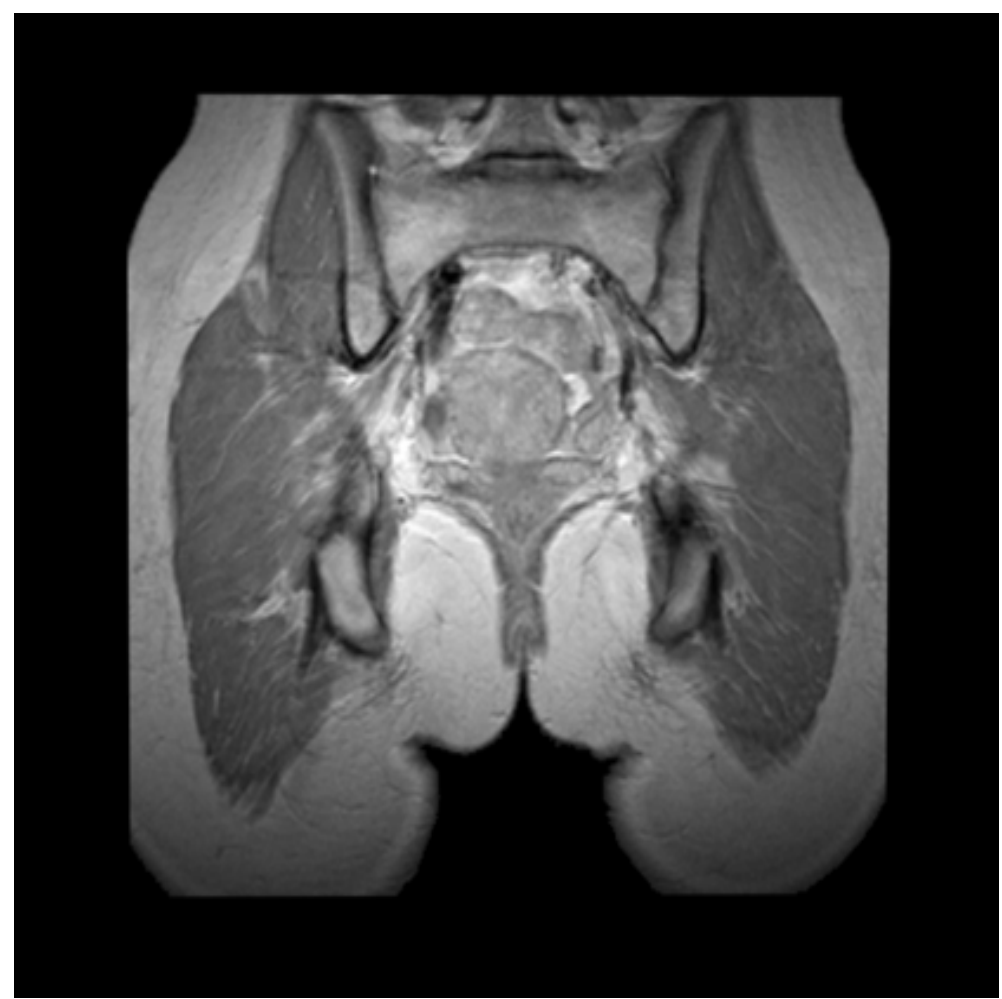

Figura 51. Imagen de un corte coronal de RM de la pelvis. 
Resultados

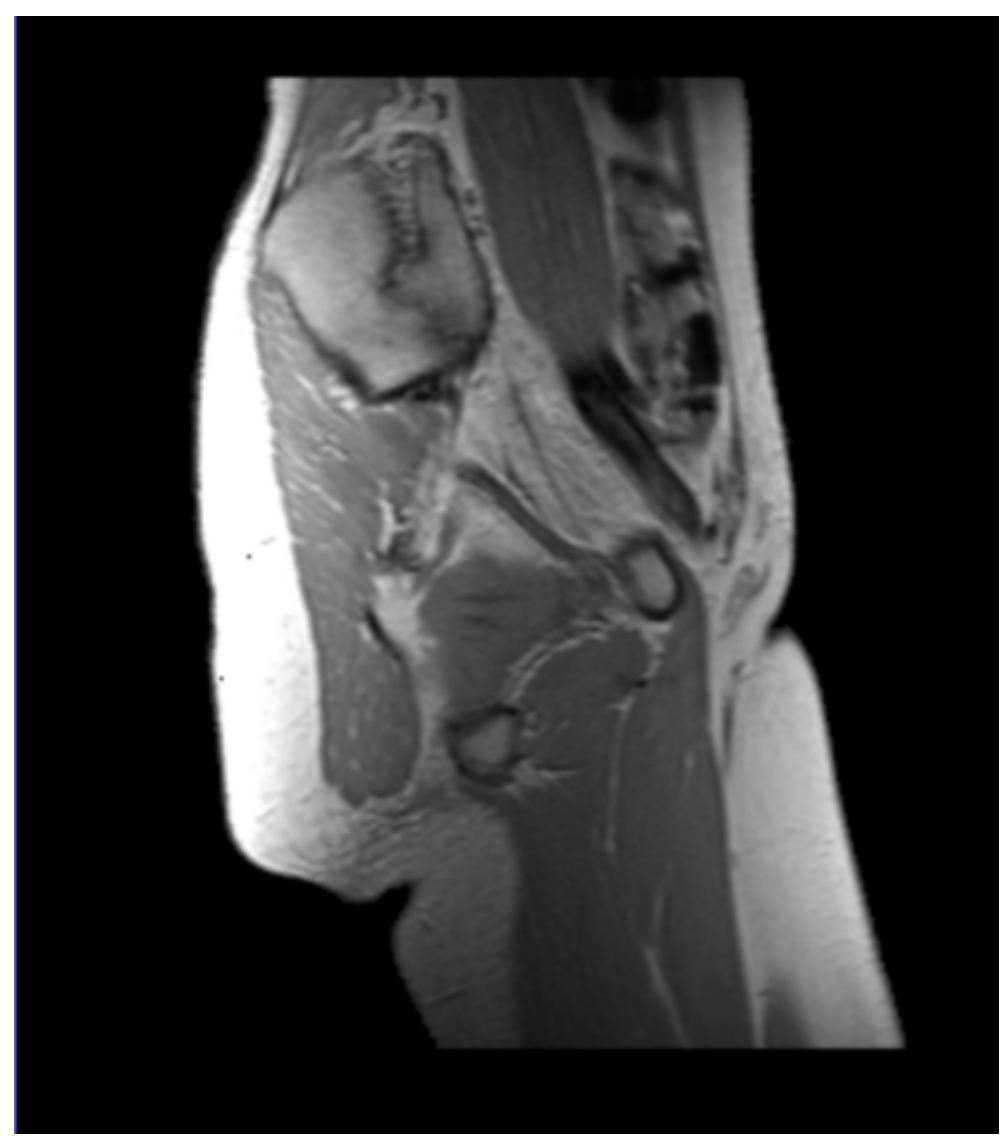

Figura 52. Imagen de un corte sagital de RM de la pelvis. 


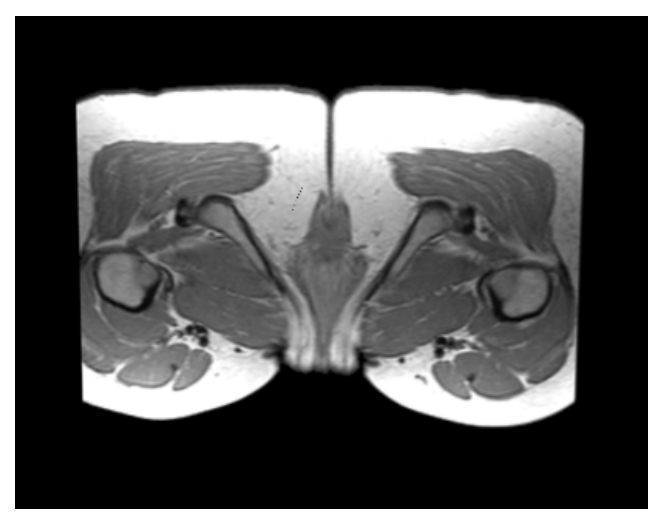

Figura 53

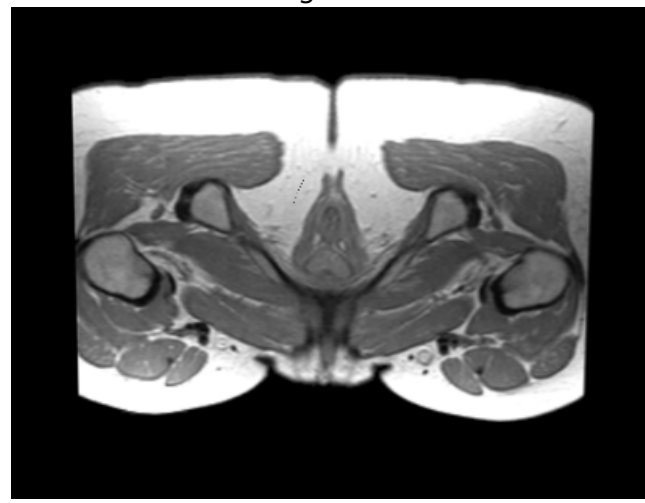

Figura 54

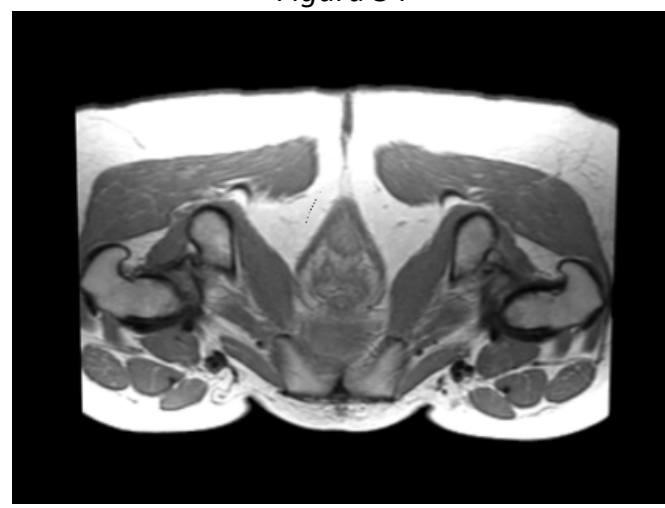

Figura 55

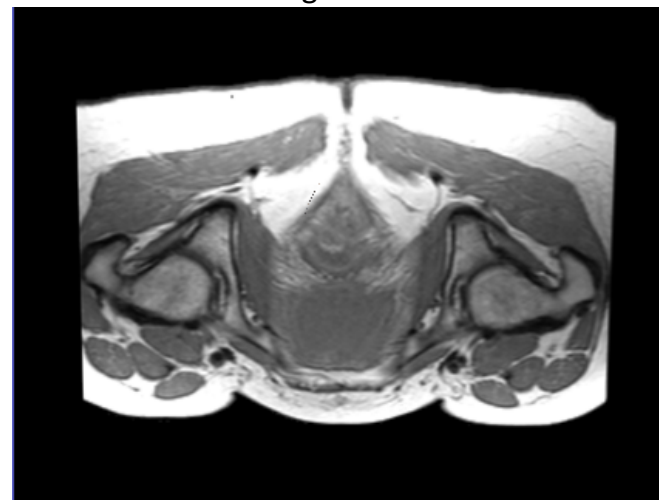

Figura 56

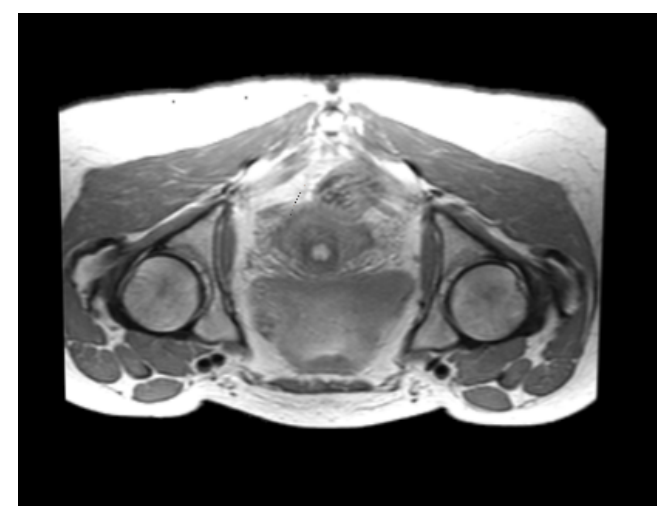

Figura 57

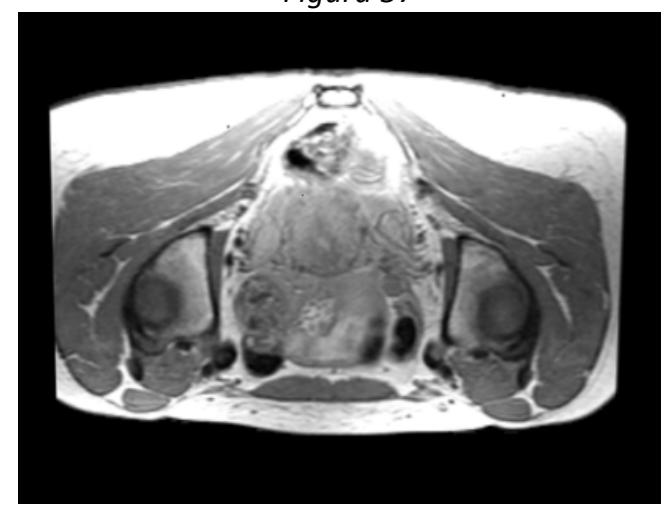

Figura 58

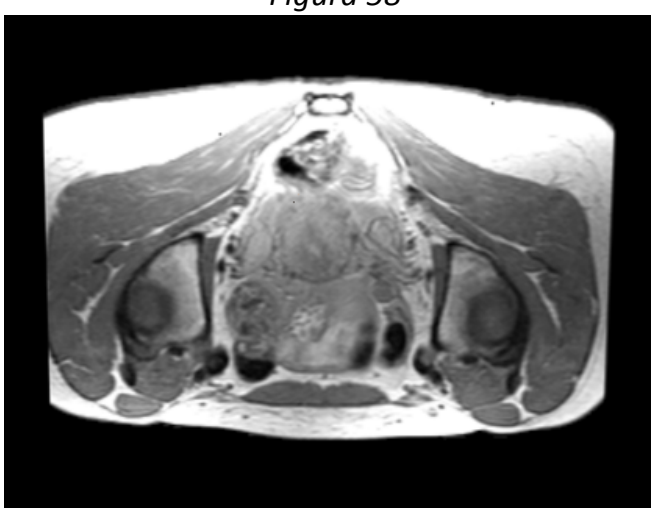

Figura 59

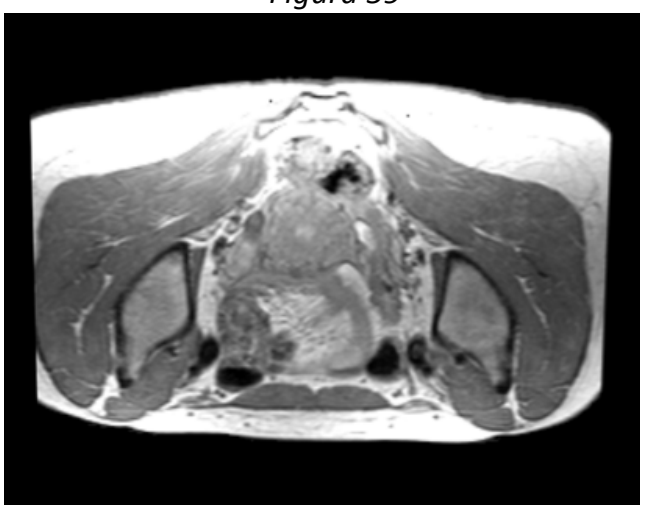

Figura 60

Figs. 53- 60. Cortes axiales seriados de RM. 


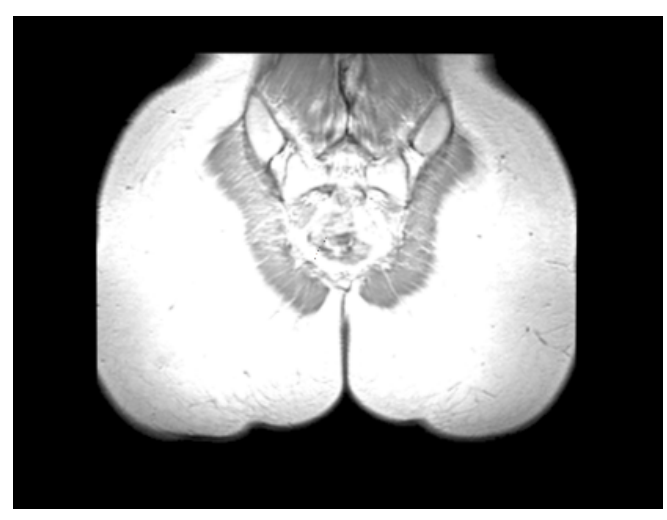

Figura 61

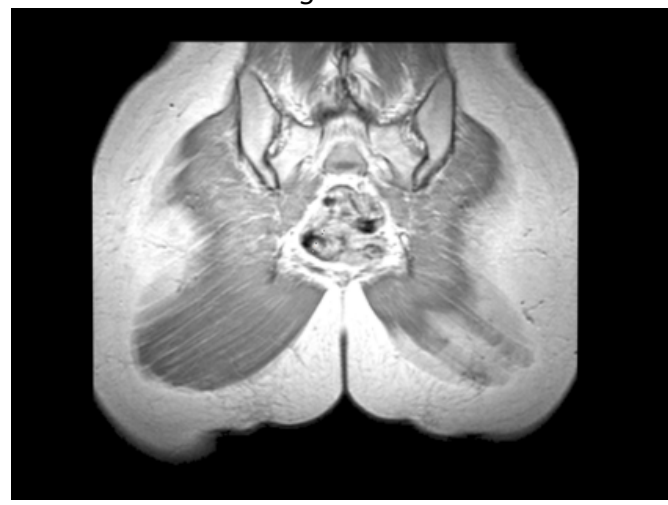

Figura 62

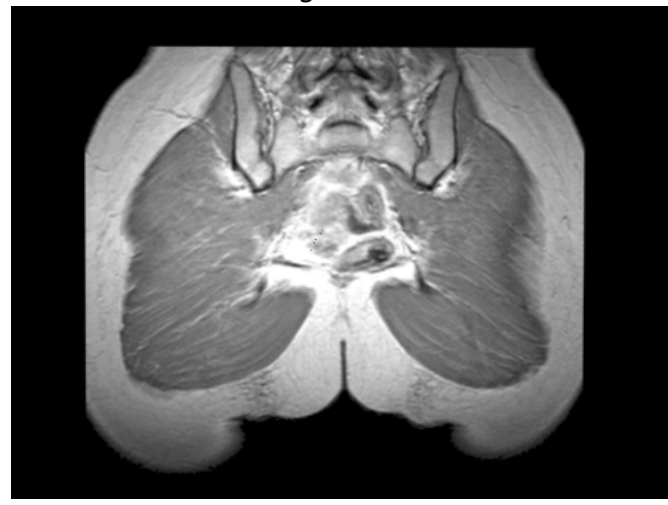

Figura 63

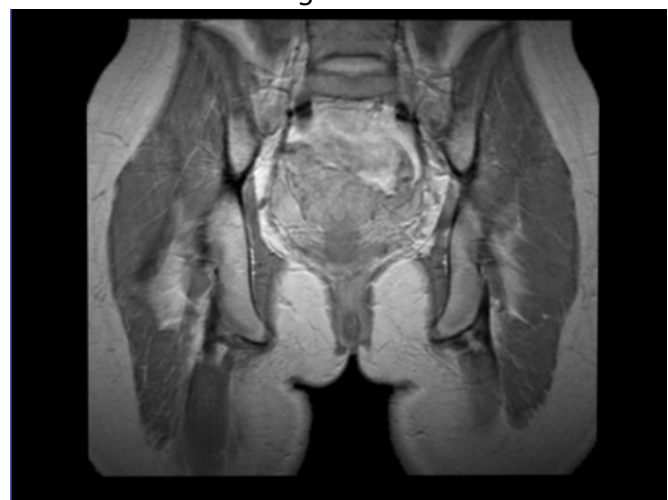

Figura 64

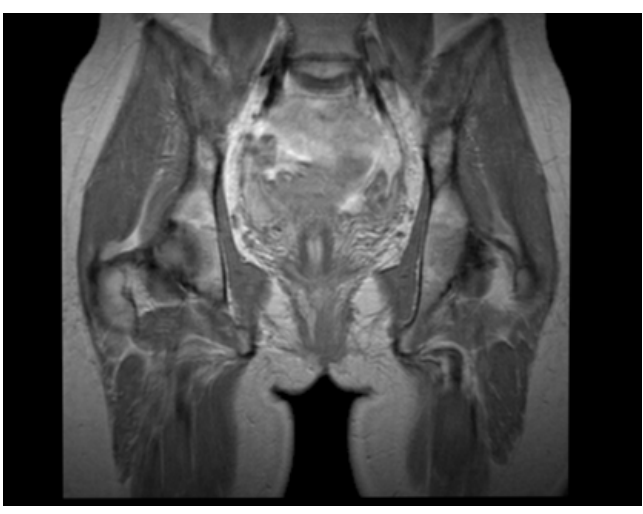

Figura 65

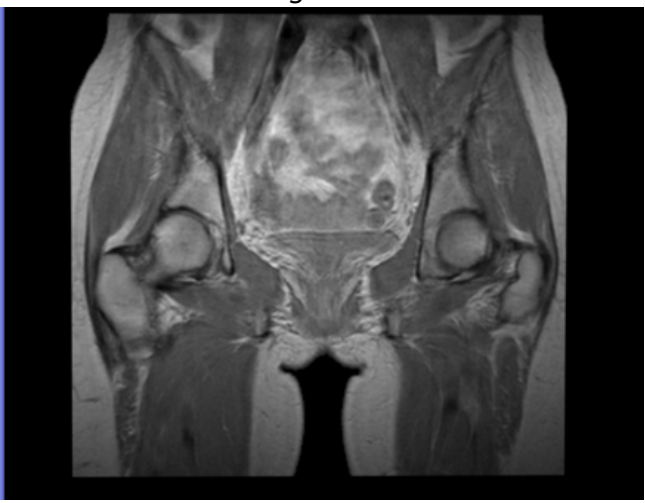

Figura 66

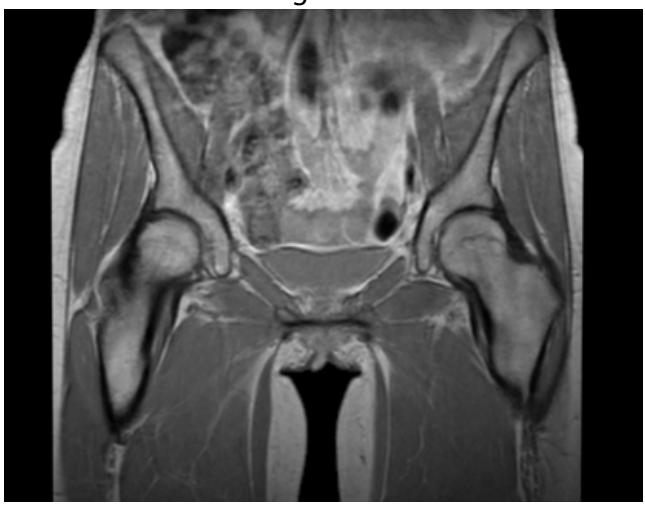

Figura 67

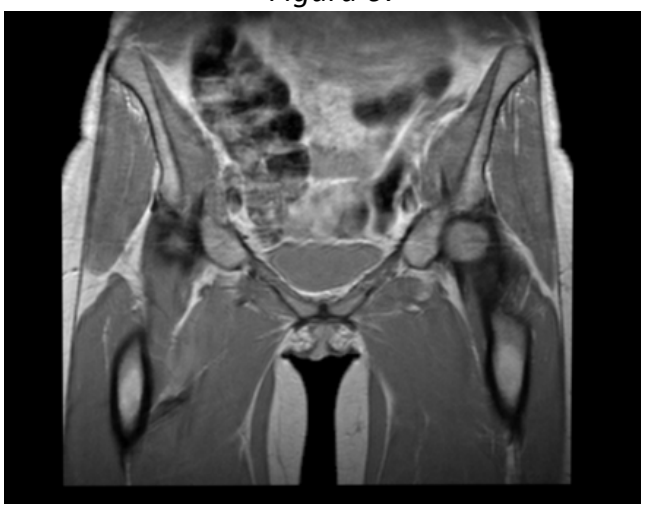

Figura 68

Figs. 61 - 68. Secciones seriadas de RM del plano coronal. 


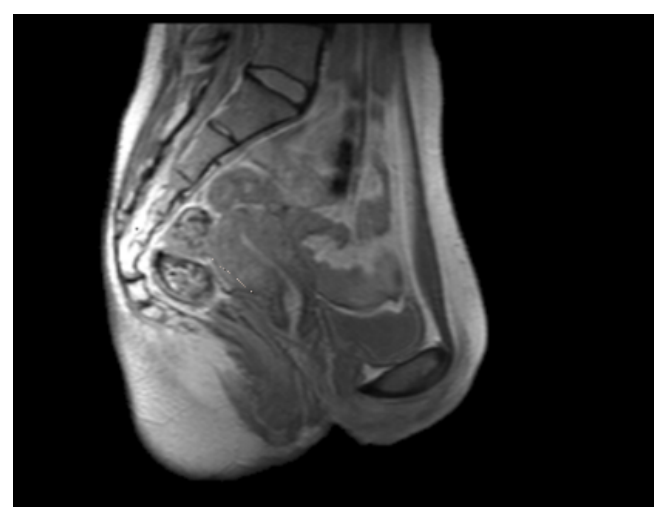

Figura 69

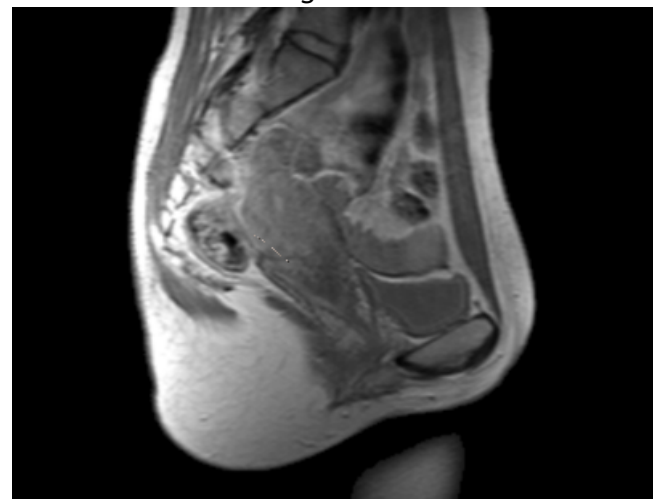

Figura 70

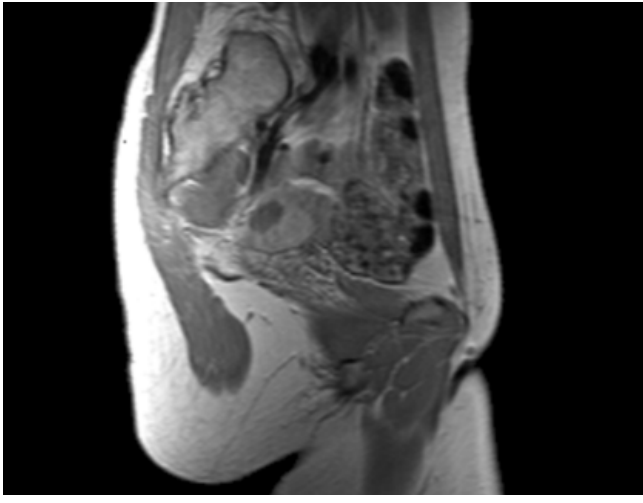

Figura 71

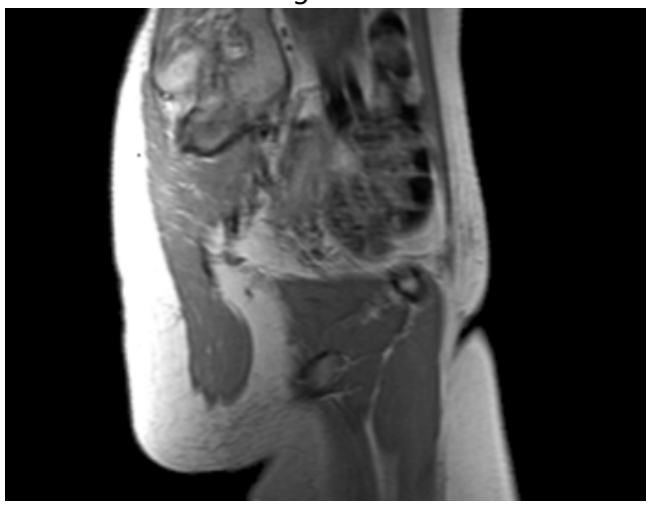

Figura 72

Figs. 69 - 72. Cortes sagitales de RM seriados.

A continuación, mostramos algunos ejemplos de las combinaciones de cortes de RM que podemos realizar con nuestro desarrollo informático. (Figs. 73 -75).

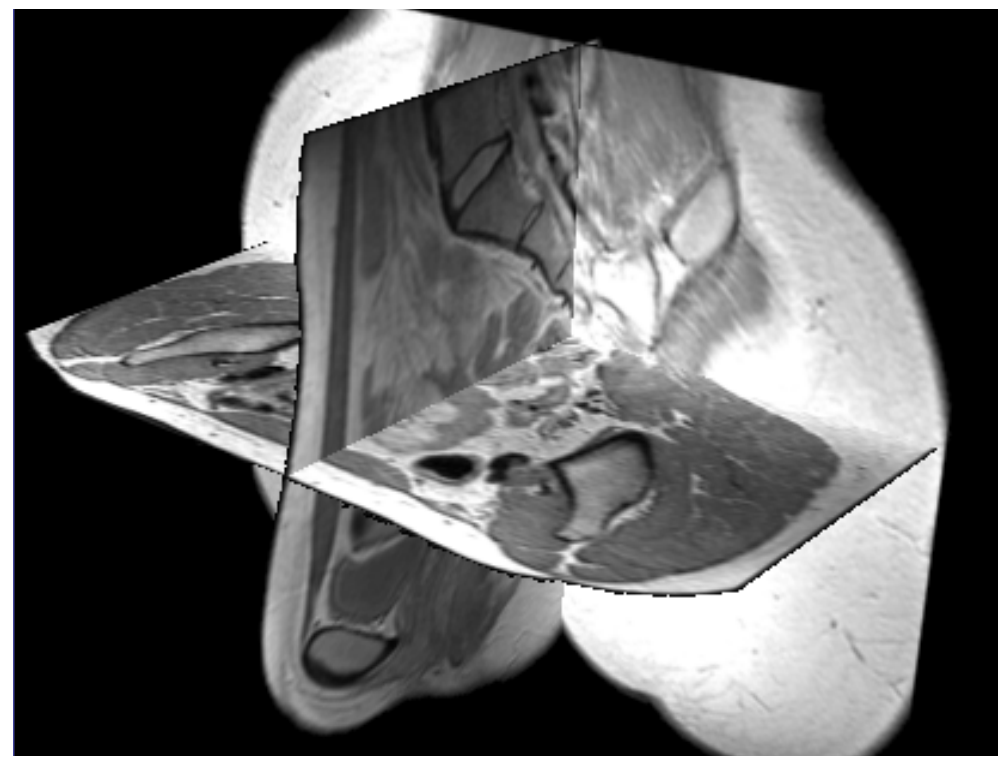

Figura 73 


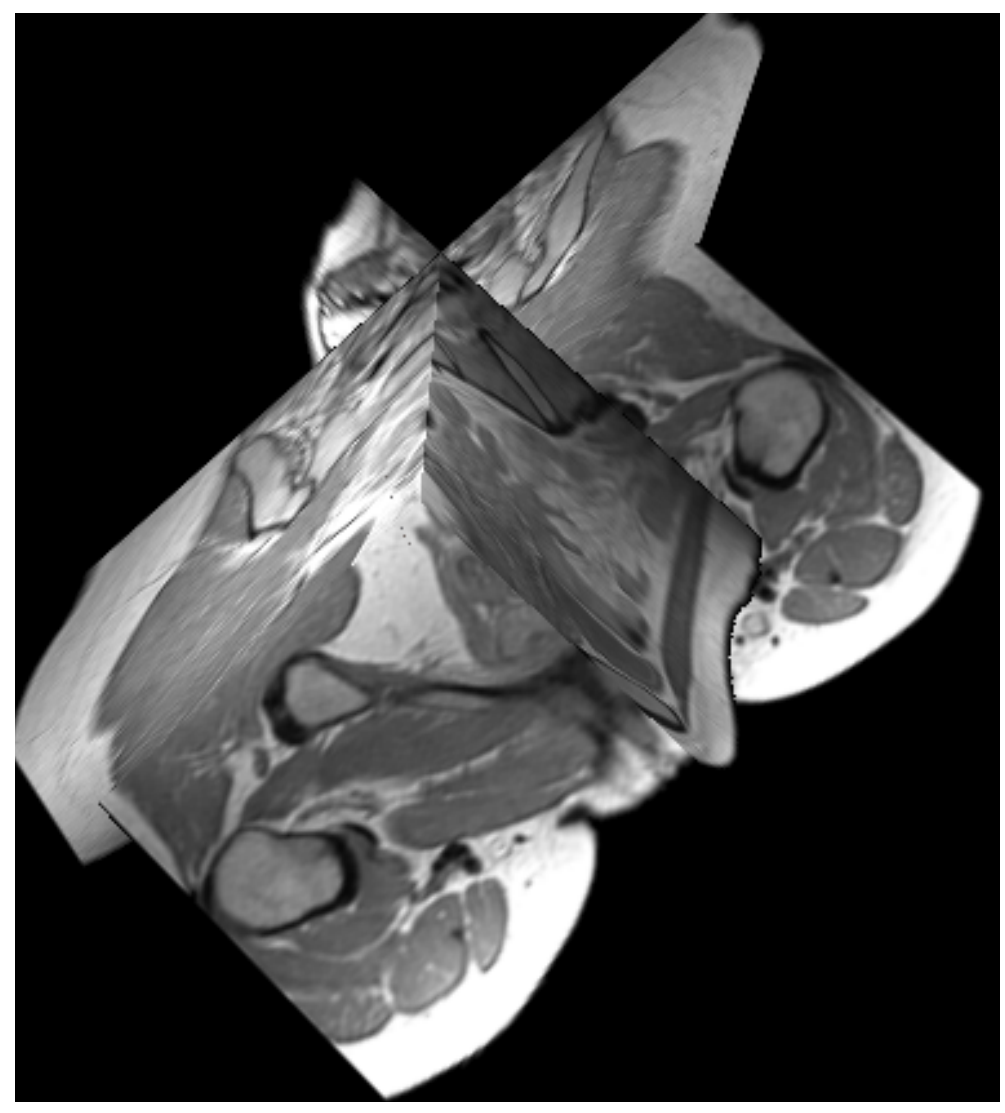

Figura 74

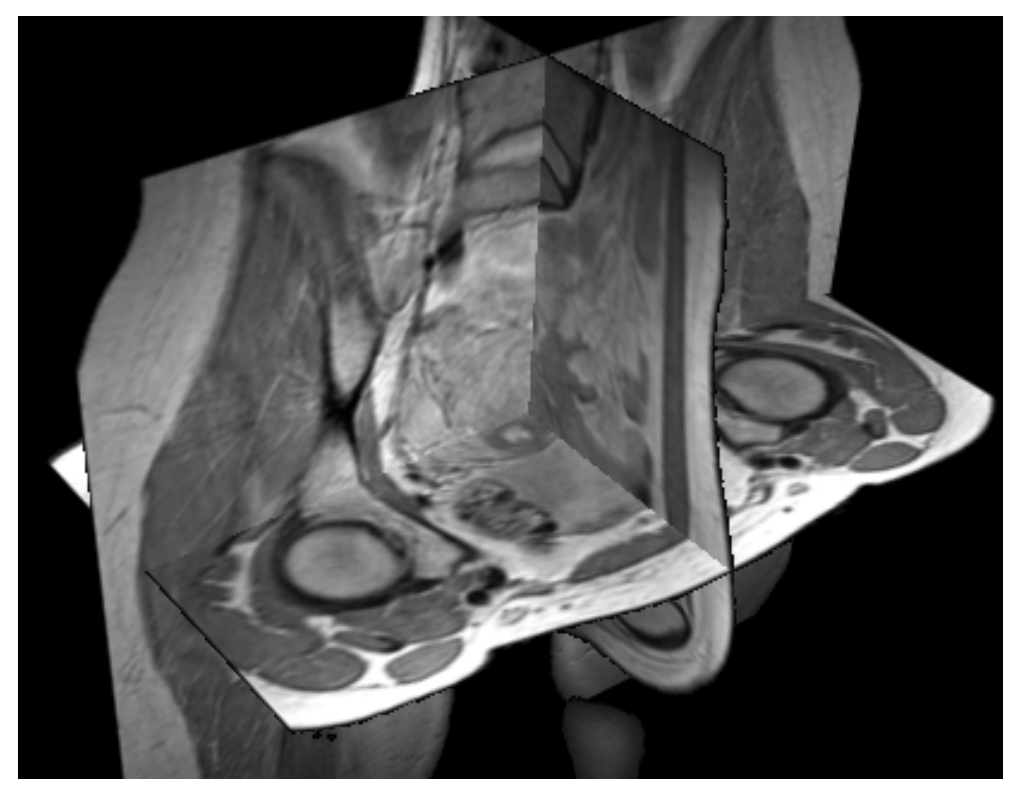

Figura 75 
1.c.- Imágenes ecográficas: Además de estas imágenes seccionales (cadáver y RM), nuestra aplicación informática permite la correlación anatómica con otra técnica de imagen, como es la ecografía. Así, podemos realizar un análisis anatómico paralelo entre secciones de RM e imágenes ecográficas (Figs. 76 y 77).

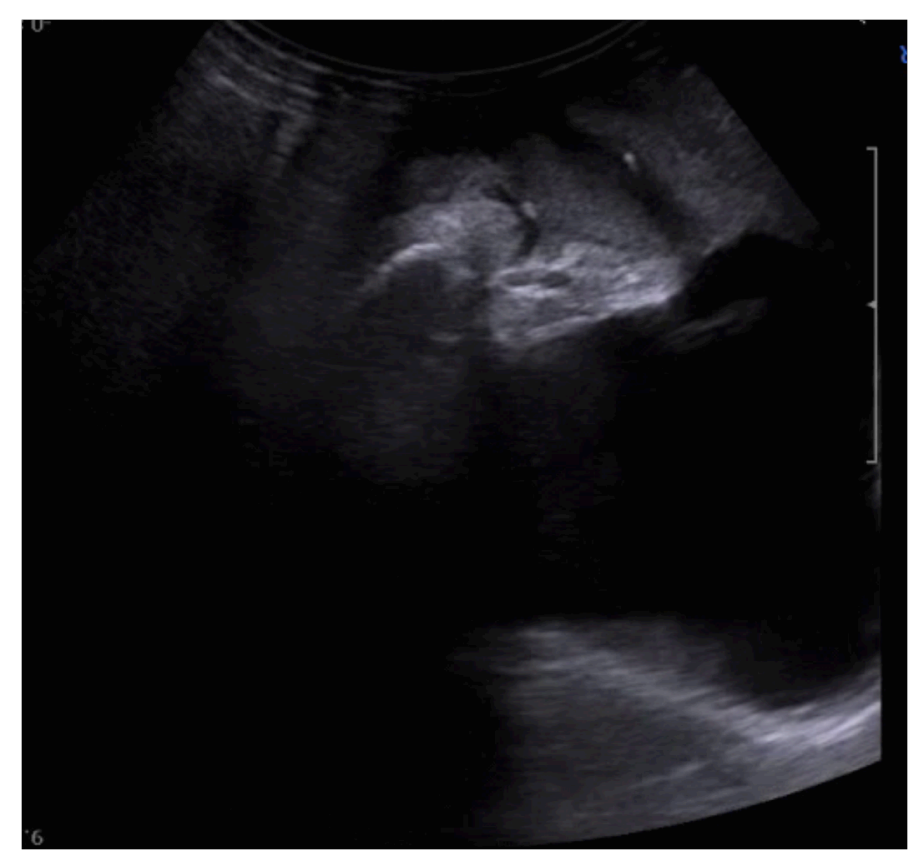

Figura 76. Imagen de ecografía.

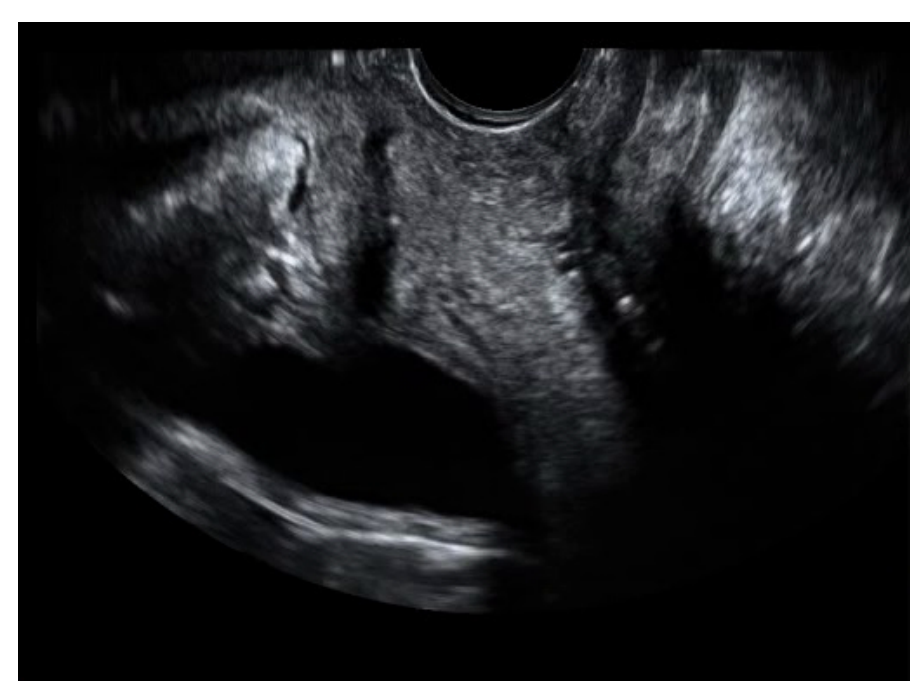

Figura 77. Imagen de ecografía.

Las imágenes anatómicas seccionales permiten analizar la estructura del cuerpo humano mediante la realización de cortes, en los tres planos del espacio, y potenciar el conocimiento de las relaciones espaciales entre diversos órganos y tejidos. Las imágenes seccionales aportan una rica información sobre las estructuras anatómicas 
y ofrecen una visión realista de las mismas, ya que reflejan fielmente su forma y posición relativa al preservar las relaciones espaciales que existen de forma natural entre ellas.

El estudio que nos permite este tipo de anatomía es muy diferente al de la observación anatómica tradicional, basada en la disección, que produce una alteración artificial de las relaciones naturales de los órganos y tejidos a la hora de exponerlos, aislarlos e identificarlos.

Como describimos en nuestro artículo "Development of 3D models of female pelvis embedded in anatomical sections from de Visible Human Project" (Asensio et al., 2017), es muy importante en cualquier aplicación anatómica para la enseñanza, ya sea con modelos tridimensionales o no, contar con un número abundante de ilustraciones anatómicas, lo que afianza la importancia de nuestra colección de imágenes seccionales seriadas de cadáver empleadas como referente anatómico para este desarrollo informático.

La aportación principal a la anatomía seccional son las imágenes que se obtienen a través de técnicas de imagen como la Tomografía Computarizada (TC), la RM y la ecografía, y las secciones cadavéricas como las que suministra el Visible Human Project.

Gracias a estos estudios de imagen, la anatomía seccional ha adquirido gran relevancia en la práctica clínica en la actualidad. Las imágenes que proporciona esta tecnología han aportado información sustancial sobre la estructura del cuerpo humano y su normal variabilidad, basada en amplias series de sujetos vivos, de todas las edades, y en diferentes estados fisiológicos.

Es cierto, que las secciones anatómicas pueden ser poco intuitivas y extremadamente complejas, puesto que necesitan que el observador posea conocimientos anatómicos y capacidad para orientarse con imágenes en 2D que son representación de estructuras 3D, especialmente en sujetos no versados en la materia. Una vez vencidas estas dificultades, las imágenes de anatomía seccional 
aportan una gran cantidad de información sobre las estructuras anatómicas, que se muestran sin alteraciones provocadas por el observador, en su localización concreta y rodeadas por sus estructuras vecinas.

La anatomía seccional seriada de RM y cadáver, nos permitió determinar las estructuras que integran la pelvis femenina y el suelo pélvico (paredes óseas, músculos, elementos viscerales y vasculares), al ofrecer un mapa anatómico claro y preciso de los elementos que los conforman, lo que facilitó tanto su identificación como su ubicación y delimitación.

La alta resolución de contraste que ofrece actualmente la RM para el estudio de los tejidos blandos, aporta un examen morfológico más nítido y conciso de las estructuras anatómicas. Disponer de estas imágenes anatómicas seriadas junto con las obtenidas de los cortes de cadáver permitió la reconstrucción de los modelos 3D pélvicos, así como la valoración anatómica completa y conjunta de la pelvis, como ya referenciamos en nuestro artículo "Anatomy-Radiological Assessment of Female Pelvis through Three-Dimensional Models Coregistered with Sectional Images of Magnetic Resonance" (Asensio et al., 2017).

La interpretación de las imágenes radiológicas, entre ellas las de RM y las ecográficas es críptica en un inicio, ya que son reproducciones de la realidad anatómica en escala de grises y en dos dimensiones.

Las imágenes de RM que se obtienen del estudio de un sujeto pueden ser potenciadas en $\mathrm{T} 1$, en T2, o en densidad protónica (DP), lo que afecta al análisis de las imágenes resultantes. Debido a esto una misma estructura puede aparecer hipointensa (negra) o hiperintensa (blanca) en función del modo que se haya utilizado. Por ejemplo, en T1 el hueso aparece hiperintenso, mientras que en T2 aparece hipointenso; otro ejemplo sería, la vejiga que, al estar llena de líquido, al igual que los vasos sanguíneos, se visualizan hipointensos en $\mathrm{T} 1$, con discreta intensidad en DP e hiperintensos en T2. El resto de las estructuras de la pelvis, como son la grasa, los músculos y las vísceras, se encuentran englobadas en los rangos de grises existentes entre el negro y el blanco. 
En cuanto a la ecografía, la valoración de las imágenes requiere unos conocimientos iniciales básicos, entre ellos entender la información que contiene codificada en negros, grises y blancos. Aparecen en negro (econegativo o anecoico) las estructuras que contienen líquido, ecomixtas, es decir en distintos grises, se verían los músculos y los órganos de la pelvis, al igual que la grasa, siendo blanco (hiperecogénico) el hueso. En una escala de ecogenicidad (de econegativo a hiperecogénico), de una forma simple, los componentes del cuerpo humano se situarían de la siguiente forma: líquido < grasa < órganos < músculo < hueso y aire.

Por todas estas diferencias anatomo-radiológicas entre la valoración de las imágenes ecográficas estáticas y las secciones de RM, nos pareció interesante, como justificamos en nuestro artículo "Technological development of visualization of magnetic resonance sectional images and pelvic floor ultrasonography for teaching purposes" (Asensio et al., 2018), enfocar también este desarrollo informático en ayudar a correlacionar e interpretar la anatomía mostrada en estas dos técnicas de imagen tan dispares. 


\section{2. - Modelos anatómicos tridimensionales.}

Con las imágenes seccionales de cadáver y de RM, elaboramos como se describió en el apartado de material y métodos, modelos anatómicos en 3D de las estructuras que constituyen la pelvis femenina, tanto de su continente (huesos y músculos) como de su contenido (órganos, vasos y nervios) (Figs. 78- 150).

En nuestro artículo "3D Models of Female Pelvis Structures Reconstructed and Represented in Combination with Anatomical and Radiological Sections" (Asensio et al., 2018) mostramos un ejemplo de todos los modelos 3D, correlacionados con imágenes de cadáver y RM, como iremos desarrollando más ampliamente en este apartado de nuestro trabajo.

\section{2.a.- Modelos óseos de la pelvis femenina:}

Las estructuras óseas fueron fáciles de identificar en los cortes seccionales, lo que nos permitió reconstruir todo el sustrato óseo que configura la pelvis femenina (sacro, cóccix, coxal).

Estos modelos óseos pueden verse aislados o embebidos dentro de las imágenes seccionales de cadáver y RM (Figs. 78 - 87).

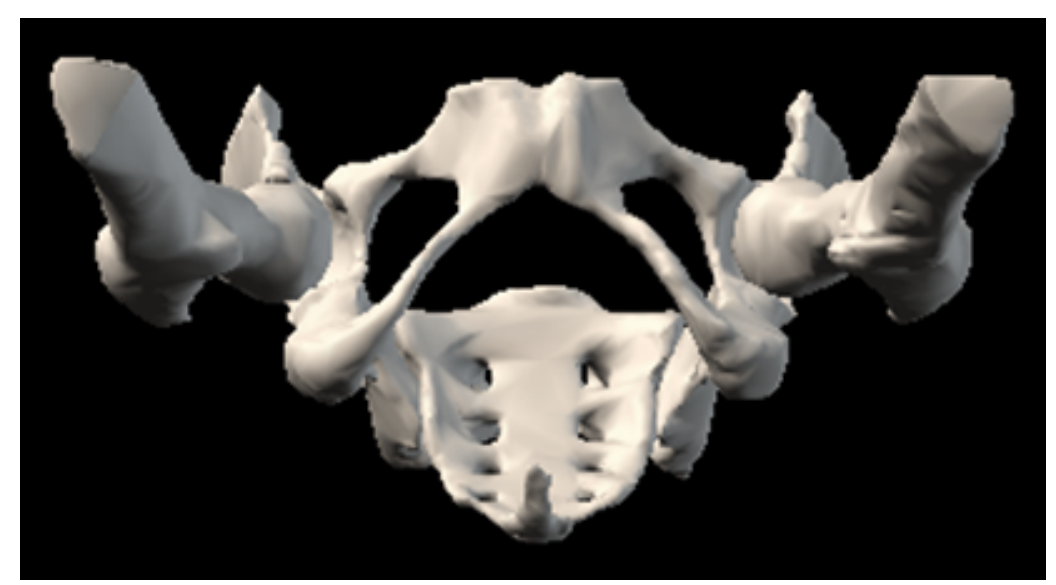

Figura 78. Visión inferior de las estructuras óseas que conforman la pelvis femenina (el sacro, el cóccix, y ambos huesos coxales). 
Resultados

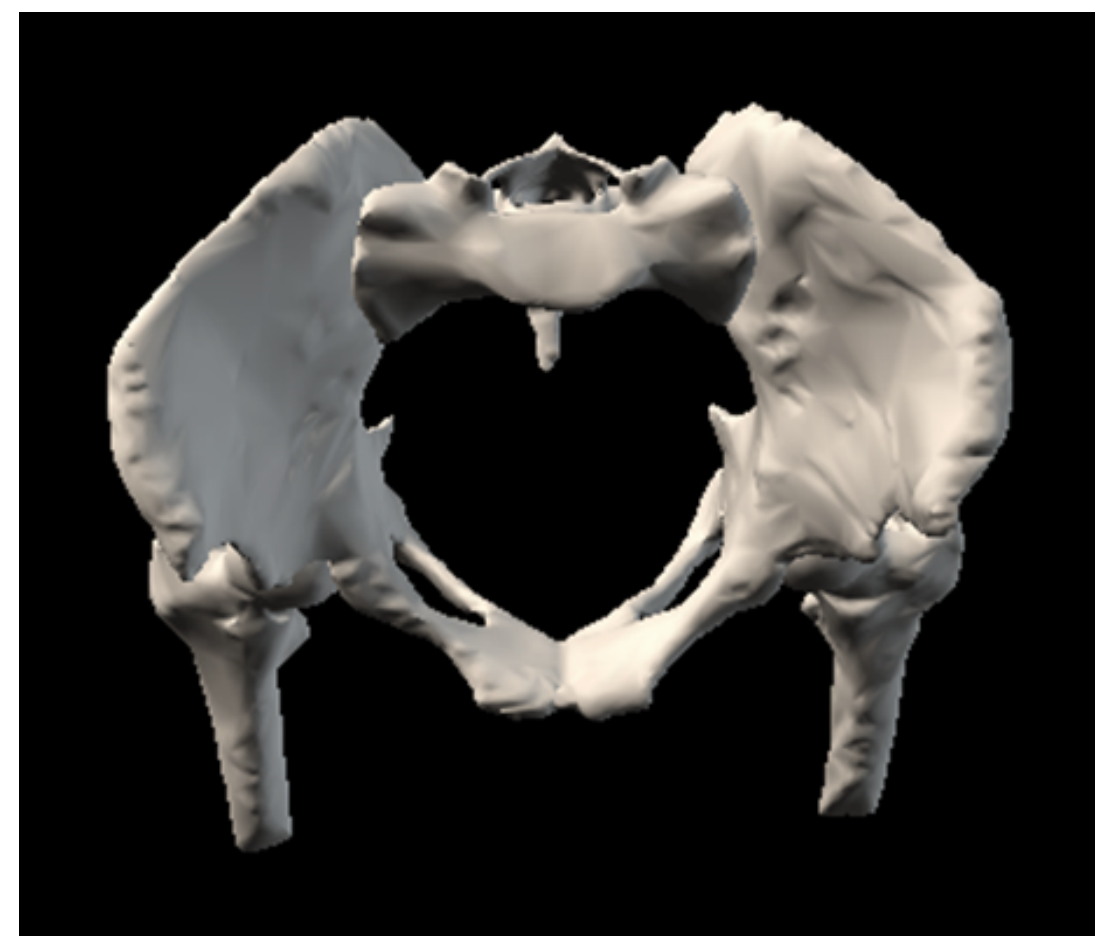

Figura 79. Modelo 3D de la pelvis femenina, vista desde arriba.

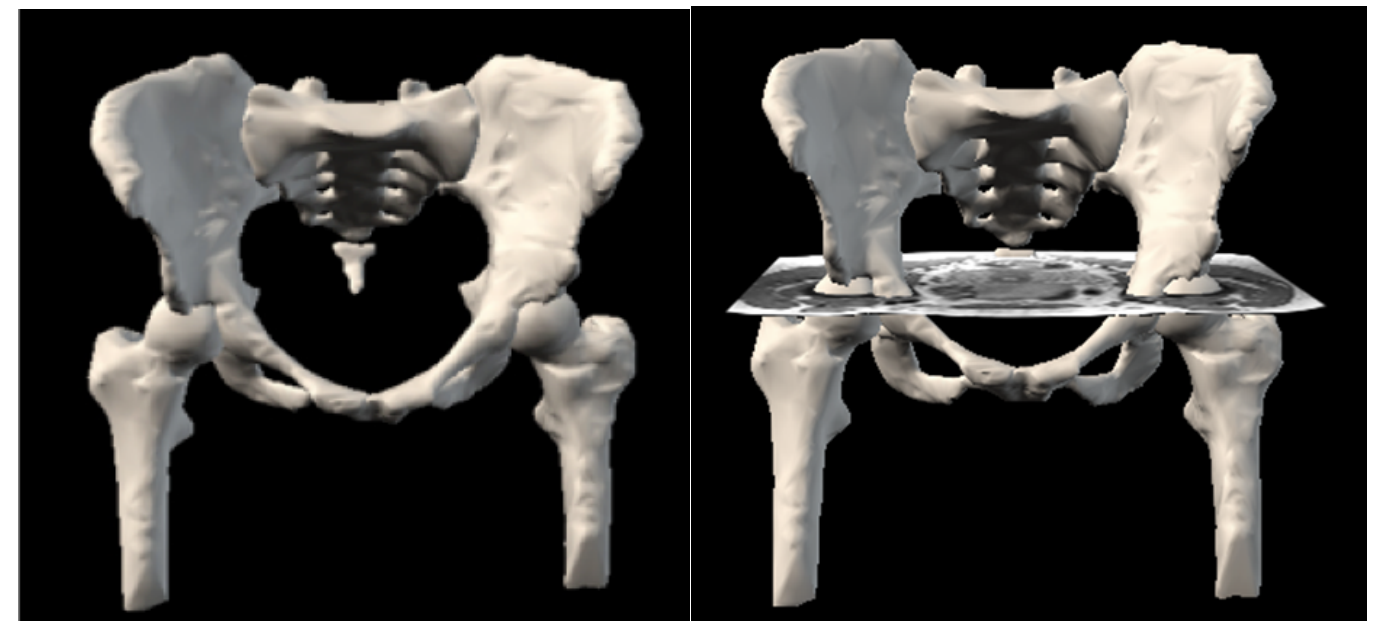

Figuras 80 y 81. La de la izquierda es una imagen de la pelvis ósea en 3D y la imagen de la derecha es el mismo modelo 3D embebido en una sección axial de RM como referencia, a nivel de la zona del acetábulo. 


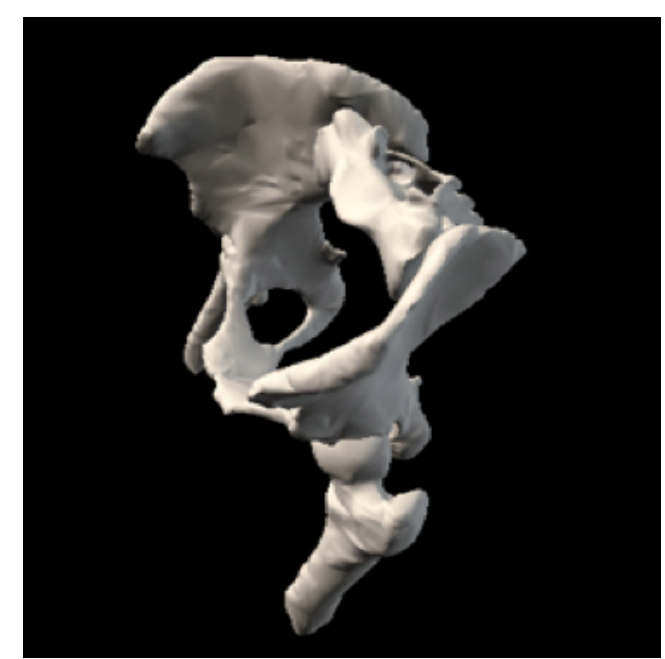

Figura 82. Modelo óseo 3D, visión lateral.

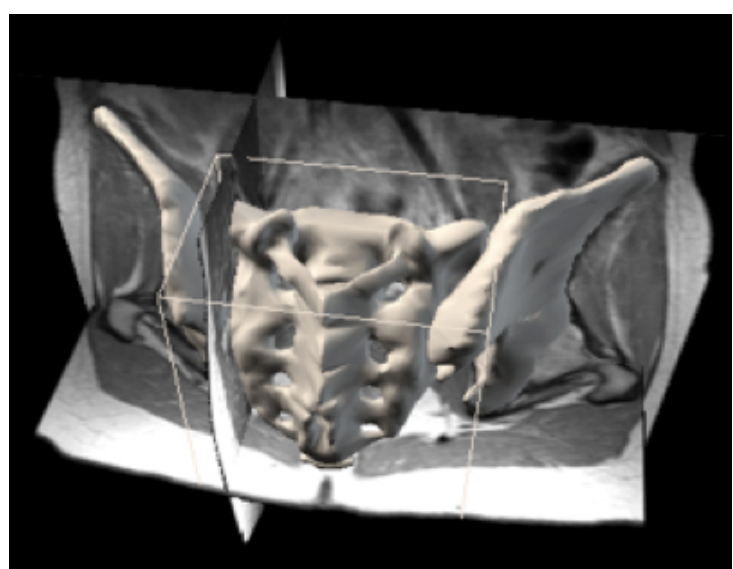

Figura 83. Modelo óseo 3D, con cortes axial, coronal y sagital de RM.

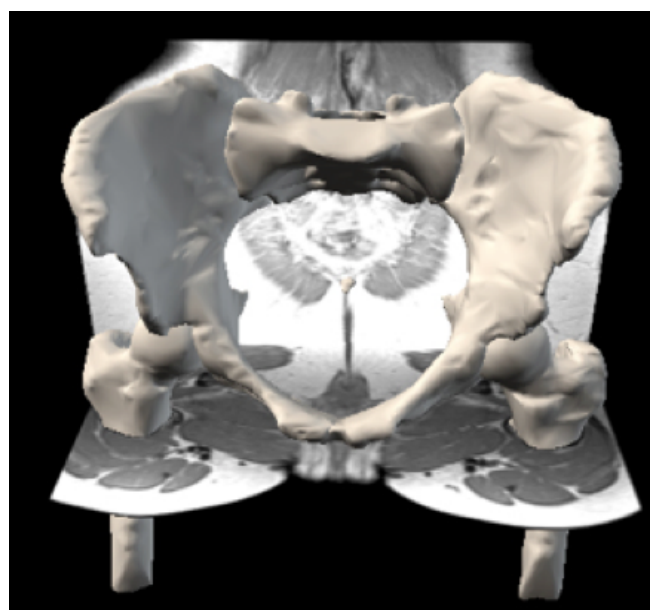

Figura 84. Modelo 3D de estructuras óseas, correlacionado con dos cortes de RM.

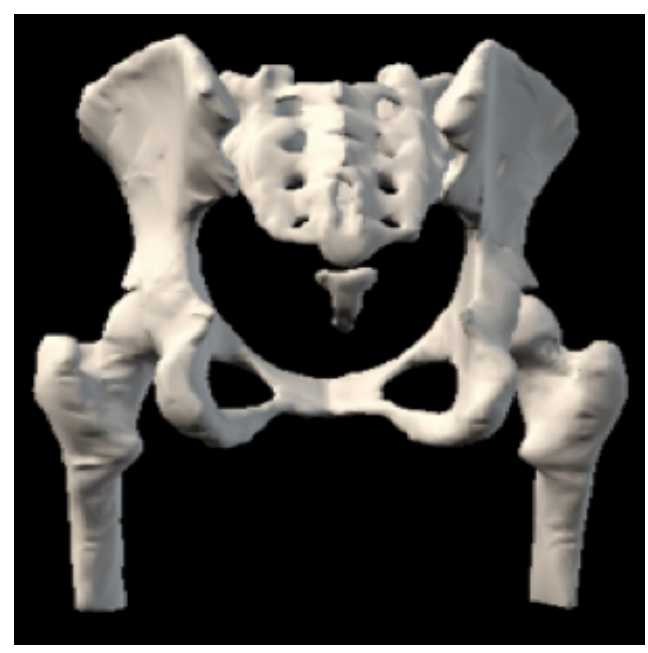

Figura 85. Modelo óseo 3D de la pelvis femenina.

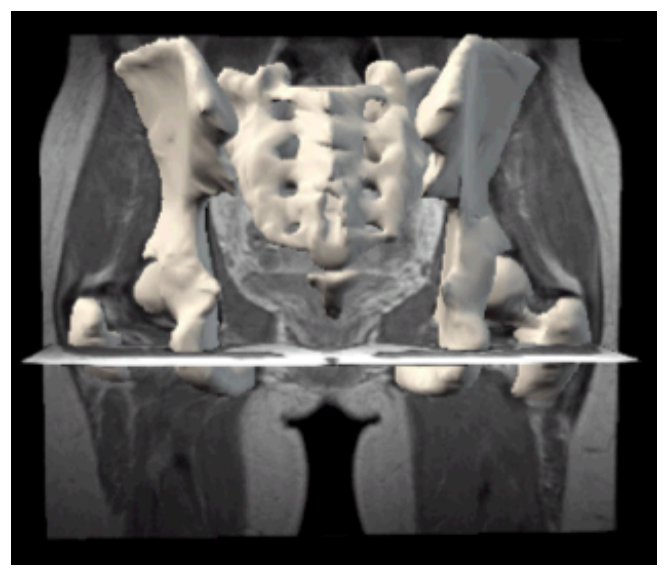

Figura 86. Corte coronal y axial de RM, combinado con modelos $3 D$ de los huesos coxales, sacro y cóccix.

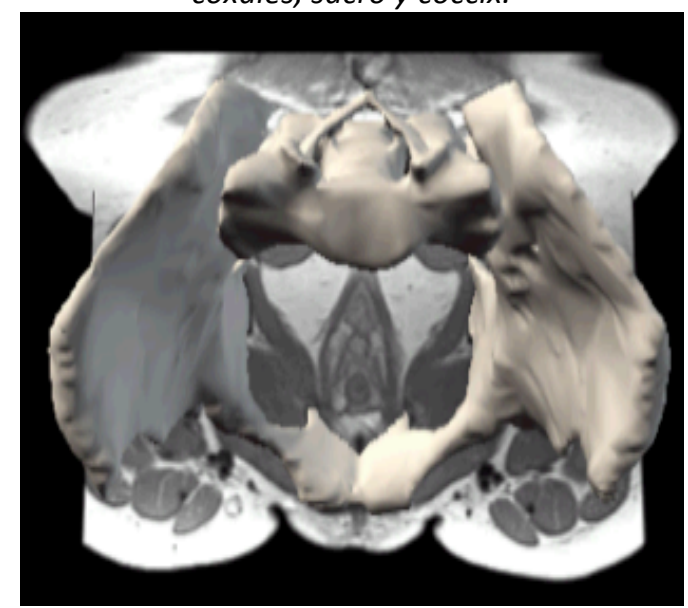

Figura 87. Combinación de un modelo tridimensional de la pelvis con un corte axial de $R M$, visualizado desde arriba. 


\section{2.b. - Modelos musculares 3D de la pelvis femenina:}

De las imágenes seccionales se reconstruyeron los músculos de la pelvis, entre ellos los que conforman el periné, y que constituyen el diafragma pélvico.

A continuación, mostramos algunos ejemplos de composiciones y visualizaciones que conseguimos mediante la manipulación de nuestra aplicación informática. Se pueden seleccionar los músculos: superficiales del cérvix, coccígeo, elevador del ano (junto con sus fascículos), obturadores interno y externo, piramidal o piriforme, ilíaco y psoas-ilíaco, entre otros. (Figs. 88 - 92)

En todo momento el usuario puede observar las estructuras musculares insertadas en los huesos correspondientes y embebidas en el plano de corte deseado de RM y de cadáver.

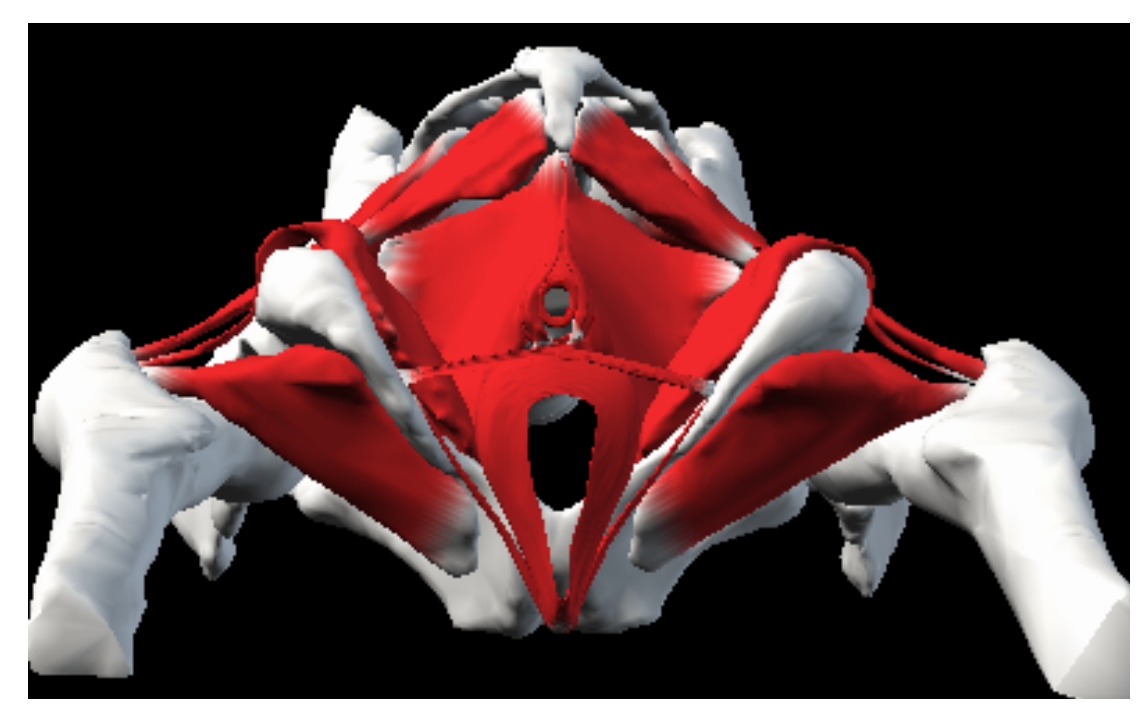

Figura 88. Visualización inferior de los músculos del periné en 3D, siendo anterior lo inferior y posterior lo superior. Aparecen entre otros músculos, el elevador del ano, isquiocavernoso, transverso superficial y obturadores interno y externo. 


\section{Resultados}

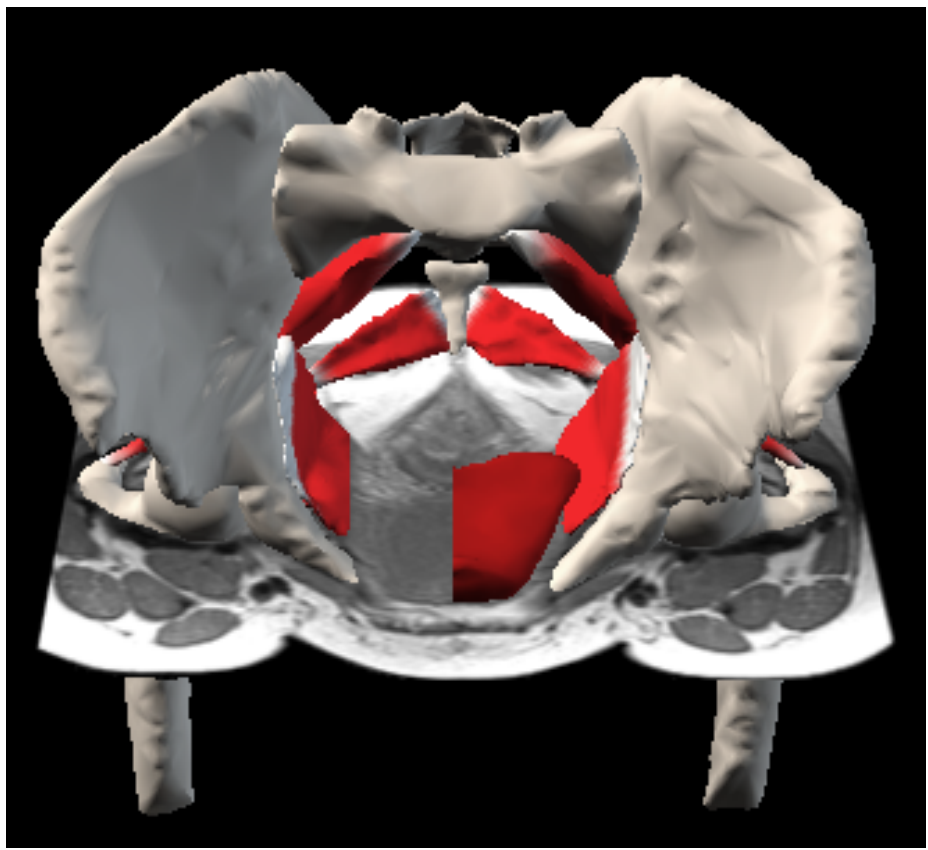

Figura 89. Visualización de las estructuras óseas con las inserciones de algunos de los músculos de la pelvis femenina en $3 D$, junto con una sección axial de RM. Podemos visualizar los siguientes músculos: piriforme, coccígeo y obturador interno.

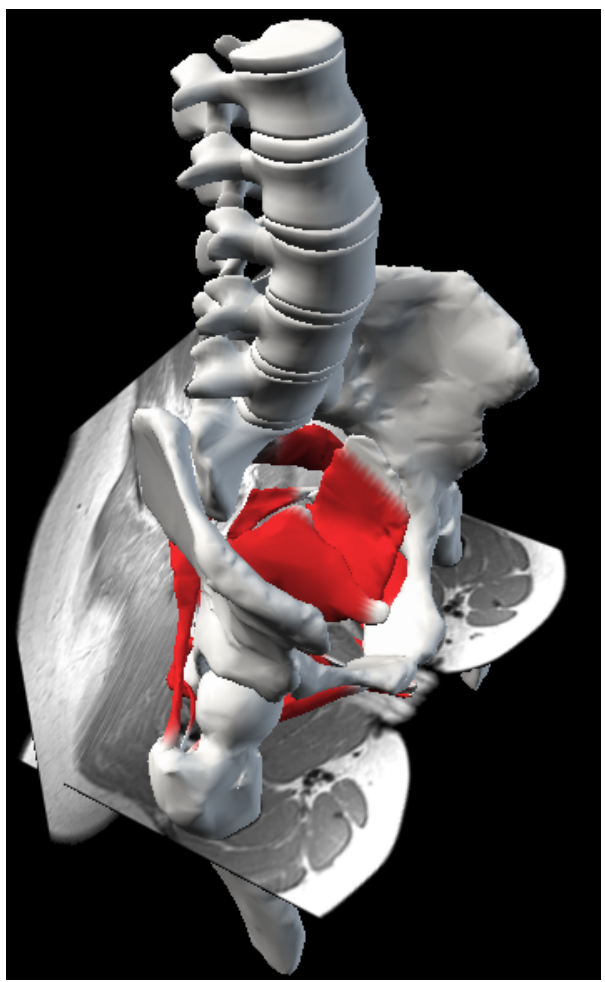

Figura 90. Al visualizarse el modelo muscular 3D, desde otro ángulo (superior y lateral) vemos mejor el músculo piramidal, entre otros. 

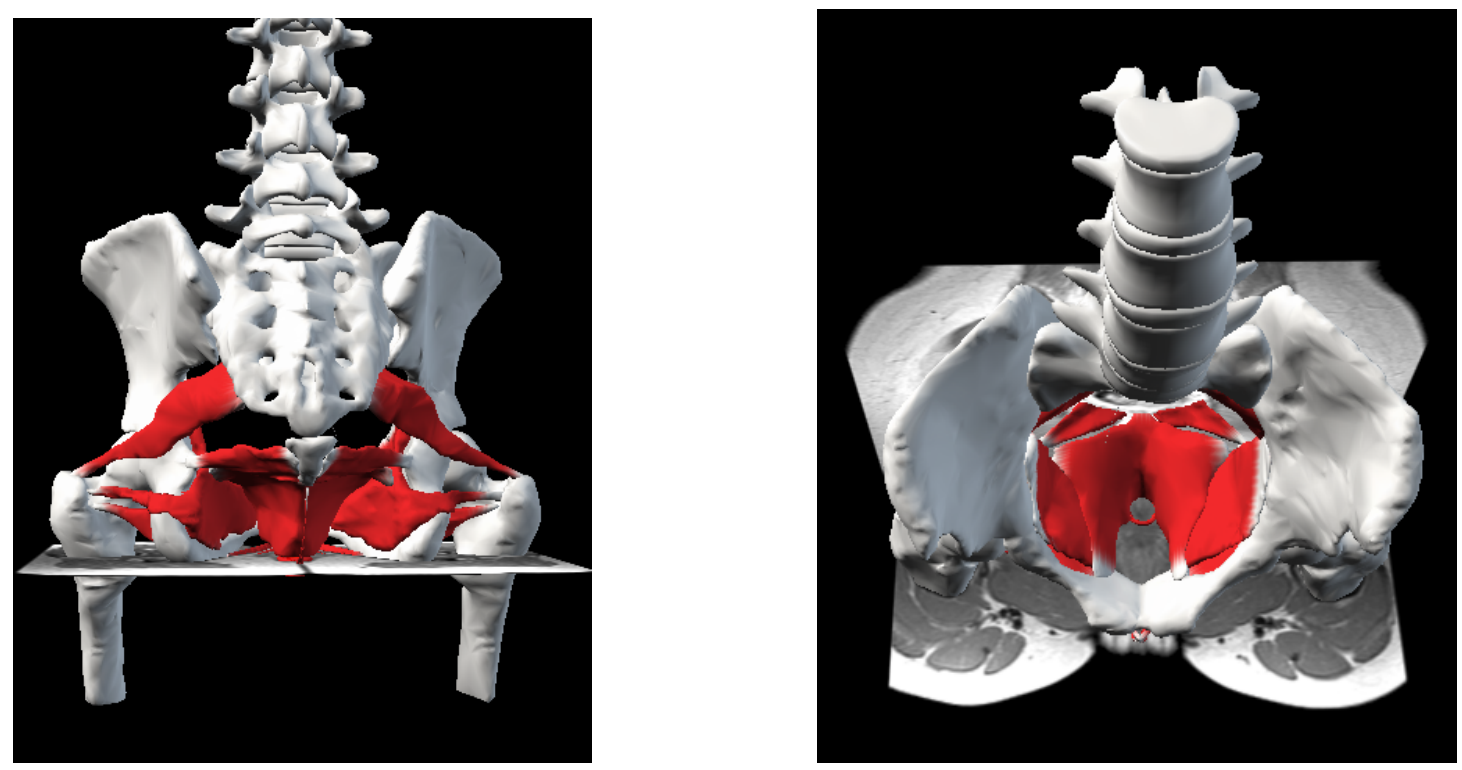

Figuras 91 y 92. Combinaciones de modelos óseos y musculares 3D de la pelvis femenina desde distintas posiciones espaciales con secciones axial (izquierda) y axial y coronal (derecha) de RM como referencia.

Una de las partes de la pelvis más complejas de representar y visualizar claramente es el periné, por eso en nuestra publicación "3D Reconstruction of the Female Perineal Musculature, from Sections of Magnetic Resonance." (Asensio et al., 2019), hacemos hincapié en esta región, su importancia y la necesidad de implementar el uso de las nuevas tecnologías como complemento para su enseñanza y aprendizaje.

\section{2.c. - Reconstrucciones en 3D de estructuras nerviosas de la pelvis femenina:}

El sistema nervioso fue el más complicado y difícil de resolver, dado que las imágenes seccionales no nos aportaron una información muy precisa para seguir el trayecto de los nervios, por lo que tuvimos que recurrir al conocimiento anatómico para diferenciar estas entidades e intuir su trazado. Teniendo esto en cuenta, hemos reconstruido el plexo lumbar, el plexo sacro, el plexo sacro-coccígeo, la inervación del aparato genital, la inervación ano-rectal y la inervación del aparato urinario inferior, de una manera didáctica (Figs. 93 - 100). 


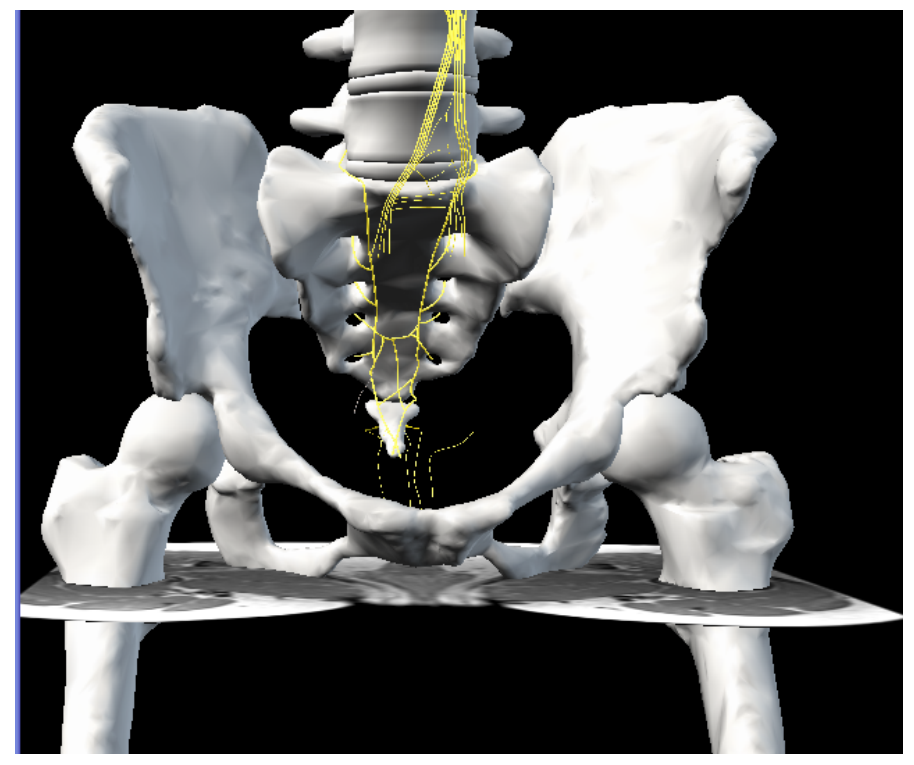

Figura 93. Imagen del plexo hipogástrico, junto con el componente óseo de la pelvis.

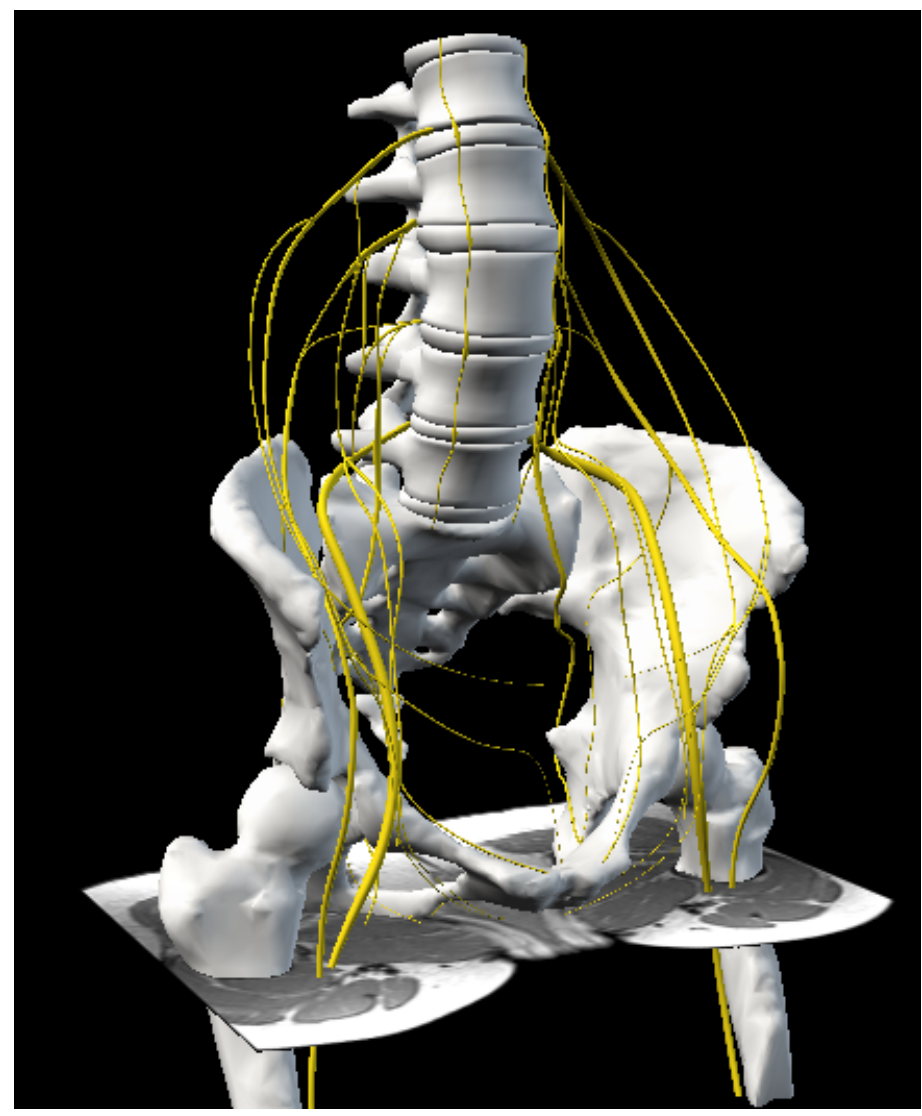

Figura 94. Imagen del plexo lumbar completo, localizado en la parte posterior del abdomen, con el tronco lumbosacro y el nervio obturador.

En la figura 94, visualizamos el plexo lumbar completo, con todas las divisiones y ramos nerviosos que se originan a partir de él. De este conjunto de fibras nerviosas, se constituyen, entre otros nervios, el nervio obturador y el nervio femoral (los de 
mayor tamaño), ambos pueden visualizarse en la imagen, así como su recorrido hacia el miembro inferior.

El nervio obturador tiene importancia en las cirugías pélvicas ya que discurre por la pared pélvica lateral entre los vasos ilíacos internos y externos, pudiendo lesionarse, pero a su vez sirviendo como referencia anatómica fundamental.

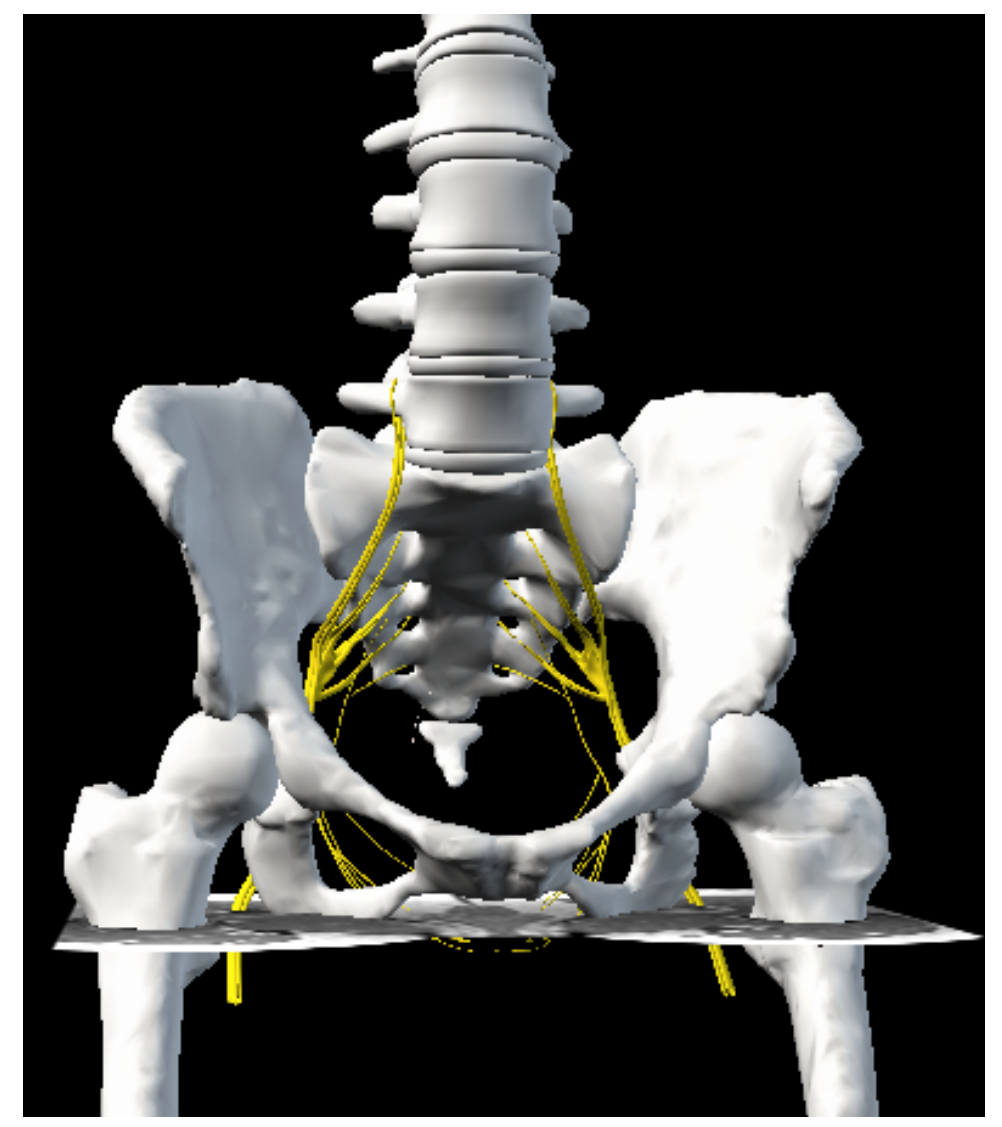

Figura 95. Imagen del plexo sacro completo, compuesto por el tronco lumbosacro y el ramo anterior de los nervios S1 a S4. Podemos visualizar además el nervio ciático en la parte posterior de la imagen, continuando hacia los miembros inferiores. 


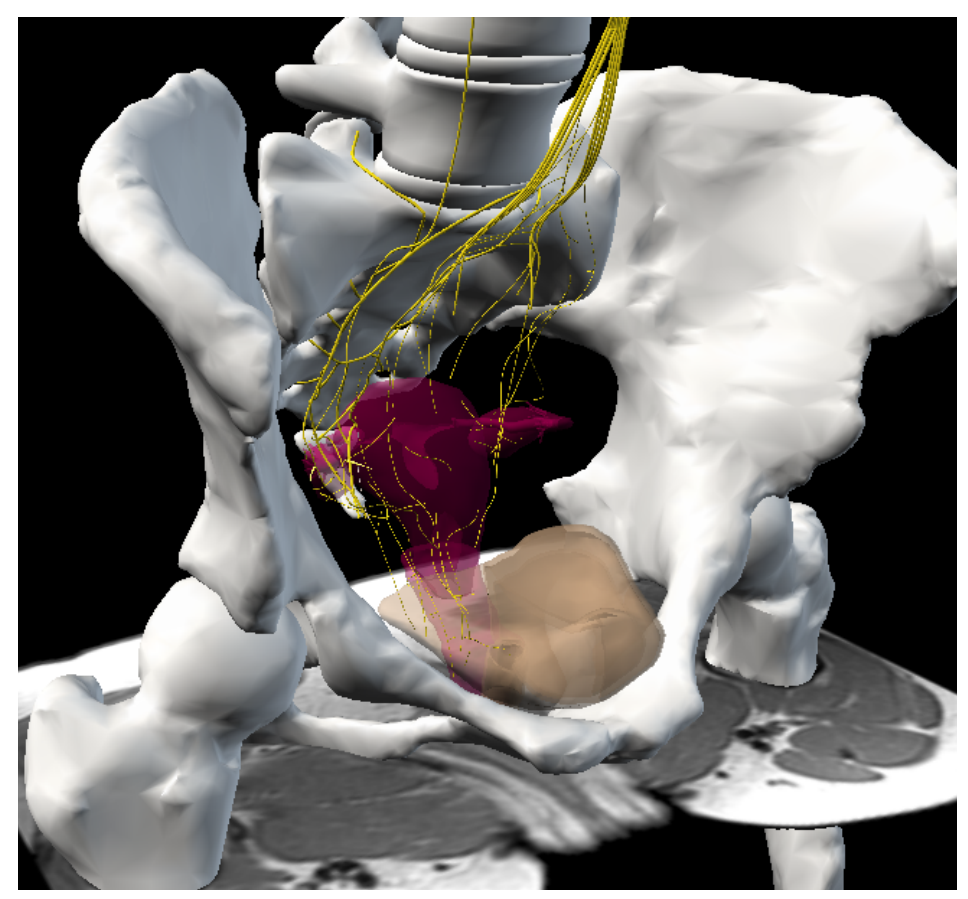

Figura 96. Plexo sacro-coccígeo completo, acompañado por un modelo óseo y de estructuras viscerales de la pelvis con transparencia, además de un plano axial de RM.

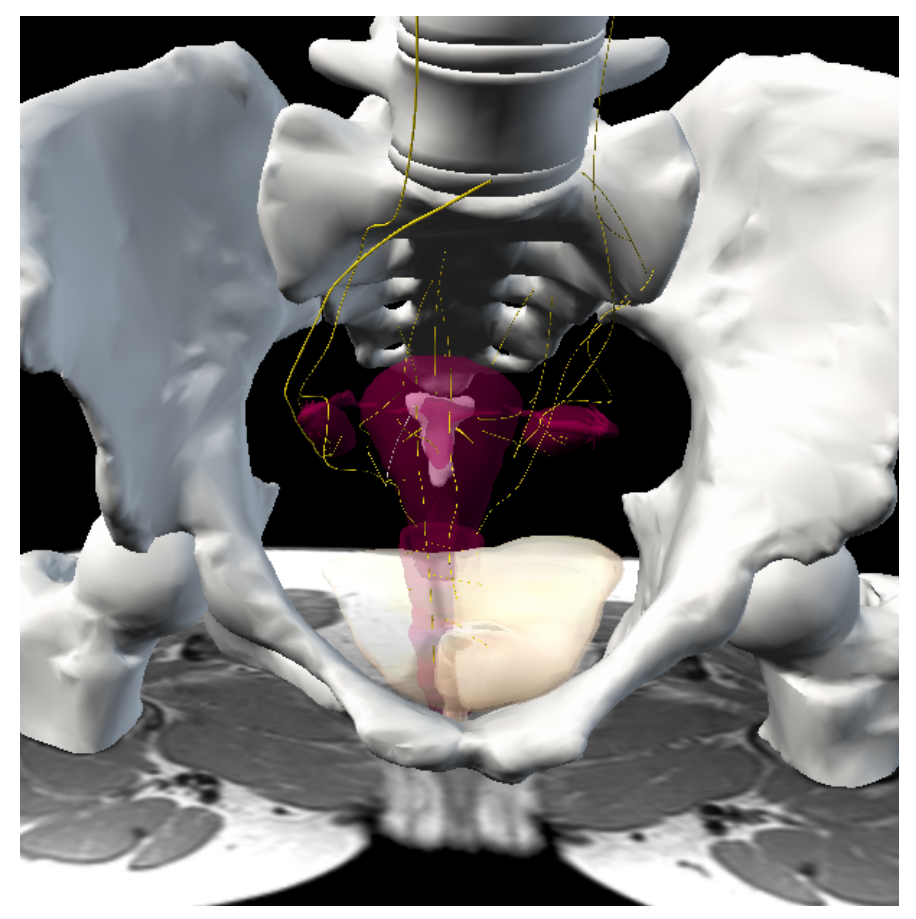

Figura 97. Inervación uterina y ovárica aislada, junto con otros modelos tridimensionales y un corte axial de RM. En este modelo se objetiva lo finas que son las redes nerviosas reconstruidas. 

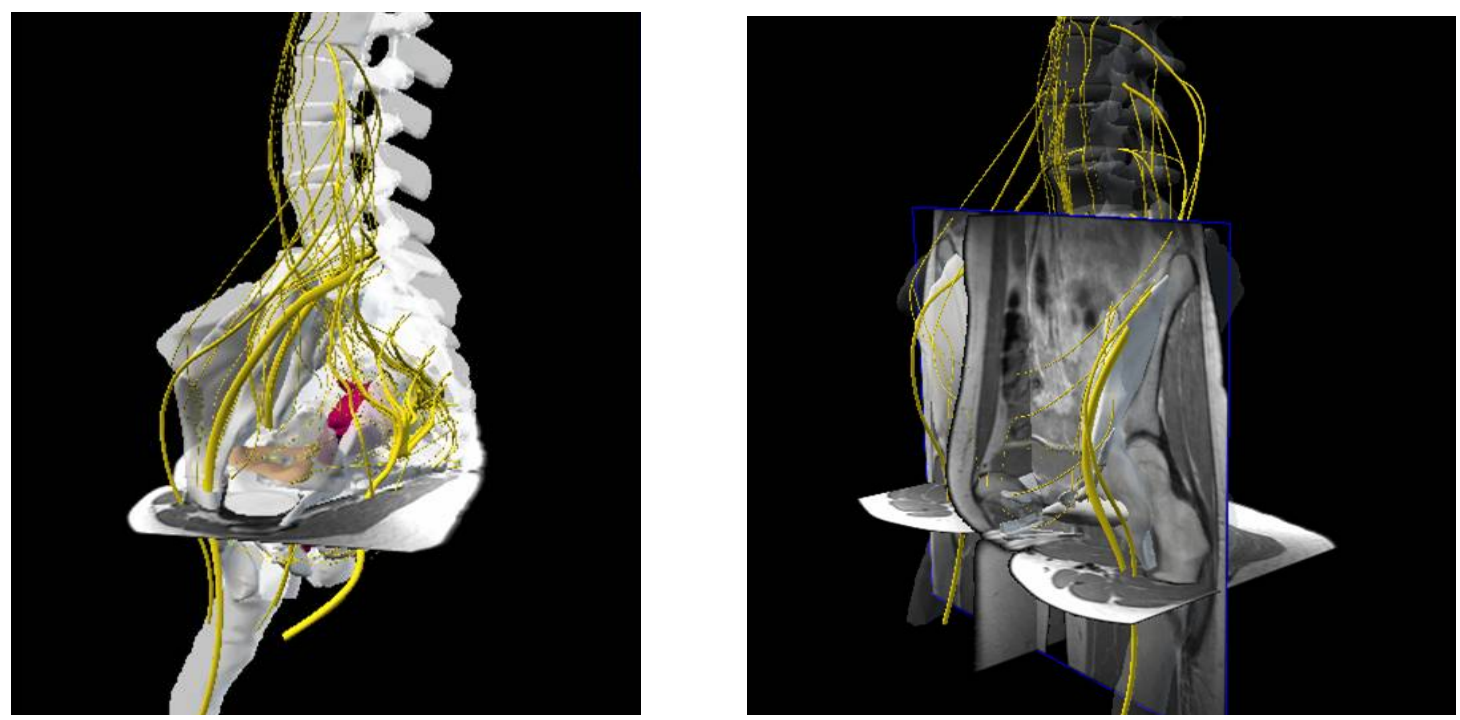

Figuras 98 y 99. Modelos 3D de estructuras nerviosas.

En la figura 98, una visión lateral del modelo tridimensional nos deja observar el descenso de los nervios femoral y ciático hacia el miembro inferior y las raíces nerviosas de las que se originan y conforman los diferentes plexos. Podemos apreciar también la intrincada red nerviosa que conforman los nervios de la pelvis (Fig. 98 100). En la figura 99 apreciamos esos mismos nervios con referencias anatómicas proporcionadas por los planos de RM en los tres ejes del espacio, mientras que los modelos óseos aparecen con transparencia.

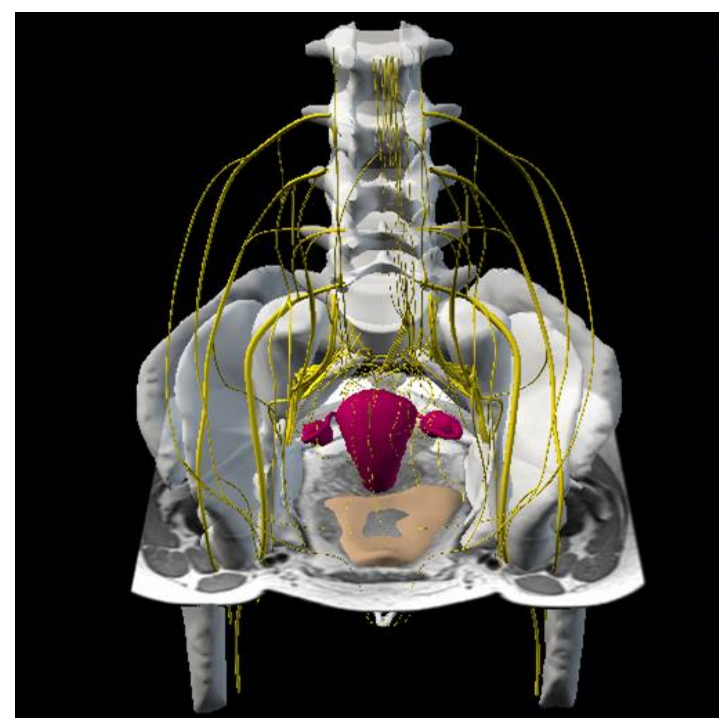

Figura 100. Visualización de todos los nervios de la pelvis. 


\section{2.d. - Modelos 3D de la vascularización (arterias y venas):}

La irrigación de la pelvis fue, dentro de su complejidad, más asequible en cuanto al seguimiento de su recorrido que la inervación, puesto que la información de estas estructuras que aportan la RM y las secciones de cadáver es mayor. Por la importancia anatómica que constituye conocer el trayecto de estas entidades, a pesar de la variabilidad individual existente, en nuestro artículo "Technological Advances in the Visualization of the Vascularization of the Pelvis under Interactive Threedimensional Environments" (Asensio et al., 2018) dimos especial importancia a la representación 3D de la vascularización de la pelvis.

En nuestro caso se pudieron reconstruir arterias de gran calibre sin problema, y con un grado más elevado de dificultad las de menor calibre, que irrigan la pelvis femenina, incluyendo (Figs. $101-125)$ :

- Arterias: aorta abdominal, femorales, iliacas (comunes, externas e internas con sus troncos posteriores y anteriores), mesentérica inferior, perineales, pudendas (externas e internas), rectales (inferior, media y superior), sacra media, uterinas, vaginales y vesicales (inferiores y superiores). (Figs. $101-$ 111).

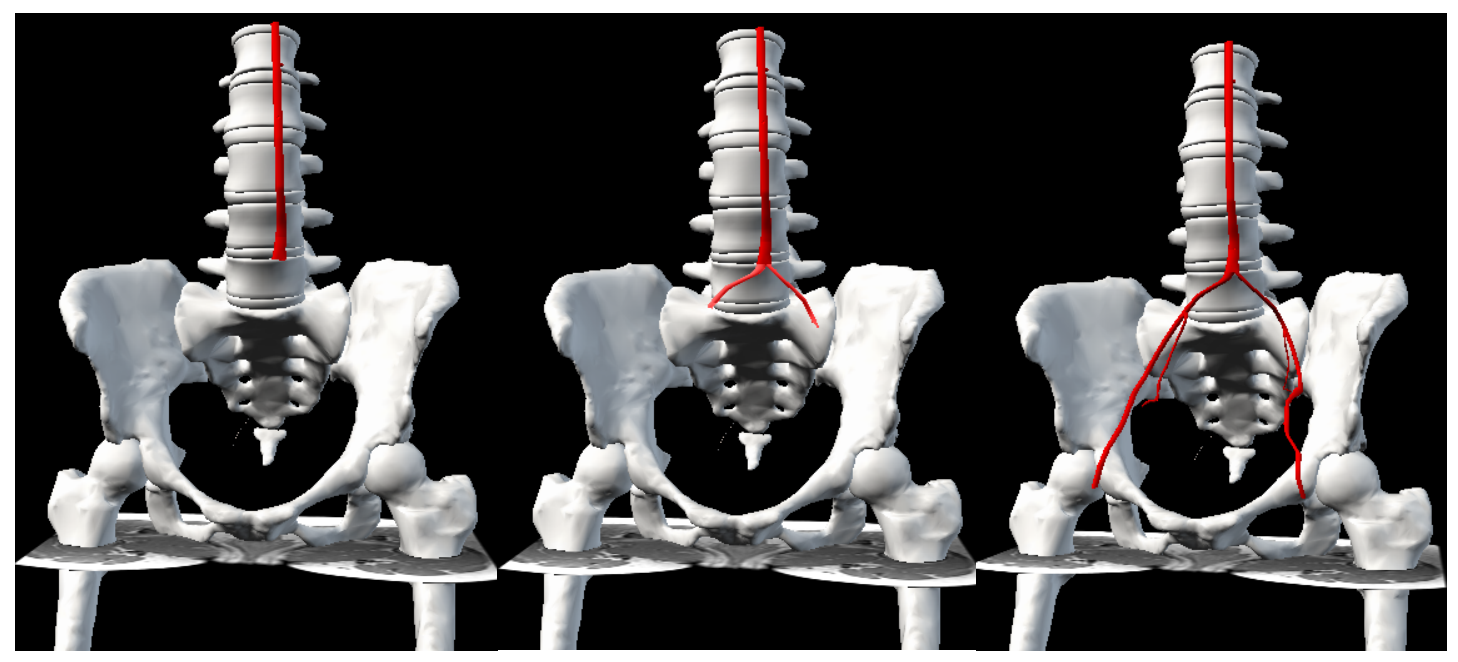

Figura 101. Imagen con tres modelos tridimensionales de arterias.

En la figura 101, podemos observar a la izquierda, la aorta abdominal. En el centro, la aorta se continúa con ambas arterias iliacas comunes y a la derecha visualizamos la división de las arterias iliacas comunes en las arterias iliacas externas e internas. En la 
figura 102 vemos la rama terminal de la aorta, la sacra media, que no aparece representada en la imagen anterior.

Estos elementos se encuentran enmarcados por estructuras óseas en 3D y secciones de RM, axial (Fig.101) y axial y coronal (Fig. 102), como referencia anatómica.

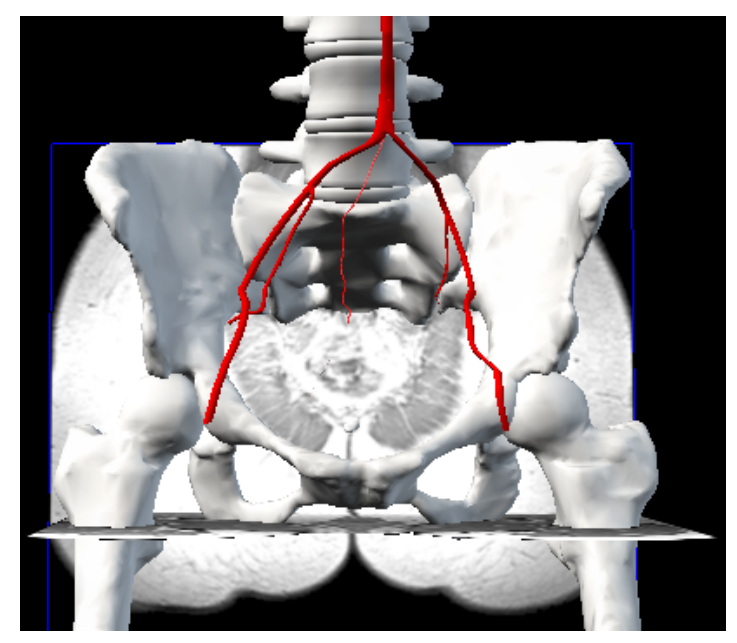

Figura 102. Imagen de la arteria sacra media, rama de terminal de la aorta. En el fondo se objetiva un corte coronal de RM posterior y a nivel del periné una sección axial de RM.

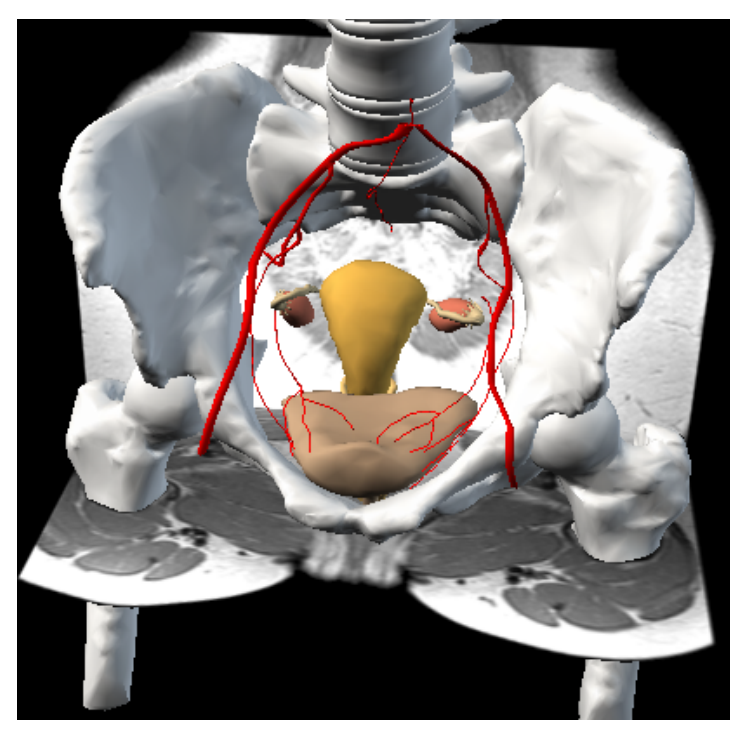

Figura 103. Imagen de la vascularización de la vejiga proporcionada por las arterias vesicales, superiores e inferiores, visualizando además las arterias iliacas externas, internas y comunes. En esta imagen podemos apreciar modelos $3 D$ viscerales (ovarios, trompas, útero y vejiga) junto con los modelos óseos y dos cortes (axial y coronal) de RM. 

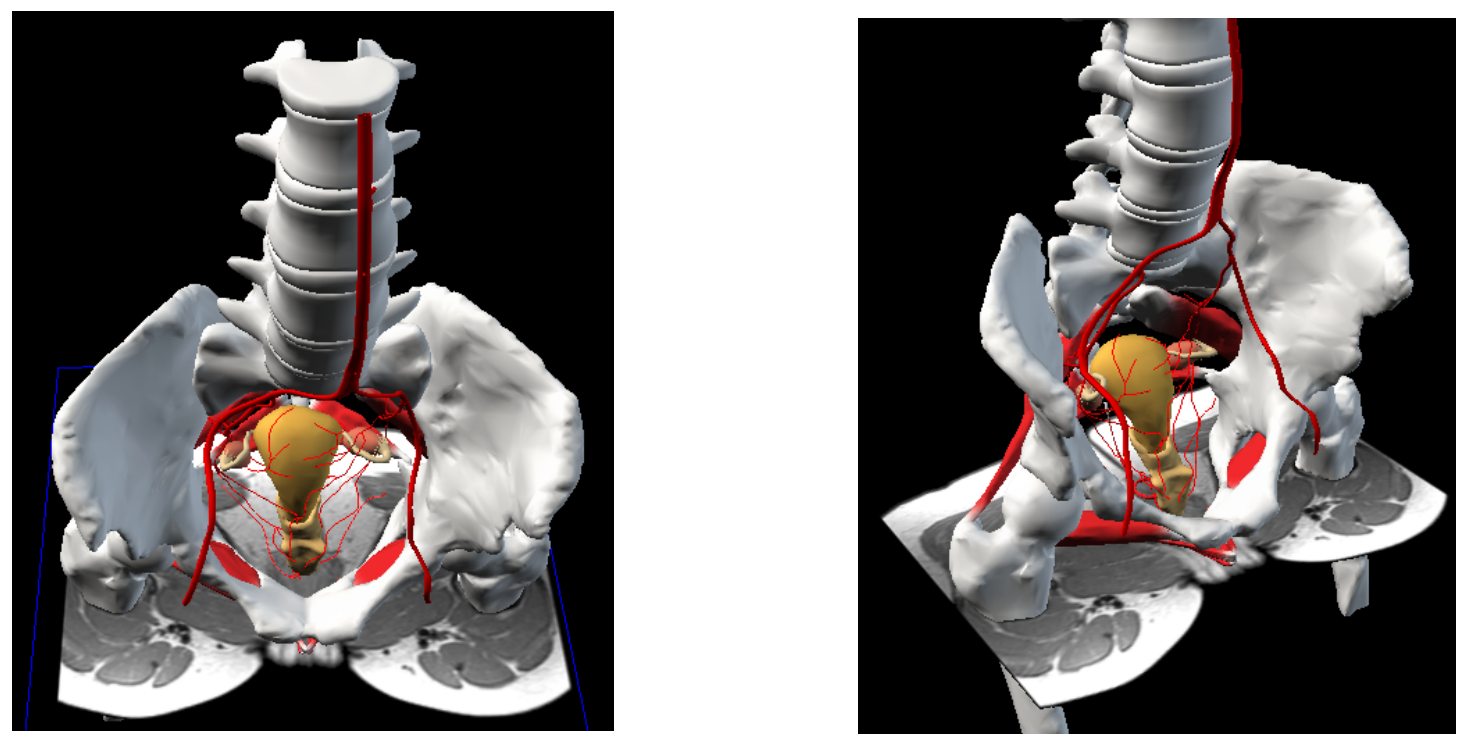

Figuras 104 y 105. Imágenes de las arterias perineales, procedentes de las arterias pudendas internas, ramas a su vez de la bifurcación anterior de la arteria iliaca interna.
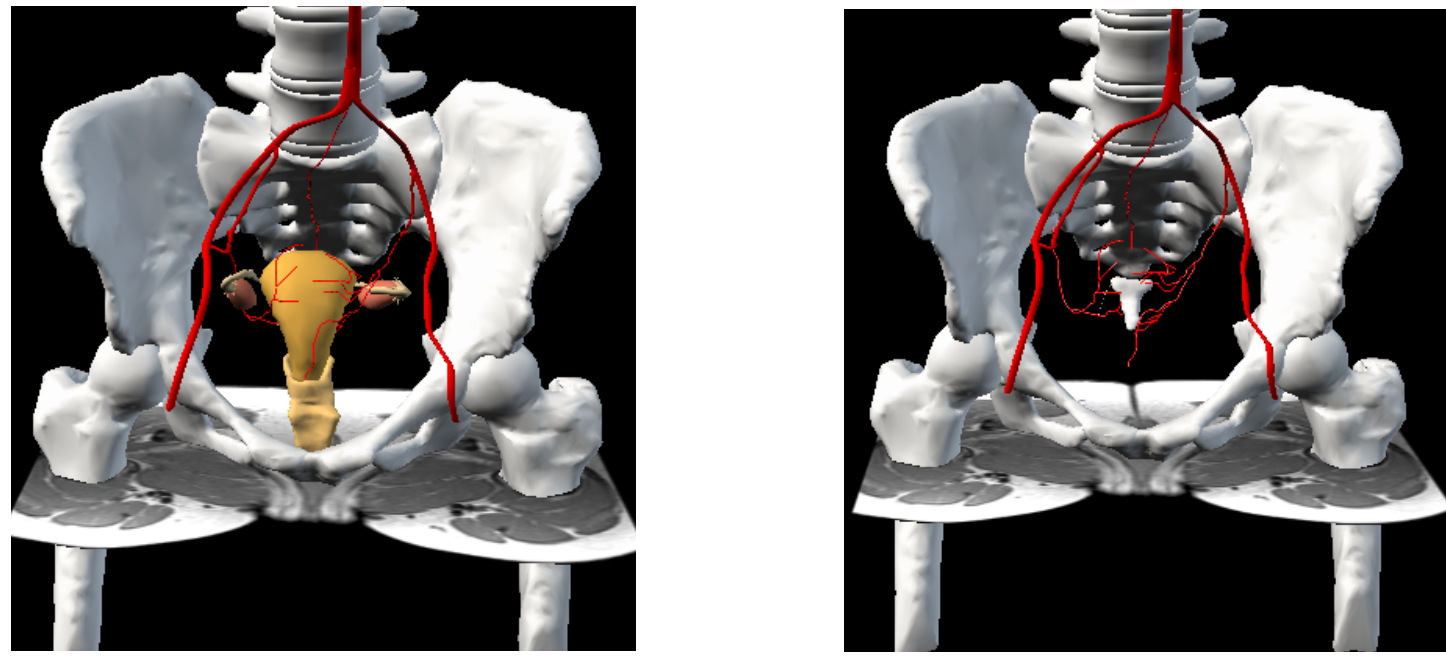

Figuras 106 y 107. Vascularización del útero y de los anejos, en la de la izquierda con el modelo 3D de los órganos y a la derecha sin ellos.
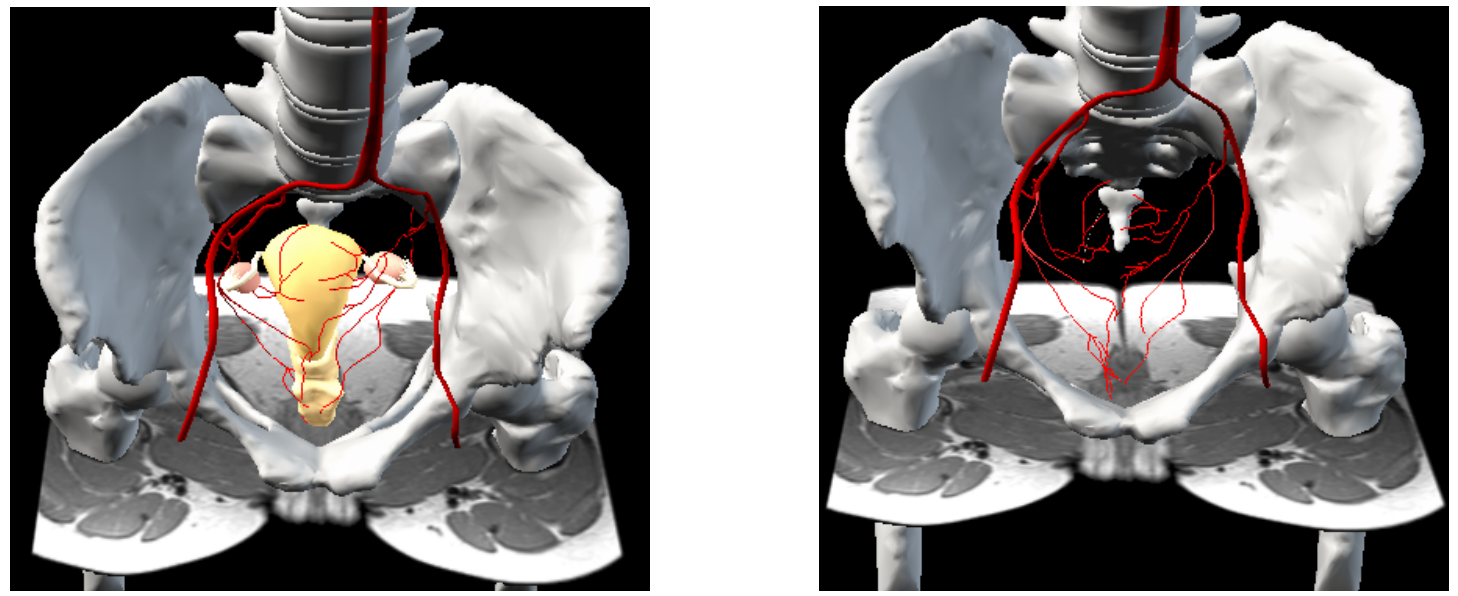

Figuras 108 y 109. Reconstrucciones 3D de las arterias vaginales, que irrigan la vagina. 

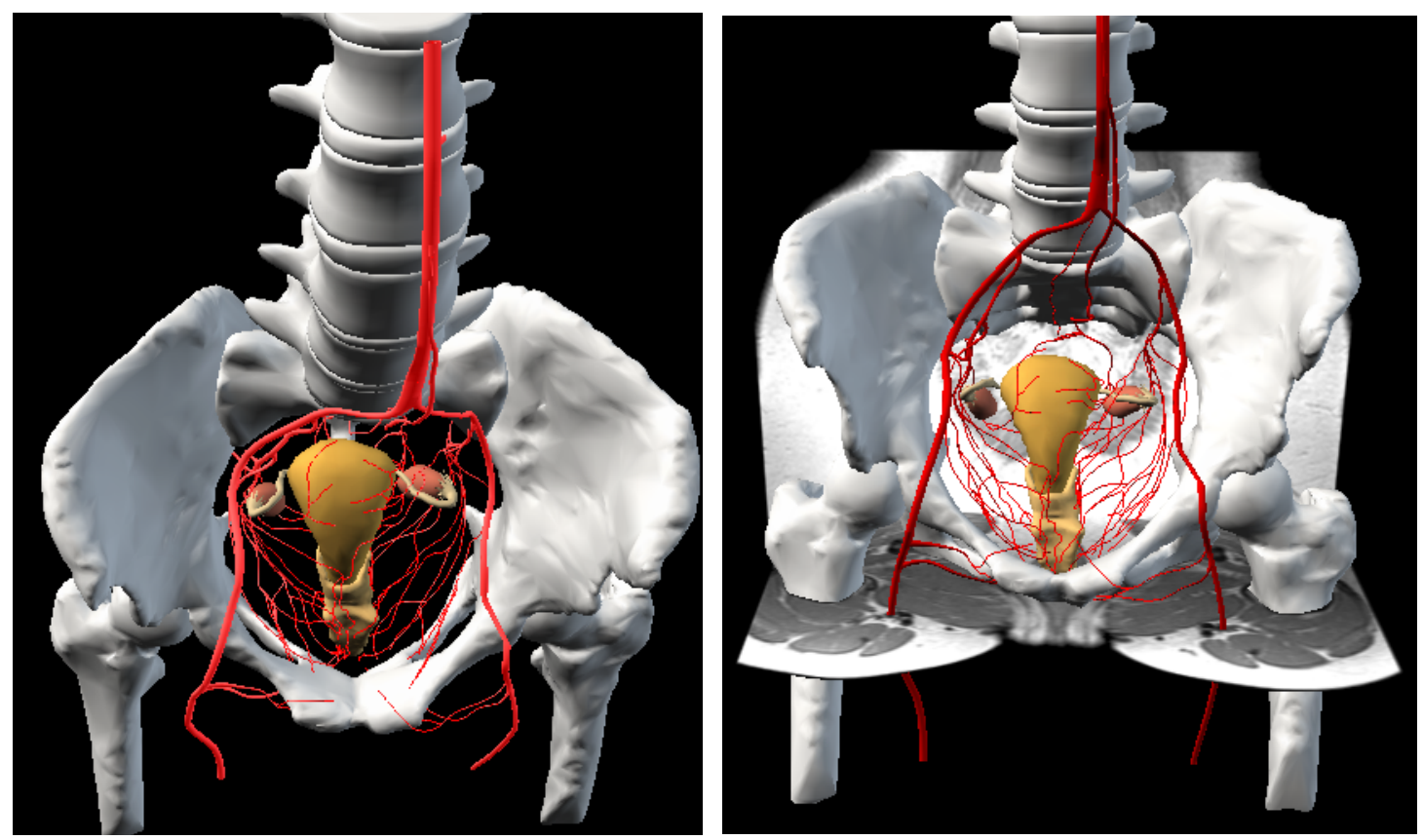

Figuras 110 y 111. A la izquierda, imagen de la irrigación arterial de la zona pélvica. A la derecha, irrigación arterial pélvica junto con los modelos $3 D$ viscerales y embebida en un corte axial y otro coronal de RM.

En las imágenes anteriores (Figs. 110 y 111) podemos ver la red arterial en 3D con las vísceras genitales femeninas y el marco de la estructura ósea de la pelvis. En la figura 111, los modelos tridimensionales se encuentran embebidos en dos cortes de RM, uno axial a nivel del periné y otro coronal en la zona posterior de la pelvis, tras el sacro.

Los conductos venosos representados son los siguientes:

- Venas: ácigos de la vagina, cava inferior, femoral, iliacas (común, externa e interna), mesentérica inferior, perineales, pudendas (externas e internas), rectales (inferior, media y superior), sacra media, safena mayor, uterinas, vaginales, y vesicales (superiores e inferiores) (Figs. 112 - 121). 

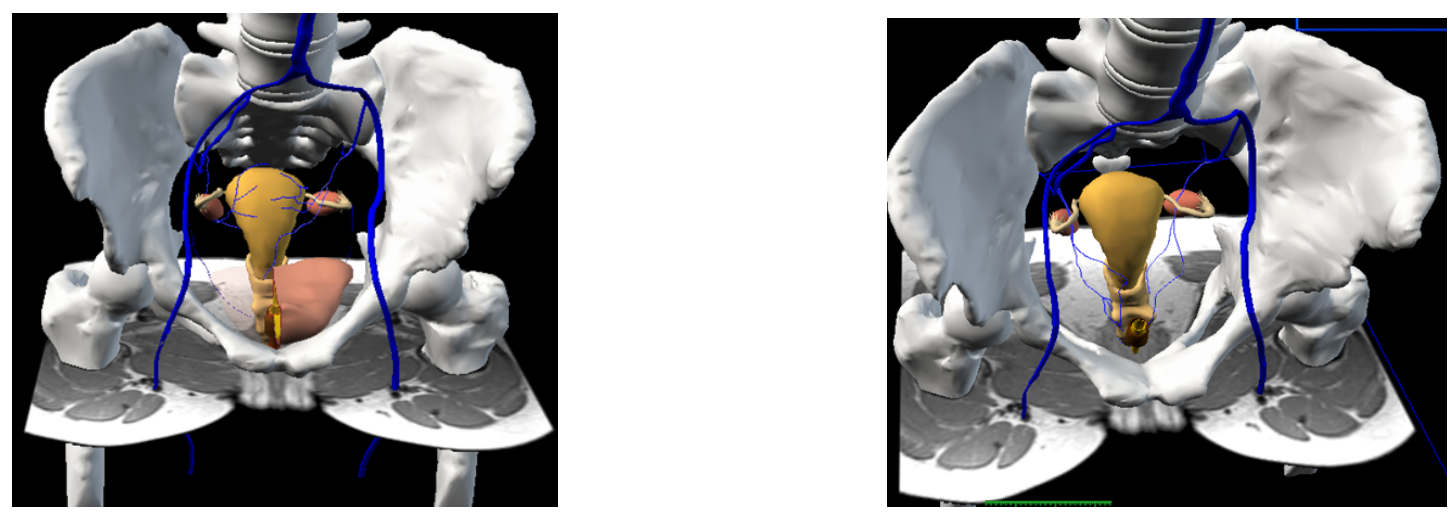

Figuras 112 y 113. Imágenes de las venas uterinas, a la izquierda y de las venas vaginales a la derecha, junto a otras estructuras venosas, vísceras genitales, óseas y una sección axial de RM.
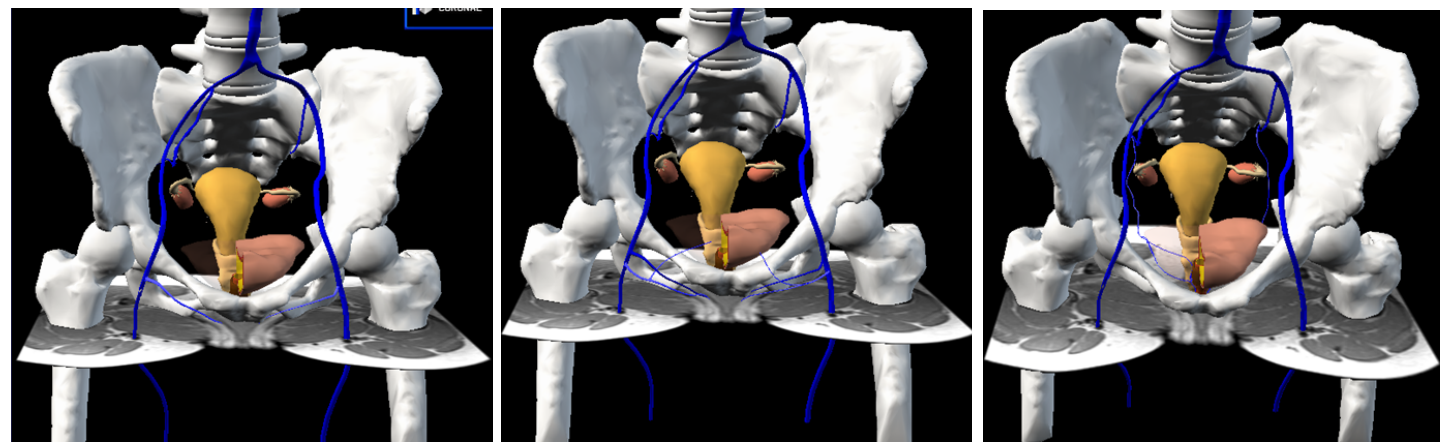

Figuras 114,115 y 116. Imágenes de las venas pudendas externas profundas, de las venas pudendas externas superiores y de las venas pudendas internas.

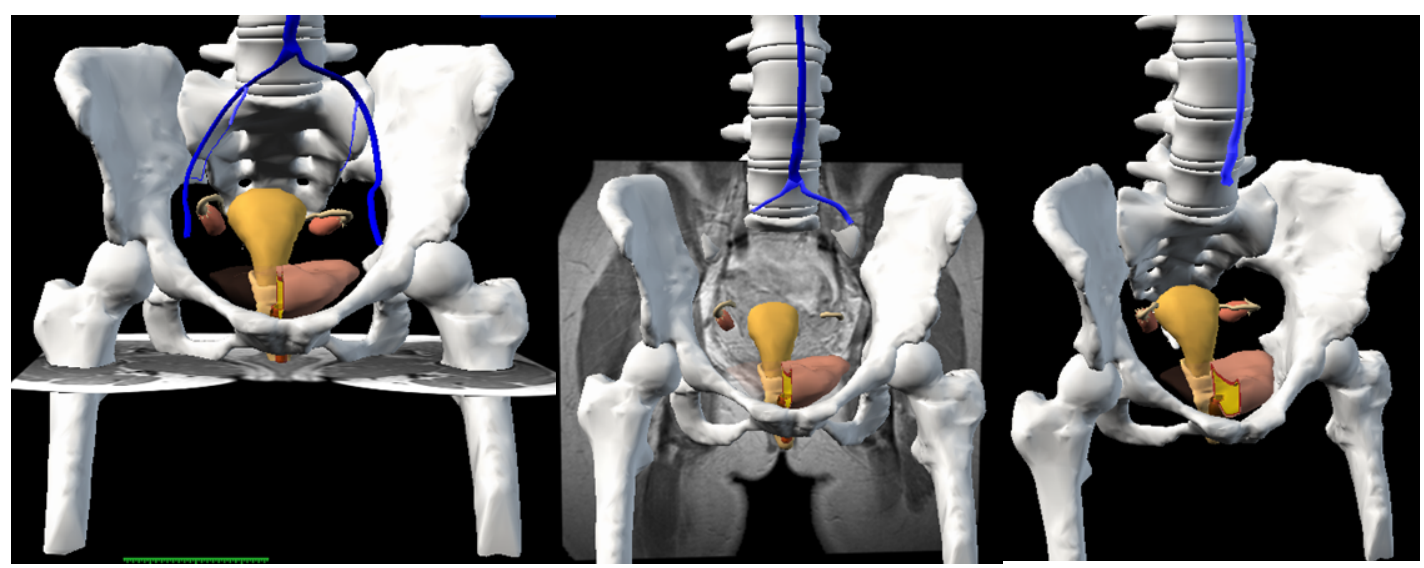

Figuras 117, 118 y 119. Imágenes del drenaje venoso de la pelvis, en las que se aprecian las venas ilíacas internas a la izquierda, las venas ilíacas comunes en la figura central y la vena cava inferior en la imagen de la derecha.

Las venas ilíacas internas se unen con las ilíacas externas, para formar las venas ilíacas comunes, que se fusionan a nivel de la cuarta o quinta vértebra lumbar para constituir la vena cava inferior, como se muestra en las figuras $117-119$. 

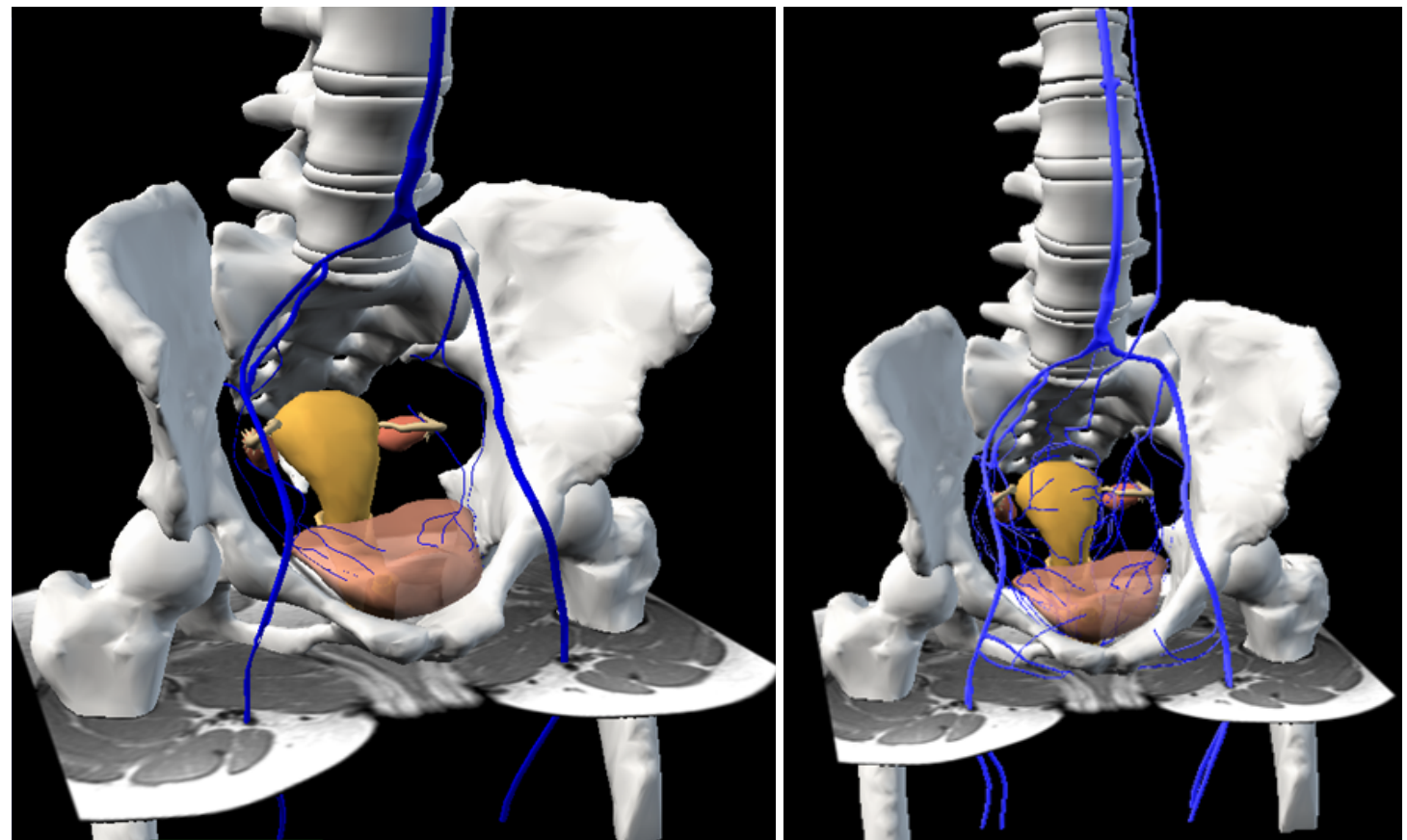

Figuras 120 y 121. Imágenes de modelos 3D de la vascularización venosa de la pelvis.

En las figuras 120 y 121, se representan los plexos venosos pélvicos, formados por venas y capilares venosos que rodean las vísceras de la pelvis. Los diversos plexos, dentro de la pelvis menor (rectal, vesical, uterino y vaginal), se unen y drenan principalmente a las venas ilíacas internas, aunque alguno de ellos drena, a través de la vena rectal superior, a la vena mesentérica inferior o a través de las venas sacras laterales, al plexo venoso vertebral interno.
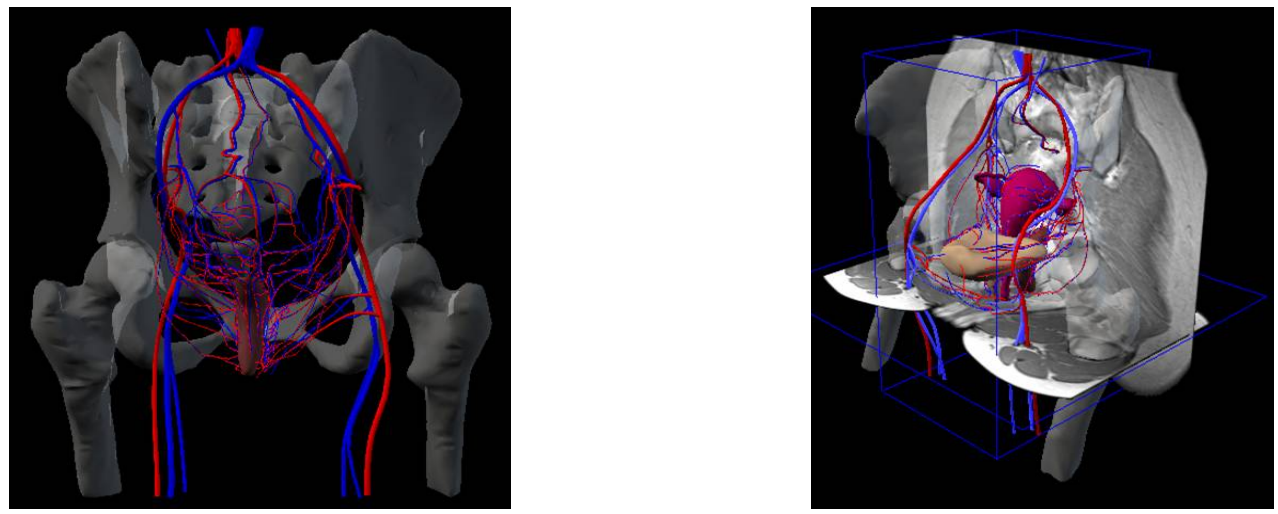

Figuras 122 y 123. Combinación de modelos tridimensionales de vasos arteriales y venosos. 

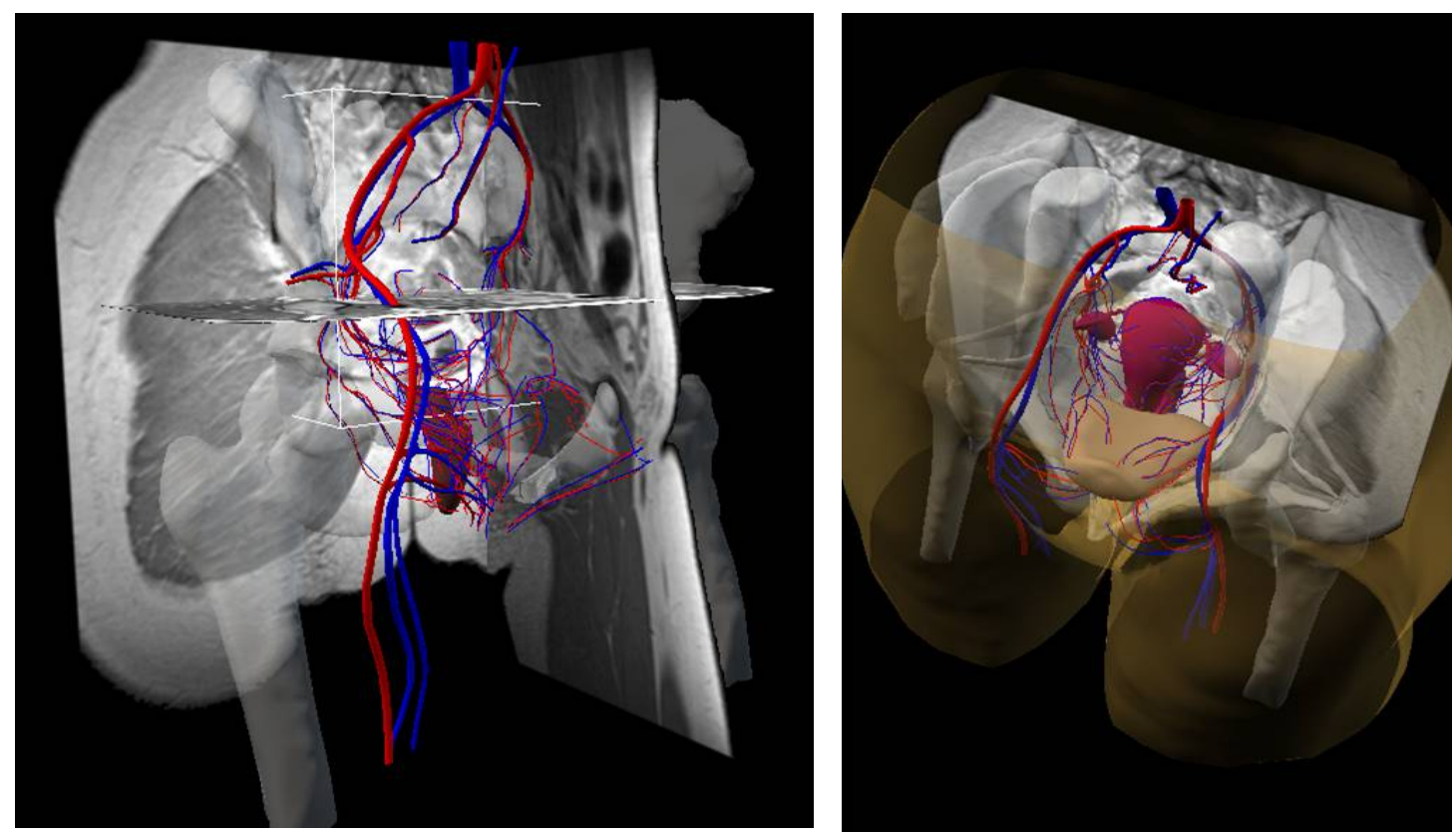

Figuras 124 y 125. Modelos 3D de los vasos sanguíneos de la pelvis con los modelos óseos transparentes, algunos viscerales y embebidos en secciones de RM.

En las figuras 122 - 125, vemos la combinación de las arterias y las venas en una misma imagen, desde distintos ángulos y con diferentes combinaciones, pudiendo apreciar lo intricada que es la red vascular y lo difícil que es la delimitación de los capilares, especialmente en torno a zonas de gran vascularización, como son los órganos y los músculos.

\section{2.e. - Modelos tridimensionales de las vísceras:}

Los órganos pélvicos femeninos fueron mucho más fáciles de reconstruir desde las imágenes seccionales de las que disponíamos, con alguna excepción debido a su tortuosidad y disposición espacial, como es el caso de la trompa de Falopio, por ejemplo.

Se han reconstruido modelos tridimensionales de los órganos genitales internos (vagina, útero, trompas de Falopio y ovarios) y externos, aparato urinario inferior (vejiga y uretra), y aparato digestivo terminal (recto y canal anal) (Figs. 126 - 150). 


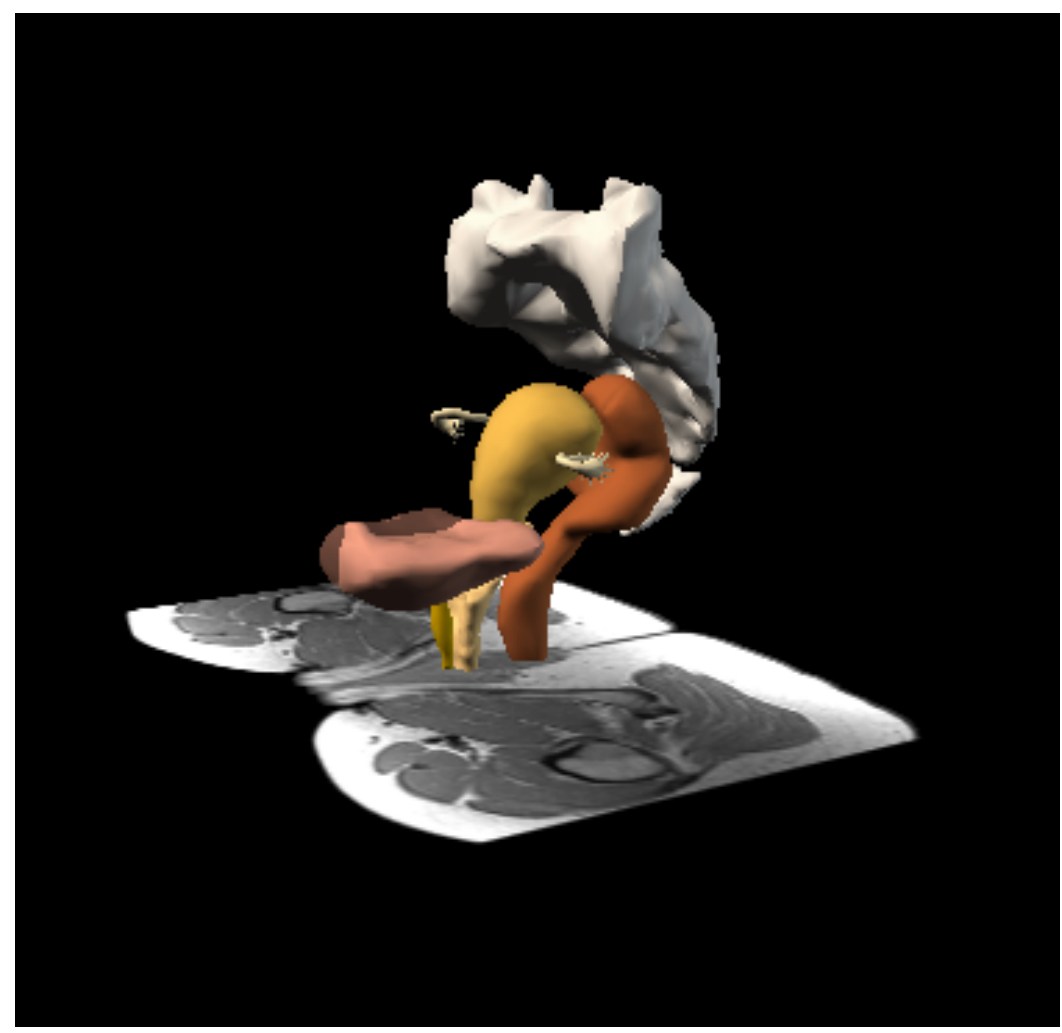

Figura 126. Imagen que muestra la relación anatómica existente entre sacro, cóccix, recto, canal anal, útero, vagina y vejiga. Se aprecia una sección de RM axial del periné, que determina la distancia a la que se encuentran el introito vaginal (con la parte inferior de la vagina) y el ano (con la parte inferior del recto y el canal anal).

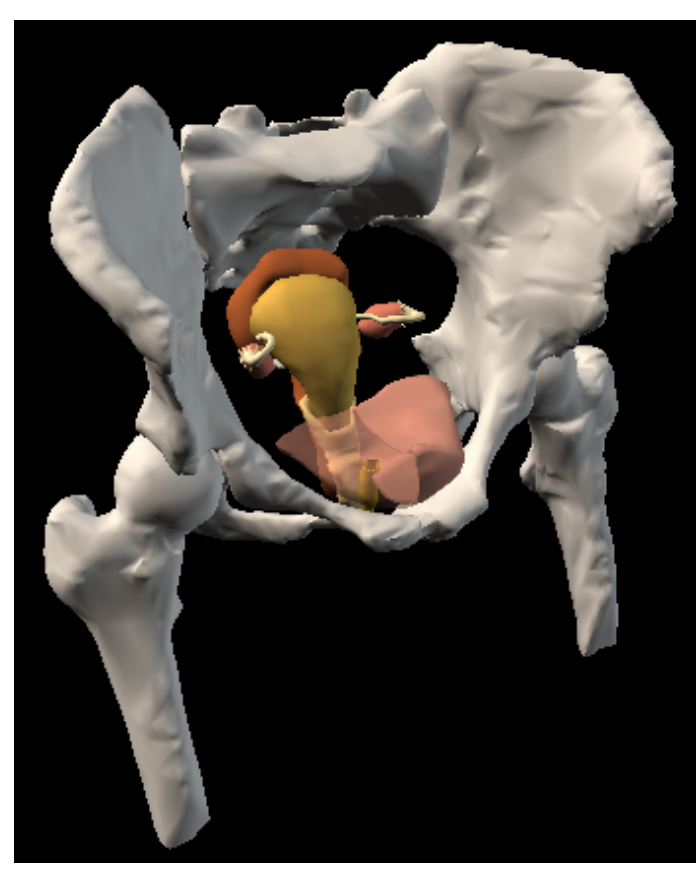

Figura 127. Modelo 3D del marco óseo de la pelvis, con las vísceras que contiene: vejiga, útero, trompas, ovarios, colon sigmoide y recto. 
$\underline{\text { Resultados }}$

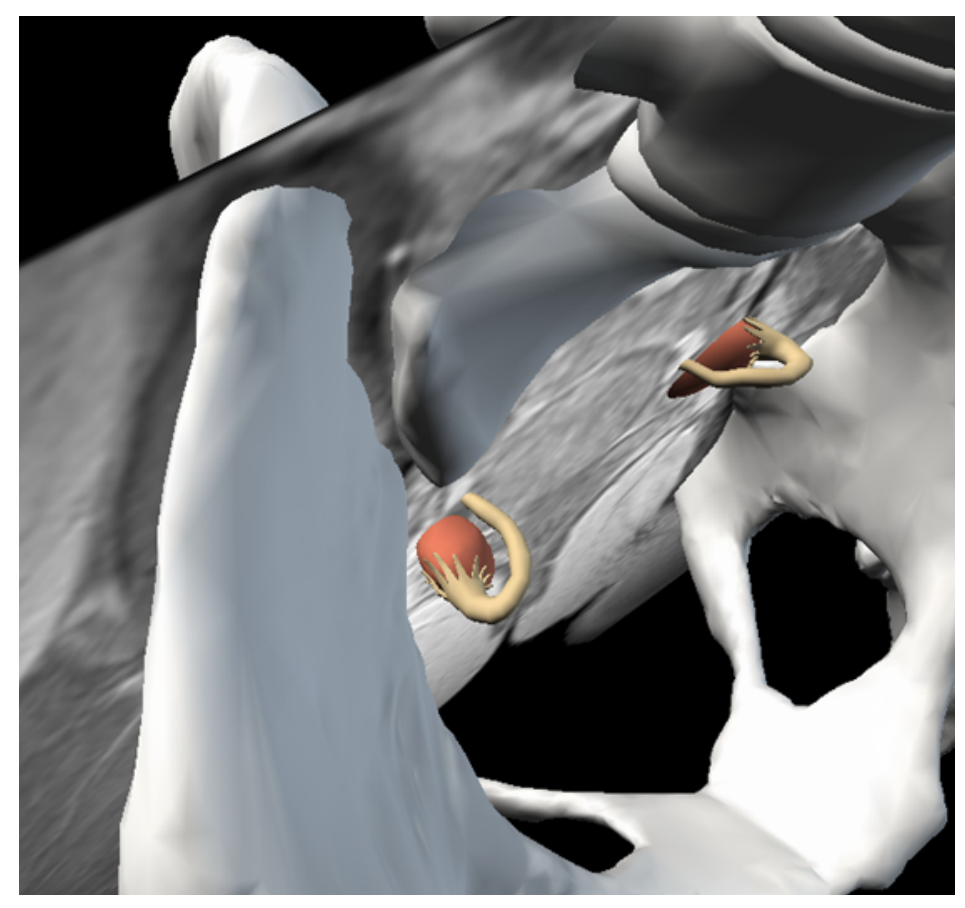

Figura 128. Ampliación en detalle de los ovarios y las trompas de Falopio en 3D embebidas en una sección de RM como referencia, en el plano coronal.

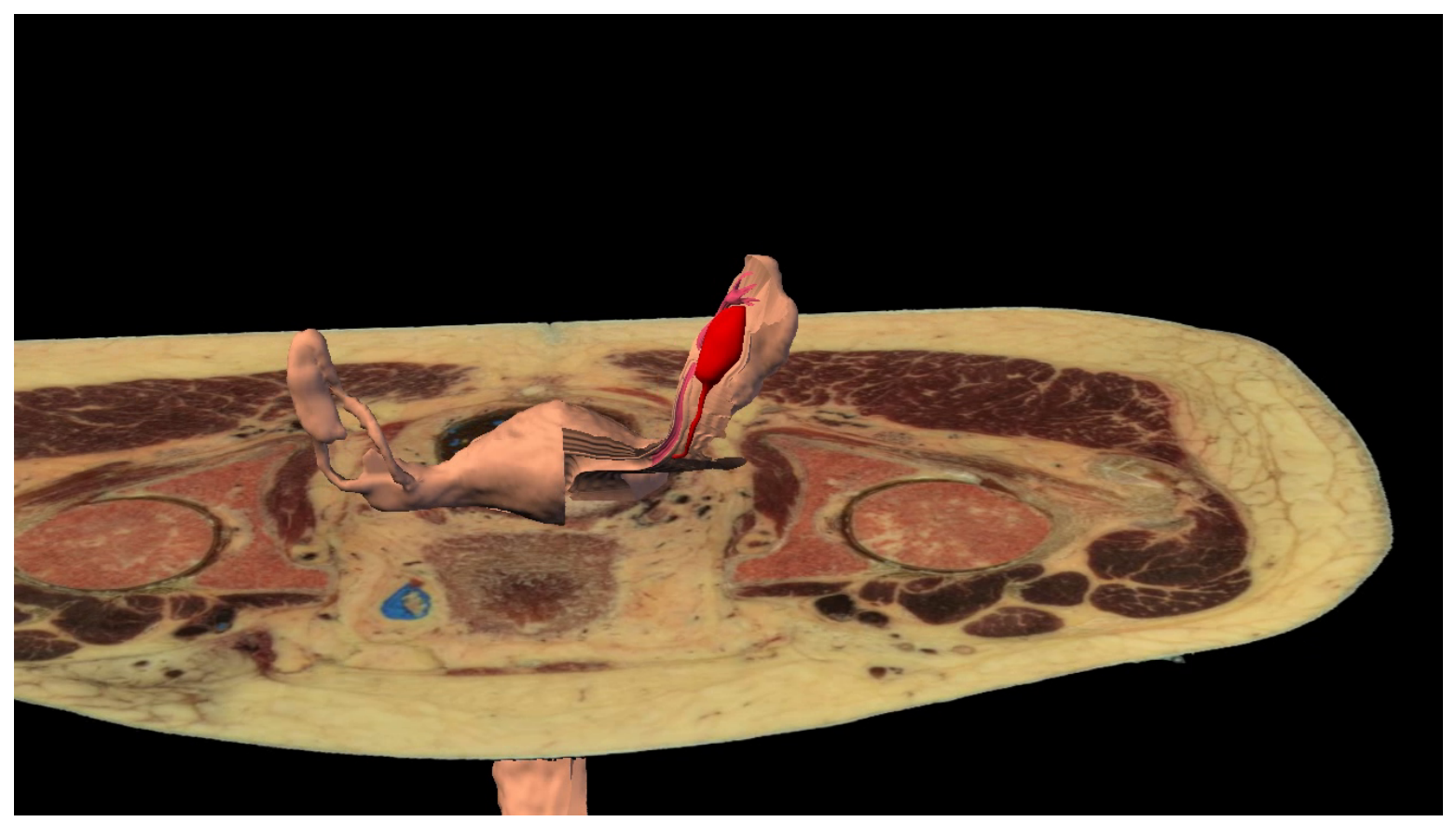

Figura 129. Ovario tridimensional en color rojo, con sección de cadáver axial. 


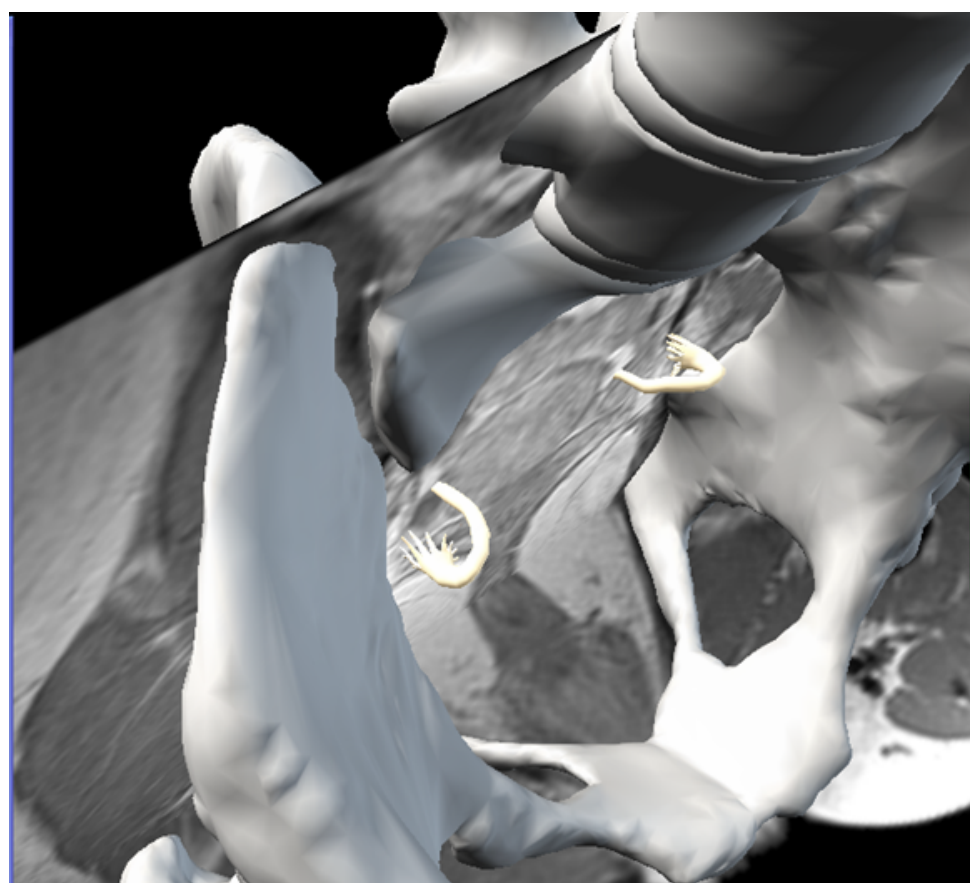

Figura 130. Imagen igual que la fig. 127, pero en este caso, se ha deseleccionado la visualización de los ovarios y solo se observa el modelo $3 D$ de las trompas de Falopio, en color blanco, pudiendo observar las fimbrias.

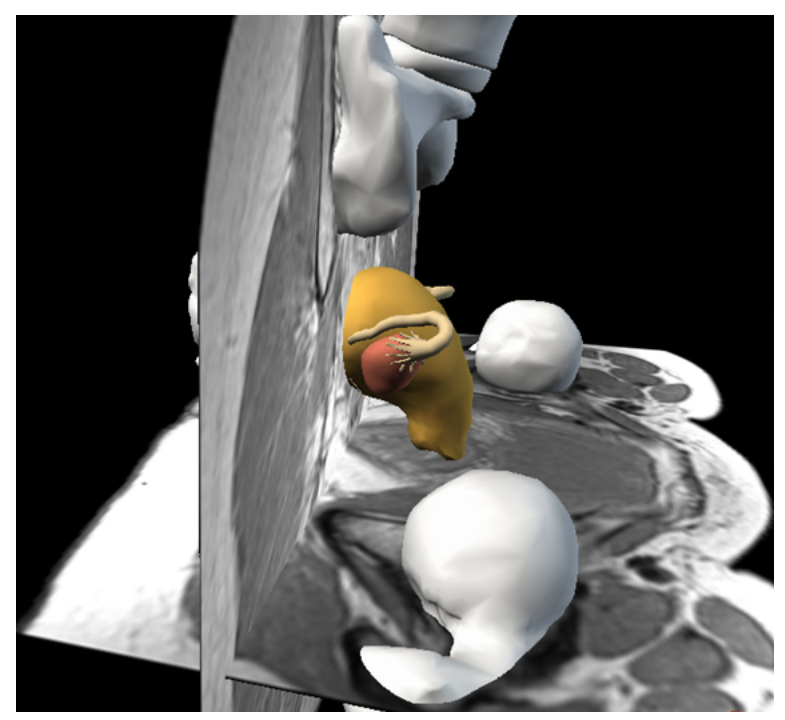

Figura 131. Representación 3D del útero, las trompas y los ovarios, junto con la parte terminal de la columna vertebral y la cabeza del fémur, sin visualizar el hueso coxal. Utilizamos como referencia anatómica en este caso, dos cortes de RM, uno axial y otro coronal. 

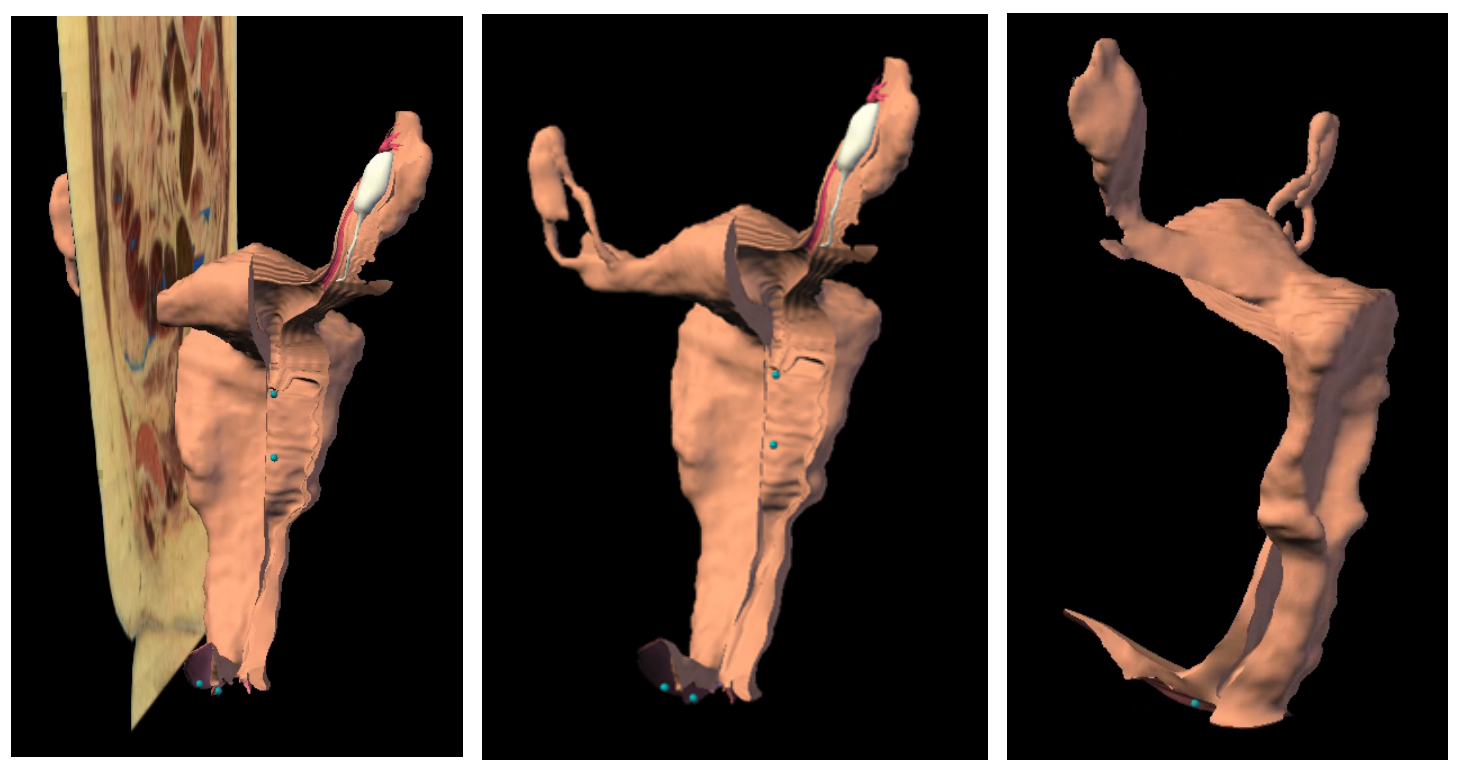

Figuras 132, 133 y 134. Modelos 3D de los órganos reproductores femeninos (ovarios, trompas de Falopio, útero, vagina y genitales externos), analizados desde diferentes ángulos. En la primera de las imágenes contamos con un corte sagital de cadáver como referencia anatómica.

En las imágenes 132, 133 y 134, analizamos el mismo modelo 3D desde diferentes ángulos de visión, como permite realizar nuestra aplicación y en la imagen de la izquierda se ha añadido a la composición un corte sagital de cadáver, que nos facilita la comprensión de las relaciones con sus estructuras vecinas. Se puede ver el útero conectado con ambos ovarios a través de las trompas de Falopio, así como el ángulo que forman el cérvix uterino y la vagina.

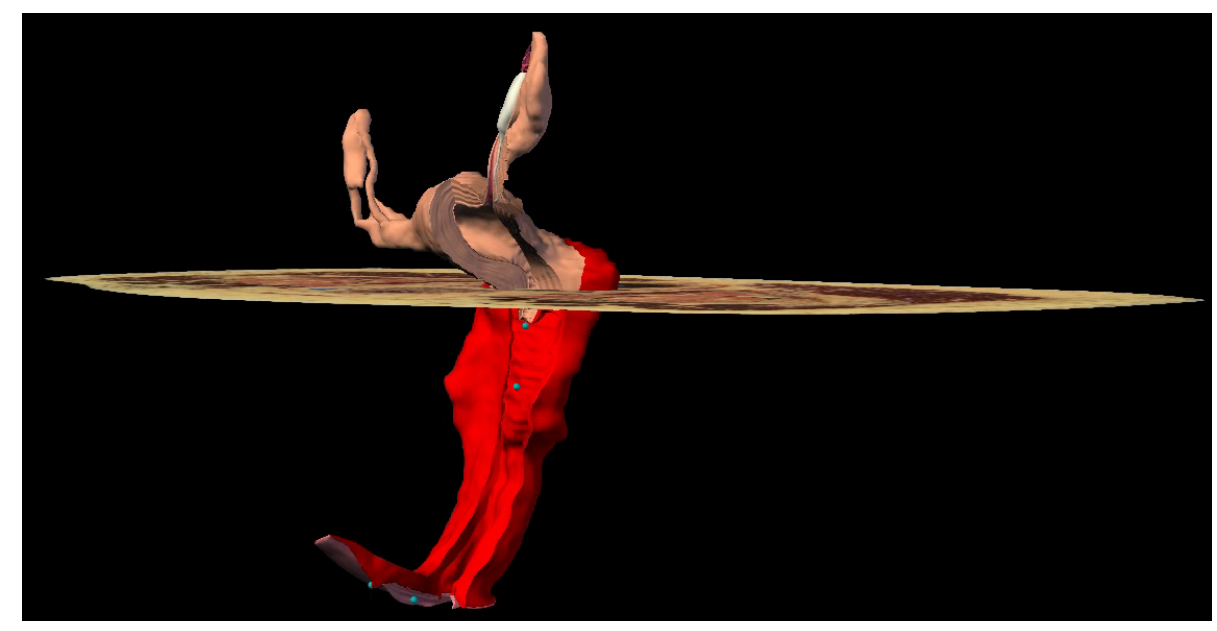

Figura 135. Modelo tridimensional con la vagina marcada en color rojo.

En la figura 135, la vagina está seleccionada en rojo, lo que permite el acceso a una información más completa sobre la misma y su manipulación visual. La imagen 
incluye un corte sagital del modelo 3D del útero, en el que vemos solamente la mitad de este órgano, apreciando que se trata de una cavidad, junto con una sección axial de cadáver a nivel del cérvix uterino.

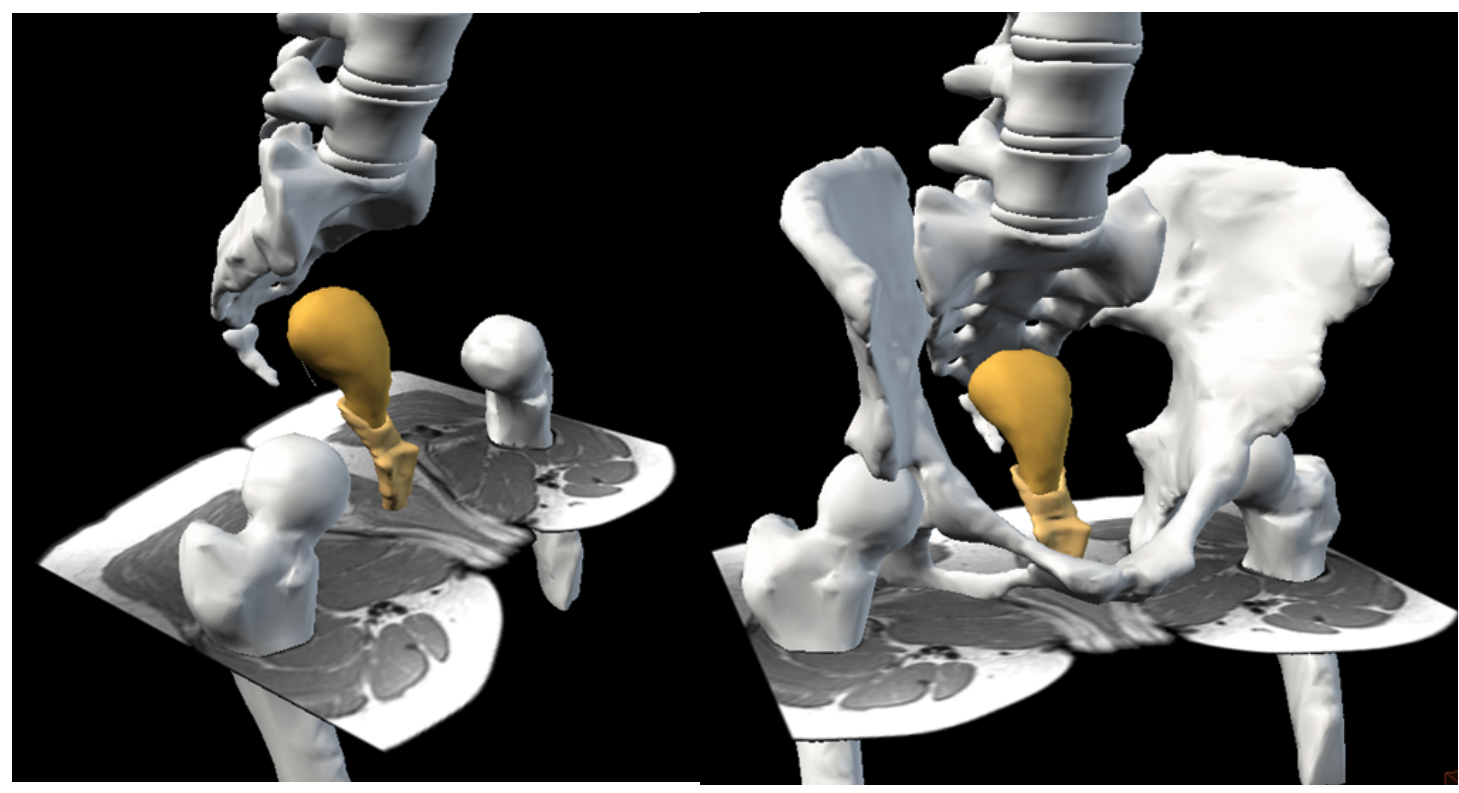

Figuras 136 y 137. Representaciones del útero y la vagina en 3D junto a estructuras de la pelvis ósea. En la de la izquierda se ha sustraído el hueso coxal, mientras que en la imagen de la derecha sí se visualiza.

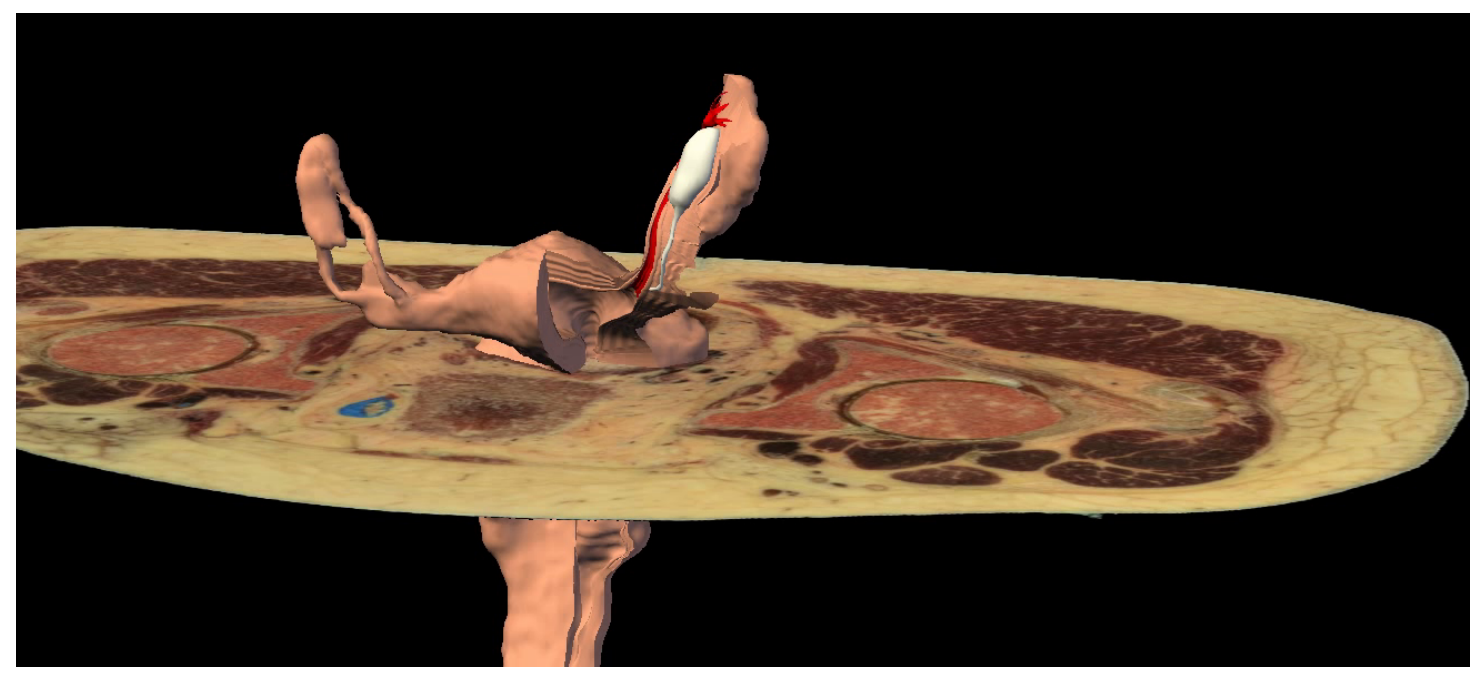

Figura 138. En la que se aprecian el útero, los ovarios, las trompas, y parte de la vagina junto con una sección axial de cadáver. El ovario aparece en color blanco y en rojo la cavidad virtual que sería el trayecto de la trompa de Falopio. 
$\underline{\text { Resultados }}$

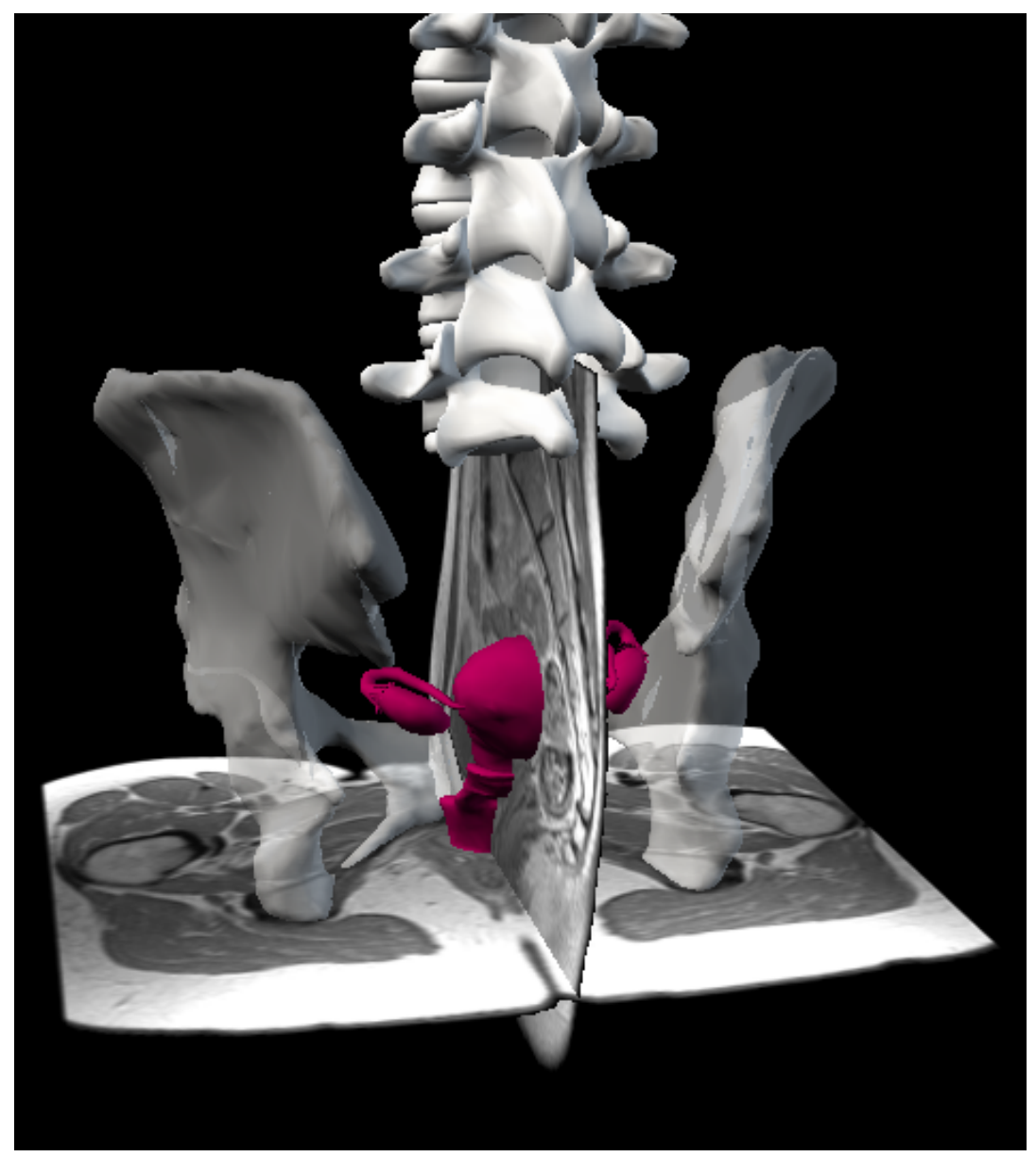

Figura 139. Modelo en 3D de la vagina, útero y anejos junto con modelos 3D óseos transparentes (sin sacro ni cóccix) y dos secciones de RM en distintos planos del espacio (axial y sagital).
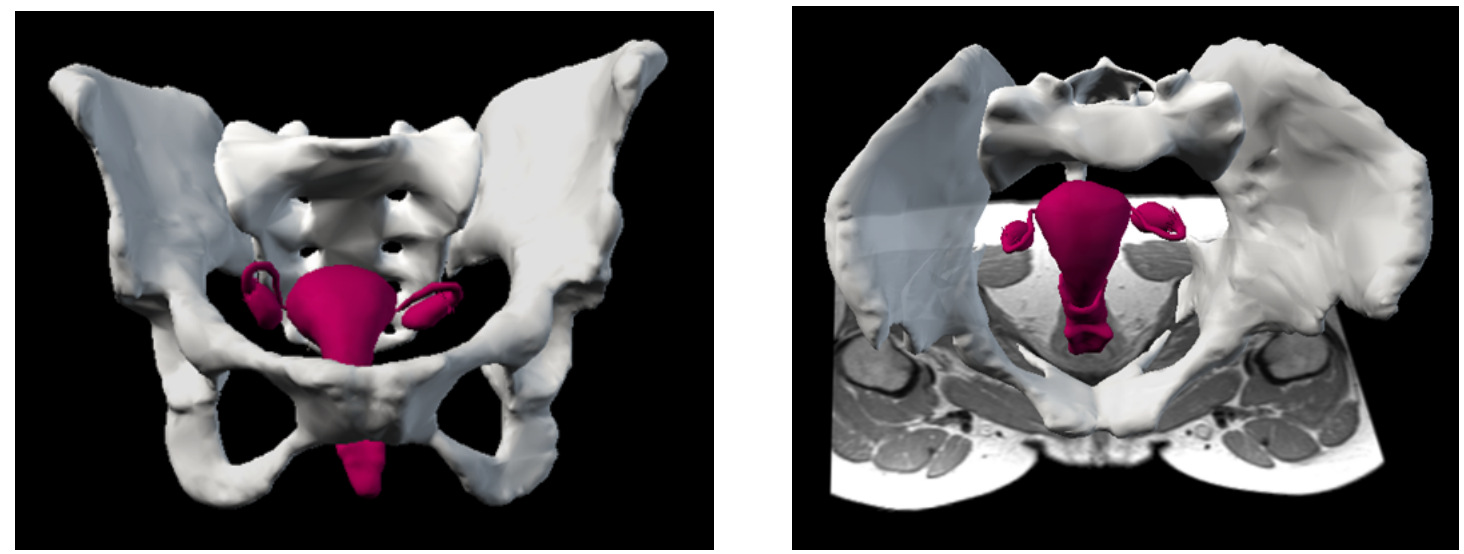

Figuras 140 y 141. Representaciones del útero y ambos anejos junto con la pelvis ósea en 3D, desde diferentes ángulos de visualización y con una sección axial de RM en la imagen de la derecha. 

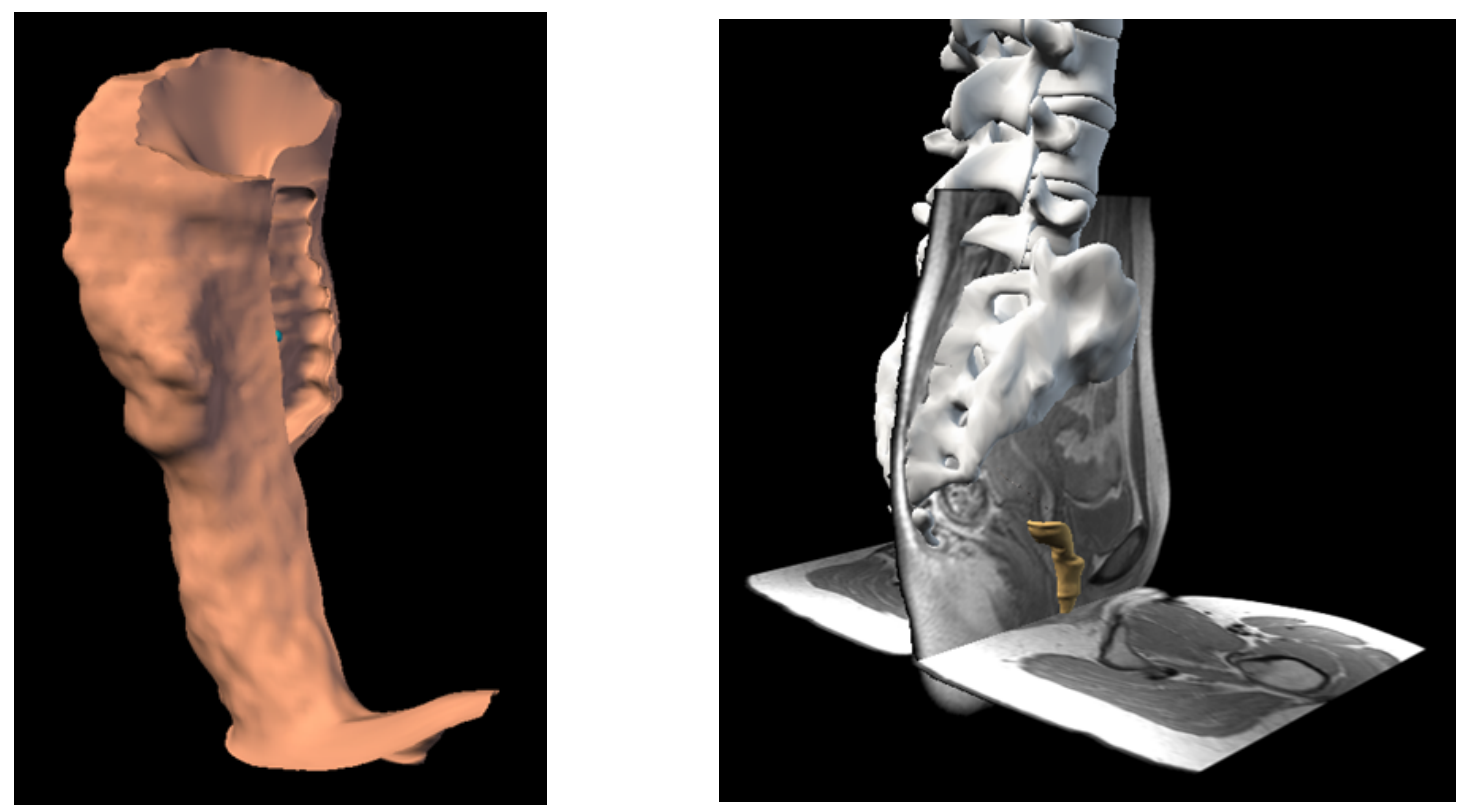

Figura 142 y 143. Reconstrucción tridimensional de la vagina, sin visualizar otros órganos adyacentes. En la imagen de la derecha se observa también la parte final de la columna vertebral junto con dos secciones (axial y sagital) de RM, perpendiculares entre sí, en las que se encuentra embebida la vagina.

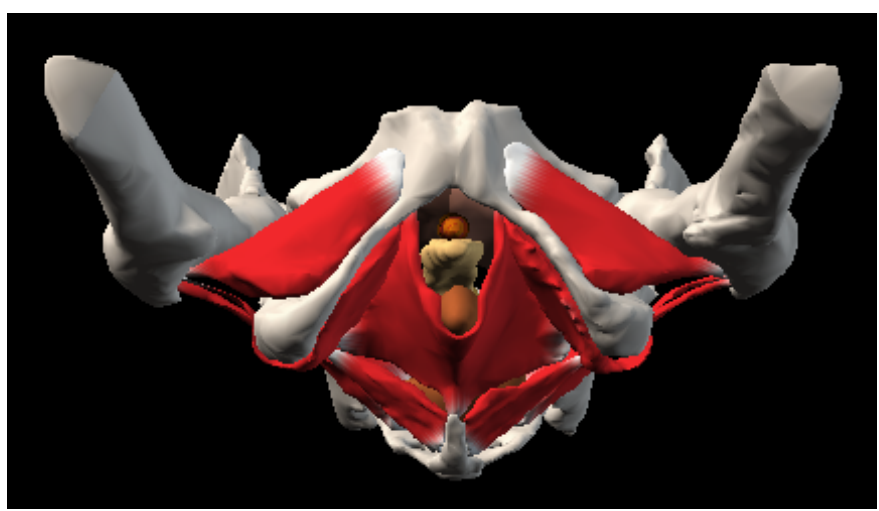

Figura 144. Visión inferior de la acomodación de los órganos pélvicos con el soporte de los músculos del periné.

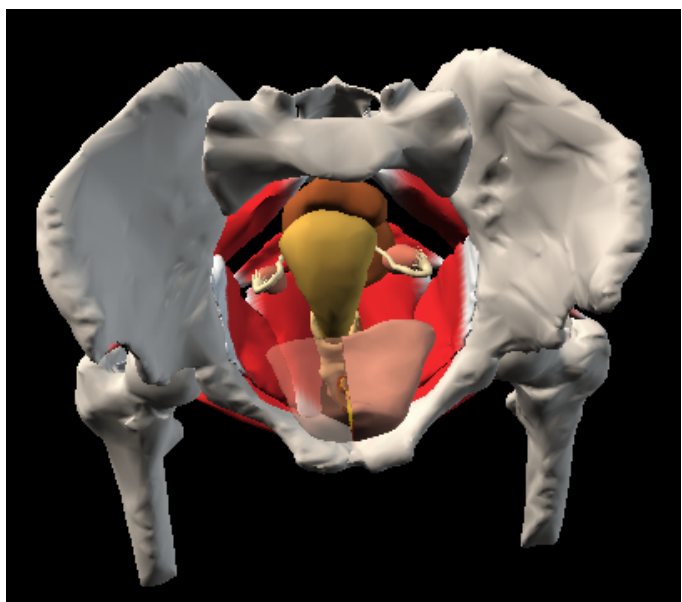

Figura 145. Visión superior de la acomodación de los órganos pélvicos con el soporte de los músculos del periné. 

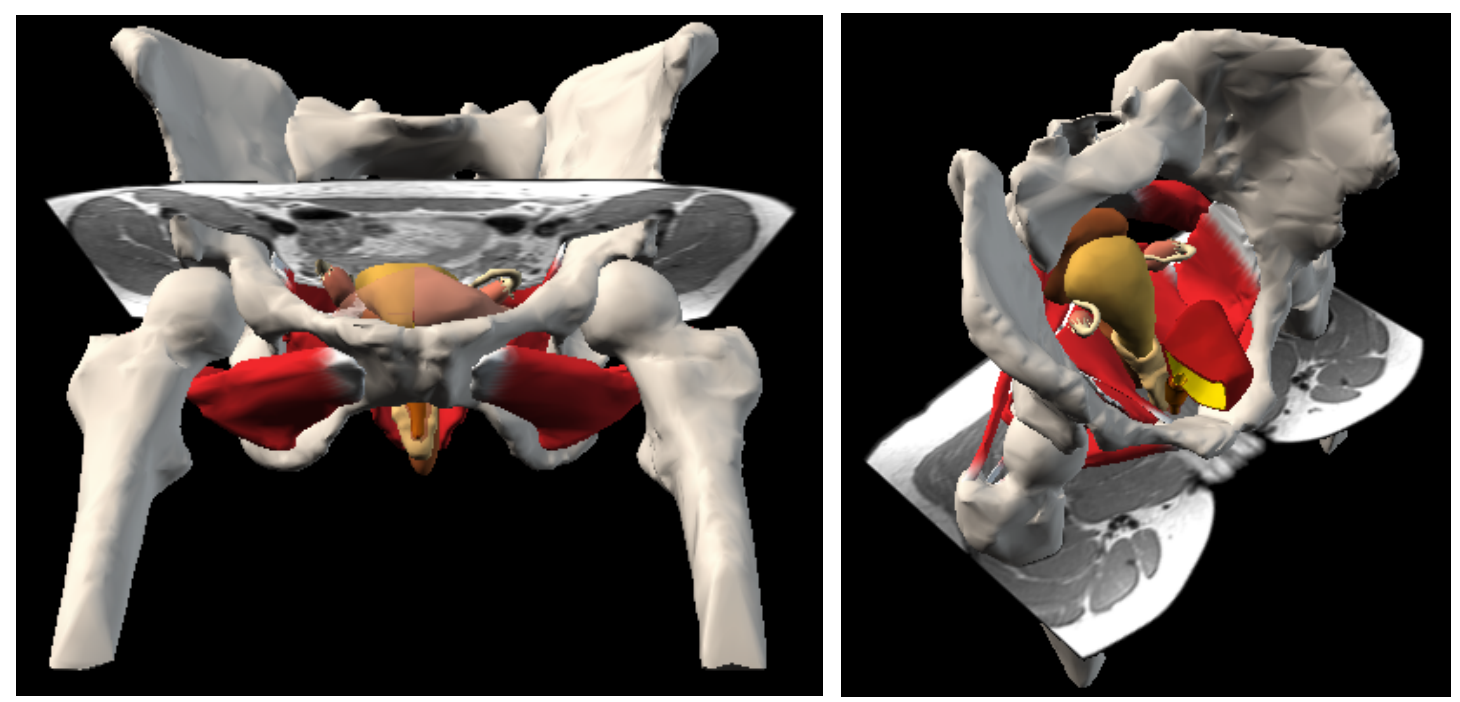

Figuras 146 y 147. Imágenes similares a las previas en las que se observa una sección de RM que referencia la composición tridimensional formada por partes óseas, vísceras y músculos, sin incorporar estructuras vasculares ni nerviosas.

En las figuras 144-147, se visualiza un conjunto de modelos 3D, las vísceras y los músculos del suelo pélvico, permitiendo analizar la importante función de sostén del periné que ejercen los músculos y como es la relación de éstos con los órganos pélvicos.

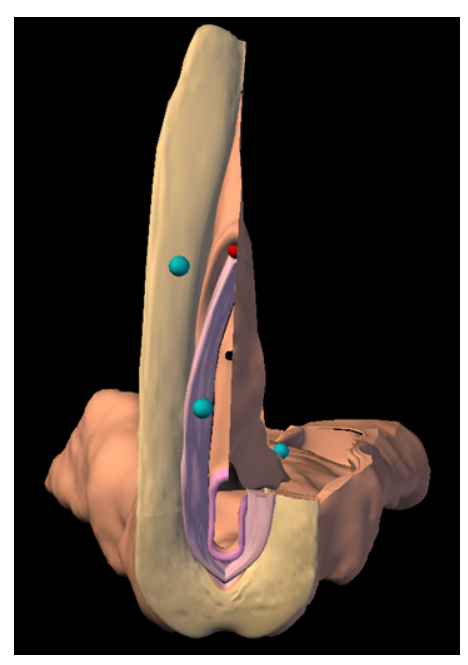

Figura 148. Representación 3D de los genitales externos femeninos: clítoris, labio menor y mayor, uretra e introito vaginal.

También disponemos de una representación esquemática de la disposición de los genitales externos, como vemos en la figura 148. 


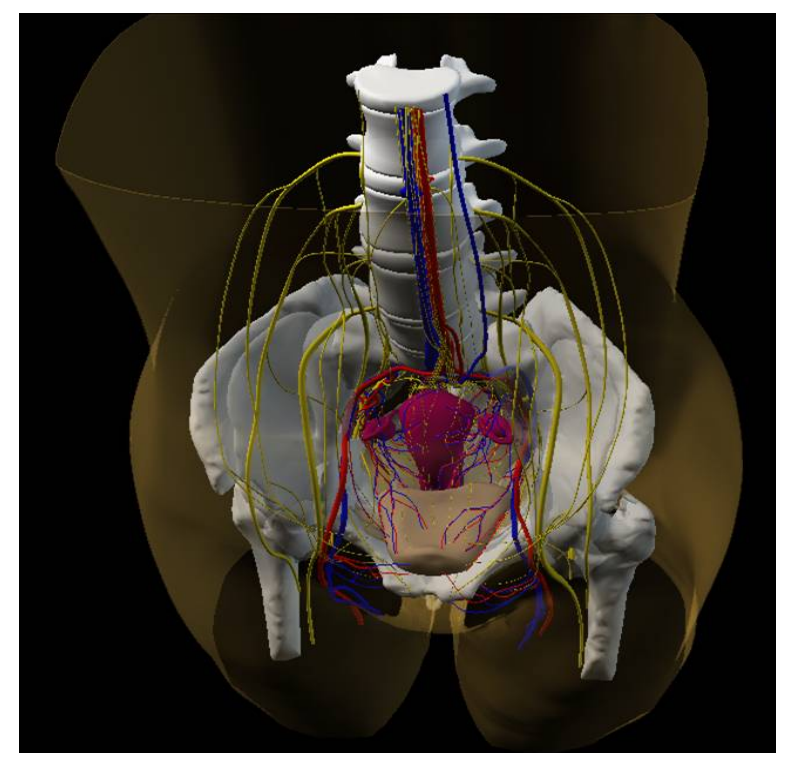

Figura 149. Ejemplo de un modelo 3D con diversas estructuras de la pelvis.

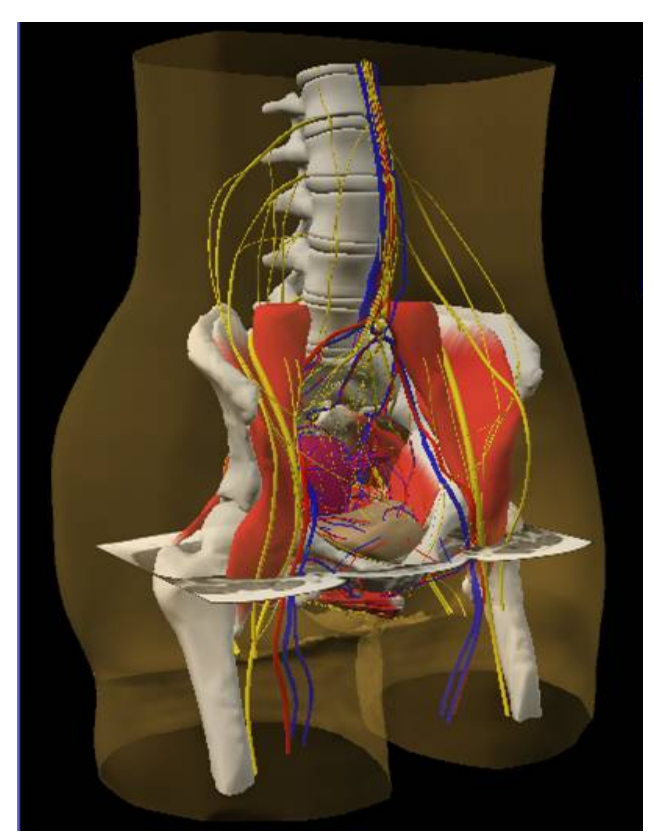

Figura 150. Modelos 3D de las estructuras de la pelvis, combinados con un corte axial de RM.

En las figuras 149 y 150 observamos dos representaciones tridimensionales de la realidad anatómica de la pelvis femenina. En el modelo de la figura 149 faltarían por añadirse los modelos 3D de los músculos que constituyen esta región, que podemos apreciar en la figura 150 junto con el resto de las estructuras reconstruidas. En ambas representaciones aparece la piel con transparencia. 


\section{3. - Funcionalidad de la aplicación informática: Interfaz de usuario.}

Las posibilidades de combinación y variación de los dos módulos de los que disponemos (imágenes seccionales y modelos 3D) son múltiples, lo que permite la representación de diferentes zonas anatómicas de la pelvis femenina desde distintos ángulos y posiciones en el espacio.

La interfaz gráfica generada para esta aplicación informática es muy clara y de fácil manejo, ya que muestra de forma evidente las diferentes opciones que posibilitan la interacción del usuario con el visor anatómico.

Nuestra interfaz de usuario exhibe el uso de ventanas flotantes que pueden ser reubicadas, cuya visualización puede o no seleccionarse, y que se muestran en el visor anatómico. También incluimos el uso de iconos y no únicamente de texto en los diferentes apartados de la interfaz, para que sean identificables y permitan un acceso cómodo a las diferentes funciones, como podemos apreciar en las figuras 151 y 152. En esta última (Fig. 152) se muestra la posibilidad de deseleccionar una de las ventanas flotantes, al no visualizarse el control de modelos.

La interfaz de usuario se divide en cuatro partes: visor anatómico, control de visualización, control de planos y control de modelos.

Para comenzar explicaremos la función principal de nuestro programa, que "permite observar las estructuras anatómicas de la pelvis femenina en tres dimensiones, teniendo como patrón de referencia las secciones de cadáver o de RM, ambas en los tres planos del espacio (coronal, axial y sagital)", aunque admite, a petición del usuario, otras funciones que serán explicadas más adelante en los siguientes apartados.

Para que el planteamiento y la descripción de las distintas partes de la interfaz y de las posibilidades que representa su adecuada utilización, sean patentes y entendibles, iremos explicando cada zona, así como las diferentes opciones que permiten de interacción usuario-ordenador y viceversa. 


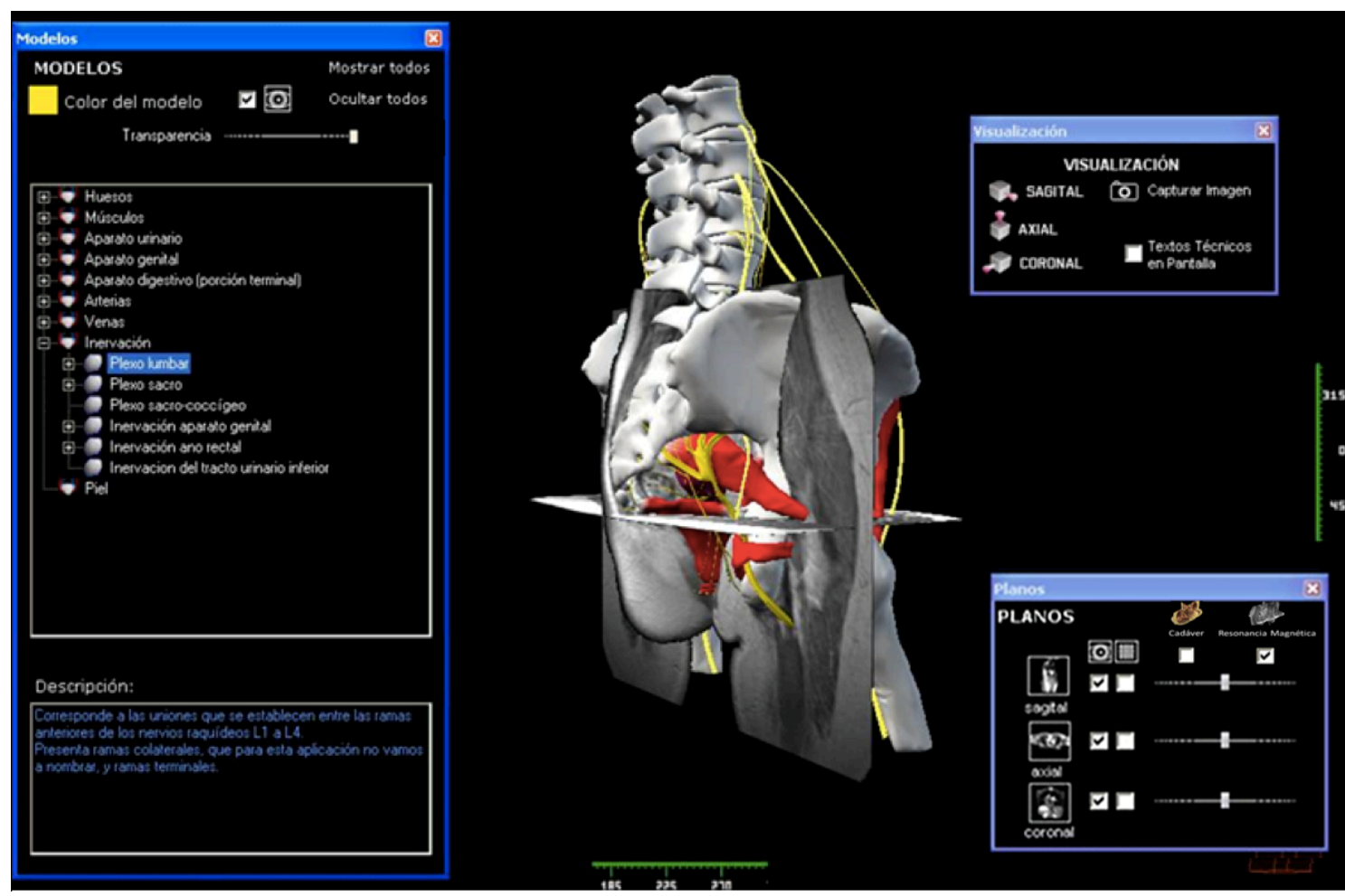

Figura 151. Muestra de la interfaz de nuestra aplicación, los tres menús de control y el visor anatómico con una reconstruccion tridimensional de varias estructuras pélvicas junto con imágenes de RM en los tres planos del espacio.

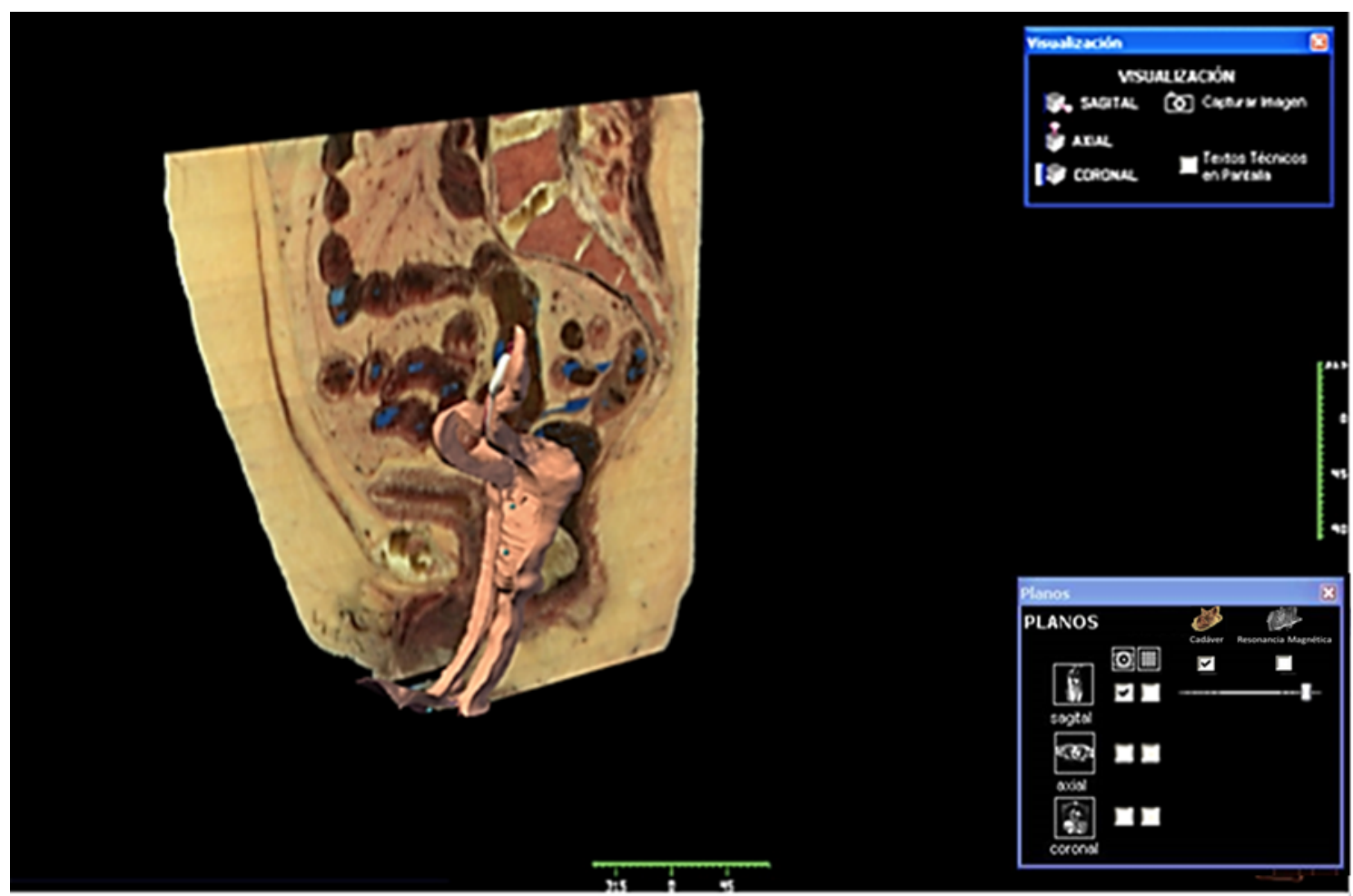

Figura 152. Visión de una captura de pantalla de la aplicación en la que podemos apreciar las ventanas flotantes de planos y de visualización, y una imagen de los órganos del aparato reproductor en $3 D$ junto con un corte sagital de cadáver. 


\section{3.a. - Visor anatómico:}

Todas las interacciones con los elementos de la escena visual (rotaciones, traslaciones, zoom y selección) se realizan situando el cursor sobre el visor, usando el ratón del ordenador.

1.1.- Rotaciones: Para rotar la imagen del visor, mantener pulsado el botón principal (izquierdo) del ratón mientras se desplaza el cursor sobre la pantalla.

1.2.- Traslaciones: Para trasladar la imagen del visor en el plano de la pantalla, mantener pulsados los dos botones del ratón mientras se desplaza el cursor.

1.3.- Zoom: Para ampliar o reducir el tamaño de la imagen que se muestra en el visor, mantener presionado el botón secundario del ratón desplazando el cursor hacia arriba (ampliar) o hacia abajo (reducir).

1.4.- Selección: Haciendo clic en el visor, sin mover el ratón, se seleccionará la estructura sobre la que se pulse, teniendo en cuenta el nivel de jerarquía que tenga abierto. También se puede seleccionar la imagen seccional de referencia, lo que se indicará con un recuadro azul. La posición espacial del plano seleccionado se podrá variar pulsando la tecla "mayúsculas" y desplazando el ratón sin tener ningún botón pulsado.

A continuación, se muestran imágenes (capturas de pantalla) del visor anatómico y de las diferentes posibilidades que permite la aplicación: (Fig. 153 -160).

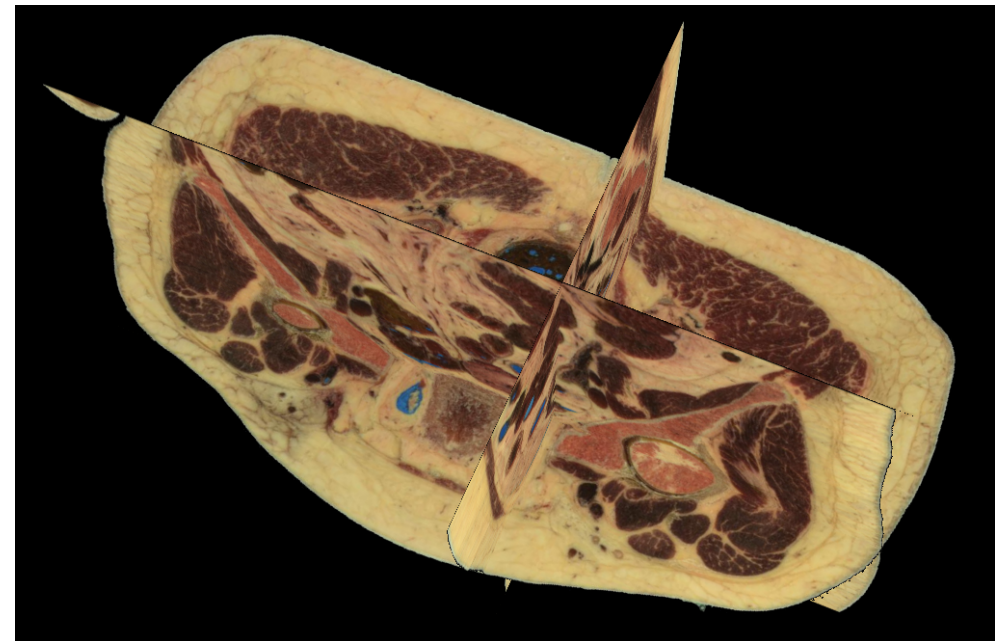

Figura 153. En esta figura vemos una imagen compuesta por cortes de cadáver en los tres planos del espacio (sagital, axial y coronal). 


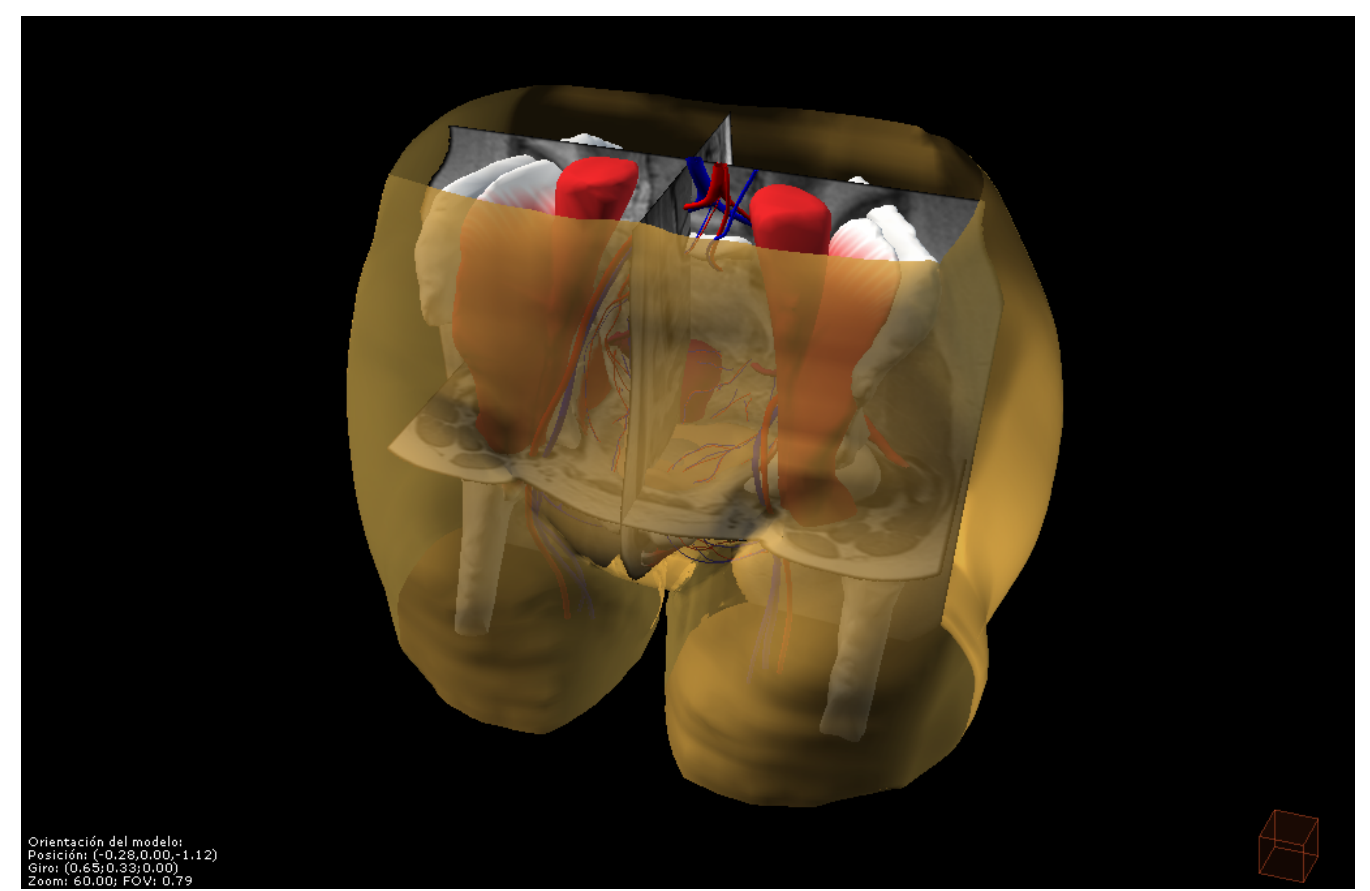

Figura 154. Modelo 3D con todas las estructuras pélvicas visto de frente, en la que se puede visualizar la piel con efecto transparencia.

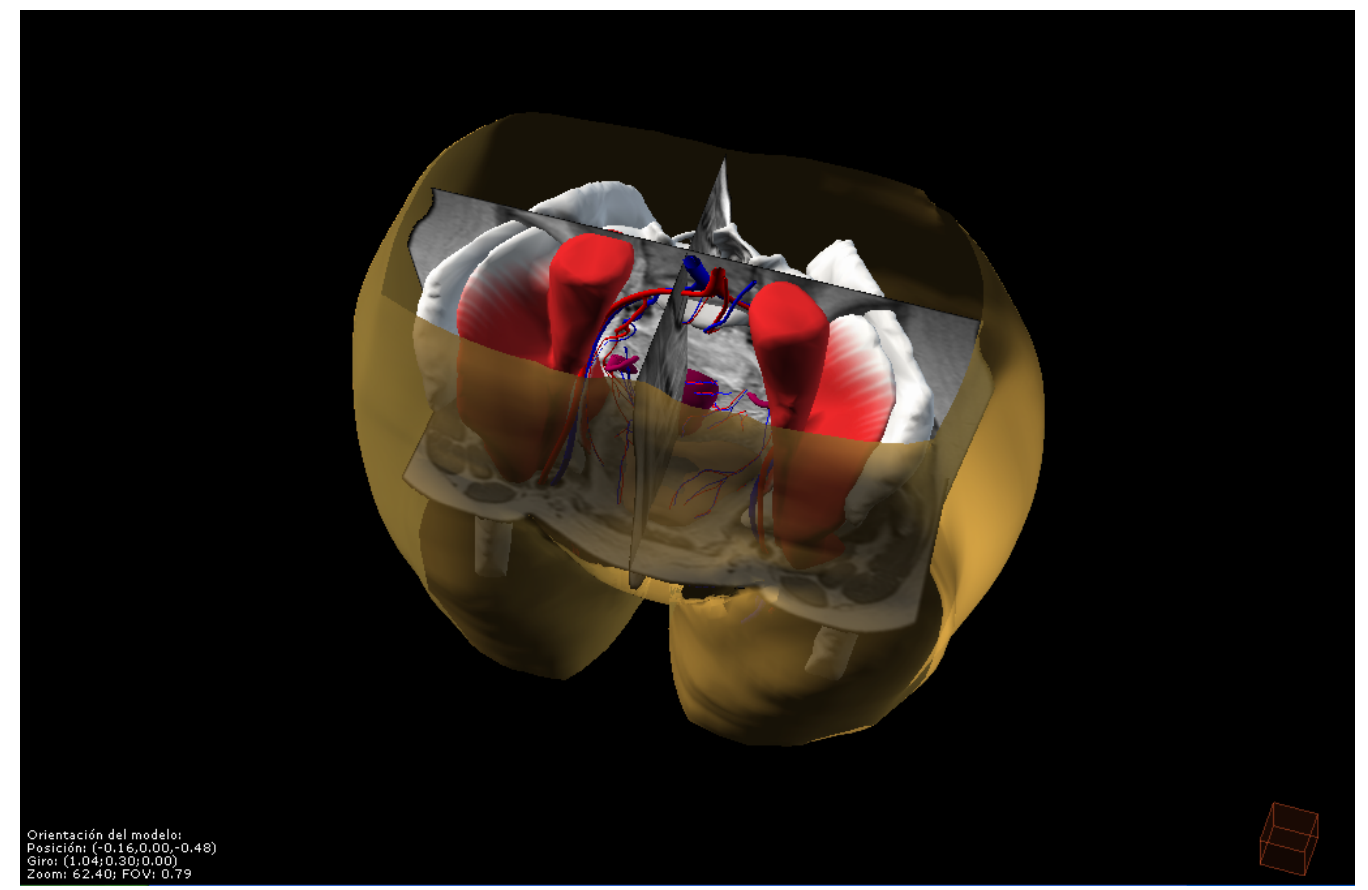

Figura 155. El mismo modelo previo con las estructuras pélvicas en 3D, incluida la piel, visualizado desde la parte superior. 


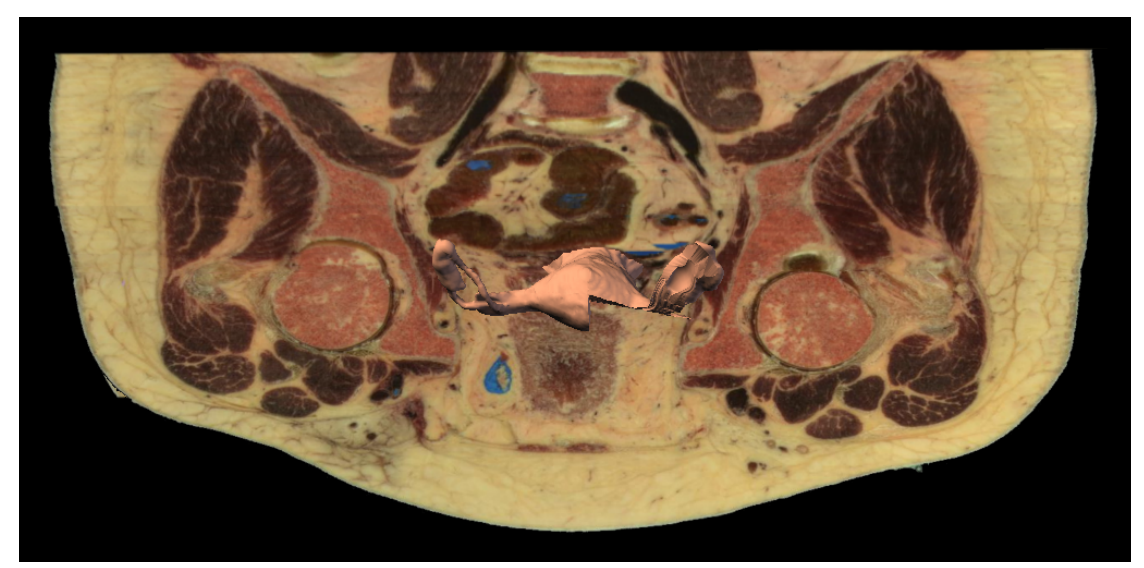

Figura 156. Visor anatómico de nuestro desarrollo informático en el que se visualiza un corte axial del "Visible Human" junto con un modelo 3D del útero, ovarios y trompas de Falopio vistos desde arriba.

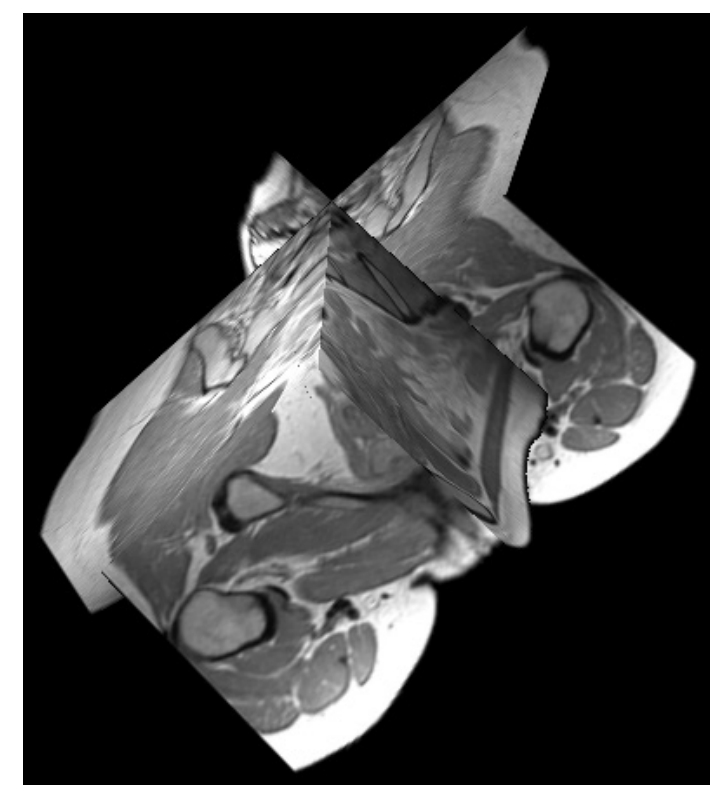

Figura 157. Composición con tres secciones de RM en distintos planos del espacio.

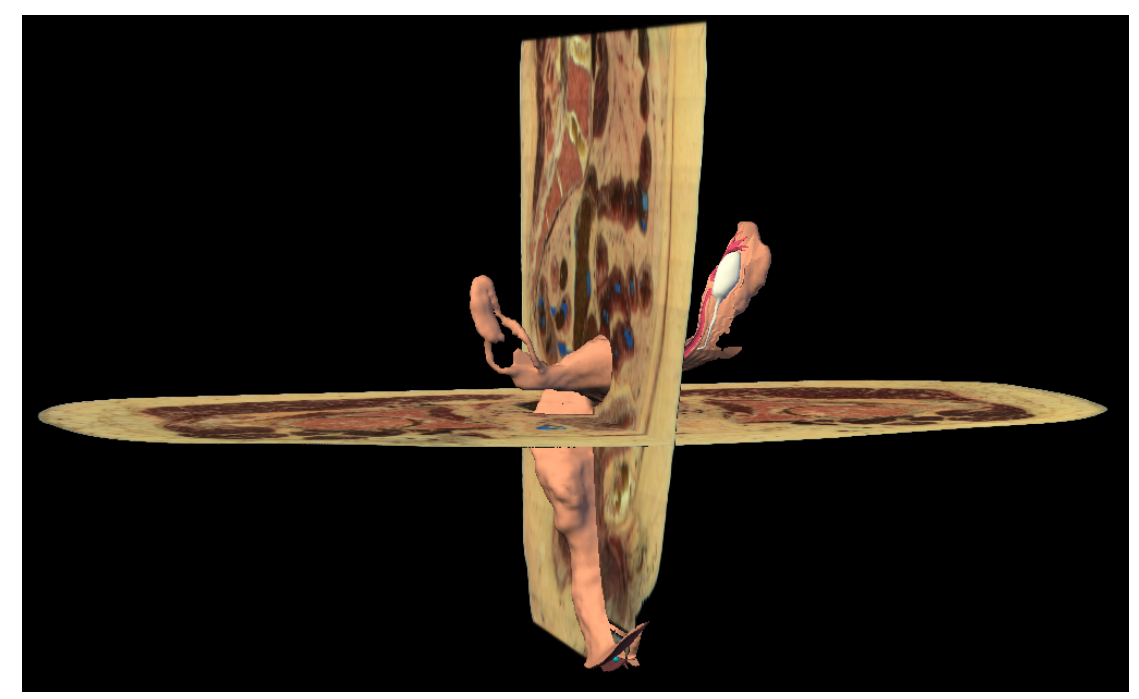

Figura 158. Composición en la que podemos apreciar el uso combinado de los cortes sagital y axial de las secciones de cadáver del "Visible Human" y un modelo 3D visceral. 

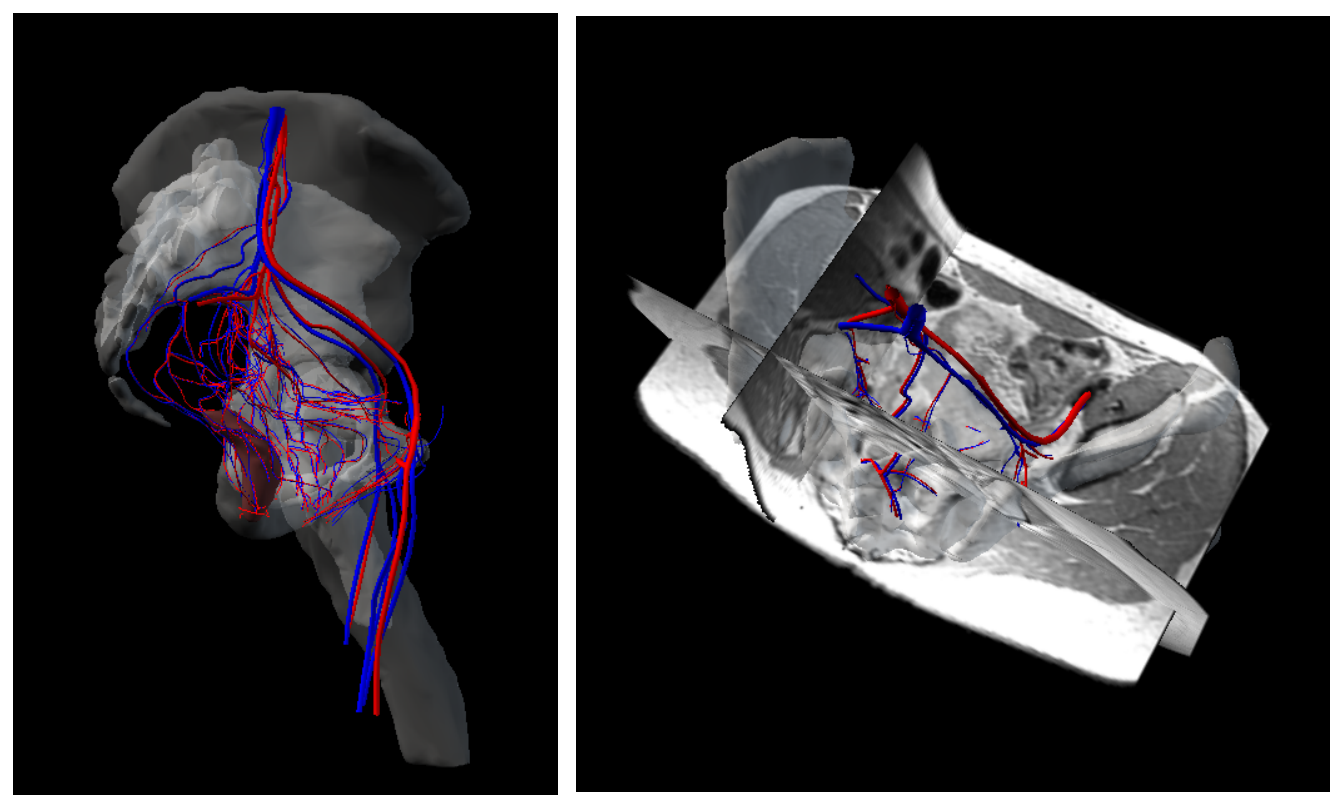

Figura 159 y 160. A la izquierda, vascularización de la pelvis con secciones de RM y modelos 3D de la pelvis ósea en transparencia como referencia. A la derecha, representación en $3 D$ de la vascularización de la pelvis vista lateralmente.

\section{3.b. - Control de visualización:}

Existen tres perspectivas predefinidas por nuestro programa para observar la composición que aparece representada en el visor anatómico, que pueden seleccionarse mediante los botones que aparecen en el control de visualización. Esas perspectivas son sagital (enfoca la imagen del visor anatómico desde el lateral), axial (lo vemos desde arriba) y coronal (presenta una visión frontal), que posteriormente pueden ser modificadas por el usuario al mover mediante el ratón el modelo 3D, la imagen seccional o el conjunto de ambas.

La escena representada en el visor anatómico, tras realizar las modificaciones (rotaciones, traslaciones o zoom) que el usuario desee, puede ser almacenada como una imagen en un fichero con formato bitmap (.bmp), mediante la opción "capturar imagen" para compartirla o estudiarla posteriormente (Fig. 161 y 162).

Mediante la opción de textos técnicos que puede seleccionarse en este menú, aparece información técnica de la imagen de RM. 


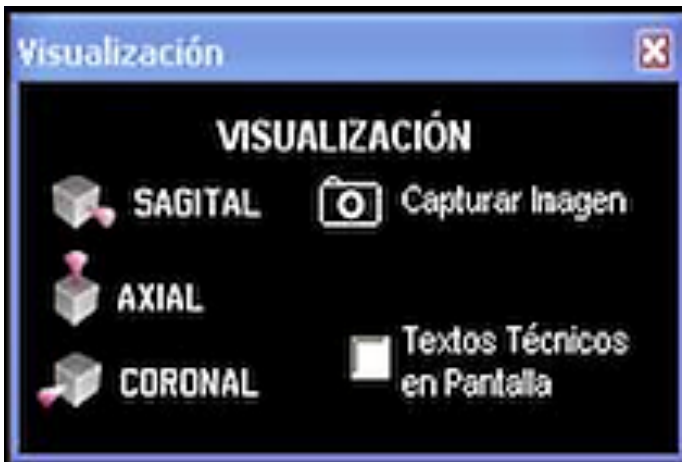

Figura 161. Control de visualización.

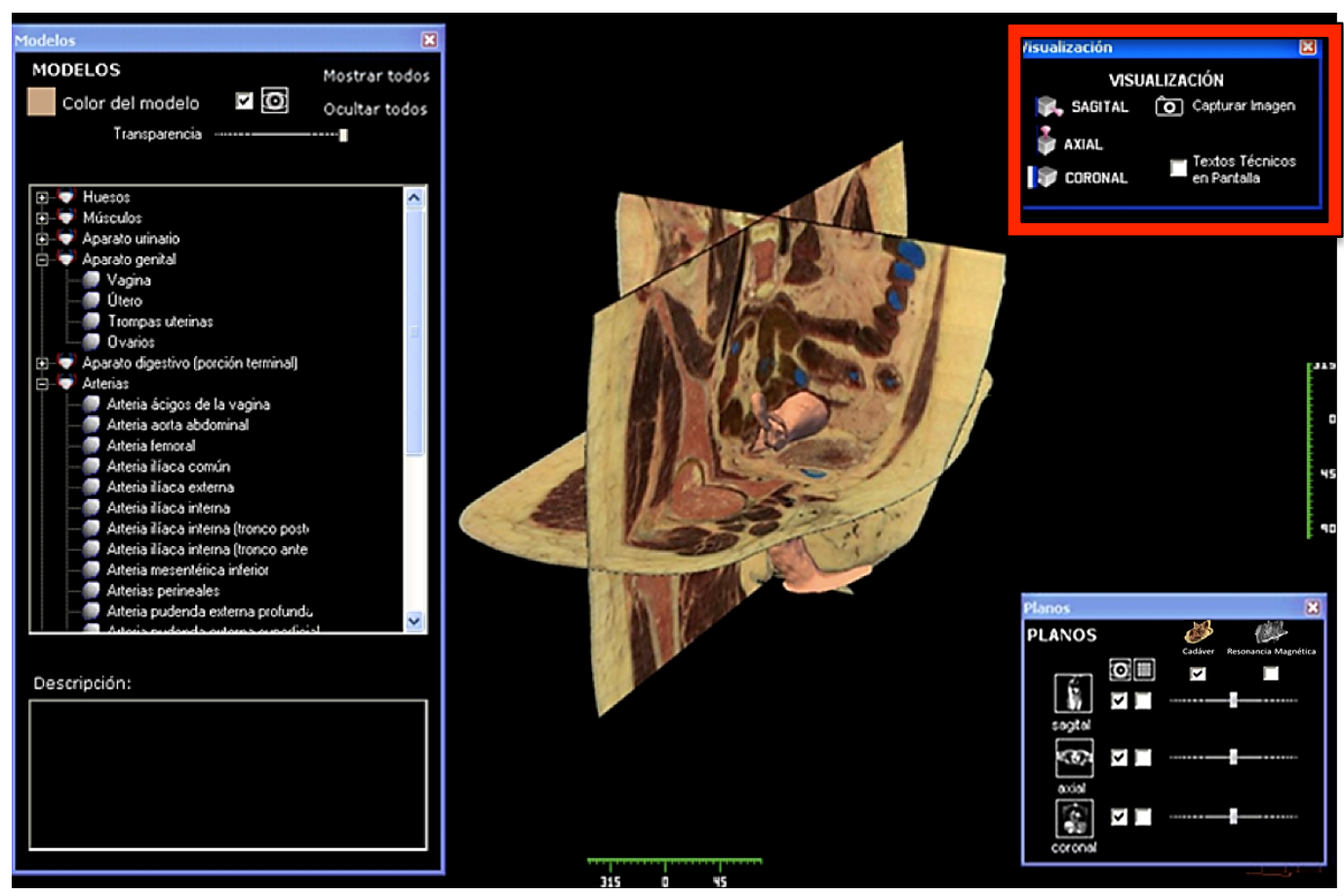

Figura 162. En esta imagen reflejamos el menú de visualización en la parte superior derecha, remarcado con un cuadro rojo, como aparece en el visor anatómico.

\section{3.c. - Control de planos:}

La sección "Planos", contiene los controles necesarios para manejar las secciones de RM y de cadáver de la pelvis femenina presentadas en el visor (Figs. 163 y 164). En la parte superior derecha de la ventana de control de planos, vemos dos casillas en las que podemos seleccionar que imágenes queremos utilizar, de cadáver o de RM.

Existen tres planos de orientación: axial (horizontal), sagital (lateral) y coronal (frontal). Cada plano, al activar su visualización, posee una barra de desplazamiento que permite cambiar la altura del corte en el plano concreto que estamos manipulando y un control de selección para activar o desactivar su visibilidad. 
También se puede cambiar la posición del plano seleccionado moviendo el cursor horizontalmente sobre el visor mientras se pulsa Mayúsculas, sin mantener pulsado ningún botón del ratón. El último plano desplazado aparece enmarcado en el color azul.

El icono que simula una cuadrícula permite la aparición de cuadros de 1-10 mm (el tamaño depende del que el usuario desee aplicar), para poder medir estructuras, puesto que los modelos 3D están realizados a escala, como podemos visualizar en el ejemplo de las figuras 165 y 166.

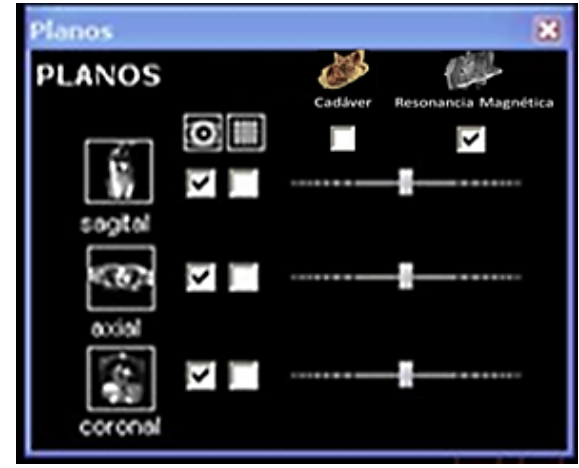

Figuras 163. Control de planos.

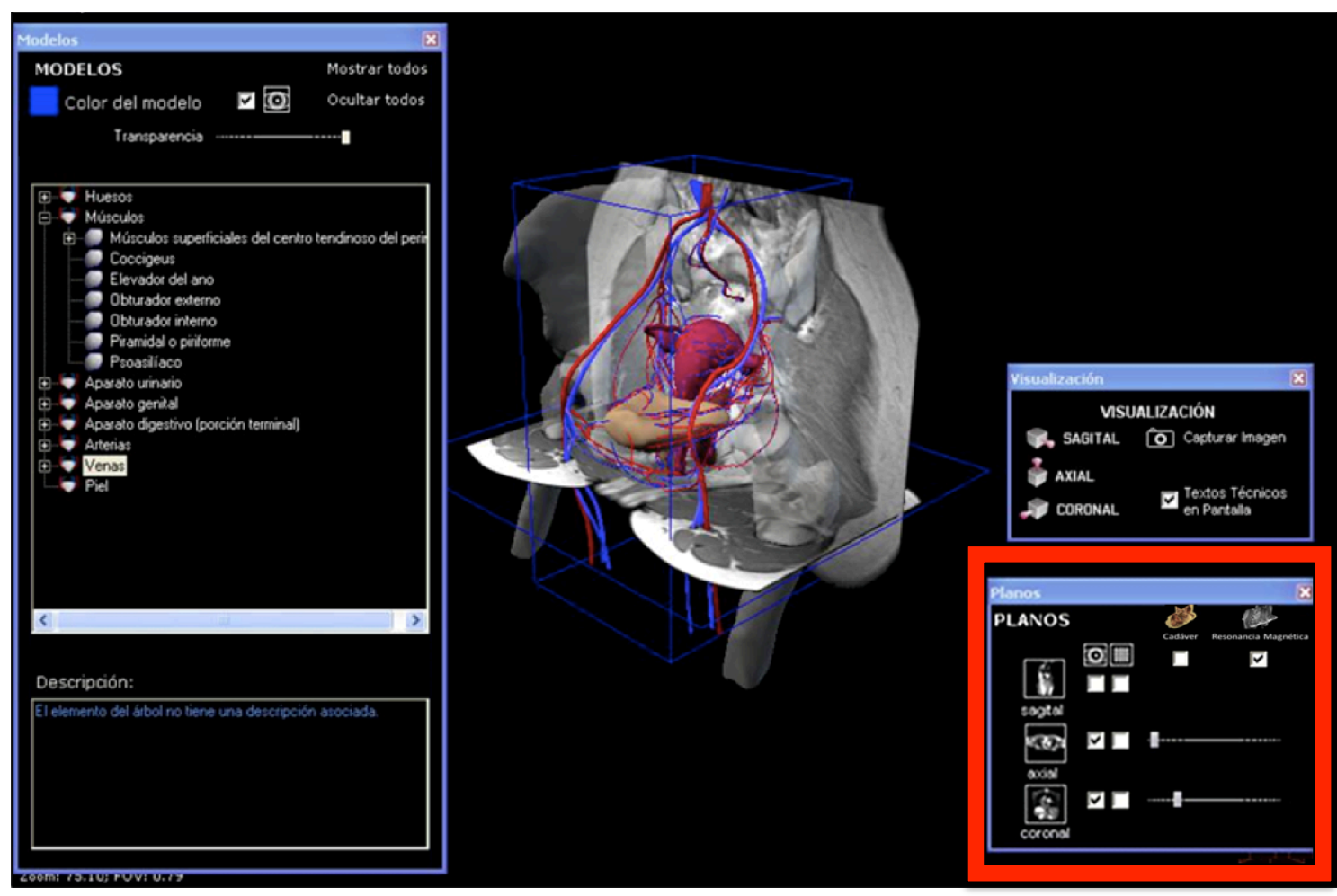

Figura 164. Esta imagen es un ejemplo de cómo nuestra interfaz puede ser modificada a gusto del usuario: hemos desplazado el menú de visualización a una zona inferior. En un recuadro rojo enmarcamos el control de planos. 

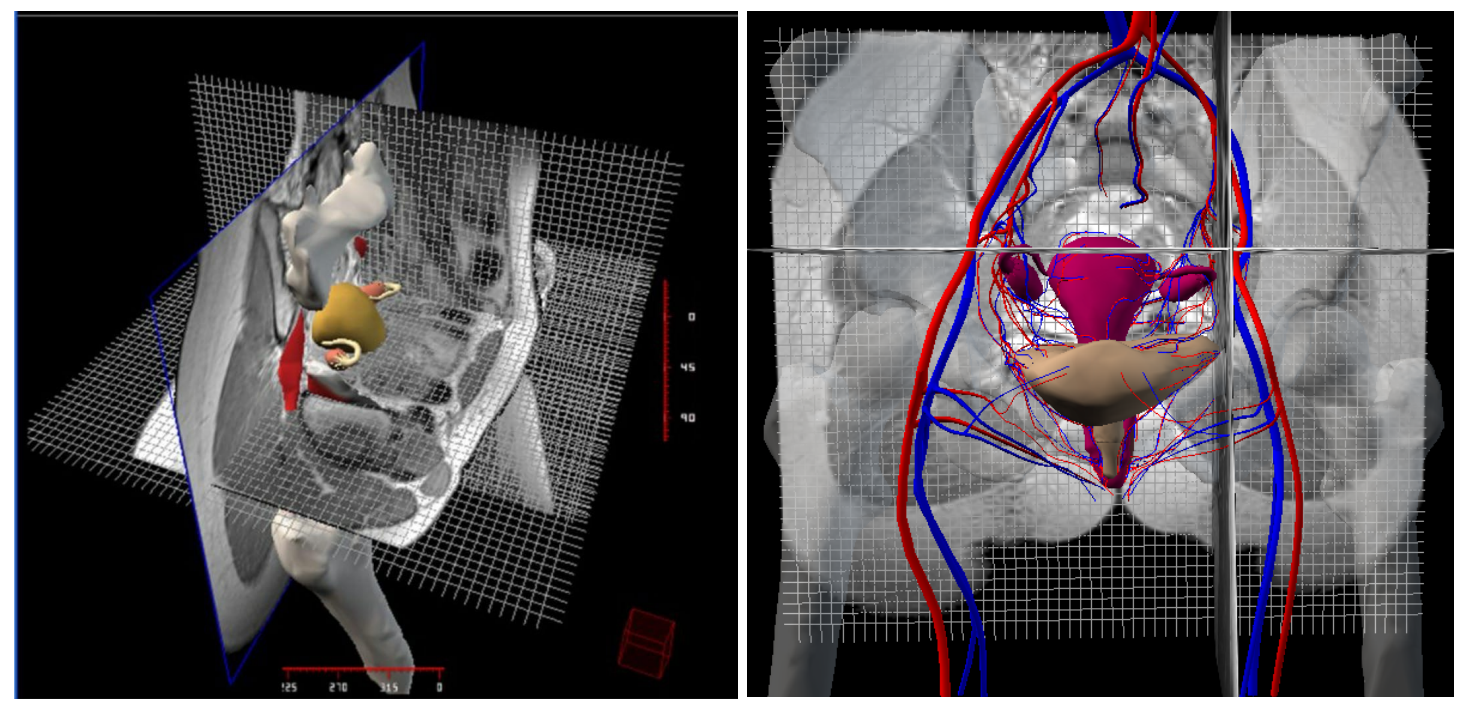

Figura 165 y 166. Representación de la cuadrícula con secciones de RM, sirve para medir estructuras. Es una rejilla que el usuario puede modificar a su gusto, y que va desde un tamaño de uno hasta los diez milímetros.

\section{3.d. - Control de los modelos 3D de las estructuras anatómicas de la pelvis:}

La sección "Modelos" controla las estructuras anatómicas representadas mediante modelos tridimensionales.

Seleccionando sobre el color podremos modificarlo y asignar el que más le guste al usuario.

El cuadro de selección visible permite activar o desactivar la visibilidad del modelo seleccionado, igualmente podemos activar o desactivar la visibilidad del conjunto de modelos 3D.

La barra transversa que aparece junto al rótulo "Transparencia", facilita la visualización del conjunto de estructuras al poder determinar el grado de translucidez (si queremos o no, ver a través de ese modelo 3D).

En la ventana "Árbol" podremos seleccionar/deseleccionar los modelos de forma independiente e ir visualizándolos según la selección, abriendo las distintas ramas para ver las estructuras (modelos 3D) disponibles y su relación jerárquica.

El cuadro de texto inferior muestra una pequeña descripción anatómica de cada estructura seleccionada, siempre que tengamos algún modelo anatómico seleccionado, si no, aparece carente de información (Fig. 167 y 168). 


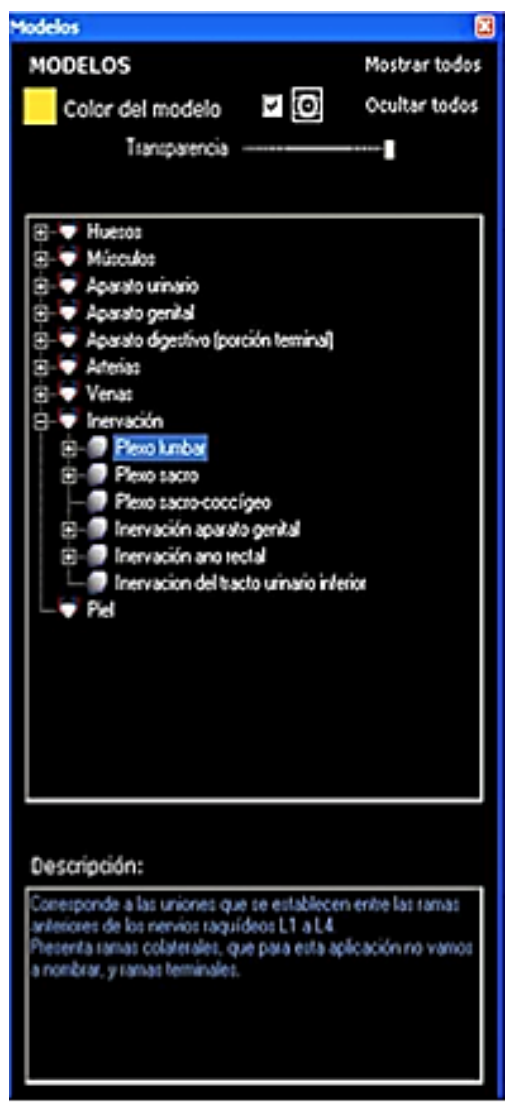

Figura 167. Control de modelos 3D.

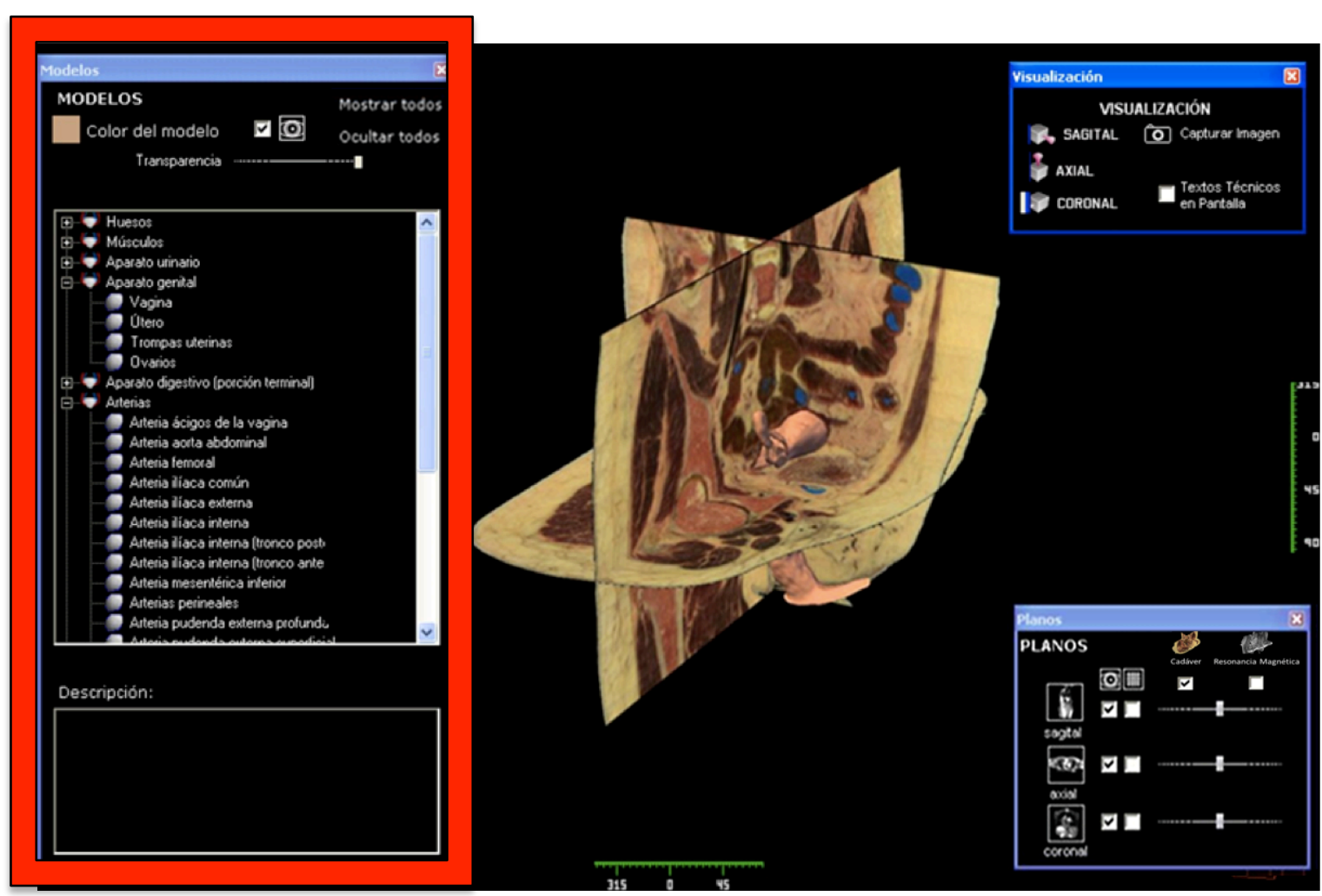

Figura 168. En esta imagen vemos resaltada la zona de control de modelos de la que hemos hablado previamente, con el desplegable sin tener seleccionada ninguna estructura, por lo que el cuadro de descripción está vacío. 
3.e. - Correlación entre imágenes de resonancia magnética e imágenes ecográficas: La aplicación informática se ha diseñado de manera que permita manejar a voluntad todas las opciones que ofrece, lo que se traduce en una auténtica interacción con el programa, evitando que el usuario se convierta en un mero espectador.

Constituye una herramienta docente, rigurosamente cuidada y elaborada, que pretende facilitar el conocimiento y comprensión de esta región corporal, al posibilitar el análisis de las estructuras anatómicas que la componen en tres dimensiones y desde cualquier posición espacial.

Ante la necesidad de correlacionar las imágenes de RM con las obtenidas mediante ecografía, desarrollamos otra aplicación que permitió la integración de la información anatómica proporcionada por ambos estudios de imagen, como complemento a nuestro desarrollo tecnológico, ya que una de las aplicaciones más importantes de la ecografía es la valoración de la pelvis femenina y del suelo pélvico, lo que también pusimos de manifiesto en nuestro artículo "Computer Application of Ultrasound and Nuclear Magnetic Resonance Images for the Anatomical Learning of the Pelvis and the Female Pelvic Floor" (Asensio et al., 2019).

Este apartado complementario a nuestra aplicación informática dispone de imágenes seccionales seriadas de RM y de diferentes imágenes de ultrasonidos obtenidas mediante distintos modos ecográficos. Los abordajes para la obtención de las imágenes ecográficas fueron transperineal/transintroital, endovaginal y endoanal, realizados mediante la utilización de varias sondas (convexa convencional 2D, endovaginal convencional 2D, multifrecuencia 3D/4D, electrónica biplanar 3D, mecánica rotacional $360^{\circ} 3 \mathrm{D}$ ) y con la paciente en diferentes estados (en reposo, Valsalva y contracción); las imágenes se adquirieron en los 3 planos del espacio (axial, sagital y coronal) como aparece representado en la figura 169. 


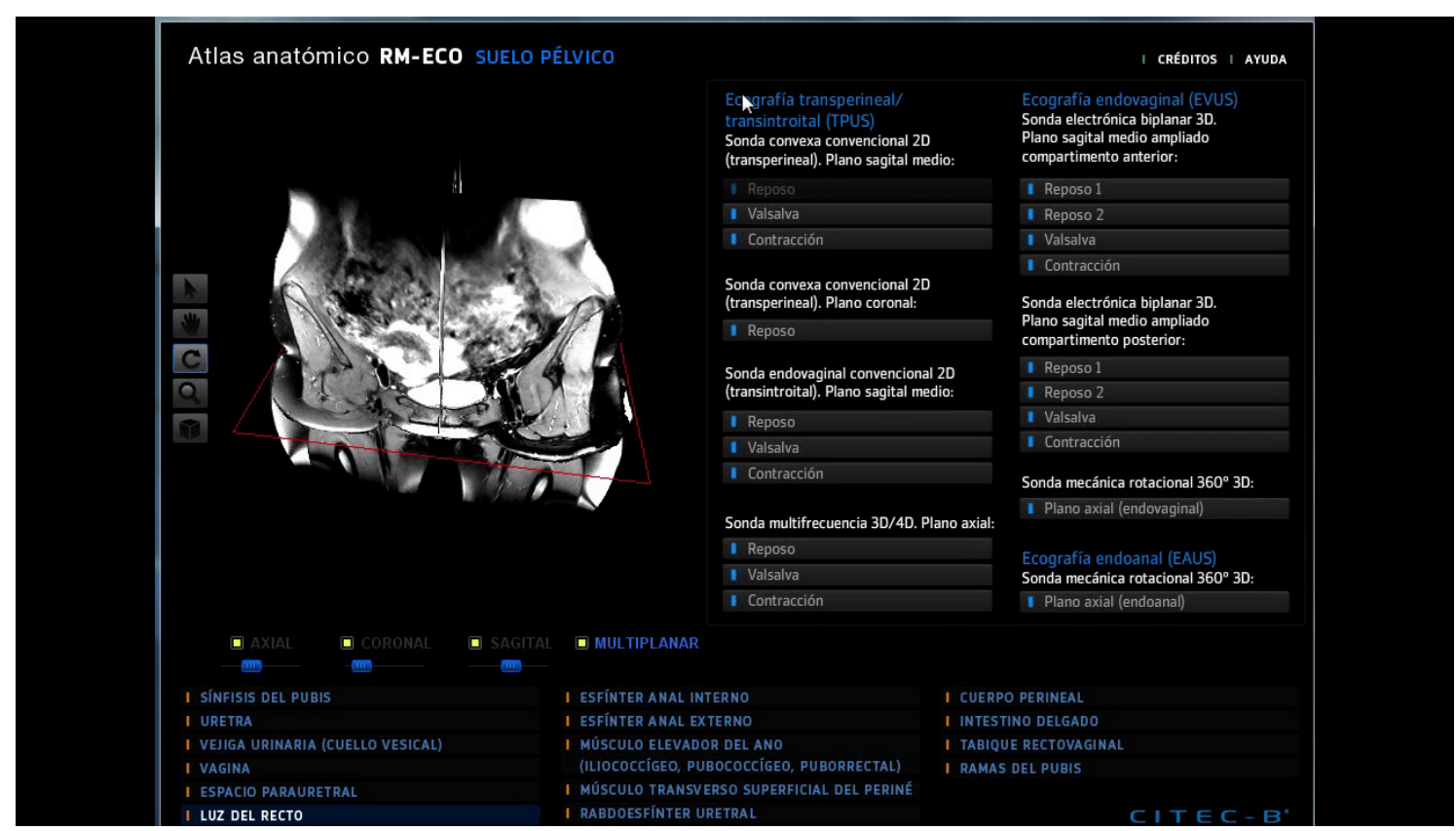

Figura 169. Pantalla del visor anatomo-radiológico del suelo pélvico en el lado izquierdo con una imagen de RM y una lista de las principales estructuras anatómicas en el área inferior; en el lado derecho se muestran las opciones de valoración ecográfica.

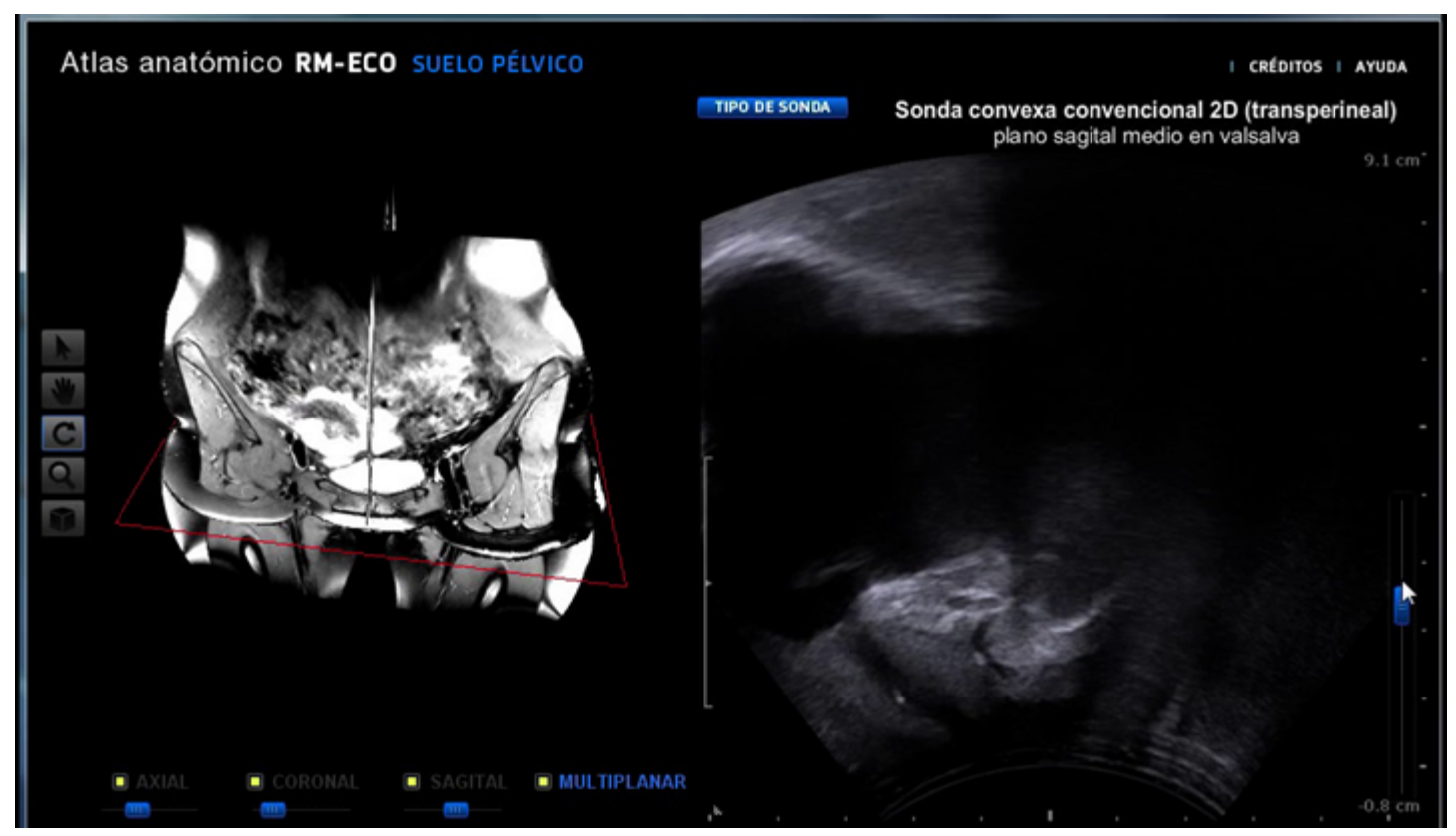

Figura 170. Imágenes de RM y ultrasonido permitiendo su valoración simultánea.

En la figura 170 se puede visualizar una sección de RM y una imagen ecográfica estática en el lado derecho. Puesto que la ecografía es una prueba dinámica, con la barra de la derecha, al desplazarse sobre ella, nos posibilita la visualización de unos segundos de movimiento, simulando la realidad de esta técnica de imagen. 


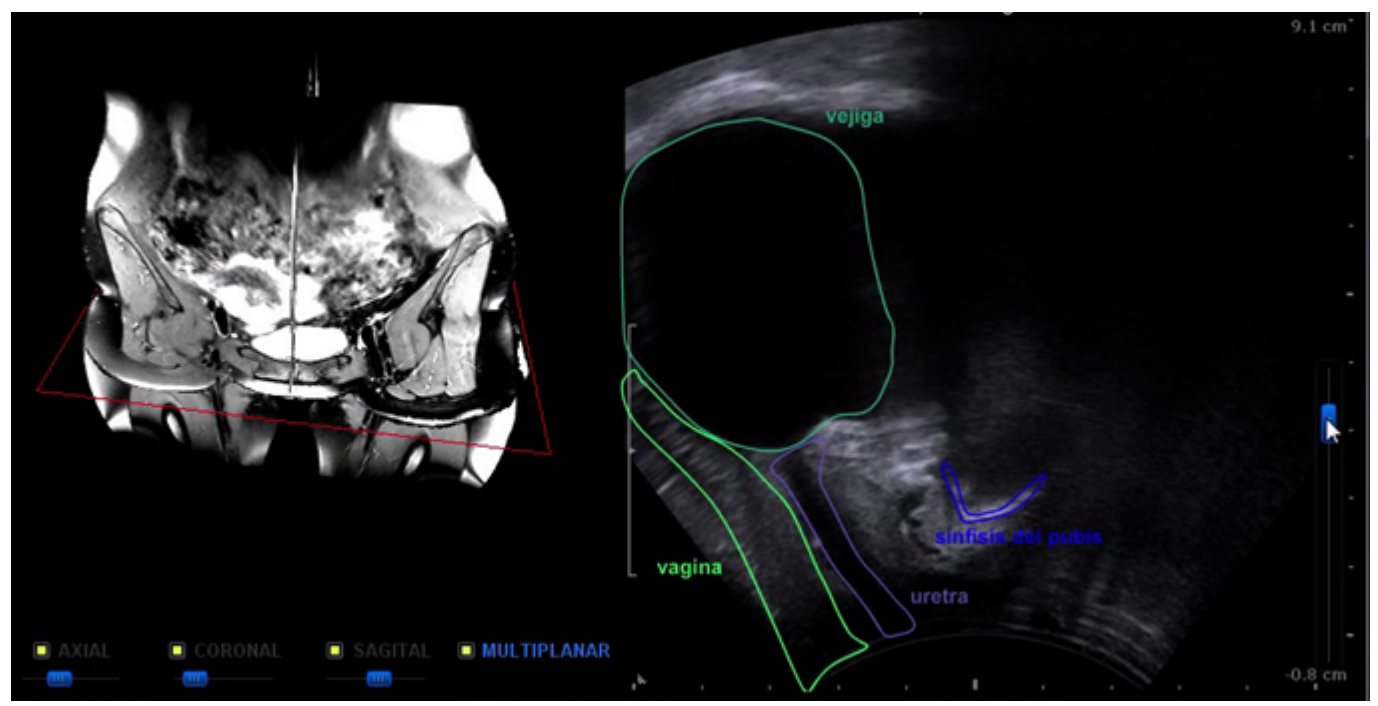

Figura 171. Imagen ecográfica con la identificación de las diferentes estructuras que aparecen en la ecografía, mediante la delimitación con color de cada estructura.
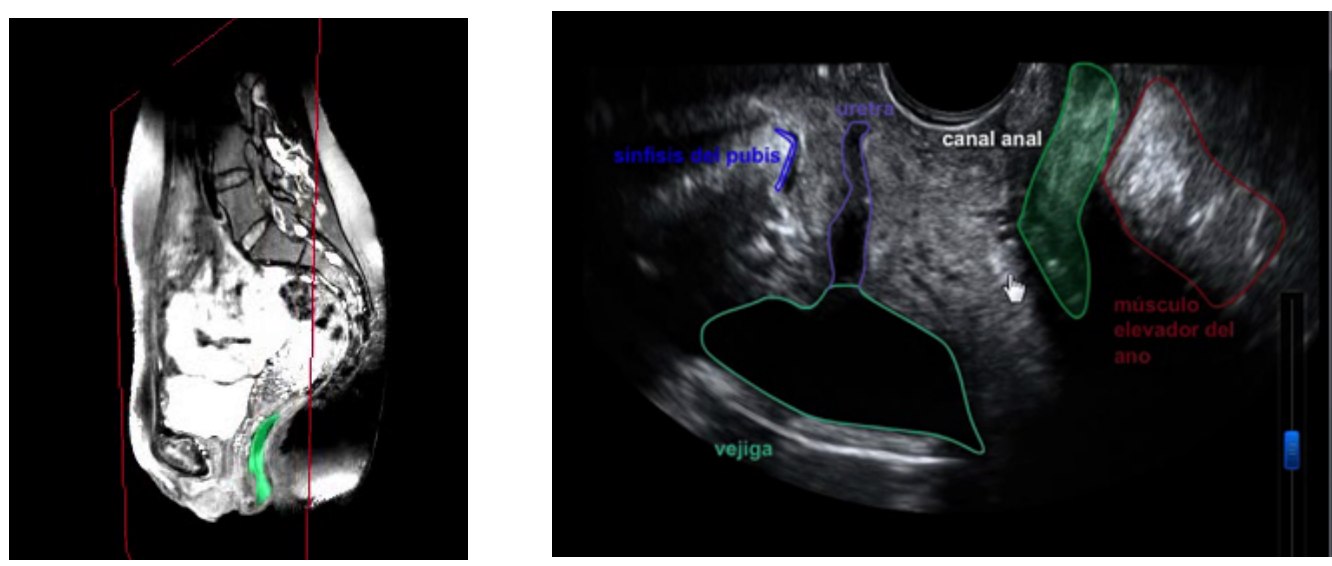

Figura 172 y 173. En la imagen de RM de la izquierda, captura de pantalla del visor anatomoradiológico que muestra en verde la luz rectal. A la derecha, imagen ecográfica con la identificación del canal anal y que, cuando situamos el cursor sobre dicha estructura o la seleccionamos, aparece coloreada en toda su extensión.

Las figuras 171-173, ejemplifican como podemos observar las estructuras anatómicas delimitadas y diferenciadas con distintos colores. Al pasar el cursor por una o seleccionarla con el ratón, como vemos en la figura 173 se rellena del mismo color que aparece en la imagen de RM, figura 172, facilitando así su identificación en ambas imágenes.

A continuación, exponemos algún ejemplo más de esta aplicación (Figs. 174-177). 


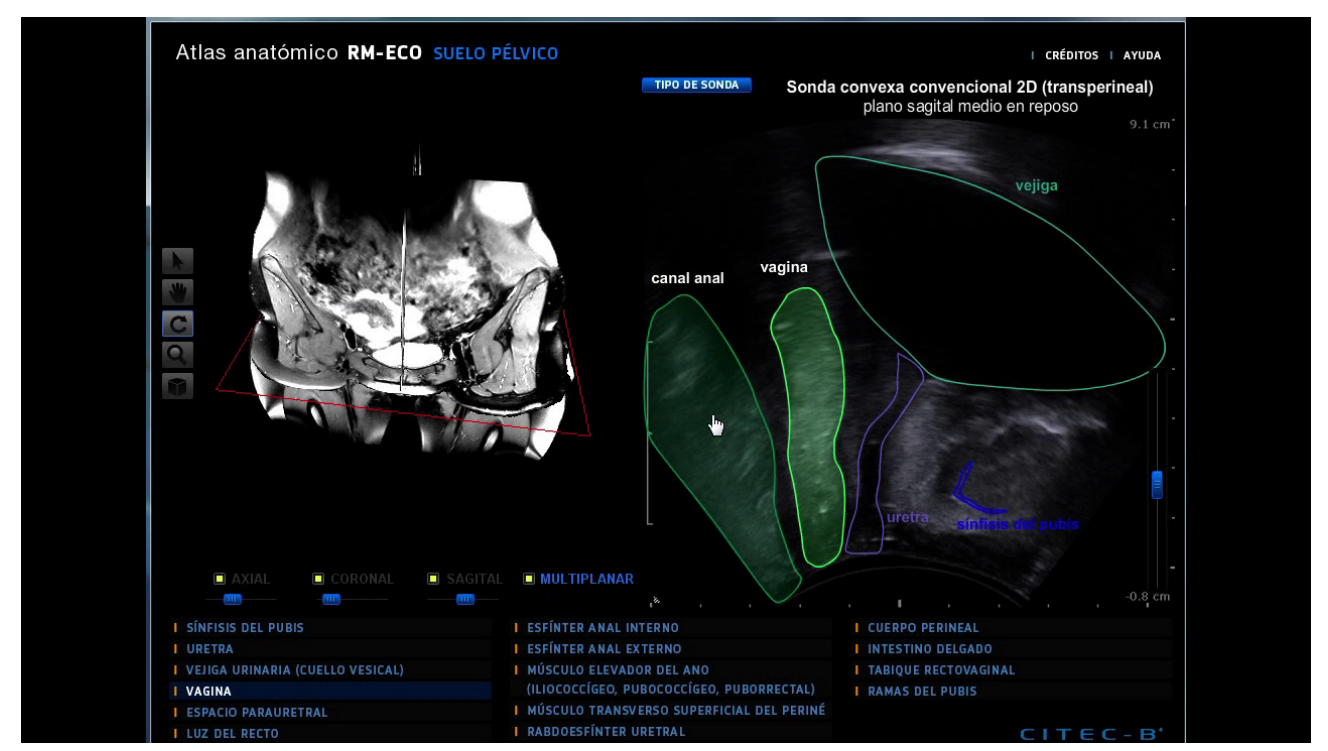

Figura 174. En esta ecografía podemos ver delimitadas la vejiga, la uretra, la sínfisis del pubis, la vagina y el canal anal.

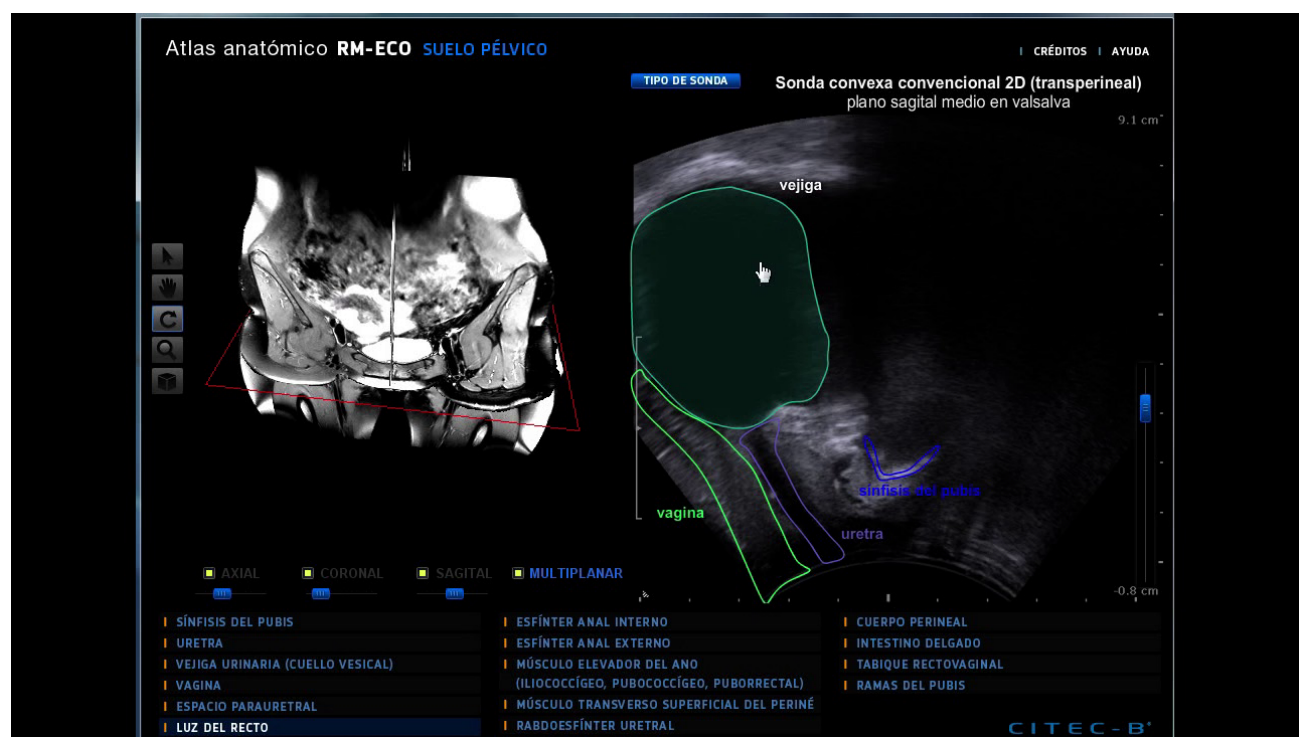

Figura 175. Esta es otra imagen ecográfica en las que visualizamos las mismas estructuras, pero más centrada en el compartimento anterior, sin visualizar por tanto la parte posterior (canal anal). 


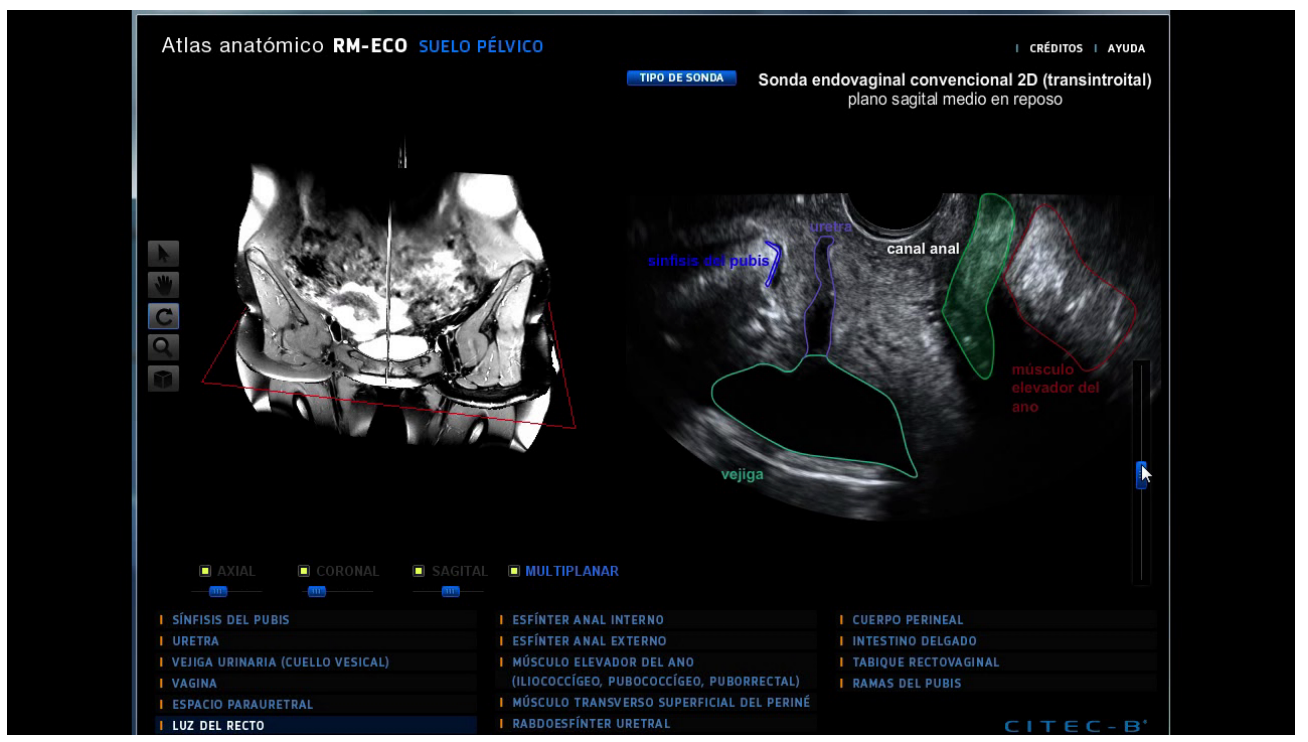

Figura 176. Ecografía realizada mediante otra colocación de la sonda, en este caso es trasintroital (apoyada en el introito, sin sobrepasarlo).

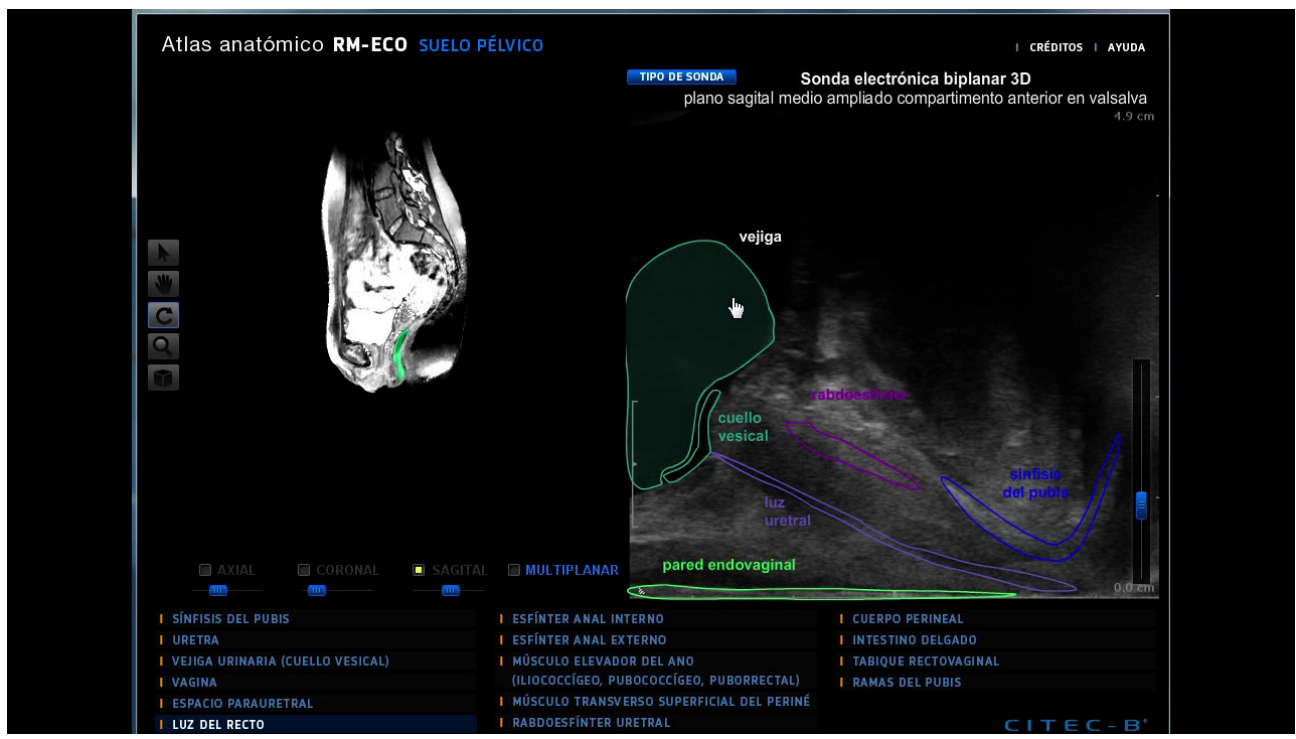

Figura 177. A la derecha, ecografía centrada en la vejiga, uretra y vagina, es un corte sagital medio, en el lado izquierdo, una sección sagital de RM. 


\section{4. - Encuesta de valoración de los usuarios.}

Realizamos dos encuestas diferentes a los estudiantes una, más centrada en nuestra aplicación y su valoración tras hacer uso de ella, y otra más genérica sobre el uso de la tecnología en la actualidad, que vamos a comentar a continuación.

En el marco de la utilización de dispositivos tecnológicos por la población estudiantil podemos reflejar las siguientes consideraciones extraídas de la encuesta practicada.

Todos los datos recogidos en la primera encuesta se detallan de forma individual en la tabla siguiente. Los ítems han sido descritos previamente en el apartado de material y métodos:

\begin{tabular}{|c|c|c|c|c|c|c|c|c|c|c|c|c|c|c|c|c|c|}
\hline $\mathbf{N}$ & $\mathrm{A}$ & $\mathrm{B}$ & $\mathrm{C}$ & $\mathrm{D}$ & $\mathrm{E}$ & $\mathrm{F}$ & $\mathrm{G}$ & $\mathrm{H}$ & $\mathrm{I}$ & $\mathrm{J}$ & $\mathrm{K}$ & $\mathrm{L}$ & $\mathrm{M}$ & $\mathrm{N}$ & 0 & $\mathrm{P}$ & $\mathrm{Q}$ \\
\hline $\mathbf{1}$ & 19 & $\mathrm{~F}$ & 2 & 1 & 2 & 1 & 1 & 2 & 3 & 3 & 4 & 3 & 2 & 1 & 2 & 2 & 2 \\
\hline $\mathbf{2}$ & 19 & $\mathrm{~F}$ & 2 & 3 & 2 & 1 & 1 & 1 & 3 & 2 & 4 & 3 & 3 & 1 & 2 & 2 & 2 \\
\hline $\mathbf{3}$ & 20 & $\mathrm{~F}$ & 3 & 1 & 1 & 1 & 1 & 2 & 4 & 3 & 4 & 2 & 4 & 1 & 2 & 2 & 3 \\
\hline $\mathbf{4}$ & 19 & $\mathrm{~F}$ & 3 & 3 & 3 & 1 & 1 & 2 & 4 & 1 & 4 & 3 & 2 & 1 & 2 & 2 & 3 \\
\hline $\mathbf{5}$ & 19 & $\mathrm{~F}$ & 3 & 1 & 3 & 1 & 1 & 2 & 4 & 2 & 3 & 3 & 2 & 1 & 2 & 2 & 2 \\
\hline $\mathbf{6}$ & 21 & $\mathrm{M}$ & 3 & 1 & 3 & 1 & 1 & 2 & 4 & 3 & 4 & 2 & 3 & 1 & 1 & 1 & 2 \\
\hline $\mathbf{7}$ & 19 & $\mathrm{M}$ & 3 & 3 & 4 & 1 & 1 & 1 & 4 & 3 & 4 & 2 & 3 & 1 & 2 & 2 & 2 \\
\hline $\mathbf{8}$ & 19 & $\mathrm{~F}$ & 3 & 1 & 1 & 1 & 1 & 2 & 3 & 2 & 3 & 2 & 3 & 1 & 2 & 2 & 3 \\
\hline $\mathbf{9}$ & 20 & $\mathrm{~F}$ & 3 & 2 & 2 & 1 & 1 & 2 & 4 & 3 & 4 & 4 & 3 & 1 & 1 & 2 & 2 \\
\hline $\mathbf{1 0}$ & 24 & $\mathrm{~F}$ & 3 & 2 & 2 & 1 & 1 & 1 & 4 & 3 & 4 & 3 & 3 & 1 & 2 & 2 & 2 \\
\hline $\mathbf{1 1}$ & 19 & $\mathrm{~F}$ & 2 & 3 & 4 & 1 & 1 & 1 & 3 & 3 & 4 & 2 & 3 & 1 & 1 & 1 & 2 \\
\hline $\mathbf{1 2}$ & 19 & $\mathrm{~F}$ & 2 & 1 & 3 & 1 & 1 & 2 & 2 & 2 & 3 & 3 & 3 & 1 & 2 & 2 & 2 \\
\hline $\mathbf{1 3}$ & 20 & $\mathrm{~F}$ & 3 & 3 & 2 & 1 & 1 & 2 & 3 & 3 & 4 & 3 & 4 & 1 & 2 & 2 & 2 \\
\hline $\mathbf{1 4}$ & 19 & $\mathrm{M}$ & 3 & 1 & 2 & 1 & 1 & 2 & 4 & 1 & 4 & 2 & 3 & 1 & 1 & 2 & 2 \\
\hline $\mathbf{1 5}$ & 20 & $\mathrm{~F}$ & 3 & 3 & 4 & 1 & 1 & 2 & 4 & 1 & 4 & 3 & 3 & 1 & 1 & 1 & 2 \\
\hline $\mathbf{1 6}$ & 22 & $\mathrm{M}$ & 3 & 1 & 4 & 1 & 1 & 2 & 4 & 2 & 3 & 3 & 3 & 1 & 2 & 2 & 3 \\
\hline $\mathbf{1 7}$ & 19 & $\mathrm{~F}$ & 3 & 3 & 2 & 1 & 1 & 1 & 3 & 3 & 3 & 2 & 4 & 1 & 2 & 2 & 2 \\
\hline $\mathbf{1 8}$ & 19 & $\mathrm{~F}$ & 2 & 2 & 2 & 1 & 1 & 1 & 3 & 1 & 4 & 3 & 3 & 1 & 1 & 2 & 2 \\
\hline $\mathbf{1 9}$ & 21 & $\mathrm{~F}$ & 2 & 3 & 3 & 1 & 1 & 2 & 4 & 3 & 4 & 3 & 3 & 1 & 1 & 1 & 2 \\
\hline $\mathbf{2 0}$ & 19 & $\mathrm{~F}$ & 2 & 2 & 3 & 1 & 1 & 2 & 4 & 3 & 4 & 3 & 4 & 1 & 1 & 1 & 2 \\
\hline
\end{tabular}




\begin{tabular}{|l|l|l|l|l|l|l|l|l|l|l|l|l|l|l|l|l|l|}
\hline $\mathbf{2 1}$ & 19 & $\mathrm{~F}$ & 2 & 2 & 3 & 1 & 1 & 1 & 3 & 3 & 3 & 4 & 3 & 1 & 2 & 2 & 2 \\
\hline $\mathbf{2 2}$ & 19 & $\mathrm{M}$ & 2 & 3 & 4 & 1 & 1 & 2 & 4 & 3 & 4 & 3 & 3 & 1 & 2 & 2 & 2 \\
\hline $\mathbf{2 3}$ & 20 & $\mathrm{~F}$ & 3 & 1 & 1 & 1 & 1 & 2 & 4 & 3 & 4 & 4 & 4 & 1 & 1 & 1 & 2 \\
\hline $\mathbf{2 4}$ & 21 & $\mathrm{M}$ & 3 & 3 & 2 & 1 & 1 & 1 & 4 & 1 & 4 & 3 & 4 & 1 & 2 & 2 & 2 \\
\hline $\mathbf{2 5}$ & 19 & $\mathrm{~F}$ & 3 & 3 & 3 & 1 & 1 & 2 & 3 & 3 & 4 & 3 & 3 & 1 & 2 & 2 & 3 \\
\hline $\mathbf{2 6}$ & 19 & $\mathrm{~F}$ & 3 & 2 & 3 & 1 & 1 & 1 & 4 & 3 & 3 & 4 & 3 & 1 & 1 & 2 & 2 \\
\hline $\mathbf{2 7}$ & 23 & $\mathrm{~F}$ & 3 & 1 & 2 & 1 & 1 & 1 & 4 & 1 & 4 & 4 & 3 & 1 & 2 & 2 & 2 \\
\hline $\mathbf{2 8}$ & 19 & $\mathrm{M}$ & 2 & 2 & 5 & 1 & 1 & 2 & 4 & 3 & 4 & 3 & 3 & 1 & 1 & 1 & 2 \\
\hline $\mathbf{2 8}$ & 19 & $\mathrm{~F}$ & 3 & 3 & 2 & 1 & 1 & 2 & 4 & 3 & 4 & 3 & 3 & 1 & 2 & 2 & 2 \\
\hline $\mathbf{3 0}$ & 20 & $\mathrm{~F}$ & 3 & 3 & 3 & 1 & 1 & 2 & 4 & 1 & 4 & 2 & 3 & 1 & 2 & 2 & 3 \\
\hline $\mathbf{3 1}$ & 20 & $\mathrm{~F}$ & 3 & 1 & 3 & 1 & 1 & 2 & 3 & 1 & 3 & 3 & 3 & 1 & 2 & 2 & 2 \\
\hline $\mathbf{3 2}$ & 19 & $\mathrm{M}$ & 3 & 3 & 2 & 1 & 1 & 1 & 4 & 1 & 4 & 3 & 3 & 1 & 1 & 2 & 2 \\
\hline $\mathbf{3 3}$ & 19 & $\mathrm{~F}$ & 3 & 3 & 2 & 1 & 1 & 2 & 4 & 3 & 4 & 3 & 3 & 1 & 1 & 2 & 2 \\
\hline $\mathbf{3 4}$ & 20 & $\mathrm{~F}$ & 2 & 2 & 2 & 1 & 1 & 2 & 4 & 2 & 4 & 3 & 4 & 1 & 2 & 2 & 2 \\
\hline $\mathbf{3 5}$ & 19 & $\mathrm{~F}$ & 3 & 1 & 3 & 1 & 1 & 2 & 3 & 3 & 4 & 2 & 3 & 1 & 2 & 2 & 2 \\
\hline
\end{tabular}

Ya no llama la atención que el mayor porcentaje de estudiantes en cualquiera de las titulaciones de ciencias de la salud sean del sexo femenino. En las encuestas practicadas a un grupo de alumnos voluntarios, el resultado es del $77 \%$ mujeres y el 23\% varones (Gráfica 1 ).

\section{Sexo}

\section{M \\ $23 \%$}

F

$77 \%$

Gráfica 1 
La edad media de los alumnos encuestados fue entre 18 y 19 años (Gráfica 2).

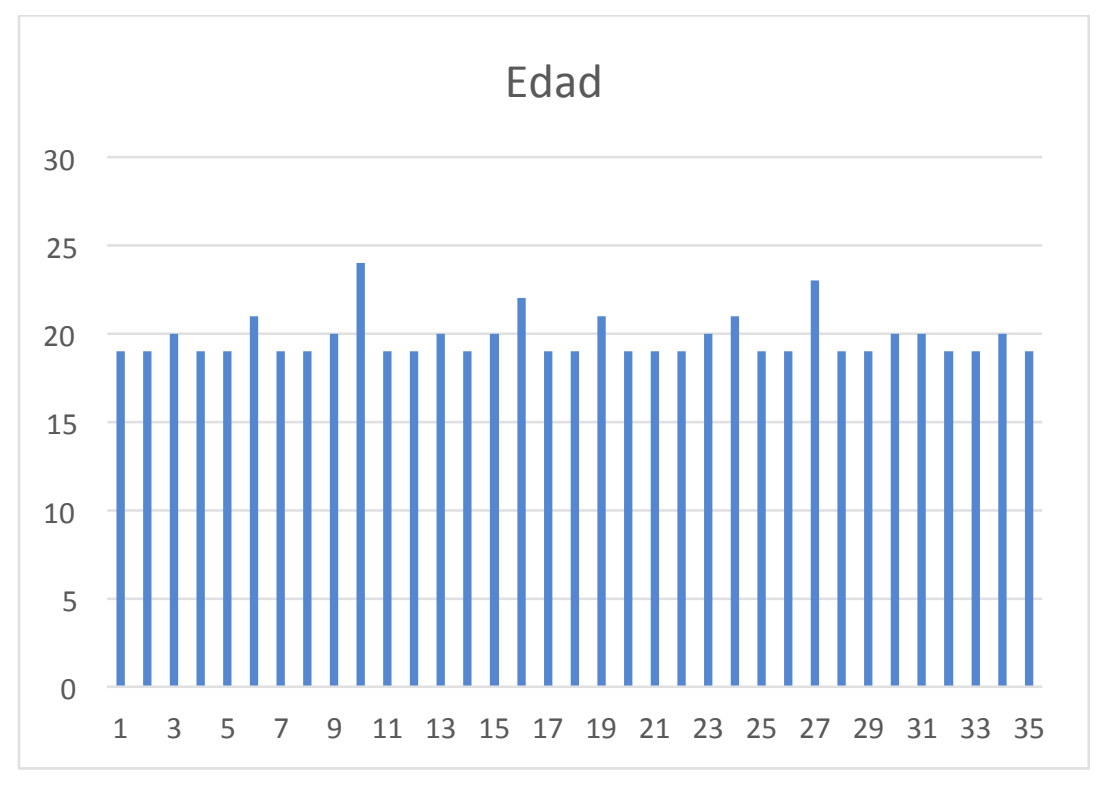

Gráfica 2

En relación al sistema operativo más utilizado en sus dispositivos móviles Android fue el más destacado, seguido de iOs (Gráfica 3); siendo las marcas de teléfono móvil más extendidas Samsung, Huawei y Xiaomi (Gráfica 4).

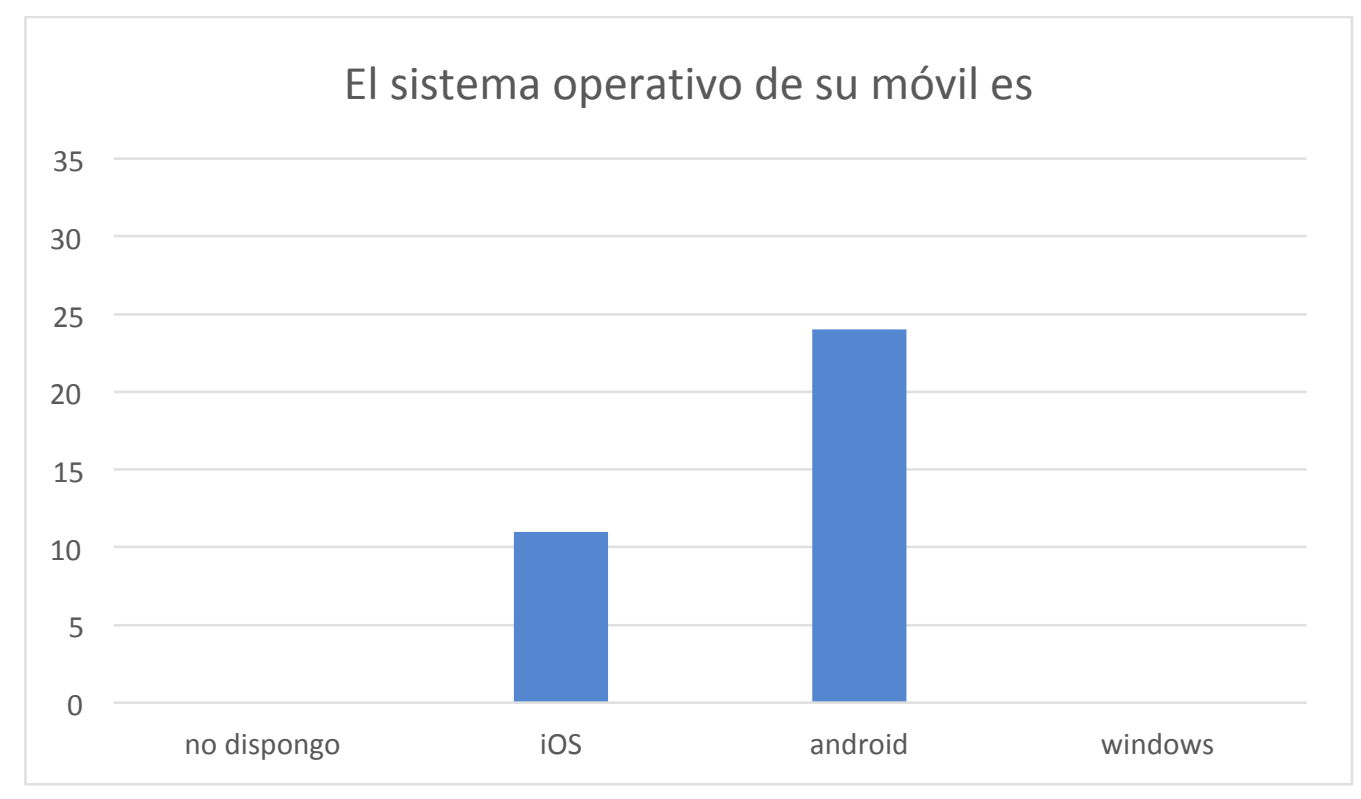

Gráfica 3 


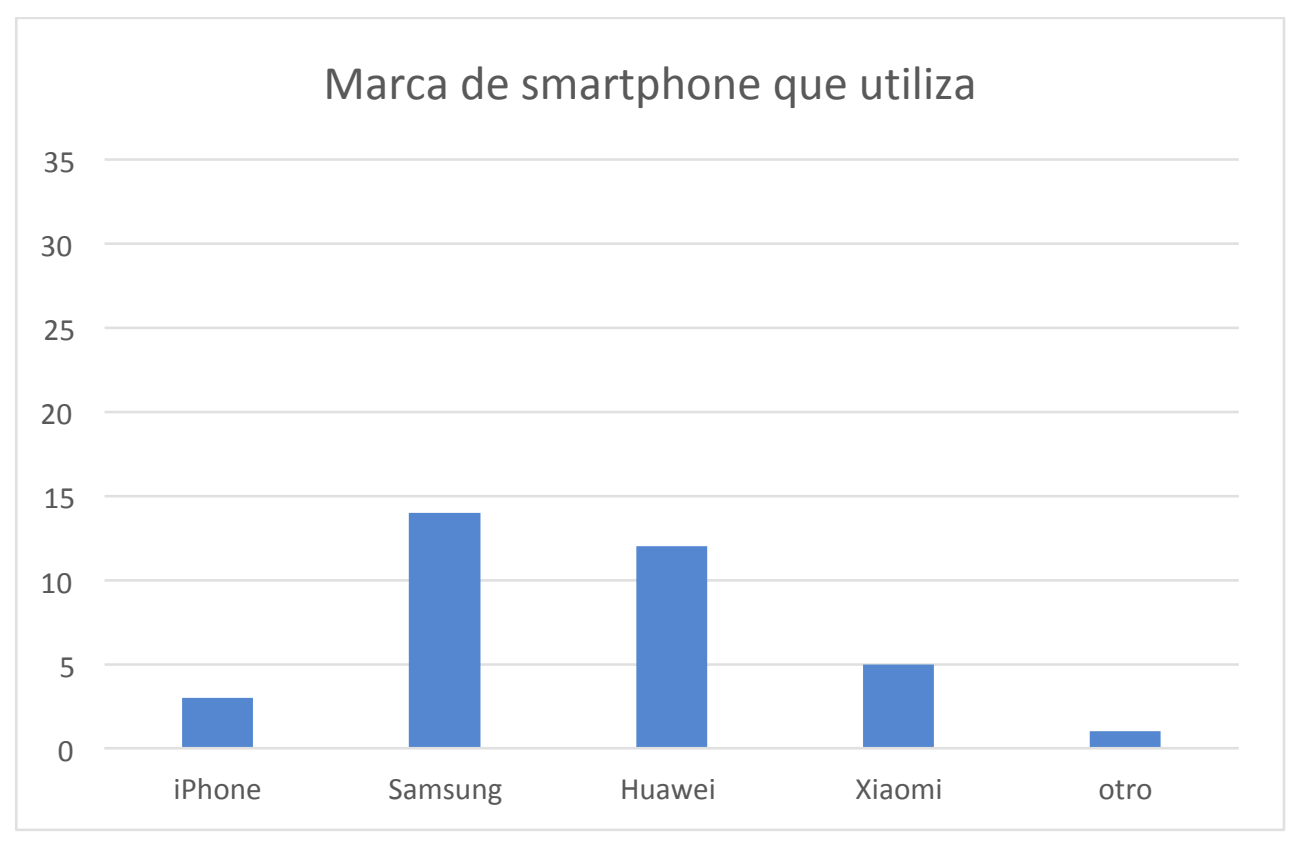

Gráfica 4

Si bien todos los alumnos disponen de un smartphone con tecnología Touch y 4G, sin embargo, no todos disponen de una Tablet; y de los que la poseen, destacan las del sistema operativo Android. (Gráfica 5).

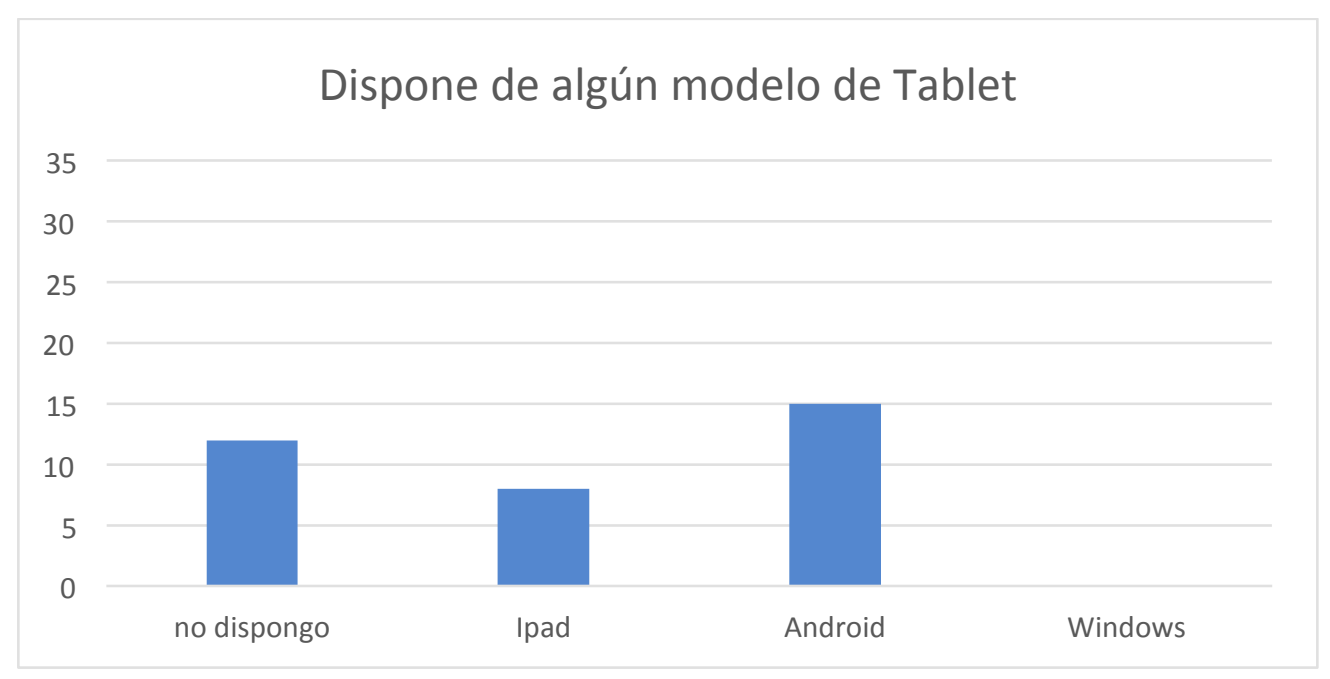

Gráfica 5

El uso fundamental del teléfono móvil es para llamadas personales y las redes sociales, y no es muy frecuente su utilización en el ámbito docente, aunque si es consultado de forma ocasional (Gráfica 6). 


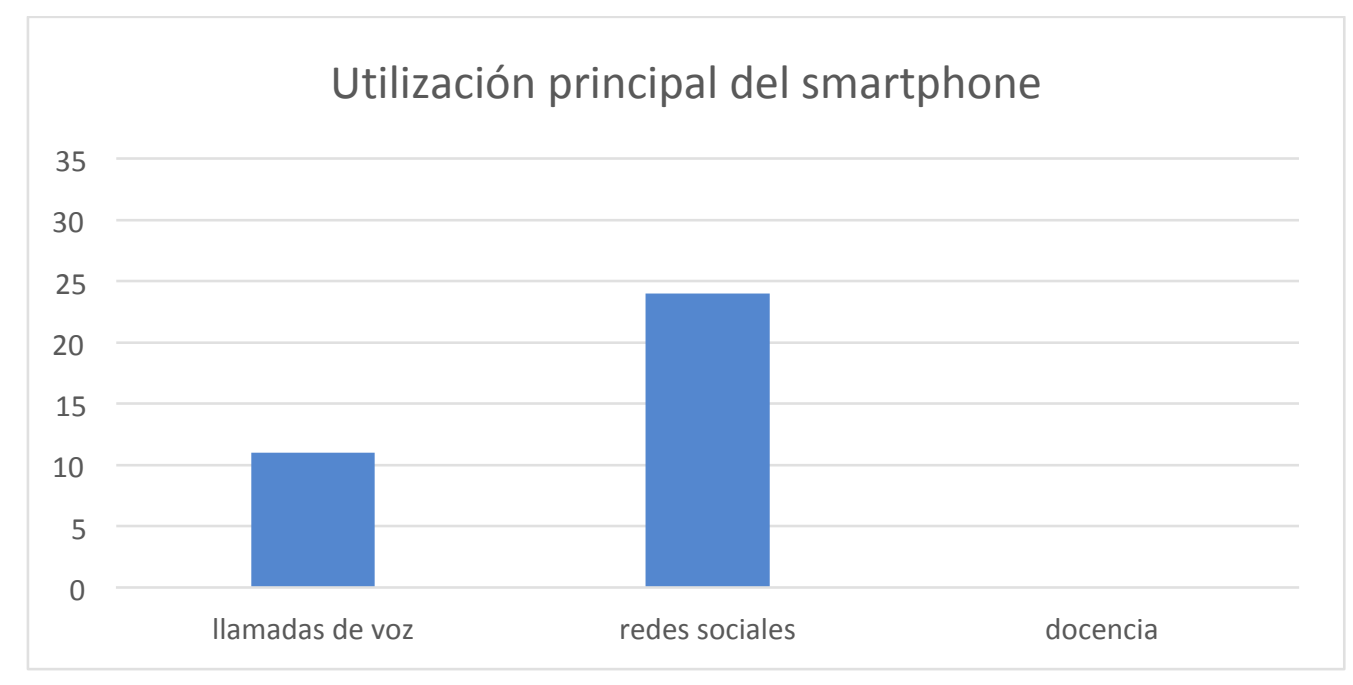

Gráfica 6

Destaca de manera muy significativa el tiempo dedicado a la utilización del dispositivo portable, llegando a las tres horas diarias para algunos, y superando las cinco horas al día para una gran mayoría (Gráfica 7). Esto indica la gran dependencia de estos dispositivos tecnológicos existente en la población joven. Además, la mayor proporción de este tiempo empleado es utilizado para el entretenimiento seguido, ya a distancia, del manejo de información y de la lectura de noticias (Gráfica 8).

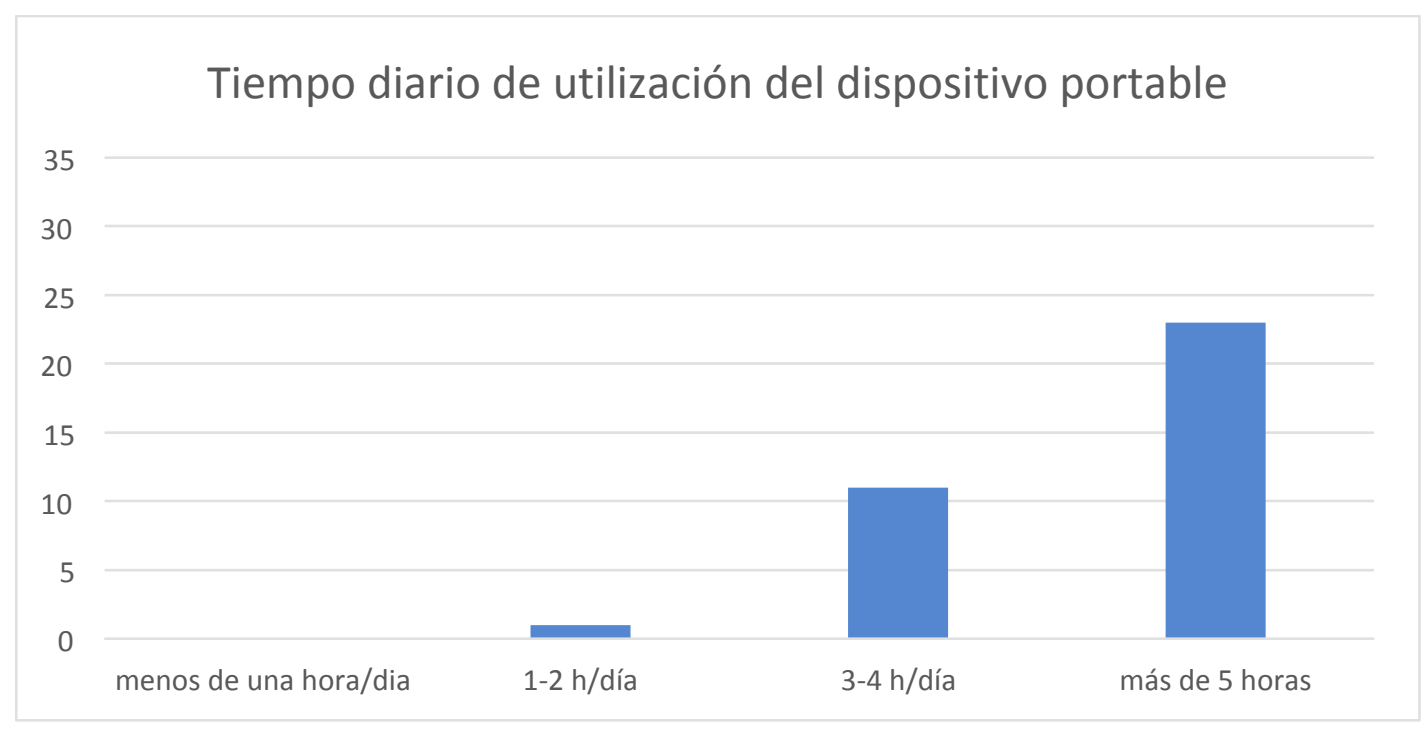

Gráfica 7 


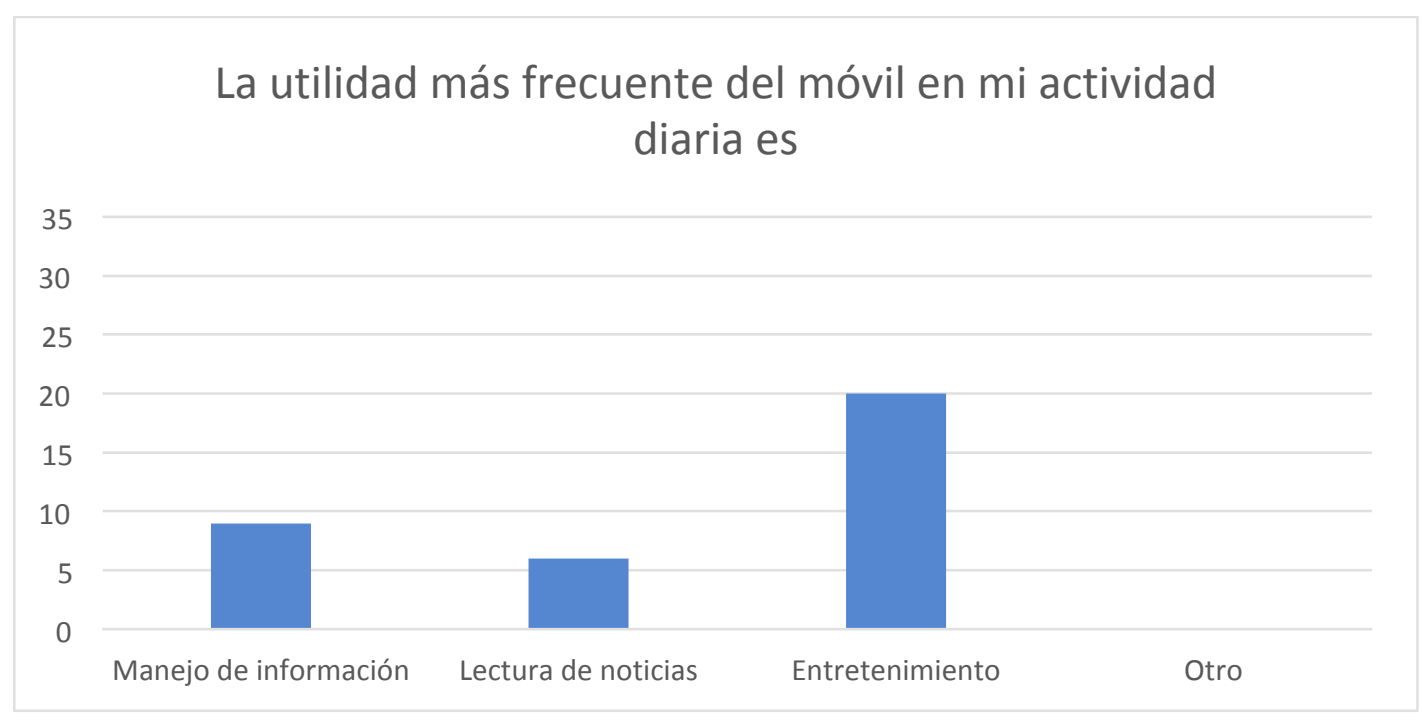

Gráfica 8

La mayoría de ellos tienen una buena destreza en la instalación o desinstalación de diferentes aplicaciones para estos dispositivos. Sin embargo, la utilización de estas aplicaciones (App) para su formación académica solamente es utilizada de forma esporádica, como se refleja en la Gráfica 9. Solo un grupo reducido las utiliza de forma frecuente, y algunos otros casi ninguna vez.

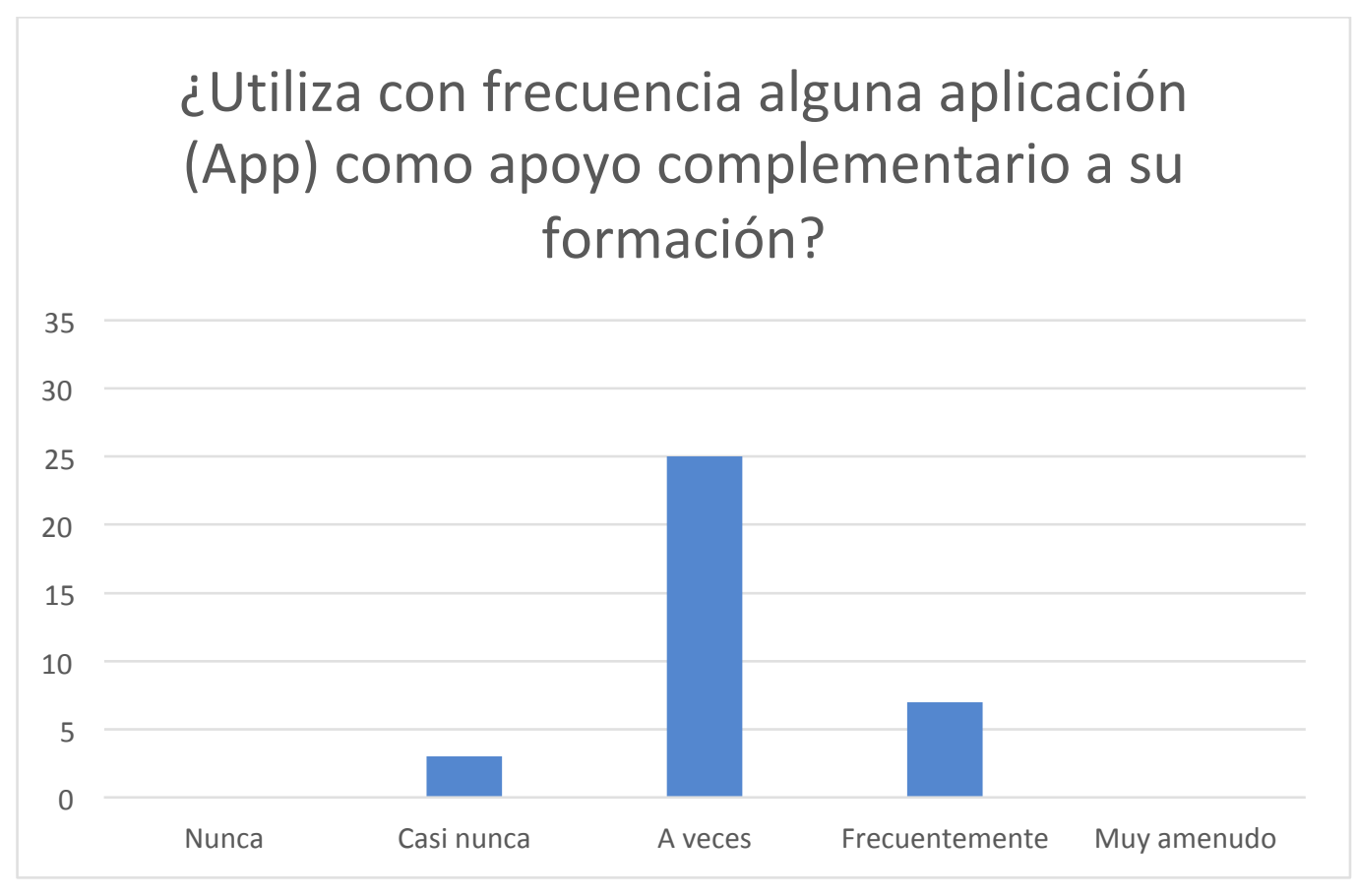

Gráfica 9 
En todos los casos hay unanimidad en que la utilización de recursos de carácter multimedia (texto, imágenes, videos...), facilita un mejor entendimiento y conocimiento de los temas consultados (Gráfica 10).

Implementa su conocimiento con formatos multimedia

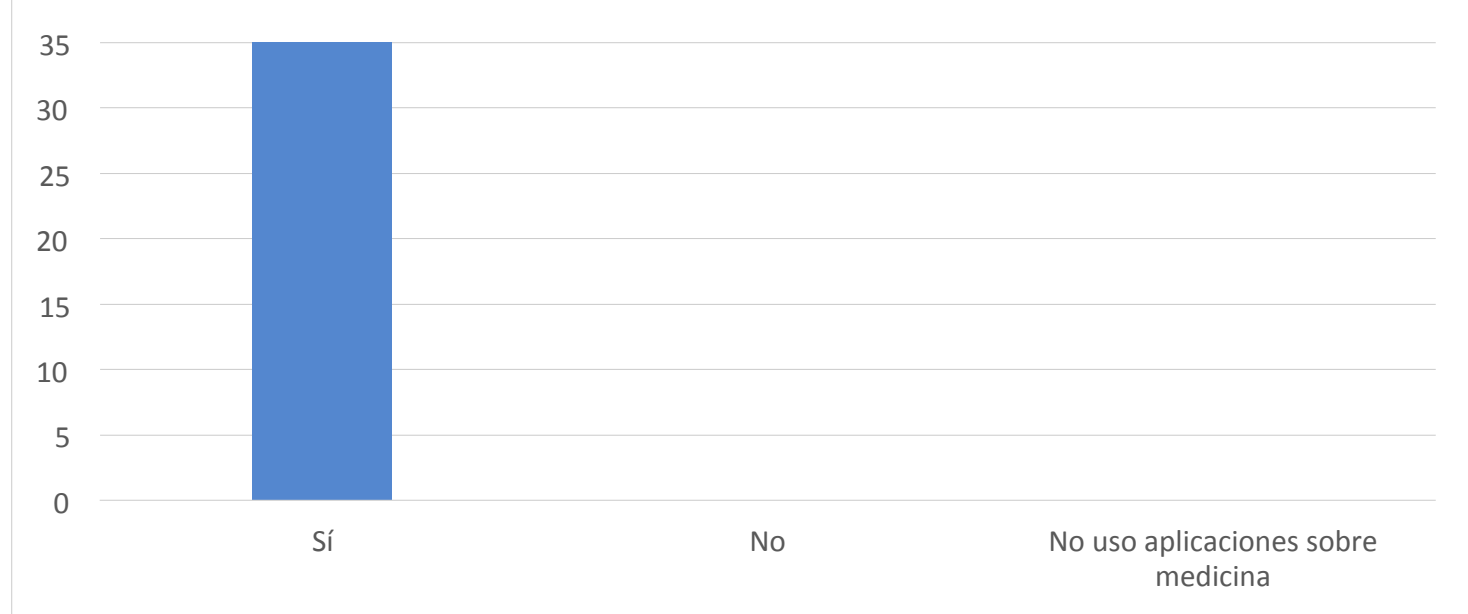

Gráfica 10

En relación con el conocimiento y experimentación con técnicas de visión estereoscópica de realidad virtual, hay un predominio (63\%) de los que no han utilizado estas tecnologías como se recoge en la Gráfica 11.

\section{HA EXPERIMENTADO ALGUNA VEZ UN SIMULADOR DE REALIDAD VIRTUAL}

- Sí No No sé que es

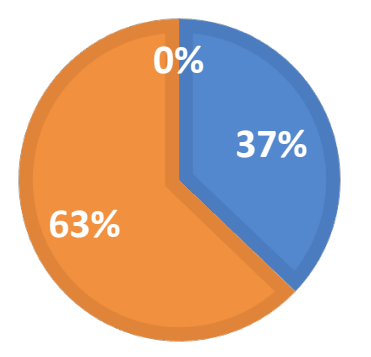

Gráfica 11 
La poca experimentación con estos dispositivos tecnológicos lo refleja también la escasez de alumnos que disponen de unas gafas de realidad virtual (Gráfica 12), tan solo un $20 \%$ de ellos.

\section{¿DISPONE DE ALGUNA GAFA DE REALIDAD VIRTUAL?}

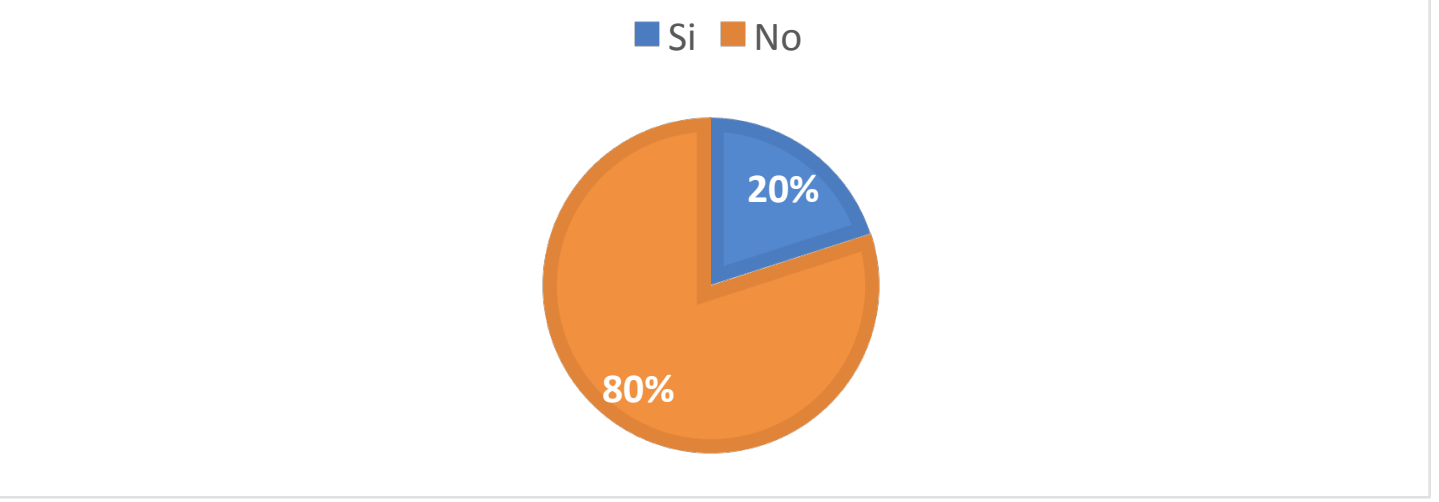

Gráfica 12

Sin embargo, a pesar de la escasa utilización y manejo de estos procedimientos tecnológicos de realidad virtual, la gran mayoría consideran que puede ser un buen recurso docente si se aplica adecuadamente (Gráfica 13).

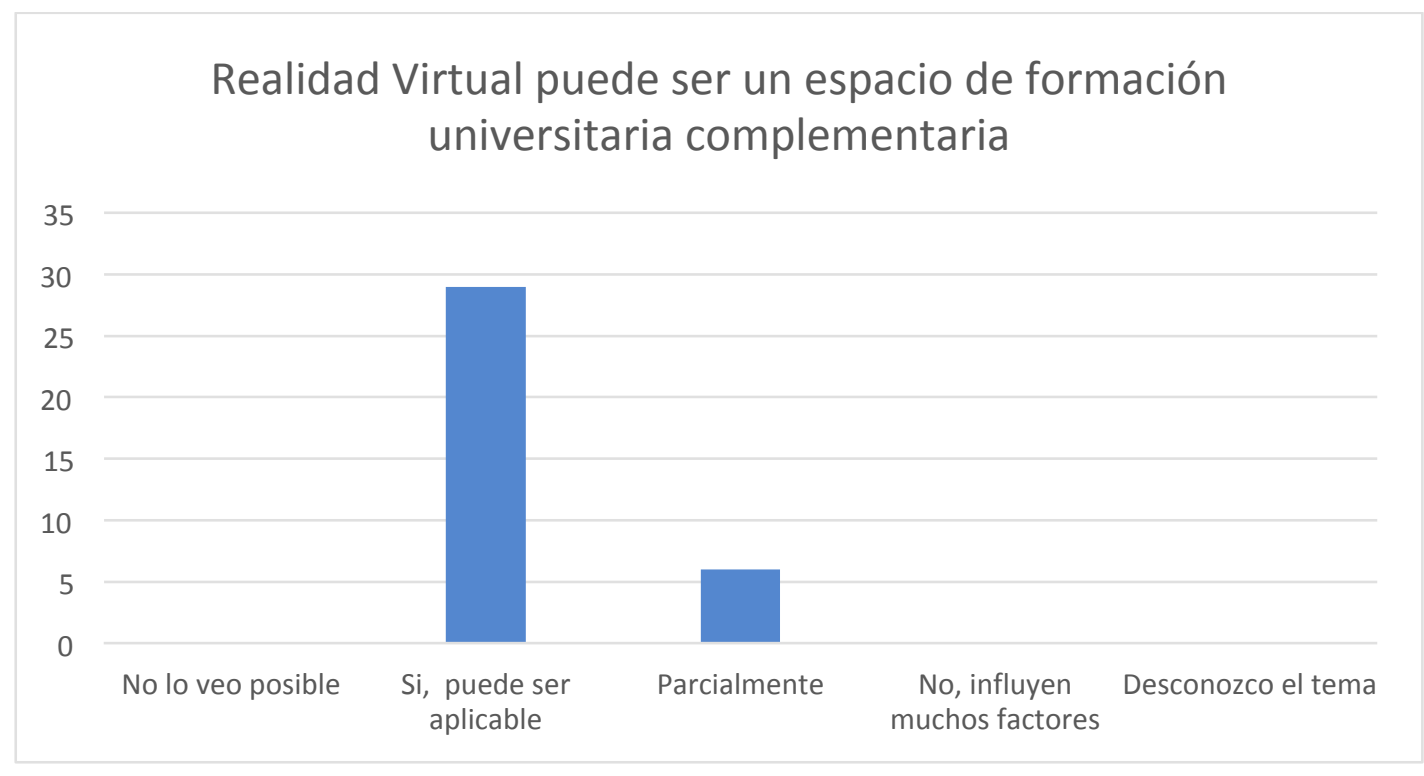

Gráfica 13 
Los resultados obtenidos en la encuesta llevada a cabo sobre la valoración del software de anatomía radiológica de la pelvis femenina presentan datos muy positivos en cuanto a la satisfacción y aprendizaje mediante la utilización de esta herramienta tecnológica.

La tabla 2, recoge los resultados obtenidos en cada una de las preguntas formuladas, y que hemos descrito en el apartado de material y métodos.

\begin{tabular}{|c|c|c|c|c|c|c|c|c|c|c|c|c|c|c|c|}
\hline $\mathbf{N}$ & $\mathrm{A}$ & $\mathrm{B}$ & $\mathrm{C}$ & $\mathrm{D}$ & $\mathrm{E}$ & $\mathrm{F}$ & $\mathrm{G}$ & $\mathrm{H}$ & $\mathrm{I}$ & $\mathrm{J}$ & $\mathrm{K}$ & $\mathrm{L}$ & $\mathrm{M}$ & $\mathrm{N}$ & 0 \\
\hline $\mathbf{1}$ & 5 & 5 & 5 & 4 & 5 & 4 & 3 & 4 & 5 & 5 & 4 & 4 & 5 & 4 & 4 \\
\hline $\mathbf{2}$ & 5 & 5 & 5 & 4 & 5 & 5 & 3 & 4 & 5 & 5 & 4 & 4 & 5 & 4 & 4 \\
\hline $\mathbf{3}$ & 5 & 5 & 5 & 5 & 5 & 4 & 3 & 5 & 5 & 5 & 4 & 4 & 5 & 4 & 4 \\
\hline $\mathbf{4}$ & 4 & 5 & 4 & 4 & 4 & 3 & 3 & 5 & 5 & 5 & 5 & 4 & 5 & 4 & 5 \\
\hline $\mathbf{5}$ & 4 & 4 & 4 & 3 & 5 & 3 & 4 & 4 & 4 & 5 & 3 & 3 & 5 & 3 & 4 \\
\hline $\mathbf{6}$ & 5 & 5 & 5 & 4 & 5 & 4 & 2 & 3 & 4 & 4 & 4 & 4 & 5 & 5 & 5 \\
\hline $\mathbf{7}$ & 5 & 4 & 4 & 4 & 4 & 3 & 3 & 3 & 5 & 5 & 3 & 4 & 4 & 4 & 5 \\
\hline $\mathbf{8}$ & 5 & 5 & 5 & 4 & 5 & 4 & 3 & 5 & 5 & 5 & 4 & 5 & 5 & 4 & 5 \\
\hline $\mathbf{9}$ & 5 & 5 & 5 & 4 & 5 & 4 & 3 & 4 & 5 & 4 & 4 & 5 & 5 & 4 & 4 \\
\hline $\mathbf{1 0}$ & 5 & 5 & 5 & 4 & 5 & 5 & 4 & 4 & 4 & 5 & 5 & 4 & 5 & 5 & 5 \\
\hline $\mathbf{1 1}$ & 5 & 5 & 5 & 4 & 5 & 4 & 3 & 4 & 4 & 5 & 4 & 4 & 5 & 3 & 4 \\
\hline $\mathbf{1 2}$ & 5 & 5 & 5 & 3 & 4 & 5 & 3 & 4 & 4 & 4 & 4 & 4 & 5 & 4 & 5 \\
\hline $\mathbf{1 3}$ & 5 & 5 & 5 & 4 & 5 & 5 & 4 & 3 & 5 & 5 & 4 & 4 & 5 & 4 & 5 \\
\hline $\mathbf{1 4}$ & 4 & 4 & 3 & 4 & 4 & 3 & 3 & 5 & 5 & 5 & 5 & 5 & 5 & 4 & 5 \\
\hline $\mathbf{1 5}$ & 4 & 4 & 4 & 3 & 5 & 4 & 3 & 5 & 4 & 4 & 3 & 3 & 5 & 5 & 5 \\
\hline $\mathbf{1 6}$ & 5 & 5 & 5 & 5 & 5 & 5 & 3 & 4 & 5 & 5 & 4 & 4 & 5 & 5 & 4 \\
\hline $\mathbf{1 7}$ & 5 & 5 & 5 & 5 & 5 & 5 & 2 & 5 & 5 & 4 & 5 & 4 & 4 & 3 & 4 \\
\hline $\mathbf{1 8}$ & 5 & 5 & 5 & 5 & 5 & 4 & 3 & 4 & 5 & 5 & 5 & 5 & 5 & 4 & 5 \\
\hline $\mathbf{1 9}$ & 5 & 5 & 5 & 4 & 4 & 4 & 3 & 4 & 5 & 5 & 5 & 4 & 5 & 4 & 4 \\
\hline $\mathbf{2 0}$ & 5 & 5 & 5 & 4 & 5 & 4 & 3 & 4 & 5 & 5 & 4 & 4 & 5 & 5 & 4 \\
\hline $\mathbf{2 1}$ & 4 & 5 & 5 & 3 & 4 & 3 & 4 & 4 & 5 & 4 & 4 & 4 & 5 & 5 & 4 \\
\hline $\mathbf{2 2}$ & 5 & 5 & 5 & 4 & 5 & 4 & 4 & 5 & 5 & 5 & 5 & 4 & 5 & 5 & 5 \\
\hline $\mathbf{2 3}$ & 5 & 5 & 5 & 4 & 5 & 5 & 3 & 4 & 4 & 5 & 4 & 3 & 5 & 5 & 5 \\
\hline
\end{tabular}




\begin{tabular}{|l|l|l|l|l|l|l|l|l|l|l|l|l|l|l|l|}
\hline $\mathbf{2 4}$ & 4 & 4 & 4 & 4 & 4 & 4 & 3 & 4 & 5 & 5 & 4 & 4 & 5 & 3 & 4 \\
\hline $\mathbf{2 5}$ & 5 & 5 & 4 & 4 & 5 & 4 & 2 & 5 & 5 & 5 & 4 & 5 & 4 & 4 & 5 \\
\hline $\mathbf{2 6}$ & 5 & 5 & 5 & 4 & 5 & 5 & 3 & 4 & 4 & 5 & 5 & 4 & 4 & 4 & 5 \\
\hline $\mathbf{2 7}$ & 5 & 5 & 5 & 5 & 5 & 5 & 3 & 4 & 5 & 5 & 4 & 5 & 5 & 4 & 5 \\
\hline $\mathbf{2 8}$ & 5 & 5 & 5 & 5 & 5 & 4 & 4 & 4 & 4 & 5 & 5 & 5 & 5 & 5 & 5 \\
\hline $\mathbf{2 8}$ & 5 & 5 & 5 & 4 & 4 & 3 & 4 & 5 & 5 & 4 & 4 & 4 & 5 & 5 & 5 \\
\hline $\mathbf{3 0}$ & 4 & 5 & 4 & 3 & 5 & 4 & 3 & 4 & 5 & 5 & 3 & 4 & 5 & 4 & 4 \\
\hline $\mathbf{3 1}$ & 5 & 5 & 5 & 4 & 5 & 4 & 3 & 4 & 5 & 5 & 4 & 5 & 5 & 5 & 4 \\
\hline $\mathbf{3 2}$ & 4 & 4 & 3 & 4 & 5 & 3 & 3 & 4 & 4 & 5 & 5 & 4 & 5 & 5 & 5 \\
\hline $\mathbf{3 3}$ & 4 & 5 & 4 & 4 & 4 & 4 & 3 & 4 & 4 & 4 & 5 & 4 & 5 & 4 & 4 \\
\hline $\mathbf{3 4}$ & 5 & 5 & 5 & 5 & 5 & 5 & 3 & 5 & 5 & 5 & 4 & 4 & 5 & 4 & 5 \\
\hline $\mathbf{3 5}$ & 5 & 5 & 5 & 4 & 5 & 5 & 3 & 5 & 5 & 5 & 5 & 5 & 5 & 5 & 5 \\
\hline
\end{tabular}

Tabla 2

Como se observa en la Gráfica 14, de forma global, la apreciación de los usuarios que manejaron el software ha sido muy satisfactoria, superando prácticamente en todas las situaciones formuladas el nivel del 4, salvo en la pregunta relacionada con el contenido teórico de lo que se describe, que bajó hasta el 3,11.
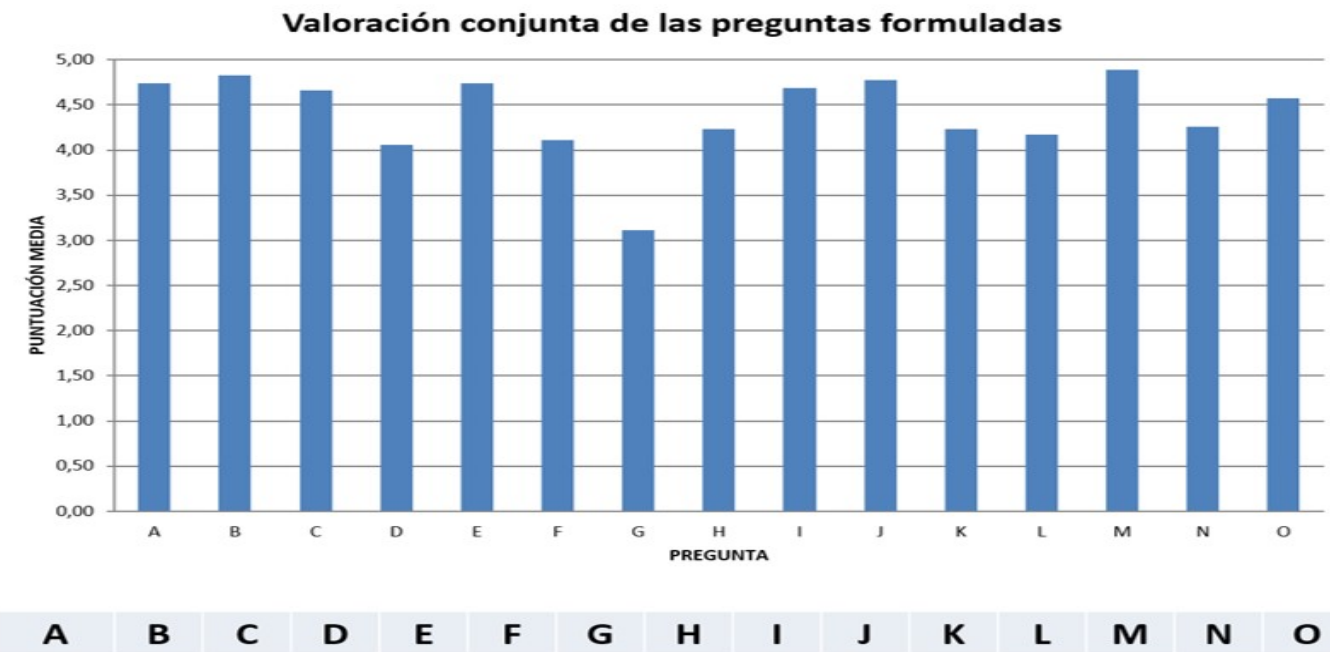

4,74 4,83 4,66 4,06 4,74 4,11 3,11 4,23 4,69 4,77 4,23 4,17 4,894,26 4,57 
Lo que sí destaca en su valoración global es el software (Gráfica 15), señalando un $88 \%$ de los encuestados, que su instalación es sencilla (Gráfica 16), y que prácticamente el $100 \%$ de los usuarios han señalado que la aplicación no se bloquea nunca o casi nunca (Gráfica 17), la navegación por el programa es muy intuitiva (Gráfica 18), los comentarios explicativos breves de las estructuras anatómicas que se visualizan, son bien valorados (Gráfica 19), y la interfaz del programa es muy intuitiva y de fácil manejo, respuesta dada por casi el 100\% de los usuarios (Gráfica 20).

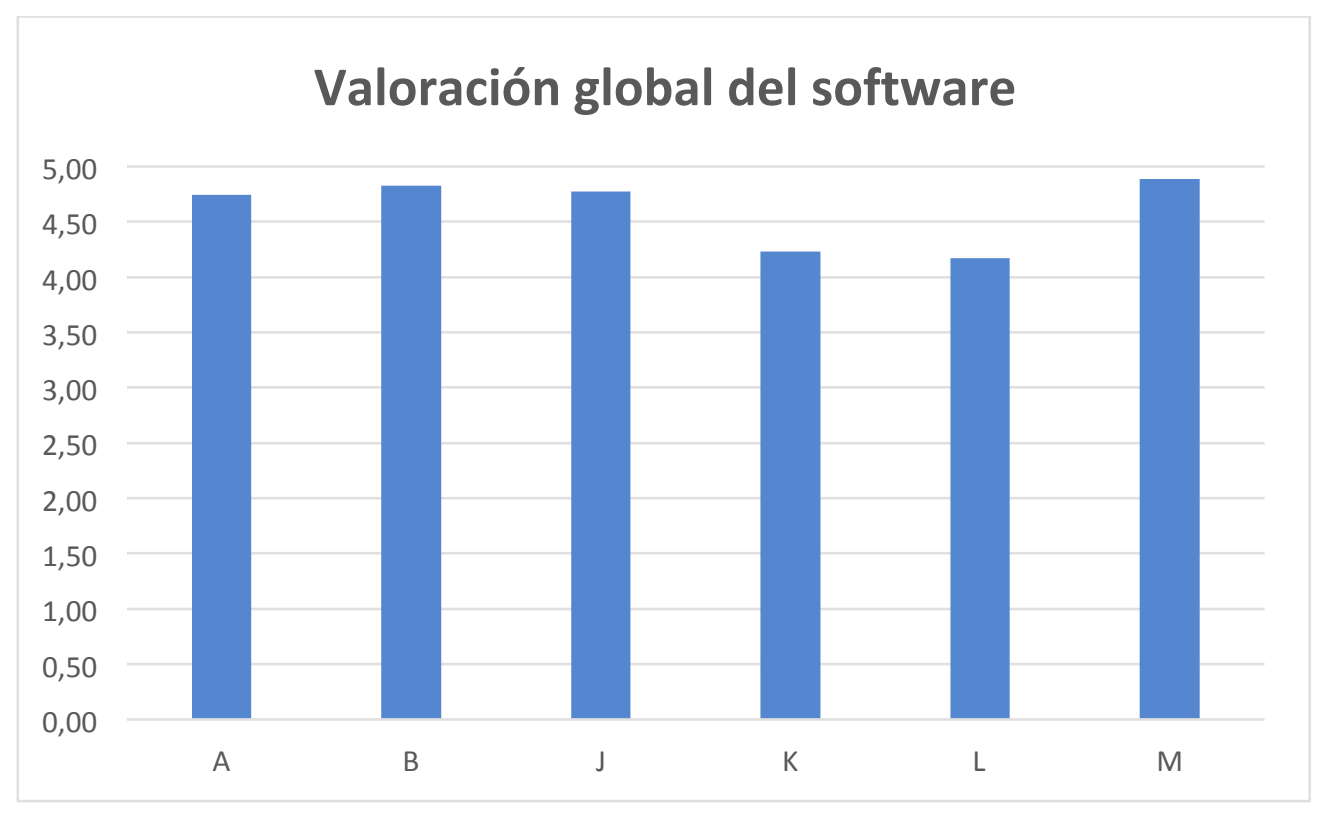

Gráfica 15

Pregunta A. La instalación del software fue

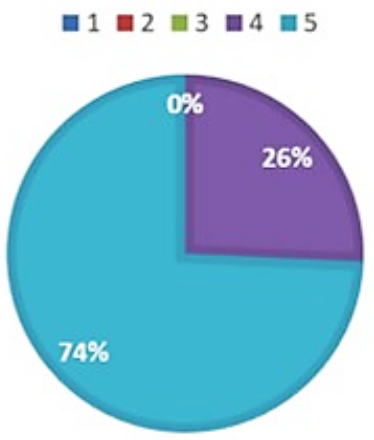

\begin{tabular}{cc} 
valoración & A \\
complicada & $0 \%$ \\
\hline Más bien dificil & $0 \%$ \\
De dificultad & $0 \%$ \\
\hline media & $0 \%$ \\
\hline Mas bien fácil & $26 \%$ \\
muy sencilla & $74 \%$
\end{tabular}

Gráfica 16 
Pregunta B. ¿Con qué frecuencia se bloquea el software?

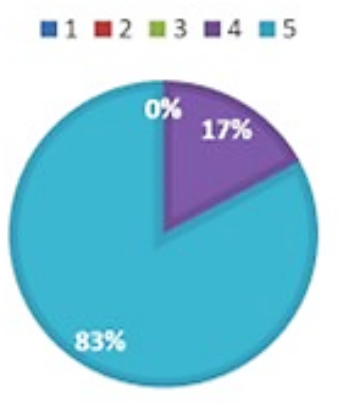

$\begin{array}{cc}\text { valoración } & \text { B } \\ \text { muy a menudo } & 0 \% \\ \text { Frecuentemente } & 0 \% \\ \text { A veces } & 0 \% \\ \text { Casi nunca } & 17 \% \\ \text { nunca } & 83 \%\end{array}$

Gráfica 17

Pregunta K. La navegación por el programa es muy intuitiva
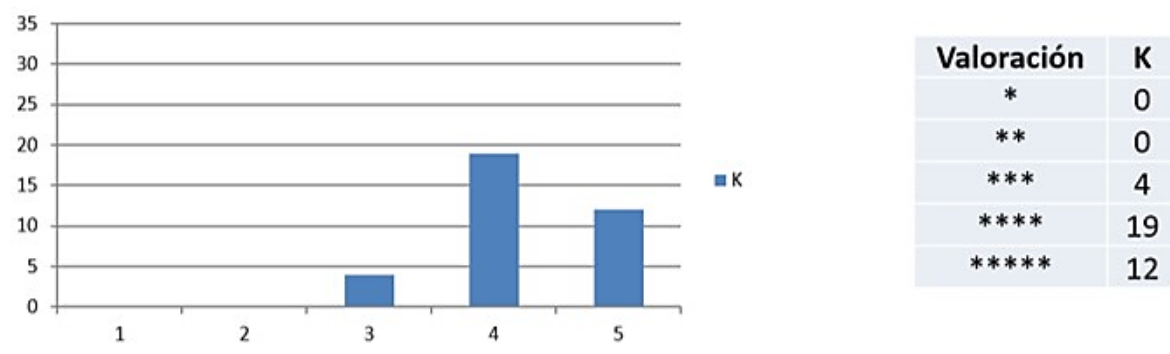

Pregunta K. La navegación por el programa es muy intuitiva

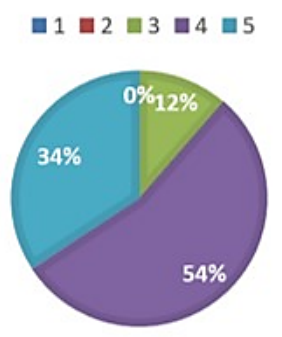

\begin{tabular}{|c|c|}
\hline Valoración & $\mathrm{K}$ \\
\hline$*$ & $0 \%$ \\
\hline$* *$ & $0 \%$ \\
\hline$* * *$ & $11 \%$ \\
\hline$* * * *$ & $54 \%$ \\
\hline$* * * *$ & $34 \%$ \\
\hline
\end{tabular}

Gráfica 18 


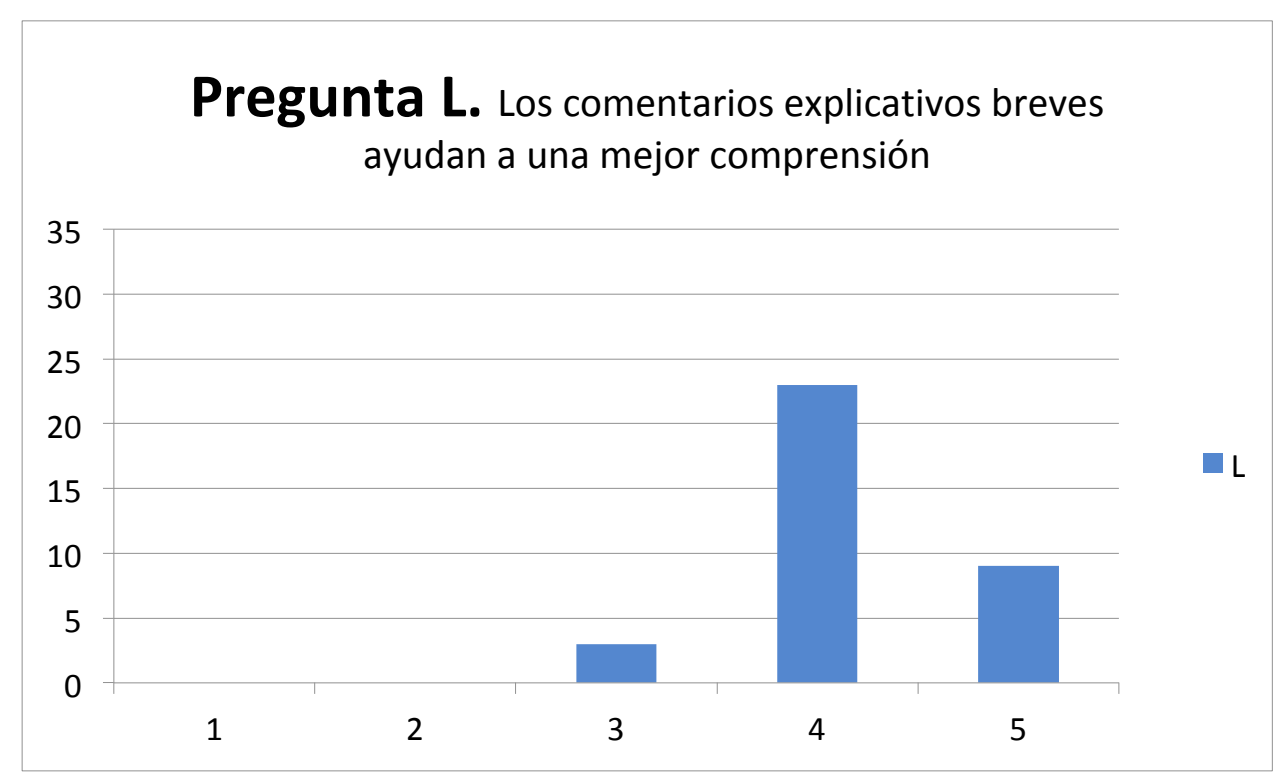

Gráfica 19

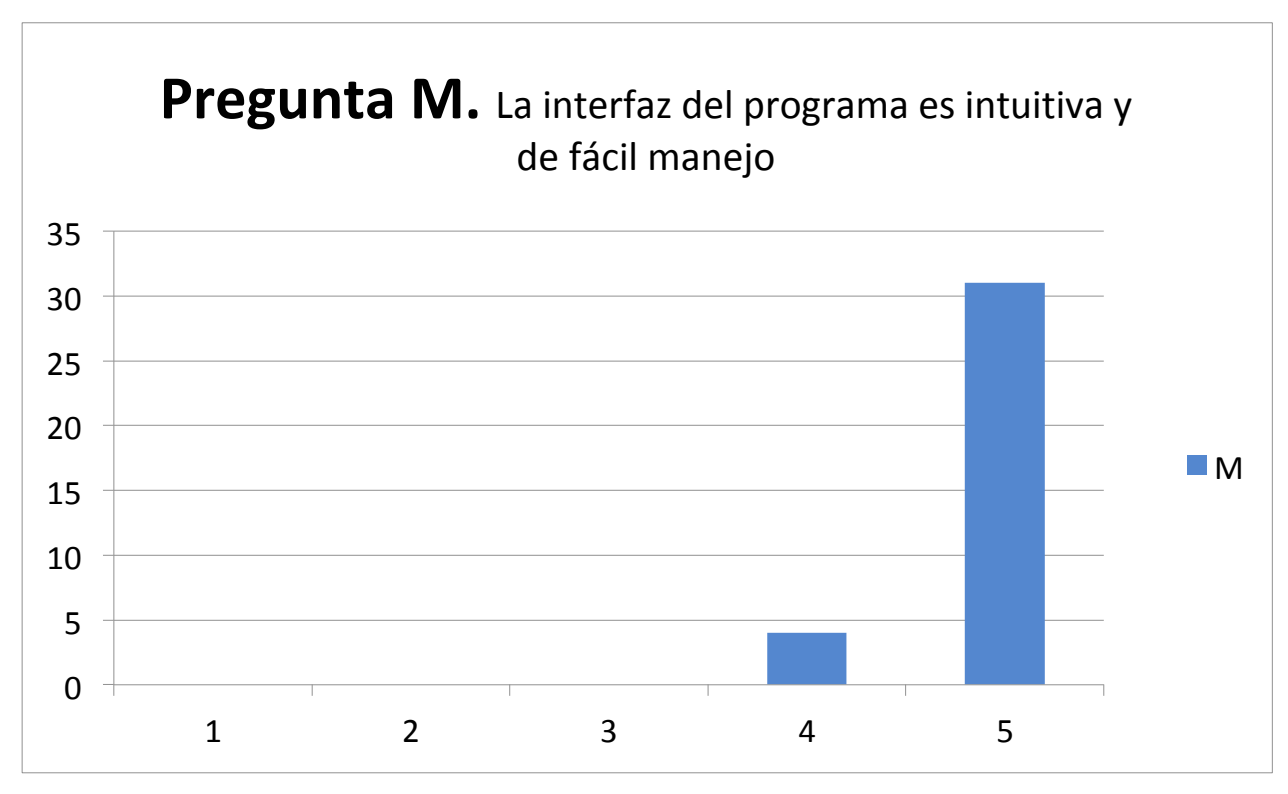

Gráfica 20

En relación a las consideraciones de los usuarios sobre lo que aporta este desarrollo tecnológico en el proceso de enseñanza-aprendizaje, sobresale igualmente un alto grado de satisfacción (Gráfica 21). 


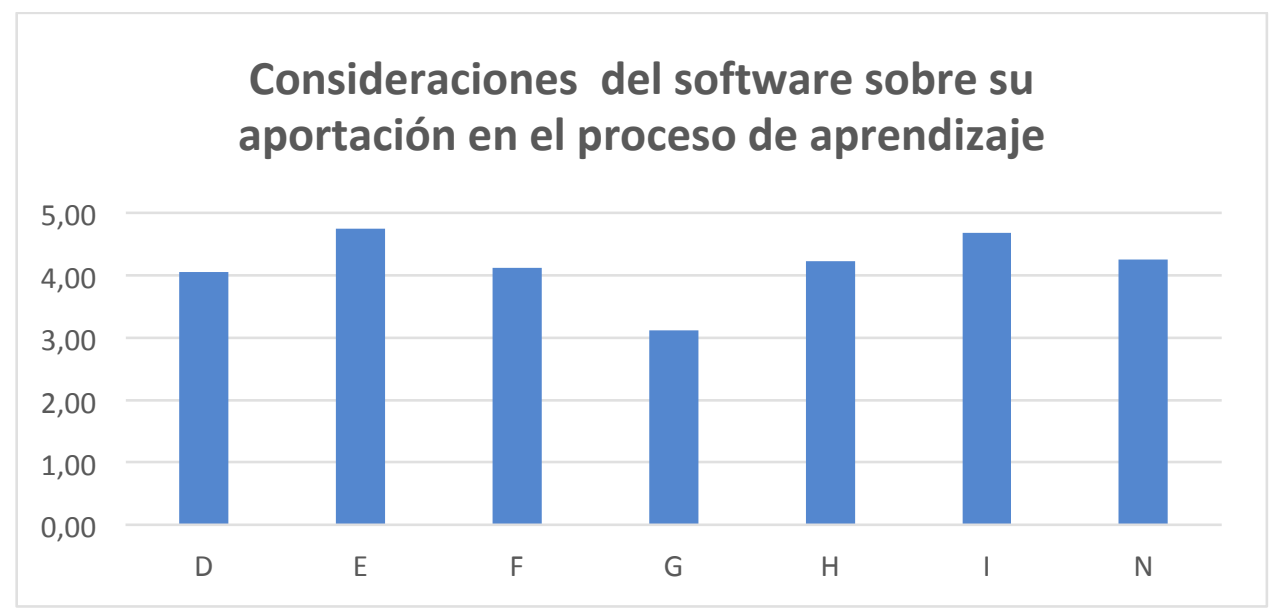

Gráfica 21

Desde el punto de vista docente destaca la valoración como un buen recurso didáctico como complemento para el estudio (Gráfica 22). Además, la visión tridimensional de las estructuras anatómicas es muy valorada por los usuarios, llegando a un alto grado de satisfacción (Gráfica 23). Por otra parte, un buen grupo de encuestados señalaron que esta herramienta supone un buen medio que supera a muchos atlas anatomo-radiológicos que son estáticos (Gráfica 24). La presentación visual de los contenidos es muy atractiva, siendo por tanto muy bien valorada por los estudiantes (Gráfica 25). Todo el desarrollo es muy beneficioso, siendo recomendable según los usuarios para otros compañeros o alumnos (Gráfica 26).
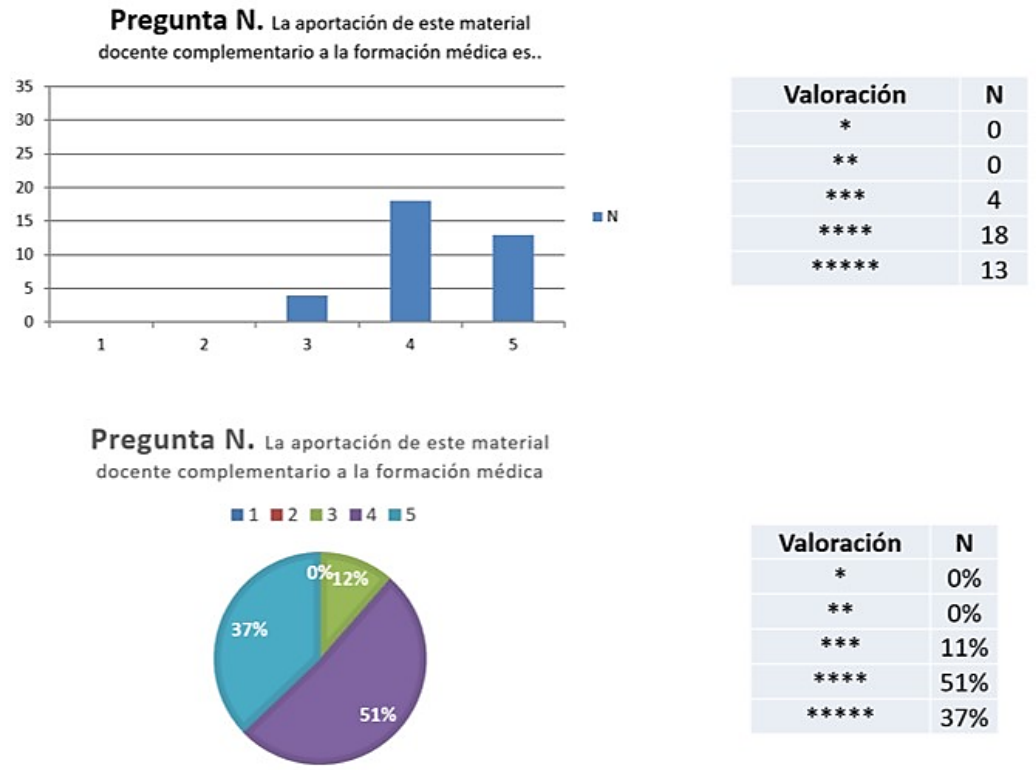

Gráfica 22 
Pregunta H. Con la visión 3D utilizo menos tiempo de aprendizaje, respecto a otros métodos clásicos

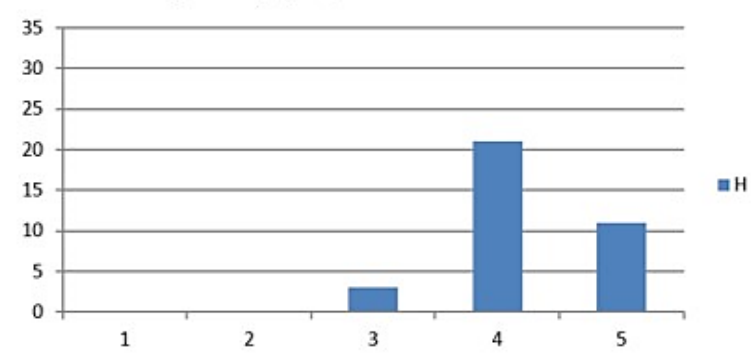

Pregunta H. Con la visión 3D utilizo menos tiempo de aprendizaje, respecto a otros métodos clásicos

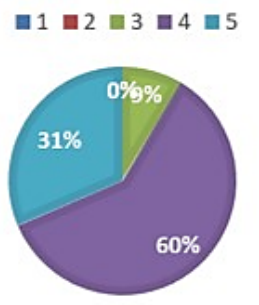

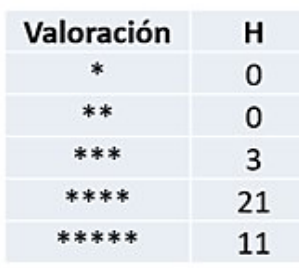

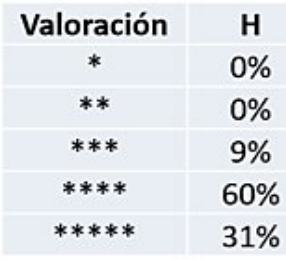

Gráfica 23

Pregunta F. Este software es mejor que muchos atlas anatómo-radiológicos
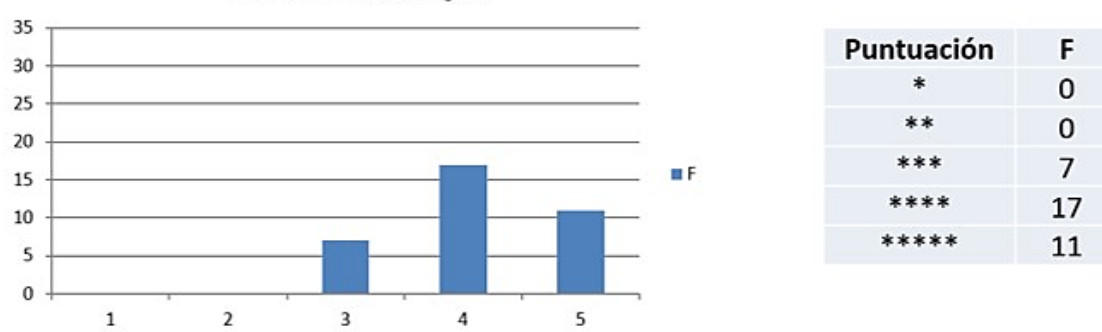

Pregunta F. Este software es mejor que muchos atlas anatómo-radiológicos

$$
\text { घ } 12=3 \square 4=5
$$
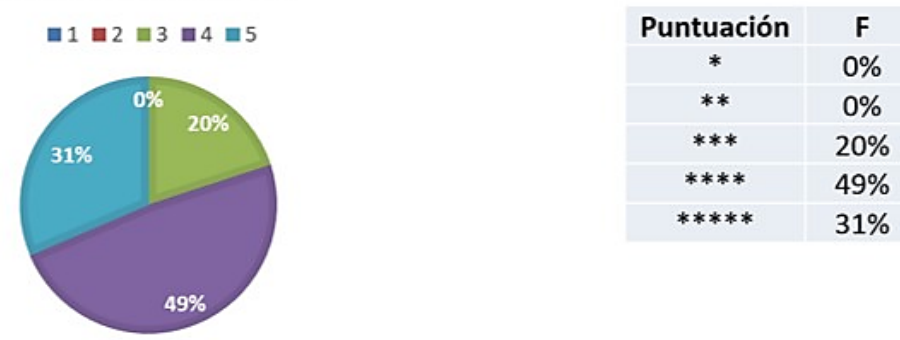
Pregunta J. La presentación de los contenidos visuales es

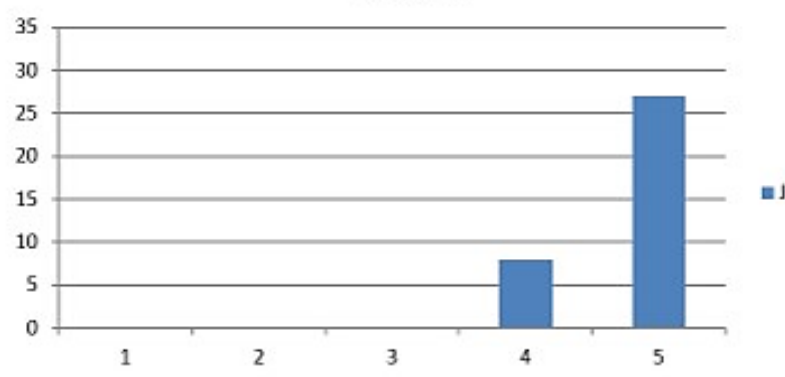

Pregunta J. La presentación de los contenidos visuales es

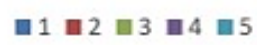

\section{$0 \%$}

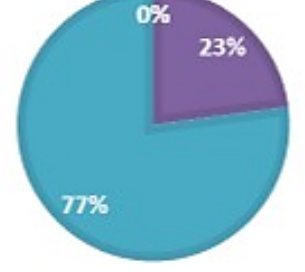

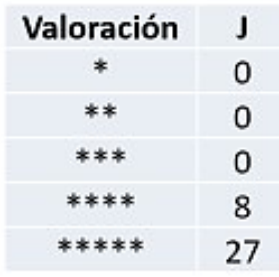

Gráfica 25

Pregunta O. Recomendaría a otros compañeros estos desarrollos informáticos
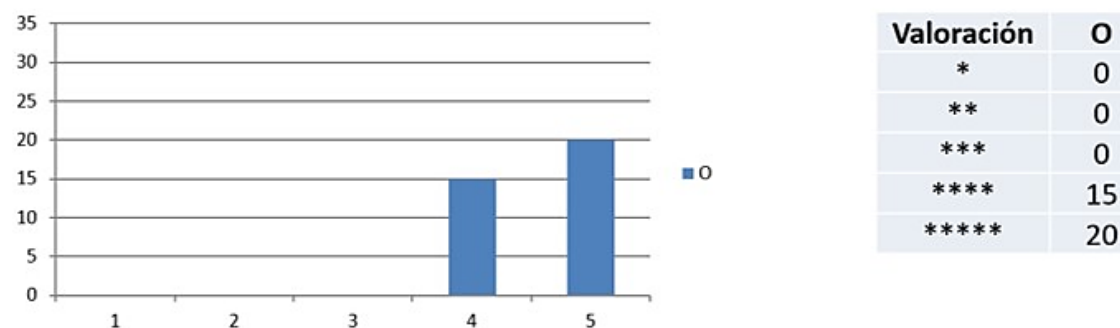

Pregunta O. Recomendaría a otros compañeros estos desarrollos informáticos
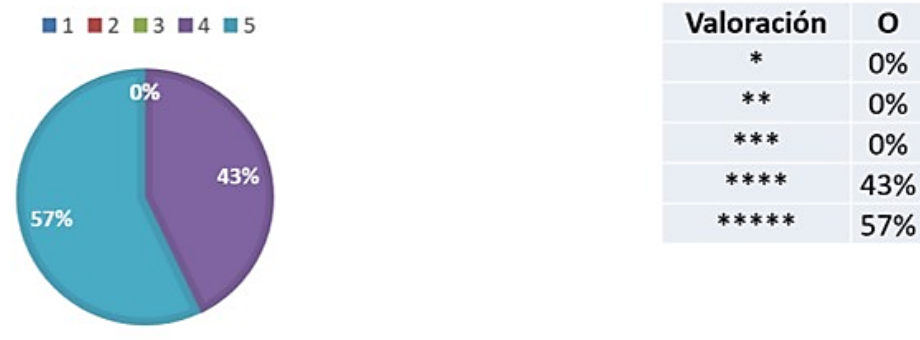

Gráfica 26 


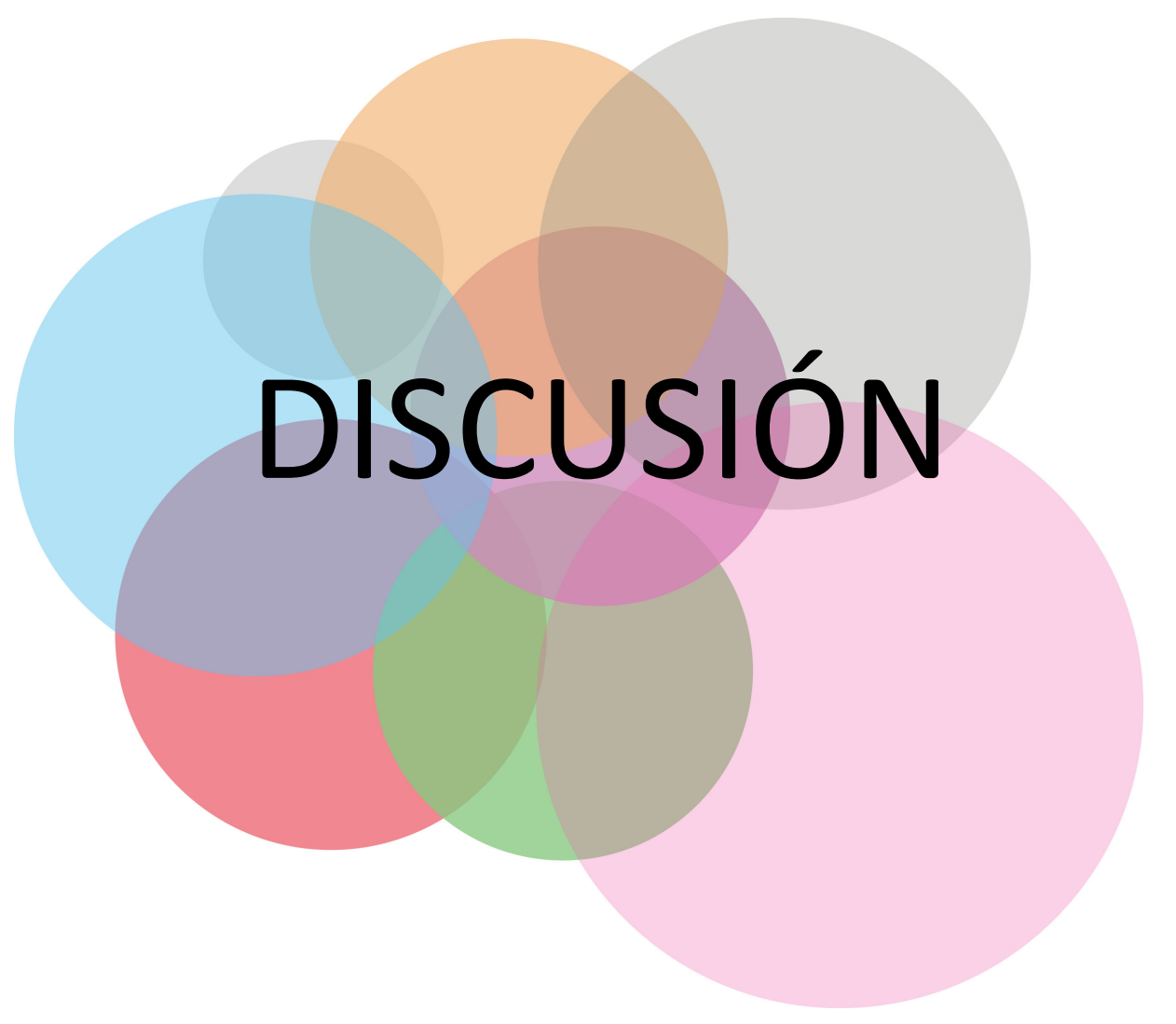


En las últimas décadas las tecnologías de la información y la comunicación (TIC) han revolucionado todos los ámbitos sociales y han irrumpido con fuerza en el sistema educativo, evidenciando la necesidad de establecer cambios en los modelos pedagógicos tradicionales para adaptarlos de manera más acorde a las demandas de la sociedad actual y a las características de un alumnado acostumbrado a convivir cotidianamente con la tecnología (Martínez et al., 2017; Veloz et al., 2012).

En esta línea, apreciamos que los alumnos a los que se les ofreció realizar el estudio de la anatomía pélvica con nuestra aplicación estaban bastante familiarizados con las herramientas tecnológicas, disponiendo la mayoría de teléfonos móviles de última generación con potentes sistemas operativos, que utilizaban durante varias horas diarias, principalmente para las relaciones sociales y el entretenimiento, siendo ocasionalmente empleados para la obtención de información o consulta de noticias y en muy pocas ocasiones para temáticas relacionadas con el ámbito docente. La mayoría de ellos contaba con una buena destreza en la instalación o desinstalación de diferentes aplicaciones para estos dispositivos móviles, pero solamente las empleaban de forma esporádica para la formación académica, aunque reconocían que la utilización de recursos de carácter multimedia (texto, imágenes, videos...), facilitaba el conocimiento y la comprensión de los temas consultados y que otros procedimientos tecnológicos, como la realidad virtual, implementados adecuadamente, podían ser un buen recurso didáctico.

La familiaridad de estas nuevas generaciones de estudiantes con los medios digitales, la constatación de que la enseñanza tradicional basada en la clase magistral del profesor y la evaluación mediante un examen final de los alumnos, basado en la memorización y la reproducción de la información, ha resultado ser una herramienta poco eficaz en el proceso de enseñanza-aprendizaje, la enorme potencialidad que ofrece la tecnología en la transmisión de conocimientos y la predisposición de los estudiantes actuales a incorporar en sus estudios metodologías más innovadoras sustentadas en los avances tecnológicos, son las cuestiones fundamentales que han conducido a considerar la aplicación de las TIC en la enseñanza del siglo XXI como una premisa esencial en la educación (Astudillo et al., 2018; Sáez López, 2018; 
Guerrero, 2014; Juanes y Ruisoto, 2014; Belloch, 2012; Morrisey, 2010; Vázquez et al., 2007).

Los avances tecnológicos han introducido nuevos y valiosos conceptos en los modelos de aprendizaje. El aprendizaje centrado en el estudiante, continuo, interactivo, autónomo, flexible, o colaborativo son términos que han adquirido gran relevancia en la metodología didáctica de las últimas décadas (Domínguez Merlano, 2010). Sin embargo, para dotarlos de auténtico valor formativo es necesaria la transformación tanto de los escenarios educativos, en los que el profesor es el centro de atención, como del papel tradicionalmente adoptado por los profesores y los estudiantes, pues el aprendizaje se construye fundamentalmente, mediante el proceso de interacción y retroalimentación permanente entre ambos (Pickering y Swinnerton, 2018).

La metodología que nosotros presentamos promueve el aprendizaje autónomo y convierte al estudiante en protagonista directo de su proceso de aprendizaje. La interacción continua con la aplicación informática, además de estimular el desarrollo de habilidades para mejorar la capacitación informática y audiovisual, despierta el interés y la motivación en el estudio de la anatomía pélvica y reduce el tiempo necesario para el aprendizaje de la misma, como señalaron los estudiantes tras la implementación de nuestro recurso didáctico, que permitió así mismo una implicación en la tarea libre de barreras espaciotemporales. Coincidimos con las opiniones de Papadopoulou et al. (2019), Pickering y Swinnerton (2018) y Hampton y Shung (2010) en que la aplicación de metodologías tecnológicas puede ayudar a los estudiantes a mejorar los resultados de aprendizaje al aumentar la participación e involucración de los mismos en la actividad de estudio. Sin embargo, para Golenhofen et al. (2020) el éxito de estas aplicaciones tecnológicas sobre el aprendizaje depende únicamente de la motivación o predisposición de los estudiantes para su empleo, que además parece ser mayor en los que muestran mejor rendimiento académico general.

Nuestro recurso didáctico interactivo proporciona una metodología complementaria a la enseñanza tradicional, centrada en los procesos de exploración e indagación, 
estimulantes del pensamiento crítico, a diferencia de la mayoría de las aplicaciones estudiadas por Martínez et al. (2017), que en su opinión, se basan únicamente en proporcionar nueva información pero sin potenciar habilidades que favorezcan la construcción del conocimiento en los estudiantes, lo que para Moreira (2019), Gutiérrez Tapias (2018), Svirko y Mellanby (2017), y García y López (2011) es fundamental en el proceso de enseñanza y aprendizaje y que principalmente se consigue a través de la observación, la investigación, la experiencia, la reflexión y el razonamiento.

Según Ricardo Barreto y Díazgranados (2017) todos estos cambios en las metodologías y en el entorno educativo no reflejarán los resultados esperados sobre el aprendizaje si no se tienen en cuenta premisas esenciales como la adecuación de las exigencias y de los materiales al nivel de desarrollo y capacidades del alumnado, la adaptación de los contenidos a los conocimientos previos de los estudiantes y fundamentalmente, el interés en la formación y en la integración de las nuevas metodologías didácticas en las aulas por parte de los profesores y de las instituciones educativas. Tam et al. (2009) señalan también que estos recursos didácticos pueden ser herramientas útiles para el aprendizaje siempre que estén bien diseñados e integrados en los planes de estudio de las disciplinas.

En el área de las ciencias de la salud, y especialmente en Medicina, la enseñanza de anatomía está a la vanguardia de la integración de metodologías tecnológicas innovadoras en sus planes de estudio (Clunie et al., 2018). El gran potencial de las TIC, junto con el vertiginoso desarrollo de la tecnología basada en imágenes (tomografía axial computarizada, resonancia magnética, ecografía, etc.), dirigida principalmente al diagnóstico y a la clínica médica, y la posibilidad de combinación de ambas, ha abierto nuevas fuentes de enseñanza complementarias a la metodología tradicional, que clásicamente se venía ejerciendo a través de los libros de texto, las ilustraciones y la disección cadavérica (Papadopoulou et al., 2019; Ghosh, 2015; Juanes y Ruisoto, 2014).

La extraordinaria calidad visual de las imágenes digitales que proporciona actualmente esta tecnología médica, permitiendo diferenciar densidades biológicas y 
gracias a ello, estructuras anatómicas, y la posibilidad de conseguir imágenes seccionales de las mismas, ha supuesto una extraordinaria herramienta base para el desarrollo de recursos didácticos innovadores, como el que nosotros presentamos, en la docencia de anatomía. La utilidad pedagógica de las imágenes seccionales, que también pueden proceder de cortes anatómicos de cadáver, como los de la base de datos del VHP (Visible Human Project), CVH (Chinese Visible Human) o VKH (Visible Korean Human), reside en dos aspectos fundamentales, preservan las relaciones espaciales existentes entre las estructuras vecinas, reflejando escrupulosamente la configuración y la ubicación de todos los tejidos y órganos de una zona anatómica, por lo que difieren del estudio anatómico tradicional mediante la disección, y además permiten realizar a través de procedimientos informáticos, una reconstrucción anatómica de diversos órganos, regiones corporales (en nuestro trabajo de la región pélvica femenina), o incluso del cuerpo entero, proporcionando una visualización volumétrica de los mismos (Noetscher et al., 2016; Bertrand et al., 2014; Shin et al.,2013; Wu et al., 2012; Yuan et al., 2008; Heng et al., 2006; Li et al., 2006; Uhl et al., 2006; Zhang et al., 2006).

El uso de tecnologías basadas en imágenes, especialmente las basadas en la representación en 3D, como la herramienta didáctica que nosotros desarrollamos, reflejan lo que se está enseñando en la teoría, pero con una visión tridimensional de las estructuras, lo que permite comprender y asimilar de forma más significativa el contenido que se está estudiando. Con estos medios se obtiene un nivel de visualización imposible de alcanzar con los métodos didácticos en $2 \mathrm{D}$, puesto que proporcionan una visión de las estructuras con una profundidad de campo más realista, permitiendo ilustrar conceptos y principios que de otro modo serían muy difíciles de comprender por los estudiantes, especialmente aquellos que requieren habilidad espacial (Hassinger et al., 2010). La visualización volumétrica de una región anatómica, como la que aporta nuestro desarrollo informático, ofrece un completo análisis de la morfología, al poder valorar la forma, localización y situación de las diferentes estructuras que la componen y de las relaciones que mantienen con las adyacentes (Arantes et al., 2018; Darras et al., 2017; Allen et al., 2016; Arrondo et al., 2016; Berney et al., 2015; Prats-Galino, 2010). Además de ser útiles en la enseñanza, 
tienen una interesante aplicación médica clínica, pues el conocimiento de las estructuras anatómicas en el individuo sano facilita el diagnóstico de patologías y puede servir de base para la planificación de un abordaje quirúrgico en la zona de estudio (Keenan y Awadh, 2019; Sanchís López, 2015; De Notaris et al., 2013).

Hoy día existen multitud de aplicaciones 3D, como la que hemos desarrollado en este trabajo, susceptibles de ser utilizadas para el aprendizaje de anatomía y otras disciplinas relacionadas con el área de la salud, algunas incluso con una finalidad comercial además de educativa.

Las aplicaciones que vamos a citar a continuación son una pequeña representación de los numerosos recursos digitales 3D que se han ido aportando a lo largo de los últimos años para la enseñanza-aprendizaje de la anatomía, general o regional. Cada uno de ellos tiene unas características específicas que sería muy largo de comentar, pero sí haremos referencia a consideraciones generales que a nuestro juicio parecen más valiosas o trascendentes, atendiendo de la misma manera a aquellas que definen nuestra aplicación. Enumeramos para ello algunos ejemplos, con una resumida descripción de las mismas, comparándolas frente a nuestra propia aplicación.

- Human Anatomy (https://human-anatomy-atlas-2018-complete-3d-humanbody.softonic.com/):

Atlas virtual de anatomía humana en 3D que ofrece un completo modelo de anatomía con visualización de estructuras de todos los sistemas anatómicos en el hombre y en la mujer. El entorno cuenta con una gran biblioteca de modelos. Presenta una colección más amplia de modelos tridimensionales y de texto complementario que nuestro desarrollo, abarcando un mayor campo de conocimiento anatómico, ya que nosotros nos centramos únicamente en la pelvis femenina. Esto hace que fomente que algunos detalles anatómicos no sean excesivamente concisos, al contrario de lo que suele ocurrir en aplicaciones centradas en una única región anatómica. A diferencia de nuestra herramienta 
informática, no presenta la posibilidad de ver imágenes seccionales de RM ni de cadáver, puesto que las imágenes seccionales que se pueden valorar son obtenidas únicamente de los modelos 3D desarrollados. Otro inconveniente, es que los propios desarrolladores incluyen en "contras" que familiarizarse con la aplicación integral puede ser intimidante, por lo que su manejo no será tan intuitivo y fácil como con nuestra aplicación.

- Visible Body (https://www.visiblebody.com/es/anatomy-and-physiologyapps/human-anatomy-atlas):

Aplicación de pago de modelos tridimensionales de todo el cuerpo humano bastante completa, presenta imágenes de cadáver seccionales y de TC, no se muestran los modelos 3D embebidos dentro de las imágenes seccionales, pero sí aparecen al lado para que puedan ser comparadas. Se puede instalar en ordenadores y en dispositivos móviles, a diferencia de nuestra aplicación que es para ordenador.

- BioDigital human (https://www.biodigital.com/):

Es un software interactivo de imágenes tridimensionales de anatomía, a diferencia de nuestro trabajo, presenta información de enfermedades y sus posibles tratamientos, pero no presenta imágenes seccionales de cadáver ni radiológicas.

- Visión Médica Virtual (VMV) 3D (https://visionmedicavirtual.com/es):

Herramienta 3D "on-line" para la presentación y estudio de la anatomía humana, con mucha información disponible además de los modelos anatómicos (imágenes radiológicas, datos e imágenes histológicas...). Su mayor diferencia radica en su acceso online, sin necesidad de realizar una instalación en un dispositivo propio, y como obstáculo, solicita una suscripción anual para poder hacer uso de ella. Además, aunque posee una importante compilación de imágenes radiológicas no permite su 
comparación, ni la visualización conjunta con los modelos 3D como posibilita nuestra aplicación 3D.

- Anatomía Humana 3D (http://anatomiahumana3d.com/):

Proyecto consistente en la digitalización de estructuras anatómicas del cuerpo humano en modelos tridimensionales (los modelos son reales), que permite la visualización de las mismas desde diferentes ángulos, y con la posibilidad de usar realidad aumentada, reproducible a través de un móvil o tablet. Su acceso es gratuito y aporta clases anatómicas en pdf. Un importante hándicap de esta aplicación frente a nuestro desarrollo es que no hace referencia a la pelvis ni las estructuras que la constituyen y que permite únicamente la valoración de estructuras aisladas, no su valoración conjunta, aunque sea de casi todas las estructuras del cuerpo humano, y sin soporte de imágenes seccionales por lo que de cara a fomentar el estudio y aprendizaje de las relaciones espaciales nuestra aplicación es mucho más completa.

- Zygote body (https://www.zygotebody.com/):

Aplicación virtual que ofrece modelos de anatomía 3D del cuerpo humano con finalidad pedagógica. Presenta un modelo anatómico 3D complejo, en el que se pueden ver sus componentes en su conjunto y seleccionar uno en concreto permitiendo visualizar su posición y trayecto en el caso de vasos y nervios. Tiene funciones a las que únicamente se puede acceder mediante pago. Carece de imágenes reales seccionales ya sean de cadáver o de RM. Su manejo no es muy intuitivo, ya que cuesta discernir para que es cada botón y cómo manejar la aplicación, así como las posibilidades que ofrece, lo que puede hacer que su aprovechamiento sea inferior al que aporta, aunque puede que esto se deba también a las funcionalidades deshabilitadas en la versión gratuita. Por tanto, nuestra aplicación parece superior en cuanto a la incorporación de las imágenes 
seccionales y a que el uso de la misma es más entendible y sencillo por parte del usuario.

- Bio TK (https://www.biotk.co/site/index.php?lang=es):

Atlas de anatomía en 3D generado a partir de cortes de cadáver humano, por lo que es preciso y realista. Permite la valoración de imágenes seccionales de cadáver (no de RM como nuestra herramienta informática) y de los modelos 3D embebidos en ella, al igual que nuestra aplicación, pero a diferencia de la nuestra, permite simular una disección de cadáver en la que extraes los órganos y los valoras de manera independiente. Las composiciones pueden ser almacenadas y compartidas, igual que con nuestra aplicación. Bio TK es compatible con prácticamente todas las plataformas de hardware y se integra fácilmente a plataformas de E-learning, permite un acceso parcial de forma gratuita y tiene versiones Premium de pago.

- Proyecto HDM (Human Dissection Models) (https://www.proyectohdm.com/):

Basado en la creación de modelos tridimensionales a partir de órganos o estructuras diseccionadas de cuerpos humanos, que proporciona su valoración aislada y mediante realidad aumentada. Nuestra aplicación es más completa en cuanto a usabilidad, y a la contribución a la formación médica, ya que esta aplicación únicamente proporciona imágenes con tecnología de visión tridimensional, no son modelos 3D reconstruidos.

- Mesa de Disección 3D Sectra (http://www.simulat.com.ar/productos/mesa-sectra) (https://www.medicalexpo.es/prod/touch-of-life-technologies-toltech/product81270-644641.html):

Representación digitalizada de estructuras del cuerpo humano en diferentes planos, empleando imágenes de cortes de cadáver, provenientes de la base de datos del 
"Visible Human Project" y de resonancia magnética. Las imágenes se trabajaron usando el programa VH Dissector instalado en una mesa de visualización digital 3D táctil del fabricante SECTRA. El que para su uso precise de esta mesa de visualización específica, hace que únicamente sea posible utilizarla en universidades o grandes centros, lo que limita ampliamente su disponibilidad frente a nuestra aplicación, que para su empleo solamente se requiere un ordenador de los que prácticamente todos los estudiantes disponen actualmente en su domicilio.

- Human Body (male)

(https://play.google.com/store/apps/details?id=com.rendernet.humanmale\&hl=en_ US):

Como indica su nombre inglés, solo dispone de anatomía humana masculina. Cubre varios sistemas biológicos y modelos 3D de órganos (dispone de narraciones y animaciones), pero de una forma sencilla, sin entrar en demasiados detalles ni realismo. No hace uso de imágenes seccionales. Es una aplicación cuyo fin no es fomentar el conocimiento anatómico de estudiantes de medicina puesto que se queda corta en el aporte de información, mientras que nuestro desarrollo, al contrario que en este caso, necesita de conocimientos anatómicos previos, puesto que la información que aporta es más completa y compleja y requiere habilidades adquiridas previamente en la interpretación de imágenes seccionales. A diferencia que nuestra aplicación, puede ser utilizada en dispositivos portátiles.

- 3D Bones and Organs

(https://play.google.com/store/apps/details?id=com.hssn.anatomy3dlite\&hl=es):

Plataforma de anatomía humana en 3D. El entorno es completamente gratuito y cuenta con ricos modelos 3D de sistemas y órganos biológicos humanos. Al igual que con la aplicación anterior, la contribución al aprendizaje anatómico de estudiantes de medicina es pobre, al contrario que con nuestra herramienta, como ya hemos 
comentado previamente. Como ventaja, igualmente, puede utilizarse en dispositivos móviles.

- Anatomy Learning (http://anatomylearning.com/):

Ofrece una amplia gama de la anatomía humana con varios sistemas biológicos (hombre y mujer), junto con modelos 3D de diferentes partes del cuerpo y órganos. Se basa en modelos 3D muy esquemáticos, para uso en móviles, tablets y ordenadores vía online. No relaciona la anatomía con imágenes seccionales, por lo que no colabora en el aprendizaje anatómico como nuestra aplicación informática. Permite navegar y encontrar los contenidos que se buscan, pero la forma de utilizar el contenido (interfaz) no siempre es intuitiva y se necesitan instrucciones de uso, aunque los enlaces funcionan correctamente.

- Sistema Óseo en 3D (Anatomía)

(https://play.google.com/store/apps/details?id=com.androiddevelopermx.blogspot. bones3d\&hl=es_419):

Proporciona información sobre la anatomía del esqueleto humano mediante modelos simplificados en tres dimensiones de los huesos. Es una aplicación bastante escasa y simple en contenidos anatómicos, al contrario que nuestro desarrollo informático.

- Complete Anatomy de 3D 4 MEDICAL (Elsevier) (https://3d4medical.com/):

Plataforma de publicación para la educación con anatomía 3D para interacción con los más pequeños detalles del cuerpo humano. Es una aplicación de pago, con muchas posibilidades, entre ellas favorecer el interés por la anatomía en los estudiantes gracias a sus características de realidad aumentada. Sus modelos tridimensionales son muy realistas, permitiendo animaciones y representaciones de 
determinadas funcionalidades del cuerpo humano. Nuestra aplicación aporta frente a esta, el uso de la anatomía seccional como base para el estudio de las relaciones anatómicas reales entre estructuras adyacentes al usar secciones de cadáver y RM, e incluso aportar imágenes ecográficas.

- Modelo 3D para el estudio de la pelvis femenina (Balaya et al., 2016):

Especial mención a esta aplicación puesto que es muy similar al desarrollo que nosotros hemos realizado, pero más rudimentario en cuanto a su interfaz y visualización. La reconstrucción de los modelos 3D es de secciones de cadáver, pero no se pueden visualizar los cortes seccionales junto con los modelos 3D. Algunas estructuras no aparecen representadas, especialmente las de menor calibre y tamaño, probablemente por la dificultad de su identificación durante la segmentación y posterior reconstrucción.

Además de las comentadas previamente, existen muchas otras aplicaciones informáticas, cuya finalidad es similar a la nuestra, aportar un recurso informático para la enseñanza de determinadas regiones del cuerpo humano que, por sus características intrínsecas, son catalogadas como "difíciles" por las habilidades espaciotemporales que precisa su estudio, como son las siguientes:

- Aplicación 3D para el estudio del tracto urogenital masculino (Uhl et al., 2006):

Reconstrucción tridimensional del tracto urogenital masculino a partir de imágenes seccionales de cadáver, pero no emplea como también hacemos en nuestra aplicación imágenes seccionales de resonancia magnética. El modelo no incluye músculos relacionados con el sistema urogenital como el diafragma pélvico y los músculos perineales, y sólo muestra modelos 3D, pero no imágenes seccionales a diferencia de nuestra aplicación. Incluye un modo de visualización especial para 
proporcionar un efecto estereoscópico mediante el uso de gafas de color verde y rojo.

- Modelo 3D para el estudio del suelo pélvico femenino (Hampton y Sung, 2010):

Muestra órganos pélvicos y sus estructuras de soporte, pero no incluye estructuras vasculares ni nerviosas, por lo que cuenta con menor detalle anatómico que nuestra aplicación. Además, el recorrido por la pelvis se realiza siguiendo un itinerario guiado, no como en nuestro recurso, que se realiza a voluntad del usuario. Muestra modelos 3D, pero no imágenes seccionales. Tiene voz en off, animaciones y videoclips. Compagina los modelos tridimensionales con módulos de enseñanza de patologías del suelo pélvico.

- Herramienta 3D para el estudio de la vía óptica y el sistema oculomotor (Juanes et al., 2014d):

Muy similar a nuestra aplicación. Emplea para la reconstrucción tridimensional imágenes de resonancia magnética de alta resolución. No hay imágenes seccionales de cadáver como en nuestro recurso.

- Aplicación 3D para estudio del cuerpo perineal (Larson et al., 2010):

Modelo tridimensional con órganos pélvicos y estructuras del cuerpo perineal. Cuenta con menor detalle anatómico que nuestra aplicación, ya que no contiene estructuras vasculares ni nerviosas. Muestra modelos 3D e imágenes seccionales de RM, no de cadáver como también aparecen en nuestro desarrollo informático. La aplicación no hace referencia a que se pueda interactuar con los modelos 3D. 
- Recurso 3D para el estudio de los músculos y nervios craneales del sistema oculomotor (Allen et al., 2015):

Emplea para la reconstrucción secciones del VHP, pero solo muestra modelos, no imágenes seccionales. Como diferencia con nuestra aplicación, va acompañado de narración, empleando lo que denominan efecto de personalización (voz personal y acogedora). Según los autores al recibir la información por dos canales sensoriales, como la vista y el oído se reduce la carga cognitiva y se mejora el aprendizaje.

- Aplicación 3D para el estudio de la red venosa de la extremidad inferior en el feto humano (Kurobe et al., 2015):

Modelos tridimensionales reconstruidos a partir de extremidades inferiores fetales, en las que los autores realizaron los cortes seccionales. Muestra modelos e imágenes seccionales de sus cortes anatómicos, pero reconocen que la reconstrucción se mejoraría, empleando también imágenes seccionales de RM o TC, como realizamos en nuestra aplicación. En su trabajo no describen si hay posibilidad de interactuar con los modelos.

- Aplicación 3D para el estudio del sistema ventricular del cerebro (Gonzalo Domínguez et al., 2016):

Valora la morfología del sistema ventricular del cerebro en su conjunto y desde cualquier posición espacial. Muestra modelos 3D e imágenes seccionales de RM, pero no de cadáver, como también aparecen en nuestro desarrollo informático. Permite la interacción con los modelos y cuenta con una interfaz intuitiva al igual que en nuestra aplicación. 
- Aplicación 3D para el estudio de la base del cráneo (Tabernero Rico et al., 2017):

Reconstrucción tridimensional realizada a través de imágenes seccionales de TC. Muestra imágenes seccionales de TC (no de cadáver y RM) y modelos 3D con los que se puede interactuar, como en nuestra aplicación.

Reseñamos a continuación, las cuestiones que consideramos más significativas de nuestro desarrollo interactivo 3D. Son, principalmente, la fidelidad anatómica que refleja, entre otras razones gracias a la calidad de las imágenes seccionales empleadas, la utilidad didáctica/práctica y la funcionalidad, determinada básicamente por la interfaz de usuario.

Un estudio realizado por Zilverschoon et al. (2018), tras el análisis de varias herramientas 3D concluye que las aplicaciones que utilizan imágenes seccionales son más completas y proporcionan un mayor realismo anatómico al permitir la inclusión de estructuras biológicas pequeñas. Además, las que emplean imágenes obtenidas por técnicas diagnósticas como la resonancia magnética permiten observar la existencia de diferencias anatómicas entre distintos individuos. Las que tienen finalidad comercial, suelen tener mejor funcionalidad al ser diseñadas por "expertos", pero más complejidad, se pueden aplicar a cualquier sistema operativo en general, incluidos los dispositivos móviles, y muestran mayor extensión anatómica (del cuerpo entero en los atlas) pero menor detalle estructural. Según su opinión, las aplicaciones con finalidad principalmente didáctica, como es el caso de nuestro recurso pélvico, suelen restringirse a zonas anatómicas concretas y cuentan en general con mayor detalle anatómico, permitiendo una mejor comprensión de regiones estructuralmente complejas.

En referencia a los detalles anatómicos, Kraima et al. (2013) ponen de manifiesto que, para realizar una reconstrucción anatómica fiable, con la inclusión de pequeñas estructuras anatómicas, es preferible emplear imágenes seccionales de cadáver e imágenes seccionales proporcionadas por técnicas diagnósticas como la RM. 
Las imágenes seccionales ofrecen una visión fidedigna tanto de la forma como de la posición relativa de los órganos y estructuras anatómicas de una región corporal, ofrecidas en una visión bidimensional, que convertiremos en tridimensional mediante la adicción de secciones sucesivas (Clascá et al., 2002). En nuestra aplicación, la generación volumétrica de las estructuras anatómicas de la pelvis femenina se llevó a cabo a partir de imágenes seccionales de cadáver del "Visible Human Project" e imágenes obtenidas a través de técnicas diagnósticas de imagen (RM), y con el propósito de dotar de la mayor fiabilidad y robustez a la generación de los modelos tridimensionales, como la reconstrucción vascular, y nerviosa, realizamos la segmentación manual de las imágenes seccionales marcando estas estructuras en cada una de ellas, con la colaboración de especialistas expertos, fue una de las tareas más complicadas y laboriosas del trabajo por la gran precisión requerida. Los modelos de algunos autores, con aplicaciones similares, como Balaya et al. (2016), Hassinger et al. (2010), Temkin et al. (2006), no pudieron mostrar estructuras nerviosas de pequeño calibre, incluso a pesar de que el primero de ellos, también realizó la segmentación manual de las imágenes seccionales pélvicas. Para el proceso de segmentación de las imágenes hay que tener en cuenta que, aunque las segmentaciones automática y semiautomática son claramente más rápidas y cómodas, no permiten en muchas ocasiones diferenciar estructuras pequeñas con densidad o contraste similar (Erolin, 2019; An et al., 2017).

Nuestro trabajo proporciona una colección iconográfica de imágenes seccionales de cadáver, resonancia magnética y ecografía de gran calidad, pudiendo aplicarse a distintas funciones como instruir a los estudiantes en la interpretación de imágenes de resonancia magnética o ecografía, como también señalan Drapkin et al. (2015), para la evaluación de diferencias anatómicas entre distintos sujetos, como ya comentamos en las apreciaciones de Zilverschoon et al. (2018) y como así mismo afirman Moore et al. (2017), o como herramienta de apoyo docente para futuros proyectos y aplicaciones que involucren interpretaciones o descripciones anatómicas.

Es una característica importante de nuestro desarrollo informático la posibilidad de correlacionar dos técnicas de imagen tan importantes en el estudio de la pelvis, 
especialmente la femenina, como son la RM y la ecografía, ya que son totalmente distintas en cuanto a su obtención y especialmente en su interpretación. Ambos estudios de imagen son fundamentales para el diagnóstico de múltiples patologías pélvicas, así como para la planificación de su tratamiento, como se aprecia en los trabajos de numerosos autores (Chan y Tse, 2018; Graupera et al., 2018; Kaniewska et al., 2018; Kim et al., 2018; Vellucci et al., 2018; Dietz, 2017; Murad-Regadas et al., 2017; Ram et al., 2017; Salsi et al., 2017; Wlaźlak et al., 2017; Xuang et al., 2017; Xue et al., 2017; Peng et al., 2016; Terracciano et al., 2016; Thibault-Gagnon et al., 2016; Portilla et al., 2015; Van Delft et al., 2015; Youssef et al., 2015; Bitti et al., 2014; Dietz, 2014; García del Salto et al., 2014; Hennemann et al., 2014; Morin et al.,2014; Murad-Regadas et al., 2014; Nardos et al., 2014; Rostaminia et al., 2014a; Rostaminia et al., 2014b; Dietz et al., 2012), siendo su uso muchas veces conjunto (Chamié et al.,2018; Javadian et al., 2017; Vergeldt et al., 2016; Notten et al., 2014). La mayoría de los estudiantes se sienten intimidados la primera vez que tienen contacto con las imágenes de ultrasonidos, puesto que a diferencia de las radiológicas (radiografías, TC y RM) que pueden ser interpretadas fácilmente por cualquier persona con suficientes conocimientos anatómicos y nociones básicas de esas técnicas imagen, las imágenes ecográficas son operador-dependiente para su interpretación; esto hace que sea una prueba diagnóstica difícil de analizar por personas no instruidas en su uso habitual. Por tanto, nuestra aplicación contribuye a que los estudiantes comprendan mejor las imágenes de ultrasonidos pélvicas gracias a la posibilidad de seleccionar la misma estructura en la imagen de RM y en la de ecografía.

Consideramos que nuestro desarrollo pélvico 3D interactivo es un atlas anatómico regional dinámico, que se posiciona como un instrumento apropiado y útil para la enseñanza descriptiva de anatomía, especialmente para la comprensión de conceptos que requieren habilidad espacial, como confirman varios autores tras el empleo didáctico de este tipo de recursos (Jamil et al., 2019; Guimaráes et al., 2018; Balaya et al., 2016; Morris et al., 2016; Pujol et al., 2016; Allen et al., 2015; Berney et al., 2015; Hoyek et al., 2014; Lewis et al., 2014; Framiñán et al., 2013; Luo et al., 2011; Sergovich et al., 2010). Una visualización en tres dimensiones y desde distintas perspectivas, como la que proporciona nuestra aplicación, que además muestra 
modelos tridimensionales embebidos en imágenes seccionales de cadáver y de resonancia magnética, permite apreciar la morfología, la localización y la topografía de las estructuras pélvicas, así como las relaciones de vecindad que establecen, facilitando la comprensión de esta región, especialmente compleja. Las imágenes seccionales axiales proporcionan una visión más clara de las estructuras individuales dentro de esta región, mientras que las sagitales ilustran mejor las relaciones cráneo caudales existentes, lo que se mejora aún más con los modelos tridimensionales. De hecho, la visión volumétrica de nuestro recurso 3D fue muy valorada por los estudiantes, manifestando que nuestra aplicación les facilitó el entendimiento y la comprensión de las estructuras anatómicas que constituyen la región pélvica femenina.

Estimamos así mismo, que representa una herramienta atractiva para que residentes y profesionales de diferentes especialidades médicas la aprovechen como medio auxiliar para la planificación de un escenario quirúrgico en algunas regiones corporales, como opinan con sus trabajos varios autores (Mavar-Haramija et al., 2015; Juanes et al., 2014d; De Notaris et al., 2013; Kraima et al., 2013), aunque según Kostusiak et al. (2017) hacen falta estudios rigurosos que certifiquen la utilidad de estas aplicaciones para el entrenamiento quirúrgico. Sin embargo si presenta, a nuestro juicio, gran interés para suministrar a los pacientes una información más clara y sencilla sobre una posible intervención quirúrgica y los riesgos inherentes a la misma (Balaya et al., 2016), para complementar exploraciones físicas (Kearney et al., 2006) o para mejorar la comprensión de la funcionalidad de ciertas estructuras anatómicas en algunas patologías (Abdulaziz et al., 2017; Chen et al., 2017; Doumouchtsis et al., 2017; Giannini et al., 2017; Juanes et al., 2015; Kraima et al., 2013; Hoyte et al.,2001).

Es una tecnología de aprendizaje de gran valor para complementar los métodos tradicionales (Houser y Kondrashov, 2018; Hu et al., 2018), como manifestaron la mayoría de nuestros estudiantes, y muy eficaz para el proceso de enseñanza y aprendizaje, como avalan los resultados de los estudios realizados por varios autores (Triepels et al., 2019; Wilson et al., 2019; Deng et al., 2018; Hech y Larrázabal, 2018; Mitrousias et al., 2018; Allen et al., 2016; Morris et al., 2016; Legendre et al., 2015; 
Sanchís López, 2015; Das y Mitchell, 2013; Noguera et al., 2013; Ruisoto et al., 2012; Abid et al., 2010). Sin embargo, para ciertos autores (O'Rourke et al., 2020; Azer y Azer, 2016; Peterson y Mlynarczyk, 2016; Van Nuland y Rogers, 2016; Keedy et al., 2011; Corton et al., 2006) esta metodología no aventaja a los tradicionales atlas anatomo-radiológicos estáticos (opinión que comparten algunos de nuestros alumnos) e incluso para otros (Yammine y Violato, 2016; Lombardi et al., 2014; Yammine y Violato, 2014; Preece et al., 2013) es superada por instrumentos didácticos como los modelos físicos. Para Estai y Bunt (2016), que defienden el enfoque multimodal de la enseñanza, la mayor efectividad de estos modelos didácticos se obtiene mediante su combinación con varios recursos pedagógicos.

Lai y Bower (2020), tras la revisión bibliográfica realizada en su trabajo, sobre la aplicación de las metodologías digitales interactivas en la enseñanza, afirman que son herramientas que mejoran los resultados de aprendizaje y las percepciones afectivas (satisfacción), siendo más efectivas aquellas cuyo enfoque metodológico involucra la interacción, el constructivismo y el aprendizaje centrado en el estudiante, objetivo que siempre tuvimos en cuenta para el desarrollo e implementación de nuestro desarrollo informático, ya que promueve los procesos de exploración e indagación por parte de los usuarios como ya reflejamos en un párrafo anterior del capítulo.

Aunque, como se puede apreciar, hay distintos puntos de vista sobre el mejor modelo de aprendizaje, todos los autores mencionados sugieren que las aplicaciones 3D interactivas facilitan el aprendizaje y aumentan la satisfacción de los estudiantes, como también reflejaron los resultados de nuestro trabajo. Los estudiantes que emplearon nuestra aplicación consideraron que se trataba de una herramienta muy beneficiosa para el apoyo y complemento de la enseñanza tradicional, con contenidos bastante completos e ilustrativos de la anatomía pélvica y con una visión tridimensional de las estructuras que proporcionaba una mejor comprensión y análisis de las mismas, aumentaba la motivación para el estudio de esta región anatómica e incrementaba la satisfacción percibida con su utilización, de manera que la recomendarían a otros compañeros para el estudio de la anatomía y la radiología de la pelvis, suelo pélvico y su contenido. 
En referencia a la funcionalidad, destacar que prácticamente la totalidad de los programas informáticos, tengan o no una finalidad educativa, están estructurados como un conjunto dividido en tres partes: una que contiene los datos del programa, debidamente organizados, otra que se encarga de combinar y gestionar la comunicación con el mismo y, una tercera, que se ocupa de tratar dichos datos y dar respuesta a los requerimientos formulados por los usuarios. Es necesario que exista una fácil interacción entre el programa y la persona que lo utiliza, que es de lo que se encarga la denominada interfaz de usuario (conjunto de controles y canales sensoriales mediante los cuales un ser humano puede comunicarse con una máquina).

Estos medios tienen que ser fáciles de entender y de accionar, lo que en lenguaje informático se entiende como "intuitivos y amigables". Entendida de esta forma, la interfaz de usuario sería el espacio donde se producen las interacciones entre las personas y las máquinas $y$, en ella podríamos distinguir una interfaz de hardware (dispositivos empleados para ingresar, procesar y entregar los datos, como el teclado, el ratón, la pantalla, etc.), otra de software (para proporcionar información de los procesos y herramientas de control, normalmente a través de lo que el usuario observa en la pantalla) y una interfaz software-hardware que sirve de puente entre la máquina, permitiéndole entender las instrucciones, y el usuario, traduciendo el código binario a una información humanamente comprensible.

La interfaz de usuario se puede clasificar en función de su construcción o de su forma de interactuar con el usuario. Según su construcción pueden ser interfaces de hardware, con teclas o dispositivos para que el usuario intercambie datos con la máquina (pulsadores, botones, teclas, etc.) o interfaces de software, programas (o parte de los mismos) que facilitan dar las órdenes a la computadora o visualizar sus respuestas. Si tenemos en cuenta la forma de interactuar del usuario, podríamos hablar de interfaces de línea de comandos (Comand Line Interface, CLI) basados en comandos de texto, interfaces gráficas de usuario (Graphic User Interface, GUI), con representaciones gráficas de los elementos de control y, por último, de una interfaz natural de usuario (Natural User Interface, NUI) asentada en pantallas táctiles, reconocimiento del habla o del movimiento. Son estas últimas las que, con el 
desarrollo de las tecnologías multimedia y de la Inteligencia Artificial permiten la constitución de entornos de comunicación máquina/humano más intuitivos y naturales.

Para optimizar el aprendizaje con programas informáticos docentes es importante atender al diseño de la interfaz de usuario, en la que hemos cuidado aspectos como la composición, la estética y la funcionalidad. Pensamos que la forma o disposición en la que se distribuyen los elementos influye en la respuesta de los usuarios, haciendo que mantengan la atención sobre el desarrollo informático y que se despierte el interés por el contenido didáctico. La estética atractiva estimula al estudiante a permanecer más tiempo sobre los contenidos del programa $y$, por tanto, a retener mejor los conceptos transmitidos con la aplicación. Una buena funcionalidad que permita explorar la aplicación informática de forma sencilla y sin dedicar excesivo tiempo para su manejo también resultará más atractiva y dinámica para los usuarios (Juanes Méndez et al., 2010).

El diseño de la interfaz debe asegurar que el proceso de interacción se realice de manera fácil e intuitiva para que el usuario pueda ejecutar las acciones que desea de la manera más simple posible, y en ese sentido estimamos de gran ayuda, la incorporación de iconos representativos de la función a utilizar.

El estándar ISO/IEC 9241-9:2001 sobre la ergonomía de la interacción entre personasistema, especifica una serie de principios aplicables al diseño de la interfaz, tales como claridad (el contenido de la información se presenta de forma clara y concisa), discriminabilidad (la información que se visualiza se distingue de forma precisa), concisión (los usuarios no son sobrecargados con información irrelevante), consistencia (el diseño es único y conforme a las expectativas del usuario), detectabilidad (la atención del usuario es dirigida hacia la información necesaria), legibilidad (la información es fácil de leer) y comprensibilidad (el significado es claramente inteligible y reconocible).

El diseño de la interfaz de nuestro desarrollo informático se ajusta a las premisas comentadas anteriormente, y estimamos que su configuración la hace atractiva, fácil de entender y muy sencilla de manejar, permitiendo a los usuarios navegar por la 
aplicación de una manera rápida y eficaz. Según Bringman-Rodenbarger y Hortsch (2020) muchos usuarios seleccionan para el estudio aquellas aplicaciones que cuentan con una interfaz atractiva, obviando otros aspectos, como la importancia didáctica o formativa de las mismas.

Además de la visión tridimensional de las estructuras, la facilidad de interacción con la aplicación es una de las principales ventajas que ofrece nuestro procedimiento. Es sencillo de manejar, incluso para estudiantes con conocimientos básicos de informática y sin que requieran apoyo o capacitación adicionales, aspecto que señalan Morris et al. (2016) como característica muy destacada de su aplicación. Para O’Rourke et al. (2020), por el contrario, la implementación de estos recursos precisa conocimientos previos en el manejo de este tipo de tecnología informática.

El visor anatómico tridimensional desarrollado permite valorar las estructuras óseas, musculares y especialmente las viscerales, así como la irrigación arterial y venosa de la región pélvica e incluso su inervación, describiendo y analizando los principales elementos que se sitúan en esta zona. Permite la traslación, rotación, zoom, selección, adicción, sustracción y captura de las imágenes, algo que no todos los desarrollos informáticos permiten, como la aplicación de Hassinger et al. (2010) en la que las funciones de adicción y sustracción no están incluidas o la de Lone et al. (2018), en la que la rotación de las imágenes no fue efectiva y la calidad de las mismas no reproducía totalmente la anatomía dental, aunque según la opinión de Fenesi et al. (2017), la calidad de las imágenes no tiene una importancia determinante en el estudio de anatomía y se plantean si merece la pena invertir en la elaboración de este tipo de recursos didácticos.

El programa permite al usuario navegar libremente por las imágenes de cadáver, resonancia magnética y ultrasonido, pudiendo analizar las estructuras anatómicas pélvicas desde cualquier ángulo y en los tres planos del espacio (axial, coronal y sagital).

Nuestra aplicación informática ha sido elaborada rigurosamente, de manera que permita manejar a voluntad todas las opciones que ofrece, lo que significa establecer una interacción continua con el programa, motivando al usuario y convirtiendo a 
este en constructor activo y responsable directo de su proceso de aprendizaje, lo que a su vez repercute en una optimización del tiempo dedicado al estudio. El individuo puede estudiar de forma autónoma, marcando el lugar, horario y ritmo de aprendizaje.

La calidad de nuestro recurso didáctico se sometió a la valoración de los estudiantes y reflejó que tanto la instalación y el funcionamiento (no se bloqueaba nunca o casi nunca) como el manejo de la aplicación, son sencillos, la navegación por el programa fácil e intuitiva y la presentación visual de los contenidos, atractiva. Además, la aplicación es accesible para los estudiantes, ya que la disponibilidad de equipos informáticos con alto rendimiento tecnológico, compatibles con las necesidades de ejecución de software de enseñanza con características hipermedia, que requieren gran capacidad de memoria, es prácticamente generalizada en la actualidad.

Ya no llama la atención que el mayor porcentaje de estudiantes en cualquiera de las de ciencias de la salud sean del sexo femenino, aunque parece que el sexo de los estudiantes no influye en los resultados que se obtienen tras el empleo de los softwares educativos en la enseñanza, como se aprecia en algún estudio realizado al respecto (Guimaráes et al., 2018; Sanchís López, 2015). Sin embargo, para Jamil et al. (2019), la percepción espacial ofreció mejores resultados en los estudiantes del sexo masculino.

Como comentábamos al principio de la discusión, la familiaridad de nuestros alumnos con los recursos tecnológicos, nos plantean nuevos retos, como la posibilidad de adaptar en un futuro nuestra aplicación para su utilización en dispositivos móviles, dado el creciente uso social de esta tecnología y los excelentes resultados que aporta sobre el aprendizaje, como han demostrado los estudios de algunos autores (Golenhofen et al., 2020; Briz et al., 2014; Noguera et al., 2013).

De la misma manera, la naturaleza dinámica y en continua evolución de la educación médica y sanitaria y las cada vez mayores posibilidades que ofrece la tecnología para capacitar a los profesionales de la salud, que requieren conocimientos más experienciales y prácticos que en otras disciplinas, nos han llevado a pensar en un posible desarrollo de nuestro trabajo hacia metodologías aún más innovadoras como 
la realidad aumentada y la realidad virtual no inmersiva e inmersiva, en pleno auge actualmente (Moro et al., 2020; Moro et al., 2019; Moro y Gregory, 2019; Izard et al., 2018; Jiménez López et al., 2017; Wohlrab et al., 2017; Juanes et al., 2014b).

La realidad virtual es una tecnología innovadora, basada en representaciones de la realidad generadas de forma artificial por sofisticados sistemas informáticos, que permite percibir escenas, imágenes u objetos de forma real a través de la utilización de accesorios variados como sistemas de visualización (gafas), cascos de audio o dispositivos hápticos (guantes). Esta capacidad de simular la realidad hace que esta tecnología, principalmente en su variedad inmersiva, pueda ser aplicable a numerosos campos y áreas del conocimiento en Medicina, además del formativo o educacional, en el que se presenta como una excelente herramienta de aprendizaje basada en la resolución de problemas, que favorece especialmente la adquisición de habilidades prácticas (Birbara et al., 2020; Pardos, 2017; Bakr et al., 2015; Juanes et al., 2014a; Dobson et al., 2003).

La simulación clínica bajo entornos tecnológicos abre grandes posibilidades en la práctica médica, permitiendo numerosas funciones como por ejemplo el adiestramiento en el manejo de equipos médicos como el desfibrilador o el entrenamiento en habilidades prácticas complejas como la endoscopia, la laparoscopia o la navegación endovascular, proporcionando además la opción de realizarlo en grupo y no solo de forma individual. En el campo de la cirugía posibilita la simulación de intervenciones quirúrgicas, tantas veces como sea necesario, e incluso en el propio paciente, tras la creación de un modelo digital del mismo. También se está empleando para la rehabilitación neurológica, en el campo de la psicopatología para el tratamiento de fobias o ansiedad, para ayudar a desenvolverse en ciertos ambientes en el autismo o en la reducción del dolor percibido tras la amputación de un miembro (Bin et al., 2020). Sin embargo, para Triepels et al. (2019) estas tecnologías de realidad aumentada y realidad virtual son bastante novedosas y existe poca literatura que permita corroborar la eficacia que actualmente prometen. 
Es evidente que en el entorno educativo, y especialmente en la formación médica, la tendencia indica que la tecnología y la educación evolucionarán de forma paralela, de manera que las necesidades educativas impulsarán el progreso tecnológico y éste a su vez inducirá cambios en los modelos educativos, lo que en definitiva confirma que en la era de la información y la comunicación, el binomio educación-tecnología será uno de los pilares básicos para el desarrollo, el crecimiento y el progreso de la sociedad. 


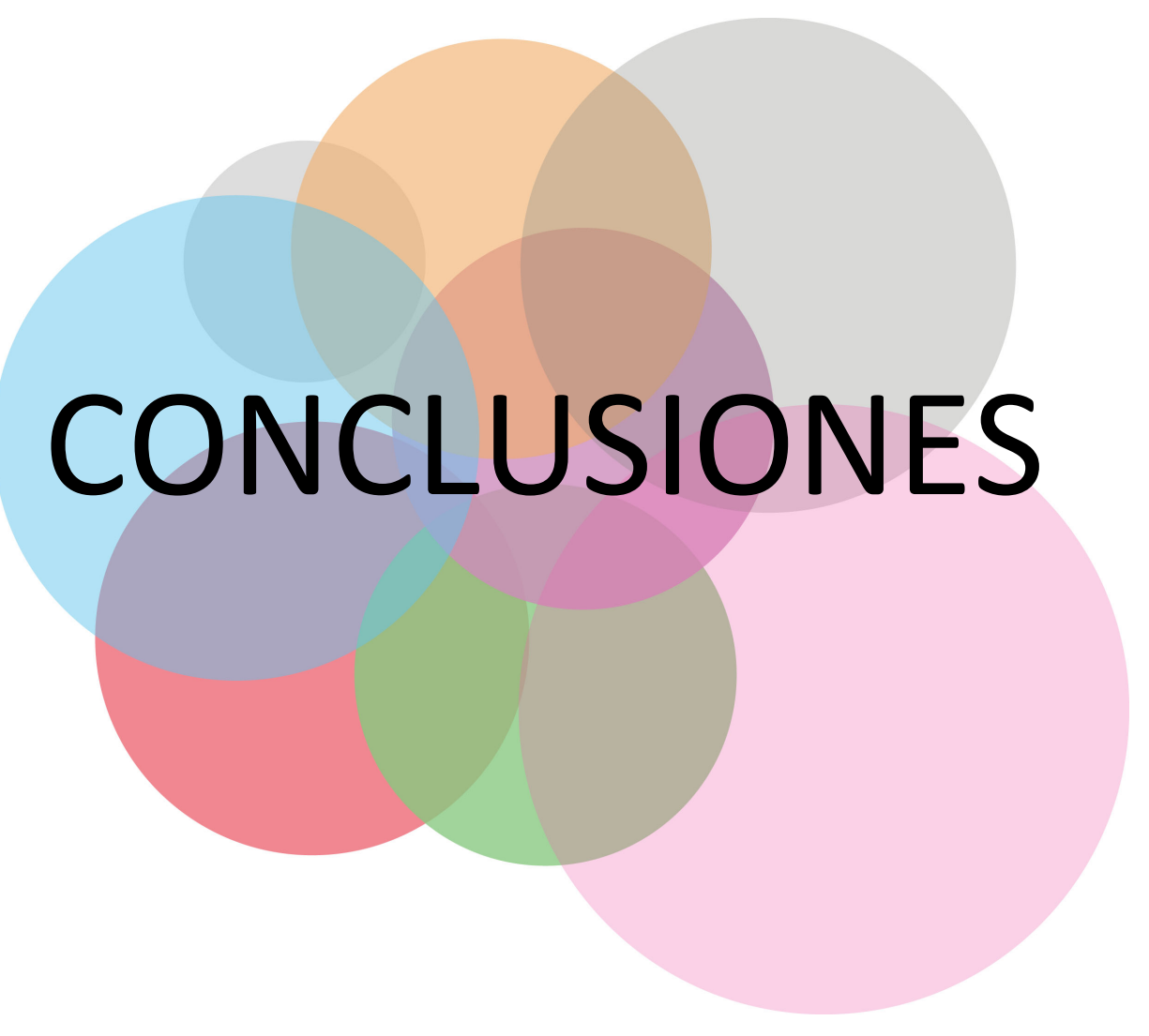


Tras desarrollar y analizar una herramienta informática docente interactiva, para la visualización 3D de las estructuras anatómicas de la pelvis femenina, con el fin de servir de ayuda y complemento a la formación anatómica tradicional de nuestros alumnos de Medicina u otras titulaciones de las Ciencias de la Salud, hemos llegado a las siguientes conclusiones:

1ạ. - Las imágenes seccionales axiales de cadáver, y los cortes de Resonancia Magnética de alta resolución empleados en nuestro estudio, han constituido unos excelentes recursos para la identificación y la segmentación manual de las estructuras anatómicas que integran la pelvis femenina (paredes óseas, músculos, elementos viscerales y vásculo-nerviosos), consiguiendo así un excelente atlas anatómico tridimensional interactivo de las estructuras pélvicas.

2a. - Nuestro desarrollo informático, está controlado totalmente por el usuario. Es él quien decide la forma de visualizar las imágenes y en la posición espacial que desee, por lo que consideramos que nuestra aplicación informática constituye una verdadera herramienta docente en la que existe una interacción entre el ordenador y el usuario, evitando así, en la medida de lo posible, que éste último se convierta en un mero espectador.

3a. - Los estudiantes que manejaron la herramienta, han considerado que se trata de un diseño informático muy innovador, que facilita el estudio, comprensión y aprendizaje de la anatomía de la pelvis femenina, posibilitando así, de una manera atractiva, dinámica, visual y animada; la adquisición de los conocimientos necesarios de los elementos anatómicos de la pelvis femenina. 
4ạ. - El procedimiento tecnológico desarrollado, está dotado de una buena interactividad entre el usuario y el ordenador, aumentando de esta forma la motivación y promoviendo un aprendizaje activo y autónomo en los alumnos, lo que se traduce a su vez, en una optimización del tiempo dedicado al estudio.

5a. - La incorporación y utilización de recursos informáticos de visualización 3D, como el que hemos desarrollado, aplicados al aprendizaje de la anatomía, abren nuevas perspectivas de enseñanza, más próximas a la realidad anatómica del cuerpo humano, y acordes a la sociedad tecnológica actual, lo que supone disponer de herramientas con gran utilidad docente, tanto para los estudiantes como para el profesorado en la formación médica.

6a. - En la actualidad los alumnos, que estudian en nuestras aulas universitarias de la Facultad de Medicina, son de predominio femenino. Todos ellos disponen de algún dispositivo electrónico portable (Smartphone y/o Tablet), al que le dedican un alto porcentaje de tiempo al día; constituyéndose estos recursos tecnológicos en herramientas útiles y complementarias para su uso docente. Por ello, incorporar programas informáticos de visión 3D, como el propuesto en nuestro trabajo de Tesis se considera necesario y útil como parte de sus herramientas formativas.

7ạ. - Los alumnos que manejaron nuestra aplicación interactiva, resaltaron su alto valor docente, de fácil manejo por su interfaz intuitiva; considerando este recurso tecnológico con un alto nivel de satisfacción en su proceso de enseñanza-aprendizaje, dado su carácter visual en 3D muy atractivo. Por todo ello, los alumnos consideran recomendable su utilización en su formación médica. 


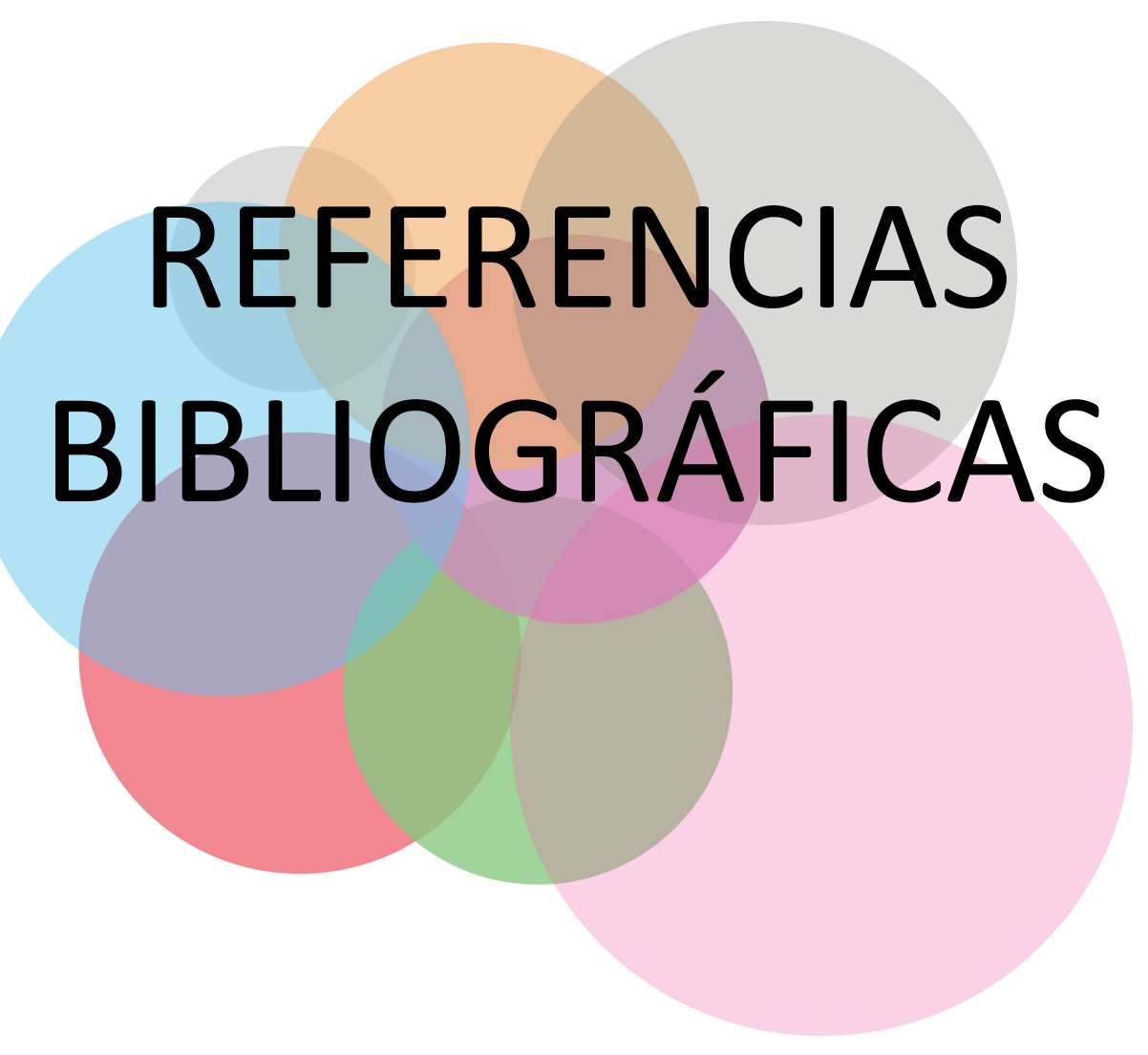


Abdulaziz, M., Deegan, E. G., Kavanagh, A., Stothers, L., Pugash, D. y Macnab, A. (2017). Advances in basic science methodologies for clinical diagnosis in female stress urinary incontinence. Canadian Urological Association Journal, 11 (6S2), 117-120. https://doi.org/10.5489/cuaj.4583

Abid, B., Hentati, N., Chevallier, J. M., Ghorbel, A. y Delmas, V. (2010). Traditional versus three-dimensional teaching of peritoneal embryogenesis: a comparative prospective study. Surg Radiol Anat, 32, 647-652. https://doi.org/10.1007/s00276-010-0653-1

Ackerman, M. J. (2016). The visible human project ${ }^{\circledR}$ : From body to bits. 38th Annual International Conference of the IEEE Engineering in Medicine and Biology Society (EMBC), 3338-3341. https://doi.org/10.1109/EMBC.2016.7591442

Alapati, S. y Jambhekar, K. (2017). Dynamic Magnetic Resonance Imaging of the Pelvic Floor. Seminars in Ultrasound, CT and MRI, 38 (3), 188-199. https://doi.org/10.1053/j.sult.2016.11.002

Allen, L. K., Bhattacharyya, S. y Wilson, T. D. (2015). Development of an interactive anatomical three-dimensional eye model. Anat Sci Educ, 8, 275-282. https://doi.org/10.1002/ase.1487

Allen, L. K., Eagleson, R. y De Ribaupierre, S. (2016). Evaluation of an online threedimensional interactive resource for undergraduate neuroanatomy education. Anatomical Sciences Education, 9, 5, 431-439. https://doi.org/10.1002/ase.1604

Alt, C. D., Hampel, F., Hallscheidt, P., Sohn, C., Schlehe, B. y Brocker, K. A. (2016). 3 T MRIbased measurements for the integrity of the female pelvic floor in 25 healthy nulliparous women. Neurourology and Urodynamics, 35 (2), 218-223. https://doi.org/10.1002/nau.22697

An, G., Hong, L., Zhou, X.-B., Yang, Q., Li, M.-Q. y Tang, X.-Y. (2017). Accuracy and efficiency of computer-aided anatomical analysis using $3 \mathrm{D}$ visualization software based on semi-automated and automated segmentations. Annals of Anatomy - Anatomischer Anzeiger, 210, 76-83. https://doi.org/10.1016/j.aanat.2016.11.009

Arantes, M., Arantes, J. y Ferreira, M. A. (2018). Tools and resources for neuroanatomy education: a systematic review. BMC Medical Education, 18, 94. https://doi.org/10.1186/s12909-018-1210-6

Araujo Cuauro, J. C. (2018). Aspectos históricos de la enseñanza de la anatomía humana desde la época primitiva hasta el siglo XXI en el desarrollo de las ciencias morfológicas. Revista Argentina Anatomía Online, 9 (3), 87 - 97. Recuperado de http://www.revista-anatomia.com.ar/archivos-parciales/2018-3-revista-argentinade-anatomia-online-d.pdf

Araujo Júnior, E., Jármy-Di Bella, Z. I. K., Diniz Zanetti, M. R., Poli Araujo, M., Dellabarba Petricelli, C., Martins, W. P., Alexandre, S. M. y Uchiyama Nakamura, M. (2014). 
Assessment of pelvic floor of women runners by three-dimensional ultrasonography and surface electromyography. A pilot study. Medical Ultrasonography, 16 (1), 21-26. Recuperado de http://www.ncbi.nlm.nih.gov/pubmed/24567920

Arrondo, G., Bernacer, J. y Robredo, L. D. (2016). Visualización de modelos digitales tridimensionales en la enseñanza de anatomía: principales recursos y una experiencia docente en neuroanatomía. Educación Médica, 18 (4), 267-269. https://doi.org/10.1016/j.edumed.2016.06.022

Asensio Romero, L., Asensio Gómez, M., Juanes Méndez, J. A. y Prats-Galino, A. (2017). Anatomy-radiological assessment of female pelvis through three-dimensional models coregistered with sectional images of magnetic resonance. ICERI 2017 Proceedings, 1466-1472. https://doi.org/10.21125/iceri.2017.0466

Asensio Romero, L., Asensio Gómez, M., Prats-Galino, A. y Juanes Méndez, J. A. (2018). 3D Models of Female Pelvis Structures Reconstructed and Represented in Combination with Anatomical and Radiological Sections. Journal of Medical Systems, 42 (3), 37. https://doi.org/10.1007/s10916-018-0891-z

Asensio Romero, L., Asensio Gómez, M., Prats-Galino, A. y Juanes Méndez, J. A. (2018). Technological development of visualization of magnetic resonance sectional images and pelvic floor ultrasonography for teaching purposes. Proceedings of the Sixth International Conference on Technological Ecosystems for Enhancing Multiculturality - TEEM'18, 357-361. https://doi.org/10.1145/3284179.3284240

Asensio Romero, L., Asensio Gómez, M., Prats-Galino, A. y Juanes Méndez, J. A. (2018). Technological advances in the visualization of the vascularization of the pelvis under interactive three-dimensional environments. Edulearn 18 Proceedings, 802-811. https://doi.org/10.21125/edulearn.2018.0286

Asensio Romero, L., Asensio Gómez, M., Prats-Galino, A. y Juanes Méndez, J. A. (2019). Computer Application of Ultrasound and Nuclear Magnetic Resonance Images for the Anatomical Learning of the Pelvis and the Female Pelvic Floor. Journal of Medical Systems, 43 (5), 110. https://doi.org/10.1007/s10916-019-1240-6

Asensio Romero, L., Asensio Gómez, M., Prats-Galino, A. y Juanes Méndez, J. A. (2019). 3D Reconstruction of the Female Perineal Musculature, from Sections of Magnetic Resonance. Proceedings of the Seventh International Conference on Technological Ecosystems for Enhancing Multiculturality - TEEM'19, 380-385. https://doi.org/10.1145/3362789.3362829

Asensio Romero, L., Asensio Gómez, M., y Juanes Méndez, J. A. (2017). Development of 3D models of female pelvis embedded in anatomical sections from de Visible Human Project. Proceedings of the Fifth International Conference on Technological Ecosystems for Enhancing Multiculturality - TEEM'17, 53, 1-7. https://doi.org/10.1145/3144826.3145403 
Astudillo, M., Pinto, B., Arboleda, J. y Anchundia, Z. (2018). Aplicación de las TIC como herramienta de aprendizaje en la educación superior. Revista Científica Mundo de la Investigación y el Conocimiento, 2 (2), 585-598. Recuperado de http://recimundo.com/index.php/es/article/view/247

Azer, S. A. y Azer, S. (2016). 3D Anatomy Models and Impact on Learning: A Review of the Quality of the Literature. Health Profession Education, 2 (2), 80-98. https://doi.org/10.1016/j.hpe.2016.05.002

Bakr, M. M., Massey, W. L. y Alexander, H. (2015) Can Virtual Simulators Replace Traditional Preclinical Teaching Methods: A Students' Perspective?. Int J Dent Oral Health, 2, 1, 1-6. https://doi.org/10.16966/2378-7090.149

Balaya, V., Uhl, J. F., Lanore, A., Salachas, C., Samoyeau, T., Ngo, C., Bensaid, C., Cornou, C., Rossi, L., Douard, R., Bats, A. S., Lecuru, F. y Delmas, V. (2016). Modélisation anatomique $3 \mathrm{D}$ du pelvis féminin par dissection anatomique assistée par ordinateur: applications et perspectives. Journal de Gynécologie Obstétrique et Biologie de La Reproduction, 45 (5), 467-477. https://doi.org/10.1016/j.jgyn.2016.01.006

Barbeito, A., Painho, M., Cabral, P. y O’Neill, J. G. (2017). Beyond Digital Human Body Atlases. International Journal of E-Health and Medical Communications, 8 (1), 19-36. https://doi.org/10.4018/IJEHMC.2017010102

Barrie, M., Socha, J. J., Mansour, L. y Patterson, E. S. (2019). Mixed Reality in Medical Education: A Narrative Literature Review. Proceedings of the International Symposium on Human Factors and Ergonomics in Health Care, 8, 1, 28-32. https://doi.org/10.1177/2327857919081006

Belle, M., Godefroy, D., Couly, G., Malone, S. A., Collier, F., Giacobini, P. y Chédotal, A. (2017). Tridimensional Visualization and Analysis of Early Human Development. Cell, 169 (1), 161-173.e12. https://doi.org/10.1016/j.cell.2017.03.008

Belloch, C. (2012). Las Tecnologías de la Información y Comunicación en el aprendizaje. Material docente [on-line]. Departamento de Métodos de Investigación y Diagnóstico en Educación. Universidad de Valencia. Recuperado de http://www.uv.es/bellochc/pedagogia/EVA1.pdf

Berney, S., Bétrancourt, M., Molinari, G. y Hoyek, N. (2015). How spatial abilities and dynamic visualizations interplay when learning functional anatomy with 3D anatomical models. Anatomical Sciences Education, 8 (5), 452-462. https://doi.org/10.1002/ase.1524

Bertrand, M. M., Macri, F., Mazars, R., Droupy, S., Beregi, J. P. y Prudhomme, M. (2014). MRI-based 3D pelvic autonomous innervation: a first step towards image-guided pelvic surgery. European Radiology, 24 (8), 1989-1997. https://doi.org/10.1007/s00330-014-3211-0 
Bin, S., Masood, S. y Jung, Y. (2020). Chapter Twenty - Virtual and augmented reality in medicine. En D. D. Feng (Ed.) Biomedical Engineering. Biomedical Information Technology (pp. 673-686). Academic Press, Elsevier. https://doi.org/10.1016/B978-012-816034-3.00020-1

Birbara, N. S., Sammut, C. y Pather, N. (2020). Virtual Reality in Anatomy: A Pilot Study Evaluating Different Delivery Modalities. Anat Sci Educ., 0, 1-13. https://doi.org/10.1002/ase.1921

Bitti, G. T., Argiolas, G. M., Ballicu, N., Caddeo, E., Cecconi, M., Demurtas, G., Matta, G., Peltz, M. T., Secci, S. y Siotto, P. (2014). Pelvic Floor Failure: MR Imaging Evaluation of Anatomic and Functional Abnormalities. RadioGraphics, 34 (2), 429-448. https://doi.org/10.1148/rg.342125050

Bringman-Rodenbarger, L. y Hortsch, M. (2020). How students choose E-learning resources: The importance of ease, familiarity, and convenience. FASEB BioAdvances, 00, 1- 10. https://doi.org/10.1096/fba.2019-00094

Briz Ponce, L., Juanes Méndez, J. A. y García Peñalvo, F. J. (2014). A systematic review of using mobile devices in medical education. 2014 International symposium on computers in education (SIIE), 205-210. https://doi.org/10.1109/SIIE.2014.7017731

Briz Ponce, L., Juanes Méndez, J. A., y García-Peñalvo, F. J. (2014). First approach of mobile applications study for medical Education purposes. Proceedings of the Second International Conference on Technological Ecosystem for Enhancing Multiculturality TEEM'14, 647-651. https://doi.org/10.1145/2669711.2669968

Briz, L., Juanes, J. A., y García, F. J. (2014). Analysis of mobile devices as a support tool for professional medical education in the University School. EDULEARN14 Proceedings, 4653-4658. Recuperado de http://hdl.handle.net/10366/125034

Briz-Ponce, L. y García-Peñalvo, F. J. (2015). An empirical assessment of a technology acceptance model for apps in medical education. J Med Syst, 39, 176. https://doi.org/10.1007/s10916-015-0352-x

Briz-Ponce, L., Pereira, A., Carvalho, L., Juanes-Méndez, J. A. y García-Peñalvo, F. J. (2017). Learning with mobile technologies - Students' behavior. Computers in Human Behavior, 72, 612-620. https://doi.org/10.1016/j.chb.2016.05.027

Brown, K. M., Handa, V. L., Macura, K. J. y De Leon, V. B. (2013). Three-dimensional shape differences in the bony pelvis of women with pelvic floor disorders. International Urogynecology Journal, 24 (3), 431-439. https://doi.org/10.1007/s00192-012-1876-y

Bustos Sánchez, A. y Coll Salvador, C. (2010). Los entornos virtuales como espacios de enseñanza y aprendizaje: una perspectiva psicoeducativa para su caracterización y análisis. Revista Mexicana de Investigación Educativa, 44, 15, 163-194. Recuperado de http://www.scielo.org.mx/scielo.php?script=sci_arttext\&pid=S1405$66662010000100009 \& \operatorname{lng}=e s \&$ tlng=es 
Cael, C. (2010). Anatomía Funcional. Estructura, función y palpación del aparato locomotor para terapeutas manuales. Madrid, España. Panamericana.

Calderwood, C. S., Thurmond, A., Holland, A., Osmundsen, B. y Gregory, W. T. (2017). Comparing 3-Dimensional Ultrasound to 3-Dimensional Magnetic Resonance Imaging in the Detection of Levator Ani Defects. Female Pelvic Medicine \& Reconstructive Surgery, 24 (4), 295-300. https://doi.org/10.1097/SPV.0000000000000485

Campohermoso Rodríguez, O. F., Soliz Soliz, R. E., Campohermoso Rodríguez, O. y Zúñiga Cuno, W. (2016). Galeno de pérgamo "príncipe de los médicos". Cuadernos Hospital de Clínicas, 57 (2), 84-93. Recuperado de http://www.scielo.org.bo/scielo.php?script=sci_arttext\&pid=S1652$67762016000200014 \& \operatorname{lng}=e s \& \operatorname{tng}=$

Canals, M. (2008). Historia de la resonancia magnética de Fourier a Lauterbur y Mansfield: en ciencias, nadie sabe para quien trabaja. Revista chilena de radiología, 14 (1), 39 45. http://dx.doi.org/10.4067/S0717-93082008000100009

Canby, C. A. (2007). Anatomía basada en la resolución de problemas. Barcelona, España. Elsevier.

Chakraborty, T. R. y Cooperstein, D. F. (2018). Exploring anatomy and physiology using iPad applications. Anat Sci Educ, 11, 336-345. https://doi.org/10.1002/ase.1747

Chamié, L. P., Ribeiro, D. M. F. R., Caiado, A. H. M., Warmbrand, G. y Serafini, P. C. (2018). Translabial US and Dynamic MR Imaging of the Pelvic Floor: Normal Anatomy and Dysfunction. RadioGraphics, 38 (1), 287-308. https://doi.org/10.1148/rg.2018170055

Chan, L. y Tse, V. (2018). Pelvic floor ultrasound in the diagnosis of sling complications. World Journal of Urology, 36 (5), 753-759. https://doi.org/10.1007/s00345-0182253-3

Chen, L., Lenz, F., Alt, C. D., Sohn, C., De Lancey, J. O. y Brocker, K. A. (2017). MRI visible Fe3O4 polypropylene mesh: 3D reconstruction of spatial relation to bony pelvis and neurovascular structures. International Urogynecology Journal, 28 (8), 1131-1138. https://doi.org/10.1007/s00192-017-3263-1

Clascá, F., Bover, R., Burón, J. A. y Castro Calvo, A. (2002). Anatomía seccional. Atlas de esquemas axiales y Guía de referencia. Barcelona, Elsevier-Masson.

Clunie, L., Morris, N. P., Joynes, V. C. y Pickering, J. D. (2018). How comprehensive are research studies investigating the efficacy of technology-enhanced learning resources in anatomy education? A systematic review. American Association of Anatomists, 11, 303-319. https://doi.org/10.1002/ase.1762 
Comaniciu, D., Engel, K., Georgescu, B., y Mansi, T. (2016). Shaping the future through innovations: From medical imaging to precision medicine. Medical Image Analysis, 33, 19-26. https://doi.org/10.1016/j.media.2016.06.016

Cook, D. A., Hatala, R., Brydges, R., Zendejas, B., Szostek, J. H., Wang, A. T., Erwin, P. J. y Hamstra, S. J. (2011). Technology-enhanced simulation for health professions education: A systematic review and meta-analysis. JAMA, 306, 978-988. Recuperado de http://jama.ama-assn.org/content/306/9/978.abstract

Corton, M. M., McIntire, D. D., Wai, C. Y., Ling, F. V. y Wendel, G. D. Jr. (2006). A comparison of an interactive computer-based method with a conventional reading approach for learning pelvic anatomy. Am J Obstet Gynecol,195, 5, 1438-1443. https://doi.org/10.1016/j.ajog.2006.06.076

Dai, J. X., Chung, M. S., Qu, R. M., Yuan, L., Liu, S. W. y Shin, D. S. (2012). The Visible Human Projects in Korea and China with improved images and diverse applications. Surg Radiol Anat, 34 (6), 527-534. https://doi.org/10.1007/s00276-012-0945-8

Darras, K. E., De Bruin, A. B. H., Nicolaou, S., Dahlström, N., Persson, A., Van Merriënboer, J. y Forster, B. B. (2018). Is there a superior simulator for human anatomy education? How virtual dissection can overcome the anatomic and pedagogic limitations of cadaveric dissection. Med Teach, 40, 7, 752-753. https://doi.org/10.1080/0142159X.2018.1451629

Darras, K. E., Forster, B. B., Nicolaou, S. y Munk, P. L. (2017). A Golden Opportunity for Radiologists: Bringing Clinical Relevance to Undergraduate Anatomy Through Virtual Dissection. Can Assoc Radiol J, 68, 3, 232-233. https://doi.org/10.1016/j.carj.2016.08.006

Das, S., y Mitchell, P. (2013). Comparison of three aids for teaching lumbar surgical anatomy. British Journal of Neurosurgery, 27, 475-478. https://doi.org/10.3109/02688697.2013.771723

De Notaris, M., Prats-Galino, A., Cavallo, L. M., Esposito, F., laconetta, G., Gonzalez, J. B., Montagnani, S., Ferrer, E. y Cappabianca, P. (2010). Preliminary experience with a new three-dimensional computer-based model for the study and the analysis of skull base approaches. Childs Nerv. Syst. 26, 621-626. https://doi.org/10.1007/s00381010-1107-0

De Notaris, M., Solari, D., Cavallo, L. M., Enseñat, J., Alobid, I., Soria, G., Gonzalez, J. B., Ferrer, E. y Prats-Galino, A. (2011). The use of a three-dimensional novel computerbased model for analysis of the endonasal endoscopic approach to the midline skull base. World Neurosurg. 75, 106-113. https://doi.org/10.1016/j.wneu.2010.09.033

De Notaris, M., Topczewski, T., De Angelis, M., Enseñat, J., Alobid, I., Gondolbleu, A. M., Soria, G., Gonzalez, J. B., Ferrer, E. y Prats-Galino, A. (2013). Anatomic Skull Base Education Using Advanced Neuroimaging Techniques. World Neurosurg. 79, S16.e913. https://doi.org/10.1016/j.wneu.2012.02.027 
Deng, X., Zhoub, G., Xiao, B., Zhao, Z., He, Y. y Chen, C. (2018). Effectiveness evaluation of digital virtual simulation application in teaching of gross anatomy. Annals of Anatomy - Anatomischer Anzeiger, 218, 276-282. https://doi.org/10.1016/j.aanat.2018.02.014

Dietz, H. P. (2014). Translabial ultrasound in the assessment of pelvic floor and anorectal function in women with defecatory disorders. Techniques in Coloproctology, 18 (5), 481-494. https://doi.org/10.1007/s10151-013-1117-5

Dietz, H. P. (2017). Pelvic Floor Ultrasound: A Review. Clinical Obstetrics and Gynecology, 60 (1), 58-81. https://doi.org/10.1097/GRF.0000000000000264

Dietz, H. P., Velez, D., Shek, K. L. y Martin, A. (2012). Determination of postvoid residual by translabial ultrasound. International Urogynecology Journal, 23 (12), 1749-1752. https://doi.org/10.1007/s00192-012-1769-0

Dobson, H. D., Pearl, R. K., Orsay, C. P., Rasmussen, M., Evenhouse, R., Ai, Z., Blew, G., Dech, F., Edison, M., Silverstein, J. y Abcarian, H. (2003). Virtual reality: new method of teaching anorectal and pelvic floor anatomy. Dis Colon Rectum, 46, 349-352. https://doi.org/10.1007/s10350-004-6554-9

Domínguez Merlano, E. (2010). Análisis comparativo de tres modelos de aprendizaje: colaborativo virtual, colaborativo presencial y magisterial. En Congreso Internacional de Educación Mediada con Tecnología, Universidad de Barcelona. Recuperado de https://docplayer.es/5244475-Analisis-comparativo-de-tres-modelos-deaprendizaje-colaborativo-virtual-colaborativo-presencial-y-magistral.html

Doumouchtsis, S. K., Nazarian, D. A., Gauthaman, N., Durnea, C. M. y Munneke, G. (2017). Three-dimensional volume rendering of pelvic models and paraurethral masses based on MRI cross-sectional images. International Urogynecology Journal, 28 (10), 1579-1587. https://doi.org/10.1007/s00192-017-3317-4

Drapkin, Z. A., Lindgren, K. A., Lopez, M. J. y Stabio, M. E. (2015). Development and assessment of a new 3D neuroanatomy teaching tool for MRI training. Anatomical Sciences Education, 8, 6, 502-509. https://doi.org/10.1002/ase.1509

Dykes, M. y Watson, W. (2010). Lo esencial en Anatomía. Barcelona, España. Elsevier Mosby.

Ekstrand, C., Jamal, A., Nguyen, R., Kudryk, A., Mann, J. y Mendez, I. (2018). Immersive and interactive virtual reality to improve learning and retention of neuroanatomy in medical students: a randomized controlled study. CMAJ Open, 6, 1, E103-E109. https://doi.org/10.9778/cmajo.20170110

Ellington, D. R., Shum, P. C., Denis, E. A., Willis, H. L. Szychowski, J. M. y Rithcher, H. E. (2018). Female Pelvic Floor Immersive Simulation: A Randomized Trial to Test the Effectiveness of a Virtual Reality Anatomic Model on Resident Knowledge of Female Pelvic Anatomy. J Minim Invasive Gynecol, 26, 5, 897-901.

https://doi.org/10.1016/j.jmig.2018.09.003 
Erolin, C. (2019). Interactive 3D Digital Models for Anatomy and Medical Education. En: P. Rea (Ed.) Biomedical Visualisation. Advances in Experimental Medicine and Biology, 1138, (pp. 1-16). Springer, Cham. https://doi.org/10.1007/978-3-030-14227-8_1

Estai, M. y Bunt, S. (2016). Best teaching practices in anatomy education: A critical review. Annals of Anatomy - Anatomischer Anzeiger, 208, 151-157. https://doi.org/10.1016/j.aanat.2016.02.010

Estevez, M. E., Lindgren, K. A. y Bergethon, P. R. (2010). A novel three-dimensional tool for teaching human neuroanatomy. Anatomical Sciences Education, 3, 309-317. https://doi.org/10.1002/ase.186

Fang, B., Wu, Y., Chu, C., Li, Y., Luo, N., Liu, K., Tan, L. y Zhang, S. (2017). Creation of a Virtual Anatomy System based on Chinese Visible Human data sets. Surgical and Radiologic Anatomy, 39 (4), 441-449. https://doi.org/10.1007/s00276-016-1741-7

Feneis, H. y Dauber, W. (1998). Feneis. Nomenclatura anatómica ilustrada. Barcelona, España. Elsevier Masson.

Fenesi, B., Mackinnon, C., Cheng, L., Kim, J. A. y Wainman, B. C. (2017). The effect of image quality, repeated study, and assessment method on anatomy learning. Anatomical Sciences Education, 10 (3), 249-261. https://doi.org/10.1002/ase.1657

Ferrando Castro, M. (8 de diciembre de 2019). Historia de la anatomía humana: origen y personajes destacados. RedHistoria. Recuperado de https://redhistoria.com/historiade-la-anatomia-humana-origen-y-personajes/

Framiñán, A., Ruisoto, P., García, D. y Juanes, J. A. (2013). Advanced neuroimage processing for the study of the neurovascular system. Proceedings of the First International Conference on Technological Ecosystem for Enhancing Multiculturality - TEEM'13, 37-41. https://doi.org/10.1145/2536536.2536543

García Barrios, C., Mejías Rodríguez, I. y Castillo del Río, M. (1999). Origen e historia de la disección anatómica. Revista Archivo Médico de Camagüey, 3 (2). Recuperado de http://scielo.sld.cu/scielo.php?script=sci_arttext\&pid=S1025-02551999000200016

García del Salto, L., Miguel Criado, J., Aguilera del Hoyo, L. F., Gutiérrez Velasco, L., Fraga Rivas, P., Manzano Paradela, M., Díez Pérez de las Vacas, M. I., Marco Sanz, A.G. y Fraile Moreno, E. (2014). MR Imaging-based Assessment of the Female Pelvic Floor. RadioGraphics, 34 (5), 1417-1439. https://doi.org/10.1148/rg.345140137

García Porrero, J. A. y Hurlé, J. M. (2005). Anatomía Humana. Madrid, España. McGraw Hill Interamericana.

García, F. y López, F. (2011). Influencia de las TIC en al Aprendizaje significativo (TFM). Universidad Internacional de la Rioja. Recuperado de https://reunir.unir.net/bitstream/handle/123456789/94/TFM_GARCIA_ROMERO_FE LIX_OSCAR.pdf?sequence $=1$ 
Ghosh, S. K. (2015). Evolution of illustrations in anatomy: A study from the classical period in Europe to modern times. Anatomical Sciences Education, 8 (2), 175-188. https://doi.org/10.1002/ase.1479

Giannini, A., lodice, V., Picano, E., Russo, E., Zampa, V., Ferrari, V. y Simoncini, T. (2017). Magnetic Resonance Imaging-Based Three Dimensional Patient-Specific Reconstruction of Uterine Fibromatosis: Impact on Surgery. Journal of Gynecologic Surgery, 33 (4), 138-144. https://doi.org/10.1089/gyn.2016.0119

Gilroy, A. M., MacPherson, B. R., Ross, L. M., Schünke, M., Schulte, E. y Schumacher U. (2008). Prometheus, Atlas de Anatomía. Madrid, España. Panamericana.

Golenhofen, N., Heindl, F., Grab-Kroll, C., Messerer, D. A., Böckers, T. M. y Böckers, A. (2020). The Use of a Mobile Learning Tool by Medical Students in Undergraduate Anatomy and its Effects on Assessment Outcomes. Anat Sci Educ, 13, 8-18. https://doi.org/10.1002/ase.1878

Gonzalo Domínguez, M., Hernández, C., Ruisoto, P., Juanes, J. A., Prats, A. y Hernández, T. (2016). Morphological and Volumetric Assessment of Cerebral Ventricular System with 3D Slicer Software. Journal of Medical Systems, 40, 6. https://doi.org/10.1007/s10916-016-0510-9

Govsa, F., Yagdi, T., Ozer, M. A., Eraslan, C. y Alagoz, A. K. (2017). Building 3D anatomical model of coiling of the internal carotid artery derived from CT angiographic data. Eur Arch Oto-Rhino-Laryngology, 274, 2, 1097-1102. https://doi.org/10.1007/s00405016-4355-0

Graupera, B., Pascual, M. À., Hereter, L. y Pedrero, C. (2018). Role of 3D Ultrasound in the Evaluation of Uterine Anomalies. En A. Tinelli, L. A. Pacheco y S. Haimovich (Eds.), Hysteroscopy (pp. 69-82). Cham: Springer International Publishing. https://doi.org/10.1007/978-3-319-57559-9_8

Guerrero, M. R. (2014). Metodologías activas y aprendizaje por descubrimiento. Las TIC y la educación. Marpadal Interactive Media S.L.

Guimarães, B., Firmino-Machado, J., Tsisar, S., Viana, B., Pinto-Sousa, M., Vieira-Marques, P., Cruz-Correia, R. y Ferreira, M. A. (2018). The Role of Anatomy Computer-Assisted Learning on Spatial Abilities of Medical Students. Anatomical Sciences Education, 12, 2, 138-153. https://doi.org/10.1002/ase.1795

Guiraldes, H., Oddó, H., Mena, B., Velasco, N. y Paulos, J. (2001). Enseñanza de la anatomía humana: experiencias y desafíos en una escuela de medicina. Revista chilena de anatomía, 19 (2), 205-212. http://dx.doi.org/10.4067/S0716-98682001000200013

Gutiérrez Tapias, M. (2018). Estilos de aprendizaje, estrategias para enseñar. Su relación con el desarrollo emocional y "aprender a aprender". Tendencias pedagógicas, 31, 83-96. http://dx.doi.org/10.15366/tp2018.31.004 
Hackett, M. y Proctor, M. (2016). Three-Dimensional Display Technologies for Anatomical Education: A Literature Review. Journal of Science Education and Technology, 25, 4, 641-654. https://doi.org/10.1007/s10956-016-9619-3

Hampton, B. S. y Sung, V. W. (2010). Improving medical student knowledge of female pelvic floor dysfunction and anatomy: a randomized trial. American Journal of Obstetrics and Gynecology, 202 (6), 601.e1-601.e8. https://doi.org/10.1016/j.ajog.2009.08.038

Hassinger, J. P., Dozois, E. J., Holubar, S. D., Camp, J. C., Farley, D. R., Fidler, J. L., Pawlina, W., Robb, R. A. y Larson, D. W. (2010). Virtual pelvic anatomy simulator: a pilot study of usability and perceived effectiveness. J Surg Res, 161, 23-27. https://doi.org/10.1016/j.jss.2009.06.016

Hecht, L. P. y Larrazábal, M. A. (2018). Uso de nuevos recursos tecnológicos en la docencia de un curso de anatomía con orientación clínica para alumnos de medicina. Int. J. Morphol., 36 (3), 821-828. Recuperado de https://scielo.conicyt.cl/pdf/ijmorphol/v36n3/0717-9502-ijmorphol-36-03-00821.pdf

Heng, P. A., Zhang, S. X., Xie, Y. M., Wong, T. T., Chui, Y. P. y Cheng, C. Y. (2006). Photorealistic virtual anatomy based on Chinese Visible Human data. Clinical Anatomy, 19 (3), 232-239. https://doi.org/10.1002/ca.20314

Hennemann, J., Kennes, L. N., Maass, N. y Najjari, L. (2014). Evaluation of established and new reference lines for the standardization of transperineal ultrasound. Ultrasound in Obstetrics \& Gynecology, 44 (5), 610-616. https://doi.org/10.1002/uog.13318

Houser, J. J. y Kondrashov, P. (2018). Gross Anatomy Education Today: The Integration of Traditional and Innovative Methodologies. Missouri medicine, 115, 1, 61-65. Recuperado de https://www.ncbi.nlm.nih.gov/pubmed/30228685

Hoyek, N., Collet, C., Di Rienzo, F., De Almeida, M. y Guillot, A. (2014). Effectiveness of threedimensional digital animation in teaching human anatomy in an authentic classroom context. American Association of Anatomists, 7, 430-437. https://doi.org/10.1002/ase.1446

Hoyte, L., Schierlitz, L., Zou, K., Flesh, G. y Fielding, J. R. (2001). Two- and 3-dimensional MRI comparison of levator ani structure, volume, and integrity in women with stress incontinence and prolapse. Am J Obstet Gynecol, 185 (1), 11-19. https://doi.org/10.1067/mob.2001.116365

Hu, M., Wattchow, D. y De Fontgalland, D. (2018). From ancient to avant-garde: a review of traditional and modern multimodal approaches to surgical anatomy education. ANZ J Surg, 88, 146-151. https://doi.org/10.1111/ans.14189

Inzunza, O., Caro, I., Mondragón, G., Baeza, F., Burdiles, A. y Salgado, G. (2015). 3D impressions, new technology that supports anatomical teaching. Int. J. Morphol., 33 (3), 1176-1182. Recuperado de https://diseno.uc.cl/wp/wpcontent/uploads/2017/06/Inzunzalmpre3D-2.pdf 
Izard, S. G., Juanes, J. A., García Peñalvo, F. J., Estella, J. M. G., Ledesma, M. J. S. y Ruisoto, P. (2018). Virtual Reality as an Educational and Training Tool for Medicine. Journal of Medical Systems, 42, 50. https://doi.org/10.1007/s10916-018-0900-2

Jamil, Z., Saeed, A. A., Madhani, S., Baig, S., Cheema, Z. y Fatima, S. S. (2019). Threedimensional Visualization Software Assists Learning in Students with Diverse Spatial Intelligence in Medical Education. Anat Sci Educ, 12, 5, 550-560. https://doi.org/10.1002/ase.1828

Javadian, P., O'Leary, D., Rostaminia, G., North, J., Wagner, J., Quiroz, L. H. y Shobeiri, S. A. (2017). How does 3D endovaginal ultrasound compare to magnetic resonance imaging in the evaluation of levator ani anatomy? Neurourology and Urodynamics, 36 (2), 409-413. https://doi.org/10.1002/nau.22944

Jiménez López, M., García-Peñalvo, F. J., Ruisoto, P., González Izard, S., Juanes Méndez, J. A. y Pastor Vázquez, F. (2017). $360^{\circ}$ vision applications for medical training. Proceedings of the Fifth International Conference on Technological Ecosystems for Enhancing Multiculturality - TEEM'17, 55, 1-7. https://doi.org/10.1145/3144826.3145405

Juanes Méndez, J. A., Prats-Galino, A. y Gómez Borrallo, J. (2010): Avances en el desarrollo de interfaces de usuario de programas docentes: importancia de su diseño para la eficacia y optimización del aprendizaje. En J. A. Juanes Méndez (Coord.), Avances tecnológicos digitales en metodologías de innovación docente en el campo de las Ciencias de la Salud en España. Revista Teoría de la Educación: Educación y Cultura en la Sociedad de la Información, 11 (2), 101-116. Universidad de Salamanca. Recuperado de http://campus.usal.es/ revistas_trabajo/index.php/revistatesi/article/view/7073/71 06

Juanes, J. A. y Ruisoto, P. (2014). Technological Advances and Teaching Innovation Applied to Health Science Education. Journal of Information Technology Research,7, 2, 1-6. https://doi.org/10.4018/jitr.2014040101

Juanes, J. A. y Ruisoto, P. (2015). Computer Applications in Health Science Education. J Med Syst, 39, 97. https://doi.org/10.1007/s10916-015-0283-6

Juanes, J. A., Hernández, D., Ruisoto, P., García, E., Villarrubia, G. y Prats, A. (2014a). Augmented reality techniques, using mobile devices, for learning human anatomy. Proceedings of the Second International Conference on Technological Ecosystems for Enhancing Multiculturality - TEEM'14, 7-11. https://doi.org/10.1145/2669711.2669870

Juanes, J. A., Ruisoto, P., Cabrero, F. J. y Prats-Galino, A. (2014b). An Update on Health Information Technology. Journal of Information Technology Research, 7, 2, 63-74. https://doi.org/10.4018/jitr.2014040106 
Juanes, J. A., Ruisoto, P., Obeso, J. A., Prats, A. y San-Molina, J. (2015). Computer-Based Visualization System for the Study of Deep Brain Structures Involved in Parkinson's Disease. J Med Syst, 39, 151. https://doi.org/10.1007/s10916-015-0348-6

Juanes, J. A., Ruisoto, P., Prats-Galino, A. y Framiñán, A. (2014c). Open Source Applications for Image Visualization and Processing in Neuroimaging Training. Journal of Information Technology Research (JITR), 7 (2), 75-87. https://doi.org/10.4018/jitr.2014040107

Juanes, J. A., Ruisoto, P., Prats-Galino, A., Framiñán, A. y Riesco, J. M. (2014d). Computed anatomical modelling of the optic pathway and oculomotor system using magnetic resonance imaging, Journal of Neuroradiology, 41, 3, 168-176. https://doi.org/10.1016/j.neurad.2013.06.005

Juanes, J. A., Ruisoto, P., Velasco, M. A. y Gómez, J. J. (2013). Advance technology for enhanced study of the brain from neuroimaging. En: L. Gómez Chova, I. Candel Torres y A. López Martínez (Eds.), Proceedings of the 5th International Technology, Education and Development Conference (INTED), 5073-5082. Valencia. Recuperado de https://library.iated.org/view/JUANES2013ADV

Kaniewska, M., Gołofit, P., Heubner, M., Maake, C. y Kubik-Huch, R. A. (2018). Suspensory Ligaments of the Female Genital Organs: MRI Evaluation with Intraoperative Correlation. RadioGraphics, 38 (7), 2195-2211. https://doi.org/10.1148/rg.2018180089

Karakas, A. B., Govsa, F., Ozer, M. A. y Eraslan, C. (2018). 3D Brain Imaging in Vascular Segmentation of Cerebral Venous Sinuses. Journal of Digital Imaging, 32, 2, 314-321. https://doi.org/10.1007/s10278-018-0125-4

Kearney, R., Miller, J. M. y DeLancey, J. O. L. (2006). Interrater reliability and physical examination of the pubovisceral portion of the levator ani muscle, validity comparisons using MR imaging. Neurourol Urodyn, 25 (1), 50-54. https://doi.org/10.1002/nau.20181

Keedy, A. W., Durack, J. C., Sandhu, P., Chen, E. M., O'Sullivan, P. S. y Breiman, R. S. (2011). Comparison of traditional methods with 3D computer models in the instruction of hepatobiliary anatomy. Anat Sci Ed, 4, 84-91. https://doi.org/10.1002/ase.212

Keenan, I. D. y Awadh, A. (2019). Integrating 3D Visualisation Technologies in Undergraduate Anatomy Education. En P. Rea (Ed.), Biomedical Visualisation, 1120, (pp. 39-53). Springer, Cham. https://doi.org/10.1007/978-3-030-06070-1_4

Kenway, L. C. y Bakr, M. M. (2019). The Use of Digital Software Applications and Digital Atlases to Supplement Anatomy Teaching to Undergraduate Allied Health Students. En M. Khosrow-Pour (Ed.), Virtual Reality in Education. Breakthroughs in Research and Practice (pp. 824-845). Information Resources Management Association (EEUU). https://doi.org/10.4018/978-1-5225-8179-6.ch039 
Khot, Z., Quinlan, K., Norman, G. R. y Wainman, B. (2013). The relative effectiveness of computer-based and traditional resources for education in anatomy. Anatomical Sciences Education, 6, 211-215. https://doi.org/10.1002/ase.1355

Kim, K. Y., Cheng, J. W., Shen, J. K., Wagner, H. y Staack, A. (2018). Translabial Ultrasound Evaluation of Pelvic Floor Structures and Mesh in the Urology Office and Intraoperative Setting. Urology, 120, 267. https://doi.org/10.1016/j.urology.2018.07.004

Kostusiak, M., Hart, M., Barone, D. G., Hofmann, R., Kirollos, R., Santarius, T. y Trivedi, R. (2017). Methodological shortcomings in the literature evaluating the role and applications of 3D training for surgical trainees. Medical Teacher, 39, 11, 1168-1173. https://doi.org/10.1080/0142159X.2017.1362102

Kraima, A. C., Smit, N. N., Jansma, D., Wallner, C., Bleys, R. L., Van de Velde, C. J., Botha, C. P. y DeRuiter, M. C. (2013) Toward a highly-detailed 3D pelvic model: approaching an ultra-specific level for surgical simulation and anatomical education. Clin Anat 26 (3):333-338. https://doi.org/10.1002/ca.22207

Kurobe, N., Hakkakian, L., Chahim, M., Delmas, V., Vekemans, M. y Uhl, J. F. (2015). Threedimensional reconstruction of the lower limb's venous system in human fetuses using the computer-assisted anatomical dissection (CAAD) technique. Surgical and Radiologic Anatomy, 37 (3), 231-238. https://doi.org/10.1007/s00276-014-1350-2

Labovitz, J. y Hubbard, C. (2020). The Use of Virtual Reality in Podiatric Medical Education, Clinics in Podiatric Medicine and Surgery, 37, 2, 409-420. https://doi.org/10.1016/j.cpm.2019.12.008

Lai, J. W. M. y Bower, M. (2020). Evaluation of technology use in education: Findings from a critical analysis of systematic literature reviews. J Comput Assist Learn, 2020, 1-19. https://doi.org/10.1111/jcal.12412

Larson, K. A., Yousuf, A., Lewicky-Gaupp, C., Fenner, D. E. y DeLancey, J. O. (2010). Perineal body anatomy in living women: 3-dimensional analysis using thin-slice magnetic resonance imaging. Am J Obstet Gynecol 203, 494.e15-494.e21. https://dx.doi.org/10.1016/j.ajog.2010.06.008

Legendre, G., Sahmoune Rachedi, L., Descamps, P. y Fernández, H. (2015). Apport d'un simulateur virtuel d'anatomie périnéale (Pelvic Mentor ${ }^{\circledR}$ ) dans l'apprentissage de la pelvi-périnéologie: résultats d'une étude préliminaire. Journal de Gynécologie Obstétrique et Biologie de La Reproduction, 44 (1), 72-77. https://doi.org/10.1016/j.jgyn.2014.04.004

Lewis, T. L., Burnett, B., Tunstall, R. G. y Abrahams, P. H. (2014). Complementing anatomy education using three-dimensional anatomy mobile software applications on tablet computers. Clin. Anat., 27, 313-320. https://doi.org/10.1002/ca.22256 
Li, L., Liu, Y. X. y Song, Z. J. (2006). Three-dimensional reconstruction of registered and fused Chinese Visible Human and patient MRI images. Clinical Anatomy, 19 (3), 225-231. https://doi.org/10.1002/ca.20291

Lippert, H. (2009). Anatomía con orientación clínica para estudiantes. Madrid, España. Marbán.

Lombardi, S. A., Hicks, R. E., Thompson, K. V. y Marbach-Ad, G. (2014). Are all hands-on activities equally effective? Effect of using plastic models, organ dissections, and virtual dissections on student learning and perceptions. Advances in Physiology Education, 38, 80-86. https://doi.org/10.1152/advan.00154.2012

Lone, M., Vagg, T., Theocharopoulos, A., Cryan, J. F., Mckenna, J. P., Downer, E. J. y Toulouse, A. (2018). Development and Assessment of a Three-Dimensional Tooth Morphology Quiz for Dental Students. Anatomical Sciences Education, 12, 3, 284299. https://doi.org/10.1002/ase.1815

Luo, J., Ashton-Miller, J. A. y DeLancey, J. O. (2011). A model patient: female pelvic anatomy can be viewed in diverse 3-dimensional images with a new interactive tool. Am J Obstet Gynecol, 205, 4, 391E1-391E2. https://doi.org/10.1016/j.ajog.2011.08.018

Martínez, G. F., Mir, F. y Garcia Romano, L. (2017). Caracterización de aplicaciones móviles para la enseñanza y el aprendizaje de la anatomía humana. Enseñanza de las Ciencias: revista de investigación y experiencias didácticas, Extra 0, 1597-1604. Recuperado de https://ddd.uab.cat/record/184395

Mavar-Haramija, M., Prats-Galino, A., Méndez, J. A. J., Puigdelívoll-Sánchez, A. y De Notaris, M. (2015). Interactive 3D-PDF Presentations for the Simulation and Quantification of Extended Endoscopic Endonasal Surgical Approaches. J Med Syst, 39, 127. https://doi.org/10.1007/s10916-015-0282-7

Mitrousias, V., Varitimidis, S. E., Hantes, M. E., Malizos, K. N. Arvanitis, D. L. y Zibis, A. H. (2018). Anatomy learning from prosected cadaveric specimens versus threedimensional software: A comparative study of upper limb anatomy. Annals of Anatomy - Anatomischer Anzeiger, 218, 156-164. https://doi.org/10.1016/j.aanat.2018.02.015

Mompeó-Corredera, B. (2014). Metodologías y materiales para el aprendizaje de la anatomía humana: percepciones de los estudiantes de medicina "nativos digitales". FEM: Revista de la Fundación Educación Médica, 17 (2), 99-104. https://dx.doi.org/10.4321/S2014-98322014000200007

Montemayor Flores, B. G. (2006). El Significado de la Práctica de Disección para los Estudiantes de Medicina. International Journal of Morphology, 24 (4), 575-580. https://dx.doi.org/10.4067/S0717-95022006000500010

Moore, C. W., Wilson, T. D. y Rice, C. L. (2017). Digital preservation of anatomical variation: 3D-modeling of embalmed and plastinated cadaveric specimens using $\mathrm{UCT}$ and MRI. 
Annals of Anatomy - Anatomischer Anzeiger, 209, 69-75. https://doi.org/10.1016/j.aanat.2016.09.010

Moore, K. L. y Agur, A. M. R. (2007). Compendio de Anatomía con orientación clínica. Barcelona, España. Elsevier Masson.

Moreira, P. (2019). Las TIC en el aprendizaje significativo y su rol en el desarrollo social y cognitivo de los adolescentes. Rehuso, 4 (2), 1-12. Recuperado de https://dialnet.unirioja.es/descarga/articulo/7047160.pdf

Morin, M., Bergeron, S., Khalifé, S., Mayrand, M. y Binik, Y. M. (2014). Morphometry of the Pelvic Floor Muscles in Women With and Without Provoked Vestibulodynia Using 4D Ultrasound. The Journal of Sexual Medicine, 11 (3), 776-785. https://doi.org/10.1111/jsm.12367

Moro, C. y Gregory, S. (2019). Utilising Anatomical and Physiological Visualisations to Enhance the Face-to-Face Student Learning Experience in Biomedical Sciences and Medicine. En P. Rea (Ed.), Biomedical Visualisation. Advances in Experimental Medicine and Biology, 1156, (pp. 41-44). Springer, Cham. https://doi.org/10.1007/978-3-030-19385-0_3

Moro, C., Smith, J. y Stromberga, Z. (2019). Multimodal Learning in Health Sciences and Medicine: Merging Technologies to Enhance Student Learning and Communication. En P. Rea (Ed.), Biomedical Visualisation. Advances in Experimental Medicine and Biology, 1205, (pp.71-78). Springer, Cham. https://doi.org/10.1007/978-3-03031904-5_5

Moro, C., Stromberga, Z. y Birt, J. (2020). Technology Considerations in Health Professions and Clinical Education. En D. Nestel, G. Reedy, L. McKenna y S. Gough (Eds), Clinical Education for the Health Professions (pp. 1-22). Springer, Singapore. https://doi.org/10.1007/978-981-13-6106-7_118-1

Moro, C., Stromberga, Z., Raikos, A. y Stirling, A. (2017). The Effectiveness of Virtual and Augmented Reality in Health Sciences and Medical Anatomy. Anatomical Sciences Education, 10, 6, 549-559. https://doi.org/10.1002/ase.1696

Morris, N. P., Lambe, J., Cicconet, J. y Swinnerton, B. (2016). Mobile technology: students perceived benefits of apps for learning neuroanatomy. J Comp Assisted Learning, 32, 5, 430-442. https://doi.org/10.1111/jcal.12144

Morrissey, J. (2010). El uso de TIC en la enseñanza y el aprendizaje. Cuestiones y desafíos. En R. Aparici (Coord.), Conectados en el ciberespacio (pp. 235-246). Madrid, UNED. Recuperado de https://dialnet.unirioja.es/servlet/libro?codigo=493731

Moszkowicz, D., Alsaid, B., Bessede, T., Zaitouna, M., Penna, C., Benoit, G. y Peschaud, F. (2011). Neural Supply to the Clitoris: Immunohistochemical Study with ThreeDimensional Reconstruction of Cavernous Nerve, Spongious Nerve, and Dorsal Clitoris Nerve in Human Fetus. The Journal of Sexual Medicine, 8 (4), 1112-1122. https://doi.org/10.1111/j.1743-6109.2010.02182.x 
Murad-Regadas, S. M., Karbage, S. A., Bezerra, L. S., Regadas, F. S. P., Da Silva Vilarinho, A., Borges, L. B., Regadas Filho, F. S. P. y Veras, L. B. (2017). Dynamic translabial ultrasound versus echodefecography combined with the endovaginal approach to assess pelvic floor dysfunctions: How effective are these techniques? Techniques in Coloproctology, 21 (7), 555-565. https://doi.org/10.1007/s10151-017-1658-0

Murad-Regadas, S., Regadas Filho, F. S., Regadas, F. S., Rodrigues, L., De J. R. Pereira, J., Da S. Fernandes, G., Dealcanfreitas, I. y Mendonca Filho, J. (2014). Use of Dynamic 3Dimensional Transvaginal and Transrectal Ultrasonography to Assess Posterior Pelvic Floor Dysfunction Related to Obstructed Defecation. Diseases of the Colon \& Rectum, 57 (2), 228-236. https://doi.org/10.1097/DCR.0000000000000028

Nardos, R., Thurmond, A., Holland, A. y Gregory, W. T. (2014). Pelvic Floor Levator Hiatus Measurements: MRI Versus Ultrasound. Female Pelvic Medicine \& Reconstructive Surgery, 20 (4), 216-221. https://doi.org/10.1097/SPV.0000000000000079

Netter, F. H. (2007). Atlas de Anatomía Humana. Barcelona, España. Elsevier Masson.

Noetscher, G. M., Yanamadala, J., Tankaria, H., Louie, S., Prokop, A., Nazarian, A. y Makarov, S. N. (2016). Computational human model VHP-FEMALE derived from datasets of the national library of medicine. 38th Annual International Conference of the IEEE Engineering in Medicine and Biology Society (EMBC), 3350-3353. https://doi.org/10.1109/EMBC.2016.7591445

Noguera, J. M., Jiménez, J. J. y Osuna-Pérez, M. C. (2013). Development and evaluation of a 3D mobile application for learning manual therapy in the physiotherapy laboratory. Comput Educ 69, 96-108. https://doi.org/10.1016/j.compedu.2013.07.007

Notten, K. J. B., Kluivers, K. B., Fütterer, J. J., Schweitzer, K. J., Stoker, J., Mulder, F. E., BeetsTan, R. G., Vliegen, R. F. A., Bossuyt, P. M., Kruitwagen, R. F. P. M., Roovers, J. P. W. R. y Weemhoff, M. (2014). Translabial Three-Dimensional Ultrasonography Compared With Magnetic Resonance Imaging in Detecting Levator Ani Defects. Obstet. Gynecol. 124, 6, 1190-1197. https://doi.org/10.1097/AOG.0000000000000560

Nowinski, W. L., Chua, B. C., Johnson, A., Qian, G., Poh, L. E., Yi, S. H. W., Bivi, A. y Nowinska, N. G. (2013). Three-dimensional interactive and stereotactic atlas of head muscles and glands correlated with cranial nerves and surface and sectional neuroanatomy. Journal of Neuroscience Methods, 215 (1), 12-18. https://doi.org/10.1016/j.jneumeth.2013.02.005

O'Rourke, J. C., Smyth, L., Webb, A. L. y Valter, K. (2020). How Can We Show You, If You Can't See It? Trialing the Use of an Interactive Three-Dimensional Micro-CT Model in Medical Education. Anat Sci Educ, 13, 2, 206-217. https://doi.org/10.1002/ase.1890

Papadopoulou, P., Chui, K. T., Daniela, L. y Lytras, M. D. (2019). Virtual and Augmented Reality in Medical Education and Training: Innovative Ways for Transforming Medical Education in the 21st Century. En M. Lytras, N. Aljohani, L. Daniela, y A. Visvizi (Eds.), 
Cognitive Computing in Technology-Enhanced Learning (pp. 109-150). Hershey, PA: IGI Global. https://doi.org/10.4018/978-1-5225-9031-6.ch006

Pardos, E. (2017). Realidad Virtual y medicina: usos y aplicaciones. Recuperado el 15 de mayo de 2020 de https://baboonlab.odoo.com/blog/noticias-de-marketinginmobiliario-y-tecnologia-1/post/realidad-virtual-y-medicina-usos-y-aplicaciones-27

Peng, Y., Khavari, R., Nakib, N. A., Boone, T. B. y Zhang, Y. (2016). Assessment of urethral support using MRI-derived computational modeling of the female pelvis. International Urogynecology Journal, 27 (2), 205-212. https://doi.org/10.1007/s00192-015-2804-8

Perlemuter, L. (1999). Anatomo-Fisiología. Barcelona, España. Masson.

Peterson, D. C. y Mlynarczyk, G. S. A. (2016). Analysis of traditional versus three-dimensional augmented curriculum on anatomical learning outcome measures. Anatomical Sciences Education, 9 (6), 529-536. https://doi.org/10.1002/ase.1612

Pickering, J. D. y Swinnerton, B. J. (2018). Exploring the dimensions of medical student engagement with technology-enhanced learning resources and assessing the impact on assessment outcomes. Anat Sci Educ, 12, 2, 117-128. https://doi.org/10.1002/ase.1810

Portilla, F., Rubio Manzanares Dorado, M., Pino Díaz, V., Vázquez Monchul, J. M., Palacios, C., Díaz Pavón, J. M., Sánchez Gil, J. M. y García Cabrera, A. M. (2015). Utilidad de la ecografía dinámica tridimensional en el estudio del suelo pélvico. Cirugía Española, 93 (8), 530-535. https://doi.org/10.1016/j.ciresp.2014.11.005

Prats Galino, A. (2010). VIX: Una aplicación informática abierta para la visualización y estudio interactivo de la anatomía en 3D. En J. A. Juanes Méndez (Coord.), Avances tecnológicos digitales en metodologías de innovación docente en el campo de las Ciencias de la Salud en España. Revista Teoría de la Educación: Educación y Cultura en la Sociedad de la Información, 11, (2), 171-193. Recuperado de http://campus.usal.es/ revistas_trabajo/index.php/revistatesi/article/view/7076/71 09

Preece, D., Williams, S. B., Lam, R. y Weller, R. (2013). "Let's Get Physical": Advantages of a physical model over 3D computer models and textbooks in learning imaging anatomy. Anatomical Sciences Education, 6 (4), 216-224. https://doi.org/10.1002/ase.1345

Pujol, S., Baldwin, M., Nassiri, J., Kikinis, R. y Shaffer, K. (2016). Using 3D Modeling Techniques to Enhance Teaching of Difficult Anatomical Concepts. Academic Radiology, 23 (4), 507-516. https://doi.org/10.1016/j.acra.2015.12.012

Ram, R., Oliphant, S. S., Barr, S. A. y Pandey, T. (2017). Imaging of Pelvic Floor Reconstruction. Seminars in Ultrasound, CT and MRI, 38 (3), 200-212. https://doi.org/10.1053/j.sult.2016.11.003 
Rea, P. M. (2016). Advances in Anatomical and Medical Visualisation. En M. Pinheiro, y D. Simões (Eds.), Handbook of Research on Engaging Digital Natives in Higher Education Settings (pp. 244-264). Hershey, PA: IGI Global. https://doi.org/10.4018/978-1-52250039-1.ch011

Ricardo Barreto, C. y Diazgranados, F. (2017). Las TIC en la educación superior. Experiencias de innovación. Barranquilla, Colombia: Editorial Universidad del Norte. Recuperado de http://rd.unir.net/sisi/research/resultados/15119077649789587418552\%20eLas\%20 TIC\%20en\%20la\%20educacion\%20superior.pdf

Rodríguez Rubio, R., Shehata, J., Kournoutas, I., Chae, R., Vigo, V., Wang, M., El-Sayed, I. y Abla, A. A. (2019). Construction of Neuroanatomical Volumetric Models Using 3Dimensional Scanning Techniques: Technical Note and Applications. World Neurosurgery, 126, 359-368. https://doi.org/10.1016/j.wneu.2019.03.099

Rodríguez-Herrera, R., Losardo, R. J. y Binvignat, O. (2019). La Anatomía Humana como Disciplina Indispensable en la Seguridad de los Pacientes. International Journal of Morphology, 37 (1), 241-250. https://dx.doi.org/10.4067/S071795022019000100241

Rohen, J. W, Yokochi, C. y Lütjen-Drecoll, E. (2011). Atlas de anatomía humana. Barcelona, España. Elsevier.

Romero Reveron, R. (2007). Andreas Vesalius (1514-1564): Fundador de la Anatomía Humana Moderna. International Journal of Morphology, 25 (4), 847-850. https://dx.doi.org/10.4067/S0717-95022007000400026

Rostaminia, G., Manonai, J., Leclaire, E., Omoumi, F., Marchiorlatti, M., Quiroz, L. H. y Shobeiri, S. A. (2014). Interrater reliability of assessing levator ani deficiency with $360^{\circ} 3 \mathrm{D}$ endovaginal ultrasound. International Urogynecology Journal, 25 (6), 761766. https://doi.org/10.1007/s00192-013-2286-5

Rostaminia, G., White, D., Quiroz, L. H. y Shobeiri, S. A. (2014). 3D pelvic floor ultrasound findings and severity of anal incontinence. International Urogynecology Journal, 25 (5), 623-629. https://doi.org/10.1007/s00192-013-2278-5

Rouviére, H. y Delmas, A. (1987). Anatomía humana descriptiva, topográfica y funcional. Barcelona, España. Masson.

Ruisoto Palomera, P., Juanes Méndez, J. A. y Prats-Galino, A. (2014). Enhancing neuroanatomy education using computer-based instructional material. Computers in Human Behavior, 31, 446-452. https://doi.org/10.1016/j.chb.2013.03.005

Ruisoto, P., Juanes, J. A., Contador, I., Mayoral, P. y Prats-Galino, A. (2012). Experimental evidence for improved neuroimaging interpretation using three-dimensional graphic models. Anatomical Sciences Education, 5, 3, 132-137. https://doi.org/10.1002/ase.1275 
Ruiz, E., Martínez, N. y Galindo, R. (2012). Aprendizaje colaborativo en ambientes virtuales y sus bases socioconstructivistas como vía para el aprendizaje significativo. Apertura. Revista de innovación educativa, 4, 2. Recuperado de https://dialnet.unirioja.es/servlet/articulo?codigo $=5547146$

Sáez-López, J. M. (2018). Estilos de aprendizaje. Escuela y posmodernidad. Una nueva escuela para una sociedad en cambio. En Estilos de aprendizaje y métodos de enseñanza (pp.9-21). Madrid, UNED. Recuperado de http://portal.uned.es/portal/page?_pageid=93,23377989\&_dad=portal\&IdArticulo= 2330249MR01A01

Salsi, G., Cataneo, I., Dodaro, M. G., Rizzo, N., Pilu, G., Sanz Gascón, M. y Youssef, A. (2017). Three-dimensional/four-dimensional transperineal ultrasound: clinical utility and future prospects. International Journal of Women's Health, 9, 643-656. https://doi.org/10.2147/IJWH.S103789

Sanchís López, L. A. (2015). Eficacia comparada entre modelos 3D y modelos físicos en el aprendizaje de estructuras anatómicas en zoología (TFG Biología). Facultad de Ciencias de las Islas Baleares. Recuperado de https://dspace.uib.es/xmlui/bitstream/handle/11201/1697/TFG_GBIO_LLASanchisLo pez. pdf? sequence=1\&isAllowed $=y$

Seixas-Mikelus, S. A., Adal, A., Kesavadas, T., Baheti, A., Srimathveeravalli, G., Hussain, A., Chandrasekhar, R., Wilding, G. E. y Guru, K. A. (2010). Can image-based virtual reality help teach anatomy?. Journal of Endourology, 24, 629-634. https://doi.org/10.1089/end.2009.0556

Sergovich, A., Johnson, M. y Wilson, T. D. (2010). Explorable three-dimensional digital model of the female pelvis, pelvic contents, and perineum for anatomical education. Anatomical Sciences Education, 3 (3), 127-133. https://doi.org/10.1002/ase.135

Shin, D. S., Jang, H. G., Hwang, S. B., Har, D. H., Moon, Y. L. y Chung, M. S. (2013). Twodimensional sectioned images and three-dimensional surface models for learning the anatomy of the female pelvis. Anatomical Sciences Education, 6 (5), 316-323. https://doi.org/10.1002/ase.1342

Shünke, M., Schulte, E., Schumacher, U., Voll, M. y Wesker, K. (2005). Prometheus. Texto y Atlas de Anatomía. Madrid, España. Panamericana.

Smit, N., Lawonn, K., Kraima, A., DeRuiter, M., Sokooti, H., Bruckner, S., Eisemann, E. y Vilanova, A. (2017). PelVis: Atlas-based Surgical Planning for Oncological Pelvic Surgery IEEE Transactions on Visualization and Computer Graphics, 23 (1), 741-750. https://doi.org/10.1109/TVCG.2016.2598826

Sora, M. C., Jilavu, R. y Matusz, P. (2011). Computer aided three-dimensional reconstruction and modeling of the pelvis, by using plastinated cross sections, as a powerful tool for morphological investigations. Surg Radiol Anat, 34 (8), 731-736. https://doi.org/10.1007/s00276-011-0862-2 
Svirko, E. y Mellanby, J. (2017). Teaching neuroanatomy using computer-aided learning: What makes for successful outcomes?. Anatomical Sciences Education, 10, 6, 560569. https://doi.org/10.1002/ase.1694

Tabernero Rico, R. D., Juanes Méndez, J. A. y Prats Galino, A. (2017). New Generation of Three-Dimensional Tools to Learn Anatomy. Journal of Medical Systems, 41 (5), 88. https://doi.org/10.1007/s10916-017-0725-4

Tam, M. D. B. S., Hart, A. R., Williams, S., Heylings, D. y Leinster, S. (2009). Is learning anatomy facilitated by computer-aided learning? A review of the literature. Medical Teacher, 31, 9, e393-e396. https://doi.org/10.1080/01421590802650092

Temkin, B., Acosta, E., Malvankar, A. y Vaidyanath, S. (2006). An interactive threedimensional virtual body structures system for anatomical training over the internet. Clinical Anatomy, 19 (3), 267-274. https://doi.org/10.1002/ca.20230

Terracciano, F., Scalisi, G., Bossa, F., Scimeca, D., Biscaglia, G., Mangiacotti, M., Valvano, M. R., Perri, F., Simeone, A. y Andriulli, A. (2016). Transperineal ultrasonography: First level exam in IBD patients with perianal disease. Digestive and Liver Disease, 48 (8), 874-879. https://doi.org/10.1016/j.dld.2016.03.027

Thibault-Gagnon, S., McLean, L., Goldfinger, C., Pukall, C. y Chamberlain, S. (2016). Differences in the Biometry of the Levator Hiatus at Rest, During Contraction, and During Valsalva Maneuver Between Women With and Without Provoked Vestibulodynia Assessed by Transperineal Ultrasound Imaging. The Journal of Sexual Medicine, 13 (2), 243-252. https://doi.org/10.1016/j.jsxm.2015.12.009

Torres Merchán, N. Y. (2013). Enseñanza de Anatomía: Una experiencia a partir de cuestionamientos propuestos en situaciones contextuales. Escenarios, 11 (1), 131138. Recuperado de https://r.search.yahoo.com/_ylt=AwrP4nY4wL5eNgcAZUIU04IQ;_ylu=X3oDMTByaW 11dnNvBGNvbG8DaXIyBHBvcwMxBHZOaWQDBHNIYwNzcg-$/ R V=2 / R E=1589588152 / R O=10 / R U=h t t p s \% 3 a \% 2 f \% 2$ fdialnet.unirioja.es\%2fdescarga \%2farticulo\%2f4714954.pdf/RK=2/RS=JEge_xzvizOdUZihBBMB8ANmyE-

Tortora, G. J. y Derrickson, G. J. (2007). Introducción al cuerpo humano. Fundamentos de Anatomía y Fisiología. Madrid, España. Panamericana.

Trelease, R. B. (2016). From chalkboard, slides, and paper to e-learning: How computing technologies have transformed anatomical sciences education. Anatomical Sciences Education, 9 (6), 583-602. https://doi.org/10.1002/ase.1620

Triepels, C. P. R., Smeets, C. F. A., Notten, K. J. B., Kruitwagen, R. F. P. M., Futterer, J. J., Vergeldt, T. F. M. y Van Kuijk, S. M. J. (2019). Does three-dimensional anatomy improve student understanding?. Clinical Anatomy, 33, 1, 25-33.

https://doi.org/10.1002/ca.23405 
Ugidos Lozano, M. T., Blaya Haro, F., Molino Diaz, C., Manzoor, S., Ferrer Ugidos, G. y Juanes Méndez, J. A. (2017). 3D Digitization and Prototyping of the Skull for Practical Use in the Teaching of Human Anatomy. Journal of Medical Systems, 41, 83. https://doi.org/10.1007/s10916-017-0728-1

Ugidos Lozano, M. T., Blaya Haro, F., Ruggiero, A., Manzoor, S. y Juanes Méndez, J. A. (2019). Evaluation of the Applicability of 3d Models as Perceived by the Students of Health Sciences. Journal of Medical Systems, 43, 5. https://doi.org/10.1007/s10916-019$1238-0$

Ugidos Lozano, M. T., Juanes Méndez, J. A., Molino Díaz, C., Manzoor, S., Ferrer Ugidos, G. y Blaya Haro, F. (2016). Processing and additive manufacturing of bones for the teaching of human anatomy. ACM International Conference Proceeding Series, 533536. http://dx.doi.org/10.1145/3012430.3012569

Uhl, J. F., Park, J. S., Chung, M. S. y Delmas, V. (2006). Three-dimensional reconstruction of urogenital tract from Visible Korean Human. The Anatomical Record Part A: Discoveries in Molecular, Cellular, and Evolutionary Biology, 288A (8), 893-899. https://doi.org/10.1002/ar.a.20348

Valenzuela Torres, D., Zúñiga Herranz, F. y Zúñiga Rocha, S. (2010). Doscientos años de la enseñanza de la Medicina. La experiencia chilena como ejemplo de los procesos de independencia hispanoamericana y los cambios en educación médica. Bordón, 62 (2), 81-91. Recuperado de https://r.search.yahoo.com/_ylt=AwrP4IA4wr5e9CAAIChU04IQ;_ylu=X3oDMTByaW1 1 dnNvBGNvbG8DaXlyBHBvcwMxBHZOaWQDBHNIYwNzcg-$/ R V=2 / R E=1589588664 / R O=10 / R U=h t t p s \% 3 a \% 2$ f\%2frecyt.fecyt.es\%2findex.php\%2fB ORDON\%2farticle\%2fdownload\%2f29182\%2f15574/RK=2/RS=dKAT1_CQi7WsMhDU EKsPuEgJ_aw-

Van Delft, K., Thakar, R. y Sultan, A. H. (2015). Pelvic floor muscle contractility: digital assessment vs transperineal ultrasound. Ultrasound in Obstetrics \& Gynecology, 45 (2), 217-222. https://doi.org/10.1002/uog.13456

Van Nuland, S. E. y Rogers, K. A. (2016). The anatomy of E-Learning tools: Does software usability influence learning outcomes? Anatomical Sciences Education, 9 (4), 378390. https://doi.org/10.1002/ase.1589

Van Nuland, S. E. y Rogers, K. A. (2017). The skeletons in our closet: E-learning tools and what happens when one side does not fit all. Anatomical Sciences Education, 10, 6, 570-588. https://doi.org/10.1002/ase.1708

Vázquez, R., Riesco, J. M., Juanes, J. A., Blanco, E., Rubio, M. y Carretero, J. (2007). Educational strategies applied to the teaching of anatomy. The evolution of resources. European Journal of Anatomy, 11 (1), 31-43. Recuperado de http://eurjanat.com/data/pdf/eja.07S10031.pdf 
Vellucci, F., Regini, C., Barbanti, C. y Luisi, S. (2018). Pelvic floor evaluation with transperineal ultrasound: a new approach. Minerva Ginecologica, 70 (1), 58-68. https://doi.org/10.23736/S0026-4784.17.04121-1

Veloz-Martínez, M. G., Almanza-Velasco, E., Uribe-Ravell, J. A., Libiend-Díaz González, L., Quintana-Romero, V., y Alanís-López, P. (2012). Uso de tecnologías en información y comunicación por médicos residentes de ginecología y obstetricia. Investigación en educación médica, 1 (4), 183-189. Recuperado de http://www.scielo.org.mx/scielo.php?script=sci_arttext\&pid=S2007$50572012000400005 \&$ lng=es\&tlng=es

Vergeldt, T. F. M., Notten, K. J. B., Stoker, J., Fütterer, J. J., Beets-Tan, R. G., Vliegen, R. F. A., Schweitzer, K. J., Mulder, F. E. M., Van Kuijk, S. M. J., Roovers, J. P. W. R., Kluivers, K. B. y Weemhoff, M. (2016). Comparison of translabial three-dimensional ultrasound with magnetic resonance imaging for measurement of levator hiatal biometry at rest. Ultrasound in Obstetrics \& Gynecology, 47 (5), 636-641. https://doi.org/10.1002/uog.14949

Vernez, S. L., Okhunov, Z., Wikenheiser, J., Khoyilar, C., Dutta, R., Osann, K., Kaler, K., Lee, T. K., Clayman, R. V. y Landman, J. (2017). Precise Characterization and 3-Dimensional Reconstruction of the Autonomic Nerve Distribution of the Human Ureter. Journal of Urology, 197 (3 Part 1), 723-729. https://doi.org/10.1016/j.juro.2016.08.118

Vesalius, A. (1543). De Humani Corporis Fabrica. Recuperado de http://www.bl.uk/turningthe-pages/?id=69a49930-a67d-11db-873d-0050c2490048\&type=book

Ward, T. M., Wertz, C. I. y Mickelsen, W. (2018). Anatomage table enhances radiologic technology education. Radiol Technol, 89, 304-306. Recuperado de https://www.ncbi.nlm.nih.gov/pubmed/29298946?dopt=Abstract

Weinstock, P., Rehder, R., Prabhu, S. P., Forbes, P. W., Roussin, C. J. y Cohen, A. R. (2017). Creation of a novel simulator for minimally invasive neurosurgery: fusion of 3D printing and special effects. J Neurosurg Pediatr, 20, 1, 1-9. https://doi.org/10.3171/2017.1.PEDS16568

Wilson, A. B., Brown, K. M., Misch, J., Miller, C. H., Klein, B. A., Taylor, M. A., Goodwin, M., Boyle, E. K., Hoppe, C. y Lazarus, M. D. (2019). Breaking with Tradition: A Scoping Meta-Analysis Analyzing the Effects of Student-Centered Learning and ComputerAided Instruction on Student Performance in Anatomy. American Association of Anatomists, 12, 61-73. https://doi.org/10.1002/ase.1789

Wineski, L. E. (2019). Snell Anatomía clínica por regiones. Barcelona, España. Wolters Kluwer.

Wlaźlak, E., Kluz, T., Kociszewski, J., Frachowicz, K., Janowska, M., Wlaźlak, W. y Surkont, G. (2017). The analysis of repeatability and reproducibility of bladder neck mobility measurements obtained during pelvic floor sonography performed introitally with 
2D transvaginal probe. Ginekologia Polska, 88 (7), 360-365.

https://doi.org/10.5603/GP.a2017.0068

Wohlrab, K., Jelovsek, J. E. y Myers, D. (2017). Incorporating simulation into gynecologic surgical training. American Journal of Obstetrics and Gynecology, 217 (5), 522-526. https://doi.org/10.1016/j.ajog.2017.05.017

Wu, Y., Tan, L. W., Li, Y., Fang, B. J., Xie, B., Wu, T. N., Li, Q. Y., Qiu, M. G., Liu, G. J., Li, K., Xu, H. T., Luo, N. y Zhang, S. X. (2012). Creation of a female and male segmentation dataset based on Chinese Visible Human (CVH). Computerized Medical Imaging and Graphics, 36 (4), 336-342. https://doi.org/10.1016/j.compmedimag.2012.01.003

Xuan, Y., Yue, S., Sun, L., Pei, Y., Wang, J., Tan, L., Lu Z., Yang, L., An, Y., Jiang, Y. y Wu, Q. (2017). Repeatability of Female Midurethral Measurement Using High-Frequency 3Dimensional Transvaginal Ultrasonography. Journal of Ultrasound in Medicine, 37 (6), 1389-1395. https://doi.org/10.1002/jum.14477

Xue, Y. H., Ding, S. Q., Ding, Y. J. y Pan, L. Q. (2017). Role of three-dimensional endoanal ultrasound in assessing the anal sphincter morphology of female patients with chronic proctalgia. World Journal of Gastroenterology, 23 (21), 3900. https://doi.org/10.3748/wjg.v23.i21.3900

Yammine, K. y Violato, C. (2014). A meta-analysis of the educational effectiveness of threedimensional visualization technologies in teaching anatomy. Anat SciEduc, 8, 525538. https://doi.org/10.1002/ase.1510

Yammine, K. y Violato, C. (2016). The effectiveness of physical models in teaching anatomy: a meta-analysis of comparative studies. Adv in Health Sci Educ 21, 883-895. https://doi.org/10.1007/s10459-015-9644-7

Yanamadala, J., Noetscher, G. M., Louie, S., Prokop, A., Kozlov, M., Nazarian, A. y Makarov, S. N. (2016). Multi-purpose VHP-female version 3.0 cross-platform computational human model. 10th European Conference on Antennas and Propagation (EUCAP), 1-5. https://doi.org/10.1109/EuCAP.2016.7481298

Yiasemidou, M., Glassman, D., Mushtaq, F., Athanasiou, C., Williams, M. M., Jayne, D. y Miskovic, D. (2017). Mental practice with interactive 3D visual aids enhances surgical performance. Surgical Endoscopy, 31 (10), 4111-4117. https://doi.org/10.1007/s00464-017-5459-3

Youssef, A., Montaguti, E., Sanlorenzo, O., Cariello, L., Awad, E. E., Pacella, G., Ghi T., Pilu, G. y Rizzo, N. (2015). A New Simple Technique for 3-Dimensional Sonographic Assessment of the Pelvic Floor Muscles. Journal of Ultrasound in Medicine, 34 (1), 65-72. https://doi.org/10.7863/ultra.34.1.65

Yuan, Y., Qi, L. y Luo, S. (2008). The reconstruction and application of virtual Chinese human female. Computer Methods and Programs in Biomedicine, 92 (3), 249-256.

https://doi.org/10.1016/j.cmpb.2008.05.011 
Zhang, S. X., Heng, P. A. y Liu, Z. J. (2006). Chinese visible human project. Clinical Anatomy, 19 (3), 204-215. https://doi.org/10.1002/ca.20273

Zilverschoon, M., Kotte, E. M. G., Van Esch, B., Ten Cate, O., Custers, E. J. y Bleys, R. L. A. W. (2018). Comparing the critical features of e-applications for three-dimensional anatomy education. Annals of Anatomy - Anatomischer Anzeiger, 222, 28-39. https://doi.org/10.1016/j.aanat.2018.11.001

Nota: todas las direcciones que se adjuntan han sido validadas hasta la fecha de edición de esta Tesis Doctoral, pudiendo variar a lo largo del tiempo. 


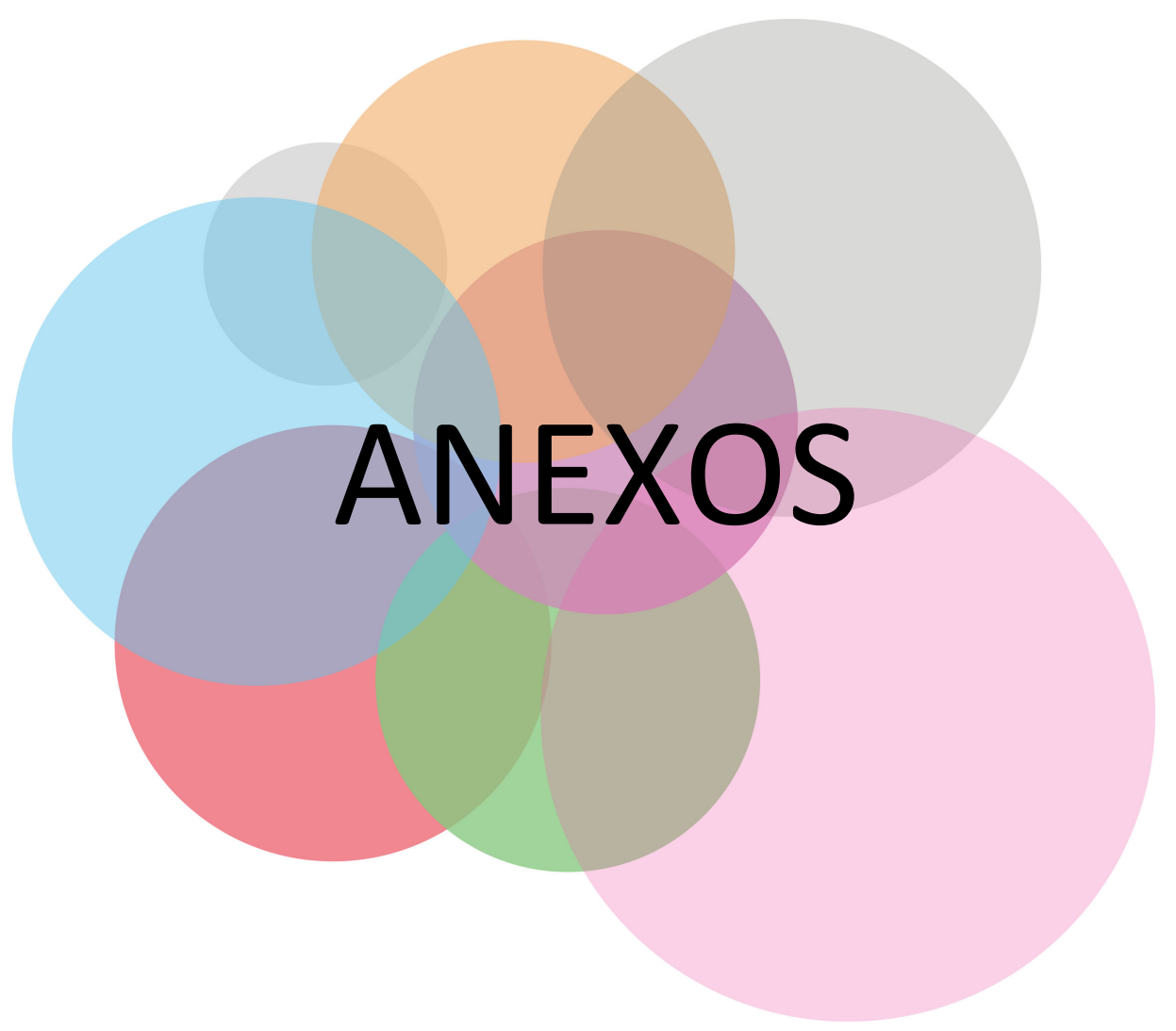


Anexo 1

ENCUESTA SOBRE LA USABILIDAD DE DISPOSITIVOS TECNOLÓGICOS PORTABLES

https://www.survio.com/survey/d/I9E4T2N5N5U9H2H8K

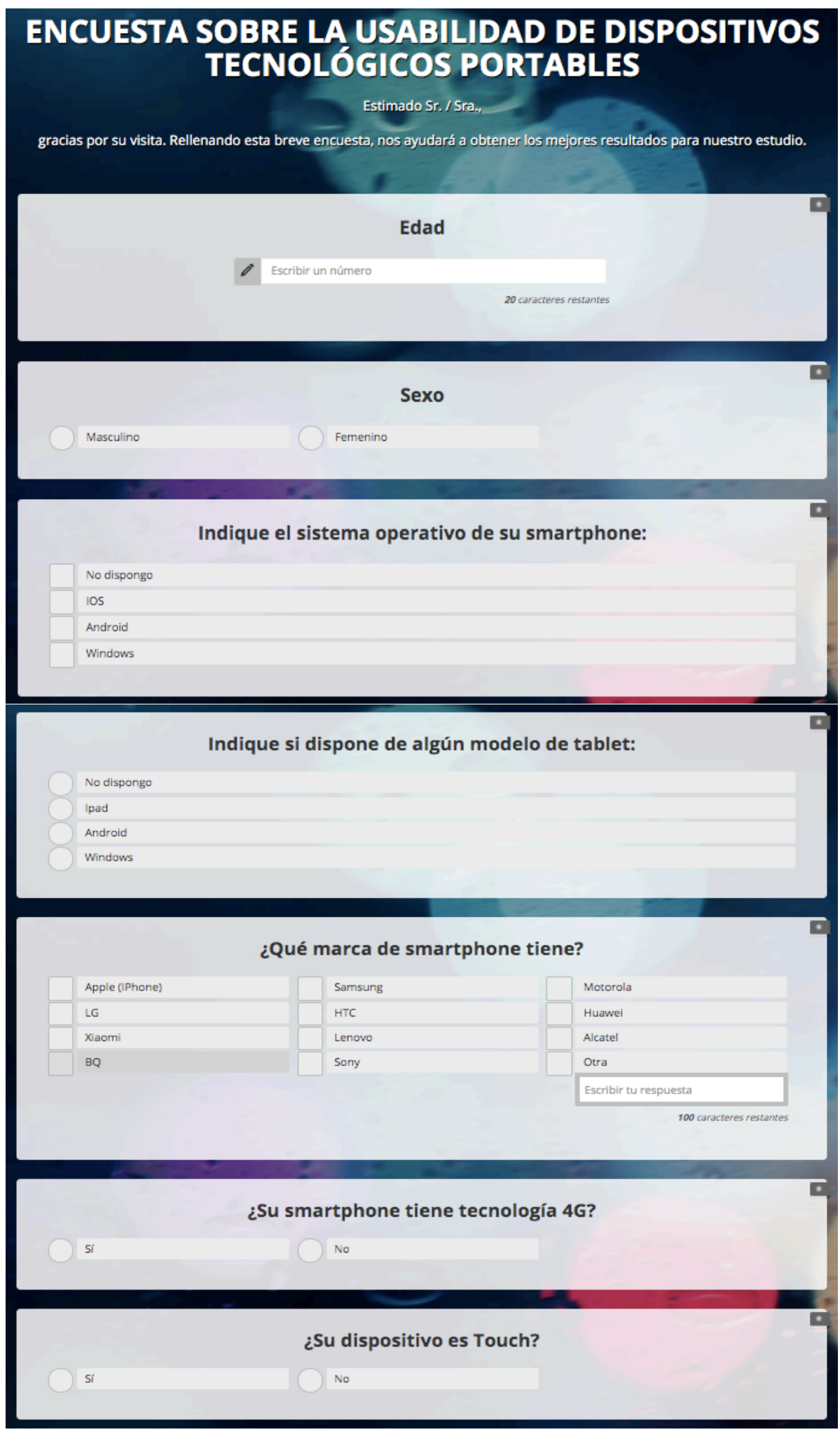


El uso que hace de su smartphone es principalmente:

Personal, llamadas de voz

Personal, redes sociales, SMS, Whatsapp.

Actividades docentes (campus virtual)

El tiempo que utiliza al día su dispositivo portatil es:

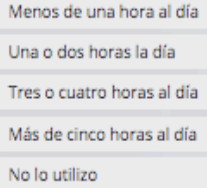

¿Qué tipo de aplicaciones utiliza de forma más frecuente con su smartphone en su actividad diaria?

Manejo de información

Lectura de noticias

Entretenimiento

Otros

Escribir tu respuesta

100 caracteres restantes

La destreza que tiene con su smartphone para la instalación/desintalación de Apps es:

Mala

Regular

Muy buena

El uso de su smartphone le ayuda a mejorar el aprendizaje y su rendimiento docente en la formación médica:

Nada

Un poco en algunas cosas

Mucho, si se utiliza adecuadamente

En el futuro serán herramientas indispensables

¿Utiliza con frecuencia alguna aplicación (App) como apoyo complementario a su formación medica?

Muy a menudo

Frecuentemente

A veces

Casi nunca

Nunca 
En el supuesto de utilizar aplicaciones en su smartphone como soporte para mejorar su formación médica, las aplicaciones, además de aportar información en formato texto, jimplementan su conocimiento con formatos multimedia del tipo imágenes y vídeos?
No
No uso aplicaciones sobre medicina

¿Ha experimentado alguna vez un simulador de Realidad Virtual?

$\mathrm{Si}$

No

No sé qué es

¿Dispone de alguna gafa de Realidad Virtual?

¿Cree que la Realidad Virtual puede ser un espacio de formación universitaria complementaria?

No lo veo posible

Si, pienso que puede ser aplicable

Parcialmente, porque influyen muchos factores

No, influyen muchos factores

Desconozco el tema

\section{ENVIAR ENCUESTA $\bigcirc$}


Anexo 2

ENCUESTA SOBRE EL SOFTWARE DE ANATOMIA DEL SUELO PELVICO Y DE LA PELVIS FEMENINA

https://www.survio.com/survey/d/W306Q0T1G6L5T6O5L

\title{
ENCUESTA SOBRE EL SOFTWARE DE ANATOMIA DEL SUELO PELVICO Y DE LA PELVIS FEMENINA
}

\author{
Estimado Sr. / Sra., \\ gracias por su visita. \\ Rellenando esta breve encuesta, nos ayudará a obtener los mejores resultados.
}

La instalación del software fue:

Complicada
Más bien fácl Mús biendficil

¿Con que frecuencia se bloquea el software?

¿Que grado de satisfacción tiene con el software empleado?

Muy insatisfecto

Satisfecha

La ayuda para complementar el estudio que aporta el software es:

Totalmente inút!

Más bien iti
Más bien inútil

Muyát!

Normal

La visión tridimensional de las estructuras viscerales de la pelvis le facilita una mejor comprensión y análisis de cada una de ellas

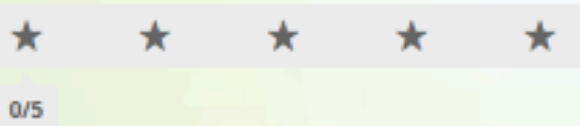


Considera este procedimiento tecnológico mejor que muchos atlas anatómicos para el estudio morfológico de la anatomía de la pelvis femenina y del suelo pélvico.

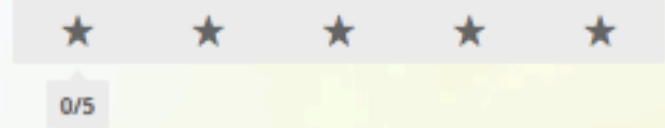

El contenido incorporado en el programa informático es suficiente para su formación académica, siendo bastante completo e ilustrativo.

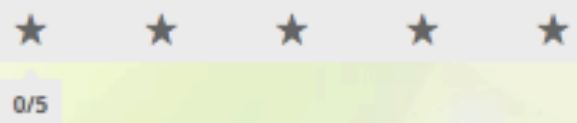

Mediante la tecnología de visión tridimensional utilizada ha empleado menos tiempo para el aprendizaje de la anatomía de la pelvis femenina, respecto a otros métodos tradicionales (uso de libros ilustrados, clases teóricas, prácticas, videos, etc....)

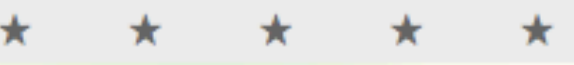

$0 / 5$

Considera esta tecnología de visión de visión 3D interactiva un buen recurso docente complementario para el proceso de enseñanza y aprendizaje.

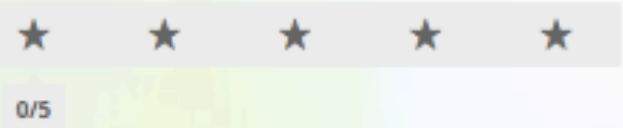

Desde el punto de vista de presentación visual, ¿cómo evaluaría los contenidos visualizados?

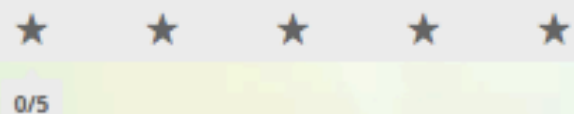


La navegación por el programa es muy intuitiva y presenta un desarrollo metodológico que motiva su aprendizaje de forma ágil y sencilla.

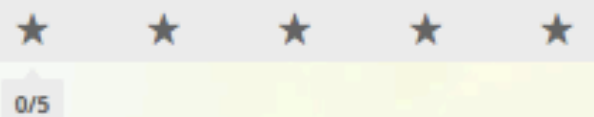

Los comentarios explicativos breves y concisos que aparecen en la pantalla le ayudan a comprender mejor la anatomía de la pelvis femenina, así como a afianzar su conocimiento.

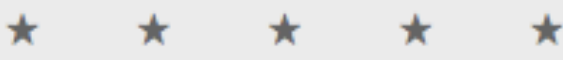

$0 / 5$

La interfaz del programa es intuitiva y de fácil manejo.

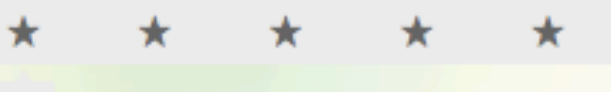

$0 / 5$

Cómo considera la aportación de este material docente complementario a la formación médica para el estudio de la pelvis femenina.

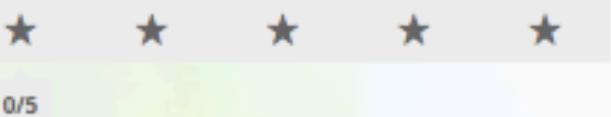

Recomendaría a otros compañeros estos desarrollos informáticos para el aprendizaje y estudio de la Anatomía y Radiología de la pelvis femenina, del suelo pélvico y su contenido.

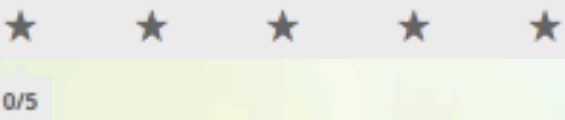




\section{Anexo 3}

Trabajo presentado en el congreso TEEM 17 (International Conference Technological Ecosystems for Enhancing Multiculturality 2017), que tuvo lugar en Cádiz, los días 1820 de octubre de 2017. Posteriormente fue publicado en ACM library.

Título del trabajo: "Desarrollo de modelos 3D de la pelvis femenina embebidos en secciones anatómicas del Proyecto Visible Human".

Resumen: Se presenta un desarrollo informático que permite visualizar e interactuar, en un entorno virtual, con las principales estructuras anatómicas de la pelvis femenina, reconstruidas a partir de secciones seriadas de cadáver, procedentes del proyecto Visible Human de la Biblioteca Médica de Estados Unidos. Las posibilidades de representar tridimensionalmente estas estructuras en cualquier orientación espacial, junto con imágenes seccionales en los tres planos del espacio (axial, coronal y sagital), facilitan la comprensión e identificación anatómica del conjunto de estructuras viscerales de esta región. Con una interfaz gráfica muy intuitiva, nuestro procedimiento tecnológico permite la observación de las principales vísceras pelvianas femeninas en tres dimensiones. Esta aplicación informática representa una importante herramienta para la formación, tanto para estudiantes de medicina como para especialistas en ginecología, y también como paso previo en la planificación de intervenciones quirúrgicas del suelo pélvico.

Referencia: Asensio Romero, L., Asensio Gómez, M., y Juanes Méndez, J. A. (2017). Development of 3D models of female pelvis embedded in anatomical sections from de Visible Human Project. TEEM 2017: Proceedings of the 5th International Conference on Technological Ecosystems for Enhancing Multiculturality, 53, 1-7. https://doi.org/10.1145/3144826.3145403 


\section{Development of 3D models of female pelvis embedded in anatomical sections from de Visible Human Project}

\author{
Lourdes Asensio Romero \\ Dpt. Human Anatomy, Faculty of \\ Medicine, University of Salamanca \\ 37007 Salamanca Spain \\ lourdes90.ar@gmail.com
}

\author{
Manuel Asensio Gómez \\ Dpt. Human Anatomy, Faculty of \\ Medicine, University of Salamanca \\ 37007 Salamanca Spain \\ mago59@usal.es
}

\author{
Juan A. Juanes Méndez \\ Dpt. Human Anatomy, Faculty of \\ Medicine, University of Salamanca \\ 37007 Salamanca Spain \\ jajm@usal.es
}

\begin{abstract}
We present a computerized development that allows visualizing and interacting in a virtual environment with the main anatomical structures of female pelvis. They are reconstructed from serial sections of corpse, from the Visible Human project of the Medical Library of the United States. The possibilities of representing these three-dimensional structures in any spatial orientation, together with sectional images in the three planes of space (axial, coronal and sagittal) facilitate the anatomical comprehension and identification of the set of visceral structures of this region. Our technological procedure allows the observation of the main female pelvis viscera in three dimensions with a very intuitive graphic interface. This computer application represents an important training tool for both medical students and specialists in gynecology and as a preliminary step in the planning of pelvic floor surgery.
\end{abstract}

\section{CCS CONCEPTS}

-Human-centered computing Visualization toolkits

\section{KEYWORDS}

"sectional a natomy", "pelvic viscera", "3D models", "software development".

Permission to make digital or hard copies of all or part of this work for personal or classroom use is granted without fee provided that copies are not made or distributed for profit or commercial advantage and that copies bear this notice and the full citation on the first page. Copyrights for components of this work owned by others than ACM must be honored. Abstracting with credit is permitted. To copy otherwise, or republish, to post on servers or to redistribute to lists, requires prior specific permission and/or a fee. Request permissions from Permissions@acm.org.

TEEM 2017, October 18-20,2017, Cádiz, Spain (C) 2017 Association for Computing Machinery. ACM ISBN 978-1-4503-5386-1/17/10 ...\$15.00 https://doi.org/10.1145/3144826.3145403

\section{INTRODUCTION}

The pelvis is one of the most difficult anatomic regions to study in a live individual or in a corpse, specially in the case of the female pelvis $[1,2]$. The female pelvis contains organs of irregular morphology (rectum, uterus, vagina and bladder) as well as structures of the pelvic floor (support structures aponeuroses and muscles) located on different planes. These structures are hard to represent and comprehend through two-dimensional diagrams. On the other hand, the anatomic studies made in corpses have been carried out knowing that there are some major post-mortem changes that may alter the form of the anatomic spaces and the different relationships between the pelvic organs [3]. The study of the female pelvis, like other studies of the human body, has evolved along with the available formats and technologies of the time $[4,5]$.

Therefore, three-dimensional visualization of anatomic structures embedded in corpse sections (axial, coronal, sagittal) constitutes the clearest and more intuitive form of morphological analysis of the female pelvis $[6,7,8]$. Thus, the objective of the present work is the 3D modeling and its representation in a OS PC of the main visceral structures in normal female pelvis. This allows the visualization and interaction with the 3D models in sectional images of corpses. The use of this kind of techniques in the field of gynecology has recently allowed to obtain images that contribute to a better anatomical knowledge of the female pelvis $[9,10]$. Accordingly, we display a computer development based on 3D analysis and visualization of the female pelvis anatomic structures with simultaneous sections of corpse from the Visible Human project, that constitutes an excellent and useful tool in gynecology.

\section{MATHERIAL AND METHOD}

\subsection{Corpse sectional images}

We used multiple axial sections of $0,33 \mathrm{~mm}$ thick of high resolution obtained from a woman corpse from the Visible 
Human Female CD 2.0 Version of the National Library of Medicine in the USA, under authorized license.

We utilized Autodesk ${ }^{\circledR}$ Maya ${ }^{\circledR}$ for the volumetric nonprobabilistic creation of anatomic structures. It is a 3D animation software that provides a complete group of creative functions. The tools enable to create animation, modelling, simulation, rendering, motion tracking and composition in a production platform highly expandable. Maya ${ }^{\circledR}$ aid to accomplish the demanding requirements of production with specific tools conceived for the creation of visual effects, game development, post production and other 3D-animation projects.

Size and format adjustment of the images were made with Pixresizer Software version 2.0.4®. The final format was jpg, 380 pixels wide, optimized for the presentation in $800 \times 600$ px resolution screens.

The delimitation of the response area for the location of the target structure in every task was made through Image Mappier version $1.0 \AA$. This area was defined from the coordinates $(\mathrm{x}-\mathrm{y})$ established for each and every one of the images, which ranged from 50 to 500 coordinates according to the structure.

\subsection{Programming}

The computer application has been developed for Windows $®$ platforms and programmed in Visual C++. This programming system, being a development-integrated environment, allowed us to create an object-oriented programming (OOP) under $\mathrm{C}, \mathrm{C}++$ and $\mathrm{C}++/ \mathrm{CLI}$ programming languages, along with Windows' SDK development system (also known as APIApplication Programming Interface).

Visual $\mathrm{C}++$ enabled the development and depuration of written code for Microsoft Windows API's, DirectX and Microsoft.NET Framework technology.

An html file was elaborate for each 3D rebuilt model with a short anatomic description, supplementing the information that will be showed in the developed computer application.

\subsection{User's interface}

The user's interface is made up of the following areas (Fig. 1):

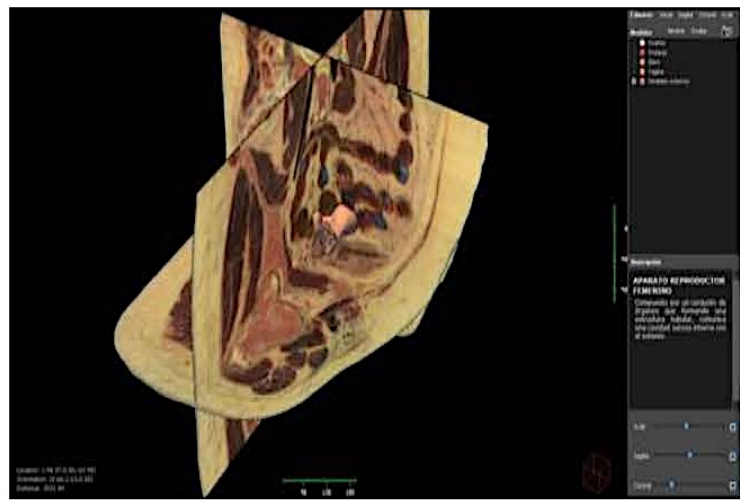

Figure 1: User's interface of the computer application developed.

- 3D Visor, for the representation of different graphic elements (planes and surface models).

- Control area, with the different controls for the interaction with the sectional images and the models represented in the visor (visibility, color model).

- Scene selector, defined in a text file external to the application. It is a drop-down menu through which the virtual scene to represent can be selected.

The image file contains the information to arrange the sectional images in a proper orientation and spatial position, determined by the following parameters:

- Dimension $(x, y, z)$ : they point out the total dimension of the volume from which the images have been obtained; that is, the total number of slices $(300 \times 280 \times 280)$.

- Pixelsize: $(\mathrm{x}, \mathrm{y}, \mathrm{z})$ : voxel size, in every spatial direction, expressed in millimetres ( $1 \mathrm{mmx} 1 \mathrm{mmx} 1 \mathrm{~mm})$

- Origin $(x, y, z)$ : origin (central reference) of the volume $(148,131,139)$.

- Orientation: may be sagittal, coronal or axial.

- Image file name, followed by the corresponding slice.

The text file contains the specifications of every 3D model, with the definition and characteristics of each anatomical structure modeled.

The main used nodes in this kind of text file are:

- Model \{f: it defines the creation of a new model, whose characteristics are specified between braces.

- Name: name of the model that will be showed in the selection drop-down menus

- Label: model identifier, for intern use.

- File: DirectX format file with the model geometry.

- Color: model color, in RGB, with component values between 0 and 1.

- Transparency range: it specifies the variation range of the transparency factor. In general, 0 for non-transparent objects and 1 for the highest transparency.

- Draw style: it specifies the style with which the polygonal net is represented, being able to select between shaded or lines. 
-Visible: node used to define the initial visibility of the model 0 means "not visible" and 1 means "visible".

- Documentation: Html format file that contains the documentation associated to the model.

\section{RESULTS}

Our computer application allows visualizing and interacting simultaneously with:

1.- Sectional corpse images of the female pelvis, in the three orthogonal axis of the space (axial, coronal and sagittal) (Fig 2).

2.- 3D anatomical models of some visceral structures (bladder, uterus, vagina). Theses aspects may be observed in a representative way in figures $3,4,5$ and 6 .

The graphic user's interface is very intuitive (Figs. 7, 8 and 9). There can be seen the different options that allow interaction with the anatomic visor. These options permit a 3D visualization of the anatomic structures at the user request (Figs. 5 and 6). It takes the corpse sections as a reference in the three planes of the space (coronal, axial and sagittal), being able to activate or deactivate every one of them (Figs. 3 and 4).

The computer development allows representing and interacting with 2 types of main visual elements: Planes and Models. Every interaction with the elements of the visual scene (rotations, translations, zoom and selection) is made pointing with the cursor on the visor by using the computer mouse.

The resultant view of carrying out rotations, translations or zoom may be stored in a file through the suitable button. It is possible to save the represented scene in the visor as a bitmap (.bmp) format file, thanks to the option "capture image". This option is represented in the menu with a camera icon (Fig. 8). The Planes button is the screen where the Visor and its configuration interact. This button contains the necessary controls to manage the sectional images of female pelvis showed in the visor. There are three orientation planes: Sagittal, Axial and Coronal. Each plane has a selection control to activate or

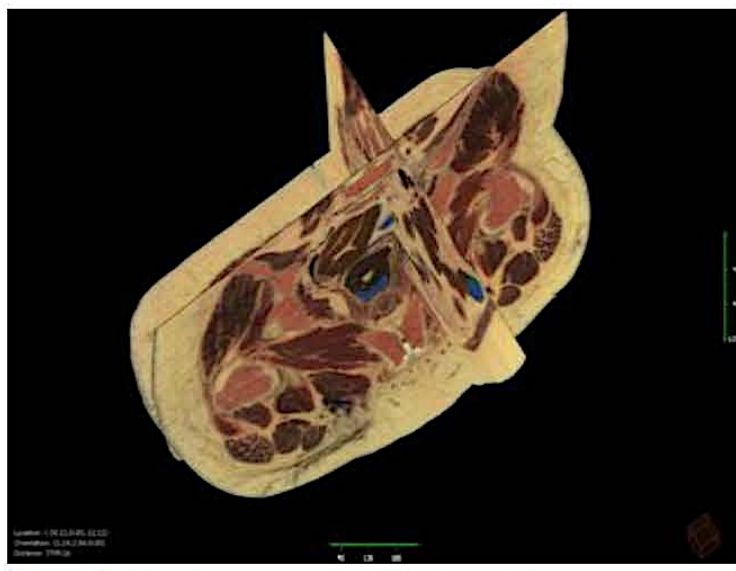

Figure 2: Simultaneous visualization of three anatomical sections (axial, coronal and sagittal).

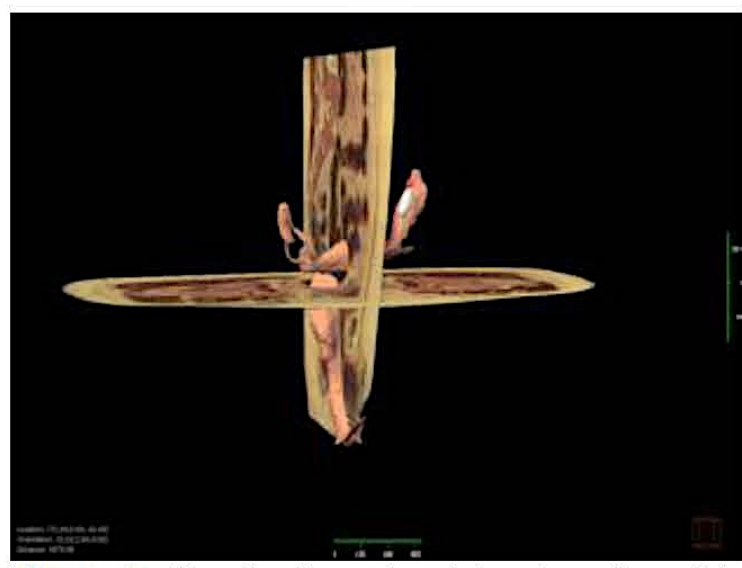

Figure 3: Visualization of pelvic visceral models embedded in two anatomical sections (axial, and sagittal)

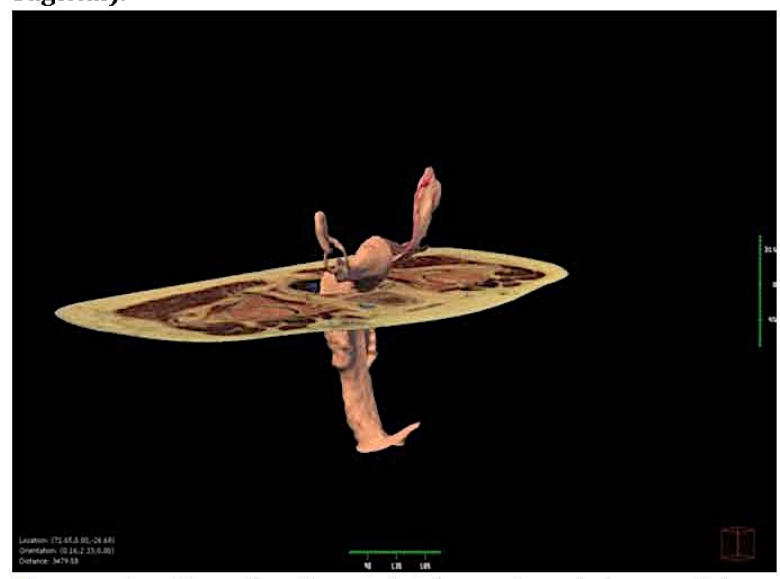

Figure 4: Visualization of visceral pelvic models embedded in an axial anatomical section. 


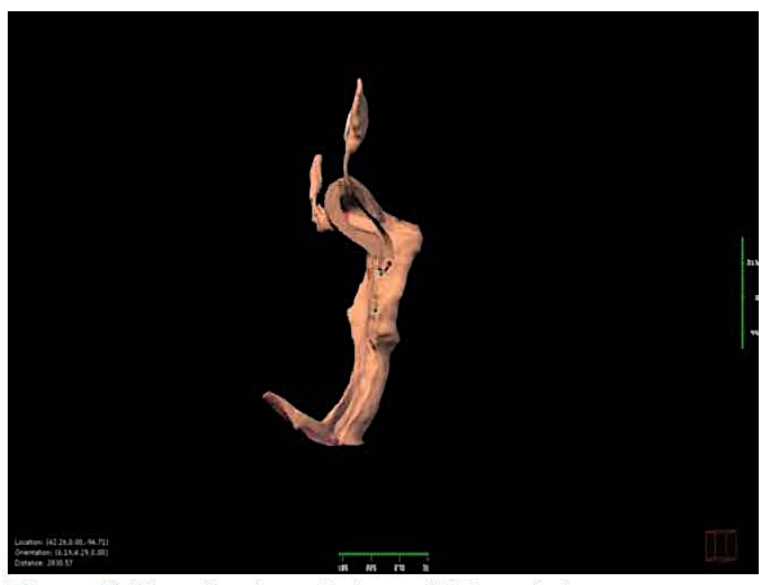

Figure 5: Visualization of visceral 3D model.

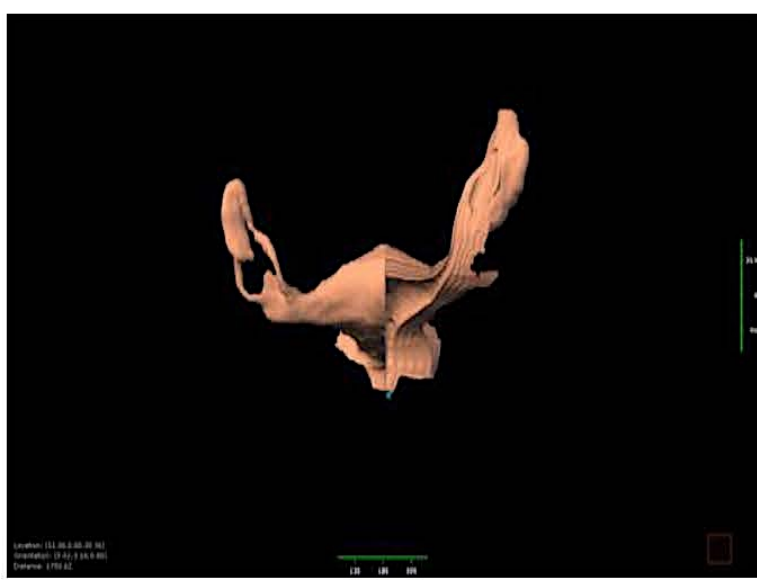

Figure 6: Visualization of visceral model 3D.

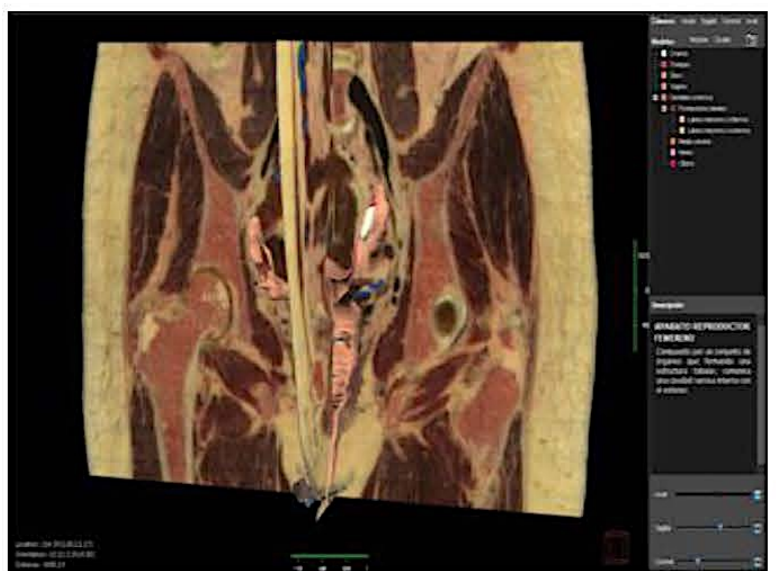

Figure 7: Visualization of user's interface of the computer application.

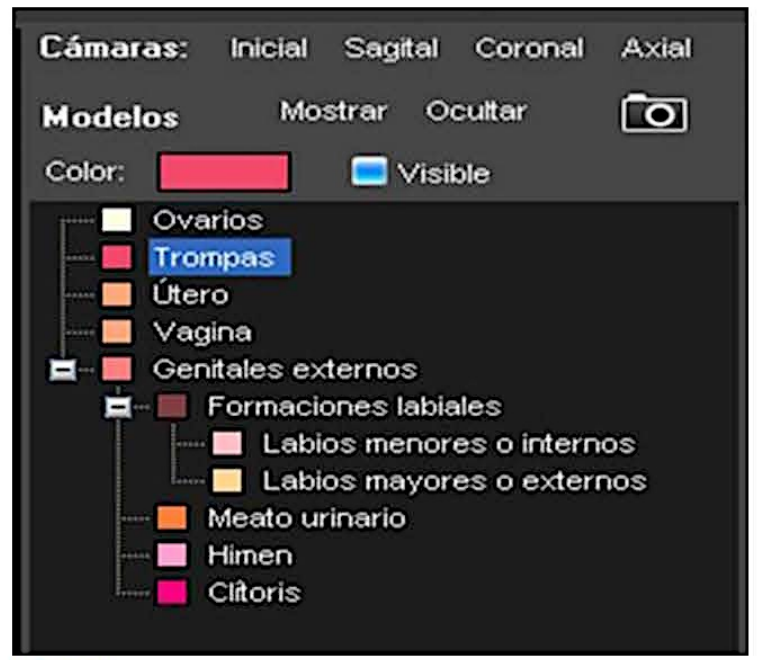

Figure 8: User's in terface. Activation zone of 3D models.

deactivate its visibility (Fig. 9). We will also be able to change the position of the selected plane, moving horizontally the cursor over the visor.

All our computer system is controlled at the user's will. Therefore, a real interaction between the computer and the user exists, avoiding, as much as possible, that the later becomes a mere spectator.

Finally, we point out the fact that this computer development also constitutes a teaching tool, firmly conscientious and elaborated, so that the users may develop all the process of learning in an automatic way, especially in the field of gynecology. This will lead to a better knowledge and comprehension of this body region, because its anatomic structures will be accessible to analysis from any spatial position and in its three dimensions.

\section{DISCUSSION}

The generation of 3D images of the human body is increasing in the past few years, being its use generalized in different medical environments $[11,12,13,14,15,16,17]$. The growing implementation of advanced computer application in the visualization of 3D models of anatomic structures allows the comprehension of its structure and spatial relationships $[18,19,20,21,22,23]$

The computer programs, as teaching resources in medical training, constitute a very useful tool in every field of medical science $[24,25,26]$

There is an increasing availability of computers with high technological features that satisfy the optimal execution needs of many teaching computer programs with hypermedia characteristics that require a high capacity of memory in the computers where they are going to be executed. 


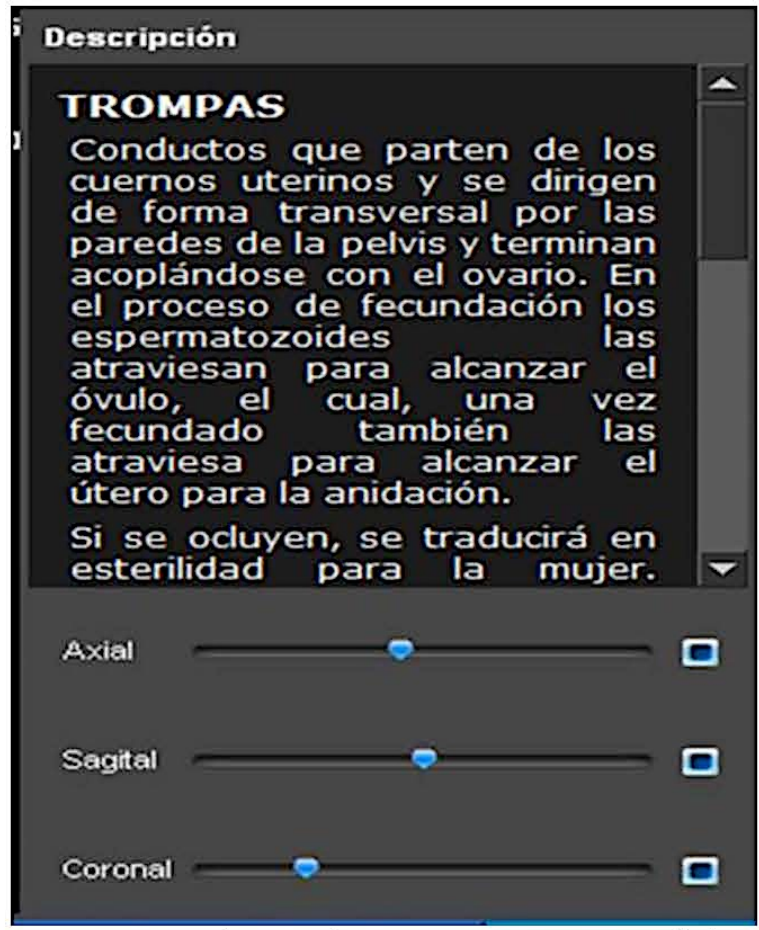

Figure 9: User's interface. Description zone of the selected 3D model and activation of serial anatomical sections of corpse.

The advances in computer technologies and recent communication techniques have been added to the teaching field in medical sciences. The objective of these incorporations are increase the efficiency of the teaching process and searching to contribute to the learning procedure with a more scientific base and a technique that will make the teaching more productive $[27,28,29,30]$.

The user's interface is made up of a group of components used by the customers to communicate with the program that is been executed in the computer. The user is the one who really manages the running of the computer program thanks to diverse instructions of usability. We can say that an interface is the part of a computer application that is seen by the user and with which he interacts. It is related to the underlying structure, the architecture and software code [31].

Agood interface like the one we are showing in this computer development for the visualization of anatomic structures of female pelvis is easy to understand and very simple to manage. This interface allows the users to carry out a learning task in the easiest and fastest way [32]. This may be probably one of the main advantages that our procedure offers, apart from the visual feature of tri-dimensional images.

It seems evident that the new interfaces that are to come in the next years will not be essentially very different from what we know today. A radical change of conception is yet quite far, at least as far as computer standards are concerned, and there is no other serious development known which has been carried out this way. However, the evolution of graphic interfaces is awaited by the adoption of new threedimensional paradigms, far away from the traditional ones. Teaching computer programs based on simulations present a dynamic model or environment (generally thanks to the use of interactive graphics or animations) that facilitate its exploration and may fulfill inductive or deductive learning through observation and manipulations of the underlying structure. This way, they can discover the model elements and its interrelationships, and some decisions can be made, acquiring direct experience in front of situations that would be difficult to reach in real life, like the possibility to simulate a virtual surgical approach, through the use of different techniques of image diagnosis that visualize the anatomic reality of the patient $[33,34,35]$.

The image studies can facilitate the anatomy knowledge and the diagnosis of pathological processes that affect anatomic structures like the pelvis. These techniques have changed over the years, no just related to the diagnosis accuracy in itself, but also as an element of basic decision when deciding a therapeutic plan [36].

Female pelvis is an area of special anatomic complexity, so a three-dimensional visualization of this region would make the learning of this body part easier. Therefore, our computer application means a good 3D visualization method of the female pelvis, facilitating its anatomic assessment, taking advantage of the advanced graphic capacities that computers offer nowadays. With a very intuitive graphic interface, our procedure allows the observation of different anatomic parts in a three-dimensional environment at the user's request, based on the sections of corpse from the Visible Human project, being able to activate or deactivate the visualization of every one of them. Moreover, it offers documental information about the selected 3D anatomic element. All of this has allowed us to establish a virtual three-dimensional model of the female pelvis from anatomic images arranges in series.

\section{REFERENCES}

[1] Sonia Pujol, Michael Baldwin, Joshua Nassiri, Ron Kinikis and Kitt Shaffer 2016. Using 3D Modeling Techniques to Enhance Teaching of Difficult Anatomical Concepts. Acad Radiol. 2016 Apr, 23 (4). 507-516. DOI= https://doi.org/10.1016/j.acra.2015.12.012

[2] Aimée Sergovich, Marjorie Johnson and Timothy D. Wilson. 2010 Explorable three-dimensional digital model of the female pelvis, pelvic contents, and perineum for anatomical ed ucation. Anat Sci Educ. 2010 MayJun, 3 (3). 127-133. DOI=https://doi.org/10.1002/ase.135

[3] Binji Fang, Yi Wu, Chun Chu, Ying Li, Na Luo, Kaijun Liu, Liwen Tan, and Shaoxiang Zhang. 2017. Creation of a Virtual Anatomy System based on Chinese Visible Human data sets. Surg Radiol Anat, Apr, 39 (4), 441-449. Epub 2016 Sep 23.

[4] Sanjib Kumar Ghosh. 2015. Evolution of illustrations in anatomy: a study from the classical period in Europe to modern times. Anat Sci Educ 2015 $\begin{array}{llllll}\text { Mar-Apr, } & 8 & \text { (2), } & 175-188 . & \text { Epub } 2014 & \text { Jul 22. DOI= }\end{array}$ https://doi.org/10.1002/ase.1479 
TEEM 2017, October 2017, Cádiz, Spain

[5] Mircea-Constantin Sora, Radu Jilavu and Petru Matusz. 2012. Computer aided three-dimensional reconstruction and modeling of the pelvis, by using plastinated cross sections, as a powerful tool for morphological investigations. Surg Radiol Anat. 2012 Oct, 34 (8). 731-736. Epub 2011 Aug 23.

[6] Vicent Balaya, Jean François Uhl, A. Lanore, C. Salachas, T. Samoyeau, Charlotte Ngo, C. Bensaid, C. Cornou, L. Rossi, R. Douard, Anne Sophie Bats, F. Lecuru and Vincent Delmas. 2016. 3D modeling of the female pelvis by Computer-Assisted Anatomical Dissection: Applications and perspectives. J Gynecol Obstet Biol Reprod (Paris) 2016 May, 45 (5), 467-477. DOI=https://doi.org/ 10.1016/j.jgyn.2016.01.006

[7] Dong Sun Shin, Hae Gwon Jang, Sung Bae Hwang, Dong-Hwan Har, Young Lae Moon, and Min Suk Chung. 2013. Two-dimensional sectioned images and three-dimensional surface models for learning the anatomy of the female pelvis. American Association of Anatomists, 6: 316-323. DOI= https://doi.org/10.1002/ase.1342

[8] Shao-Xiang Zhang, Pheng-Ann Heng and Zheng-Jin Liu. 2006. Chinese visible human project. Clin Anat. Apr, 19 (3). 204-215. DOI= https://doi.org/ $10.1002 /$ ca.20273

[9] Anne C. Kraima, N.N. Smit, D. Jansma, C. Wallner, R.L.A.W. Bleys, C.J.H. Van de Velde, C.P. Botha and Marco C. DeRuiter. 2012. Toward a highly-detailed 3D pelvic model: approaching an ultra-specific level for surgical simulation and anatomical education. Clin Anat. 2013 Apr, 26(3): 333-8. Epub 2012 Dec 19. DOI= https://doi.org $/ 10.1002 /$ ca. 22207

[10] G. Legendre, L. Sahmoune Rachedi, P. Descamps and H. Fernandez. 2015 Providing of a virtual simulator perineal anatomy (Pelvic Mentor() in learning pelvic perineology: results of a preliminary study. J Gynecol Obstet Biol Reprod (Paris) 2015 Jan, 44 (1), 72-77. Epub 2014 May 20. DOI= https://doi.org/10.1016/j.jgyn.2014.04.004

[11] MichaelJ. Ackerman. The visible human project (18: From body to bits. 2016 Engineering in Medicine and Biology Society (Orlando, FL, USA, 2016), IEEE, 3338-3341. DOI= https: //doi.org $/ 10.1109 /$ EMBC.2016.7591442

[12] Jing-Xing Dai, Min Suk Chung, Rong-Mei Qu, Lin Yuan, Shu-Wei Liu, and Dong Sun Shin. 2012. The Visible Human Projects in Korea and China with improved images and diverse applications. Surg Radiol Anat, 2012 Aug, 34 (6), 527-534

[13] Juan Antonio Juanes, Alberto Prats, Maria Luisa Lagándara and José Manuel Riesco. 2003. Application of the "Visible Human Project" in the field of anatomy: a review. European Journal of An atomy 2003, 7. 147-159.

[14] L. Li, Y.X. Liu and Z.J. Song. 2006. Three-Dimensional Reconstruction of Registered and Fused Chinese Visible Human and Patient MRI Images. Clin Anat, $19,225-231$. DOI= https: $/ /$ doi.org $/ 10.1002 /$ ca.20291

[15] Gregory M. Noetscher, Janakinadh Yanamadala, Harshal Tankaria, Sara Louie, Alexander Prokop, Ara Nazarian, and Sergey N. Makarov. 2016. Computational human model VHP-FEMALE derived from datasets of the national library of medicine. Engineering in Medicine and Biology Society (EMBC) (Orlando, FL, USA, 2016),IEEE,3350 3353.DOI=https://doi.org/10.1109/EMBC.2016.7591445

[16] Janakinadh Yanamadala, Gregory M. Noetscher, Sara Louie, Alexander Prokop, Mikhail Kozlov, Ara Nazarian, and Sergey N. Makarov. 2016. Multipurpose VHP-female version 3.0 cross-platform computational human model. In Antennas and Propagation (EuCAP), (2016). IEEE. 1-5. DOI= https://doi.org/10.1109/EuCAP.2016.7481298

[17] Yuan Yuan, Lina Qi and Shugian Luo. 2008. The reconstruction and application of virtual Chinese human female. Comput Methods Programs

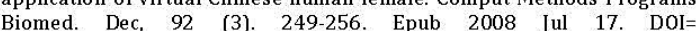
https://doi.org/10.1016/j.cmpb.2008.05.011

[18] Michael Bajka, Mirjana Manestar, J. Hug, G. Székely, Urs Haller and Peter Groscurth. 2004. Detailed anatomy of the abdomen and pelvis of the visible human female. Clin Anat 2004 Apr, 17 (3), 252-260. DOI=https://doi.org/ $10.1002 / \mathrm{ca} .10215$

[19] Sandra Berney, Mireille Bétrancourt, Gaëlle Molinari and Nady Hoyek. 2015. How spatial abilities and dynamic visualizations interplay when learning functional anatomy with 3D anatomical models. Anat Sci Educ 2015 Sep-0ct, 8 (5), 452-462. DOI= https: $/ /$ doi.org $/ 10.1002 /$ ase. 1524

[20] Richard A. Robb, and Dennis P. Hanson. 2006. Biomedical image visualization research using the Visible Human Datasets. Clin Anat. Ap 2006, 19 (3). 240-253. DOI= https://doi.org/ $10.1002 /$ ca.20332

[21] Bharti Temkin, Eric Acosta, Ameya Malvankar and Sreeram Vaidyanath. 2006. An interactive three-dimensional virtual body structures system for anatomical training over the internet. Clin Anat. 2006 Apr, 19 (3). 267-274. DOI $=$ https: $/ /$ doi.org $/ 10.1002 /$ ca.20230

[22] Jean-Fran çois Uhl, Jin Seo Park, Min Suk Chung and Vincent Delmas. 2006 Three-dimensional reconstruction of urogenital tract from Visible Korean Human. Anat Rec A Discov Mol Cell Evol boil, 2006 Aug, 288 (8). 893-899. DOI= https://doi.org/ 10.1002/ar.a.20348
L. Asensio, M. Asensio and JA. Juanes

[23] Yi Wu, Li-Wen Tan, Ying Li, Bin-Ji Fang, Bing Xie, Tong-Ning Wu, Qi-Yu Li, Ming-Guo Qiu, Guan-Jiu Liu, Kai Li, Hao-Tong Xu, Na Luo and Shao-Xiang Zhang. 2012. Creation of a female and male segmentation dataset based on Chinese Visible Human (CVH). Comput Med Imaging Graph. 2012 Jun, 36 (4). 336-342. Epub 2012 Mar 4. DOI= https://doi.org/ $0.1016 /$ j.compmedimag.2012.01.003

[24] Gao An, Li Hong, Xiao-Bing Zhou, Qiong Yang, Mei-Qing Li and Xiang-Yang Tang. 2017. Accuracy and efficiency of computer-aided anatomical analysis using 3D visualization software based on semi-automated and automated segmentations. Ann Anat. 2017 Mar, 210, 76-83. DOI= https://doi.org/ 10.1016/j.aanat.2016.11.009

[25] Bruce Campbell, Cornelius Rosse and J.F. Brinkley JF. 2001. The Virtual Anatomy Lab: a hands-on anatomy learning environment. Stud Health Technol Inform 2001, 81, 85-87.

[26] Ricardo Vázquez, José Manuel Riesco, Juan Antonio Juanes, Enrique Blanco, Manuel Rubio and José Carretero. 2007. Educational strategies applied to the teaching of anatomy. The evolution of resources. Eur J Anat 2007, 11 (1). 31-43.

[27] Mohamed Estai, and Stuart Bunt. 2016. Best teaching practices in anatomy education: A critical review. Annals of Anatomy-Anatomischer Anzeiger, 208, 151-157. DOI= https: $/ /$ doi.org $/ 10.1016 /$ j.aanat.2016.02.010

[28] Diana Coomes Peterson and Gregory S.A. Mlynarczyk. 2016. Analysis of traditional versus three-dimensional augmented curriculum on anatomical learning outcome measures. Anat Sci Educ. 2016 Nov, 9 (6).529-536. DOI= https://doi.org/10.1002/ase.1612

[29] Paul Michael Rea. 2016. Advances in Anatomical and Medical Visualisation Handbook of Research on Engaging Digital Natives in Higher Education Settings, IGI Global, 2016. 244-264. DOI= https://doi.org/10.4018/978-1 5225-0039-1.ch011

[30] Robert B. Trelease. 2016. From chalkboard, slides, and paper to e-learning: How computing technologies have transformed anatomical sciences education. Anatomical sciences education, 9 (6) 583-602. DOI=https://doi.org/10.1002/ase.1620

[31] Antonio Barbeito, Marco Painho, Pedro Cabral, and Joao Goyri O'Neill. 2017. Beyond Digital Human Body Atlases: Segmenting an Integrated 3D 
Development of 3D models of female pelvis embedded in anatomical sections from the Visible Human Project
TEEM 2017, October 2017, Cádiz, Spain

Topological Model of the Human Body. International Journal of E-Health and Medical Communications (IJEHMC), 8 (1). 19-36. DOI= https://doi.org/10.4018/IJEHMC.2017010102

[32] Roberto Tabernero Rico, Juan Antonio Juanes Méndez and Alberto Prats Galino. 2017. New Generation of Three-Dimensional Tools to Learn Anatomy. J Med Syst. 2017 May, 41 (5). 88. Epub 2017 Apr 12.

[33] P.A. Heng, S.X. Zhang, Y.M. Xie, T.T. Wong, Y.P. Chui and C.Y. Cheng. 2006 Photorealistic Virtual Anatomy Based on Chinese Visible Human Data. Clin Anat, 2006, 19.232-239. DOI = https: $/ /$ doi.org $/ 10.1002 /$ ca.20314

[34] Ameya Malvankar and Bharti Temkin. 2006. Segmenting the visible human female. Stud Health Technol Inform 119. 361-363

[35] Victor M. Spitzer and David G. Whitlock. 1998. The Visible Human datase The anatomical platform for human simulation. Anat Rec (New Anat) 1998 253, 49-57.DOI=https://doi.org/10.1002/(SICI) 1097 0185(199804)253:2<49::AID-AR8>3.0.CO;2-9

[36] Marina Yiasemidou, Daniel Glassman, Faisal Mushtaq, Christos Athanasiou, Mark-Mon Williams, David Jayne and Danilo Miskovic. 2017. Mental practice with interactive $3 \mathrm{D}$ visual aids enhances surgical performance. Surg Endosc. 1-7, 2017 Mar 10. 


\section{Anexo 4}

Trabajo presentado en el congreso ICERI 2017 (10th International Conference of Education, Research and Innovation), que tuvo lugar en Sevilla, los días 16-18 de noviembre de 2017. Posteriormente fue publicado en Proceedings of ICERI 2017.

Título del trabajo: "Valoración anatomo-radiológica de la pelvis femenina mediante modelos tridimensionales corregistrados con imágenes seccionales de resonancia magnética".

Resumen: Actualmente existen escasos estudios que analicen con detalle la anatomía radiológica de la pelvis femenina mediante modelos tridimensionales (3D) corregistrados con imágenes seccionales, haciendo uso de aplicaciones abiertas para la representación de escenas virtuales en plataformas Windows de bajo coste.

Presentamos un desarrollo informático que permite visualizar e interactuar, en un entorno virtual, con las principales estructuras anatómicas de la pelvis femenina y sus principales vasos arteriales y venosos, reconstruidas a partir de secciones seriadas de resonancia magnética de alta resolución. Las posibilidades de representar tridimensionalmente estas estructuras en cualquier orientación espacial, junto con imágenes radiológicas seccionales de resonancia magnética en los tres planos del espacio (axial, coronal y sagital), facilitan la comprensión e identificación anatómica del conjunto de los elementos óseos, musculares, viscerales y vasculares de esta región. Con una interfaz gráfica muy intuitiva, basada en menús flotantes, nuestro procedimiento tecnológico permite la observación de los principales elementos anatómicos en tres dimensiones, a petición del usuario, teniendo como patrón de referencia los cortes de resonancia magnética.

Esta aplicación informática representa una importante herramienta para la formación médica de especialistas en ginecología, así como paso previo en la planificación de intervenciones quirúrgicas del suelo pélvico.

La visualización 3D de las estructuras anatómicas de la pelvis femenina, embebidas en los datos volumétricos de resonancia magnética, constituye la forma más clara e 
intuitiva de análisis morfológico, ya que el examen individual de las imágenes de los distintos cortes que forman una secuencia de resonancia magnética nos permite una sencilla comprensión del conjunto de elementos anatómicos que componen esta zona corporal.

Referencia: Asensio Romero, L., Asensio Gómez, M., Juanes Méndez, J. A. y PratsGalino, A. (2017). Anatomy-radiological assessment of female pelvis through threedimensional models coregistered with sectional images of magnetic resonance. ICERI 2017 Proceedings, 1466-1472. https://doi.org/10.21125/iceri.2017.0466 


\title{
ANATOMY-RADIOLOGICAL ASSESSMENT OF FEMALE PELVIS THROUGH THREE-DIMENSIONAL MODELS COREGISTERED WITH SECTIONAL IMAGES OF MAGNETIC RESONANCE
}

\author{
L. Asensio Romero' ${ }^{1}$, M. Asensio Gómez ${ }^{1}$, J.A. Juanes Méndez ${ }^{1}$, A. Prats- \\ Galino $^{2}$ \\ ${ }^{1}$ Department of Human Anatomy and Histology. School of Medicine. University of \\ Salamanca (SPAIN) \\ ${ }^{2}$ Department of Human Anatomy and Embryology. School of Medicine. University of \\ Barcelona (SPAIN)
}

\begin{abstract}
Currently there are few studies that analyse in detail the radiological anatomy of the female pelvis using 3D models registered with sectional images, making use of open applications for the representation of virtual scenes on low cost Windows platforms.

We present a computer development that allows visualizing and interacting, in a virtual environment, with the main anatomical structures of the female pelvis and its main arterial and venous vessels, reconstructed from serial sections of high-resolution magnetic resonance. The possibilities of threedimensional representation of these structures in any spatial orientation, together with sectional radiological images of magnetic resonance in the three planes of space (axial, coronal and sagittal) facilitate the anatomical comprehension and identification of all the bony, muscular, visceral and vascular elements of this region. With a very intuitive graphical interface, based on floating menus, our technological procedure allows the observation of the main anatomical elements in three dimensions, at the request of the user, having as reference the magnetic resonance cuts.

This computer application represents an important tool for the medical training of specialists in gynaecology, as well as a previous step in the planning of surgical interventions of the pelvic floor.

The $3 \mathrm{D}$ visualization of the anatomical structures of the female pelvis, embedded in the volumetric data of magnetic resonance, constitutes the clearest and most intuitive form of morphological analysis, since the individual examination of the images of the different cuts that compose a sequence of resonance magnetic allows us a simple understanding of the set of anatomical elements that make up this body zone.
\end{abstract}

Keywords: Radiological pelvis anatomy, three-dimensional models, high resolution magnetic resonance, vascularization, computer development.

\section{INTRODUCTION}

The pelvis is one of the most difficult anatomic regions to study in a live individual or in a corpse, especially in the case of the female pelvis ([1]). The female pelvis contains organs of irregular morphology (rectum, uterus, vagina and bladder) as well as structures of the pelvic floor (support structures aponeuroses and muscles) located on different planes. These structures are hard to represent and comprehend through two-dimensional diagrams.

The study of the female pelvis has evolved along with the available formats and technologies of the time, like other studies of the human body.

One of the great contributions for the morphological analysis of this body region has undoubtedly been the magnetic resonance imaging (MRI). This technique of imaging has been shown to be a sensitive technique for the analysis of the various pathologies of the female pelvis, having a special relevance in the evaluation of the congenital pathology for a correct surgical approach.

The multiplanar ability of this diagnostic imaging technique and the possibility of soft tissue differentiation make MRI an excellent non-invasive diagnostic technique for both the study of the pelvic anatomy and the various pathologies that affect pelvic organs.

The study of the anatomy of the structures of the bony pelvis, as well as of the muscular elements of the pelvic floor or perineum that contain and hold the pelvic organs, and that crosses the perineum, is 
of great importance for the better understanding of functions such as urinary continence and urination ([2], [3]).

Nowadays there are few studies that analyse in detail the radiological anatomy of the female pelvis using three-dimensional (3D) models that are registered with MR sectional images, making use of open applications for the representation of virtual scenes on low cost Windows platforms.

Therefore, the 3D visualization of the anatomical structures of the female pelvis embedded in volumetric magnetic resonance data constitutes the most clear and intuitive form of morphological analysis. This is because the individual examination of different sectional images of a magnetic resonance sequence allows a simple understanding of the set of anatomical elements that constitute this body region ([4], [5])

The objective of the present article is the $3 D$ modelling of the main structures of the normal female pelvis using magnetic resonance imaging and its representation in a program designed for $P C$ environments that enables visualization and interaction with sectional images registered with $3 D$ models.

The use of this kind of techniques in the field of gynaecology has recently facilitated the obtaining images that contribute to a better anatomical knowledge of the female pelvis. Accordingly, we display a computer development based on $3 \mathrm{D}$ analysis and visualization of the female pelvis anatomic structures with simultaneous sections of MRI in the three planes of space, thus improving its study against the classic atlas and books of human anatomy.

\section{METHODOLOGY}

We proceeded to acquire high-resolution images with a spacing of $0.5 \mathrm{~mm}$ of the pelvic region, enhanced in proton density. Orthogonal sections were obtained on each of the planes (axial, coronal and sagittal) using a 1.5 Tesla scanner (HarmonyExpert, Siemens) from a 29-year-old female volunteer with no known history of gynecological pathology. A volume was reconstructed from the DICOM files. That volume was saved in ANALYZE 7.5 format by the free distribution software MRIcro (Nottingham, UK). In order to homogenize to the maximum the dimensions between the three volumes, these were aligned, taking as reference the acquired in the axial plane. They were then resized, using a Lanczos filter, resulting in an axial volume of $600 \times 560 \times 30$ slices (voxelsize = $0.5 \times 0.5 \times 3.5 \mathrm{~mm}^{3}$ ), a sagittal volume of $30 \times 560 \times 560$ slices (voxelsize $3.5 \times 0.5 \times 0.5 \mathrm{~mm}^{3}$ ) and a coronal volume of $600 \times 28 \times 560$ slices (voxelsize $0.5 \times 5.0 \times 0.5 \mathrm{~mm}^{3}$ ). To facilitate the modeling phase, the three volumes were "reslicing", obtaining isotropic images with $1 \mathrm{~mm}$ voxels, that is, with voxels that have the same size in all dimensions. The regions of interest (ROIs), also called "labels", were delimited in the isometric volumes of the anatomical structures to be reconstructed using a 3-D editor (Amira, 3.1; TGS Template Graphics Software). We obtained a triangular mesh model of the surface of these identified structures from the ROIs applying an algorithm known as "marching cubes".

Given the high resolution of MRI, the mesh was simplified and smoothed, obtaining polygonal models that could be later easily edited through specific modeling programs (3D Studio Max, Maya...)

Finally the $3 \mathrm{D}$ models were exported to the directX format, a standard graphic format compatible with $\mathrm{ViX}$, using a conversion program (3D Exploration $\vee$ 1.831, Right Hemisphere, Inc; http://www. righthemisphere.com/3dexploration/).

The female virtual pelvis was implemented in a visualization application for Windows environments, programmed by us in Visual $\mathrm{C}$, which includes ActiveX controls.

It was designed to optimize the graphical acceleration capabilities supported by current graphics cards. The interface consists of three areas:

- 3D viewer, for the representation of the different graphic elements -plains and surface models-

- Control Area, with different controls for the interaction with the sectional images and the models represented in the Viewer (visibility, color of the model).

- Scene Selector, drop-down menu by which you can select the virtual scene to represent, defined in a text file external to the application. 


\section{RESULTS}

The study with high-resolution magnetic resonance allowed us to identify the structures that integrate the female pelvis (bony walls, muscles, visceral and vascular elements), obtaining an excellent anatomical map of the perineum and the pelvic organs. The study of MRI improves identification, delimitation and posterior three-dimensional reconstruction of pelvic structures. Its high contrast resolution for the study of soft tissues gave us a clear and precise anatomical map of the intrapelvic organs.

Our computer application allows simultaneous visualization and interaction with:

- Sectional images of the pelvis, selected at intervals of $5 \mathrm{~mm}$, in the three orthogonal axes of the space.

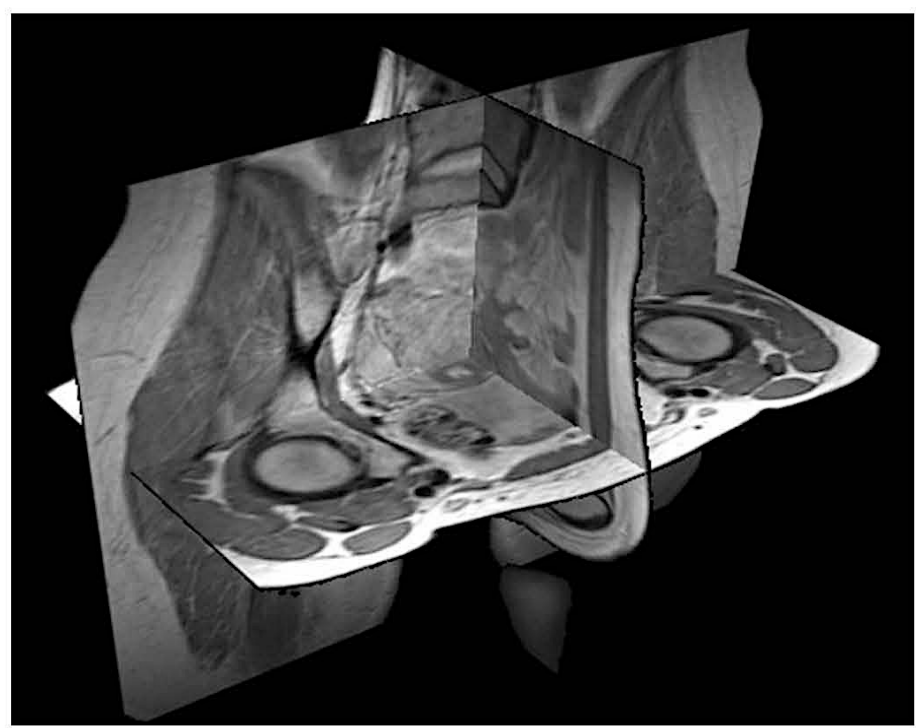

- 3D-models, which basically include structures: bony (coccyx, sacrum, proximal femoral end, L5 vertebra, intervertebral disc, symphysis pubis), muscular (external and internal obturator, piriformis, levator ani, coccyges, external sphincter of the urethra), visceral (bladder, vagina, uterus, rectum) and vascular (arterial and venous).

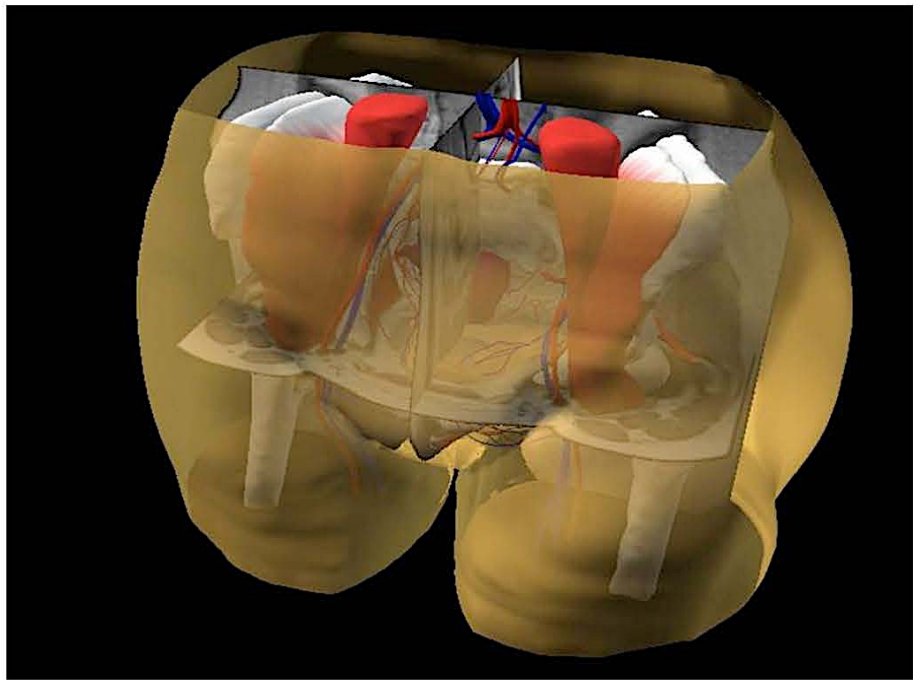




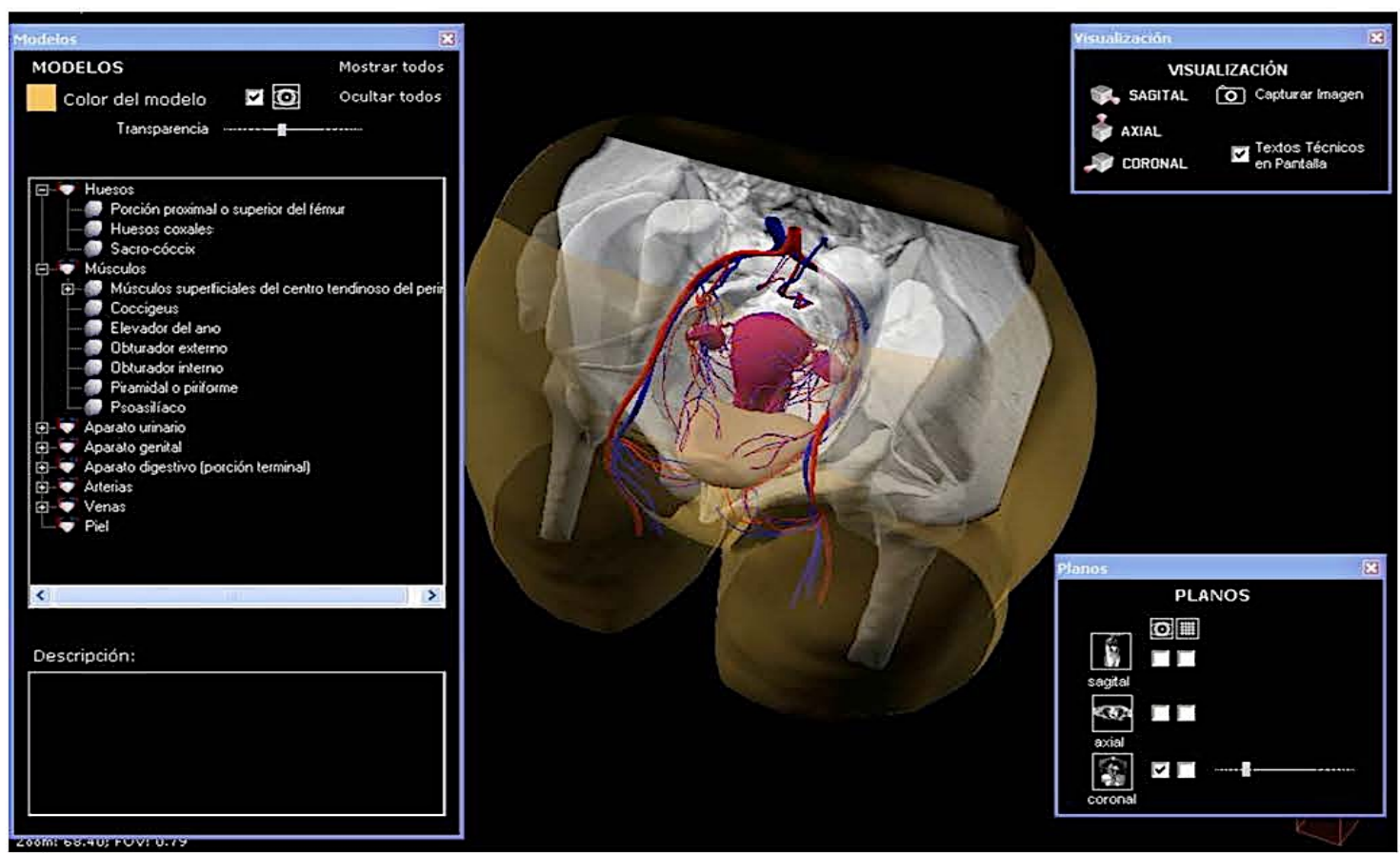

It shows the different options that allow acting with the anatomical viewer. These options enable a 3D visualization of the anatomic structures at the user request and having as reference pattern the magnetic resonance sections in the three planes of the space (coronal, axial and sagittal), being able to activate or deactivate the visualization of each one of them.

The user interacts with the elements of the visual scene (rotations, translations, zoom and selection) using the computer mouse by placing the cursor on the viewer.

All our computer system is controlled at the user's will. Therefore, there is a real interaction between the computer and the user, avoiding, as much as possible, the latter to become mere spectator.

Our computer development is a rigorous and carefully designed teaching tool. So that users can develop autonomously the whole process of medical training, especially in the field of gynecology. In order to achieve the best knowledge and understanding of this body region, being able to analyze its anatomical structures that integrate it, from any spatial position and in three dimensions.

\section{DISCUSSION}

The generation of 3D images of the human body is undergoing an increase in the last years. Its use has been generalized in different medical areas ([6], [7]). The growing implementation of advanced computer applications for the visualization of $3 \mathrm{D}$ models of anatomical structures allows us to understand their structure and spatial relationships ([8], [9], [10], [11]).

Computer program are a very useful tool in all medical specialties as didactic resources in medical training ([12], [13]).

There is a growing availability of high-tech computer equipment, which makes it possible to meet the optimum needs of many educational computer programs with hypermedia characteristics that require a high memory capacity of the computers where they are to be displayed. Advances in computer technology have been incorporated into the field of training in the medical sciences with the aim of increasing the efficiency of the training process. It seeks to contribute to the learning process a more scientific and technical basis to make teaching more productive ([14], [15], [16], [17], [18], [19]). 
The user interface is a set of components utilize by users to communicate with the program that is running on the computer. It is the user who actually directs the operation of the computer program through various usability instructions. A good interface like the one we show in this computer development for the visualization of anatomical structures of the female pelvis is easy to understand and very easy to handle. It allows users to perform learning or training task in the fast and simplest way.

Imaging studies can facilitate knowledge of the anatomy and diagnosis of pathological processes that affect anatomical structures such as those of the pelvis ([20], [21], [22], [23]). These techniques have been changing over time, not only with a view to diagnostic accuracy, but also as a fundamental decision element in establishing a therapeutic plan ([24], [25]). Therefore, in the diagnosis of pathological processes of the pelvis, diagnostic imaging techniques play a major role. In this sense, $\mathrm{MRI}$ offers multiple advantages over other imaging techniques such as computed tomography or transrectal ultrasound, although its availability is more limited ([26], [27], [28], [29]). Accordingly, MRI is an excellent tool in the evaluation and management of selected patients with gynaecological, urologic and coloproctological pathologies, both benign and malignant ([30], [31], [32], [33]). This technique also allows planning of the intervention in patients with presacral tumours and soft tissue of the perineum ([34], [35], [36], [37], [38]).

\section{REFERENCES}

[1] Parikh M, Rasmussen M, Brubaker L, Salomon C, Sakamoto K, Everhouse R, Ai Z, Damaser MS. "Three-dimensional virtual reality model of the normal female pelvic floor". Ann Biomed Eng, vol. 32, no. 2, pp. 292-296, 2004.

[2] Abdulaziz, M., Deegan, E. G., Kavanagh, A., Stothers, L., Pugash, D., \& Macnab, A. "Advances in basic science methodologies for clinical diagnosis in female stress urinary incontinence". Canadian Urological Association Journal, vol. 11(6Suppl2), pp. 117-120, 2017. doi: $10.5489 /$ cuaj. 4583

[3] Goh V, Halligan S, Kaplan G, Healy JC, Bartram C. "Dynamic MR imaging of the pelvic floor in asymptomatic subjects". AJR vol. 174, pp. 661-666, 2000.

[4] Pujol S, Baldwin M, Nassiri J, Kikinis R and Shaffer K. "Using 3D Modeling Techniques to Enhance Teaching of Difficult Anatomical Concepts". Acad Radiol. 2016 Apr, vol. 23, no. 4, pp. 507-516, 2016. doi:https://doi.org/10.1016/j.acra.2015.12.012

[5] Sora MC1, Jilavu R and Matusz P. "Computer aided three-dimensional reconstruction and modeling of the pelvis, by using plastinated cross sections, as a powerful tool for morphological investigations". Surg Radiol Anat. 2012 Oct, vol. 34, no. 8, pp. 731-736, 2011. (E-reader version).

[6] Ghosh SK. "Evolution of illustrations in anatomy: a study from the classical period in Europe to modern times". Anat Sci Educ, vol. 8, no. 2, pp.175-188, 2015. (E-reader version) doi:https://doi.org/10.1002/ase.1479

[7] Rea, PM, Advances in Anatomical and Medical Visualisation in Handbook of Research on Engaging Digital Natives in Higher Education Settings. Aveiro: IGI Global, 2016. doi:https://doi.org/10.4018/978-1-5225-0039-1.ch011

[8] Berney S, Bétrancourt M, Molinari G and Hoyek N. "How spatial abilities and dynamic visualizations interplay when learning functional anatomy with $3 \mathrm{D}$ anatomical models". Anat Sci Educ 2015 Sep-Oct, vol. 8, no. 5, pp. 452-462, 2015. DOl= https://doi.org/10.1002/ase.1524

[9] Tabernero Rico RD, Juanes Méndez JA and Prats Galino A. "New Generation of ThreeDimensional Tools to Learn Anatomy". J Med Syst. 2017 May, vol. 41, no. 5, pp. 88, 2017. (Ereader version).

[10] Temkin B, Acosta E, Malvankar A and Vaidyanath S. "An interactive three-dimensional virtual body structures system for anatomical training over the internet". Clin Anat. $2006 \mathrm{Apr}$, vol. 19, no. 3, pp. 267-274, 2006. doi:https://doi.org/10.1002/ca.20230

[11] Vázquez R, Riesco JM, Juanes JA, Blanco E, Rubio M and Carretero J. "Educational strategies applied to the teaching of anatomy. The evolution of resources". Eur J Anat 2007, vol. 11, no. 1, pp. 31-43, 2007 
[12] Legendre G, Sahmoune Rachedi L, Descamps P and Fernandez H. 2015. "Providing of a virtual simulator perineal anatomy (Pelvic Mentor $($ ) in learning pelvic perineology: results of a preliminary study". J Gynecol Obstet Biol Reprod (Paris), vol. 44, no. 1, pp. 72-77, 2014. (Ereader version). doi:https://doi.org/10.1016/j.jgyn.2014.04.004

[13] Sergovich A1, Johnson M and Wilson TD. "Explorable three-dimensional digital model of the female pelvis, pelvic contents, and perineum for anatomical education". Anat Sci Educ. 2010 May-Jun, vol. 3, no. 3, pp. 127-133, 2010. doi:https://doi.org/10.1002/ase.135

[14] Estai, M, and Bunt, S. "Best teaching practices in anatomy education: A critical review". Annals of Anatomy-Anatomischer Anzeiger, vol. 208, pp. 151-157, 2016. doi:https://doi.org/10.1016/j.aanat.2016.02.010

[15] Fenesi, B., Mackinnon, C., Cheng, L., Kim, J. A., \& Wainman, B. C. "The effect of image quality, repeated study, and assessment method on anatomy learning". Anatomical sciences education, vol. 10 , no. 3, pp. 249-261, 2017. doi:10.1002/ase.1657

[16] Hampton BS, Sung VW. "Improving medical student knowledge of female pelvic floor dysfunction and anatomy: a randomized trial". Am J Obstet Gynecol, vol. 202, no. 6, pp. 601, 2010. (E-reader version). doi: 10.1016/j.ajog.2009.08.038.

[17] Peterson DC and Mlynarczyk GS. "Analysis of traditional versus three-dimensional augmented curriculum on anatomical learning outcome measures". Anat Sci Educ, vol. 9, no. 6, pp. 529536, 2016. DOI= https://doi.org/10.1002/ase.1612

[18] Preece, D., Williams, S., Lam, R., \& Weller, R. "Let's get physical: Advantages of a physical model over 3D computer models and textbooks in learning imaging anatomy". Anat Sci Educ, vol. 6, no. 4, pp. 216-224, 2013. doi:10.1002/ase.1345

[19] Trelease, RB. "From chalkboard, slides, and paper to e-learning: How computing technologies have transformed anatomical sciences education". Anat Sci Educ, vol. 9, no. 6, pp. 583-602, 2016. doi:https://doi.org/10.1002/ase.1620

[20] Brown, K., Handa, V., Macura, K., \& DeLeon, V. "Three-dimensional shape differences in the bony pelvis of women with pelvic floor disorders". International Urogynecology Journal : Including Pelvic Floor Dysfunction, vol. 24, no. 3, pp. 431-439, 2013. doi:10.1007/s00192-0121876-y

[21] Fielding JR, Dumanli H, Scheeyer AG, Okuda S, Gering DT, Zou KH, Kikinis R, Jolesz FA. "MR-based three-dimensional modeling of the normal pelvic floor in women: quantification of muscle mass". AJR Am J Roentgenol. Vol. 174, no. 3, pp. 657-660, 2000.

[22] Fielding JR. "Practical MR imaging of female pelvic floor weakness". Radiographics, vol. 22 , pp. 295-304, 2002.

[23] Moore, C. W., Wilson, T. D., \& Rice, C. L. "Digital preservation of anatomical variation: 3Dmodeling of embalmed and plastinated cadaveric specimens using uCT and MRI". Annals of Anatomy-Anatomischer Anzeiger, vol. 209, pp. 69-75, 2017. doi:https://doi.org/10.1016/j. aanat.2016.09.010

[24] Bertrand, M., Macri, F., Mazars, R., Droupy, S., Beregi, J., \& Prudhomme, M. "MRI-based 3D pelvic autonomous innervation: A first step towards image-guided pelvic surgery". European Radiology, vol. 24, no. 8, pp. 1989-1997, 2014. doi:10.1007/s00330-014-3211-0

[25] Kearney R, Miller JM, De Lancey JO. "Interrater reliability and physical examination of the pubovisceral portion of the levator ani muscle, validity comparisons using MR imaging". Neurourol Urodyn, vol. 25, no. 1, pp. 50-54, 2006.

[26] Hubner M, Hetzer F, Weishaupt D, Hahnloser D, Clavien PA, Demartnes N. "A prospective comparison between clinical outcome and open-configuration magnetic resonance defecography findings before and after surgery for symptomatic rectocele". Colorectal Dis, vol. 8, no. 7, pp. 605-611, 2006.

[27] Peng $Y$, Khavari R, Nakib NA, Boone TB, Zhang $Y$. "Assessment of urethral support using mRIderived computational modeling of the female pelvis". International Urogynecology Journal, vol 27, no. 2, pp. 205-212, 2016. doi:10.1007/s00192-015-2804-8 
[28] Tunn R, De Lancey JO, Howard D, Ashton-Miller JA, Quin LE. "Anatomic variations in the levator ani muscle, endopelvic fascia, and urethra in nulliparas evaluated by magnetic resonance imaging". Am J Obstet Gynecol, vol. 188, no. 1, pp. 116-121, 2003.

[29] Tunn R, De Lancey JO, Quin EE. "Visibility of pelvic organ support system structures in magnetic resonance images without an endovaginal coil". Am J Obstet Gynecol, vol. 184, no. 6, pp. 1156, 2001.

[30] Chen, L., Lenz, F., Alt, C. D., Sohn, C., De, Lancey J. O., Brocker, K. A. "MRI visible Fe304 polypropylene mesh: $3 \mathrm{D}$ reconstruction of spatial relation to bony pelvis and neurovascular structures". International Urogynecology Journal and Pelvic Floor Dysfunction, vol. 28, no. 8, pp. 1131-1138, 2017. doi:10.1007/s00192-017-3263-1

[31] Hoyte L, Schierlitz L, Zou K, G, FleshG Fieding J. "Two- and 3-dimensional MRI comparison of levator ani structure, volume, and integrity in women with stress incontinence and prolapse". Am J Obstet Gynecol, vol. 185, no. 1, pp. 11-19, 2001.

[32] Novara G, Artibani W. "Imaging for urinary incontinence: a contemporary perspective". Curr Opin Urol, vol. 16, no. 4, pp. 219-223, 2006.

[33] Tunn R, Goldammer K, Neymeyer J, Gauruder-Burmester A, Hamm B, Beyersdorff D. "MRI morphology of the levator ani muscle, endopelvic fascia, and urethra in women with stress urinary incontinence". Eur J Obstet Gynecol Reprod Biol, vol. 126, no. 2, pp. 239-245, 2006.

[34] Doumouchtsis, S. K., Nazarian, D. A., Gauthaman, N., Durnea, C. M., \& Munneke, G. (2017). "Three-dimensional volume rendering of pelvic models and paraurethral masses based on MRI cross-sectional images". International Urogynecology Journal, vol. 28, pp. 1-9, 2017. doi:https://doi-org.ezproxy.usal.es/10.1007/s00192-017-3317-4

[35] Giannini, A., lodice, V., Picano, E., Russo, E., Zampa, V., Ferrari, V., \& Simoncini, T. "Magnetic Resonance Imaging-Based Three Dimensional Patient-Specific Reconstruction of Uterine Fibromatosis: Impact on Surgery". Journal of Gynecologic Surgery, vol. 33, no. 4:, pp. 138-144, 2017. doi:https://doi.org/10.1089/gyn.2016.0119

[36] Kraima AC, Smit NN, Jansma D, Wallner C, Bleys RL, van de Velde CJ, Botha CP and DeRuiter MC. "Toward a highly-detailed 3D pelvic model: approaching an ultra-specific level for surgical simulation and anatomical education". Clin Anat. Vol. 26, no. 3, pp. 333-338, 2013. (Ereader version) doi:https://doi.org/10.1002/ca.22207

[37] Smit, N., Lawonn, K., Kraima, A., DeRuiter, M., Sokooti, H., Bruckner, S., Eisemann, E. \& Vilanova, A. . "PelVis: Atlas-based Surgical Planning for Oncological Pelvic Surgery". IEEE transactions on visualization and computer graphics, vol. 23, no. 1, pp. 741-750, 2017. doi:10.1109/TVCG.2016.2598826

[38] Yiasemidou M, Glassman D, Mushtaq F, Athanasiou C, Williams MM, Jayne D and Miskovic D. "Mental practice with interactive 3D visual aids enhances surgical performance". Surg Endosc, pp1-7, 2017. 


\section{Anexo 5}

Artículo publicado en la revista Journal of Medical Systems en enero de 2018.

Título: "Modelos 3D de estructuras de la pelvis femenina reconstruidos y representados en combinación con secciones anatómicas y radiológicas".

Resumen: Presentamos una aplicación informática diseñada para visualizar e interactuar con modelos tridimensionales de las principales estructuras anatómicas de la pelvis femenina. Estos modelos 3D se reconstruyeron a partir de secciones seriadas de cadáver del proyecto Visible Human de la Biblioteca Médica de los Estados Unidos y de secciones seriadas de resonancia magnética de alta resolución. Es posible representar estas estructuras tridimensionales en cualquier orientación espacial, junto con imágenes seccionales de cadáver y resonancia magnética, en los tres planos del espacio (axial, coronal y sagital) con el objetivo de que faciliten la comprensión anatómica y la identificación del conjunto de estructuras viscerales de esta región del cuerpo. En realidad, hay pocos estudios que analicen en detalle la anatomía radiológica de la pelvis femenina utilizando modelos tridimensionales junto con imágenes seccionales, haciendo uso de aplicaciones abiertas para la representación de escenas virtuales en plataformas Windows ${ }^{\circledR}$ de bajo coste.

Nuestro desarrollo tecnológico permite la observación de las principales vísceras de la pelvis femenina en tres dimensiones con una interfaz gráfica muy intuitiva. Esta aplicación informática representa una herramienta de aprendizaje importante para estudiantes de medicina y especialistas en ginecología y para su posible uso como paso preliminar en la planificación de la cirugía ginecológica y del suelo pélvico.

Referencia: Asensio Romero, L., Asensio Gómez, M., Prats-Galino, A. y Juanes Méndez, J. A. (2018). 3D Models of Female Pelvis Structures Reconstructed and Represented in Combination with Anatomical and Radiological Sections. Journal of Medical Systems, 42 (3), 37. https://doi.org/10.1007/s10916-018-0891-z 


\title{
3D Models of Female Pelvis Structures Reconstructed and Represented in Combination with Anatomical and Radiological Sections
}

\author{
L. Asensio Romero ${ }^{1}$ (D) - M. Asensio Gómez ${ }^{1} \cdot$ A. Prats-Galino ${ }^{2} \cdot$ J. A. Juanes Méndez ${ }^{1}$
}

Received: 1 December 2017 / Accepted: 2 January 2018

(C) Springer Science+Business Media, LLC, part of Springer Nature 2018

\begin{abstract}
We present a computer program designed to visualize and interact with three-dimensional models of the main anatomical structures of the female pelvis. They are reconstructed from serial sections of corpse, from the Visible Human project of the Medical Library of the United States and from serial sections of high-resolution magnetic resonance. It is possible to represent these three-dimensional structures in any spatial orientation, together with sectional images of corpse and magnetic resonance imaging, in the three planes of space (axial, coronal and sagittal) that facilitates the anatomical understanding and the identification of the set of visceral structures of this body region. Actually, there are few studies that analysze in detail the radiological anatomy of the female pelvis using three-dimensional models together with sectional images, making use of open applications for the representation of virtual scenes on low cost Windows@ platforms. Our technological development allows the observation of the main female pelvis viscera in three dimensions with a very intuitive graphic interface. This computer application represents an important training tool for both medical students and specialists in gynecology and as a preliminary step in the planning of pelvic floor surgery.
\end{abstract}

Keywords Three-dimensional models · Corpse sections visible human project $\cdot$ Radiological female pelvis anatomy $\cdot$ Corpse female pelvis anatomy $\cdot$ High resolution magnetic resonance $\cdot$ Computer development

\section{Introduction}

The female pelvis is one of the most difficult anatomical regions to understand in a live individual or in a corpse $[1,2]$. It harbors organs of irregular morphology as well

This article is part of the Topical Collection on Education \& Training

$\triangle$ L. Asensio Romero

lourdes90.ar@gmail.com

M. Asensio Gómez

mago59@usal.es

A. Prats-Galino

aprats@ub.edu

J. A. Juanes Méndez

jajm@usal.es

1 Department of Human Anatomy and Histology, School of Medicine, University of Salamanca, Salamanca, Spain

2 Department of Human Anatomy and Embryology, School of Medicine, University of Barcelona, Barcelona, Spain as structures of the pelvic floor distributed in different planes, those are hard to represent and comprehend through two-dimensional images.

Along history the study of the human body has been carried out through the anatomical dissection of corpses, although it is known that there are some important post-mortem changes that can alter the anatomy. [3].

One of the main contributions for the morphological analysis of the human body, specially in the case of the female pelvis, has been the magnetic resonance imaging (MRI). This technique of imaging contributes to improve the analysis of the various pathologies and the suitable surgical approach in different fields of medicine. MRI is an excellent non-invasive diagnostic technique due to the multiplanar characteristic and the soft tissue differentiation capacity that achieves. Nevertheless, the individual examination of sectional images of a MRI sequence allows a simple vision [1].

The study of the female pelvis has evolved along with the available formats and technologies of the time [4]. This anatomical study of the bony pelvis and the muscular elements of the pelvic floor or perineum that harbor and hold the pelvic 


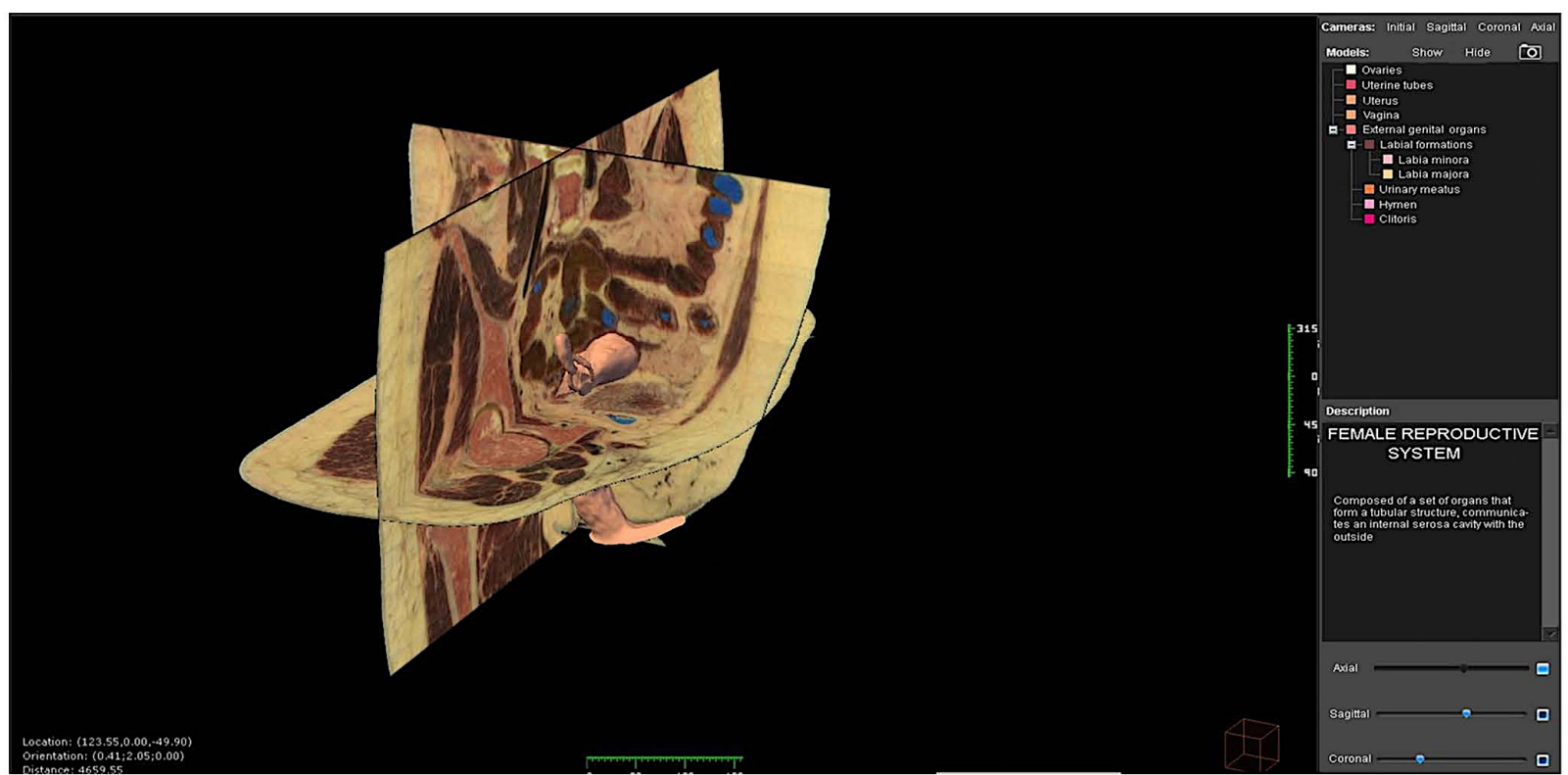

Fig. 1 Visualization of user's interface of the computer application

viscera, and constitute the perineum, are very important, for example, for a better understanding of functions such as urinary continence and urination [5].

Then, three-dimensional (3D) visualization of anatomical structures combined with corpse sections and together with volumetric MRI data establishes the most intuitive and clear kind of morphological analysis [6, 7].

Thus, the objective of this work is the 3D modeling of the main visceral structures of a normal female pelvis and its representation in an OS PC permitting its visualization and interaction. The use of this kind of techniques in the field of gynecology has recently enabled

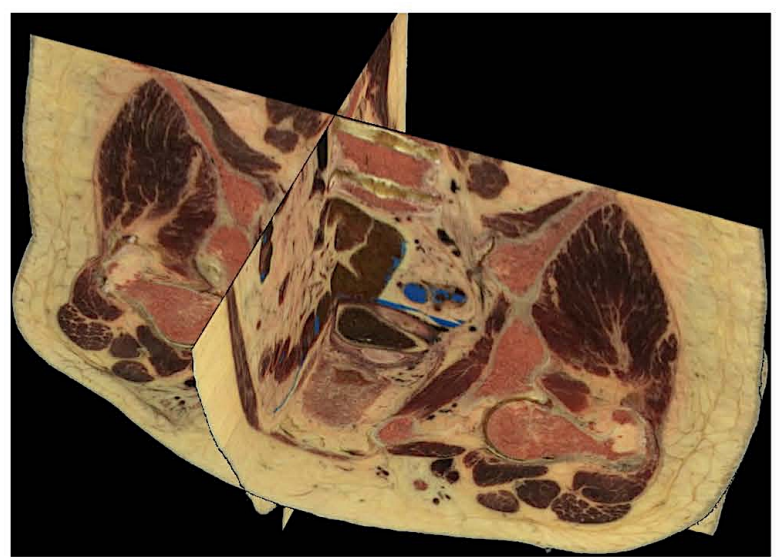

Fig. 2 Simultaneous visualization of three anatomical sections (axial, coronal and sagittal) us to get images that improve the anatomical knowledge of the female pelvis $[2,8]$. Therefore, we develop a computer program based on $3 \mathrm{D}$ visualization and study of the anatomical structures of the female pelvis with simultaneous sections of corpse from the Visible Human project and MRI images in the three planes of space.

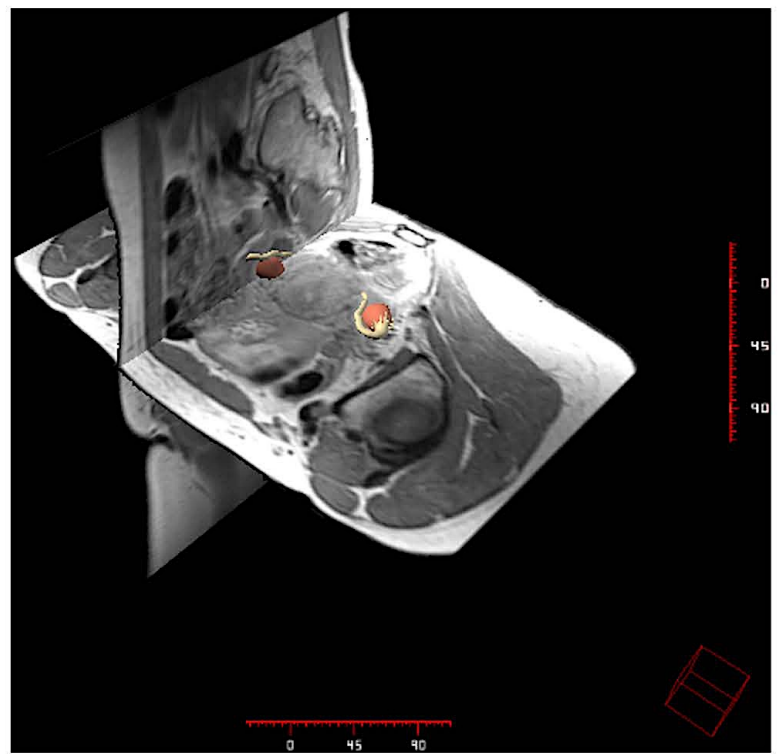

Fig. 3 Simultaneous visualization of three radiological sections (axial, coronal and sagittal)

\section{Q Springer}




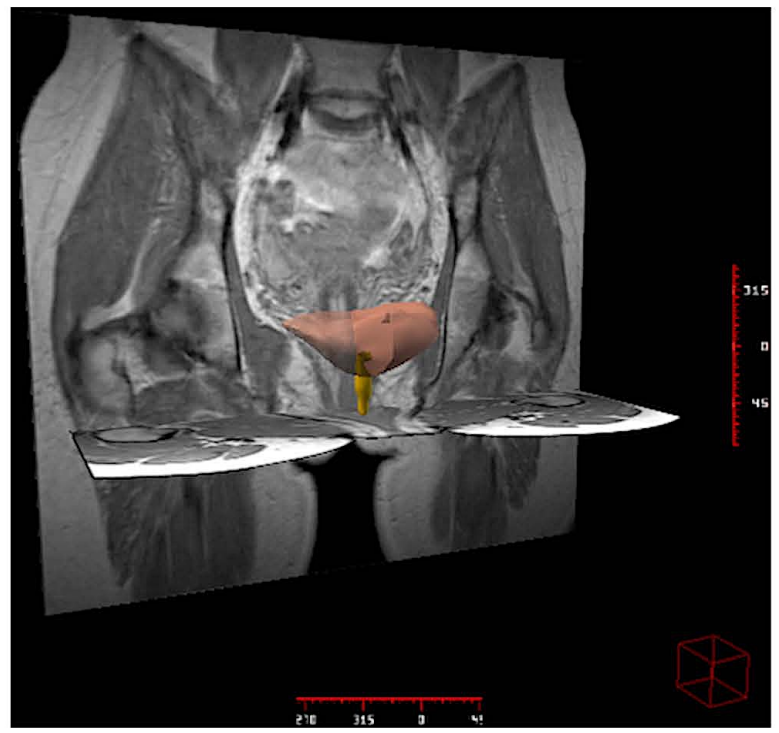

Fig. 4 Visualization of pelvic visceral 3D models in two radiological sections (axial, and coronal)

\section{Methodology}

\section{Corpse sectional images}

We obtained the corpse sectional images of multiple axial sections of $0,33 \mathrm{~mm}$ thick of high resolution obtained from a woman corpse from the Visible Human Female CD 2.0 Version $($ of the National Library of Medicine in the USA, under authorized license.

We used Autodesk Maya ${ }^{\circledR}$ for the volumetric nonprobabilistic creation of anatomic structures.

The images were adjusted in size and format with Pixresizer Software version 2.0.4®.

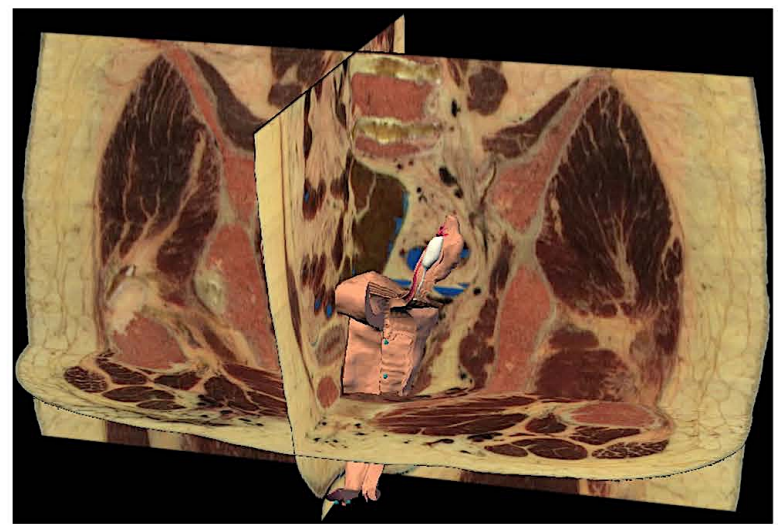

Fig. 5 Visualization of pelvic visceral 3D model in three anatomical sections (axial, coronal and sagittal)

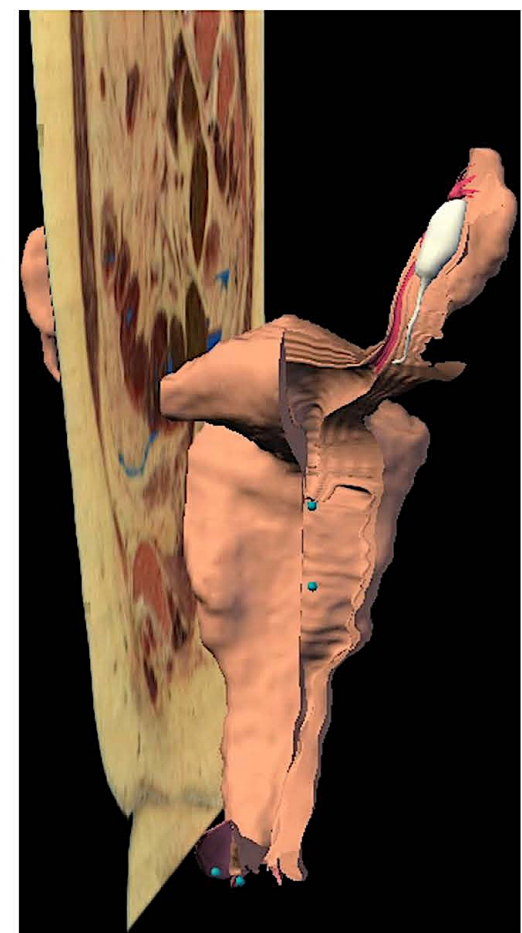

Fig. 6 Visualization of pelvic visceral 3D models in an anatomical section (sagittal)

The delimitation of the response area for the location of the target structure in every task was made through Image Mappier version $1.0 ®$.

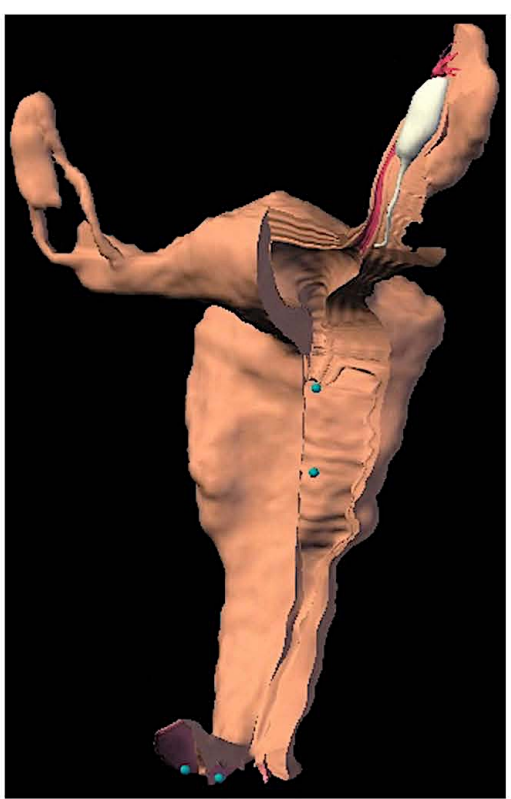

Fig. 7 Visualization of visceral model 3D 


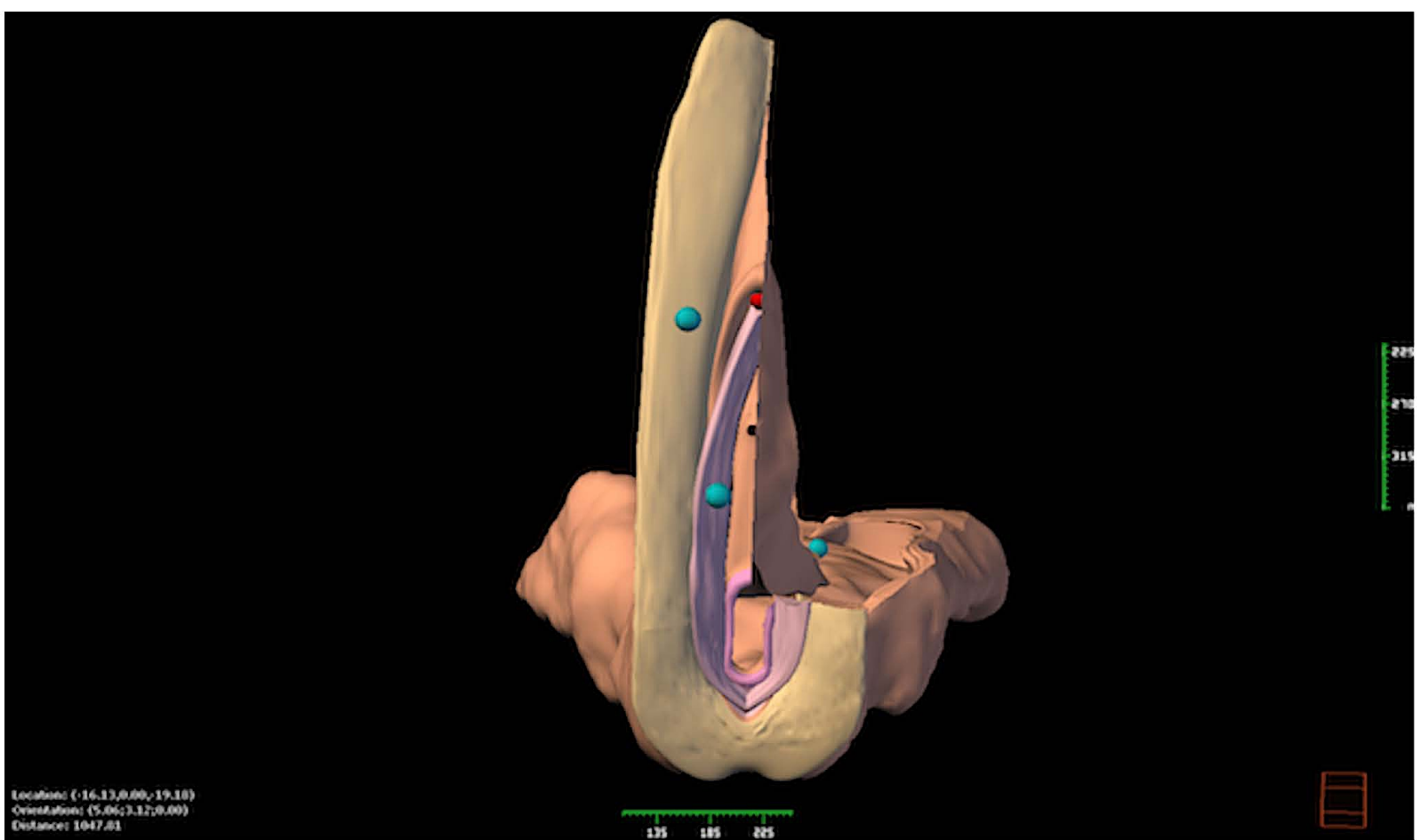

Fig. 8 Visualization of visceral model 3D

\section{MRI sectional images}

We acquire high-resolution images with a spacing of $0.5 \mathrm{~mm}$ of the pelvic region, enhanced in proton density. We get orthogonal sections from the three planes of space using a 1.5 Tesla scanner (HarmonyExpert, Siemens ${ }^{\circledR}$ ) from a 29-yearold female volunteer with no known history of gynecological pathology. A volume was reconstructed from the DICOM files and saved in ANALYZE 7.5® format. The three volumes were aligned taking as reference the volume acquire in the axial plane. The regions of interest (ROIs) or "labels" were delimited in the isometric volumes of the anatomical structures to be reconstructed using a 3-D editor (Amira, 3.1; TGS Template Graphics Software( $($ ).

\section{Programming}

The computer application has been developed for Windows ${ }^{\circledR}$ platforms and programmed in Visual $\mathrm{C}++\mathbb{B}$.

For each 3D rebuilt model we elaborate an html file with a short anatomic description in order to complementing the information that will be showed in the computer application.

\section{User's interface}

The user's interface consists of the following areas: (Fig. 1).
- 3D visor, for the representation of different graphic elements (planes and models).

- Control area, with the different controls for the interaction with the sectional images and the models (visibility, color model).

- Scene selector, is a drop-down menu through which the virtual scene to represent can be selected.

- Descriptive table with a brief anatomical description of the selected 3D model.

- Plane control area that allows modifying its position and visibility.

\section{Results}

Our computer applications enable to visualize and interact simultaneously with:

- Sectional corpse and MRI images of the female pelvis selected at intervals of $5 \mathrm{~mm}$, both in the three orthogonal axis of the space (axial, coronal and sagittal). (Figs. 2 and 3)

- $3 \mathrm{D}$ anatomical models of diverse structures of the female pelvis. (Figs. 4, 5, 6, 7, 8 and 9)

The graphic user's interface is very intuitive. It shows the different areas in order to interact with the anatomical viewer.

\section{$\underline{\text { Springer }}$}




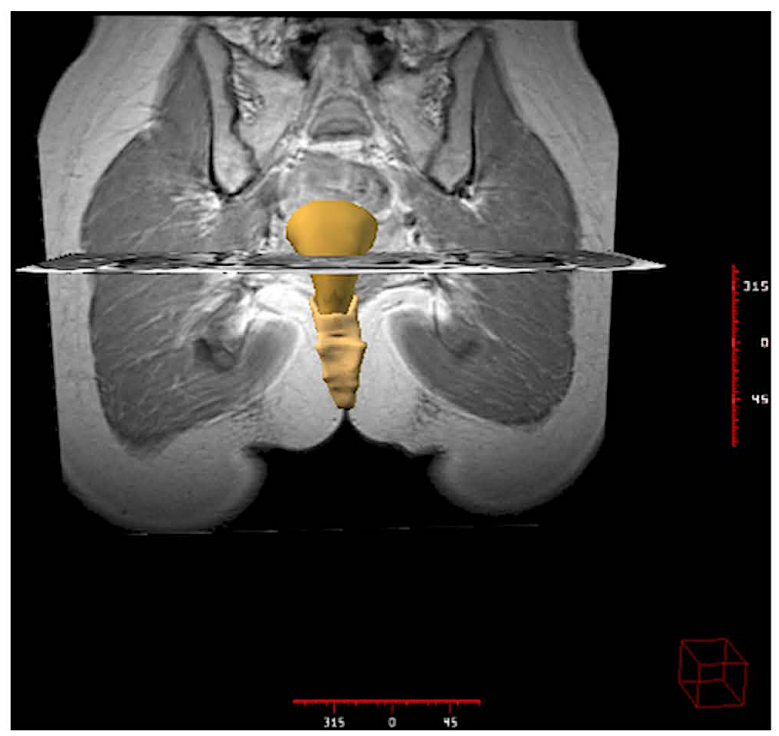

Fig. 9 Visualization of pelvic visceral 3D models in two radiological sections (axial, and coronal)

These options enable a 3D visualization of the anatomical structures at the user request. The corpse and MRI sections in the three planes of the space are taken as a reference. (Figs. 10 and 11).

Every interaction with the elements of the visual scene is made using the computer mouse, by placing the cursor on the visor. The resultant view of carrying out rotations, translations or zoom may be stored in a file. It is possible to save the scene displayed in the visor as a bitmap (.bmp) format file with the option "capture image" represented with a camera icon. (Fig. 12).

The descriptive zone includes a brief anatomical description that complements the image shown by the application. The planes button is the screen where the user may interact with the visor and its configuration. They include the necessary controls to manage the sectional images displayed in the visor. There are three orientation planes: sagittal, axial and coronal. Each plane has a selection control to activate or deactivate its visibility. We can also move horizontally the cursor over the visor, changing the position of the selected plane. (Fig. 13).

All our computer system is controlled at the user's will. Therefore, a real interaction between the computer and the user exists.

Our computer development is a meticulous and thorough elaborated teaching tool, so that the users may develop autonomously the whole process of medical training, especially in the field of gynecology. This will lead to a better knowledge and understanding of female pelvis, because the anatomical structures of this body region will be accessible to analysis from any spatial position and in three dimensions.

\section{Discussion}

The generation of 3D images of the human body is increasing in the last years. Its use has been generalized in different fields

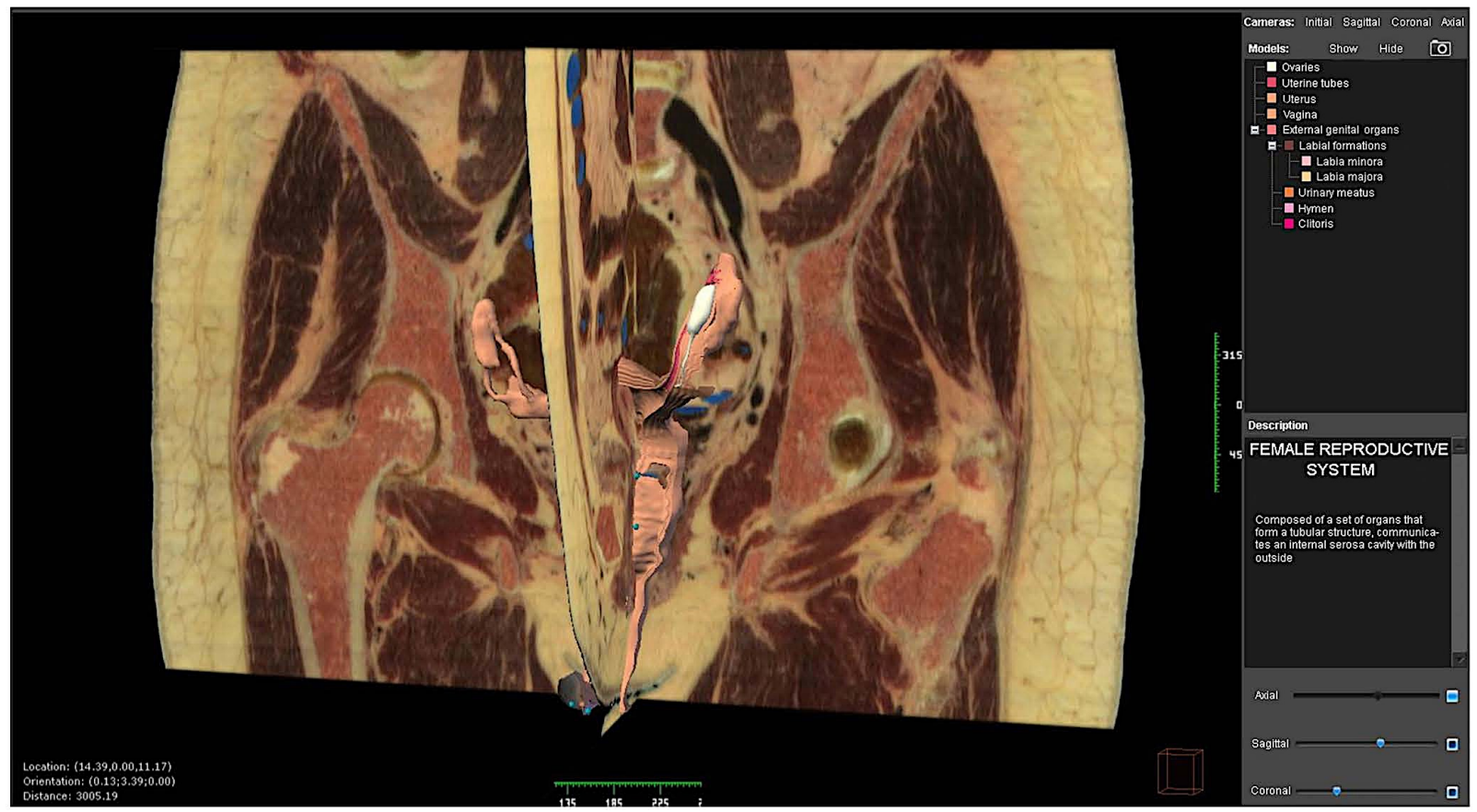

Fig. 10 User's interface of the computer application developed 


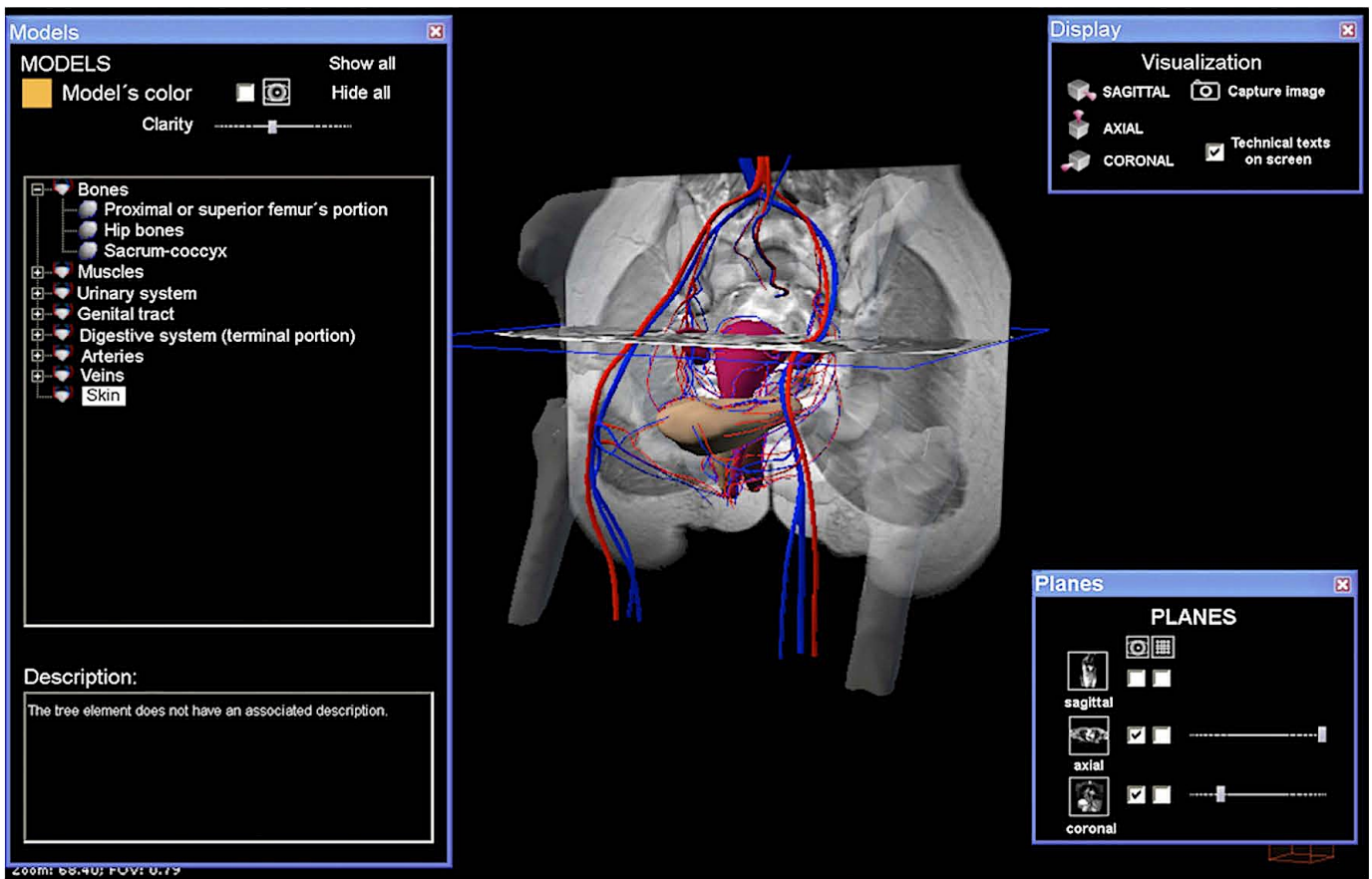

Fig. 11 User's interface of the computer application developed

of medicine [4, 9-12]. The growing implementation of advanced computer applications in the visualization of $3 \mathrm{D}$ models of anatomical structures enables a better understanding of its structure and spatial relationships [13, 14].

Computer programs are a very useful teaching and training tool in all fields of medicine $[2,15]$.

Advances in computer technology and communication techniques have been incorporated into the field of teaching and training in medical sciences with the objective of increase the efficiency and productivity of both processes [12, 16-21].

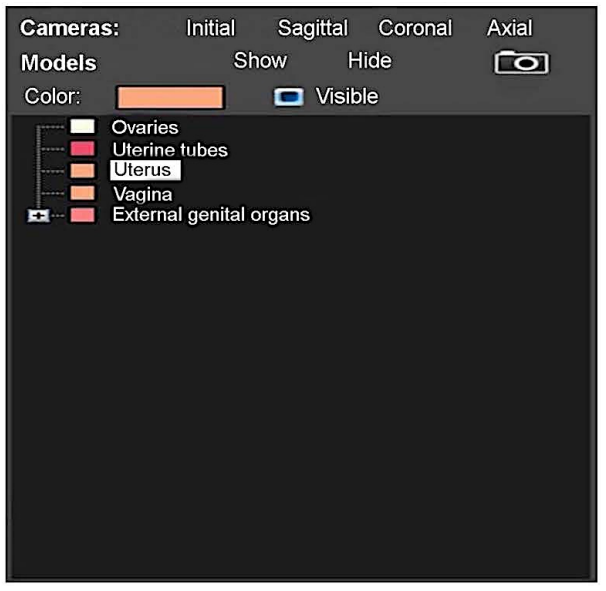

Fig. 12 User's interface. Activation zone of 3D models
The user's interface is a set of components utilize by user to communicate with the program that is running on the computer. The user is the one who really manage the functioning of the computer program thanks to diverse usability instructions.

A good interface is easy to understand and handle, allowing users to carry out learning or training task in a fast and simplest way $[14,22]$.

Imaging studies can facilitate knowledge of the anatomy and diagnosis of pathological processes that affect anatomical structures of the pelvis $[23,24]$. These techniques have

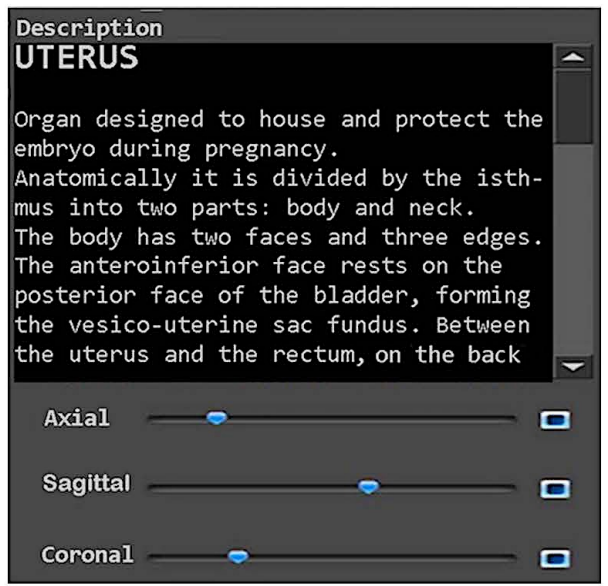

Fig. 13 User's interface. Description zone of the selected 3D model and activation of serial anatomical sections of corpse

\section{$\underline{\text { Springer }}$}


changed over time, not only in terms of diagnostic accuracy, but also as a fundamental decision element to establish a therapeutic plan $[25,26]$.

Therefore, in the diagnosis of the pathological processes of the pelvis, diagnostic imaging techniques have an important role. MRI offers multiple advantages over other imaging techniques such as computed tomography or transrectal ultrasound [27].

Consequently, MRI is an excellent tool in the evaluation and treatment of selected patients with gynecological, urological and coloproctologic pathologies [28]. This technique also allows planning a surgical intervention in certain patients $[8$, $26,29-31]$. Some therapeutic decisions can be made by acquiring direct experience in situations that would be difficult to perform in real life, such as the possibility of simulating a virtual surgical approach, through the use of different diagnostic imaging techniques like MRI.

In conclusion, female pelvis is an area of special anatomical complexity, so a $3 \mathrm{D}$ visualization of this region would make an easier learning. Therefore, our computer program is a good method of $3 \mathrm{D}$ visualization of the female pelvis, facilitating its anatomical evaluation, taking advantage of the graphic features that computers offer today. Our application allows the observation of different anatomic parts in a threedimensional environment at the user's request based on the sections of corpse from the Visible Human Project and images of MRI with a very intuitive graphic interface. All of this has enabled us to establish virtual 3D models of the female pelvis from anatomic and radiological images arranges in series.

\section{Compliance with Ethical Standards}

Conflict of Interest L. Asensio Romero declares that she has no conflict of interest. M. Asensio Gómez declares that he has no conflict of interest. A. Prats-Galino declares that he has no conflict of interest. J. A. Juanes Méndez declares that he has no conflict of interest.

Ethical Approval All procedures performed in studies involving human participants were in accordance with the ethical standards of the institutional and/or national research committee and with the 1964 Helsinki declaration and its later amendments or comparable ethical standards. This article does not contain any studies with animals performed by any of the authors.

Informed Consent Informed consent was obtained from all individual participants included in the study.

\section{References}

1. Pujol, S., Baldwin, M., Nassiri, J., Kikinis, R, and Shaffer, K. Using $3 \mathrm{D}$ modeling techniques to enhance teaching of difficult anatomical concepts. Acad. Radiol. 23(4):507-516, 2016. https:// doi.org/10.1016/j.acra.2015.12.012.

2. Legendre, G., Sahmoune Rachedi, L., Descamps, P., and Fernandez, H., Providing of a virtual simulator perineal anatomy (pelvic mentor ${ }^{\circ}$ ) in learning pelvic perineology: Results of a preliminary study. J. Gynecol. Obstet. Biol. Reprod. 44(1):72-77, 2014. https://doi.org/10.1016/j.jgyn.2014.04.004.

3. Fang, B., Wu, Y., Chu, C., Li, Y., Luo, N., Liu, K., Tan, L., and Zhang, S., Creation of a virtual anatomy system based on Chinese visible human data sets. Surg. Radiol. Anat. 39(4):441-449, 2017. https://doi.org/10.1007/s00276-016-1741-7.

4. Ghosh, S.K., Evolution of illustrations in anatomy: A study from the classical period in Europe to modern times. Anat. Sci. Educ. 8(2):175-188, 2015. https://doi.org/10.1002/ase.1479.

5. Abdulaziz, M., Deegan, E.G., Kavanagh, A., Stothers, L., Pugash, D., and Macnab, A., Advances in basic science methodologies for clinical diagnosis in female stress urinary incontinence. Can. Urol. Assoc. J. 11 $(6,2): 117-120,2017$. https://doi.org/10.5489/cuaj. 4583.

6. Balaya, V., Uhl, J.F., Lanore, A., Salachas, C., Samoyeau, T., Ngo, C., Bensaid, C., Cornou, C., Rossi, L., Douard, R., Bats, A.S., Lecuru, F., and Delmas, V., 3D modeling of the female pelvis by computer-assisted anatomical dissection: Applications and perspectives. J. Gynecol. Obstet. Biol. Reprod. 45(5):467-477, 2016. https://doi.org/10.1016/j.jgyn.2016.01.006.

7. Shin, D.S., Jang, H.G., Hwang, S.B., Har, D.H., Moon, Y.L., and Chung, M.S., Two-dimensional sectioned images and threedimensional surface models for learning the anatomy of the female pelvis. Am. Assoc. Anatomists. 6:316-323, 2013. https://doi.org/10. 1002/ase. 1342

8. Kraima, A.C., Smit, N.N., Jansma, D., Wallner, C., Bleys, R.L., van de Velde, C.J., Botha, C.P., and DeRuiter, M.C., Toward a highlydetailed 3D pelvic model: Approaching an ultra-specific level for surgical simulation and anatomical education. Clin. Anat. 26(3): 333-338, 2013. https://doi.org/10.1002/ca. 22207.

9. Ackerman, M.J., The visible human project $B$ : From body to bits. Conf. Proc. IEEE Eng. Med. Biol. Soc. 2016:3338-3341, 2016 https://doi.org/10.1109/EMBC. 2016.7591442.

10. Noetscher, G.M., Yanamadala, J., Tankaria, H., Louie, S., Prokop, A., Nazarian, A., and Makarov, S.N., Computational human model VHP-FEMALE derived from datasets of the national library of medicine. Conf. Proc. IEEE Eng. Med. Biol. Soc. 2016:33503353, 2016. https://doi.org/10.1109/EMBC.2016.7591445.

11. Yanamadala, J., Noetscher, G.M., Louie, S., Prokop, A., Kozlov, M., Nazarian, A., and Makarov, S.N., Multi-purpose VHP-female version 3.0 cross-platform computational human model. Conf. Proc. IEEE Antennas Propag. (EuCAP). 2016:1-5, 2016. https:// doi.org/10.1109/EuCAP.2016.7481298.

12. Rea P.M., Advances in anatomical and medical visualisation. In Pinheiro MM, Simões D (ed) Handbook of Research on Engaging Digital Natives in Higher Education Settings. Aveiro, pp 244-264, 2016. https://doi.org/10.4018/978-1-5225-0039-1. ch011

13. Berney, S., Bétrancourt, M., Molinari, G., and Hoyek, N., How spatial abilities and dynamic visualizations interplay when learning functional anatomy with $3 \mathrm{D}$ anatomical models. Anat. Sci. Educ. $8(5): 452-462,2015$. https://doi.org/10.1002/ase.1524.

14. Tabernero Rico, R.D., Juanes Méndez, J.A., and Prats Galino, A., New generation of three-dimensional tools to learn anatomy. J. Med. Syst. 41(5):88, 2017. https://doi.org/10.1007/s10916-017$0725-4$

15. An, G., Hong, L., Zhou, X.B., Yang, Q., Li, M.Q., and Tang, X.Y., Accuracy and efficiency of computer-aided anatomical analysis using $3 \mathrm{D}$ visualization software based on semi-automated and automated segmentations. Ann. Anat. 210:76-83, 2017. https://doi. org/10.1016/j.aanat.2016.11.009.

16. Fenesi, B., Mackinnon, C., Cheng, L., Kim, J.A., and Wainman, B.C., The effect of image quality, repeated study, and assessment method on anatomy learning. Anat. Sci. Educ. 10(3):249-261, 2017. https://doi.org/10.1002/ase.1657. 
17. Preece, D., Williams, S., Lam, R., and Weller, R., Let's get physical: Advantages of a physical model over 3D computer models and textbooks in learning imaging anatomy. Anat. Sci. Educ. 6(4): 216-224, 2013. https://doi.org/10.1002/ase.1345.

18. Estai, M., and Bunt, S., Best teaching practices in anatomy education: A critical review. Ann. Anat. -Anatomischer Anzeiger. 208: 151-157, 2016. https://doi.org/10.1016/j.aanat.2016.02.010.

19. Peterson, D.C., and Mlynarczyk, G.S., Analysis of traditional versus three-dimensional augmented curriculum on anatomical learning outcome measures. Anat. Sci. Educ. 9(6):529-536, 2016. https://doi.org/10.1002/ase.1612.

20. Trelease, R.B., From chalkboard, slides, and paper to e-learning: How computing technologies have transformed anatomical sciences education. Anat. Sci. Educ. 9(6):583-602, 2016. https://doi. org/10.1002/ase. 1620 .

21. Wohlrab, K., Jelovsek, E., and Myers, D., Incorporating simulation into gynecologic surgical training. Am. J. Obstet. Gynecol. 217(5): 522-526, 2017. https://doi.org/10.1016/j.ajog.2017.05.017.

22. Barbeito, A., Painho, M., Cabral, P., and O'Neill, J.G., Beyond digital human body atlases: Segmenting an integrated 3D topological model of the human body. Int. J. E-Health Med. Commun. (IJEHMC). 8(1):19-36, 2017. https://doi.org/10.4018/IJEHMC. 2017010102.

23. Brown, K., Handa, V., Macura, K., and DeLeon, V., Threedimensional shape differences in the bony pelvis of women with pelvic floor disorders. Int. Urogynecol. J.: Including Pelvic Floor Dysfunction. 24(3):431-439, 2013. https://doi.org/10.1007/ s00192-012-1876-y.

24. Moore, C.W., Wilson, T.D., and Rice, C.L., Digital preservation of anatomical variation: $3 \mathrm{D}$-modeling of embalmed and plastinated cadaveric specimens using $\mu \mathrm{CT}$ and MRI. Ann. Anat. Anatomischer Anzeiger. 209:69-75, 2017. https://doi.org/10.1016/ j.aanat.2016.09.010.
25. Bertrand, M., Macri, F., Mazars, R., Droupy, S., Beregi, J., and Prudhomme, M., MRI-based 3D pelvic autonomous innervation: A first step towards image-guided pelvic surgery. Eur. Radiol. 24(8):1989-1997, 2014. https://doi.org/10.1007/s00330-0143211-0.

26. Yiasemidou, M., Glassman, D., Mushtaq, F., Athanasiou, C., Williams, M.M., Jayne, D., and Miskovic, D., Mental practice with interactive 3D visual aids enhances surgical performance. Surg. Endosc. Interventional Techniques. 31(10):4111-4117, 2017. https://doi.org/10.1007/s00464-017-5459-3.

27. Peng, Y., Khavari, R., Nakib, N.A., Boone, T.B., and Zhang, Y., Assessment of urethral support using mRI-derived computational modeling of the female pelvis. Int. Urogynecol. J. 27(2):205-212, 2016. https://doi.org/10.1007/s00192-015-2804-8.

28. Chen, L., Lenz, F., Alt, C.D., Sohn, C., De Lancey, J.O., and Brocker, K.A., MRI visible Fe3O4 polypropylene mesh: 3D reconstruction of spatial relation to bony pelvis and neurovascular structures. Int. Urogynecol. J. Pelvic Floor Dysfunct. 28(8):1131-1138, 2017. https://doi.org/10.1007/s00192-017-3263-1.

29. Doumouchtsis, S.K., Nazarian, D.A., Gauthaman, N., Durnea, C.M., and Munneke, G., Three-dimensional volume rendering of pelvic models and paraurethral masses based on MRI crosssectional images. Int. Urogynecol. J. 28:1-9, 2017. https://doi.org/ $10.1007 / \mathrm{s} 00192-017-3317-4$.

30. Giannini, A., Iodice, V., Picano, E., Russo, E., Zampa, V., Ferrari, V., and Simoncini, T., Magnetic resonance imaging-based three dimensional patient-specific reconstruction of uterine fibromatosis: Impact on surgery. J. Gynecol. Surg. 33(4):138-144, 2017. https:// doi.org/10.1089/gyn.2016.0119.

31. Smit, N., Lawonn, K., Kraima, A., DeRuiter, M., Sokooti, H., Bruckner, S., Eisemann, E., and Vilanova, A., PelVis: Atlas-based surgical planning for oncological pelvic surgery. IEEE Trans. Vis. Comput. Graph. 23(1):741-750, 2017. https://doi.org/10.1109/ TVCG.2016.2598826. 


\section{Anexo 6}

Trabajo presentado en el congreso EDULEARN 18 (International Conference on Education and New Learning Technologies), que tuvo lugar en Barcelona, los días 2-4 de julio de 2018. Posteriormente fue publicado en Proceedings of EDULEARN 18.

Título del trabajo: "Avances tecnológicos en la visualización de la vascularización de la pelvis bajo entornos interactivos tridimensionales".

Resumen: Presentamos un desarrollo informático que permite visualizar e interactuar con las estructuras anatómicas de la pelvis femenina normal reconstruidas a partir de secciones seriadas de resonancia magnética de alta resolución en un entorno tridimensional. Las posibilidades de representar elementos vasculares tridimensionales en cualquier orientación espacial junto con imágenes seccionales de resonancia magnética radiológica en los tres planos del espacio (axial, coronal y sagital), facilitan la comprensión, la identificación y el conocimiento anatómico de las arterias y venas que irrigar esta región anatómica.

Por lo tanto, nuestro propósito con este trabajo ha sido modelar en 3D las principales estructuras esqueléticas, musculares y viscerales de la pelvis femenina normal con especial incidencia en su vascularización a partir de imágenes de resonancia magnética y su representación en un programa diseñado para entornos de PC, que permite visualizar e interactuar con imágenes seccionales integradas con los modelos 3D.

Nuestro programa informático interactivo permite la observación del modelo 3D de los principales vasos sanguíneos en el plano de visión deseado por el usuario con una interfaz gráfica muy intuitiva y ventanas flotantes. Tomamos como patrón de referencia las secciones de resonancia magnética y los modelos 3D de las estructuras viscerales que albergan la pelvis femenina para nuestro desarrollo. Esta aplicación informática representa una herramienta importante para la formación y el aprendizaje de estudiantes de medicina y residentes en el área de uro-ginecología, 
ya que también sirve como un recurso tecnológico visual para planificar intervenciones quirúrgicas pélvicas.

Referencia: Asensio Romero, L., Asensio Gómez, M., Prats-Galino, A. y Juanes Méndez, J. A. (2018). Technological advances in the visualization of the vascularization of the pelvis under interactive three-dimensional environments. Edulearn 18 Proceedings, 802-811. https://doi.org/10.21125/edulearn.2018.0286 


\title{
TECHNOLOGICAL ADVANCES IN THE VISUALIZATION OF THE VASCULARIZATION OF THE PELVIS UNDER INTERACTIVE THREE- DIMENSIONAL ENVIRONMENTS
}

\author{
Lourdes Asensio Romero', Manuel Asensio Gómez ${ }^{1}$, Alberto Prats-Galino ${ }^{2}$, \\ Juan A. Juanes Méndez ${ }^{1}$ \\ ${ }^{1}$ School of Medicine. University of Salamanca (SPAIN) \\ ${ }^{2}$ School of Medicine. University of Barcelona (SPAIN)
}

\begin{abstract}
We present a computer development that allows to visualize and interact with the anatomical structures of the normal female pelvis reconstructed from serial sections of high resolution magnetic resonance in a three-dimensional environment. The possibilities of representing three-dimensionally vascular elements in any spatial orientation together with radiological magnetic resonance sectional images in the three planes of space (axial, coronal and sagittal), facilitate the understanding, the identification and the anatomical knowledge of the arteries and veins that irrigate this region.

Therefore, our purpose with this work has been to model in 3D the main skeletal, muscular and visceral structures of the normal female pelvis with special incidence in its vascularization from magnetic resonance images and its representation in a program designed to PC environments, which allows for visualizing and interacting with sectional images integrated with 3D models.

Our interactive computer program allows the observation of the 3D model of the main blood vessels in the plane of vision desired by the user with a very intuitive graphic interface, and floating windows. We take as a reference pattern the magnetic resonance sections and the 3D models of the visceral structures that harbor the female pelvis for our computer program. This computer application represents an important tool for the training of medical students as well as residents in the area of urogynecology, also serving as a visual technological resource for planning pelvic floor surgical interventions.
\end{abstract}

Keywords: pelvis vascularization, three-dimensional models, high resolution magnetic resonance, computer development, interactive resource, medical training.

\section{INTRODUCTION}

The incursion in the medical training of computer technologies for the teaching-learning process is an effective tool in the teaching of medicine. The use of interactive technological resources, complementary to face-to-face teaching, undoubtedly contributes to an improvement in learning. The use of technologies in medical training is being introduced with increasing force because their different subjects require mastery of a large amount of information, these technological resources are good tools that facilitate this acquisition of knowledge. Probably one of the most relevant disciplines in the professional career of the medical student is Human Anatomy. Therefore, the use of interactive learning environments and three-dimensional vision of body structures, facilitates a better understanding and analysis of one of the subjects considered an important part of the basis of medicine.

Focusing on the specialties that concern the female pelvis, gynecological / obstetric surgery is developed mainly on four anatomical fields: the pelvic floor (vulvar, perineal and vaginal), abdominal, pelvic and mammary. For its surgical approach it is necessary to have an adequate morphological knowledge of the anatomical structures that form it, of the viscera that compose it and of the relationship between them, as well as on the fixation and support systems and their rich and abundant vascularization. Therefore, having technological resources that allow an integral assessment of these anatomical structures and their three-dimensional vision in any spatial position, will entail an enrichment and an optimization of their possible surgical approach to the pathologies that require it.

Taking into account these previous considerations, our objective with this work has been to develop a computer program that allows to visualize and interact with the anatomical structures of the normal female pelvis in a three-dimensional environment, reconstructed from serial sections of magnetic 
resonance (MRI), highlighting especially the vascular part of this anatomical region, because it is an important reference in surgical interventions. On the other hand, our purpose with this technological application is to serve as an important tool for the training of medical students as well as resident physicians in the area of gynecology.

\section{METHODOLOGY}

Initially, we proceeded to the acquisition of high resolution images, with a spacing of $0.5 \mathrm{~mm}$, boosted in DP (proton density), from the pelvic region of a young volunteer woman of 29 years, with no known history of gynecological pathology. We specifically obtained three orthogonal IRMs, each in a different spatial plane, using a 1.5 Tesla scanner. A DP volume was reconstructed for each orientation from the DICOM raw data files, which was saved in ANALYZE 7.5 format, using the free distribution software MRIcro (Nottingham, UK). In order to homogenize the dimensions between the three volumes to the maximum, they were aligned, taking as reference the acquired in the axial plane. From each of these volumes, images in PNG format were exported for their representation in a 3D viewer that we have developed. To facilitate the modeling phase, the three volumes were resized (reslicing), obtaining isotropic images with voxels of $1 \mathrm{~mm}$, that is, with voxels that have the same size in all dimensions. To obtain 3D surface models, consisting of geometric models delimited by polygonal meshes (triangular), the following phases have been followed:

1 Using a 3D editor (Amira, 3.1, TGS Template Graphics Software), the regions of interest (ROIs) were delimited in the isometric volumes.

2 From the ROIs, and applying an algorithm known as marching cubes, a triangular mesh model of the surface of each of these identified structures was obtained.

3 Finally, the $3 \mathrm{D}$ models were exported to the directX format, a standard graphic format compatible with ViX, using a conversion program (3D Exploration $\vee 1.831$, Right Hemisphere, Inc.; http://www. righthemisphere.com/3dexploration/).

For each one of the reconstructed 3D models, a file in html format with a brief anatomical description was elaborated, which complements the information that will show the three-dimensional anatomical viewer, programmed in Visual $\mathrm{C}$, that includes ActiveX controls. It is designed to optimize the graphic acceleration capabilities that current cards support.

\section{RESULTS}

The visualization of anatomical structures in 3D offers students a complete analysis of morphology, to be able to assess the relationships maintained by each structure with its adjacent in different special positions (Fig. 1). In this way, a very useful teaching environment is achieved for the learning process and medical training, under devices and interactive technological means. The study with high resolution MRI used in our study allowed us to identify the structures that integrate the female pelvis (bone walls, muscles and visceral elements), obtaining an excellent anatomical map of the perineum and pelvic organs, for identification, delimitation and subsequent three-dimensional reconstruction.

The three-dimensional anatomical viewer that we have developed allows to evaluate the arterial and venous irrigation of the pelvic region; describing and analyzing the main blood vessels that are located in this area. We briefly describe the main vascular elements that we incorporate into our threedimensional interactive computer application. 


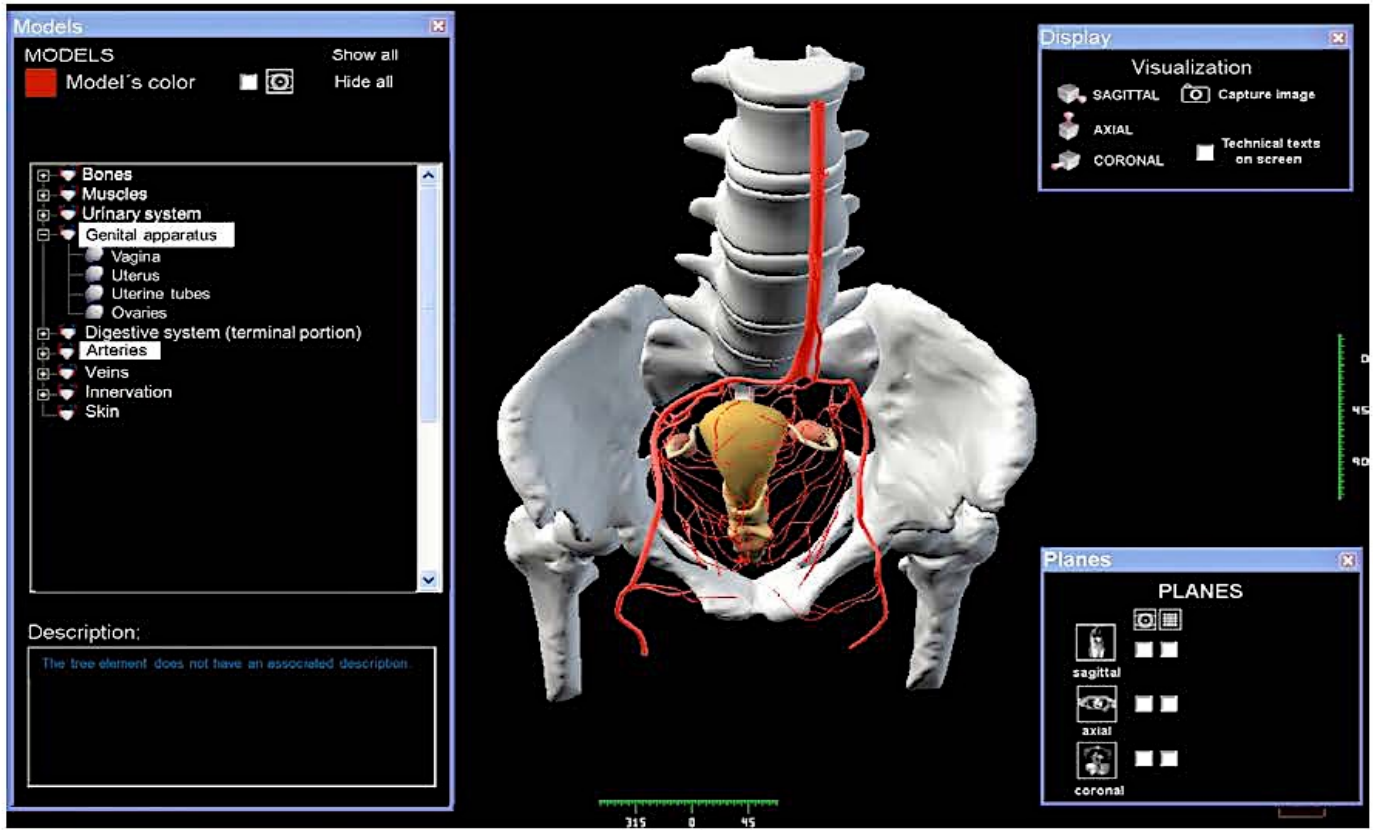

Figure 1. 3D models of pelvic bones, arteries, and female intemal genital apparatus.

The pelvic viscera are irrigated by the hypogastric branches of the common iliac arteries, with the exception of the ovarian, superior hemorrhoidal, and middle sacral arteries.

The ovarian arteries are direct branches of the aorta. They are born at a variable level, in a range between the renal arteries and the inferior mesenteric artery. They are directed downward, laterally following the psoas major muscle and the ureter. They enter the pelvis by crossing the common iliac artery before its bifurcation and penetrate into the broad ligament. Irrigate the ovary, besides anastomosing with the ovarian branches of the uterine arteries, and also irrigate the tube, the ureter and the round ligament.

The superior hemorrhoidal artery is a branch of the inferior mesenteric artery, anastomosed with the middle hemorrhoidal vessels of the hypogastric artery and the inferior hemorrhoidal branches of the internal pudendal artery.

The middle sacral artery extends the aorta in the pelvis and represents the atrophic pelvic segment of the aortic trunk. The common iliac arteries are branches of the aorta and are divided into the external iliac artery and the hypogastric or internal iliac artery approximately at the level of the lower edge of the fifth lumbar vertebra (Fig. 2). The right common iliac artery is crossed by the ovarian vessels, the ureter and the sympathetic nerve fibers that descend into the superior hypogastric plexus. The left common iliac artery is also crossed by the sigmoid colon and the mesocolon, and by the terminal end of the inferior mesenteric artery. 


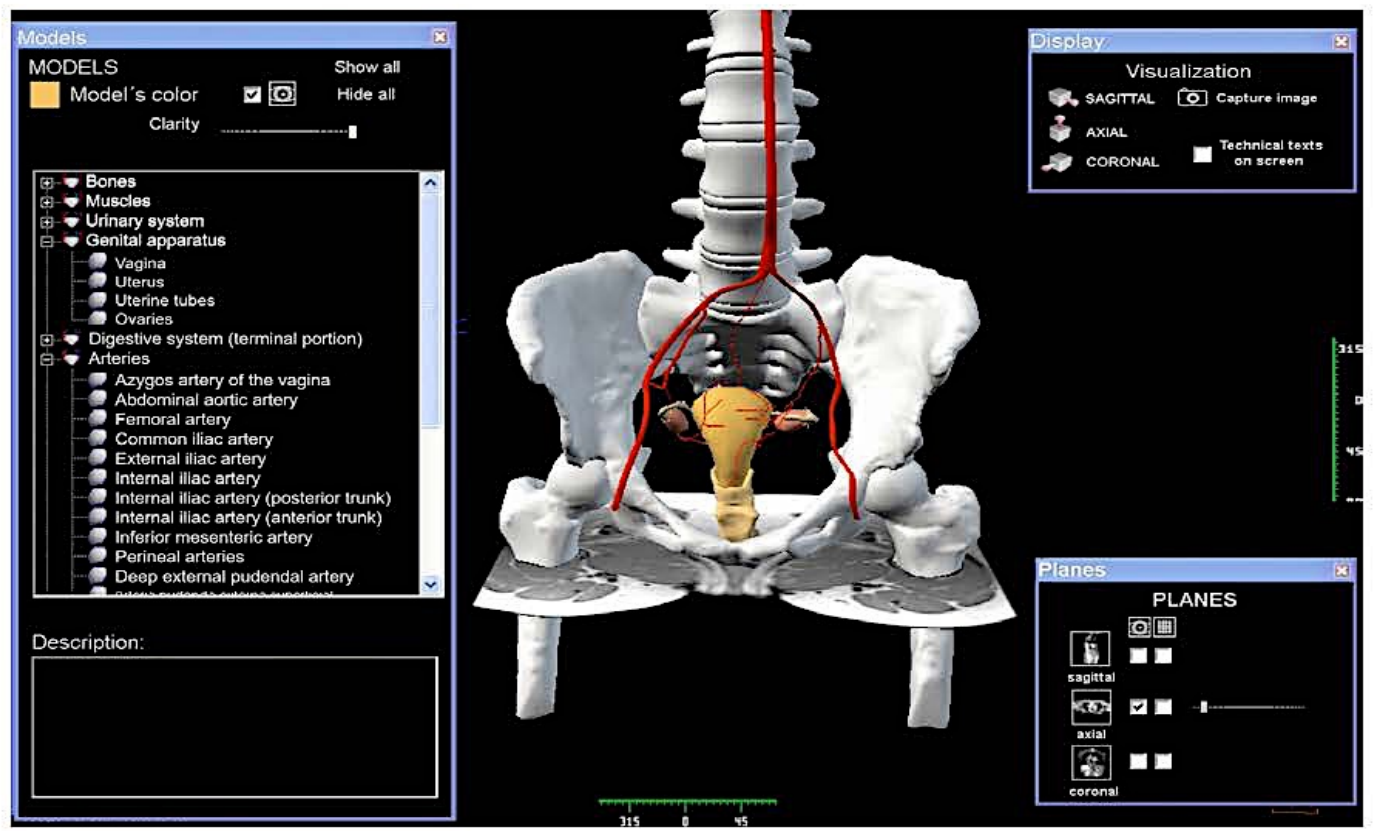

Figure 2. 3D model of common iliac artery and its bifurcation.

The hypogastric or internal iliac artery originates at the level of the lumbosacral joint and descends to the upper edge of the greater sciatic spine, giving various branches that are mostly born from two trunks; one before and one after. Its posterior trunk gives rise to three parietal branches; the iliolumbar artery, the lateral sacral artery and the superior gluteal artery. The anterior trunk produces parietal branches; obturator, inferior gluteal and internal pudenda and visceral branches; upper bladder, middle hemorrhoidal, uterine and vaginal. The obturator artery runs over the aponeurosis of the internal obturator, between the obturator nerve that is above and the vein that is below. It produces iliac, bladder, pubic branches and branches that irrigate bone structures, anastomosing with branches of the inferior epigastric artery and the external iliac artery. The umbilical artery follows the lateral wall of the pelvis, from the hypogastric to the navel. In the adult, only the pelvic section is permeable, giving numerous upper bladder branches that branch off into the upper and lateral wall of the bladder, the lowermost of which is sometimes called the middle bladder artery.

The uterine artery comes from the anterior branch of the hypogastric artery. After penetrating the broad ligament, it is surrounded by the uterine veins at the level of the parametrium and by a sheet of dense connective tissue.

the perineum. It irrigates the ischiocavernosus, bulbocavernosus and transverse perineal muscles. The terminal branches of the perineal artery, or posterior labial arteries, pass through Colles' fascia to irrigate the labia majora and minor.

- The artery of the clitoris runs through the deep transverse perineal muscle and the sphincter of the membranous urethra, finally giving four branches that irrigate the erectile tissue of the superficial perineal compartment.

The pelvic venous plexuses are formed by interconnected veins that surround the viscera of the pelvis. The various plexuses, within the lower pelvis (bladder rectal, uterine and vaginal) are joined and drained mainly by the internal iliac veins; but some of them drain through the superior rectal vein, in the inferior mesenteric vein or through the lateral sacral veins in the internal vertebral venous plexus. Additional venous drainage pathways from the lower pelvis include the middle parietal sacral vein, the superior rectal vein, and the ovarian veins (Fig. 3 ). 


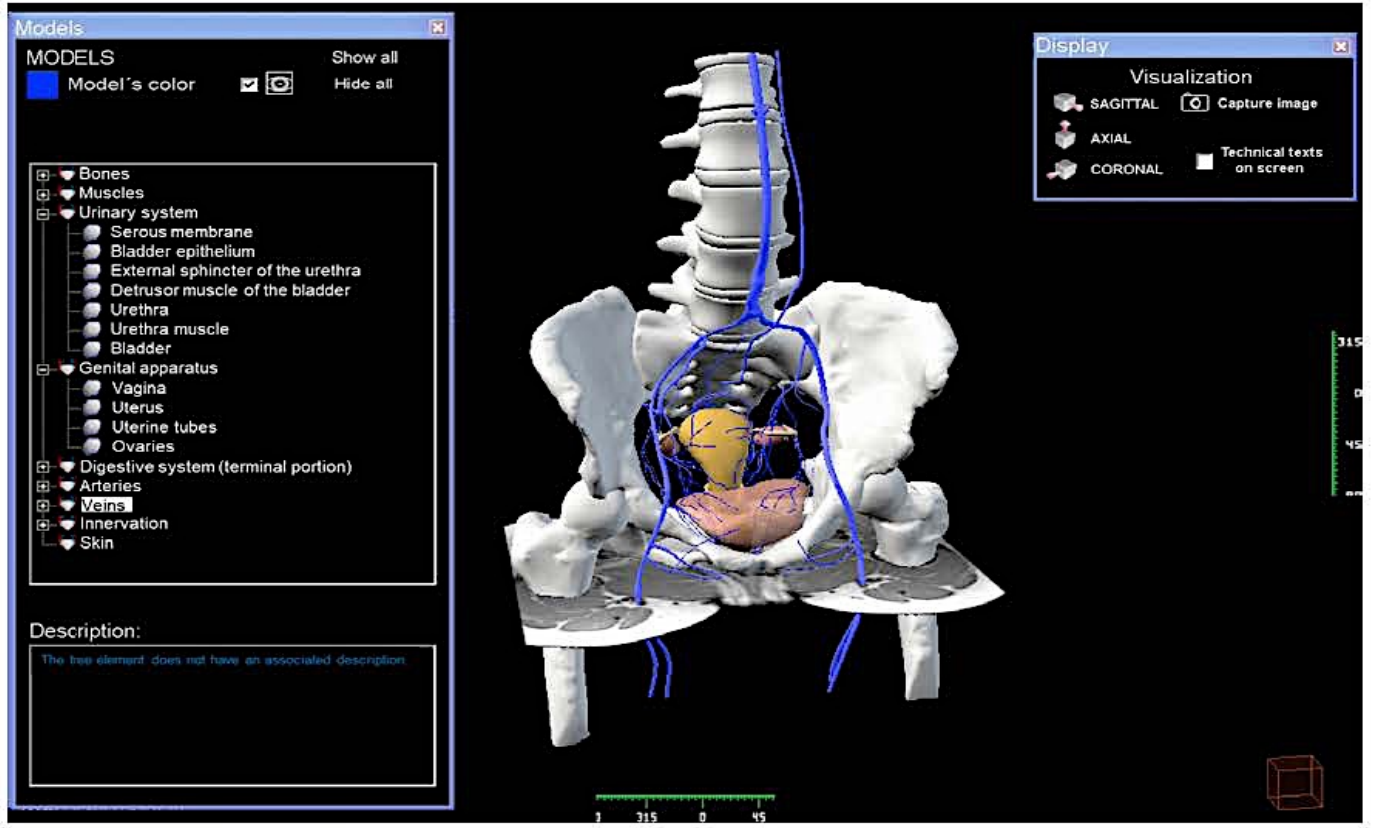

Figure 3. All the veins of the pelvis.

The intemal iliac veins join with the external iliac, to form the common iliac veins; which at the level of the fourth or fifth lumbar vertebra are fused to form the inferior vena cava (Fig. 4).

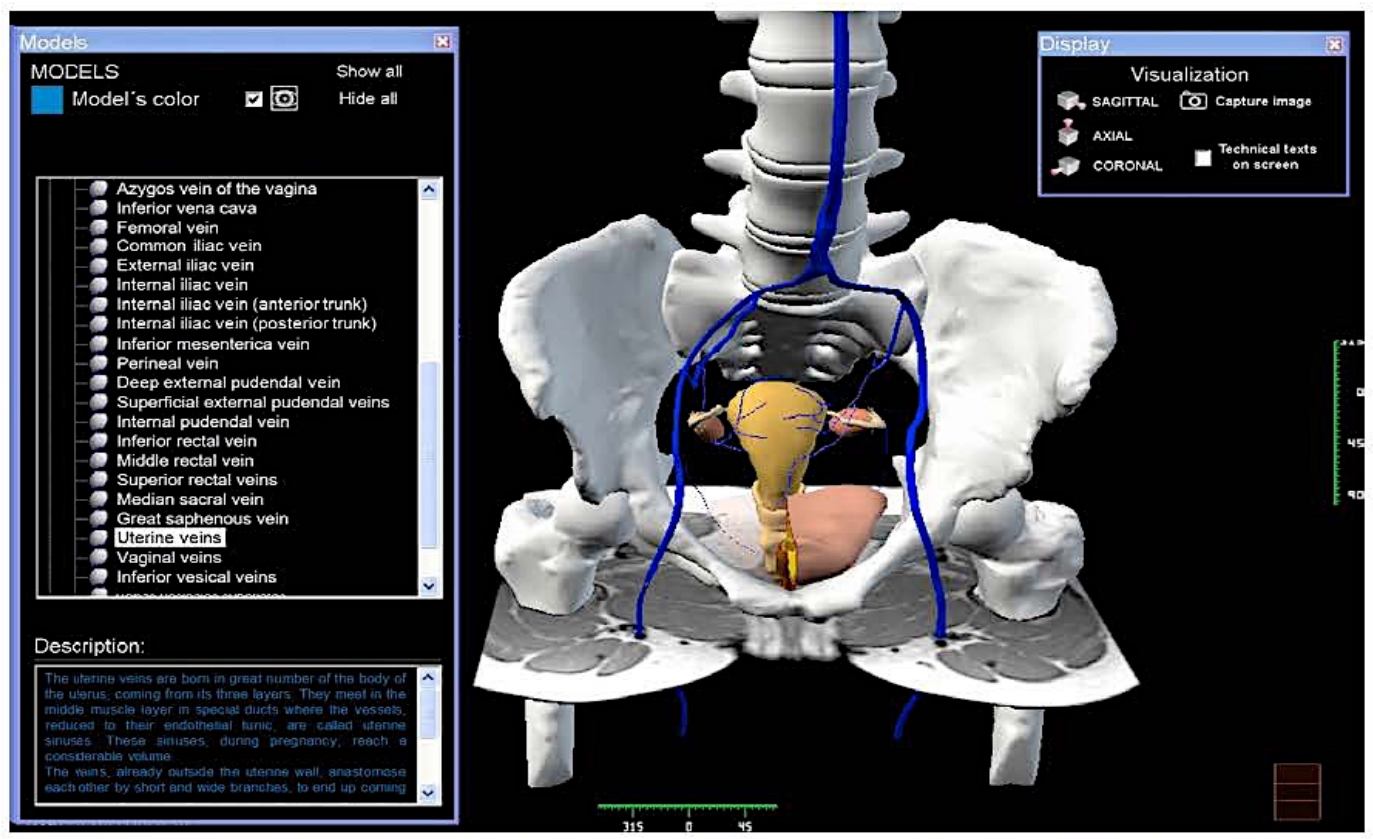

Figure 4. The intemal iliac veins join with the extemal iliac, to form the common iliac veins; to form the inferior vena cava.

The graphic user interface generated is very intuitive. In it appear the different options that allow to act with the anatomical viewer, allowing the visualization of the anatomical structures in three dimensions, 
at the request of the user. Having as a reference pattern the sections of magnetic resonance in the three planes of space (coronal, axial and sagittal), being able to activate or deactivate the visualization of each of them.

The computer development allows to represent and interact with two types of main visual elements: plans and models. All the interactions with the elements of the visual scene (rotations, translations, zoom and selection) are made by placing the cursor on the viewer, using the computer mouse.

The resulting view of making rotations, translations or zoom can be stored as a file through the button to the effect, which allows saving the scene represented in the viewer in a file with bitmap format (.bmp), through the option "capture image".

The screen is where the Viewer interacts with its configuration. The Planes button contains the necessary controls to handle the sectional images of the female pelvis that are presented in the viewer. There are three planes of orientation: Sagittal Plane, Axial Plane and Coronal Plane. Each plane has a selection control to activate or deactivate its visibility. We can also change the position of the selected plane by moving the cursor horizontally on the anatomical viewfinder.

All our computer system is controlled at the will of the user, therefore there is a real interaction between the computer and the user, avoiding as far as possible, that the latter becomes a mere spectator.

In the field of gynecology, the use of this type of technological resources has allowed in the last years to obtain three-dimensional images that contribute to better understand the anatomy of the female pelvis. In this sense, the computer development that we present and its application in gynecology, constitute an excellent tool for visualization and 3D analysis of the anatomical structures of the female pelvis, with simultaneous sections of MR in the three planes of space.

The versatility, flexibility and comfort that these medical training technological resources can offer are very attractive and useful in the teaching-learning process. Thanks to our developed computer tool we have built a theoretical framework that allows us to acquire elementary knowledge of the vascularization of the pelvic region in a three-dimensional visual way, which assesses the spatial relationships of each anatomical structure of this region, which surpasses the traditional anatomical atlases.

\section{CONCLUSIONS}

The generation of $3 D$ images of the human body is increasing in the past few years, being its use generalized in different medical environments. The growing implementation of advanced computer application in the visualization of $3 \mathrm{D}$ models of anatomic structures allows the comprehension of its structure and spatial relationships $[1,8]$.

The computer programs, as teaching resources in medical training, constitute a very useful tool in every field of medical science $[9,10]$.

There is an increasing availability of computers with high technological features that satisfy the optimal execution needs of many teaching computer programs with hypermedia characteristics that require a high capacity of memory in the computers where they are going to be executed.

The advances in computer technologies and recent communication techniques have been added to the teaching field in medical sciences. The objectives of these incorporations are increase the efficiency of the teaching process and searching to contribute to the learning procedure with a more scientific base and a technique that will make the teaching more productive [11-19].

The user's interface is made up of a group of components used by the customers to communicate with the program that is been executed in the computer. The user is the one who really manages the running of the computer program thanks to diverse instructions of usability. We can say that an interface is the part of a computer application that is seen by the user and with which he interacts. It is related to the underlying structure, the architecture and software code [20].

A good interface like the one we are showing in this computer development for the visualization of anatomic structures of female pelvis is easy to understand and very simple to manage. This interface allows the users to carry out a learning task in the easiest and fastest way [21-22]. This may be probably one of the main advantages that our procedure offers, apart from the visual feature of threedimensional images. 
It seems evident that the new interfaces that are to come in the next years will not be essentially very different from what we know today. A radical change of conception is yet quite far, at least as far as computer standards are concerned, and there is no other serious development known which has been carried out this way. However, the evolution of graphic interfaces is awaited by the adoption of new three-dimensional paradigms, far away from the traditional ones.

Teaching computer programs based on simulations present a dynamic model or environment (generally thanks to the use of interactive graphics or animations) that facilitate its exploration and may fulfill inductive or deductive learning through observation and manipulations of the underlying structure. This way, they can discover the model elements and its interrelationships, and some decisions can be made, acquiring direct experience in front of situations that would be difficult to reach in real life, like the possibility to simulate a virtual surgical approach, through the use of different techniques of image diagnosis that visualize the anatomic reality of the patient [23]

The image studies can facilitate the anatomy knowledge and the diagnosis of pathological processes that affect anatomic structures like the pelvis. These techniques have changed over the years, no just related to the diagnosis accuracy in itself, but also as an element of basic decision when deciding a therapeutic plan [24-27].

Therefore, in the diagnosis of the pathological processes of the pelvis, imaging techniques play a predominant role. Its contribution is essential in the study of any type of pathological process of the pelvis, sometimes as a complement to the clinical exploration, others establishing the need for the use of other diagnostic, cytological or histological techniques, making possible the contribution of these through the exact location of the pathological area and as a guide to obtain material for its study. All this explains the importance of imaging techniques in the diagnosis of pelvic pathology. In addition, nowadays they are required to contribute, sometimes decisively, in the choice of the most appropriate therapy based on the information they can provide

In this sense, MRI offers multiple advantages over other imaging techniques such as computed tomography or ultrasound, although its availability is more limited. The MRI technique has benefited from an important progress in the technology, improving the antennas (coils) and the acquisition sequences to obtain high resolution studies. The progressive development has allowed to use an endo-rectal coil in combination to a pelvic coil, thus allowing a complete and effective study of the entire pelvis.

Therefore, MRI is an excellent tool in the evaluation and management of selected patients with gynecological, urological and coloproctologic pathology, both benign and malignant.

This technique also allows planning the intervention in patients with presacral and soft tissue tumors of the perineum.

In the field of Urogynecology or pathology of the pelvic floor of women, although the physical examination is still the usual method of evaluation of anatomical lesions and alterations of pelvic static, the truth is that the anatomical complexity of this region, and the need to obtain a better evaluation regarding the location of a lesion, the adjacent compromise and the possibilities of surgical treatment, have made the images obtained through the use of MRI are considered increasingly useful in the management of patients with genital prolapse, urine and fecal incontinence [28-34]. However, there is still no consensus on when they should be applied and it is not clear the impact that the application of MRI can have on the final result of the treatments applied to patients with pelvic floor dysfunctions.

The female pelvis is a region of special anatomical complexity, so a visualization of this area in three dimensions, would facilitate the learning of this part of the human body [35]. Therefore, our computer application is a good method of 3D visualization of the female pelvis, which facilitates its anatomical assessment, making use of the advanced graphic capabilities that computers offer today [36]. With a very intuitive graphic interface, our procedure allows the observation of the different anatomical parts in three dimensions at the request of the user, having as a reference pattern the magnetic resonance sections in the three space planes (coronal, axial and sagittal), being able to activate or deactivate the visualization of each of them. In addition, it offers us a documentary information on the selected 3D anatomical element. All this has allowed us to establish a three-dimensional virtual model of the female pelvis, from images obtained by magnetic resonance.

The future use of multimodal studies (CT, angio-MRI, endoluminal MRI, etc.) will allow us to analyze in greater detail the anatomical structure of the pelvis, including its vascularization [37] 


\section{REFERENCES}

[1] B. Fenesi, C. Mackinnon, L. Cheng, J. A. Kim, and B. C. Wainman, "The effect of image quality repeated study, and assessment method on anatomy learning," Anat. Sci. Educ., vol. 10, no. 3, pp. 249-261, 2017.

[2] G. M. Noetscher, J. Yanamadala, H. Tankaria, S. Louie, A. Prokop, A. Nazarian, and S. N Makarov, "Computational human model VHP-FEMALE derived from datasets of the national library of medicine," 38th Annual International Conference of the IEEE Engineering in Medicine and Biology Society (EMBC), pp. 3350-3353, 2016.

[3] J. Yanamadala, G. M. Noetscher, S- Louie, A. Prokop, M. Kozlov, A. Nazarian, and S. N. Makarov, "Multi-purpose VHP-female version 3.0 cross-platform computational human model," 10th European Conference on Antennas and Propagation (EUCAP), pp. 1-5, 2016.

[4] J. A. Juanes, A. Prats, M. L. Lagándara, and J. M. Riesco, "Application of the 'Visible Human Project' in the field of anatomy: a review," Eur. J. Anat., vol. 7, pp. 147-159, 2003.

[5] S. Berney, M. Bétrancourt, G. Molinari, and N. Hoyek, "How spatial abilities and dynamic visualizations interplay when learning functional anatomy with 3D anatomical models," Anat. Sci. Educ., vol. 8, no. 5, pp. 452-462, 2015.

[6] S. K. Ghosh, "Evolution of illustrations in anatomy: A study from the classical period in Europe to modern times," Anat. Sci. Educ., vol. 8, no. 2, pp. 175-188, 2015.

[7] B. Fang, Y. Wu, C. Chu, Y Li, N. Luo, K Liu, L. Tan, and S. Zhang, "Creation of a Virtual Anatomy System based on Chinese Visible Human data sets," Surg Radiol Anat, vol. 39, no. 4, pp. 441-449, 2016.

[8] Y. Wu, L. Tan, Y. Li, B. Fang, B. Xie, T. Wu, Q. Li, M. Qiu, G. Liu, K. Li, H. Xu, N. Luo, and S. Zang, "Creation of a female and male segmentation dataset based on Chinese Visible Human (CVH)," Comput. Med. Imaging Graph., vol. 36, no. 4, pp. 336-342, 2012.

[9] G. An, L. Hong, X. Zhou, Q. Yang, M. Li, and X. Tang, "Accuracy and efficiency of computeraided anatomical analysis using $3 \mathrm{D}$ visualization software based on semi-automated and automated segmentations," Ann. Anat. - Anat. Anzeiger, vol. 210, pp. 76-83, 2017.

[10] R. Vázquez, J. M. Riesco, J. A. Juanes, E. Blanco, M. Rubio, and J. Carretero, "Educational strategies applied to the teaching of anatomy. The evolution of resources," Eur J Anat, vol. 11, no. 1, pp. 31-43, 2007.

[11] A. Barbeito, M. Painho, P. Cabral, and J. G. O'Neill, "Beyond Digital Human Body Atlases," Int. J. E-Health Med. Commun., vol. 8, no. 1, pp. 19-36, 2017

[12] D. C. Peterson, and G. S. A. Mlynarczyk, "Analysis of traditional versus three-dimensional augmented curriculum on anatomical learning outcome measures," Anat. Sci. Educ., vol. 9, no. 6, pp. 529-536, 2016.

[13] D. Preece, S. B. Williams, R. Lam, and R. Weller, "'Let's Get Physical': Advantages of a physical model over 3D computer models and textbooks in learning imaging anatomy," Anat. Sci. Educ., vol. 6, no. 4, pp. 216-224, 2013.

[14] D. S. Shin, H. G. Jang, S. B. Hwang, D. H. Har, Y. L. Moon, and M. S. Chung, "Twodimensional sectioned images and three-dimensional surface models for learning the anatomy of the female pelvis," Anat. Sci. Educ., vol. 6, no. 5, pp. 316-323, 2013

[15] L. Asensio, M. Asensio, and J. A. Juanes, "Development of 3D models of female pelvis embedded in anatomical sections from de Visible Human Project," TEEM 2017: Proceedings of the $5^{\text {th }}$ International Conference on Technological Ecosystems for Enhancing Multiculturality, 2017

[16] M. Estai, and S. Bunt, "Best teaching practices in anatomy education: A critical review," Ann. Anat. - Anat. Anzeiger, vol. 208, pp. 151-157, 2016.

[17] R. B. Trelease, "From chalkboard, slides, and paper to e-learning: How computing technologies have transformed anatomical sciences education," Anat. Sci. Educ., vol. 9, no. 6, pp. 583-602, 2016 
[18] S. Pujol, M. Baldwin, J. Nassiri, R. Kikinis, and K. Shaffer, "Using 3D Modeling Techniques to Enhance Teaching of Difficult Anatomical Concepts," Acad. Radiol., vol. 23, no. 4, pp. 507-516, 2016.

[19] A. Sergovich, M. Johnson, and T. D. Wilson, "Explorable three-dimensional digital model of the female pelvis, pelvic contents, and perineum for anatomical education," Anat. Sci. Educ., vol. 3 , no. 3, 2010

[20] M. C. Sora, R. Jilavu, and P. Matusz, "Computer aided three-dimensional reconstruction and modeling of the pelvis, by using plastinated cross sections, as a powerful tool for morphological investigations," Surg Radiol Anat, vol. 34, no. 8, pp. 731-736, 2011.

[21] L. Asensio, M. Asensio, A. Prats-Galino, and J. A. Juanes, "3D Models of Female Pelvis Structures Reconstructed and Represented in Combination with Anatomical and Radiological Sections," J. Med. Syst., vol. 42, no. 3, pp. 37, 2018.

[22] L. Asensio, M. Asensio, J. A. Juanes, and A. Prats-Galino, "Anatomy-radiological assessment of female pelvis through three-dimensional models coregistered with sectional images of magnetic resonance," $10^{\text {th }}$ annual International Conference of Education, Research and Innovation, pp. 1466-1472, 2017.

[23] R. D. Tabernero, J. A. Juanes, and A. Prats, "New Generation of Three-Dimensional Tools to Learn Anatomy," J. Med. Syst., vol. 41, no. 5, pp. 88, 2017.

[24] M. M. Bertrand, F. Macri, R. Mazars, S. Droupy, J. P. Beregi, and M. Prudhomme, "MRI-based 3D pelvic autonomous innervation: a first step towards image-guided pelvic surgery," Eur. Radiol., vol. 24, no. 8, pp. 1989-1997, 2014.

[25] K. Wohlrab, J. E. Jelovsek, and D. Myers, "Incorporating simulation into gynecologic surgical training," Am. J. Obstet. Gynecol., vol. 217, no. 5, pp. 522-526, 2017.

[26] A. C. Kraima, N. N. Smit, D. Jansma, C. Wallner, R. L. A. W. Bleys, C. J. H. Velde, C. P. Botha, and M. C. DeRuiter, "Toward a highly-detailed 3D pelvic model: Approaching an ultra-specific level for surgical simulation and anatomical education," Clin. Anat., vol. 26, no. 3, pp. 333-338, 2013.

[27] M. Yiasemidou, D. Glassman, F. Mushtaq, C. Athanasiou, M. Williams, D. Jayne, and D. Miskovic, "Mental practice with interactive 3D visual aids enhances surgical performance," Surg Endosc., vol. 31, no. 10, pp. 4111-4117, 2017

[28] M. Abdulaziz, E. G. Deegan, A. Kavanagh, L. Stothers, D. Pugash, and A. Macnab, "Advances in basic science methodologies for clinical diagnosis in female stress urinary incontinence," Can. Urol. Assoc. J., vol. 11, no. 6S2, pp. 117, 2017.

[29] K. M. Brown, V. L. Handa, K. J. Macura, and V. B. DeLeon, "Three-dimensional shape differences in the bony pelvis of women with pelvic floor disorders," Int. Urogynecol. J., vol. 24, no. 3, pp. 431-439, 2013.

[30] L. Chen, F. Lenz, C. D. Alt, C. Sohn, J. O. De Lancey, and K. A. Brocker, "MRI visible Fe3O4 polypropylene mesh: $3 \mathrm{D}$ reconstruction of spatial relation to bony pelvis and neurovascular structures," Int. Urogynecol. J., vol. 28, no. 8, pp. 1131-1138, 2017.

[31] S. K. Doumouchtsis, D. A. Nazarian, N. Gauthaman, C. M. Durnea, and G. Munneke, "Threedimensional volume rendering of pelvic models and paraurethral masses based on MRI crosssectional images," Int. Urogynecol. J., vol. 28, no. 10, pp. 1579-1587, 2017.

[32] A. Giannini, V. lodice, E. Picano, E. Russo, V. Zampa, V. Ferrari, and T. Simoncini, "Magnetic Resonance Imaging-Based Three-Dimensional Patient-Specific Reconstruction of Uterine Fibromatosis: Impact on Surgery," J. Gynecol. Surg., vol. 33, no. 4, pp. 138-144, 2017.

[33] B. S. Hampton, and V. W. Sung, "Improving medical student knowledge of female pelvic floor dysfunction and anatomy: a randomized trial," Am. J. Obstet. Gynecol., vol. 202, no. 6, pp. 601.e1-601.e8, 2010

[34] Y. Peng, R. Khavari, N. A. Nakib, T. B. Boone, and Y. Zhang, "Assessment of urethral support using MRI-derived computational modeling of the female pelvis," Int. Urogynecol. J., vol. 27, no 2, pp. 205-212, 2016. 
[35] V. Balaya, J. Uhl, A. Lanore, C, Salachas, T. Samoyeau, C. Ngo, C. Bensaid, C. Cornou, L. Rossi, R. Douard, A. Bats, F. Lecuru, and V. Delmas, "Modélisation anatomique 3D du pelvis féminin par dissection anatomique assistée par ordinateur: applications et perspectives," $J$ Gynécologie Obs. Biol. la Reprod., vol. 45, no. 5, pp. 467-477, 2016.

[36] G. Legendre, L. Sahmoune Rachedi, P. Descamps, and H. Fernández, "Apport d'un simulateur virtuel d'anatomie périnéale (Pelvic Mentor®) dans l'apprentissage de la pelvi-périnéologie: résultats d'une étude préliminaire," J. Gynécologie Obs. Biol. la Reprod., vol. 44, no. 1, pp. 72$77,2015$.

[37] C. W. Moore, T. D. Wilson, and C. L. Rice, "Digital preservation of anatomical variation: 3Dmodeling of embalmed and plastinated cadaveric specimens using uCT and MRI," Ann. Anat. Anat. Anzeiger, vol. 209, pp. 69-75, 2017. 


\section{Anexo 7}

Trabajo presentado en el congreso TEEM 18 (Sixth Edition International Conference Technological Ecosystems for Enhancing Multiculturality 2018), que tuvo lugar en Salamanca, los días 24-26 de octubre de 2018. Posteriormente fue publicado en ACM library.

Título del trabajo: "Desarrollo tecnológico de visualización de imágenes seccionales de resonancia magnética y ecografía del suelo pélvico con fines didácticos".

Resumen: Los desarrollos informáticos como recursos didácticos están adquiriendo un papel cada vez más relevante, a medida que las nuevas tecnologías se integran en la actividad docente. En el campo de la medicina, un buen conocimiento e interpretación de los procedimientos radiológicos, como la resonancia magnética y la ecografía, es esencial para realizar diagnósticos clínicos correctos, especialmente en un área anatómica tan compleja como la pelvis y el suelo pélvico femenino. La necesidad de formar a estudiantes, residentes y especialistas en ginecología en la anatomía de esta región anatómica, en la interpretación de imágenes diagnósticas y, especialmente, en anatomía quirúrgica, hace que esta forma de aprendizaje a través de recursos tecnológicos, como la que presentamos, sea vista como una nueva alternativa o como un complemento a los que ya se utilizan en la actualidad.

Referencia: Asensio Romero, L., Asensio Gómez, M., Prats-Galino, A. y Juanes Méndez, J. A. (2018). Technological development of visualization of magnetic resonance sectional images and pelvic floor ultrasonography for teaching purposes. Proceedings of the Sixth International Conference on Technological Ecosystems for Enhancing Multiculturality - $\quad$ TEEM'18, 357-361. https://doi.org/10.1145/3284179.3284240 


\section{Technological development of visualization of magnetic resonance sectional images and pelvic floor ultrasonography for teaching purposes}

\author{
Lourdes Asensio Romero \\ School of Medicine. University of \\ Salamanca \\ lourdes90.ar@gmail.com
}

\author{
Manuel Asensio Gómez \\ School of Medicine. University of \\ Salamanca \\ mago59@usal.es \\ Juan A. Juanes Méndez \\ School of Medicine \\ VisualMed System Group \\ University of Salamanca \\ jajm@usal.es
}

\author{
Alberto Prats-Galino \\ School of Medicine. University of \\ Barcelona \\ aprats@ub.edu
}

\begin{abstract}
Computer developments as didactic resources are gaining an increasingly relevant role as new technologies are integrated into the teaching activity. A good knowledge and interpretation of radiological procedures, such as nuclear magnetic resonance and ultrasound, is essential to carry out correct clinical diagnoses, especially in an anatomical area as complex as the pelvis and the female pelvic floor. The need for training both students, residents and specialists in gynecology in the anatomy of that area, in the interpretation of diagnostic images and, especially, in surgical anatomy, makes this form of learning through technological resources, such as the one we present, is seen as a new alternative or as a complement to those already used up to the present time
\end{abstract}

\section{CCS CONCEPTS}

- Human-centered computing - Computing education $\rightarrow$ information technology education.

\section{KEYWORDS}

Computer development, anatomical-radiological atlas, pelvic floor, radiological image, magnetic resonance, ultrasound.

Permission to make digital or hard copies of all or part of this work for personal or classroom use is granted without fee provided that copies are not made or distributed for profit or commercial advantage and that copies bear this notice and the full citation on the first page. Copyrights for components of this work owned by others than ACM must be honored. Abstracting with credit is permitted. To copy otherwise, or republish, to post on servers or to redistribute to lists, requires prior specific permission and/or a fee. Request permissions from Permissions@acm.org.

TEEM'18, October 24-26, 2018, Salamanca, Spain 2018 ACM. ISBN 978-1-4503-6518-5..\$15.00 http://dx,doi.org/10.1145/3284179.3284240
ACM Reference format:

L. Asensio Romero, M. Asensio Gómez, A. Prats-Galino and J. A. Juanes Mendez. 2018. Technological development of visualization of magnetic resonance sectional images and pelvic floor ultrasonography for teaching purposes. In Proceedings of the 6th International Conference on Technological Ecosystems for Enhancing Multiculturality (TEEM 2018) (Salamanca, Spain, October 24-26, 2018), F. 7. García-Peñalvo Ed. ACM New York, NY, USA, 5 pages. https://doi.org/10.1145/3284179.3284240.

\section{INTRODUCTION}

The progress of medical informatics, initiated many years ago and intensified in the last decade, has opened a revolution in medical training. Computer developments as didactic resources are gaining an increasingly relevant role as new technologies are integrated into the teaching activity. The advances of these technologies have been incorporated into the educational field in medicine with the aim of increasing the efficiency of the teaching process and providing a more technical and modern basis that makes teaching more productive in the different areas of medical knowledge [1-7].

On the other hand, imaging studies can facilitate knowledge of the anatomy and diagnosis of pathological processes that affect various anatomical structures such as those of the female pelvis and the pelvic floor, and that is why good knowledge and interpretation of these radiological procedures is essential to carry out correct clinical diagnoses. Taking into account these considerations, our purpose has been to develop a computer program to have a teaching tool, based on tutorial systems that present magnetic resonance images (MRI) and ultrasound (endovaginal-transperineal-endoanal) visual information, which will guide users in their learning task using this interactive procedure. All this constitutes a true anatomo-radiological atlas of the pelvic floor [8-17].

The female pelvic floor is the supporting structure of the pelvic organs. It is composed of muscle groups, and connective structures such as fascia and ligaments. From the anatomo- 
functional point of view three compartments are established: anterior, middle or central and posterior, difficult to visualize, so for the diagnosis of pelvic floor pathologies, complementary tests have been used, such as conventional radiology with contrast, MRI and ultrasound [18-26].

Therefore, our purpose is to help the last courses of medicine students and gynecology residents to build a model of knowledge based on highly interactive technological procedures that facilitate the correct interpretation of radiological images that are commonly used in the clinical practice of health professionals.

The need for training both students, residents and specialists in gynecology in the anatomy of that area, in the interpretation of diagnostic images and, especially, in surgical anatomy, makes this form of learning through technological resources, such as the one we present, is seen as a new alternative or as a complement to those already used up to the present time [27-32].

\section{METHODOLOGY}

\subsection{Acquisition and processing of radiological images}

All images were obtained from a 29-year-old volunteer woman with no known history of gynecological pathology.

\subsection{Nuclear magnetic resonance}

High resolution images were obtained, enhanced in different sequences, T1, T2 and proton density (DP) in the three orthogonal planes (axial, coronal and sagittal) of the abdominopelvic region, for the global anatomical study of the pelvis. However, for the computer procedure, only highresolution images with a spacing of $0.5 \mathrm{~mm}$, enhanced in DP (proton density), of the pelvic region were acquired. Specifically three orthogonal images were obtained, each in a different spatial plane, using a 1.5 Tesla unit (Magnetom Healthineers, Siemens).

The acquisition protocol consisted of sequences in two dimensions (2D) of the abdomino-pelvic region with the following parameters common to the three orientations: repetition time $=3220$; echo time $=14 ; 3-\mathrm{mm}$ slice thickness; matrix $=512 \times 512$; flip angle $=150^{\circ}$. The acquisition parameters specific to each orientation were: axial and sagittal planes: slice spacing $=3.6 \mathrm{~mm}$; pixel spacing $=0.547 \mathrm{~mm} \times 0.547 \mathrm{~mm}$; Coronal plane: slice spacing $=4.8 \mathrm{~mm}$; pixel spacing $=0.586 \mathrm{~mm} \times 0.586$ mm.

\subsection{Ultrasound}

Ultrasound images of the pelvic floor and pelvis were obtained by using two ultrasound equipment (Siemens Acuson Antares and Voluson E6) that support different image modes (B-mode, $M$-mode, color Doppler, intensity Doppler, Pulsed Doppler (PW), Continues Doppler (CW), and three/four dimensions (3D / 4D)).

These ultrasound machines allow the acquisition of anatomical and volumetric images of great clarity from virtually any plane, with advanced volume contrast, and differentiating irregularly shaped structures with great precision. All this thanks to the technical specifications of both devices (tissue elasticity, SIECLEAR Advance Space, Siescape, EQT, MultiHertz Multi-Frequency Image and Lens Transduction technology, ATO high-resolution zoom, HPRF, SonoVCAD, TruScan, VCI, SonoAVCfollicle, SonoVCADheart, TUI, CE, XTD Extended view, SRI II, CRI) and the possibility of using different types of probes: convex probe $\mathrm{CH}$-2 [2-6 MHz] (with matrix of up to 512 piezoelectric elements, in curved surface, forming a fan beam), endovaginal probe EV9F4 [4-9 MHz] (with piezoelectric elements that produce the sweep without the need for movement), intracavitary probe IC5-9-D [4-9 MHz] and 3D/4D convex probe RAB4-8-D [2-8 MHz].

The exploration routes used were vaginal, transintroital, rectal or endoanal and transperineal. The transintroital route is used for the acquisition of images in which different pelvic structures are assessed and their disposition. For the evaluation of the pelvic floor, for the comfort of the patient and to produce less anatomical and functional alteration, it is advisable to use the transperineal approach (supporting the distal part of the probe at the vaginal introitus level and modify its inclination in function of the area to be explored). In the case of the assessment of cavities, with the new probes it can be done endoanally or endovaginally, obtaining images in $360^{\circ}$. For the acquisition of three dimensions (3D) volumes, the sweep angle must be wide enough to include the entire region, generally $70-90^{\circ}$. The ideal is to capture a sagittal section from the symphysis pubis to the levator ani, including the anal sphincter surface and the depth of the bladder in discrete filling ( $30 \mathrm{cc}$ ).

For our computer development, different probes (conventional convex, biplanar electronic, rotational mechanics, multifrequency) were used to capture the images (at rest, in contraction and with the Valsalva maneuver) by different routes (transperineal, transintroital, endovaginal, endoanal), of the patient in the position of dorsal lithotomy with the hips flexed, slightly in abduction and with the heels close to the buttocks.

\subsection{Installation and minimum system requirements}

The installation program is ready for self-execution.

The minimum recommended software technical requirements are the following: Microsoft Windows 98, 2000, or XP operating systems. DirectX 8 software or higher.

The minimum computer equipment requirements are: Graphics card with at least $32 \mathrm{MB}$ of memory that supports DirectX 8.0 in window mode, Pentium III processor at $450 \mathrm{MHz}$ or higher; $128 \mathrm{MB}$ of RAM and $40 \mathrm{MB}$ of free hard disk memory.

However, the following elements are recommended in the computer equipment: Graphic card with at least $64 \mathrm{MB}$ of memory that supports; DirectX 9.0 in window mode; Pentium III processor at $600 \mathrm{MHz}$ or higher; $256 \mathrm{MB}$ of RAM and $240 \mathrm{MB}$ of free hard disk memory.

On the other hand, to correctly visualize this developed computer application, it is necessary to have, in the computer equipment, a 3D acceleration card that supports DirectX 9.0 in window mode. Most of the cards present in the market are 
Technological development of visualization of magnetic resonance sectional images and pelvic floor ultrasonography for teaching purposes

capable of this, being between these the GeForce range of NVidia or the Radeon range of ATI

All our computer development has been programmed in Visual C, which includes ActiveX controls, which is designed to optimize the graphic acceleration capabilities that support the graphics cards of current computer equipment.

\section{RESULTS}

Most of the teaching computer programs have three clearly defined main modules: the module that manages the communication with the user, the module that contains the information of the program and the module that manages the actions of the computer and their responses to the actions of the users.

The interface is the environment through which the computer programs establish the dialogue with their users and is what enables the interactivity characteristic of these materials.

An interface like the one we show in this computer development for the visualization of anatomical structures of the female pelvis, using diagnostic imaging techniques such as MRI and ultrasound, is easy to understand and very easy to use, allowing users (students or resident doctors) perform a learning or training task in a simple and fast way.

A toolbar of small illustrative icons indicates the possibilities of working with the image, where a magnifying glass is included to make a zoom and thus be able to focus closely on the image and assess a detail for its best analysis, move the image on the screen, add or remove a cutting plane, etc. (Fig. 1)

Our computer application, based on MRI and ultrasound sectional images, leaves the user free to navigate through the application as they wish. In this way each person will identify with what is of most interest to him/her for some specific reason.

As seen in Figure 1, MRI sections can be analyzed from any spatial position and in its three planes of space (axial, coronal and sagittal). On the other hand, a list of the main anatomical structures of the female pelvis appears in the lower area of the screen: the selection of any of them allows us to see where it is located in the MRI (Fig. 1). The computerized procedure developed allows to carry out radiological correlations between the MRI and the ultrasound image (Fig. 2).

Ultrasound images can be evaluated serially, including an identification of each structure that is displayed, when the cursor is moved over the image (Fig. 3). Our ultrasound viewer includes images of transperineal, endovaginal and endoanal ultrasonography; having used different echographic probes, such as: conventional 2D convex; 3D / 4D multi-frequency probe, 3D biplane electronic probe and $360^{\circ} 3 \mathrm{D}$ rotational mechanical probe (Fig. 1)

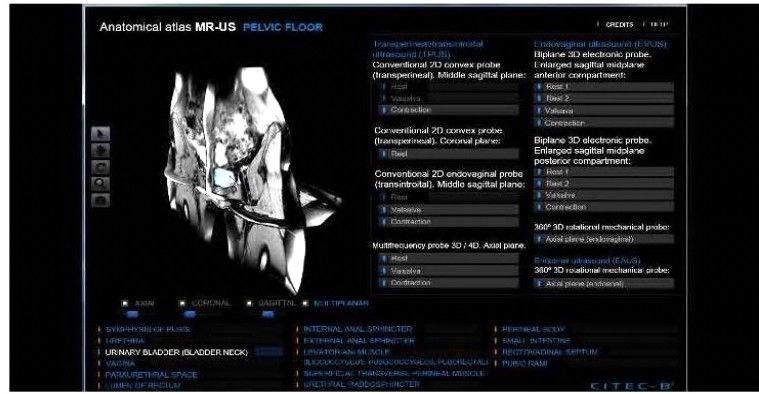

Figure 1: Screen of the anatomo-radiological viewer of the pelvic floor. On the left side of the image, simultaneous sections of MRI are seen; on the right side the ultrasound vision options are displayed

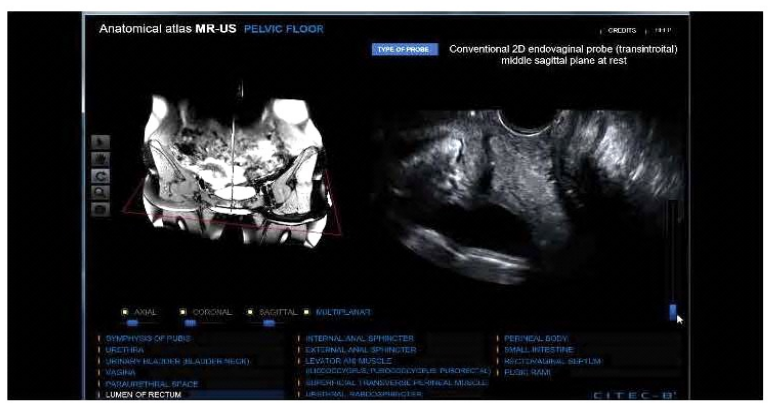

Figure 2: Screen of the anatomo-radiological viewer of the pelvic floor. On the left side, magnetic resonance images are shown; on the right side, an ultrasound image is displayed simultaneously according to the type of probe selected

\section{CONCLUSIONS}

Currently, technological and computer resources are increasingly incorporated into our daily lives, innovating and facilitating many aspects of it. This is not different in the field of education in which there is also a renewed effort to incorporate technological developments in medical teaching with the aim of facilitating the study and learning of the student and simplifying teaching to the teacher, providing support didactic at the same time $[1-4,28,29]$ 


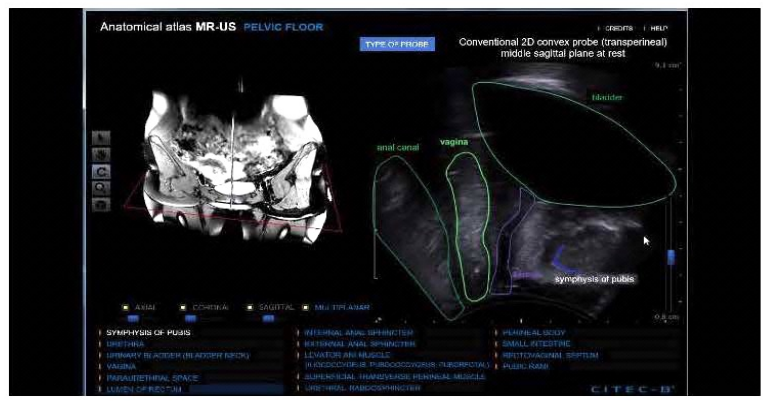

Figure 3: Screen of the anatomo-radiological viewer. The ultrasound image on the right shows the identification of the anatormical structures that can be recognized

The use of computer programs in the study of human anatomy and the use of diagnostic tests based on anatomical representation and analysis, such as radiological studies, are particularly important. Imaging studies can facilitate knowledge of the anatomy and diagnosis of pathological processes that affect anatomical structures such as pelvic structures. These techniques have been changing over time, not only with a view to the diagnostic accuracy itself, but also as fundamental decision elements when establishing a therapeutic plan. Therefore, diagnostic imaging techniques play a major role in the analysis of the pathological processes of the pelvis. His contribution is essential in the study of any type of pelvic pathology, sometimes as a complement to the clinical exploration, and others establishing the need to use other diagnostic and therapeutic techniques, serving as a guide for them. In addition, today they are required to contribute, sometimes decisively, to the choice of the most appropriate therapy in each particular case based on the information that these imaging techniques can provide [8-13, 15-17, 27, 33-35]

In the field of Urogynecology, although physical examination is still the usual method of evaluation of anatomical lesions and alterations of pelvic static, the truth is that the anatomical complexity of this region, and the need to obtain a better evaluation regarding the location of the lesion, the adjacent anatomical structures involved and the possibilities of surgical treatment, have made the images obtained through the use of MRI and ultrasound (abdominal, transvaginal, transperineal or endoanal) are considered increasingly useful in the management of patients with pelvic floor disease [14, 18-26, 36-38].

For this reason, computer developments such as the one we present are a good tool for medical teaching, either in the university environment or in the performance of a specific specialty such as Gynecology. Our computer development emphasizes and focuses on an area of special anatomical and functional complexity such as the pelvis and the female pelvic floor. We present MRI and ultrasound images with their joint assessment, allowing the user to correlate both images and the anatomical information that is provided. The MRI provided by our computer development allow an assessment of the three axes of the space, of any anatomical structure of the pelvis and of the female pelvic floor and its correlation with the ultrasound image obtained from different routes of exploration (abdominal, transvaginal, transintroital, transperineal, endoanal) and with different probes. The user interface of our computer program is simple and intuitive and allows the user to focus on a specific pelvic structure, its information and its location in different planes of space and through different imaging techniques. All this means that we consider our computer development as a good teaching tool that can be useful for the diagnosis and treatment of pelvic floor pathology $[30,32]$.

\section{ACKNOWLEDGEMENT}

This research work has been completed within the Ph.D program in Education in the Knowledge Society of the University of Salamanca, Spain [39-40]

\section{REFERENCES}

[1] Robert B. Trelease. 2016. From chalkboard, slides, and paper to e-learning: How computing technologies have transformed anatomical science education. Anat. Sci. Educ. 9, 6 (November 2016), 583-602. DOI

] Roberto D. Tabernero Rico, Juan A. Juanes Méndez, and Alberto Prats Galino 2017. New Generation of Three-Dimensional Tools to Learn Anatomy. 7. Med Syst. 41, 5 (May 2017), 88. DOI: https://doi.org/10.1007/s10916-017-0725-4

[3] Dong Sun Shin, Hae Gwon Jang, Sung Bae Hwang, Dong-Hwan Har, Youn Lae Moon, and Min Suk Chung. 2013. Two-dimensional sectioned images and three-dimensional surface models for learning the anatomy of the female pelvis Anat. Sel. Educ. 6, 5 (September 2013), 316-323. DOI

[4] Manuel Rubio, José Carretero, Ricardo Vázquez, José Manuel Riesco, Juan Antonio Juanes and Rnrique Blanco. 2007. Educational strategies applied to the teaching of anatomy. The evolution of resources. Eur J Anat 11, 1 (2007), 31

[5] Sanjib Kurnar Ghosh. 2015. Evolution of illustrations in anatomy: A study from the classical period in Europe to modern times. Anat. Sai. Educ. 8, 2 (March 2015), 175-188. DOI: https://doi.org/10.1002/ase.1479

[6] Mohamed Estai and Stuart Bunt. 2016. Best teaching practices in anatomy education: A critical review. Ann. Anat. - Anat. Anzeiger 208 (November 2016) 151-157. DO1: hitps://doi.org/10.1016/.anas.2016.02.010

[7] Sandra Berney, Mireille Bétrancourt, Gaëlle Molinari, and Nady Hoyek, 2015. How spatial abilities and dynamic visualizations interplay when learnin functional anatomy with anatomical models. Anat. Sci. Educ. 8, 5 (September 2015), 452-462. DOI: https://doi.org/10.1002/ase.1524

[8] Yun Peng, Rose Khavari, Nissrine A. Nakib, Timothy B. Boone, and Yingchun Zhang. 2016. Assessment of urethral support using MRI-derived computatione modeling of the female pelvis. Int. Urogynecol. $f .27,2$ 212. DOI: https://doi.org/10.1007/s00192-015-2804-8.

[9] Andrea Giannini, Veronica Iodice, Eugenia Picano, Eleonora Russo, Virna Zampa, Vincenzo Ferrari, and Tommaso Simoncini. 2017. Magnetic Resonance Imaging-Based Three Dimensional Patient-Specific Reconstruction of Uterin Fibromatosis: Impact on Surgery. F. Gynecol. Surg. 33, 4 (August 2017), 138144. DOI: https://doi.org/10.1089/gyn.2016.0119.

[10] Laura García del Salto, Jaime de Miguel Criado, Luis Felipe Aguilera del Hoyo, Leticia Gutiérrez Velasco, Patricia Fraga Rivas, Marcos Manzano Paradele, Maria Isabet Díez Pérez de las Vacas, Ana Gloria Marco Sanz, and Eduardo Fraile Moreno. 2014. MR Imaging-based Assesament of the Female Pelvic Floor. RadioGraphics 34, 5 (September 2014), 1417-1439. DO

[11] Grazia T. Bitti, Giovanni M. Argiolas, Nicola Ballicu, Elisabetta Caddeo, Martina Cecconi, Giovanna Demurtas, Gildo Matta, M. Teresa Peltz, Simona Secci, and Paolo Siotto. 2014. Pelvic Floor Failure: MR Imaging Evaluation of Anatomic and Functional Abnoralites. Radichaphics 34 429-448. DOI: https://doi.org/10.1148/rg.342125050.

[12] M. M. Bertrand, F. Mari, R. Mazars, S. Droupy, J. P. Beregi, and M. Prudhomme. 2014. MRI-based 3D pelvic autonomous innervation: a first step towards image-guided pelvic surgery. Eur. Radiol. 24, 8 (August 2014), 19891997. DOr: https./dol.org/10.1007/so030

[13] F. Vellucci, C. Regini, C. Barbanti and S. Luisi. 2018. Pelvic floor evaluation with transperineal ultrasound: a new approach. Minerva Ginecol. 70, 1 (2018) 
Technological development of visualization of magnetic resonance sectional images and pelvic floor ultrasonography for teaching purposes

[14] G. Rostaminia, J. Manonai, B. Leclaire, F. Omoumi, M. Marchiorlatti, L. H. Quiroz, and S. A. Shobeiri. 2014. Interrater reliability of assessing levator ani 2014), 761-766. DOI: https://doi.org/10.1007/s00192-013-2286-5.

[15] Hans Peter Dietz. 2017. Pelvic Floor Ultrasound. Clin. Obstet Gynecol. 60, 1 (March 2017), 58-81. DOI: https://doi.org/10.1097/GRF.0000000000000264.

[16] Fernando de la Portilla, Mercedes Rubio Manzanares Dorado, Verónica Pino Diaz, Jorge M. Vazquez Monchul, Carmen Palacios, José M. Diaz Pavón, José M. Sánchez Gil, and Ana María García Cabrera. 2015. Utilidad de la ecografia dinámica tridimensional en el estudio del suelo pélvico. Cirugía Española 93, 8 (October 2015), 530-535. DOI: https://doi.org/10.1016/j.ciresp.2014.11.005.

[17] Luciana P. Chamié, Duarte Miguel Ferreira Rodrigues Ribeiro, Angela H. M. Caiado, Gisele Warmbrand, and Paulo C. Serafini. 2018. Translabial US and Dynamic MR Imaging of the Pelvic Floor: Normal Anatomy and Dysfunction. RadioGraphics 38, 1 (January 2018), 287-308. hadioGraphics 1 38, 1 doiorg/10.1148/rg.2018170055.

[18] Céline D. Alt, Franziska Hampel, Peter Hallscheidt, Christof Sohn, Bettina Schlehe, and Kerstin A. Brocker. 2016. 3 T MRI-based measurements for the integrity of the female pelvic floor in 25 healthy nulliparous women. integrity of the female pelvic floor in 25 healthy nulliparous women.
Newrourol. Urodym. 35, 2 (February 2016), 218-223. DOI: heurourol. Urodym. 35,22

[19] Sindhura Alapati and Kedar Jambhekar. 2017. Dynamic Magnetic Resonance Imaging of the Pelvic Floor. Semin. Ultrasound, CT MRI 38, 3 (June 2017), 188199. DOI: https://doi.org/10.1053/j.sult.2016.11.002.

[20] Aly Youssef, Elisa Montaguti, Olimpia Sanlorenzo, Luisa Cariello, Elsayed Elbadawy Awad, Giuseppina Pacella, Tullio Ghi, Gianluigi Pilu, and Nicola Rizzo. 2015. A New Simple Technique for 3-Dimensional Sonographic Assessment of the Pelvic Floor Muscles. f. Uttrasound Med. 34, 1 January 2015), 65-72. DOI: https://doiorg/10.7863/ultra.34.1.65.

[21] Roopa Ram, Sallie S. Oliphant, Susan A. Barr, and Tartu Pandey. 2017. Imaging of Pelvic Floor Reconstruction. Semin. Ultrasound, CT MRI 38, 3 (June 2017), 200-212. DOI: https://doi.org/10.1053/j.sult.2016.11.003.

[22] Kim J. B. Notten, Kirsten B. Kluivers, Jurgen J. Fütterer, Karlijn J. Schweitzer, Jaap Stoker, Femke B. Mulder, Regina G. Beets-Tan, Roy F. A. Vliegen, Patrick M. Bossuyt, Roy F. P. M. Kruitwagen, Jan-Paul W. R Roovers, and Mirjam Weemhoff. 2014. Translabial Three-Dimensional Ultrasonography Compared With Magnetic Resonance Imaging in Detecting Levator Ani Defects. Obstet. Gynecol. 124, 6 (December 2014), 1190-1197. DOI:

[23] Sthela M. Murad-Regadas, Franciseo Sergio Pinheiro Regadas Filho, Francisco Sergio Pinheiro Regadas, Lusmar Veras Rodrigues, Jacyara de J. R. Pereira, Graviela Olivia da S. Fernandes Iris Daiana Dealcanfreitas, and Jose Jader Mendonca Filho 2014. Use of Dynamic 3-Dimensional Transyagingl and Mendoca 7 ho. 2014. Use of Dransvaginal and Related to Obstructed Defecation. Dis. Colon Rectum 57, 2 (February 2014), 228-236. DOI: https://doi.org/10.1097/DCR 0000000000000028.

[24] Mélanie Morin, Sophie Bergeron, Samir Khalifé, Marie-Hélène Mayrand, and Yitzchak M. Binik 2014. Morphometry of the Pelvic Floor Muscles in Women With and Without Provoked Vestibulodynia Using 4D Ultrasound. 7. Ser Med. 11, 3 (March 2014), 776-785. DOI: https://doi.org/10.1111/jsm.12367.

[25] Pouya Javadian, Dena O'Leary, Ghazaleh Rostaminia, Justin North, Jason Wagner, Lieschen H. Quiroz, and S. Abbas Shobeiri. 2017. How does 3D endovaginal ultrasound compare to magnetic resonance imaging in the evaluation of levator ani anatomy? Neurourol. Urodyn. 36, 2 (February 2017), 409-413. DOI: https://doi.org/10.1002/nau.22944.

[26] Lewis Chan and Vincent Tse. 2018. Pelvic floor ultrasound in the diagnosis of sling complications. World f. Urol. 36, 5 (May 2018), 753-759. DOEhttps://doi org/10.1007/s00345-018-2253-3.

[27] Marina Yiasemidou, Daniel Glassman, Faisal Mushtaq, Christos Athanasiou, Mark-Mon Williarns, David Jayne, and Danilo Miskovic. 2017. Mental practice with interactive 3D visual aids enhances surgical performance. Surg. Endosc.
TEEM 2018, October 2018, Salamanca, Spain

31, 10 (October 2017), 4111-4117. DOI: https://doi.org/10.1007/s00464-0175459-3.

[28] Sonia Pujol, Michael Baldwin, Joshua Nassiri, Ron Kikinis, and Kitt Shaffer. 2016. Using 3D Modeling Techniques to Enhance Teaching of Difficult Anatomical Concepts. Acad Radiol. 23, 4 (April 2016), 507-516. DOI https://doi.org/10.1016/j.acra.2015.12.012.

[29] Daniel Preece, Sarah B. Williams, Richard Lam, and Renate Weller. 2013. "Let's Get Physical": Advantages of a physical model over 3D computer models and textbooks in learning imaging anatomy. Anat. ScL. Educ. 6, 4 (July 2013), 216224. DOI: https://doi.org/10.1002/ase.1345.

[30] Diana Coomes Peterson and Gregory S.A. Mlynarczyk 2016. Analysis of traditional versus three-dimensional augmented curriculum on anatomical
learning outcome measures. Anat. Sci. Educ. 9, 6 (November 2016), 529-536. DOI: https://doi.org/10.1002/ase.1612.

[31] Brittany Star Hampton and Vivian W. Sung. 2010. Improving medical student knowledge of female pelvic floor dysfunction and anatomy: a randomized trial. Am. 7. Obstet. Gynecol 202, 6 (June 2010), 601.e1-601.e8. DOI: https://doi.org/10.1016/j.ajog.2009.08.038.

[32] Ginevra Salsi, Laria Cataneo, Maria Gaia Dodaro, Nicola Rizzo, Gianluigi Pilu, Mar Sanz Gascón, and Aly Youssef. 2017. Three-dimensional/four-dimensional transperineal ultrasound: clinical utility and future prospects. Int 7 . Womens. Health
https://doi.org/10.2147/JJWHLS10378

[33] Ya-Hong Xue, Shu-Oing Ding, Yi-Jiang Ding and Li-Oun Pan. 2017. Role of three-dimensional endoanal ultrasound in assessing the anal sphincter morphology of female patients with chronic proctalgia. World 7 Gastroentert 23, 21 (2017), 3900. DOI: https://doi.org/10.3748/wjg.v23.21.3900.

[34] Yinghua Xuan, Song Yue, Lijuan Sun, Yan Pei, Jingjing Wang, Li Tan, Zhaoling Lu, Liman Yang. Yuanyuan An, Yuxin Jiang, and Qingqing Wu 2017. Repeatability of Female Midurethral Measurement Using High-Frequency 3Dimensional Transvaginal Ultrasonography. F. Utinasound Med. (December 2017). DOI: https://doi.org/10.1002/jum.1447.

[35] Edyta Wlaslak, Tomasz Kluz, Jacek Kociszewski, Karolina Frachowicz, Magdalena Janowska, Wiktor Wlazilak, and Grzegorz Surkont. 2017. The analysis of repeatability and reproducibility of bladder nock mobility measurements obtained during pelvic floor sonography performed introitally measurements obtained during pelvic floor sonography performed introitally
with 2D transvaginal probe. Ginekol. Pol 88, 7 (July 2017), 360-365. DOI: https://doi.org/10.5603/GP.a2017.0068.

[36] T. F. M. Vergeldt, K J. B. Notten, J. Stoker, J. J. Fütterer, R. G. Beets-Tan, R. F. A. Vliegen, K. J. Schweitzer, F. E. M. Mulder, S. M. J. van Kuijk, J. P. W. R. Roovers, K. B. Kluivers, and M. Weemhoff. 2016. Comparison of translabial three-dimensional ultrasound with magnetic resonance imaging for measurement of levator hiatal biometry at rest. Ultrasound Obstet. Gynecol. 47, 5 (May 2016), 636-641. DOI: https://doiorg/10.1002/uog.14949.

[37] Stéphanie Thibault-Gagnon, Linda McLean, Corrie Goldfinger, Caroline Pukall, and Susan Chamberlain. 2016. Differences in the Biometry of the Levator Hiatus at Rest. During Contraction, and During Valsalva Maneuver Between Women With and Without Provoked Vestibulodynia Assessed by Transperineal Ultrasound Imaging. 7. Sex. Med. 13, 2 (February 2016), 243-252. DOI: https://doi.org/10.1016/j.jsscm.2015.12.009.

[38] G. Rostaminia, D. White, L. H. Quiroz, and S. A. Shobeiri 2014. 3D pelvic floor ultrasound findings and severity of anal incontinence. Int. Urogrnecol 7. 25, (May 2014), 623-629. DOI: https://doi,org/10.1007/s00192-013-2278-5.

[39] Garcia-Peńalvo, F. J., 2014. Formación en la sociedad del conocimiento, un programa de doctorado con un

[40] Garcia-Penialvo, F. J 2015. Engineering contributions to a Knowledge Society multicultural perspective. IFEE Revista Iberoamericana de Tecnologias del Aprendizaje (IEEE RITA) 10, 1, 17-18. http://dx.doi.org/10.1109/RTTA.2015.2391371. 


\section{Anexo 8}

Artículo publicado en la revista Journal of Medical Systems en marzo de 2019.

Título: "Aplicación informática de imágenes de ecografía y de resonancia magnética para el aprendizaje anatómico de la pelvis y del suelo pélvico femenino".

Resumen: Las aplicaciones informáticas se han incorporado como componentes valiosos en la enseñanza, especialmente gracias al avance y a la innovación de las nuevas tecnologías durante las últimas décadas. La implementación de estos desarrollos informáticos en medicina y en el campo de la enseñanza médica con diferentes utilidades ha sido una revolución. Esto se manifiesta con mayor intensidad en ciertas especialidades médicas y en diferentes áreas de la educación médica, por ejemplo, en el estudio de la anatomía humana, especialmente en partes del cuerpo humano de gran complejidad como la pelvis y el suelo pélvico de las mujeres.

Las nuevas tecnologías también son importantes en el uso, estudio e interpretación de pruebas radiológicas, incluyendo ultrasonidos y resonancia magnética. Esto implica un cambio en las técnicas de estudio y aprendizaje de los estudiantes, médicos residentes y especialistas en ginecología, radiodiagnóstico, urología y muchas otras especialidades médicas, considerando los nuevos desarrollos informáticos como una buena alternativa o complemento a los métodos de enseñanza existentes. Por esta razón, consideramos que los programas informáticos como el que presentamos en este trabajo pueden ser muy útiles en el futuro de la educación y más específicamente en la formación de especialistas en medicina.

Referencia: Asensio Romero, L., Asensio Gómez, M., Prats-Galino, A. y Juanes Méndez, J. A. (2019). Computer Application of Ultrasound and Nuclear Magnetic Resonance Images for the Anatomical Learning of the Pelvis and the Female Pelvic Floor. Journal of Medical Systems, 43 (5), 110. https://doi.org/10.1007/s10916-019$1240-6$ 


\title{
Computer Application of Ultrasound and Nuclear Magnetic Resonance Images for the Anatomical Learning of the Pelvis and the Female Pelvic Floor
}

\author{
Lourdes Asensio Romero $^{1}$ (D) Manuel Asensio Gómez ${ }^{1}$ - Alberto Prats-Galino ${ }^{2}$ - Juan Antonio Juanes Méndez ${ }^{1}$
}

Received: 8 January 2019 / Accepted: 6 March 2019

(C) Springer Science+Business Media, LLC, part of Springer Nature 2019

\begin{abstract}
Computer applications have been incorporated as valuable components in teaching, especially thanks to the advancement and innovation of new technologies during the last decades. The implementation of these computer developments in medicine and in the field of medical teaching with different utilities has been a revolution. This is manifested with greater intensity in certain medical specialties and in different areas of medical education, for example in the study of human anatomy, especially in parts of the human body of great complexity such as the pelvis and the pelvic floor of women. New technologies are also important in the use, study and interpretation of radiological tests, including ultrasound and nuclear magnetic resonance. This implies a change in the study and learning techniques of students, resident doctors and specialists in gynecology, radiodiagnosis, urology and many other medical specialties, considering new computer developments as a good alternative or complement to existing teaching methods. For this reason, we consider that computer programs like the one we present in this work can be very useful in the future of education and more specifically in the training of specialists in medicine.
\end{abstract}

Keywords Medical education $\cdot$ Computer development $\cdot$ Anatomical-radiological atlas $\cdot$ Female pelvic floor $\cdot$ Nuclear magnetic resonance $\cdot$ Ultrasound

\section{Introduction}

The advancement of new technologies has meant an important progress in medicine, especially in recent decades. The computer developments of which we can make use at present have stimulated a revolution in medical training, as well as in the

This article is part of the Topical Collection on Education \& Training

$\square$ Lourdes Asensio Romero

lourdes90.ar@gmail.com

Manuel Asensio Gómez

mago59@usal.es

Alberto Prats-Galino

aprats@ub.edu

Juan Antonio Juanes Méndez

jajm@usal.es

1 Department of Human Anatomy and Histology, School of Medicine, University of Salamanca, Salamanca, Spain

2 Department of Human Anatomy and Embryology, School of Medicine, University of Barcelona, Barcelona, Spain practice of medicine. Currently these technological advances are being incorporated in the field of medical education with the aim of improving the efficiency of this teaching, providing a more technical and modern basis that facilitates learning in different areas of medical knowledge [1-5].

Within the range of tools that we can use in medicine, we find image studies. These tests facilitate knowledge of the anatomy and diagnosis of many pathologies; therefore, it is essential in medical training a good knowledge and interpretation of these radiological procedures. Our aim has been to develop an interactive application that serves as a teaching tool, based on tutorial systems, which provides the user with ultrasound (endovaginal-transperineal-endoanal) images and magnetic resonance imaging (MRI) in order to guide them in their learning. In our work we have focused on a complex anatomical area such as the pelvis and the pelvic floor of women, contributing to the study of this area with a true anatomo-radiological atlas. [6-15].

The pelvic floor is the supporting structure of the organs of the pelvis. It is composed of muscle groups and connective structures (fascias and ligaments). Three compartments are established from the anatomo-functional point of view: 
Fig. 1 Toolbar of small icons in the left area of the screen

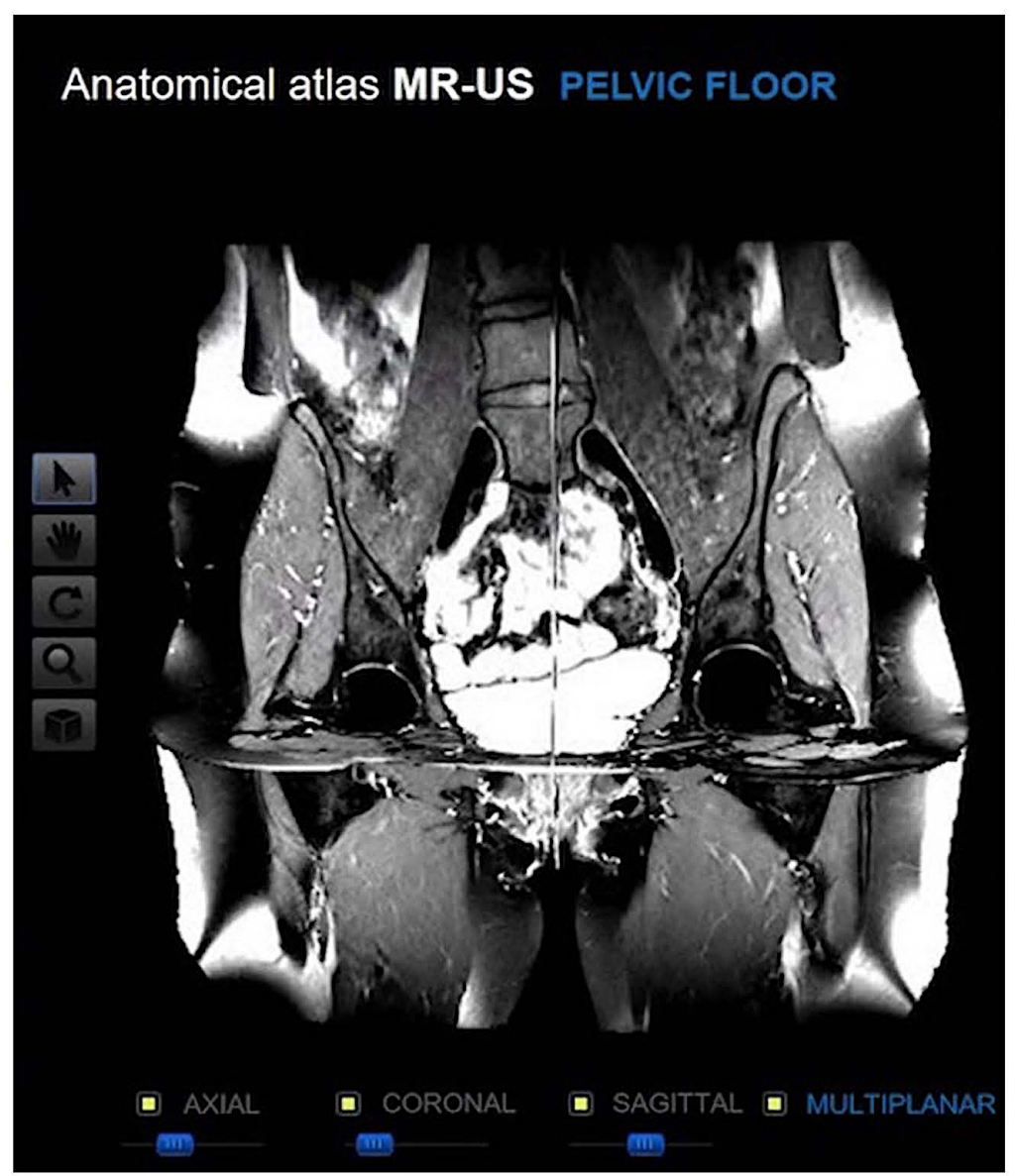

anterior, middle or central and posterior. Complementary tests such as conventional radiology with contrast, nuclear magnetic resonance (NMR) and ultrasound are used to diagnose many pathologies of this anatomical area [16-26].

Our purpose is to provide medical students and resident doctors with a tool to expand their knowledge in anatomy and in the interpretation of radiological images, through the use of interactive computer applications. This form of learning through technological resources, such as the one we present, is considered a good alternative or complement to the teaching resources currently used [25-30].

\section{Methodology}

\section{Acquisition and processing of radiological images}

All images were obtained from a 29-year-old volunteer woman with no known history of gynaecological pathology.

\section{Nuclear magnetic resonance}

We used high resolution images, enhanced in different sequences (T1, T2 and proton density) in the three planes of space (axial, coronal and sagittal) for the overall anatomical study of the abdomen and pelvis. However, we only included high resolution images of the pelvis, spaced $0.5 \mathrm{~mm}$ and improved in proton density (DP) for our computer development. We use a 1.5 Tesla unit (Magnetine Healthineers, Siemens) to obtain images of the three planes of space.

The acquisition protocol consisted of sequences in two dimensions (2D) of the abdomino-pelvic region with the following parameters common to the three orientations: repetition time $=3220$; echo time $=14$; thickness of cut of $3 \mathrm{~mm}$; matrix $=512 \times 512$; turning angle $=150^{\circ}$. The specific acquisition parameters for each orientation were for axial and sagittal planes: space between cuts $=3.6 \mathrm{~mm}$ and pixel space $=0.547 \mathrm{~mm} \times 0.547 \mathrm{~mm}$. For coronal plane: space between cuts $=4.8 \mathrm{~mm}$ and space between pixels $=$ $0.586 \mathrm{~mm} \times 0.586 \mathrm{~mm}$. 


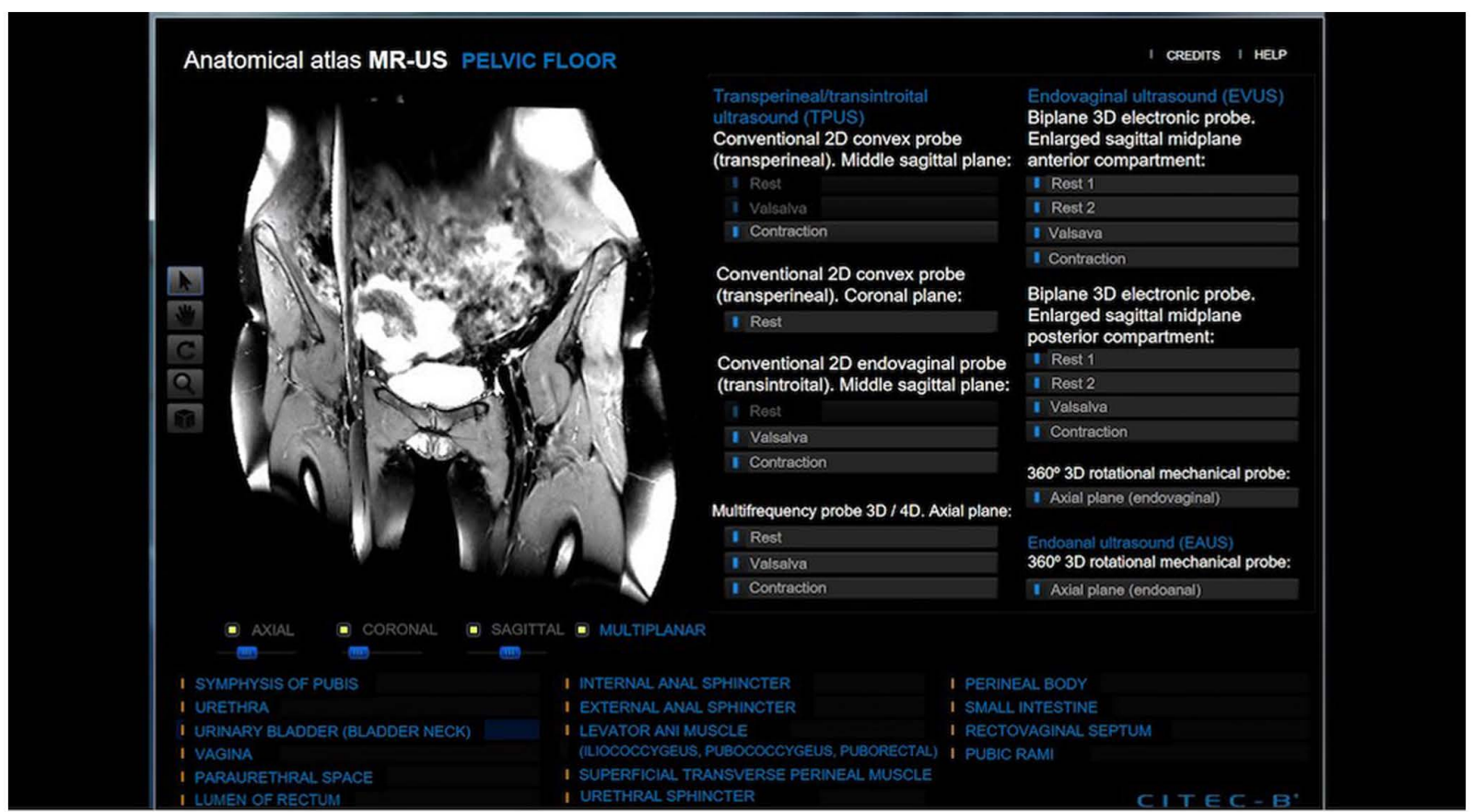

Fig. 2 Screen of the anatomo-radiological viewer of the pelvic floor. On the left side MRI with a list of main anatomical structures in the lower area; on the right side the ultrasound vision options are displayed

\section{Ultrasound}

Two ultrasound scanners (Siemens Acuson Antares and Voluson E6) were used to acquire the images of the pelvis and the pelvic floor, with different image modes [B-mode, M-mode, color Doppler, intensity Doppler, pulsed Doppler (PW), continuous Doppler (CW), and three / four dimensions (3D / 4D)].

These ultrasound devices allow the acquisition of anatomical and volumetric images from any plane, with advanced volume contrast and differentiation of structures with great precision. All this thanks to the technical specifications of both devices and the chance to use different types of probes: convex probe CH6-2 [2-6 MHz], endovaginal probe EV9F4 [4-9 MHz], intracavitary probe IC5-9-D [4-9 MHz] and convex probe 3D / 4D RAB4- 8-D [2-8 MHz].

The exploration routes used were vaginal, transintroital, rectal or endoanal and transperineal. It was necessary to place the patient in a position of dorsal lithotomy with the hips flexed, in light abduction and with the heels close to the buttocks to capture the images (at rest, contraction and with Valsalva maneuver) through the different routes of exploration.

\section{Installation and minimum system requirements}

Our computer program is prepared for self-execution.
The minimum computer equipment requirements are a 32 MB memory card that supports DirectX 8.0 in window mode, a Pentium III $450 \mathrm{MHz}$ processor; $128 \mathrm{MB}$ of RAM and $40 \mathrm{MB}$ of free memory on the hard drive. It is recommended that the computer have a $3 \mathrm{D}$ acceleration card that supports DirectX 9.0 in window mode such as NVidia's GeForce range or the ATI Radeon range.

The programming has been made in visual $\mathrm{C}$, including ActiveX controls, designed to optimize the graphic acceleration capabilities of current equipment.

\section{Results}

Generally the computer programs for teaching are formed by three modules: the module that manages the communication with the user, the module that contains the information of the program and the module that manages the actions of the computer and its answers to the actions of the users.

The interface is the element through which the communication between the users and the computer program is established.

An interface easy to understand and use, like the one we present in our computer program for the visualization and interaction with the anatomical structures of the female pelvis, through images of complementary tests such as NMR and ultrasound, allows users (students or resident doctors) improve and speed up their learning. 
Fig. 3 MRI with anatomical structure identified in the image with green color

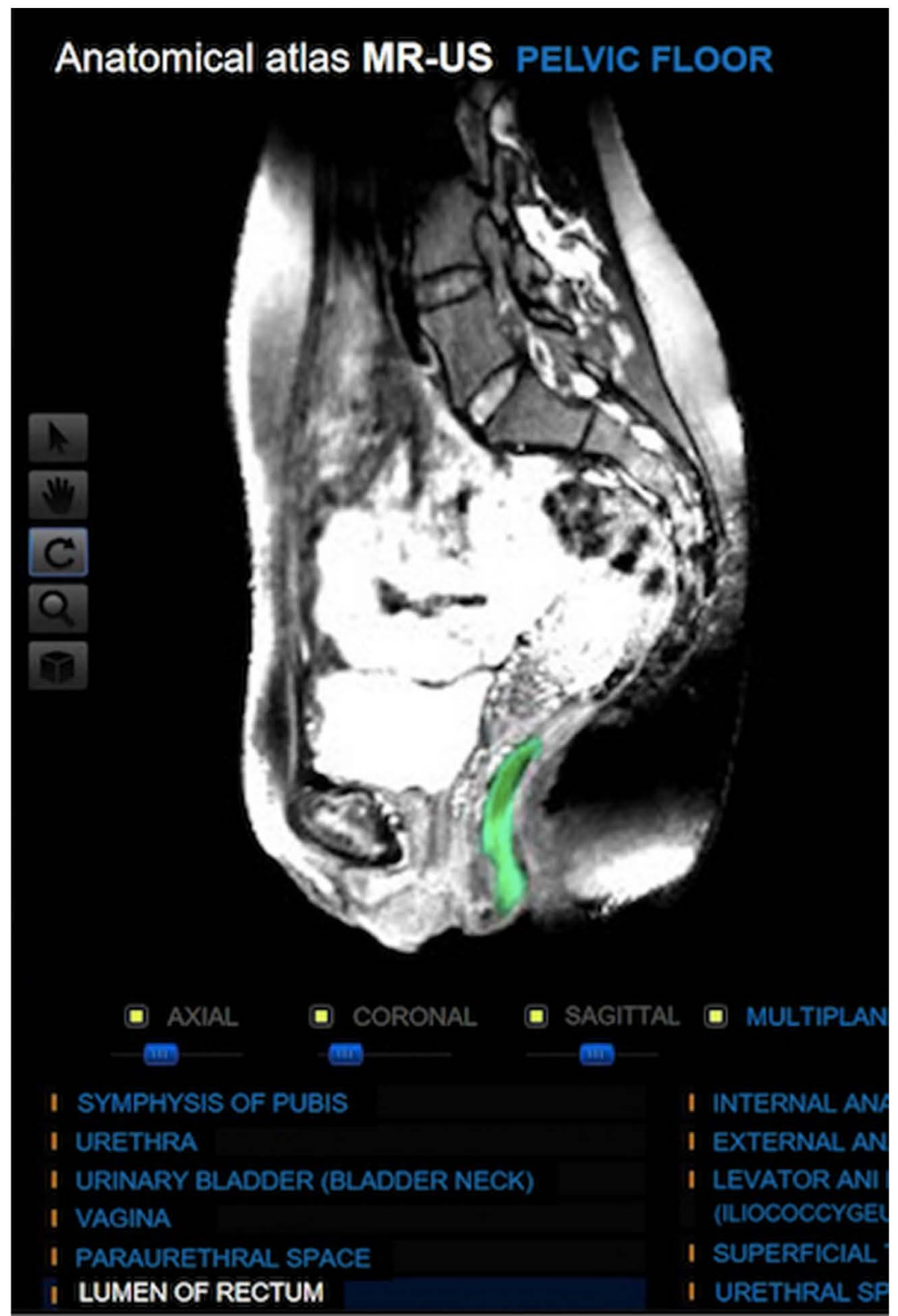

The options to handle the images are available in a toolbar with small icons (Fig. 1), which include a zoom, mobilization of the image, add or remove one of the planes of the space, and others options.

Our computer application allows the user to navigate freely through the MRI and ultrasound images. We can analyze from any angle and in the three planes of space (axial, coronal and sagittal) the sectional images of NMR. A list of the main anatomical structures of the female pelvis is shown in the lower area of the screen, being able to select any of them to locate it in the image (Figs. 2 and 3).

The ultrasound images can be evaluated one after the other, simulating movement and placement de cursor over the structure shown it can be identified (Figs. 4 and 5). Our computer development allows the simultaneous display of MRI and ultrasound images, facilitating radiological correlation (Fig. 6).

\section{Discussion}

The technological and computer resources have been incorporated into our daily lives, innovating and facilitating many aspects of it. In the field of education there is a constant desire to incorporate technological advances, in order to implement student learning and provide teaching resources [1, 2, 27, 29]. 
Fig. 4 Ultrasound image with the identification of bladder when the cursor is over it

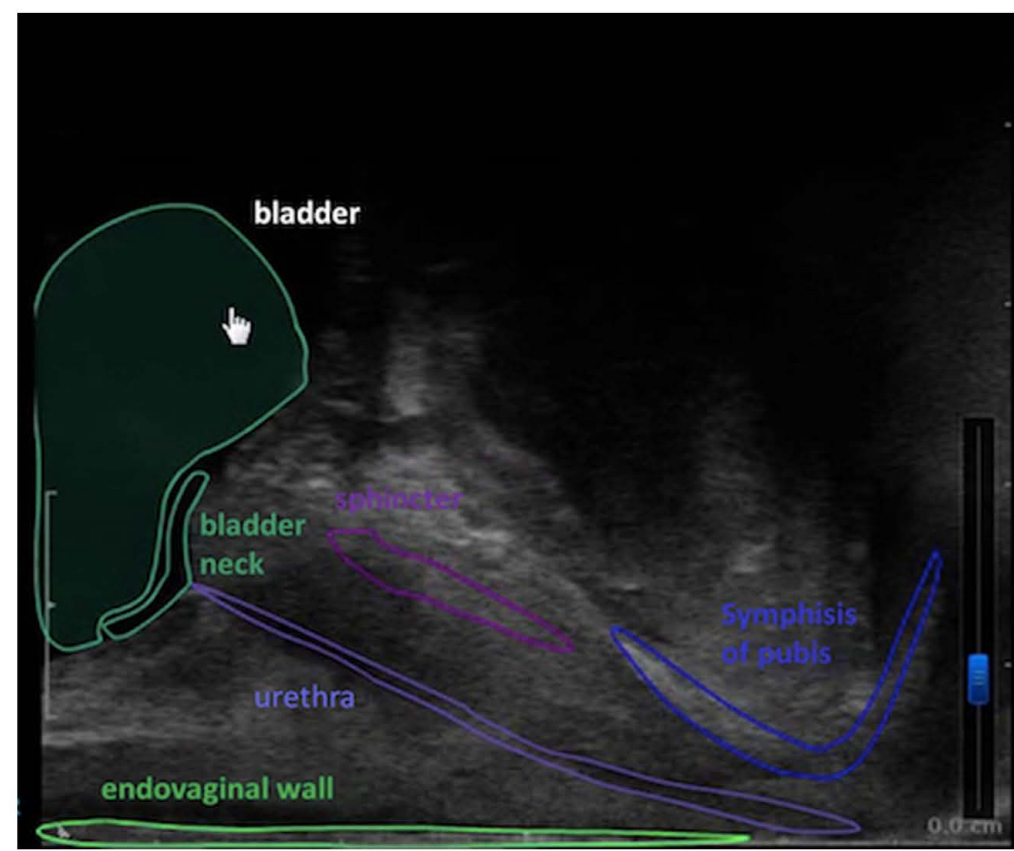

The use of computer programs is especially advantageous in the teaching of human anatomy and in the interpretation of radiological diagnostic tests, consisting of the anatomical visualization of each patient.
Imaging studies help in the knowledge of the anatomy and the diagnosis of different pathologies that affect the pelvis. These techniques have evolved over time, improving their diagnostic accuracy and serving as essential

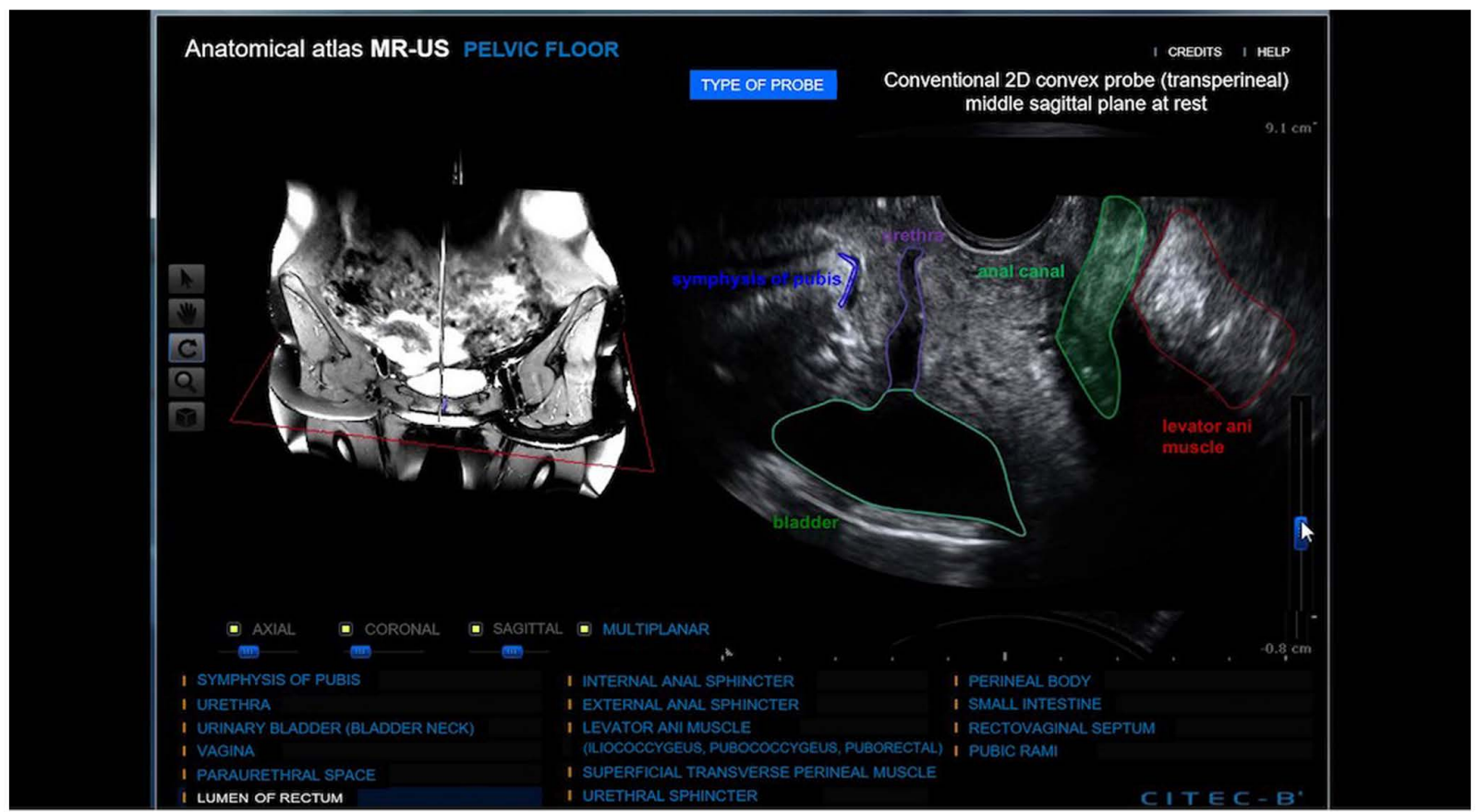

Fig. 5 Screen of the anatomo-radiological viewer. The ultrasound image on the right shows the identification of the anatomical structures that can be recognized 

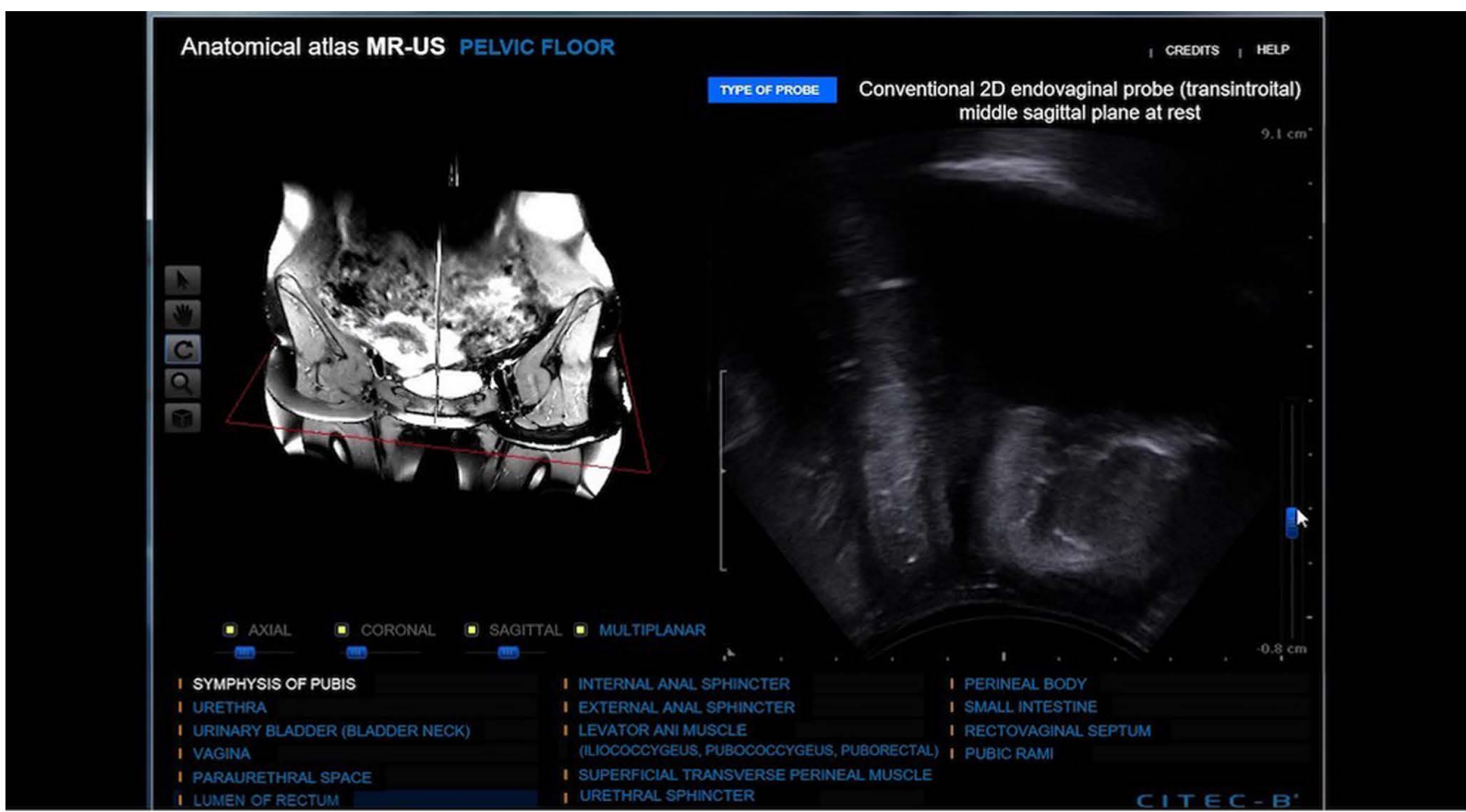

Fig. 6 Images of NMR and ultrasound are shown simultaneously

decision elements to support a therapeutic plan [6-11, 13-15, 31-33].

Physical examination is an important pillar of the assessment of anatomical lesions and alterations of pelvic static in the field of Urogynecology. Due to the anatomical complexity of the pelvis, the necessary precision in the location of the lesion, the importance of the existence of an adjacent anatomical lesion and the possibility of need surgical treatment it is necessary to use the images obtained from NMR and ultrasound for the diagnosis and treatment of some pathology processes [12, 16-26, 34-37].

For this reason, we consider that our computer development can be used as an important tool for medical education in the university or practicing a medical specialty such as gynecology. We have focused on an area of special anatomical and functional complexity such as the pelvis and the pelvic floor of women. We present images of ultrasound and NMR, with the possibility of assessing them together, making it possible for the user to relate the images and the anatomical information of each structure. The MRI of our computer program allows the visualization of the anatomical structures of the pelvis and the pelvic floor in the three planes of space. The user's interface of our computer development enables a simple and intuitive communication between user and program, permitting to focus on a specific pelvic structure, its information and its visualization using different imaging techniques. For all the reasons explained above, we consider our computer development as a good teaching tool that can be useful for the diagnosis and treatment of pelvic floor pathology $[29,31]$.

\section{Compliance with ethical standards}

Conflict of interest L. Asensio Romero declares that she has no conflict of interest. M. Asensio Gómez declares that he has no conflict of interest. A. Prats-Galino declares that he has no conflict of interest. J. A. Juanes Méndez declares that he has no conflict of interest.

Ethical approval All procedures performed in studies involving human participants were in accordance with the ethical standards of the institutional and/or national research committee and with the 1964 Helsinki declaration and its later amendments or comparable ethical standards. This article does not contain any studies with animals performed by any of the authors.

Informed consent Informed consent was obtained from all individual participants included in the study.

\section{References}

1. Trelease, R. B., From chalkboard, slides, and paper to e-learning: How computing technologies have transformed anatomical sciences education. Anat. Sci. Educ. 9(6):583-602, 2016. https://doi. org/10.1002/ase. 1620 .

2. Tabernero Rico, R. D., Juanes Méndez, J. A., and Prats Galino, A., New Generation of Three-Dimensional Tools to Learn Anatomy. J.

\section{$\underline{\text { Springer }}$}


Med. Syst. 41(5):88, 2017. https://doi.org/10.1007/s10916-017$0725-4$.

3. Ghosh, S. K., Evolution of illustrations in anatomy: A study from the classical period in Europe to modern times. Anat. Sci. Educ. 8(2):175-188, 2015. https://doi.org/10.1002/ase.1479.

4. Estai, M., and Bunt, S., Best teaching practices in anatomy education: A critical review. Ann. Anat. - Anat. Anzeiger 208:151-157, 2016. https://doi.org/10.1016/j.aanat.2016.02.010.

5. Berney, S., Bétrancourt, M., Molinari, G., and Hoyek, N., How spatial abilities and dynamic visualizations interplay when learning functional anatomy with $3 \mathrm{D}$ anatomical models. Anat. Sci. Educ. 8(5):452-462, 2015. https://doi.org/10.1002/ase.1524.

6. Peng, Y., Khavari, R., Nakib, N. A., Boone, T. B., and Zhang, Y., Assessment of urethral support using MRI-derived computational modeling of the female pelvis. Int. Urogynecol. J. 27(2):205-212, 2016. https://doi.org/10.1007/s00192-015-2804-8.

7. Giannini, A., Iodice, V., Picano, E., Russo, E., Zampa, V., Ferrari, $\mathrm{V}$., and Simoncini, T., Magnetic Resonance Imaging-Based Three Dimensional Patient-Specific Reconstruction of Uterine Fibromatosis: Impact on Surgery. J. Gynecol. Surg. 33(4):138144, 2017. https://doi.org/10.1089/gyn.2016.0119.

8. García del Salto, L., Miguel Criado, J., Aguilera del Hoyo, L. F., Gutiérrez Velasco, L., Fraga Rivas, L., Manzano Paradela, M., Díez Pérez de las Vacas, M. I., Marco Sanz, A. G., and Fraile Moreno, E., MR Imaging-based Assessment of the Female Pelvic Floor. RadioGraphics 34(5):1417-1439, 2014. https://doi.org/10.1148/ $\operatorname{rg} .345140137$.

9. Bitti, G. T., Argiolas, G. M., Ballicu, N., Caddeo, E., Cecconi, M., Demurtas, G., Matta, G., Peltz, M. T., Secci, S., and Siotto, P., Pelvic Floor Failure: MR Imaging Evaluation of Anatomic and Functional Abnormalities. RadioGraphics 34(2):429-448, 2014. https://doi.org/10.1148/rg.342125050

10. Bertrand, M. M., Macri, F., Mazars, R., Droupy, S., Beregi, J. P., and Prudhomme, M., MRI-based 3D pelvic autonomous innervation: a first step towards image-guided pelvic surgery. Eur. Radiol. 24(8):1989-1997, 2014. https://doi.org/10.1007/s00330-014-32110.

11. Vellucci, F., Regini, C., Barbanti, C., and Luisi, S., Pelvic floor evaluation with transperineal ultrasound: a new approach. Minerva Ginecol. 70(1):58-68, 2018. https://doi.org/10.23736/ S0026-4784.17.04121-1.

12. Rostaminia, G., Manonai, J., Leclaire, E., Omoumi, F., Marchiorlatti, M., Quiroz, L. H., and Shobeiri, S. A., Interrater reliability of assessing levator ani deficiency with $360^{\circ} 3 \mathrm{D}$ endovaginal ultrasound. Int. Urogynecol. J. 25(6):761-766, 2014. https://doi.org/10.1007/s00192-013-2286-5.

13. Dietz, H. P., Pelvic Floor Ultrasound. Clin. Obstet. Gynecol. 60(1): 58-81, 2017. https://doi.org/10.1097/GRF.0000000000000264.

14. Portilla, F., Rubio Manzanares Dorado, M., Pino Díaz, V., Vazquez Monchul, J. M., Palacios, C., Díaz Pavón, J. M., Sánchez Gil, J. M., and García Cabrera, A. M., Utilidad de la ecografia dinámica tridimensional en el estudio del suelo pélvico. Cirugía Española 93(8): 530-535, 2015. https://doi.org/10.1016/j.ciresp.2014.11.005.

15. Chamié, L. P., Ferreira Rodrigues Ribeiro, D. M., Caiado, A. H. M., Warmbrand, G., and Serafini, P. C., Translabial US and Dynamic MR Imaging of the Pelvic Floor: Normal Anatomy and Dysfunction. RadioGraphics 38(1):287-308, 2018. https://doi.org/ $10.1148 / \mathrm{rg} .2018170055$

16. Alt, C. D., Hampel, F., Hallscheidt, P., Sohn, C., Schlehe, B., and Brocker, K. A., 3 T MRI-based measurements for the integrity of the female pelvic floor in 25 healthy nulliparous women. Neurourol. Urodyn. 35(2):218-223, 2016. https://doi.org/10.1002/ nau. 22697.

17. Alapati, S., and Jambhekar, K., Dynamic Magnetic Resonance Imaging of the Pelvic Floor. Semin. Ultrasound, CT MRI 38(3): 188-199, 2017. https://doi.org/10.1053/j.sult.2016.11.002.
18. Youssef, A., Montaguti, E., Sanlorenzo, O., Cariello, L., Awad, E. E., Pacella, G., Ghi, T., Pilu, G., and Rizzo, N., A New Simple Technique for 3-Dimensional Sonographic Assessment of the Pelvic Floor Muscles. J. Ultrasound Med. 34(1):65-72, 2015. https://doi.org/10.7863/ultra.34.1.65.

19. Ram, R., Oliphant, S. S., Barr, S. A., and Pandey, T., Imaging of Pelvic Floor Reconstruction. Semin. Ultrasound, CT MRI 38(3): 200-212, 2017. https://doi.org/10.1053/j.sult.2016.11.003.

20. Notten, K. J. B., Kluivers, K. B., Fütterer, J. J., Schweitzer, K. J., Stoker, J., Mulder, F. E., Beets-Tan, R. G., Vliegen, R. F. A., Bossuyt, P. M., Kruitwagen, R. F. P. M., Roovers, J. P. W. R., and Weemhoff, M., Translabial Three-Dimensional Ultrasonography Compared With Magnetic Resonance Imaging in Detecting Levator Ani Defects. Obstet. Gynecol. 124(6):1190-1197, 2014. https://doi.org/10.1097/AOG.0000000000000560.

21. Graupera B, Pascual MÀ, Hereter L, Pedrero C (2018) Role of 3D Ultrasound in the Evaluation of Uterine Anomalies. In: Tinelli A, Pacheco LA, Haimovich S (eds) Hysteroscopy. Springer, Cham, pp 69-82. https://doi.org/10.1007/978-3-319-57559-9 \&

22. Kim, K. Y., Cheng, J. W., Shen, J. K., Wagner, H., and Staack, A., Translabial Ultrasound Evaluation of Pelvic Floor Structures and Mesh in the Urology Office and Intraoperative Setting. Urology 120:267, 2018. https://doi.org/10.1016/j.urology.2018.07.004

23. Murad-Regadas, S. M., Pinheiro Regadas, F. S., Veras Rodrigues, L., Pereira, J. J. R., Fernandes, G. O. S., Dealcanfreitas, I. D., and Mendonca Filho, J. J., Use of Dynamic 3-Dimensional Transvaginal and Transrectal Ultrasonography to Assess Posterior Pelvic Floor Dysfunction Related to Obstructed Defecation. Dis. Colon Rectum 57(2):228-236, 2014. https://doi.org/10.1097/ DCR. 0000000000000028

24. Morin, M., Bergeron, S., Khalifé, S., Mayrand, M. H., and Binik, Y. M., Morphometry of the Pelvic Floor Muscles in Women With and Without Provoked Vestibulodynia Using 4D Ultrasound. J. Sex. Med. 11(3):776-785, 2014. https $/ /$ doi.org/10.1111/jsm. 12367.

25. Javadian, P., O'Leary, D., Rostaminia, G., North, J., Wagner, J., Quiroz, L. H., and Shobeiri, S. A., How does 3D endovaginal ultrasound compare to magnetic resonance imaging in the evaluation of levator ani anatomy? Neurourol. Urodyn. 36(2):409-413, 2017. https://doi.org/10.1002/nau.22944.

26. Chan, L., and Tse, V., Pelvic floor ultrasound in the diagnosis of sling complications. World J. Urol. 36(5):753-759, 2018. https:// doi.org/10.1007/s00345-018-2253-3.

27. Yiasemidou, M., Glassman, D., Mushtaq, F., Athanasiou, C., Williams, M. M., Jayne, D., and Miskovic, D., Mental practice with interactive 3D visual aids enhances surgical performance. Surg. Endosc. 31(10):4111-4117, 2017. https://doi.org/10.1007/s00464017-5459-3.

28. Pujol, S., Baldwin, M., Nassiri, J., Kikinis, R., and Shaffer, K., Using 3D Modeling Techniques to Enhance Teaching of Difficult Anatomical Concepts. Acad. Radiol. 23(4):507-516, 2016. https:// doi.org/10.1016/j.acra.2015.12.012.

29. Coomes Peterson, D., and Mlynarczyk, G. S. A., Analysis of traditional versus three-dimensional augmented curriculum on anatomical learning outcome measures. Anat. Sci. Educ. 9(6):529-536, 2016. https://doi.org/10.1002/ase.1612.

30. Salsi, G., Cataneo, I., Gaia Dodaro, M., Rizzo, N., Pilu, G., Sanz Gascón, M., and Youssef, A., Three-dimensional/four-dimensional transperineal ultrasound: clinical utility and future prospects. Int. J. Women's Health 9:643-656, 2017. https://doi.org/10.2147/IJWH. S103789.

31. Xue, Y. H., Ding, S. Q., Ding, Y. J., and Pan, L. Q., Role of threedimensional endoanal ultrasound in assessing the anal sphincter morphology of female patients with chronic proctalgia. World J. Gastroenterol. 23(21):3900, 2017. https://doi.org/10.3748/wjg. v23.i21.3900. 
32. Xuan, Y., Yue, S., Sun, L., Pei, Y., Wang, J., Tan, L., Lu, Z., Yang, L., An, Y., Jiang, Y., and Wu, Q., Repeatability of Female Midurethral Measurement Using High-Frequency 3-Dimensional Transvaginal Ultrasonography. J. Ultrasound Med., 2017. https:// doi.org/10.1002/jum.1447.

33. Wlaźlak, E., Kluz, T., Kociszewski, J., Frachowicz, K., Janowska, M., Wlaźlak, W., and Surkont, G., The analysis of repeatability and reproducibility of bladder neck mobility measurements obtained during pelvic floor sonography performed introitally with $2 \mathrm{D}$ transvaginal probe. Ginekol. Pol. 88(7):360-365, 2017. https:// doi.org/10.5603/GP.a2017.0068.

34. Vergeldt, T. F. M., Notten, K. J. B., Stoker, J., Fütterer, J. J., BeetsTan, R. G., Vliegen, R. F. A., Schweitzer, K. J., Mulder, F. E. M., van Kuijk, S. M. J., Roovers, J. P. W. R., Kluivers, K. B., and Weemhoff, M., Comparison of translabial three-dimensional ultrasound with magnetic resonance imaging for measurement of levator hiatal biometry at rest. Ultrasound Obstet. Gynecol. 47(5):636-641, 2016. https://doi.org/10.1002/uog.14949.

35. Thibault-Gagnon, S., McLean, L., Goldfinger, C., Pukall, C., and Chamberlain, S., Differences in the Biometry of the Levator Hiatus at Rest, During Contraction, and During Valsalva Maneuver Between Women With and Without Provoked Vestibulodynia Assessed by Transperineal Ultrasound Imaging. J. Sex. Med. 13(2):243-252, 2016. https://doi.org/10.1016/j.jsxm.2015.12.009.

36. Rostaminia, G., White, D., Quiroz, L. H., and Shobeiri, S. A., 3D pelvic floor ultrasound findings and severity of anal incontinence. Int. Urogynecol. J. 25(5):623-629, 2014. https://doi.org/10.1007/ s00192-013-2278-5.

37. Kaniewska, M., Gołofit, P., Heubner, M., Maake, C., and KubikHuch, R. A., Suspensory Ligaments of the Female Genital Organs: MRI Evaluation with Intraoperative Correlation. RadioGraphics. 38(7):2195-2211, 2018. https://doi.org/10.1148/rg.2018180089.

Publisher's Note Springer Nature remains neutral with regard to jurisdictional claims in published maps and institutional affiliations. 


\section{Anexo 9}

Trabajo presentado en el congreso TEEM 19 (Seventh Edition International Conference Technological Ecosystems for Enhancing Multiculturality 2019), que tuvo lugar en León, los días 16-18 de octubre de 2019. Posteriormente fue publicado en ACM library.

Título del trabajo: "Reconstrucción 3D de la musculatura perineal femenina, a partir de secciones de resonancia magnética. Desarrollo informático interactivo".

Resumen: Se presenta un desarrollo informático que permite visualizar e interactuar, en un entorno virtual, con la musculatura de la pelvis femenina, reconstruida a partir de secciones seriadas de resonancia magnética de alta resolución. Las posibilidades de representar tridimensionalmente estas estructuras en cualquier orientación espacial, junto con imágenes radiológicas seccionales en los tres planos del espacio (axial, coronal y sagital), facilitan la comprensión e identificación anatómica del conjunto de los elementos óseos y musculares de esta región. Con una interfaz gráfica muy intuitiva, nuestro procedimiento permite la observación de elementos musculares en tres dimensiones, y su inserción en los huesos de la pelvis, teniendo siempre como patrón de referencia los cortes de resonancia magnética.

Esta aplicación informática representa una importante herramienta para la formación de especialistas en ginecología, y como paso previo en la planificación de intervenciones quirúrgicas del suelo pélvico.

Referencia: Asensio Romero, L., Asensio Gómez, M., Prats-Galino, A. y Juanes Méndez, J. A. (2019). 3D Reconstruction of the Female Perineal Musculature, from Sections of Magnetic Resonance. En Proceedings of the Seventh International Conference on Technological Ecosystems for Enhancing Multiculturality (pp. 380385). New York, NY, USA: ACM. https://doi.org/10.1145/3362789.3362829 


\section{D Reconstruction of the Female Perineal Musculature, from Sections of Magnetic Resonance.}

Interactive computer development.

\author{
Lourdes Asensio Romero \\ School of Medicine. University of \\ Salamanca. \\ lourdes90.ar@gmail.com
}

\author{
Manuel Asensio Gómez \\ School of Medicine. University of \\ Salamanca. \\ mago59@usal.es \\ Juan A. Juanes Méndez \\ School of Medicine. University of \\ Salamanca. \\ jajm@usal.es
}

\begin{abstract}
A computer development that allows to visualize and interact with the musculature of the female pelvis reconstructed from serial sections of high resolution magnetic resonance in a virtual environment is presented.
\end{abstract}

The possibilities of representing these structures threedimensionally in any spatial orientation, together with sectional radiological images, in the three planes of space (axial, coronal and sagittal), facilitate the understanding and anatomical identification of the whole of the bony and muscular elements of this region.

Our procedure, thanks to a very intuitive graphic interface, allows the observation of the muscular elements in three dimensions and their insertion in the bones of the pelvis, always taking as a reference pattern the magnetic resonance cuts.

This computer application represents an important tool for the training of specialists in gynecology, as well as a preliminary step in the planning of surgical interventions of the pelvic floor.

\section{CCS CONCEPTS}

- Human-centered computing; - Computing education $\rightarrow$ information technology education.

Permission to make digital or hard copies of all or part of this work for personal or classroom use is granted without fee provided that copies are not made or distributed for profit or commercial advantage and that copies bear this notice and the full citation on the first page. Copyrights for components of this work owned by others than ACM must be honored Abstracting with credit is permitted. To copy otherwise, or republish, to post on servers or to redistribute to lists, requires prior specific permission and/or a fee. Request permissions from Permissions@acm.or:

TBEM'19, October 16-18, 2019, León, Spain

2019 Association for Computing Machinery.

ACM ISBN 978-1-4503-7191-9/19/10..\$15.00

https://doi.org/10.1145/3362789.3362829

\section{KEYWORDS}

Computer development, anatomo-radiological atlas, pelvic floor muscles, radiological imaging, magnetic resonance, ultrasound.

ACM Reference format:

Lourdes Asensio Romero, Manuel Asensio Gomez, Alberto Prats-Galino, Juan A. Juanes Mendez. 2019. 3D reconstruction of the female perineal musculature, from sections of magnetic resonance: Interactive computer development In Proceedings of the Seventh International Conference on Technological Ecosystems for Enhancing Multiculturality (TEEM 2019) (León, Spain, October 16-18, 2019), ACM, New York, NY, USA, 6 pages. https://doi.org/10.1145/3362789.3362829

\section{Introduction}

The generation of images in three dimensions (3D) of the human body has undergone a great increase in recent years, having been generalized its use in different areas of medicine, with wide application for teaching purposes. The growing implementation of advanced computer applications for the visualization of 3D models of anatomical structures is facilitating a better understanding of body structures and their spatial relationships.

One of the regions of special anatomical complexity is the pelvic diaphragm, constituted by different muscles that support the pelvic viscera, which are difficult to represent and understand from schemes reproduced in two dimensions.

Magnetic resonance imaging has been an excellent resource for morphological visualization for the understanding and interpretation of complex anatomical structures, since it can obtain serial sections. Thanks to this diagnostic imaging procedure, we have been able to better understand the anatomy of the female pelvis. The high resolution of the magnetic resonance, through the use of new coils, has increased the sensitivity in the recognition of anatomical structures, which undoubtedly has facilitated the identification of anatomical elements more accurately. 
3D Reconstruction of the Female Perineal Musculature, from Sections of Magnetic Resonance: Interactive computer development

From the surgical point of view, the knowledge of the exact anatomical relationships of the visceral and parietal structures of the fernale pelvis is as essential as the diagnostic and technical skill. Without this knowledge of pelvic anatomy, surgery ceases to be a science and becomes a simple technical procedure that can be dangerous for the patient and is a constant threat to the surgeon. Therefore, anatomical knowledge should be part of the fundamental basis of every gynecological surgeon.

There are few studies that analyze in detail the radiological anatomy of the female pelvis through open applications for the representation of virtual scenes on Windows platforms of low cost.

Taking into account these previous aspects, we present a technological tool for visualization and $3 \mathrm{D}$ analysis of the female pelvic musculature, with simultaneous magnetic resonance sections in the three planes of space.

The computer application that we present allows to visualize and interact simultaneously with sectional images of the pelvis selected at intervals of $5 \mathrm{~mm}$, in the three orthogonal axes of the space, with 3D models of the bony system of the pelvis and the muscles that are inserted in these bones that make up the pelvic diaphragm.

\section{Material and methods}

\subsection{Magnetic resonance images}

Acquisition parameters: We proceeded to the acquisition of high resolution images, with a spacing of $0.5 \mathrm{~mm}$, enhanced in DP (proton density), of the pelvic region. Specifically, three orthogonal MRIs were obtained, each in a different spatial plane, using a 1.5 Tesla scanner (HarmonyExpert, Siemens) from a 29 year-old volunteer woman with no known history of gynecological pathology. The acquisition protocol was based on 2D sequences of the abdomino-pelvic region with the following parameters common to the three orientations: repetition time $=$ 3220; echo time $=14 ; 3 \mathrm{~mm}$ slice thickness; matrix $=512 \times 512$ flip angle $=150^{\circ}$. The acquisition parameters specific to each orientation were: axial and sagittal planes slice spacing $=3.6$ $\mathrm{mm}$; pixel spacing $=0.547 \mathrm{~mm} \times 0.547 \mathrm{~mm}$; coronal plane: slice spacing $=4.8 \mathrm{~mm}$; pixel spacing $=0.586 \mathrm{~mm} \times 0.586 \mathrm{~mm}$. A DP volume was reconstructed for each orientation from the raw data files DICOM, which was saved in ANALYZE 7.5 format using the free distribution software MRIcro (Nottingham, UK). In order to homogenize the dimensions between the three volumes as much as possible, they were aligned taking as reference the one acquired in the axial plane. Then they were resized by applying a Lanczos filter, resulting in an axial volume of $600 \times 560 \times 30$ slices (voxelsize $=0.5 \times 0.5 \times 3.5 \mathrm{~mm} 3$ ), a sagittal volume of $30 \times 560 \times 560$ slices (voxelsize $3.5 \times 0.5 \times 0.5 \mathrm{~mm} 3$ ) and a coronal volume of $600 \times 28 \times 560$ slices (voxelsize $0.5 \times 5.0 \times 0.5 \mathrm{~mm} 3$ ). From each of these volumes, images in PNG format were exported for representation in a $3 \mathrm{D}$ viewer (see the section on visualization and rendering). Likewise, to facilitate the modeling phase, the 3 volumes were resized, obtaining isotropic images with voxels of $1 \mathrm{~mm}$, that is, with voxels that have the same size in all dimensions.
TEEM 2019, October 2019, León, Spain

\section{$2.23 \mathrm{D}$ models}

To obtain 3D surface models, consistent geometric models delimited by polygonal meshes (triangular), the following phases have been followed:

2.2.1 Delimitation of regions of interest: Using a 3D editor (Amira, 3.1, TGS Template Graphics Software), we proceeded to delimit the regions of interest (ROIs) in the isometric volumes, also called labels, of the anatomical structures to be reconstructed. These regions include osteoarticular structures (coxal bone, bilateral, sacral-coccyx and proximal extremity of the femur, bilateral) and muscular structures (internal obturator muscle, external obturator muscle, levator ani muscle, coccygeus muscle, piriform muscle, psoas-iliac muscle).

2.2.2 Generation of 3D models: A triangular mesh model of the surface of each of these identified structures was obtained from the ROIs, and applying an algorithm known as marching cubes. Given the high resolution of the MRI, the mesh was simplified and smoothed, obtaining polygonal models that could later be edited more easily by means of specific modeling programs (3D Studio Max). For each of the reconstructed 3D models, a small file was prepared in html format with a brief anatomical description of the muscle insertion, which complements the information that the computer application wil show. All the computer procedure was finally packaged for installation on computers with Windows operating systems.

\section{Results}

The three-dimensional reconstruction of the perineal musculature that integrates the female pelvis, combined with the volumetric magnetic resonance data, constitutes a clear and intuitive form of morphological analysis, since the individual examination of the images of the different cuts that make up a sequence of magnetic resonance, allow us a simple understanding of the set of anatomical bone and muscle elements that constitute this topographic region. In this way, our computer application is a good method of $3 \mathrm{D}$ visualization, taking as a reference the magnetic resonance section in the three planes of space, which facilitates its anatomical assessment making use of the advanced graphic capabilities that today offer the computers. 


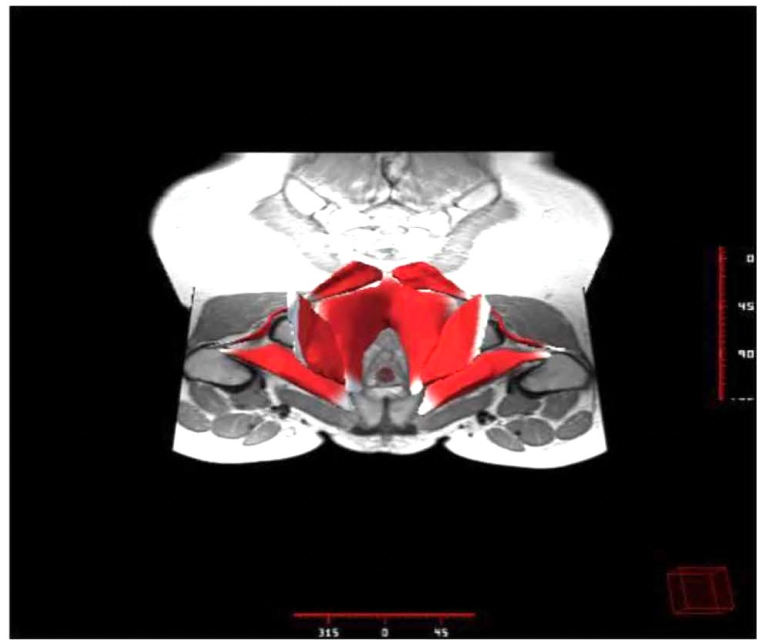

Figure 1: 3D visualization of the pelvic floor muscles.

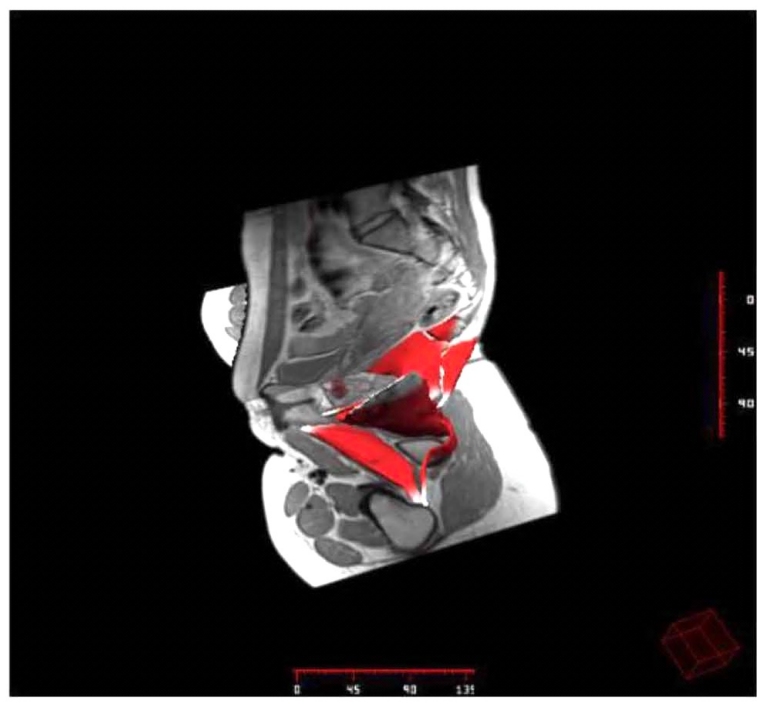

Figure 2: 3D visualization of muscular structures of the pelvis.

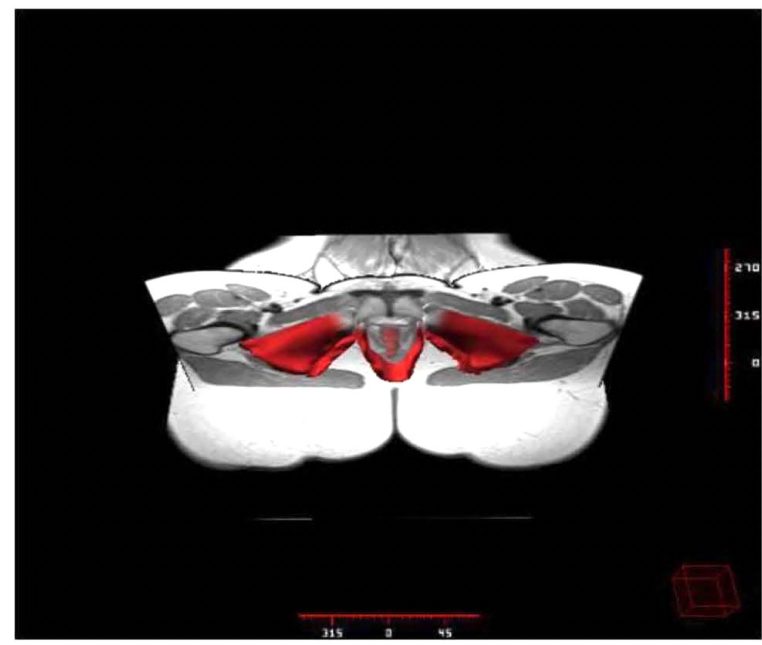

Figure 3: 3D visualization of muscular structures of the pelvis.

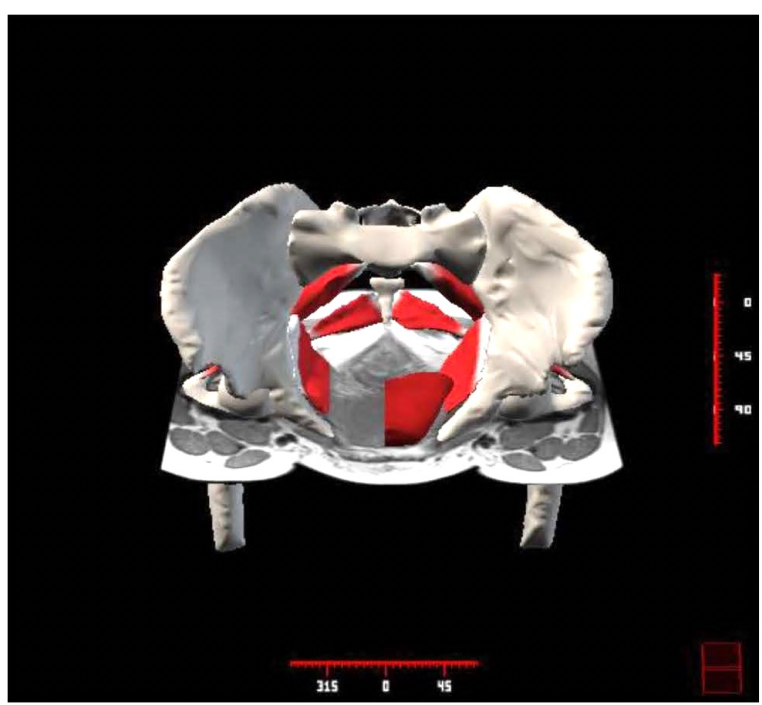

Figure 4: 3D reconstruction of the muscles of the female perineum. 
3D Reconstruction of the Female Perineal Musculature, from Sections of Magnetic Resonance: Interactive computer development.
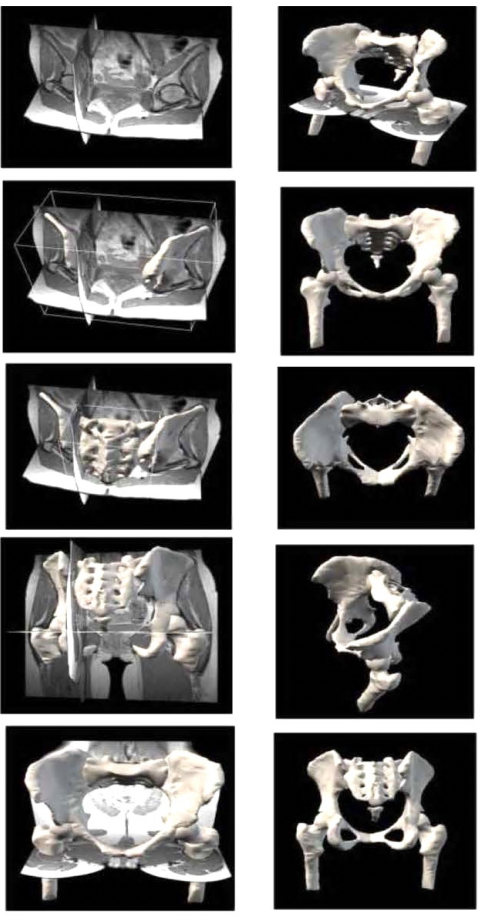

Figure 5: Three-dimensional visualization of the bony pelvis from the MR sections, correlated with the simultaneous cuts in the three planes. The bone details of the bones that make up the pelvis are perfectly appreciated.

The graphic user interface generated is very intuitive, it shows the different options of interaction with the anatomical viewer, allowing the visualization of the bone and muscle elements in three dimensions. All this at the request of the user and having as reference pattern the magnetic resonance sections in the three planes of space (coronal, axial and sagittal), being able to activate or deactivate the visualization of each one of the selected anatomical structure. In addition, each 3D model is described with a small anatomical comment.

The technological procedure developed allows the representation and interaction with two types of main visual elements: Planes and Models. You can always locate the image in the plane that the user wants with the option of "visualization".

All the actions with the elements of the visual scene (rotations, translations, zoom and selection) are performed by placing the cursor on the viewer, using the computer mouse.

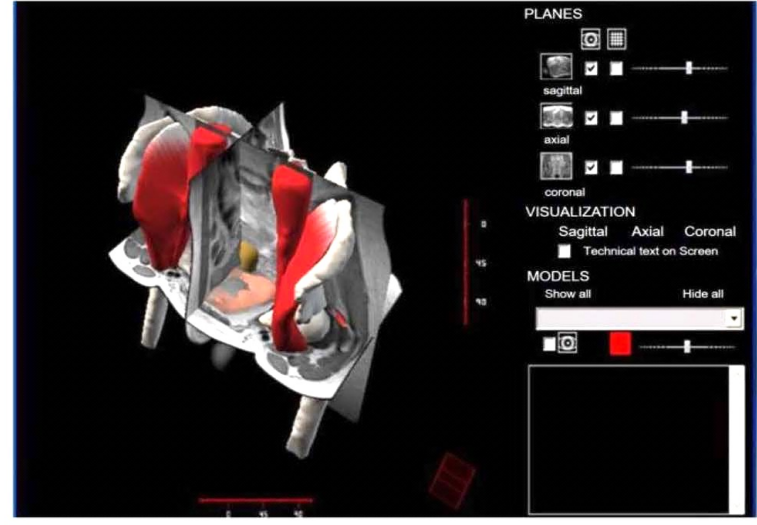

Figure 6: Program interface. Buttons of planes, display and models.

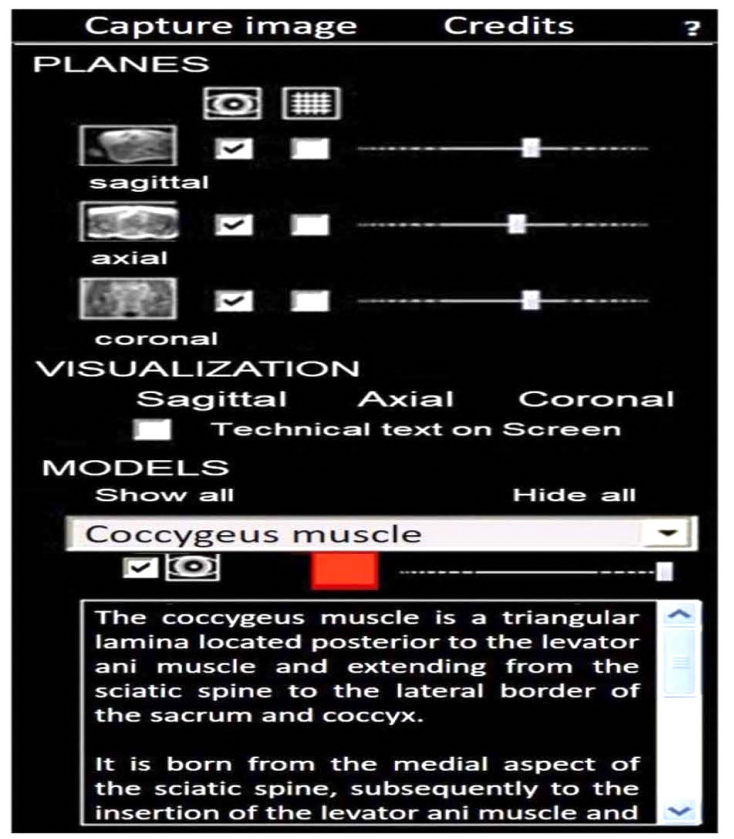

Figure 7: Program interface. Buttons of planes, display and models.

\section{Discussion}

Computer programs are a very useful tool as teaching resources in medical training, in all subjects of health sciences. 
Every time there is a greater availability of computer equipment of high technological performance, which makes it possible to meet the optimal execution needs of many teaching software with hypermedia characteristics that require a high memory capacity of the computers where they will be run.

Advances in computer technologies and the latest communication techniques have been incorporated into the educational field in medical sciences with the aim of increasing the efficiency of the training process and to help in the search to bring a more scientific and technical basis to the learning process that makes teaching more productive.

The user interface is a set of components used by users to communicate with the program that is running on the computer It is the user who actually directs the operation of the computer program through various usability instructions. We can say that an interface is the part of a computer application that the user sees and interacts with. It is related to the underlying structure, architecture, and software code.

A good interface like the one we show in this computer development for the visualization of anatomical structures of the female pelvis, is easy to understand and very easy to use, allowing users to perform a learning or training task more easily and quickly. Possibly this is one of the main advantages that our procedure offers besides the visual character of the threedimensional images.

It seems clear that the new interfaces that will arrive in the coming years will not be essentially very different from what we know today. A radical change of conception is still quite distant in time, at least for what are the standards in computing. In addition there is no known serious development that is being carried out in this regard. However, it is to be assumed that the evolution of graphical interfaces will pass through the adoption of the three dimensions and new paradigms, already far from the traditional ones.

The computer science programs based on simulations present a dynamic model or environment (usually through graphics or interactive animations) that facilitate their exploration and can perform inductive or deductive learning by observing and manipulating the underlying structure. In this way you can discover the elements of the model, their interrelations, and you can make decisions and gain direct experience in situations that would be difficult to access to reality, such as the possibility of simulating a surgical approach in a virtual way, through the management and use of different diagnostic imaging techniques that visualize the anatomical reality of the patient.

Imaging studies can facilitate knowledge of the anatomy and diagnosis of pathological processes that affect complex anatomical structures such as the pelvic ones. These techniques have been changing over time, not only with a view to the diagnostic accuracy itself, but also as a fundamental decision element when establishing a therapeutic plan.

\section{REFERENCES}

[1] Robert B. Trelease. 2016. From chalkboard, slides, and paper to e-leaming: How computing technologies have transformed anatomical sciences education. Anat Sci. Bduc. 9, 6 (November 2016), 583-602. DOI:https://doiorg/10.1002/ase.1620

[2] Colin W. Moore, Timothy D. Wilson, and Charles L. Rice. 2017. Digital preservation of anatomical variation: 3D-modeling of embalmed and plastinated cadaveric specimens using uCT and MRI. Ann. Anat. - Anat. Anzeiger $209, \quad$ Vanuary
DOI:https://doi.org/10.1016/j.aanat.2016.09.010
[5] Laura Garcia del Salto, Jaime de Miguel Criado, Luis Felipe Aguilera del Hoyo Leticia Gutiérrez Velasco, Patricia Fraga Rivas, Marcos Manzano Paradela Marín Isabel Diez Pérez de las Vacas, Ana Gloria Marco Sanz, and Eduardo Fraile Moreno. 2014. MR Imaging-based Assessment of the Female Pelvic DOL:https://doiorg/10.1148/rg.345140137

[6] Grazia T. Bitti, Giovanni M. Argiolas, Nicola Ballicu, Elisabetta Caddeo, Martina Cecconi, Giovanne Martina Cecconi, Giovanna Demurtas, Gildo Matta, M. Teresa Peltz, Simona Secci, and Paolo Siotto. 2014. Pelvic Floor Failure: MR Imaging Evaluation of 429-448. DOI:https://doiorg/10.1148/rg.342125050

[7] Luciana P. Chamié, Duarte Miguel Ferreira Rodrigues Ribeiro, Angela H. M. Luciana P. Chamié, Duarte Miguel Ferreira Rodrigues Ribeiro, Angela H. M. Caiado, Gisele Warmbrand, and Paulo C. Serafini. 2018. Translabial US and Dynamic MR Imaging of the Pelvic Floor: Normal Anatomy and Dysfunction
RadioGraphics 38, 1 (January 2018), 287-308. DOL:https://doi.org/10.1148/rg.2018170055

[8] Céline D. Alt, Franziska Hampel, Peter Hallscheidt, Christof Sohn, Betting Schlehe, and Kerstin A. Brocker. 2016. 3 T MRI-based measurements for the integrity of the female pelvic floor in 25 healthy nulliparous women Neurourol. Urodyn. 35, 2 2 (February 2016), 218-223. DOI:https://doi.org/10.1002/nau.22697

[9] Sindhura Alapati and Kedar Jambhekar. 2017. Dynamic Magnetic Resonance Imaging of the Pelvic Floor. Semin. Ultrasound, CT MRI 38, 3 (June 2017), 188199. DOI:https://doiorg/10.1053/j.sult.2016.11.002

[10] [1] Kim J. B. Notten, Kirsten B. Kluivers, Jurgen J. Futterer, Karlijn J. Schweitzer, Jaap Stoker, Femke E. Mulder, Regina G. Beets-Tan, Roy F. A Vliegen, Patrick M. Bossuyt, Roy F. P. M. Kruitwagen, Jan-Paul W. R. Roovers and Mirjam Weemhoff. 2014. Translabial Three-Dimensional Ultrasonography Compared With Magnetic Resonance Imaging in Detecting Levator An Defects. Obstet. Gynecol 124, 6 (Decem

[11] Pouya Javadian, Dena O'Leary, Ghazaleh Rostaminia, Justin North, Jason Wagner, Lieschen H. Quiroz, and S. Abbas Shobeiri. 2017. How does 3D endovaginal ultrasound compare to magnetic resonance imaging in the evaluation of levator ani anatomy? Neurourol. Urodyn 36, 2 (February 2017) 409-413. DOI:https://doi.org/10.1002/nau.22944

[12] T. F. M. Vergeldt, K. J. B. Notten, J. Stoker, J. J. Fütterer, R. G. Beets-Tan, R. F. A. Vliegen, K. J. Schweitzer, F. E. M. Mulder, S. M. J. van Kuijk, J. P. W. R. A. Vliegen, K. J. Schweitzer, F. E. M. Mulder, S. M. J. van Kuijk, J. P. W. R Roovers, K. B. Kluivers, and M. Weemhoff, 2016. Comparison of translabial three-dimensional ultrasound with magnetic resonance imaging for measurement of levator hiatal biometry at rest. Ultrasound Obstet

[13] Malwina Kaniewska, Piotr Gołofit, Martin Heubner, Caroline Maake, and Rahel A. Kubik-Huch. 2018. Suspensory Ligaments of the Remale Genital Organs: MRI Evaluation with Intraoperative Correlation. RadioGraphics 38, 7 Organs: MRI Evaluation with Intraoperative Correlation. RadioGraphics

[14] Sanjib Kumar Ghosh. 2015. Evolution of illustrations in anatomy: A study from the classical period in Europe to moderm times. An

[15] Sonia Pujol, Michael Baldwin Joshua Nassiri Ron Kikinis, and Kitt Shaffer 2016. Using 3D Maling Johniques to Ehance Teaching of Diffier. 2016. Using 3D Modeling Techniques to Enhance Teaching of Difficult Anatomical Concepts. Acad. Radiol 23,

[16] Antonio Barbeito, Marco Painho, Pedro Cabral, and Joăo Goyri O'Neill 2017. Beyond Digital Human Body Atlases. Int. J. E-Health Med. Commun. 8, 1 (January 2017), 19-36. DOI:https://doi.org/10.4018/1JEHMC.2017010102

[17] V. Balaya, J.-F. Uhl, A. Lanore, C. Salachas, T. Samoyeau, C. Ngo, C. Bensaid, C. Cornou, L. Rossi, R. Doward, A.-S. Bats, F. Lecuru, and V. Delmas. 2016 Modélisation anatomique $3 \mathrm{D}$ du pelvis féminin par dissection anatomique assistée par ordinateur : applications et perspectives. J. Gynécologie Obs. Biol. assistée par ordinateur : applications et perspectives. J. Gynécologie Obs. Biol.
la 4 (May 5 2016), 467-477. la Reprod. 45, 5 , 1 .

[18] Roberto D. Tabernero Rico, Juan A. Juanes Méndez, and Alberto Prats Galino. 2017. New Generation of Three-Dimensional Tools to Learn Anatomy. J. Med. Syst. 41, 5 (May 2017) 88. DOLbttps://doiorg/10.1007/s10916-017-0725-4

[19] Mohamed Estai and Stuart Bunt. 2016. Best teaching practices in anatomy education: A critical review. Ann. Anat - Anat Anzeiger 208, (Novenber education: A critical review. Ann. Anat. - Anat. Anzeiger 208

[20] Sandra Berney, Mireille Bétrancourt, Gaëlle Molinari, and Nady Hoyek. 2015. How spatial abilities and dynamic visualizations interplay when learning functional anatomy with $3 \mathrm{D}$ anatomical models. Anat. Sci. Educ. 8, 5 functional anatomy with 3D anatomical models. Anat. Se4.

[21] M. M. Bertrand, F. Macri, R. Mazars, S. Droupy, J. P. Beregi, and M. Prudhomme. 2014. MRI-based 3D pelvic autonomous innervation: a first step towards image-guided pelvic surgery. Eur. Radiol. 24, 8 (August 2014) 19891997. DOI:https://doiorg/10.1007/s00330-014-3211-0

[22] Marina Yiasemidou, Daniel Glassman, Faisal Mushtaq, Christos Athanasiou, Mark-Mon Williams, David Jayne, and Danilo Miskovic. 2017. Mental practice with interactive 3D visual aids enhances surgical performance. Surg. Endosc. 
3D Reconstruction of the Female Perineal Musculature, from Sections of Magnetic Resonance: Interactive computer development

31, 10 (October 2017), 4111-4117. DOI:https://doi.org/10.1007/s00464-0175459-3

[23] Diana Coomes Peterson and Gregary S.A. Mlynarczyk 2016. Analysis of traditional versus three-dimensional augmented curriculum on anatomical learning outcome measures. Anat. Sci Educ. 9, 6 (November 2016), 529-536. DOI:https://doi.org/10.1002/ase.1612

[24] Gao An, Li Hong, Xiao-Bing Zhou, Qiong Yang, Mei-Qing Li, and Xiang-Yang Tang. 2017. Accuracy and efficiency of computer-aided anatomical analysis using 3D visualization software based on semi-automated and automated segmentations. Ann. Anat. - Anat. Anzeiger 210, (March 2017), 76-83. DOI:https://doi.org/10.1016/j.annat.2016.11.009

[25] Luyun Chen, Florian Lenz, Céline D. Alt, Christof Sohn, John O. De Lancey, and Kerstin A. Brocker. 2017. MRI visible Fe3O4 polypropylene mesh: 3D reconstruction of spatial relation to bony pelvis and neurovascular structures. Int. Urogynecol. J. 28, 8 (August 2017), 1131-1138. DOI: Urogynecol. J. 28, 8 (A)

[26] Stergios K. Doumouchtsis, Daron A. Nazarian, Nivedita Gauthaman, Constantin M. Durnea, and Graham Munneke. 2017. Three-dimensiona cross-sectional images. Int. Urogynecol J. 28, 10 (October 2017), 1579-1587. DOI:https://doi.org/10.1007/s00192-017-3317-4
TEEM 2019, October 2019, León, Spain

[27] N. Kurobe, L. Hakkakian, M. Chahim, V. Delmas, M. Vekemans, and J. F. Uhl. 2015. Three-dimensional reconstruction of the lower limb's venous system in human fetuses using the computer-assisted anatomical dissection (CAAD) technique. Surg. Radiol. Anat. 37, 3 (April 2015), 231-238. DOI:Lttps://doi.org/10.1007/s00276-014-1350-2

[28] CJ. Daly. 2019. Examining Vascular Structure and Function Using Confoca Microscopy and 3D Imaging Techniques. In Rea P. (eds) Biomedical Visualisation Advances in Experimental Medicine and Biology. Springer, Cham, 97-106. DOI:https://doi.org/https://doi.org/10.1007/978-3-030-0607018

[29] Simone L. Vernez, Zhamshid Okhunov, Jamie Wikenheiser, Cyrus Khoyilar, Rahul Dutta, Kathryn Osann, Kamaljot Kaler, Thomas K Lee, Ralph V. Clayman, and Jaime Landman. 2017. Precise Characterization and 3 Dimensional Reconstruction of the Autonomic Nerve Distribution of the

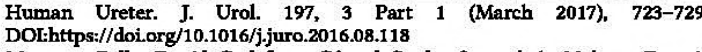

[30] Morgane Belle, David Godefroy, Gérard Couly, Samuel A. Malone, Francis Collier, Paolo Giacobini, and Alain Chédotal. 2017. Tridimensional Visualization and Analysis of Early Human Development. Cell 169, 1 (March 


\section{VNIVERSiDAD}

ĐSALAMANCA 